2012

THE POTENTIAL OF INDUSTRIAL WASTE AND AGRICULTURAL FEEDSTOCK TOWARDS SUSTAINABLE BIOFUELS PRODUCTION: TECHNO-ECONOMIC AND ENVIRONMENTAL IMPACT PERSPECTIVES

Felix K. Adom

Michigan Technological University

Follow this and additional works at: https://digitalcommons.mtu.edu/etds

Part of the Chemical Engineering Commons, and the Sustainability Commons Copyright 2012 Felix K. Adom

Recommended Citation

Adom, Felix K., "THE POTENTIAL OF INDUSTRIAL WASTE AND AGRICULTURAL FEEDSTOCK TOWARDS SUSTAINABLE BIOFUELS PRODUCTION: TECHNO-ECONOMIC AND ENVIRONMENTAL IMPACT PERSPECTIVES", Dissertation, Michigan Technological University, 2012.

https://doi.org/10.37099/mtu.dc.etds/619

Follow this and additional works at: https://digitalcommons.mtu.edu/etds

Part of the Chemical Engineering Commons, and the Sustainability Commons 


\title{
THE POTENTIAL OF INDUSTRIAL WASTE AND AGRICULTURAL FEEDSTOCK TOWARDS SUSTAINABLE BIOFUELS PRODUCTION: TECHNO-ECONOMIC AND ENVIRONMENTAL IMPACT PERSPECTIVES
}

\author{
By \\ Felix K. Adom

\begin{abstract}
A DISSERTATION
Submitted in partial fulfillment of the requirements for the degree of
\end{abstract}

DOCTOR OF PHILOSOPHY

In Chemical Engineering

MICHIGAN TECHNOLOGICAL UNIVERSITY

2012

(C2012 Felix K. Adom 
This dissertation has been approved in partial fulfillment of the requirements for the Degree of DOCTOR OF PHILOSOPHY in Chemical Engineering

Department of Chemical Engineering

Dissertation Advisor: $\quad$ Robbins Professor. David R Shonnard

Committee Member: $\quad$ Professor. Susan T Bagley

Committee Member: $\quad$ Dr. Tony N Rogers

Committee Member: $\quad$ Dr. Wenzhen $\mathrm{Li}$

Department Chair: $\quad$ Professor Komar Kawatra. 


\section{Table of contents}

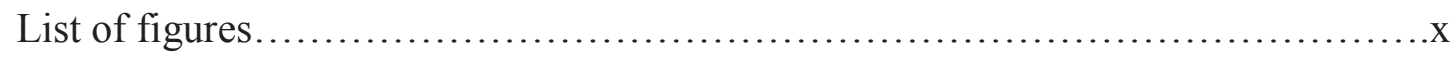

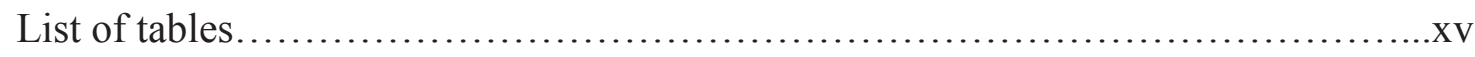

Preface...................................................................

Acknowledgements..................................................xiii

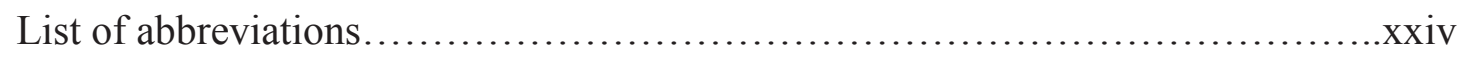

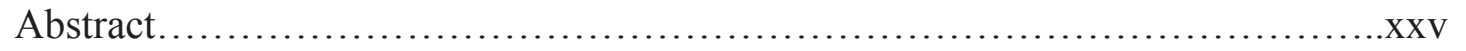

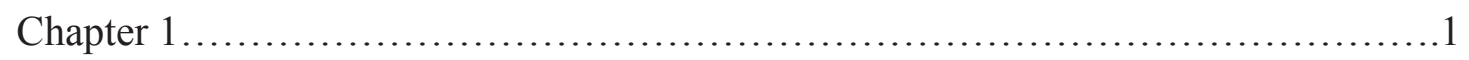

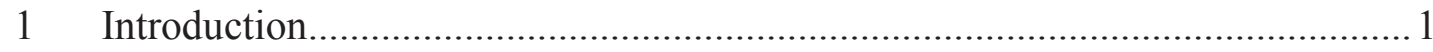

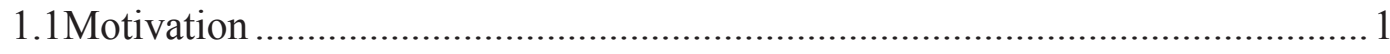

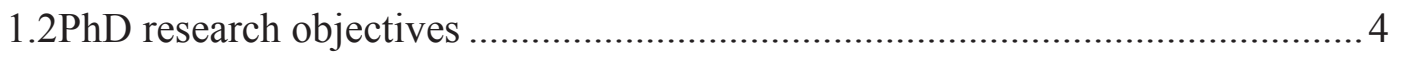

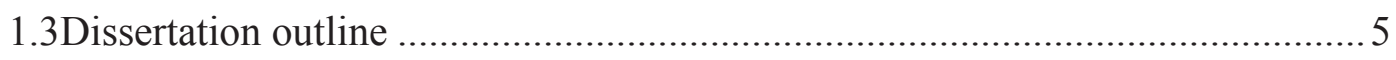

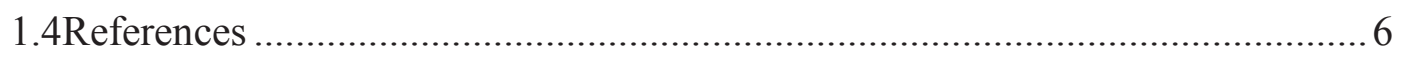

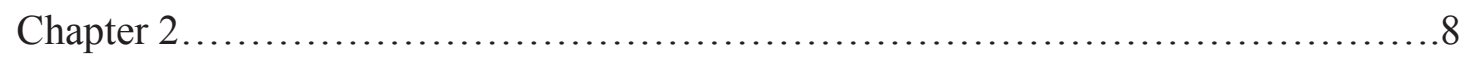

2 Compositional Analysis of Defatted Syrup from a Corn Ethanol Dry Mill as a

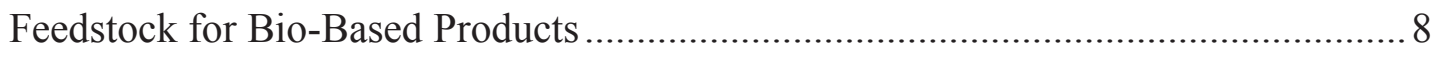

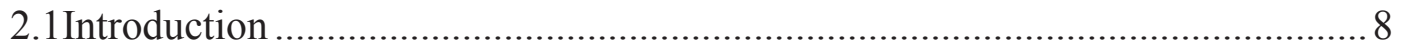

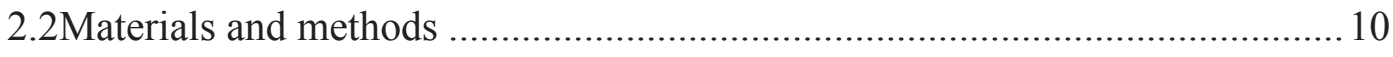

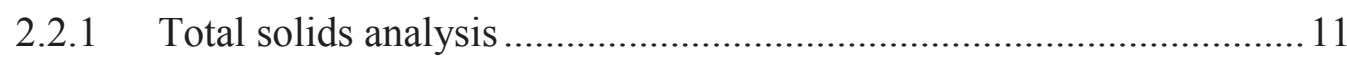

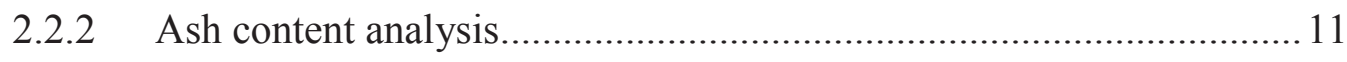

2.2.3 Inorganic element profile ..................................................... 11

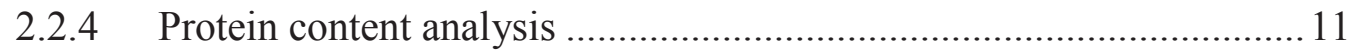

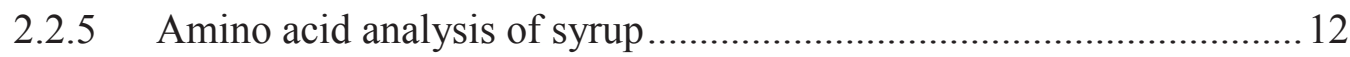

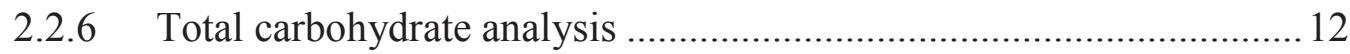




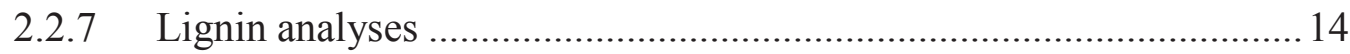

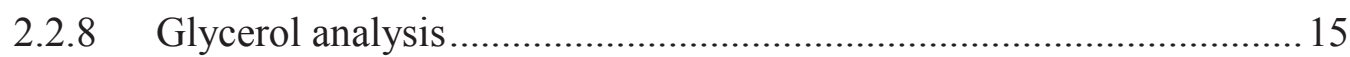

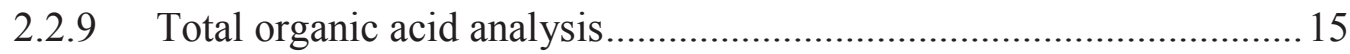

2.2.10 Functional group analysis using FTIR-ATR …………………......... 16

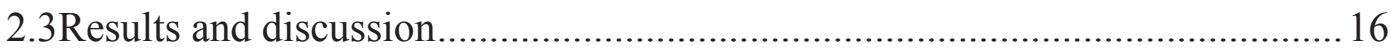

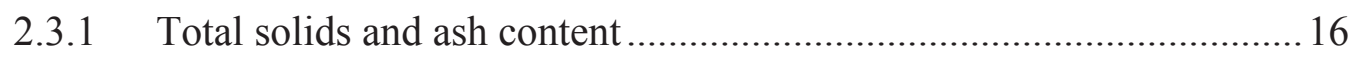

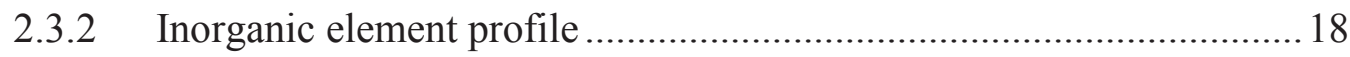

2.3.3 Protein content analysis ..................................................................... 19

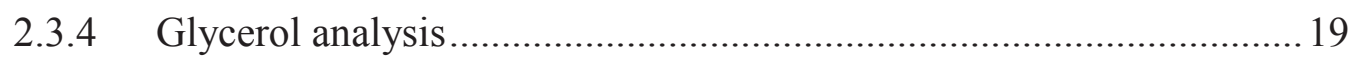

2.3.5 Total carbohydrate content analysis of DCS........................................2 20

2.3.6 Acid soluble and acid insoluble lignin analysis ...................................21

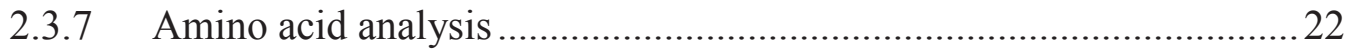

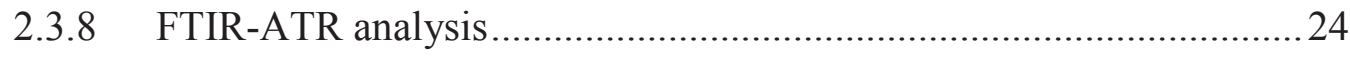

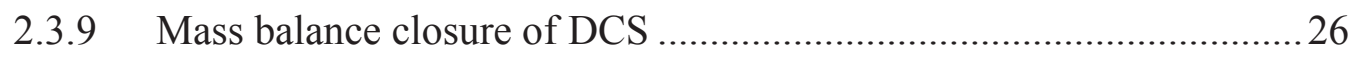

2.4Potential yields from biorefining using syrup as a feedstock.............................2 27

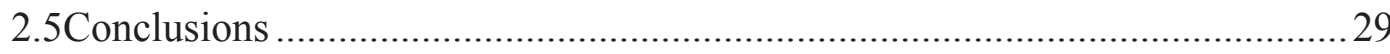

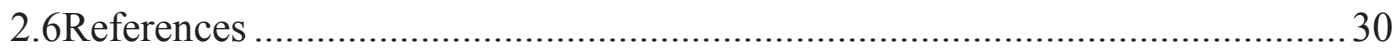

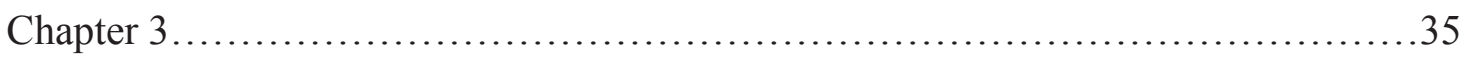

3 Optimization of the Dilute Acid and Enzymatic Pretreatment of Defatted Syrup from a Corn Ethanol Dry Mill......................................................................................35

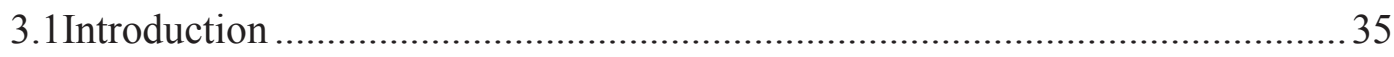

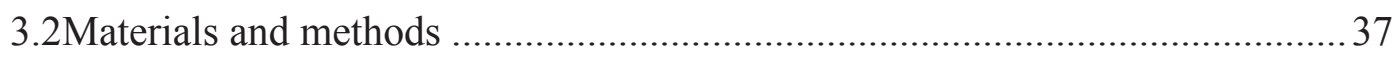

3.2.1 Hydrolysis scheme and experimental matrix ........................................37

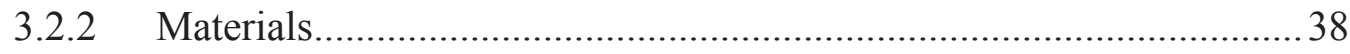

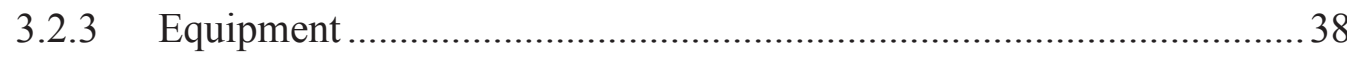


3.2.4 Characterization of soluble sugars and inhibitors ............................ 39

3.2.5 Dilute acid pretreatment (DAP) procedure (First pretreatment stage). 39

3.2.6 Oligomer analysis (Second pretreatment stage)............................... 40

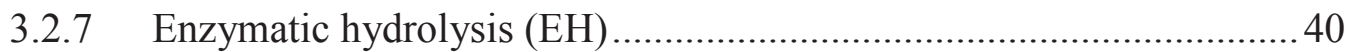

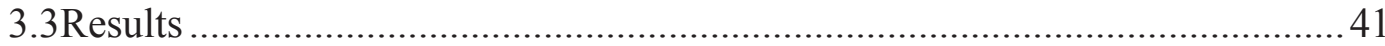

3.3.1 Results for soluble carbohydrates and inhibitors in DCS .................. 41

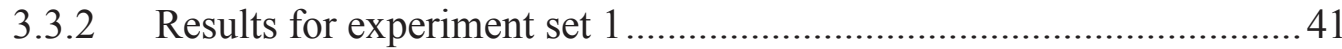

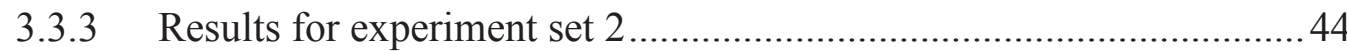

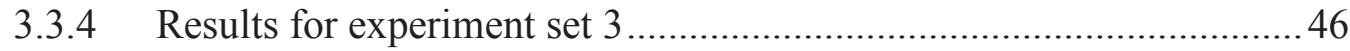

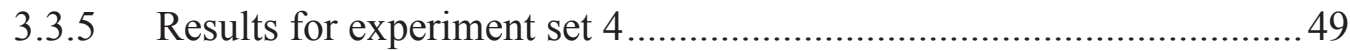

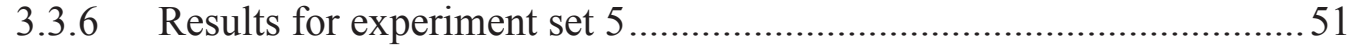

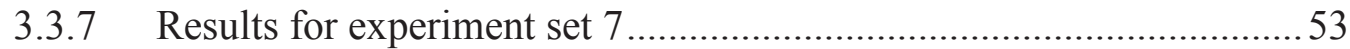

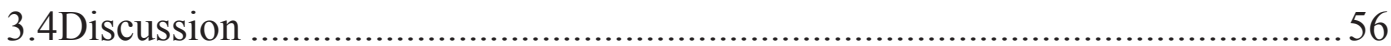

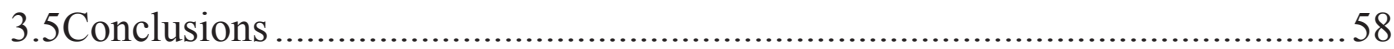

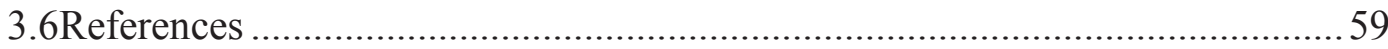

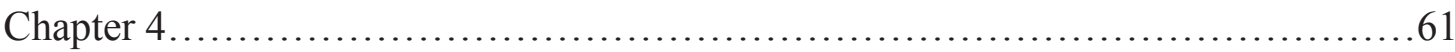

4 Optimization of the Protein Hydrolysis Scheme of Defatted Syrup from a Corn

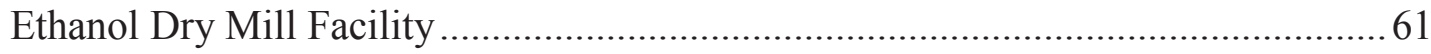

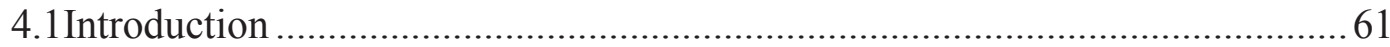

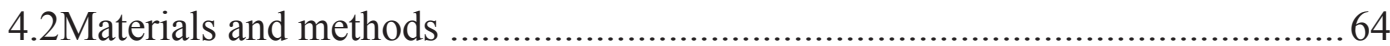

4.2.1 Protein hydrolysis scheme and experimental matrix ........................64 64

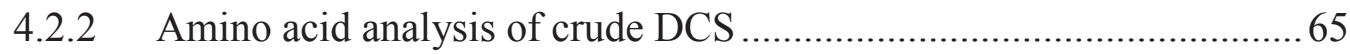

4.2.3 Hydrolysis pathway 1: Experiment description of amino acid

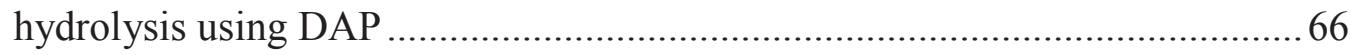


4.2.4 Hydrolysis pathway 2: Experiment description of DAP followed by

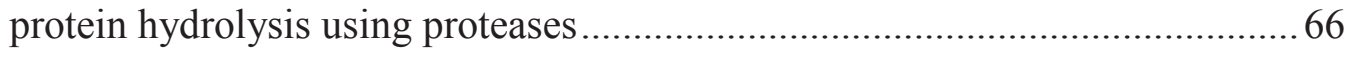

4.2.5 Hydrolysis pathway 3: Experiment description of amino acid hydrolysis on unpretreated DCS using proteases, cellulases, $\alpha$-amylase and

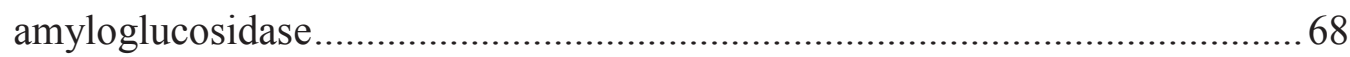

4.2.6 Hydrolysis pathway 4: Experiment description of amino acid hydrolysis using protease \& cellulases (Simultaneous Hydrolysis) ................... 70

4.2.7 HPLC analysis of amino acids ............................................................. 71

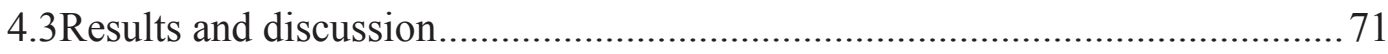

4.3.1 Results for protein content and free amino acid analysis of crude DCS 72

4.3.2 Results for hydrolysis pathway 1: Amino acid analysis using DAP....73

4.3.3 Results for hydrolysis pathway 2: DAP followed by protein hydrolysis

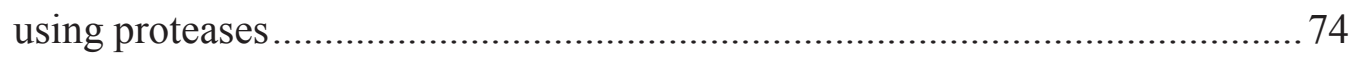

4.3.4 Results for hydrolysis pathway 3: Hydrolysis of unpretreated DCS using proteases, cellulases, $\alpha$-Amylase and AMG …………………………....... 77

4.3.5 Results for hydrolysis pathway 4: Simultaneous hydrolysis of unpretreated DCS using Protease (Protex 6L) \& Cellulases (Accellerase 1500

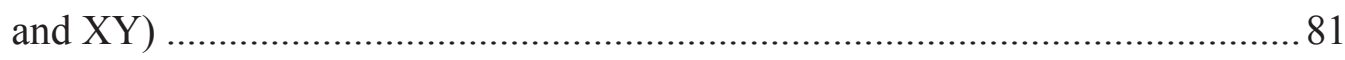

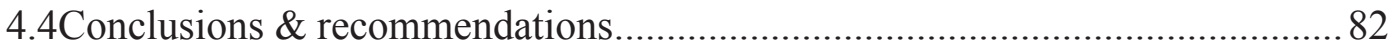

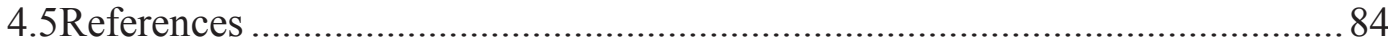

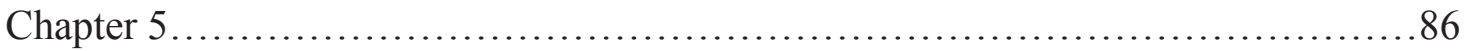

5 Modeling of Dilute Acid Pretreatment Process using Defatted Corn Syrup as Feedstock: Techno-economic Analysis and Life Cycle Assessment............................86

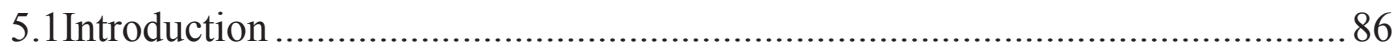

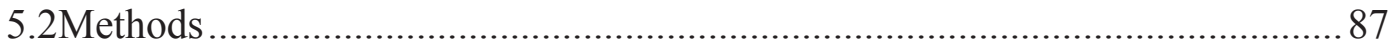




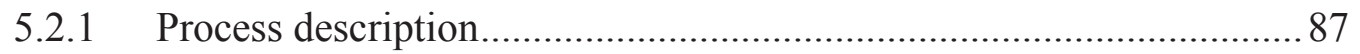

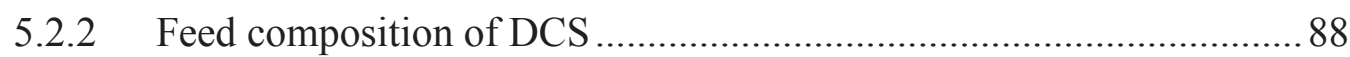

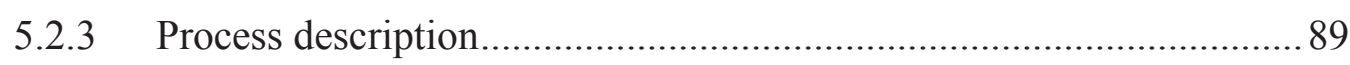

5.3Process simulation and economic calculations ....................................................93

5.4Greenhouse gas analysis of the dilute acid pretreatment processing facility .... 95

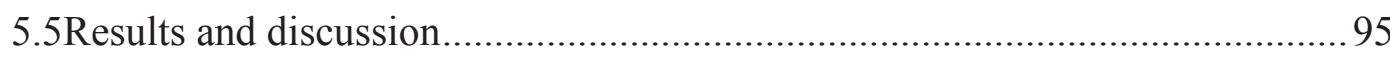

5.5.1 Mass and energy balances for process simulation in Aspen Plus ${ }^{\circledR}$...... 95

5.5.2 Results for economic analysis .......................................................... 97

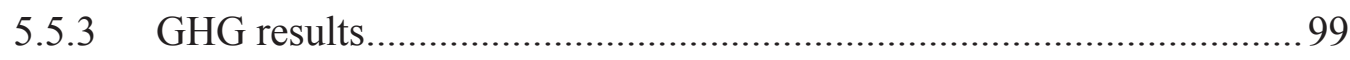

5.6Conclusions \& recommendations.................................................................... 99

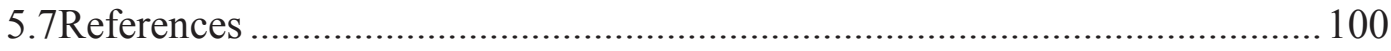

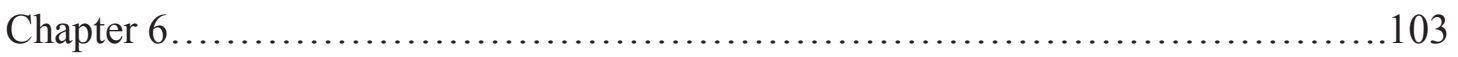

6 Regional Carbon Footprint Analysis of Dairy Feeds for Milk Production in the

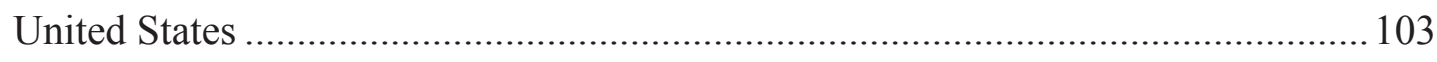

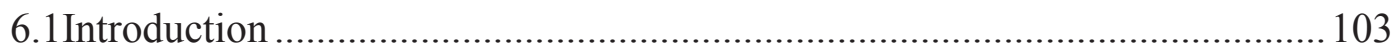

6.2Life cycle assessment methodology ............................................................. 104

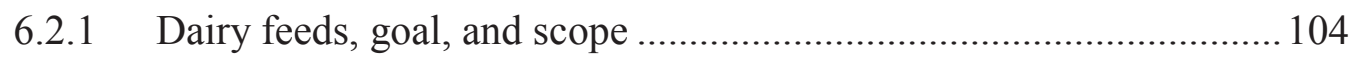

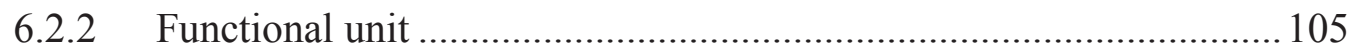

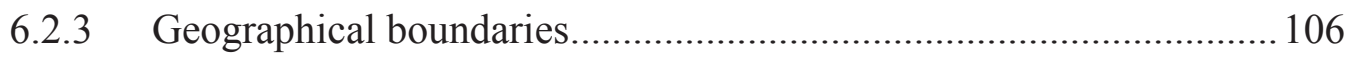

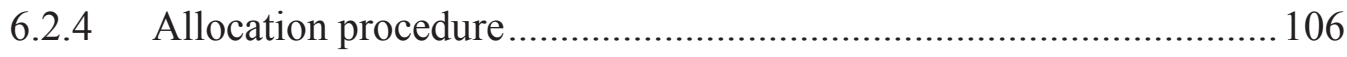

6.2.5 Inputs versus inventory data and possible limitations ........................ 107

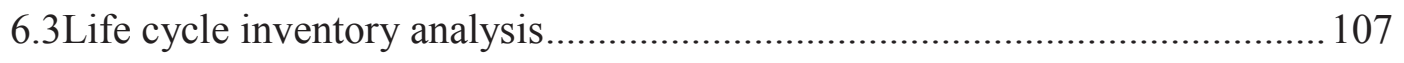

6.3.1 Production inputs and inventory for grains: corn, oats, soybeans, and

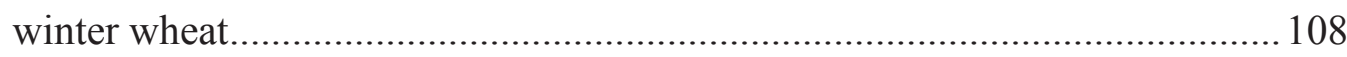

vii 
6.3.2 Production inputs and inventory for forage crops: alfalfa, alfalfa silage, grass hay, grass pasture, and grass silage

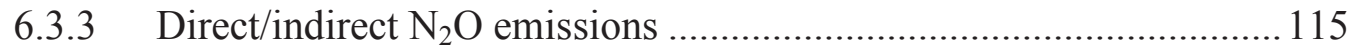

6.3.4 Crop protection chemicals .......................................................... 116

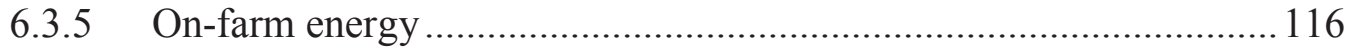

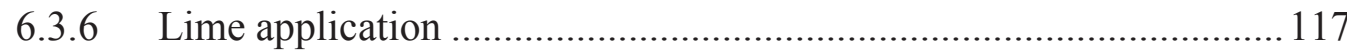

6.3.7 Crop residue effects on direct/indirect $\mathrm{N}_{2} \mathrm{O}$ emissions ................... 118

6.3.8 Emission factors for fertilizer, crop protection chemicals, and energy input 118

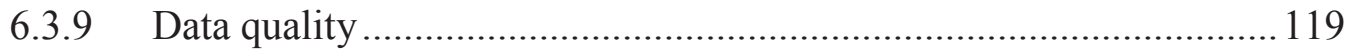

6.4Life cycle greenhouse gas impact assessment and interpretation of results ... 120

6.4.1 General assumptions for life cycle impact analysis ....................... 120

6.4.2 Regional greenhouse gas emissions of dairy feeds ......................... 120

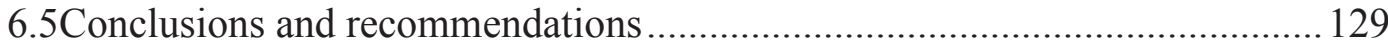

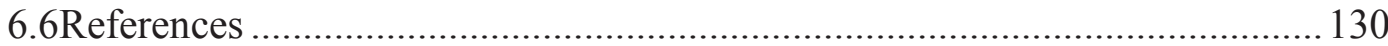

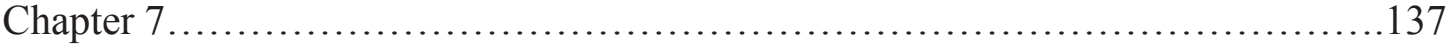

7 Carbon Footprint Analysis of Dairy Feed from a Mill in Michigan, U.S....... 137

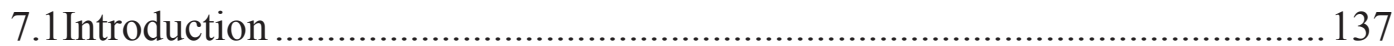

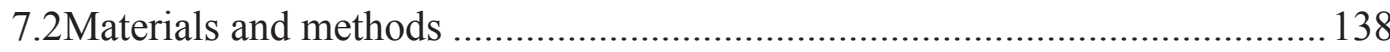

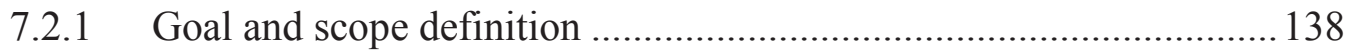

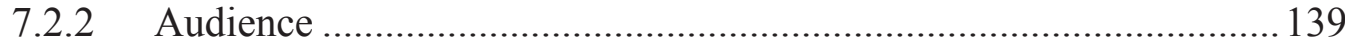

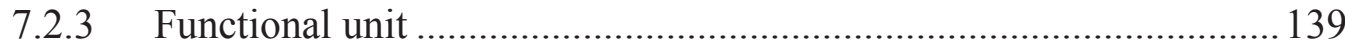

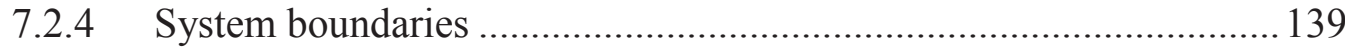

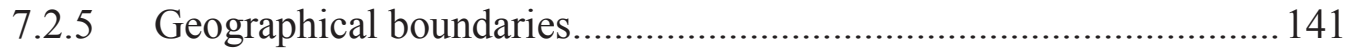

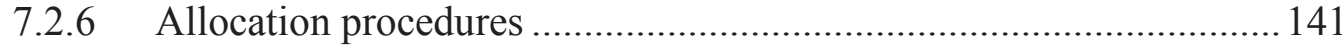

viii 


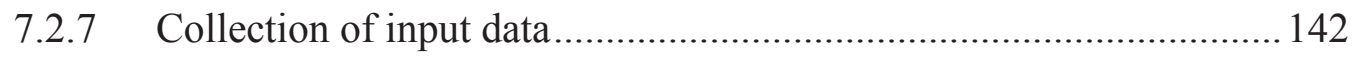

7.2.8 Developing a data collection spreadsheet (Survey) ............................ 142

7.2.9 Organization of input data for carbon footprint analysis .................... 142

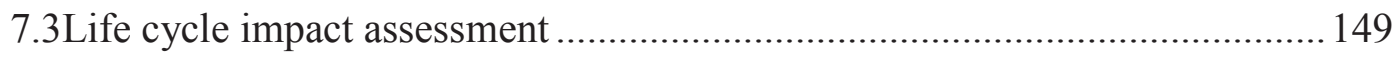

7.3.1 Emission factors for GHG analysis................................................... 149

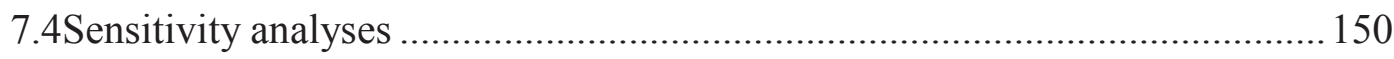

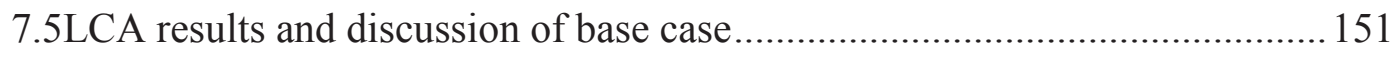

7.5.1 GHG impact of a dairy feed mill in Michigan, U.S............................ 151

7.5.2 Discussion of base case LCA results for annual emissions ................ 153

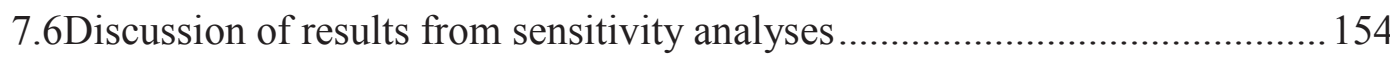

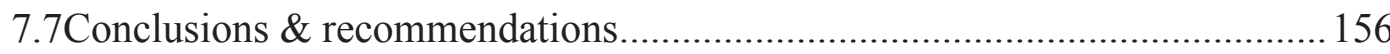

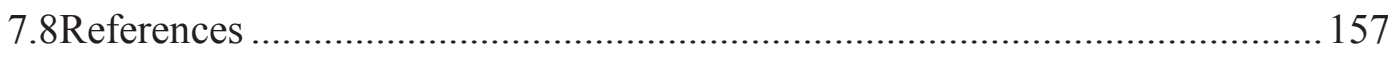

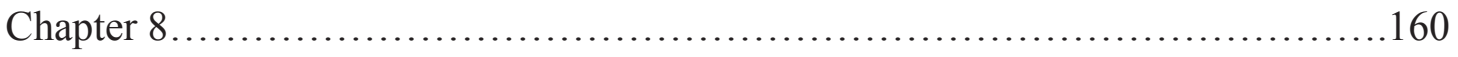

8 Summary, Conclusions, and Recommendations for Future Work ................... 160

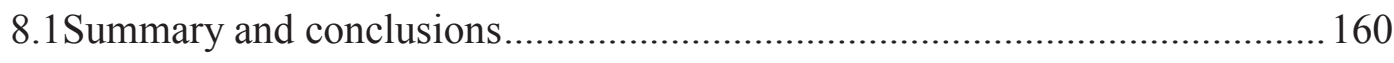

8.2Recommendations for future work.............................................................. 164

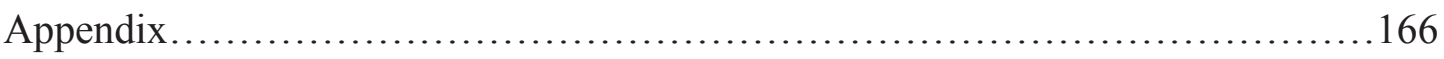

Appendix A: Supplementary information for sugar platform optimization experiments 166

Appendix B: Supplementary information for protein platform optimization experiments 182

Appendix C: Supplementary information for modeling of dilute acid pretreatment process using defatted corn syrup as feedstock..................................193 Appendix D: Supplementary information for regional carbon footprint analysis of dairy feeds for milk production in the USA. 198 
Appendix E: Supplementary information for carbon footprint analysis of dairy feed

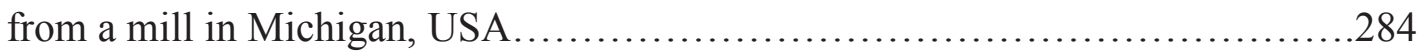

\section{List of figures}

Figure 2-1 Schematic diagram of the dry-grind corn mill facility 10

Figure 2-2 Percentage composition on a dry syrup solids basis of total ash, protein, starch and glycerol for samples "A" through to "F" (Duplicates reported as mean standard deviation) 17

Figure 2-3 . Results for acid soluble \& acid insoluble lignin of syrup on a dry solids basis .22

Figure 2-4 Free amino acid content of syrup on a dry solids basis ................................23

Figure 2-5 FTIR spectra of oven-dried syrup for samples A, B \& C ..............................24 Figure 2-6 Summary of the compositional analysis result for oven-dried syrup ..........26 Figure 3-1 Average carbohydrates (cellobiose, xylose, glucose,galactose, mannose \& mannose) sugar concentration trend after 1 minute DAP (first \& second pretreatment stage).....

Figure 3-2 Average carbohydrates (cellobiose, xylose, glucose, galactose, mannose \& mannose) sugar concentration trend after 30 minutes DAP (first \& second pretreatment stage)

Figure 3-3 Average carbohydrates (cellobiose, xylose, glucose,galactose, mannose \& mannose) sugar concentration trend after 45 minutes DAP (first \& second pretreatment stage) 47

Figure 3-4 Average carbohydrates (cellobiose, xylose, glucose,galactose, mannose \& mannose) sugar concentration trend after 60 minutes DAP (first \& second pretreatment stage) 50

Figure 3-5 Average carbohydrates (cellobiose, xylose, glucose, galactose, mannose \& arabinose) sugar concentration trend after 75 minutes DAP (first \& second pretreatment stage) 
Figure 3-6 Average carbohydrates (cellobiose, xylose, glucose,galactose, mannose \& mannose) sugar concentration trend after 90 minutes DAP (first \& second pretreatment

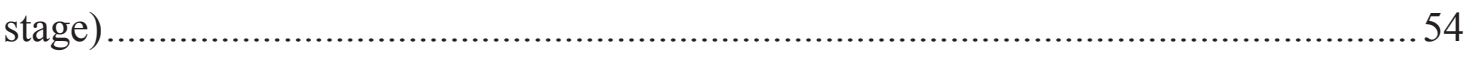

Figure 4-1 Hydrolysis pathways for the release of fermentable sugars and amino acids (DAP: dilute acid pretreatment, EH: enzymatic hydrolysis of cellulose, PH: Protein hydrolysis, FS: Fermentable Sugars)...... 65

Figure 4-2 Average amino acid concentrations for DCS received in year 2010 and 2011 [Standard deviation of duplicate samples (Adom et al. 2012a)] 72

Figure 4-3 Amino acid analysis of hydrolyzate "A \& B" before (UPDCS) and after (PDCS) dilute acid pretreatment. (Standard deviation of duplicate samples)..... 74 Figure 4-4 Total monomer sugar recovery using a combination of Accellerase 1500 / $\mathrm{XY}, \alpha$-amylase / AMG and $\alpha$-amylase alone. 81

Figure 4-5 Total monomer sugar and amino acid recovery using a combination of Protex 6L and Accellerase 1500 / XY for simultaneous hydrolysis.... 82

Figure 5-1 ASPEN-Plus process flow diagram of dilute acid pretreatment process as analyzed in this study. The entire pretreatment section comprise of (i) DCS viscosity reduction and preheating section, (ii) Dilute acid pretreatment and flash cooling section and (iii) Neutralization and unreacted residues separation section ........................... 92 Figure 5-2 Summary of cost components for all equipment used in this facility......... 98 Figure 6-1 Dairy production regions used for this study ...................................... 105 Figure 6-2 Life cycle diagram for the cultivation and harvesting of dairy feed crops. Dotted lines represent the system boundary considered in this carbon footprint analysis 108

Figure 6-3 Carbon footprint profile of soybeans harvested in the U.S..................... 123 Figure 6-4 Carbon footprint profile of Oats harvested in the U.S .......................... 124 Figure 6-5 Carbon footprint profile of Corn grain harvested in the U.S ................... 125 Figure 6-6 Carbon footprint profile of Corn silage harvested in the U.S. .................. 126 Figure 6-7 Carbon footprint profile of winter wheat harvested in the U.S................ 127 Figure 7-1 Schematic diagram of various stages for dairy feed mill carbon footprint analysis 140 
Figure 7-2 Relative contribution to GHG emissions of milled dairy feed (Base case

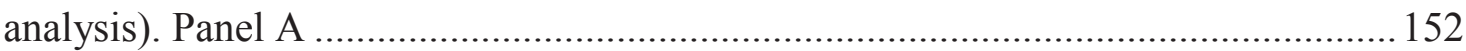

Figure 7-3 Sensitivity analysis of feed inputs to dairy feed mill greenhouse gas profile 155

Figure A-1 Flow diagram of dilute acid hydrolysis and enzymatic saccharification of DCS 166

Figure A-2 Total Solids and Ash Content for DCS used for hydrolysis 166 Figure A-3 TMS for 1-minute hydrolysis (first stage dilute acid hydrolysis +oligomer analysis) 167

Figure A-4 Concentrations of inhibitors generated for 1 minute hydrolysis scheme.. 167 Figure A-5 TMS for 30-minute hydrolysis (first stage dilute acid hydrolysis +oligomer analysis) 168

Figure A-6 Concentrations of inhibitors generated for 30 minutes hydrolysis scheme 168

Figure A-7 TMS for 45-minute hydrolysis (first stage dilute acid hydrolysis +oligomer analysis) 169

Figure A-8 Concentrations of inhibitors generated for 45 minutes hydrolysis scheme 169

Figure A-9 TMS for 60-minute hydrolysis (first stage dilute acid hydrolysis +oligomer analysis) 170

Figure A-10 Concentrations of inhibitors generated for 60 minutes hydrolysis scheme 170

Figure A-11 TMS for 75-minute hydrolysis (first stage dilute acid hydrolysis +oligomer analysis) 171

Figure A-12 Concentrations of inhibitors generated for 75-minute hydrolysis scheme 171

Figure A-13 TMS for 90-minute hydrolysis (first stage dilute acid hydrolysis +oligomer analysis)

Figure A-14 Concentrations of inhibitors generated for 90 minute hydrolysis scheme 
Weight of syrup used in hydrolysis $=10 \mathrm{~g}$, Total solids in DCS (Appendix A. Figure $\mathrm{A}-15)=28 \% \mathrm{wt}$.

Figure A-16 Effect of time and 0, $1 \& 2 \mathrm{wt} \%$ acid concentration on the yield of total monomer sugars (first stage acid pretreatment). 173

Figure A-17 Effect of $0 \mathrm{wt} \%$ acid concentration and time on the yield of monomer sugars with enzymes $(\mathrm{Ar} / \mathrm{Mn}=$ arabinose $)$ 174

Figure A-18 Effect of $1 \mathrm{wt} \%$ acid concentration and time on the yield of monomer sugars with enzymes $(\mathrm{Ar} / \mathrm{Mn}=$ arabinose $)$. 175

Figure A-19 Effect of $2 \mathrm{wt} \%$ acid concentration and time on the yield of monomer sugars with enzymes $(\mathrm{Ar} / \mathrm{Mn}=$ arabinose $)$. 176

Figure A-20 Comparison of DAP (first stage) with 72 hours EH for $0 \mathrm{wt} \%$ acid concentration DCS 177

Figure A-21 Comparison of DAP (first stage) with 72 hours EH for $1 \mathrm{wt} \%$ acid concentration DCS 178

Figure A-22 Comparison of DAP (first stage) with 72 hours $\mathrm{EH}$ for $2 \mathrm{wt} \%$ acid concentration DCS 179

Figure A-23 The concentrations of HMF and Furfural generated overtime 180

Figure B-1 Flow diagram of dilute acid hydrolysis at optimum conditions..... 182

Figure B-2 Flow diagram for dilute acid pretreatment followed by protein hydrolysis using proteases (Hydrolysis Pathway 2) 182

Figure B-3 Results for Hydrolysis Pathway 2: DAP followed by protein hydrolysis using proteases 189

Figure B-4 Amino acid hydrolysis trends of individual amino acids for control pH 6189 Figure B-5 Amino acid hydrolysis trends of individual amino acids for Pronase pH 7 190

Figure B-6 Amino acid hydrolysis trends of individual amino acids for Pronase pH 6 190

Figure B-7 Amino acid hydrolysis trends of individual amino acids for Protex pH 7191 Figure B-8 Amino acid hydrolysis trends of individual amino acids for Protex pH 6191 
Figure B-9 Amino acid hydrolysis trends of individual amino acids for Trypsin $\mathrm{pH} 7$ 192

Figure B-10 Amino acid hydrolysis trends of individual amino acids for Trypsin $\mathrm{pH} 6$ 192

Figure C-1 Detailed cost analysis of unit operation: Cyclone .................................. 194

Figure C-2 Detailed cost analysis of unit operation: Flash tank .............................. 194

Figure C-3 Detailed cost analysis of unit operation: Pump-1................................ 195

Figure C-4 Detailed cost analysis of unit operation: Pump-2 2................................. 195

Figure C-5 Detailed cost analysis of unit operation: RSTOIC-1 …......................... 196

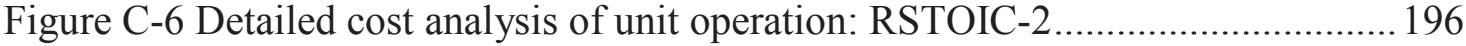

Figure C-7 Detailed cost analysis of unit operation: RSTOIC-3 .............................. 196

Figure D-1: Copyright clearance from Springer.............................. 198

Figure D-2 Dairy producer life cycle assessment survey and How-To guide (a) .......204

Figure D-3 Dairy producer life cycle assessment survey and How-To guide (b) ....... 205

Figure D-4 Dairy producer life cycle assessment survey and How-To guide (c) ....... 206

Figure D-5 Dairy producer life cycle assessment survey and How-To guide (d) .......207

Figure E-1 Copyright clearance for Elsevier (http://www.elsevier.com/authors/author-

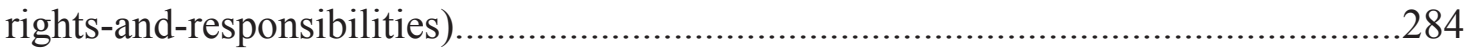

Figure E-2 Relative Contribution to GWP of Feed Mill Dairy Feed for Scenario 1 ...298 Figure E-3 Relative Contribution to GWP of Feed Mill Dairy Feed for Scenario 2 ... 299 Figure E- 4 Relative Contribution to GWP of Feed Mill Dairy Feed for Scenario 3 .. 300 


\section{List of tables}

Table 2-1 Summary of inorganic element profile. Percent is based on syrup solids content (Duplicates reported as mean standard deviation) ..................................... 18 Table 2-2 Summary of total carbohydrate content of DCS and thin stillage. Percent is

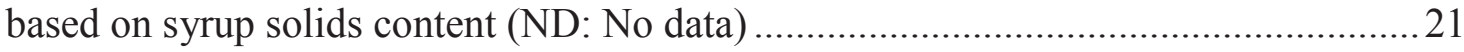

Table 2-3 Comparison of amino acid profile for syrup and thin stillage (TS), [EAAEssential Amino Acids \& NEAA-Non Essential Amino Acids]. Numbers are percent of dry solids. Source of TS data. (Refer to list of abbreviations for others) .....................23 Table 2-4 Results for functional group analysis of oven dried syrup .........................25 Table 2-5 Potential yields of bio-based chemicals using DCS as a feedstock (M:

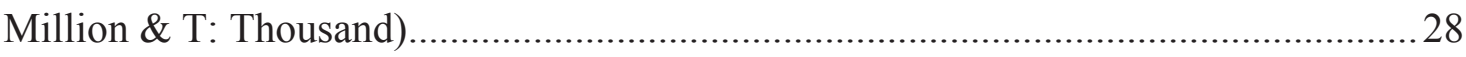
Table 3-1 Experimental matrix for dilute acid hydrolysis (10\% solids) and enzymatic

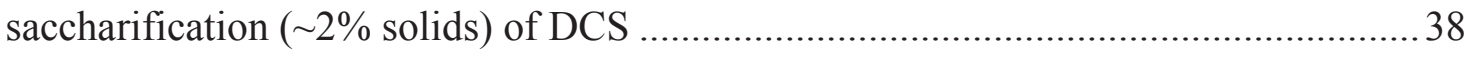

Table 3-2 Average (and Standard Deviations) TMS, furfural and HMF concentrations $\left(\mathrm{mg} \mathrm{ml}^{-1}\right)$ for Enzymatic Hydrolysis on 1 minute DAH Samples ............................... 44 Table 3-3 Average TMS, furfural and HMF concentrations ( $\mathrm{mg} \mathrm{ml}^{-1}$ ) for $\mathrm{EH}$ on 30

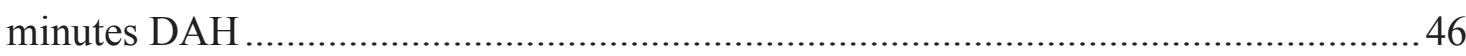
Table 3-4 Average TMS, furfural and HMF concentrations (mg ml-1) for EH on 45 minutes DAH 49

Table 3-5 Average TMS, furfural and HMF concentrations ( $\mathrm{mg} \mathrm{ml}^{-1}$ ) for $\mathrm{EH}$ on 60

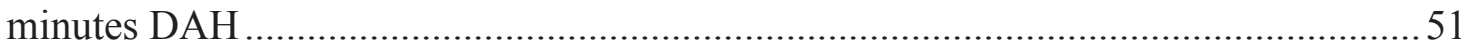

Table 3-6 Average TMS, furfural and HMF concentrations (mg ml-1) for EH on 75

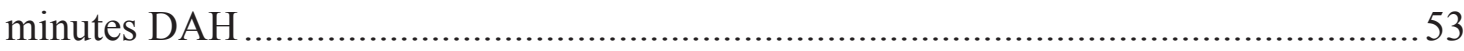

Table 3-7 Average TMS, furfural and HMF concentrations ( $\mathrm{mg} \mathrm{ml}^{-1}$ ) for $\mathrm{EH}$ on 90

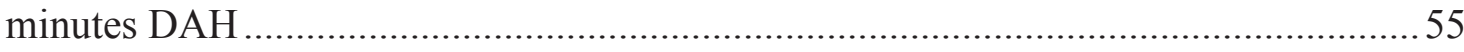

Table 4-1 Experiment matrix for protein hydrolysis scheme: pathway 2 ..................67 Table 4-2 Experiment matrix for protein hydrolysis scheme of unpretreated DCS (10\% wt. DCS $)$ : Pathway $3 . \mathrm{H}=\operatorname{High}(1.5 \mathrm{v} / \mathrm{w}), \mathrm{M}=\operatorname{Medium}(1.0 \mathrm{v} / \mathrm{w}), \mathrm{L}=\operatorname{Low}(0.5 \mathrm{v} / \mathrm{w})$ 
Table 4-3 Summary of total amino acid recovery using hydrolysis pathway 1 (DAP). 73 Table 4-4 Summary of results for hydrolysis pathway 2: amino acid analysis of dilute acid pretreated syrup followed by protease hydrolysis 75

Table 4-5 Summary of results for hydrolysis pathway 3: Amino acid analysis of DCS

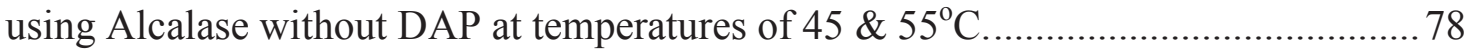
Table 4-6 Summary of results for hydrolysis pathway 3: Amino acid analysis of syrup without DAP using Pronase, Protex and Trypsin at low temperature $\left(34^{\circ} \mathrm{C}\right)$. Control contains no enzymes. Standard deviation of duplicate samples in parenthesis 79

Table 5-1 Summary of the DCS composition and their corresponding flow rates on an hourly basis used. (FAA: Fermentable amino acids, FS: Fermentable sugars, SA: Succinic acid, AIL Acid insoluble lignin, and ASL: Acid soluble lignin) .................. 88 Table 5-2 Pretreatment Reactor Conditions (RSTOIC-1) (Adom et al. 2012c) ........... 90 Table 5-3 Pretreatment Hydrolysis Reactions (Refer to list of abbreviations for the

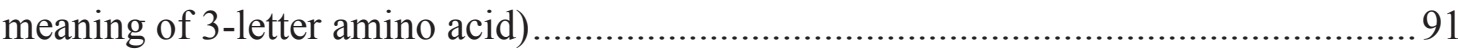

Table 5-4 Parameters used for modeling the process flow diagram..........................93

Table 5-5 Cost of raw materials and utilities used in process simulation ....................95 Table 5-6 Composition of streams for hydrolyzate to fermenter (S-16) and unreacted residues (S-13) [GLU-ACID: Glutamic Acid and ASP-ACID: Aspartic Acid]........... 96 Table 5-7 Summary of results from economic analysis from Aspen Plus ${ }^{\circledR}$ (United

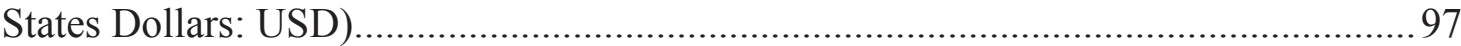

Table 5-8 Summary of GHG results from carbon footprint analysis ......................... 99

Table 6-1 Dairy feeds analyzed in this study. Shown in parenthesis are the percentage moisture content for all feed analyzed in this study (NDSU 2011).......................... 106 Table 6-2 Summary of allocation ratios and types used in this study ........................ 107 Table 6-3 Crop databases and data sources for dairy grains .................................... 111 Table 6-4 Allocation factors and GHG intensity of DDGS (See Tables D-16 and D-17)

Table 6-5 Emission Factors for Farm Input: Fertilizer, agro-chemical and energy .... 118 Table 6-6 Cradle to farm gate carbon footprint results of commonly used feeds by region and on national basis $\left(\mathrm{g} \mathrm{CO}_{2} \mathrm{e} . / \mathrm{kg}\right.$ dry feed) 
Table 7-1 Major feed inputs on a 4-month basis: soybean, dried distiller grain and other

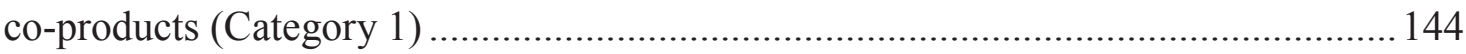

Table 7-2 Feed inputs on a 4-month basis: minerals and others (Category 2) ........... 145

Table 7-3 Summary of electricity inventory data for milling site from 2008-2009 .... 147 Table 7-4 Summary of natural gas inventory data for milling site from 2008-2009 Note: The ecoinvent profile used for natural gas is: Heat, natural gas, at boiler modulating $<100 \mathrm{~kW} / \mathrm{RER} \mathrm{S}$. The emission factor for electricity assuming Michigan grid was modified according to the study by Deru \& Torcellini, 2007 147

Table 7-5 Summary fuel usage input data (average for 2007 and 2008) for road transport of milled feed product from mill to Michigan dairy farm .......................... 148 Table 7-6 Emission factors and mill greenhouse gas analysis ............................... 149 Table A-1 Comparison of DAP (first stage) with 72 hours EH for $0 \mathrm{wt} \%$ acid

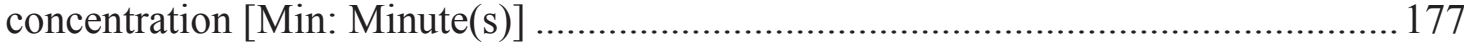
Table A-2 Comparison of DAP (first stage) with 72 hours EH for 1 wt $\%$ acid

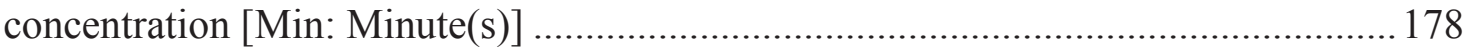
Table A-3 Comparison of DAP (first stage) with 72 hours EH for 2 wt $\%$ acid concentration [Min: Minute(s)] 179

Table A-4 Inhibitory concentrations of furfural and HMF for three types of yeast and E. coli $\mathrm{KO} 11$ 180

Table B-1 Amino acid concentrations of enzyme blanks (Pathway 2) 183

Table B-2 Amino acid concentrations of enzyme blanks (Pathway 3) experimental set 1 183

Table B-3 Amino acid concentrations of enzyme blanks (Pathway 3) experimental sets $2,3 \& 4$ 184

Table B-4 Amino acid concentrations of enzyme blanks (Pathway 3) experimental sets 5, $6 \& 7$ (ND: None detected). 185

Table B-5 Amino acid concentrations of enzyme blanks (Pathway 4): 1\% v/v Protex 6L 185

Table B-6 Amino acid concentrations of enzyme blanks (Pathway 4): 2\% v/v Protex 6L 
Table B-7 Sugar concentrations of enzyme blanks (Pathway 4): 1\% v/v Protex 6L .. 187 Table B-8 Sugar concentrations of enzyme blanks (Pathway 4): 2\% v/v Protex 6L .. 187

Table B-9 HMF and Furfural concentrations for hydrolysis pathway 3 188

Table C-1: Reactant components and chemical formular for protein model 193

Table C-2 Product components and chemical formular for protein model 193

Table D-1 Region 1 Grazing season average ration (All values reported as pounds of dry matter intake per day).

Table D-2 Region 1 Non-grazing season average ration (All values reported as pounds of dry matter intake per day) 199

Table D-3 Region 2 Grazing season average ration (All values reported as pounds of dry matter intake per day) 200

Table D-4 Region 2 Non-grazing season average ration (All values reported as pounds of dry matter intake per day) 200

Table D-5 Region 3 Grazing season average ration (All values reported as pounds of dry matter intake per day) 201

Table D-6 Region 3 Non-grazing season average ration (All values reported as pounds of dry matter intake per day) 201

Table D-7 Region 4 Grazing season average ration (All values reported as pounds of dry matter intake per day)..... 202

Table D-8 Region 4 Non-grazing season average ration (All values reported as pounds of dry matter intake per day) 202

Table D-9 Region 5 Grazing season average ration (All values reported as pounds of dry matter intake per day). 203

Table D-10 Region 5 Non-grazing season average ration (All values reported as

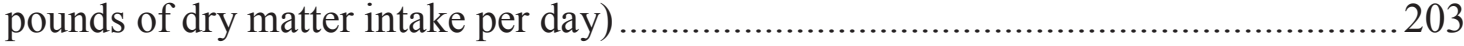

Table D-11 Soybean (GHG profile $\mathrm{Ib} \mathrm{CO}_{2}$ eq per $\mathrm{lb}$ dry soybean)..........................208

Table D-12 Corn grain (GHG profile $\mathrm{Ib} \mathrm{CO}_{2}$ eq per $\mathrm{lb}$ dry corn grain) ....................218

Table D-13 Corn Silage (Yield: wet short tons/ acre \& GHG profile Ib CO2 eq per lb

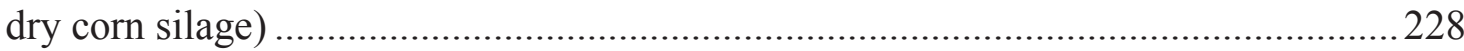

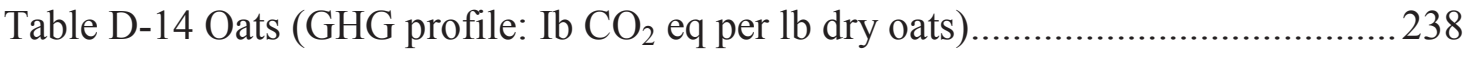

Xviii 
Table D-15 Winter wheat (GHG profile: $\mathrm{Ib} \mathrm{CO}_{2}$ eq per lb dry wheat) ...................... 248

Table D-16 Wet mill / Dry mill dried distillers grains with solubles (DDGS)...........258

Table D-17 GHG emissions on basis of $\mathrm{kgCO}_{2} \mathrm{e} / \mathrm{MJ}$ Ethanol ..................................258

Table D-18 Estimation of $\mathrm{N}$ emissions for corn from manure management system (MMS) using IPCC Tier I model: Region 1 .............................................................259

Table D-19 Estimation of N emissions for corn from MMS using IPCC Tier I model:

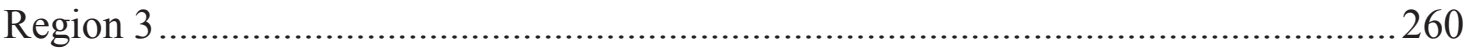

Table D-20 Estimation of N emissions for corn from MMS using IPCC Tier I model:

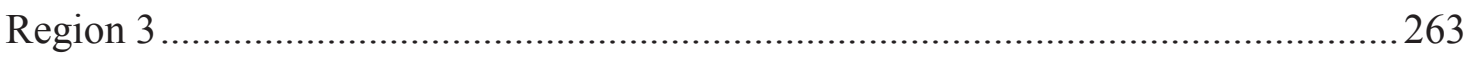

Table D-21 U.S. annual consumption of selected nitrogen materials from 2004-2007 (short tons $\mathrm{N}$ fertilizer) 265

Table D-22 Fertilizer Mixtures used in this study ( $\mathrm{N}$ fertilizer). Note that the values do not add to 1.0 because ammonia is on a total compound weight basis while all others

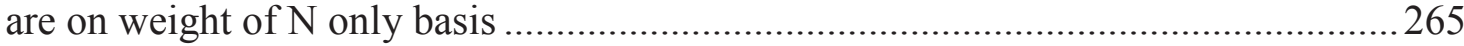

Table D-23 Fertilizer mixtures used in this study (P.K.S fertilizer).........................266

Table D-24 Estimation of nitrogen emission from major crop residues using IPPC Tier

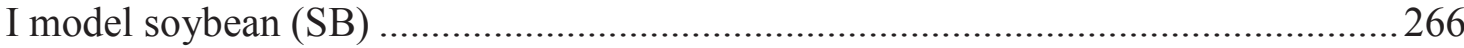

Table D-25 Estimation of nitrogen emission from major crop residues using IPPC Tier

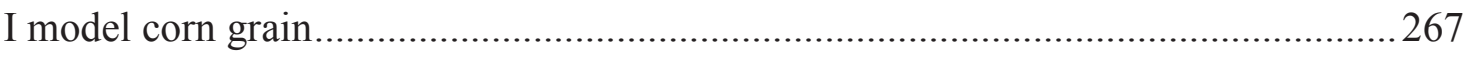

Table D-26 Estimation of nitrogen emission from major crop residues using IPPC Tier

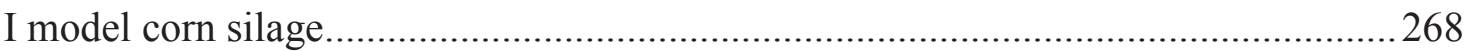

Table D-27 Estimation of nitrogen emission from major crop residues using IPPC Tier

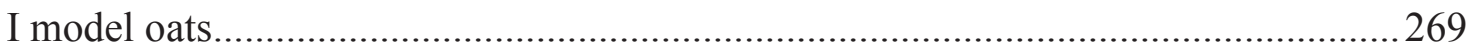

Table D-28 Estimation of nitrogen emission from major crop residues using IPPC Tier

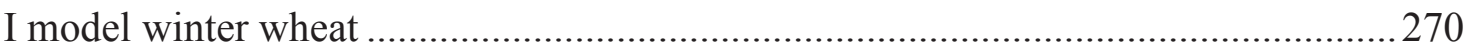

Table D-29 GHG Emission Factors of Pesticides for some major crops (Soybean)... 271 Table D-30 GHG Emission Factors of Pesticides for some major crops (corn

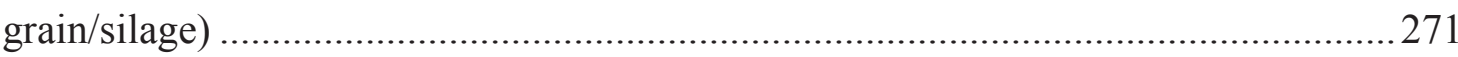

Table D-31 GHG Emission Factors of Pesticides for some major crops (oats) .......... 272 
Table D-32 GHG Emission Factors of Pesticides for some major crops (winter wheat)

Table D-33 Pedigree matrix for Soybean ........................................................... 273

Table D-34 Pedigree matrix for Corn grain/silage ...............................................2 274

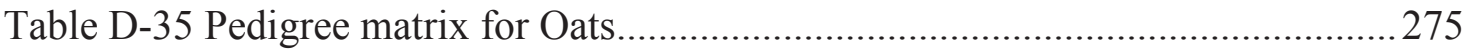

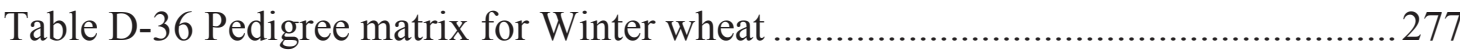

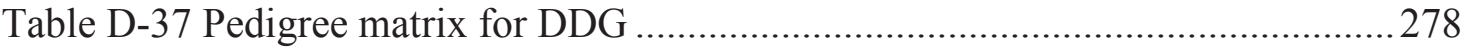

Table D-38 Pedigree matrix for Alfalfa Hay and Silage .........................................2278

Table D-39 Pedigree matrix for Grass Hay and Silage .........................................2 279

Table D-40 Pedigree matrix for Grass Pasture …...................................................2 279

Table D-41 Pedigree matrix for Soybean Meal ................................................. 280

Table D-42 Geometric standard deviation estimation (SBM: Soybean meal) ............280

Table D-43 Estimation of upper/lower bound values of grain crops........................281

Table D-44 Estimation of upper/lower bound values of forage .............................. 283

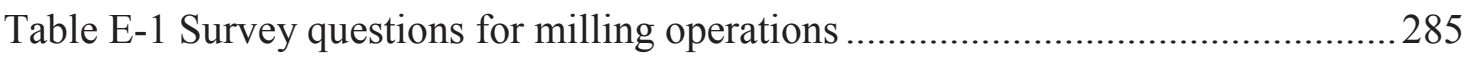

Table E-2 Survey Questions for feed ingredients inputs ......................................286

Table E-3 Survey questions for feed transportation inputs ....................................28

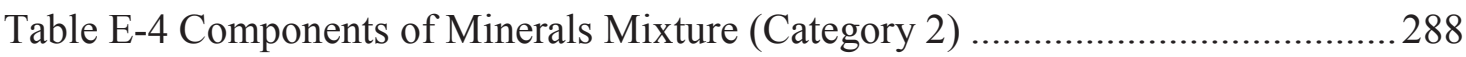

Table E-5 Feed Inputs; 4-Month Purchase History (Category 3) ............................. 289

Table E-6 Transportation Inputs for Category 1 Feed Ingredients...........................291

Table E-7 Transportation Inputs for Category 2 Feed Ingredients............................293

Table E-8 Transportation Inputs for Category 3 Feed Ingredients ...........................295 


\section{Preface}

This dissertation titled "The potential of industrial waste and agricultural feedstock towards sustainable biofuels production: Techno-economic and environmental impact perspectives," centers on the efficient utilization of biomass feedstock for the production of value added bioproducts and carbon footprint analysis. This $\mathrm{PhD}$ research work in its entirety comprises of three components; characterization studies, hydrolysis experiments and sustainability analysis.

All laboratory experiments and computer simulation works were implemented in consultation with my PhD advisor Professor David Shonnard and periodic interaction with other $\mathrm{PhD}$ committee members. With the help of Jiqing Fan (PhD candidate), Jamie Davis (undergraduate researcher) and Paul Dunn (undergraduate researcher), various analytical experiments were conducted to understand the chemical and structural components of defatted corn syrup from a dry corn mill facility for the characterization studies.

The hydrolysis experiments required the development of an optimized hydrolysis pathway to produce fermentable sugars and amino acid platform using defatted corn syrup as a feedstock. After experimental design in consultation with my advisor, Jiqing Fan, Jamie Davis and Amanda Taylor (undergraduate researcher) assisted in conducting various experiments as well as analyzing data for the sugar platform optimization. For the amino acid platform optimization using the syrup, after experimental design in consultation with my advisor, Paul Dunn and Stefan Ruccins supported in implementing various experiments as well as analyzing data.

The sustainability analysis component is comprised of three subcomponents namely techno-economic analysis (TEA) and life cycle assessment (LCA), carbon footprint of dairy feeds for milk production in the U.S., and carbon footprint of a dairy feed from a dairy mill in Michigan, U.S. The TEA and LCA models were constructed in close 
collaboration with Dr. Tony Rogers (PhD committee member). Both the research on carbon footprint analysis of dairy feed and a feed mill were a collaboration study with University of Arkansas. Ashley Maes and Charles Workman (undergraduate researchers) lent support to collected data as well as construct the carbon footprint models in excel spreadsheet. Collaborators from University of Arkansas (Greg Thoma and Zara Clayton-Niederman) helped analyze some other dairy feeds (forage crops) and provided timely feedback.

Finally, chapters 2, 3, 4, and 5 are planned manuscripts for future submission. Chapter 6 and 7 have already been published in International Journal and Life Cycle Assessment (Springer) and Internation Dairy Journal respectively (Elsevier). With the kind permission of both Springer (see Figure D-1) and Elsevier (see Figure E-1), this work has been reproduced for use in this dissertation. 


\section{Acknowledgements}

This project reflects the work of a great many people and has been completed successfully through the individual contribution and moral support of individuals and some corporate sponsors. The author is indebted to his primary advisor, Dr. David Shonnard who supervised this Ph.D. research, provided insights, academic and technical support in this study. Sincere gratitude is due to members of the supervisory committee: Dr. Susan Bagley, Dr. Tony Rogers and Dr. Wenzhen Li without whose support this study would have been defective. The author would also like to gratefully acknowledge the funding sources that made my Ph.D. work possible. The Dairy Management Incorporated and the Michigan Energy Development Center funded me. I am appreciative of my fellow graduate students particularly Michael BrodeurCampbell, Jiqing Fan, Jordan Klinger and Jifei Liu for their support. The author wishes to express appreciation to his family: my parents Samuel and Elizabeth Adom, brother Augustus Adom, sister Patricia Adom, fiancée Carolyn Adama and friends for their support during this period of study. I would also like to express my sincere gratitude to Jerry Anane Frimpong and Nicholas Kyei-Baffour for their fatherly support and advice. Their unwavering love, encouragement and belief in me have brought me this far. Finally, my biggest gratitude goes to Lord God Almighty for giving me the strength and intelligence to complete my PhD study successfully. May His name be forever extolled. 


\section{List of abbreviations}

AAA - Amino acid analysis

ABE - Acetone Butanol Ethanol

Ar/Mn - Arabinose/mannose

ASL - Acid soluble lignin

AIL - Acid insoluble lignin

Ala - Alanine

Arg - Arginine

Asn - Asparagine

Asp - Aspartic acid

BSA - Bovine Serum Albumin

CF - Correction factor (Anhydrous)

Cys - Cysteine

DAH - Dilute acid hydrolysate

DOE - Department of Energy

DAP - Dilute acid pretreatment

DCS - Defatted corn syrup

DDGS - Dried distillers grains with

solubles

DM - Dry matter

DWG - Distillers wet grains

EH - Enzymatic hydrolysis

EAA - Essential amino acids

FMOC - 9-Fluorenylmethyl

chloroformate

Gln - Glutamine

Glu - Glutamic acid

Gly - Glycine

GHG - Greenhouse gas

GWP - Global warming potential

His - Histidine

HPLC - High-performance liquid

chromatography
HMF - Hydroxymethylfurfural

Ile - Isoleucine

LAP - Laboratory analytical procedures

Leu - Leucine

LPS - Low pressure steam

Lys - Lysine

Met - Methionine

M - Million

NEAA - Non-essential amino acids

NREL - National Renewable Energy Lab

NSC - Non-starch carbohydrates

OPA - O-phthalaldehyde

Otd - Ornithine

PES - Potato extracted starch

Phe - Phenylanlanine

Pro - Proline

SD - Sustainable development

Ser - Serine

SRS - Sugar recovery standards

\%Starch - Percentage of starch

\%R starch - Starch recovery standards

T - Thousand

TBC - Target bio-based chemical

Thr - Threonine

TMS: Total monomer sugars

Try - Tryptophan

TS - Thin stillage

Tyr - Tyrosine

Val - Valine

VOC - Volatile organic compounds

$\mathbf{X}$ - Yield 


\begin{abstract}
This Ph.D. research is comprised of three major components; (i) Characterization study to analyze the composition of defatted corn syrup (DCS) from a dry corn mill facility (ii) Hydrolysis experiments to optimize the production of fermentable sugars and amino acid platform using DCS and (iii) Sustainability analyses. Analyses of DCS included total solids, ash content, total protein, amino acids, inorganic elements, starch, total carbohydrates, lignin, organic acids, glycerol, and presence of functional groups. Total solids content was $37.4 \%( \pm 0.4 \%)$ by weight, and the mass balance closure was $101 \%$. Total carbohydrates $[27 \%( \pm 5 \%)$ wt.] comprised of starch $(5.6 \%)$, soluble monomer carbohydrates $(12 \%)$ and non-starch carbohydrates $(10 \%)$. Hemicellulose components (structural and non-structural) were; xylan $(6 \%)$, xylose $(1 \%)$, mannan $(1 \%)$, mannose $(0.4 \%)$, arabinan $(1 \%)$, arabinose $(0.4 \%)$, galatactan $(3 \%)$ and galactose $(0.4 \%)$. Based on the measured physical and chemical components, bio-chemical conversion route and subsequent fermentation to value added products was identified as promising. DCS has potential to serve as an important fermentation feedstock for bio-based chemicals production.
\end{abstract}

In the sugar hydrolysis experiments, reaction parameters such as acid concentration and retention time were analyzed to determine the optimal conditions to maximize monomer sugar yields while keeping the inhibitors at minimum. Total fermentable sugars produced can reach approximately $86 \%$ of theoretical yield when subjected to dilute acid pretreatment (DAP). DAP followed by subsequent enzymatic hydrolysis was most effective for $0 \mathrm{wt} \%$ acid hydrolysate samples and least efficient towards 1 and $2 \mathrm{wt} \%$ acid hydrolysate samples. The best hydrolysis scheme DCS from an industry's point of view is standalone 60 minutes dilute acid hydrolysis at $2 \mathrm{wt} \%$ acid concentration.

The combined effect of hydrolysis reaction time, temperature and ratio of enzyme to substrate ratio to develop hydrolysis process that optimizes the production of amino 
acids in DCS were studied. Four key hydrolysis pathways were investigated for the production of amino acids using DCS. The first hydrolysis pathway is the amino acid analysis using DAP. The second pathway is DAP of DCS followed by protein hydrolysis using proteases [Trypsin, Pronase E (Streptomyces griseus) and Protex 6L]. The third hydrolysis pathway investigated a standalone experiment using proteases (Trypsin, Pronase E, Protex 6L, and Alcalase) on the DCS without any pretreatment. The final pathway investigated the use of Accellerase $1500^{\circledR}$ and Protex $6 \mathrm{~L}$ to simultaneously produce fermentable sugars and amino acids over a 24 hour hydrolysis reaction time.

The 3 key objectives of the techno-economic analysis component of this $\mathrm{PhD}$ research included; (i) Development of a process design for the production of both the sugar and amino acid platforms with DAP using DCS (ii) A preliminary cost analysis to estimate the initial capital cost and operating cost of this facility (iii) A greenhouse gas analysis to understand the environmental impact of this facility. Using Aspen Plus ${ }^{\circledR}$, a conceptual process design has been constructed. Finally, both Aspen Plus Economic Analyzer ${ }^{\circledR}$ and Simapro ${ }^{\circledR}$ sofware were employed to conduct the cost analysis as well as the carbon footprint emissions of this process facility respectively.

Another section of my $\mathrm{PhD}$ research work focused on the life cycle assessment (LCA) of commonly used dairy feeds in the U.S. Greenhouse gas (GHG) emissions analysis was conducted for cultivation, harvesting, and production of common dairy feeds used for the production of dairy milk in the U.S. The goal was to determine the carbon footprint [grams $\mathrm{CO}_{2}$ equivalents $\left(\mathrm{gCO}_{2} \mathrm{e}\right) / \mathrm{kg}$ of dry feed] in the U.S. on a regional basis, identify key inputs, and make recommendations for emissions reduction. The final section of my Ph.D. research work was an LCA of a single dairy feed mill located in Michigan, USA. The primary goal was to conduct a preliminary assessment of dairy feed mill operations and ultimately determine the GHG emissions for 1 kilogram of milled dairy feed. 


\section{Chapter 1 \\ 1 Introduction}

\subsection{Motivation}

Perhaps the most widely used definition of sustainable development (SD) is the Brundtland Commission's version, which states that “ability to make development sustainable-to ensure that it meets the needs of the present without compromising the ability of future generations to meet their own needs (Bruntland 1987)." In addition, SD was defined as "development without growth-that is, qualitative improvement in the ability to satisfy (needs and desires) without quantitative increase in throughput beyond environmental carrying capacity (Daly and Farley 2010). Carrying capacity is

the population of humans that can be sustained by a given ecosystem at a given level of consumption, with a given technology." Generally, SD is viewed as some combination of the "triple bottom line" of economic development, social development, and environmental / resource sustainability (Solomon 2010).

Driven mostly by population and gross domestic product (GDP), the annual energy consumption in the U.S. has increased steadily by more than 200\% since 1950 (Krupnick et al. 2010). Atmospheric concentrations of $\mathrm{CO}_{2}$ have increased from preindustrial levels of about 280 parts per million ( $\mathrm{ppm}$ ) to their current levels of about $395 \mathrm{ppm}$ and this increase over pre-industrial levels is mainly due to anthropogenic emissions (Pachauri 2007). Key global sustainability challenges facing the Earth's population in the $21^{\text {st }}$ century are related to the nearly total complete reliance on fossil fuel for energy consumption, energy's environmental consequences, and finally the impact of the rapid development of the four major developing continents: Africa, Asia, Latin America and other small island developing states.

Transition to bio-based raw materials as opposed to fossil resources has long been touted as the key to addressing some of these challenges (Mowrey and Spain 1999; Simmons et al. 2008; Hallac et al. 2009; Solomon 2010). The primary drivers for the 
use of biomass as a renewable feedstock includes, but is not limited to, decreasing reliance on fossil fuels (energy security), and as a means of addressing concerns over the contribution of fossil-fuel consumption by the transport sector to global warming (McKendry 2002). In the USDA-DOE billion ton update report (United States. Dept. of Energy 2011), it was established that the U.S. has enough biomass to sustainably displace about $1 / 3$ of its petroleum demand. The development of environmentally benign technologies to tap biomass resources as well as policies to promote the use of renewable energy should be complemented with the development of science-based sustainability metrics and indicators to measure progress.

The Climate Change Technology Program (CCTP) established administratively in 2002 with authorization by the Energy Policy Act in 2005 (Congress 2005), has the mandate of accelerating the development and deployment of technologies that can reduce, avoid, or capture and store greenhouse gases (GHG). Four key goals of technology strategy were identified as important; end-use efficiency and infrastructure, energy supply, carbon capture and sequestration and non-CO $\mathrm{O}_{2} \mathrm{GHG}$ 's abatement technologies. End-use efficiency and infrastructure emphasized on four major sectors; transportation, buildings, industry, and the electric grid. Improved vehicle efficiency, electric-fuel engine hybrids ("hybrid-electric" vehicles and "plug-in hybrids"), and clean diesel engines are a few examples under transportation. CCTP also emphasized on two key areas for industry. Firstly, technologies should be developed to improve efficiency of process heating and enhanced industrial plant design. These technologies should have the capability of reducing waste and material use intensity through material and waste energy recycling processes. Secondly, process technologies should increase the use of industrial by-products and waste materials as a potential energy sources and raw materials. Doing this will create an industry that can self-generate clean energy, making it more sustainable and less dependent on other sources of energy. 
CCTP has also identified energy supply as a potential for large-scale GHG mitigation. It emphasizing four major sectors namely; i. emission reduction from energy supply, ii. fossil-based fuels and power, iii. hydrogen, renewable energy \& fuels, and iv. nuclear fission. Integrated gasification combined system and oxy-fuel combustion, hydrogen production from natural gas and biomass, low-speed wind turbines, biochemical reactors for conversion of sugar to ethanol, the bio-refinery concept and gasification or pyrolysis to produce bio-fuels are some proposed sustainable energy technologies.

Carbon Sequestration focuses on carbon capture, geologic storage and terrestrial sequestration. Amine scrubbing, $\mathrm{CO}_{2}$ injection with oil or methane recovery and cropland, forestland management with advanced information technologies are examples of some of the technologies that are currently available for deployment. However, there are still some economic, environmental and political challenges. Other non- $\mathrm{CO}_{2}$ GHG such as methane, nitrous oxide $\left(\mathrm{N}_{2} \mathrm{O}\right)$, and the halocarbons (e.g. HFCs, CFCs and HCFCs typically contained in coolants) contributes to warming the atmosphere. Some technologies proposed by CCTP include; aerobic and anaerobic bioreactor treatment, advance agricultural sensors, nitrogen transformation inhibitors, controlled release fertilizers, and $\mathrm{N}_{2} \mathrm{O}$ abatement technologies for nitric acid production.

In line with the CCTP strategic goals, there is an urgent need to develop technologies capable of reducing waste and material use intensity through material recycling processes. Human beings generate tons of wastes daily, and there is also the need to increase usage of industrial by-products. Another underlying factor for SD is the establishment of scientific based sustainability metrics and indicators as a means of tracking progress in developing sustainable products / processes for various industries. In addition to the internationally established methods for measuring sustainability impacts (ISO 2006a; 2006b; Sinden et al. 2008), other researchers (Allen and Shonnard 2001; Reinhard et al. 2011; Hennecke et al. 2012) have to a great extent reported on this in the literature. 


\subsection{PhD research objectives}

The primary direction of this Ph.D. research was defined by three major components. The first component of the research is the characterization study to analyze the composition of an industrial process residue [defatted corn ethanol mill syrup (DCS)] to evaluate its suitability for conversion to biofuels and bio-products. A second research component is hydrolysis experiments which were focused on developing processing conditions and techniques to optimize the release of fermentable intermediate products (sugars \& amino acids). These intermediates may serve as a platform for the production of higher value products. The third component of this $\mathrm{Ph} . \mathrm{D}$. research program includes sustainability analyses, and has three further subcategories. The aim of subcategory "a" was to develop a conceptual process design for the production of two intermediate products; fermentable sugars and amino acids using DCS as the feedstock to investigate how the interplay between the economic and environmental impacts will influence commercial scale up in the future. The aim of subcomponent "b" was to understand the environmental impact of commonly used dairy feeds such as grains, forage crops and other co-products like soybean meal and distiller's grain cultivated and harvested across the U.S. Finally, the aim of subcomponent "c" was to analyze the carbon footprint (GHG emissions) of producing dairy feed from a feed mill in the U.S. and including transport to local dairy markets.

Specific objectives of this Ph.D. project are highlighted below;

1. A compositional analysis of DCS to investigate the following; total solids, ash content, protein and amino acids, inorganic elements, starch, structural and soluble carbohydrates, lignin, organic acids, glycerol, and functional groups.

2. Optimization of the release of fermentable sugars from DCS via dilute acid pretreatment (DAP) and enzymatic hydrolysis (EH) by varying taking into account the following process variables: reaction time, temperature and acid catalyst concentrations was also investigated. 
3. Optimization of the release of fermentable amino acids from DCS using DAP and proteases for protein hydrolysis $(\mathrm{PH})$ taking into account the following process variables: temperature, reaction time, and enzyme/substrate ratio was also investigated.

4. Application of process simulation software (Aspen plus ${ }^{\circledR}$ ) and environmental life cycle assessment software (Simapro $($ ) to model the optimized hydrolysis pathway and to investigate the initial capital cost and associated environmental impacts.

5. Determination of the carbon footprint (GHG emissions) from the cultivation and harvesting of U.S. dairy feeds on a basis of $1 \mathrm{~kg}$ of feed harvested or produced in units of grams $\mathrm{CO}_{2}$ equivalents $\left(\mathrm{gCO}_{2} \mathrm{e}\right) / \mathrm{kg}$ of dry feed.

6. The final task was to develop Life Cycle Assessment (LCA) methodology applicable to the animal feed mill industry to accommodate a large number of inputs and activities associated with dairy mill operations and to help understand its environmental impacts [Greenhouse gas (GHG) emissions only].

\subsection{Dissertation outline}

This dissertation comprise of eight chapters. The first chapter introduces the "triple bottom line" concept of sustainability and further identifies various technologies for addressing global sustainability challenges. This section further identifies what industry needs to do (a key motivation for this Ph.D. project) in order to address sustainability issues, and it emphasizes on the need to use internationally established metrics and indicators as a means of tracking progress in developing sustainable products / processes. Chapters 2-4 present the methods, results, and analyses for DCS compositional analyses, hydrolysis optimization of carbohydrates to produce sugars, and hydrolysis optimization of protein to produce amino acids. Chapter 5 reports on results from the process simulation and LCA analyses to produce sugar and amino acids as intermediate products. Chapters 6 and 7 report the LCA analyses for the various dairy feed crops as well as the mill impact analyses focusing on GHG emissions. Finally, in chapter 8, a summary of all findings from the Ph.D. research are reported, conclusions are drawn and potential future research projects have been 
recommended. Some repetition may be observed given that each major chapter has been prepared as a "stand-alone" article for publication in peer reviewed journals.

\subsection{References}

Allen DT, Shonnard DR, Green engineering: environmentally conscious design of chemical processes. Prentice Hall: 2001.

Bruntland G, Our common future: the world commission on environment and development. Oxford: Oxford University Press: 1987; Vol. 1.

Congress U. 2005. Energy Policy Act of 2005. Public Law 109:58.

Daly HE, Farley J, Ecological economics: principles and applications. Island Pr: 2010.

Hallac BB, Sannigrahi P, Pu Y, Ray M, Murphy RJ, Ragauskas AJ. 2009. Biomass characterization of Buddleja davidii: a potential feedstock for biofuel production. Journal of agricultural and food chemistry 57(4):1275-1281.

Hennecke AM, Faist M, Reinhardt J, Junquera V, Neeft J, Fehrenbach H. 2012. Biofuel greenhouse gas calculations under the European Renewable Energy Directive-A comparison of the BioGrace tool vs. the tool of the Roundtable on Sustainable Biofuels. Applied Energy.

ISO E. 2006a. 14040: 2006. Environmental management-Life cycle assessmentPrinciples and framework.

ISO E. 2006b. 14044: 2006. Environmental Management-Life Cycle AssessmentRequirements and Guidelines.

Krupnick AJ, Parry IWH, Walls M, Knowles T, Hayes K. 2010. Toward a new national energy policy: assessing the options. Washington, DC: Resources for the Future.

McKendry P. 2002. Energy production from biomass (part 1): overview of biomass. Bioresource technology 83:37-46.

Mowrey A, Spain J. 1999. Results of a nationwide survey to determine feedstuffs fed to lactating dairy cows. Journal of dairy science $82(2): 445-451$.

Pachauri RK. 2007. Climate Change 2007: Synthesis Report. Contribution of Working Groups I, II and III to the Fourth Assessment Report of the Intergovernmental Panel on Climate Change. Change 446(November). 
Reinhard J, Emmenegger MF, Widok AH, Wohlgemuth V. A LCA Tool for the Assesment of Biofuels Sustainability. 2011.

Simmons BA, Loque D, Blanch HW. 2008. Next-generation biomass feedstocks for biofuel production. Genome Biol 9(12):242.

Sinden G, Skea S, Jefferiss P, Clift R, Jackson T, Ilot T. 2008. PAS 2050: 2008, Specification for the Assessment of the Life Cycle Greenhouse Gas Emissions of Goods and Services.

Solomon BD. 2010. Biofuels and sustainability. annals of the New York Academy of Sciences 1185(1):119-134.

United States. Dept. of Energy. 2011. US Billion-Ton Update: Biomass Supply for a Bioenergy and Bioproducts Industry. Perlack, R.D., Stokes, B.J. (Leads). Oak Ridge National Laboratory. 


\section{Chapter 2}

\section{Compositional Analysis of Defatted Syrup from a Corn Ethanol Dry Mill as a Feedstock for Bio-Based Products ${ }^{1}$}

\subsection{Introduction}

Depletion of non-renewable fossil fuels and increasing greenhouse gas (GHG) emissions continue to raise economic and environmental concerns. As a result, research on bio-based fuels and chemicals has gained worldwide momentum. Lignocellulosic biomass and processing residues are two types of feedstocks which could be used to produce bio-based fuels and chemicals, while not competing with the production of food.

The USDA-DOE billion ton update report (United States. Dept. of Energy 2011) identified forest and agricultural resources as major potential sources of biomass with the potential of sustainably displacing about 1/3 of U.S. petroleum demand. The potential of feedstock such as switch grass, willow and hybrid poplar have been extensively studied (Tharakan et al. 2003; Sannigrahi et al. 2010). The investigation of process residues such as municipal solid waste, sewage sludge, defatted corn ethanol dry mill syrup (DCS), dried distillers grains with solubles (DDGS), and food processing wastes from dairy and sugar industry as potential feedstocks for bio-based products has received less attention.

Biomass characterization is an important first step in evaluating the feasibility of biomass as a potential feedstock for conversion to biofuels and bio-based products. Apart from informing the choice of conversion platform such as thermochemical, chemical and bio-chemical, it is vital for many other reasons (McKendry 2002). For

${ }^{1}$ This chapter will be submitted to the Journal of Agricultural and Food Chemistry. Citation: Adom, F., Fan, J., Davis, J., Dunn, P., Shonnard, D. (2012). Compositional Analysis of Defatted Syrup from a Corn Ethanol Dry Mill as a Feedstock for BioBased Products. Journal of Agricultural and Food Chemistry. 
example, quantification of cellulose, hemicellulose and lignin is crucial as it affects the overall economics of biorefining, especially for wet biomass conversion processes. Inorganic elements (macro \& micronutrients) analysis provide useful information on nutrients depletion of soil (Sannigrahi et al. 2010) while lignin can be used as process heat energy (Xu et al. 2006).

Figure 2-1 summarizes the basic steps for the dry-grind corn mill process, and more details are reported in another study (Rausch and Belyea 2006b). Thin stillage (TS) which is the parent stream of syrup [referred to as DCS in this article (Figure 2-1)] is the feedstock in this study. DCS stream results from the dewatering of TS through the multiple effect evaporators. DCS is golden brown in color with a slightly fermented aroma, and it is viscous compared to water. Due to the high fiber, carbohydrates and protein content it is usually added to DDGS for drying and use as a feed additive ( Rausch and Belyea 2006b).

Literature review on prior work done on DCS identified a number of studies to be relevant (Wilkie et al. 2000; Rausch and Belyea 2005; Belyea et al. 2006; Morey et al. 2006; Rausch and Belyea 2006a; Kim et al. 2008; Kim et al. 2010; Reaney et al. 2011). One study (Belyea et al. 2006) focused on characterizing the elemental concentrations of primary process streams from dry-grind ethanol plants with focus on tolerable levels of these elements as a source of animal feed. In another study, the authors (Morey et al. 2006) investigated the fuel and emission characteristics of co-products such as distillers wet grains (DWG), condensed distillers solubles (referred to as "syrup" or "DCS" in this study), DDGS, and corn stover. Technical evaluation of stillage treatment and byproduct recovery in the ethanol industry focusing on the viability of anaerobic digestion for stillage treatment was another relevant study identified (Wilkie et al. 2000). However, no single study was identified in the literature on DCS focusing on detailed characterization and evaluation of its potential towards production of biobased products \& biofuel. This study fills this gap by contributing to the knowledge of 
the potential utilization of DCS as a renewable feedstock. Three key objectives were identified in this study;

- Conduct an expansive composition analysis on DCS (i.e. total solids, ash content, protein, amino acids, inorganic elements, starch, structural and soluble carbohydrates, lignin, organic acids, glycerol, and functional groups)

- Recommend the most suitable conversion technology, i.e., thermochemical, chemical and bio-chemical for DCS

- Conduct a high level analysis of potential market for which DCS can serve as a feedstock for the production of biofuels and bio-based products

This study evaluates whether the components of DCS can serve as an important fermentation media for bio-based chemicals, pharmaceuticals, food, beverages and many other products.

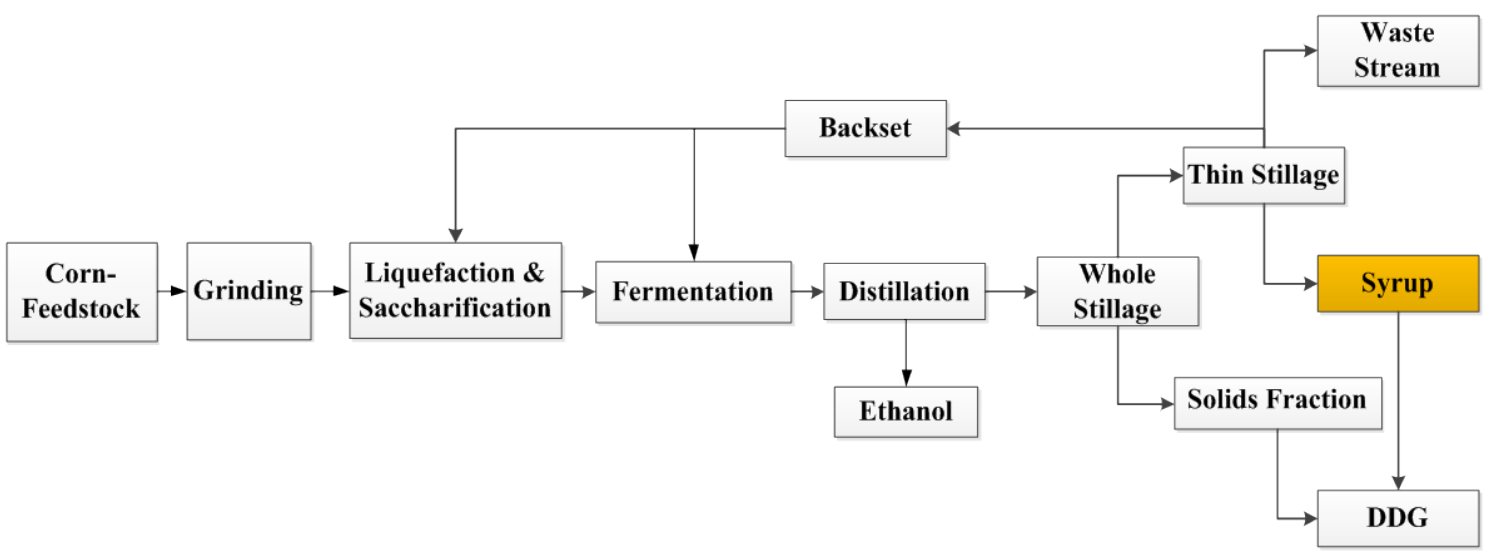

Figure 2-1 Schematic diagram of the dry-grind corn mill facility

(Adapted from Reaney et al, 2011)

\subsection{Materials and methods}

Six different samples in a $500 \mathrm{ml}$ centrifuge flasks labeled " $\mathrm{A}$ " through to " $\mathrm{F}$ " were received from a dry-grind corn ethanol milling facility and stored in a refrigerator at $5^{\circ} \mathrm{C}$ prior to any analysis. 


\subsubsection{Total solids analysis}

The total solid percentage in DCS was estimated by drying the sample in a convectiondrying oven at $105^{\circ} \mathrm{C}$ following an NREL protocol (Sluiter et al. 2008a). Remaining solid residues were sealed in Ziploc bags and stored in a desiccator for ash content analysis. DCS samples "A" through to "F" were all analyzed. All experiments were conducted in duplicate and equation (1) below was used for the analysis.

$$
\% \text { Total Solids }=\frac{[\text { Weight }(d r v p a n+d r v D C S)]-[\text { Weight (drv pan })]}{\text { Weight of DCS }}(1)
$$

\subsubsection{Ash content analysis}

The NREL protocol for ash analysis (Sluiter et al. 2008b) was used to estimate the total ash content of syrup using a Thermolyene 2000 muffle furnace (Thermo Scientific, West Palm Beach, FL). The percentage composition of ash was estimated by conducting duplicate trials at $575^{\circ} \mathrm{C}$. All samples labeled "A" through to "F" were analyzed. The quantity of ash in syrup was analyzed using equation (2):

$$
\% \boldsymbol{A s h}=\frac{\text { Weight }(\text { ash })}{\text { Weight }(\text { DCS sample })} \times 100(2)
$$

\subsubsection{Inorganic element profile}

$1 \mathrm{~g}$ of oven dried DCS ground to powder was digested in $10 \mathrm{ml}$ of $1 \% \mathrm{HNO}_{3}(\mathrm{v} / \mathrm{v})$ solution (Zarcinas et al. 1987). The solution was heated to $90^{\circ} \mathrm{C}$ for 45 minutes and subsequently increased to $140^{\circ} \mathrm{C}$ with occasional swirling until approximately $1 \mathrm{ml}$ of the solution was remaining. After cooling, $20 \mathrm{~mL}$ of $1 \mathrm{~N}$ nitric acid was added; the solution was further diluted with deionized water ( $30-60 \mathrm{x}$. dilution) for analysis using the Inductively Coupled Plasma Spectrometry (Perkin Elmer Optima 7000DV ICPOES, Waltham, MA). DCS samples "D" and "E" were analyzed for the following elements; $\mathrm{Ca}, \mathrm{Fe}, \mathrm{Mg}, \mathrm{Na}, \mathrm{K}, \mathrm{P}, \mathrm{Al}, \mathrm{Cu}, \mathrm{Zn}, \mathrm{Mn} \& \mathrm{~S}$. All experiments were conducted in duplicate.

\subsubsection{Protein content analysis}


Bradford reagent (St. Louis, MI) was used for this analysis. A detailed experimental procedure is reported in the technical bulletin (Sigma-Aldrich 2011). Using Bovine Serum Albumin (BSA) as reference protein, standards were prepared by serially diluting $100 \mathrm{mg} / \mathrm{ml} \mathrm{BSA} \mathrm{stock} \mathrm{solution:} 0$ (blank solution), 0.10, 0.25, and $0.8 \mathrm{mg}$ / $\mathrm{ml}$ of BSA with deionized water. To $100 \mu \mathrm{l}$ of DCS solution (5x diluted), $3 \mathrm{ml}$ of Bradford reagent was added in a $16 \times 100 \mathrm{~mm}$ test tube, vortexed and allowed to settle between 10-30 minutes at room temperature. Absorbance of standards and syrup solutions were measured at $595 \mathrm{~nm}$ using a Milton Roy, Spectronic 21D spectrophotometer (Champaign, IL).

\subsubsection{Amino acid analysis of syrup}

Amino acid analysis (AAA) technique by Agilent Technologies (Henderson et al. 2000) was used to analyze DCS. Briefly, $0.5 \mathrm{ml}$ of DCS was transferred into $1.5 \mathrm{ml}$ centrifuge vial using a micropipette and diluted three fold with distilled water. Ensuring uniform solution mixture by shaking with the hand, the vials were then subsequently centrifuged using VWR, Galaxy 16 Microcentrifuge (Batavia, IL) at 10,000 RPM for 25 minutes. A $0.22-\mu \mathrm{m}$ membrane was used to filter the supernatant into high-performance liquid chromatography (HPLC) vials. Samples were analyzed using an HPLC (Agilent 1200 series) equipped with Zorbax Eclipse column $(4.6 \times 150 \times 5 \mu \mathrm{m})$ at an operating temperature of $40^{\circ} \mathrm{C}$.

\subsubsection{Total carbohydrate analysis}

The total carbohydrate analysis (not including lignin) of DCS was comprised of three major components namely; (i) starch assay and (ii) soluble carbohydrate analysis (iii) non-starch carbohydrate analysis. Starch assay focused on glucose sugars generated from the starch hydrolysis enzyme taking into account the initial glucose present. Soluble carbohydrate analysis analyzed for water-soluble $\mathrm{C}_{5}$ and $\mathrm{C}_{6}$ sugars (nonstructural bound) in DCS. Non-starch carbohydrate analysis considered polymeric carbohydrates such as cellulose and hemicelluloses and any other oligomers in the DCS.

\subsubsection{Starch assay}


Detailed experimental method for the starch assay adopted for DCS is reported in an NREL report (Sluiter and Sluiter 2005). Briefly, 0.1g of oven dried DCS was hydrolyzed using $\alpha$-amylase (Sigma-Aldrich, St. Louis, MI, USA) and amyloglucosidase (Sigma-Aldrich, St. Louis, MI, USA). Hydrolysate was centrifuged, filtered $(0.22 \mu \mathrm{m})$ and analyzed for glucose using an Aminex HPX-87P column (BioRad Life Sciences, Hercules, CA) in the HPLC. A starch recovery standard was run under the same conditions simultaneously to account for unhydrolyzed starch using pure potato extracted starch (St. Louis, MI, USA). The equations (3) \& (4) were used to estimate the starch recovery standards $(\% \mathrm{R}$ starch $)$ and the percentage of starch (\%Starch) in DCS respectively.

$$
\begin{gathered}
\% \boldsymbol{R}_{(\text {Starch })=} \frac{\text { Conc. }(\text { glucose, PES }) \times \text { Volume }(P E S)}{\text { Weight }(\text { PES })} \times 100(3) \\
\% \text { Starch }=\frac{[\text { Conc. (glucose, DCS }) \times \text { Volume }(D C S)]-[\text { Mass of free glucose (oven dried, DCS })] \times 100(4)}{\% R(\text { Starch }) \times 1.11 \times \text { Weight (oven dried, DCS })}
\end{gathered}
$$

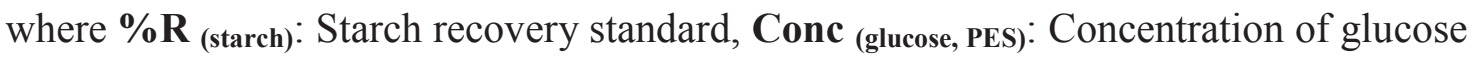
measured from the potato extracted starch (PES) hydrolysate, Conc (glucose, DCS): Concentration of glucose measured from DCS hydrolysate, Volume (PES): Volume of glucose solution for PES hydrolyzate, Volume (DCS): Volume of glucose solution for DCS hydrolyzate, Weight (PES): Weight of PES measured \& Weight (oven dried, DCS): Weight of oven dried DCS measured. "1.11" represents the glucose to starch oligomer correction factor. The mass of free glucose in the oven dry sample before application of $\alpha$-amylase and amyloglucosidase was measured using soluble carbohydrate analysis methods (in next section), total solid content analysis of DCS previously discussed, and syrup density of approximately $1000 \mathrm{mg} / \mathrm{ml}$ of syrup.

\subsubsection{Soluble carbohydrate analysis}

The concentrations of soluble carbohydrates (cellobiose, xylose, glucose, galactose, mannose, and arabinose) and fermentation inhibitors [furfural and hydroxymethylfurfural (HMF)] in DCS were determined by HPLC, (Agilent 1200, Santa Clara, CA), using Aminex HPX-87P column (Bio-Rad Life Sciences, Hercules, 
CA). Both the refractive index detector (RID) and diode array detector (DAD) were used. A 10x dilution of DCS was prepared using distilled water and mixed then filtered (0.22- $\mu \mathrm{m}$ membrane) into HPLC vials. Standards for both sugars and inhibitors were analyzed to generate four-point calibration curves. Duplicate samples were analyzed.

\subsubsection{Non-starch carbohydrate analyses}

A detailed experimental procedure for this analysis is reported in another report by NREL (Sluiter et al. 2008c). This analysis was conducted by measuring the total structural carbohydrate sugars (Sluiter et al. 2008c) and then subtracting from this the starch carbohydrate and soluble monomer sugars. Briefly, oven-dried DCS were taken through a two-step pretreatment procedure using $\mathrm{H}_{2} \mathrm{SO}_{4}$. To $0.3 \mathrm{~g}$ of oven dried DCS, $3 \mathrm{ml}$ of $72 \% \mathrm{wt} \mathrm{H}_{2} \mathrm{SO}_{4}$ was added and incubated in a water bath $\left(30^{\circ} \mathrm{C}\right)$ for 60 minutes for the first stage pretreatment step. Hydrolysate was subsequently brought to $4 \% \mathrm{wt}$ $\mathrm{H}_{2} \mathrm{SO}_{4}$ acid using distilled water and autoclaved at $121{ }^{\circ} \mathrm{C}$ for 60 minutes. For sugar recovery standards (SRS), monomer sugars of known concentration were run through the second step of the two-step procedure to account for sugar degradation and percent sugar recovered (\% R (sugar) ) using HPLC and equations (5) \& (6).

$\% \boldsymbol{R}($ sugar $)=\frac{\text { Concentration of sugar in SRS measured by HPLC (after pretreatment) }}{\text { Concentration of sugar in SRS measured by HPLC (before pretreatment })} \times 100(5)$

$\%$ Total Structural Carbohydrate $=\frac{\text { Conc }(D C S) \times C F \times \text { Volume }(D C S)}{\% R \text { sugar } \times \text { Weight }(\text { oven dried, DCS })} \times 100(6)$

In the equation (6), Conc (DCS) is the sugar concentration measured from DCS hydrolysate following two-step pretreatment while Volume (DCS) is the volume of DCS hydrolysate. Finally, anhydrous correction factor (CF), which is the molecular mass ratio of the polymeric sugars to their monomeric units, was applied in the equation above; 0.9 was assigned for glucose and galactose $\left(\mathrm{C}_{6}\right.$-sugars $)$ while 0.88 was used for xylose and arabinose ( $\mathrm{C}_{5}$-sugars).

\subsubsection{Lignin analyses}


The method for acid soluble lignin (ASL) and acid insoluble lignin (AIL) analysis by NREL (Sluiter et al. 2008c) was adopted for this study. Similar to the total carbohydrate analysis previously described, the oven-dried DCS biomass was run through a two-step pretreatment stage. The hydrolysate was separated by filtration using a membrane filter (VWR, polycarbonate membrane filter, $25 \mathrm{~mm}$ dia., $0.2 \mu \mathrm{m}$ pore size) into two fractions: a liquid fraction and an insoluble fraction. The liquid fraction containing the soluble lignin was analyzed using a UV-Visible spectrophotometer (Genensys $^{\mathrm{TM}}$ 10, Thermo Electron Corp., West Palm Beach, FL) at a wavelength of $240 \mathrm{~nm}$. AIL concentrations were corrected for protein by subtracting protein concentrations estimated under protein content analysis of DCS. The insoluble fraction was ashed at $575^{\circ} \mathrm{C}$ until constant weight and the final weight of residues was measured. Both ASL and AIL were estimated using equations (7) \& (8) below:

$$
\begin{gathered}
\% A I L=\frac{\text { Weight (residue) }- \text { Weight (ash) }- \text { Weight (protein) })}{\text { Weight (sample, DCS) }} \times 100(7) \\
\% A S L=\frac{\text { Absorbance }(240 \text { nm) } \times \text { Volume (filtrate) } \times \text { Dilution }}{\text { Absorptivity } \times \text { Weight (sample, DCS) } \times 100 \text { Pathlength }}
\end{gathered}
$$

Absorptivity was $55 \mathrm{~L} / \mathrm{g} / \mathrm{cm}$

\subsubsection{Glycerol analysis}

DCS samples were diluted five-fold using distilled water. The diluted samples were filtered into HPLC vials $(0.22 \mu \mathrm{m}$ membrane) and analyzed using HPLC with an Aminex HPX-87P column and a refractive index detector. Calibration standards were run with known concentrations of glycerol (Macron Fine Chemicals ${ }^{\text {TM }}$., Batavia, IL). Duplicate samples were analyzed.

\subsubsection{Total organic acid analysis}

Samples of DCS $(2 \mathrm{ml})$ were transferred into a $10 \mathrm{ml}$ vial. Distilled water $(2 \mathrm{ml})$ was added to dilute samples by two-fold. The syrup solution was vortexed to ensure uniform mixture. A $0.22 \mu \mathrm{m}$ membrane was used to filter the solution into an HPLC vial for organic acid analysis in the HPLC. The Rezex ROA-organic $\mathrm{H}+(8 \%)$ column 
(Phenomenex., Torrance, CA) was used for this analysis. The mobile phase was $0.005 \mathrm{~N} \mathrm{H}_{2} \mathrm{SO}_{4}$ with a flow rate of $0.6 \mathrm{ml} / \mathrm{min}$ and an operating temperature of $80^{\circ} \mathrm{C}$. Both standards and diluted syrup were analyzed using the RI detector. The following standards were analyzed on the column: oxalic acid, citric acid, succinic acid, acetic acid and lactic acid. Assuming that acetic acid in the sample was from acetate, 0.983 conversion factor of acetic acid to acetate(Sluiter et al. 2008c) was used to estimate the acetate content of DCS.

\subsubsection{Functional group analysis using FTIR-ATR}

A Fourier Transform Infrared Attenuated Total Reflectance (FTIR ATR-PerkinElmer., Waltham, MA) spectrophotometer equipped with a clean diamond ATR crystal was used to investigate the functional group components of the syrup. Oven dried DCS (at $105^{\circ} \mathrm{C}$ ) was ground into fine powder using Norpro 696 round porcelain mortar and

pestle, 1/4 Cup. Using a detection resolution of $4 \mathrm{~cm}^{-1}$ and 32 scans per sample, oven dried DCS were analyzed for their spectra. Duplicate samples each of "A", "B" \& "C" was analyzed for their functional groups. Using Speckwin32 software, (Menges 2011) observed spectra for all samples analyzed was averaged and used to represent DCS.

\subsection{Results and discussion}

Apart from amino acid analysis where samples received in the year 2010 and 2011 were averaged to represent DCS, all other reported results were for samples received in 2011. The following results will be accompanied by short discussions of potential conversion processing challenges and other issues.

\subsubsection{Total solids and ash content}

Total solids concentration was consistent in all samples ranging between $37-38 \%$ wt., on average DCS was estimated to contain $37.4 \%( \pm 0.4 \%)$ wt. of total solids [i.e. $63 \%$ $( \pm 0.4 \%)$ wt. of moisture content]. Ash percentage composition in DCS on a dry solid basis ranged from 11-12\% wt. For both analyses the average of samples (See Figure 22) "A" through to "F" was used to represent DCS. In a separate studies, the authors reported $60-70 \%$ of moisture and approximately $30-40 \%$ wt. of total solids (Morey et 
al. 2006; Kent Rausch and Belyea 2006a) and 15\% wt. of ash in DCS (Morey et al. 2006) on dry solid basis.

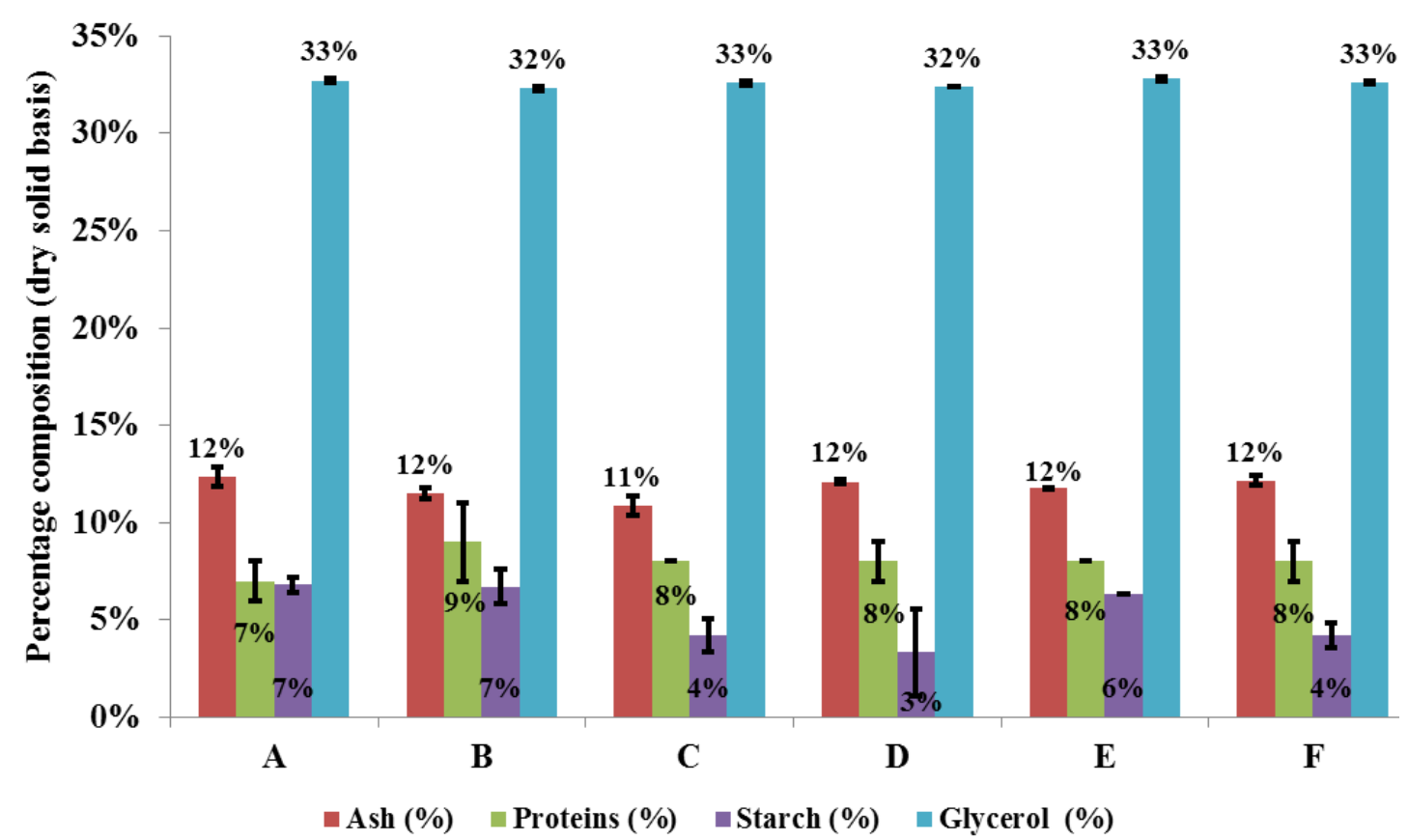

Figure 2-2 Percentage composition on a dry syrup solids basis of total ash, protein, starch and glycerol for samples " $A$ " through to "F" (Duplicates reported as mean standard deviation)

Thermochemical (pyrolysis or gasification) conversion requires low moisture content feedstock (typically <50\%) while bio-convention technology can utilize higher moisture content feedstock (McKendry 2002) making the latter more suitable for DCS. Dilute acid and enzymatic hydrolysis followed by fermentation, to produce biofuels, bio-chemicals, or other bio-products may be more suitable. Another possible implication during biochemical conversion processes such as acid pretreatment is higher consumption of acid due to the alkaline nature of ash. Finally, high ash content will likely influence the overall cost of handling and processing solid residues from non-biodegradable carbon in DCS in the downstream processing and should be considered during the biorefinery concept stage. 


\subsubsection{Inorganic element profile}

Table 2-1 summarizes the elemental composition of DCS for duplicate samples. Final concentrations accounted for any dilutions made prior to analysis on the ICP, and variability between samples "E" and "F" was insignificant. From Table I, S, K and P are the dominant elements in DCS, the authors (Rausch and Belyea 2006a) in their study reported $\mathrm{Na}, \mathrm{K}$, and $\mathrm{P}$ as dominant in their analysis of syrup.

Table 2-1 Summary of inorganic element profile. Percent is based on syrup solids content (Duplicates reported as mean standard deviation)

\begin{tabular}{|l|l|l|}
\hline Elemental & $\begin{array}{l}\text { Average of Sample } \\
(\mathbf{m g} / \mathbf{m l})\end{array}$ & $\begin{array}{l}\text { Composition } \\
\text { in syrup(\% ) }\end{array}$ \\
\hline $\mathbf{C a}$ & $0.016( \pm 0.0004)$ & $0.03 \%$ \\
$\mathbf{F e}$ & $0.003( \pm 0.0001)$ & $0.01 \%$ \\
$\mathbf{M g}$ & $0.267( \pm 0.002)$ & $0.56 \%$ \\
$\mathbf{N a}$ & $0.114( \pm 0.0039)$ & $0.24 \%$ \\
$\mathbf{K}$ & $0.884( \pm 0.0015)$ & $1.86 \%$ \\
$\mathbf{P}$ & $0.642( \pm 0.0093)$ & $1.35 \%$ \\
$\mathbf{A l}$ & $0.002( \pm 0.0001)$ & $0.003 \%$ \\
$\mathbf{C u}$ & $0.0001( \pm 0.00001)$ & $0.0002 \%$ \\
$\mathbf{Z n}$ & $0.003( \pm 0.0001)$ & $0.01 \%$ \\
$\mathbf{M n}$ & $0.001( \pm 0.0000)$ & $0.002 \%$ \\
$\mathbf{S}$ & $0.955( \pm 0.0199)$ & $2.01 \%$ \\
\hline Total & $2.889( \pm 0.0246)$ & $6.07 \%$ \\
\hline
\end{tabular}

The reactive nature of alkali metals with silica in biomass results in the formation of "slag" during thermal conversion processes, which blocks airways in furnace and boiler plants (McKendry 2002). This may be an issue during processing of high-throughput DCS via thermal conversion. Finally, large scale processing needs to consider emission 
control device such as scrubbers since $S$ (see Table 2-1) has the potential to produce harmful emissions such as SOx.

\subsubsection{Protein content analysis}

Protein concentrations in DCS ranged from 5-7 $\mathrm{mg} / \mathrm{ml}$ representing 7-9\% wt. of syrup on a dry basis (see Figure 2-2). Duplicate samples were analyzed for sample "A" through to "F" and averaged. Average protein concentration was $6.06( \pm 0.85) \mathrm{mg} / \mathrm{ml}$ of proteins representing $8 \%( \pm 0.6 \%)$ wt. of DCS on a dry basis. In a separate study, the authors (Rausch and Belyea 2006a) reported relatively higher protein concentration (29.8 g / $100 \mathrm{~g}$ on DM basis) in the syrup stream, while crude protein content of DDGS and wet distiller's grain (see Figure 2-1, solid fraction) were reported to be $30.1( \pm 1.4$ $\%$ ) and 33.1 ( $\pm 3.2 \%$ ) (Kim et al. 2010). The higher protein concentration in DDGS and wet distillers' grains as oppose to DCS is expected. After centrifugation of the whole stillage (see Figure 2-1), the solid fraction (containing most of the proteins) goes into making the DDGS and wet distiller's grain while the supernatant goes into making the TS (parent stream of syrup).

Few studies on integrated biorefinery scenarios have considered the technical feasibility, cost and environmental impact of protein recovery (Dale et al. 2009; Laser et al. 2009) using biomass feedstock. DCS is yet to be subjected to such analysis, and any attempt to extract protein from DCS makes the use of the thermochemical technologies unsuitable.

\subsubsection{Glycerol analysis}

Figure 2-2 summarizes the glycerol concentrations of sample " $\mathrm{A}$ " through to " $\mathrm{F}$ ". By averaging all glycerol results, it was estimated that DCS contained approximately 24.4 $\mathrm{mg} / \mathrm{ml}( \pm 0.25)$ of glycerol, representing 33\% $( \pm 0.2 \%)$ wt. in DCS on a dry solids basis. Glycerol percentage compositions were significant and consistent in all samples analyzed as displayed in Figure 2-2. 
Glycerol production has increased significantly from 113 million $\mathrm{kg}$ of glycerol in the U.S. from biodiesel in the year 2006 to 272 million kg currently (Johnson and Taconi 2007). A glycerol glut in the market has stimulated research into its potential use as a feedstock for the production of value-added products. The production of co-products such as 1,3-propanediol, acetic acid, butanol, acetone, etc through anaerobic fermentation of glycerol by clostridia have been reported (Johnson and Taconi 2007). Also, the production of succinic acid, a value-added chemical (Werpy et al. 2004), using glycerol as a feedstock has been successfully demonstrated (Vlysidis et al. 2011). This is another potential use of the glycerol component in DCS to improve processing plant profitability. Future conversion route for DCS should explore the optimization of the sugar platform via acid hydrolysis and enzymatic saccharification to serve as a fermentation media for the bio-based platform chemicals.

\subsubsection{Total carbohydrate content analysis of DCS}

\subsubsection{Starch assay result}

Figure 2-2 exhibits the starch content of DCS on a dry solids basis for duplicate samples of "A" through to "F". The starch content of DCS dry solids ranged from 2$8 \%$ wt., and by averaging the results obtained from samples " $\mathrm{A}$ " through to " $\mathrm{F}$ ", it was estimated that DCS contained 5.6\% $( \pm 2 \%)$ wt. of starch.

\subsubsection{Soluble monomer carbohydrate analysis results}

Duplicate samples of vials "A" and "E" were analyzed and their results were averaged to represent DCS. Glucose monomer concentration was highest in DCS being $36.9 \mathrm{mg}$ / $\mathrm{ml}( \pm 1.95)$ followed by cellobiose at $23.7 \mathrm{mg} / \mathrm{ml}( \pm 1.95)$. Relatively smaller concentrations of xylose $(3.55 \pm 0.17)$, galactose $(1.40 \pm 0.09)$, arabinose / mannose $(2.76 \pm 0.14) \mathrm{mg} / \mathrm{ml}$ were detected. Fermentation inhibitors in DCS were measured to be $0.27( \pm 0.02)$ and $0.26( \pm 0.01) \mathrm{mg} / \mathrm{ml}$ of furfural and HMF, respectively.

\subsubsection{Non-starch carbohydrates (NSC) results}

Duplicate samples of "A", "B" and " $D$ " were analyzed, and their results were averaged to represent DCS. NSC components comprised of the following; cellulose, and 
structurally bound hemicellulose components (xylan, galactan, arabinan, \& mannan) after accounting for the starch and water-soluble carbohydrate components. Cellulose was a small fraction of DCS, with the highest estimated value being approximately $1 \%$ wt. $( \pm 0.01 \%)$ on a dry solid basis. Overall hemicellulose components were approximately $9 \%$ wt., specifically; xylan 5\% wt. $( \pm 1 \%)$, galactan, $2 \%$ wt. $( \pm 0.6 \%)$, arabinan 0.65 wt. $( \pm 0.3 \%) \&$ mannan, 1 wt. $( \pm 0.5 \%)$.

Table 2-2 compares the total structural carbohydrate components results of DCS from our study to TS. In summary, the total carbohydrates (starch + soluble monomer carbohydrates + NSC) content of DCS averaged 27\% $( \pm 5 \%)$ wt. Results are compared to another study (Kim et al. 2008) in Table 2-2, and apart from galactan and mannan for which the authors did not detect any, the results are comparable.

Table 2-2 Summary of total carbohydrate content of DCS and thin stillage. Percent is based on syrup solids content (ND: No data)

\begin{tabular}{|l|l|l|}
\hline Components & $\begin{array}{l}\text { Syrup (This } \\
\text { study)- } \\
\text { Percentage } \\
\text { composition }\end{array}$ & $\begin{array}{l}\text { Thin Stillage - } \\
\text { Percentage } \\
\text { composition } \\
\text { (Kim et al. 2008) }\end{array}$ \\
\hline $\begin{array}{l}\text { Glucan } \\
\text { (soluble glucose+starch+cellulose) }\end{array}$ & $16 \%(15-16 \%)$ & $16 \%$ \\
\hline Xylan \& Xylose & $6 \%(4-6 \%)$ & $5 \%$ \\
\hline Arabinan \& Arabinose & $1 \%(0.1-1 \%)$ & $1 \%$ \\
\hline Galactan \& Galactose & $3 \%(0-3 \%)$ & ND \\
\hline Manann \& Mannose & $1 \%(0-1 \%)$ & ND \\
\hline
\end{tabular}

\subsubsection{Acid soluble and acid insoluble lignin analysis}

Figure 2-3 summarizes results obtained from lignin analysis of DCS. AIL ranged from 6-9 \% wt. on a dry solids basis for DCS while ASL varied from 1-3\% wt. Averaging all samples analyzed, it was estimated that DCS contained $8 \%( \pm 2 \%)$ wt. and $2 \%( \pm 1 \%)$ wt. of AIL and ASL, respectively. 


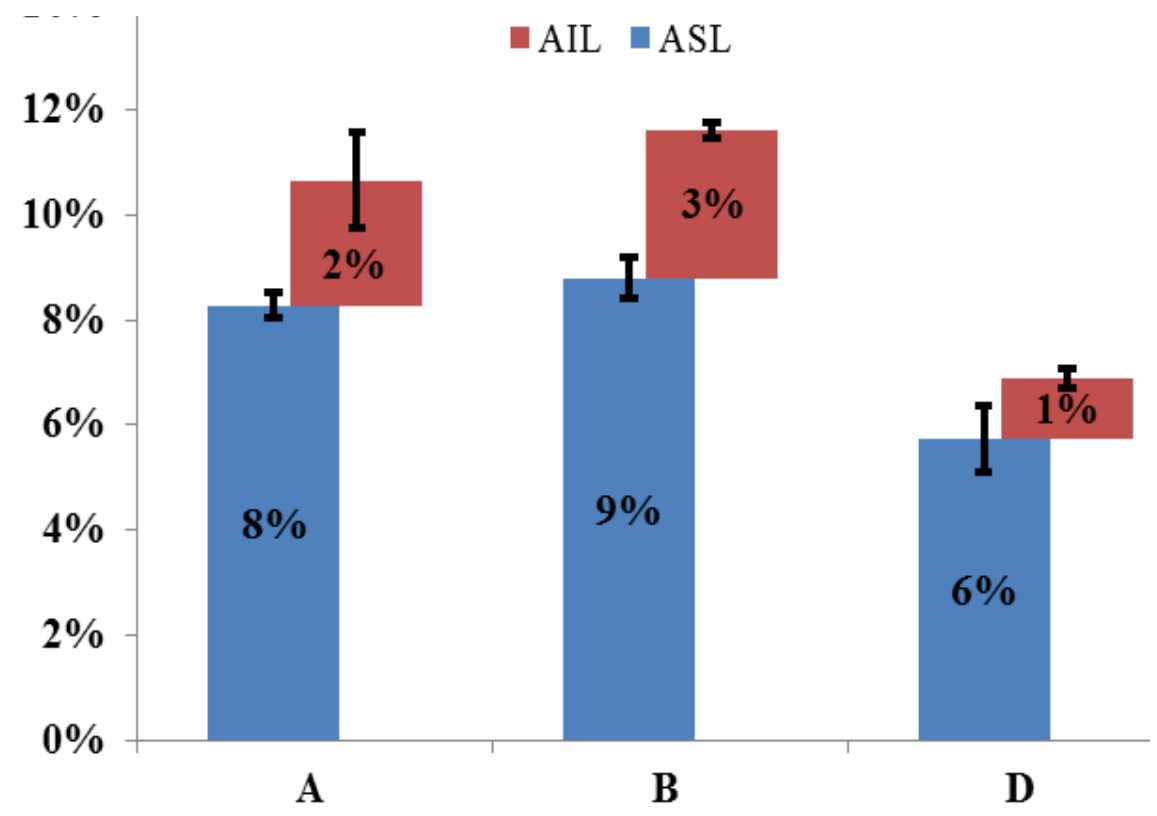

Figure 2-3 . Results for acid soluble \& acid insoluble lignin of syrup on a dry solids basis

As previously stated, lignin can further be incinerated for use as process heat (Xu et al. 2006) and should be considered in this regard for future biorefinery scale-up operations.

\subsubsection{Amino acid analysis}

A summary of the amino acid profile of DCS is displayed in Figure 2-4. Total amino acid concentrations were measured to be $3.51( \pm 0.24)$ and $3.38( \pm 0.35) \mathrm{mg} / \mathrm{ml}$ for DCS analyzed in the year 2011 and 2010 respectively. The amino acid profile comprised of the following primary amino acids: aspartic acid, glutamic acid, asparagine, serine, histidine, glycine, threonine, arginine, alanine, tyrosine, valine, methionine, phenylalanine, isoleucine, leucine and lysine. No secondary amino acids were detected. Averaging all the samples (2010 \& 2011) analyzed, it was estimated that the free amino acids in DCS were approximately $3.45 \%( \pm 0.3 \%)$ wt. on a dry basis. 


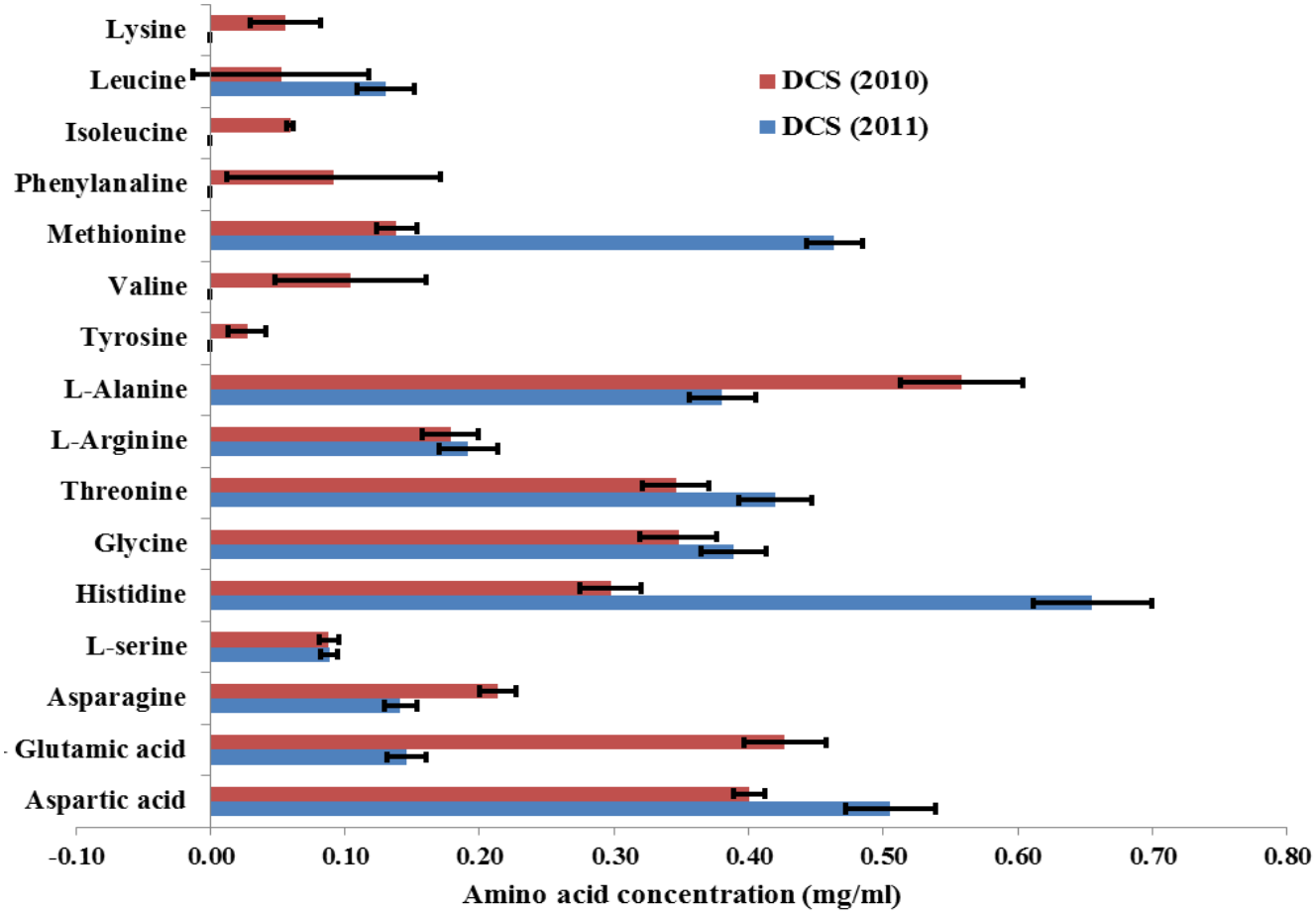

Figure 2-4 Free amino acid content of syrup on a dry solids basis

The total amino acids of TS on a dry solids basis were reported to be $1.1 \%$ (Kim et al. 2008). We expected the amino acid profile for TS to be comparable to DCS since it is the parent stream. Table 2-3 compares the amino acid profile for DCS analyzed in this study to TS reported in another study (Kim et al. 2008).

Table 2-3 Comparison of amino acid profile for syrup and thin stillage (TS), [EAAEssential Amino Acids \& NEAA-Non Essential Amino Acids]. Numbers are percent of dry solids. Source of TS data. (Refer to list of abbreviations for others)

\begin{tabular}{|c|c|c|c|c|c|c|c|c|c|c|c|c|}
\hline EAA & His & Ile & Leu & Lys & Met & Phe & Thr & Try & Val & Pro & Ser & Tyr \\
\hline Syrup & 0.14 & 0.01 & 0.03 & 0.01 & 0.09 & 0.01 & 0.1 & 0.0 & 0.02 & 0.0 & 0.03 & 0.004 \\
\hline TS & 0.0 & 0.1 & 0.1 & 0.1 & 0.0 & 0.1 & 0.1 & 0.0 & 0.1 & 0.1 & 0.1 & 0.0 \\
\hline NEAA & Ala & Arg & Asn & Asp & Cys & Glu & GIn & Gly & Otd & & & \\
\hline Syrup & 0.14 & 0.05 & 0.05 & 0.13 & 0.0 & 0.08 & 0.0 & 0.11 & 0.0 & & & \\
\hline $\mathrm{TS}$ & 0.1 & 0.1 & 0.0 & 0.1 & 0.0 & 0.1 & 0.0 & 0.1 & 0.0 & & & \\
\hline
\end{tabular}


In both samples, tryptophan was not identified, while histidine, methionine, tyrosine, and asparagine were identified in DCS, but these were missing in TS. A possible explanation could be that these amino acid residues detected in the DCS were below the detection limit in the TS given the extremely high moisture content of $92.3 \%$ (Kim et al. 2008). The presence of proteins in DCS presents an opportunity to produce more amino acids through hydrolysis reactions. Future research should explore the potential of amino acid production by hydrolysis of DCS.

\subsubsection{FTIR-ATR analysis}

Figures 2-5 shows the spectra obtained from the FTIR ATR spectrophotometer of oven-dried DCS. Spectra for all samples were averaged using Speckwin32 software, (Menges 2011) and the blue colored spectra represents DCS. About 12 major peaks were identified labeled "A" through to "L". Table 2-4 presents the various peaks identified and relates them to the expected functional groups as identified in the literature.

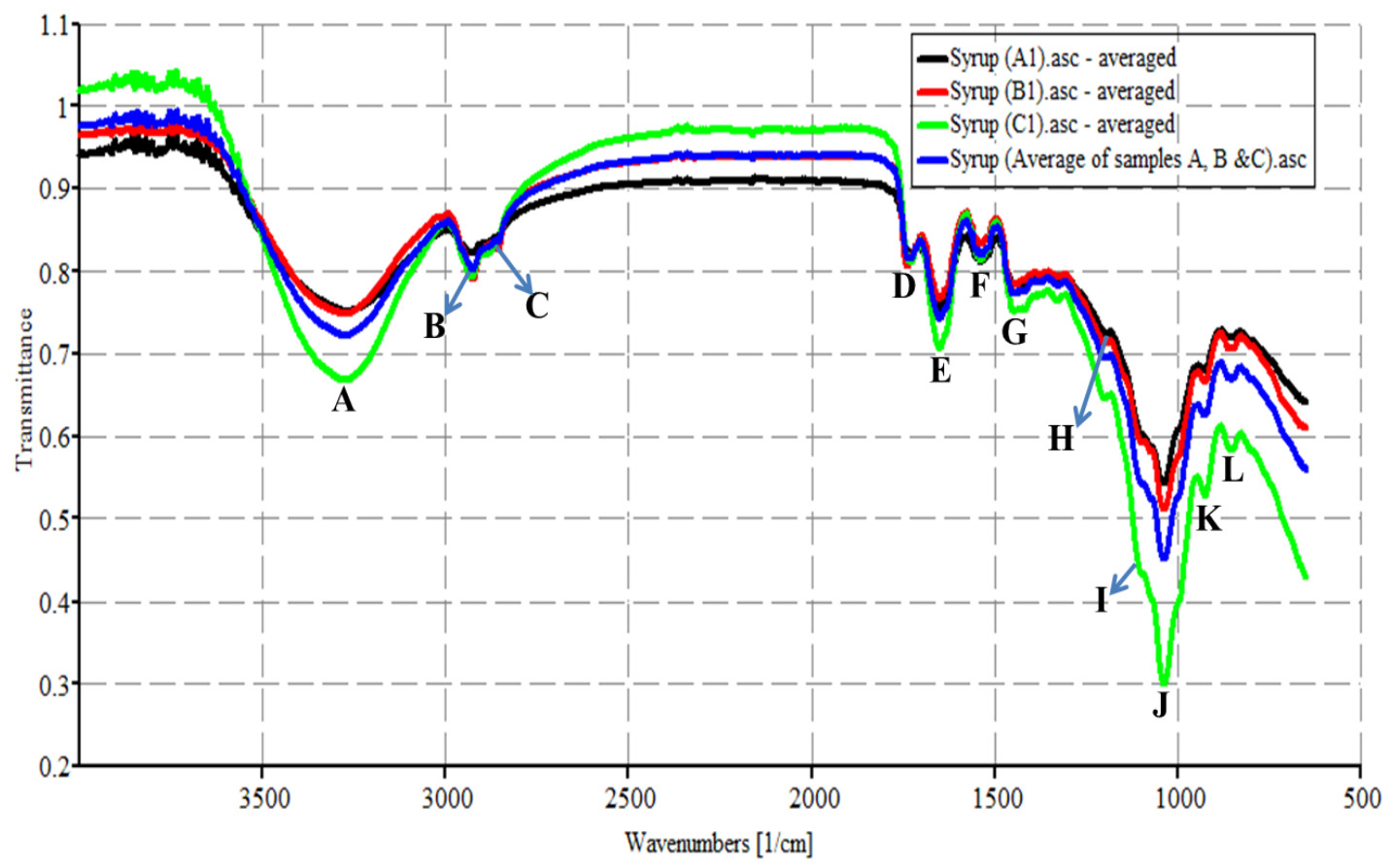

Figure 2-5 FTIR spectra of oven-dried syrup for samples A, B \& C 
Table 2-4 Results for functional group analysis of oven dried syrup

\begin{tabular}{|c|c|c|c|c|}
\hline \multicolumn{3}{|c|}{ FTIR-ATR analysis (DCS) } & \multicolumn{2}{|c|}{ Findings from Literature Review } \\
\hline Peak & $\lambda\left(\mathrm{cm}^{-1}\right)$ & Transmittance & $\begin{array}{l}\text { Reported Range } \\
\text { from Literature }\end{array}$ & Assignment \\
\hline $\mathbf{A}$ & $3271-3625$ & $0.7228-0.9535$ & $3200-3600$ & $\begin{array}{l}\text { O-H (in H-bonded ROH } \\
\text { and ArOH)(Meislich 1999) }\end{array}$ \\
\hline B & 2927 & 0.8026 & 2927 & $\begin{array}{l}\text { C-H stretching (indicates } \\
\text { rupture of } \\
\text { methyl/methylene)(Theerar } \\
\text { attananoon et al. 2010) }\end{array}$ \\
\hline $\mathbf{C}$ & 2857 & 0.836 & $2500-3000$ & $\begin{array}{l}\text { O-H in COOH } \\
\text { (Meislich 1999) }\end{array}$ \\
\hline \multirow[b]{2}{*}{$\mathbf{E}$} & \multirow[b]{2}{*}{1736} & \multirow[b]{2}{*}{0.8148} & 1740 & $\begin{array}{l}\mathbf{C}=\mathbf{O} \text { Acetyl group } \\
\text { (Mascarenhas et al. 2000) }\end{array}$ \\
\hline & & & 1738 & $\begin{array}{l}\mathbf{C}=\mathbf{O} \text { ester; strong carbonyl } \\
\text { groups in branched } \\
\text { hemicellulose (Pandey } \\
\text { 1999) }\end{array}$ \\
\hline $\mathbf{F}$ & 1653 & 0.7432 & 1653 and 1549 & $\begin{array}{l}\text { Protein strong band of } \\
\text { amide I and amide II, } \\
\text { respectively (Meislich } \\
\text { 1999) }\end{array}$ \\
\hline $\mathbf{G}$ & 1540 & 0.8196 & $1650-1440$ & $\begin{array}{l}\mathbf{C}=\mathbf{C} \text { vibrations due to the } \\
\text { presence of benzene ring } \\
\text { (Meislich 1999) }\end{array}$ \\
\hline $\mathbf{H}$ & 1447 & 0.7734 & $1453-1456$ & $\begin{array}{l}\text { Syringyl absorption of } \\
\text { hardwoods (C-H methyl } \\
\text { vibrations and methylene } \\
\text { deformation) (Corredor et } \\
\text { al. 2008) }\end{array}$ \\
\hline I & 1328 & 0.7832 & $1315-1317$ & $\begin{array}{l}\text { C-O vibration of syringyl } \\
\text { ring of lignin (Corredor et } \\
\text { al. 2008) }\end{array}$ \\
\hline $\mathbf{J}$ & 1099 & 0.7036 & 1098-1109 & $\begin{array}{l}\text { C-O vibration of crystalline } \\
\text { cellulose; glucose ring } \\
\text { stretch from } \\
\text { cellulose(Corredor et al. } \\
\text { 2008) }\end{array}$ \\
\hline \multirow[b]{2}{*}{$\mathbf{K}$} & \multirow[b]{2}{*}{1039} & \multirow[b]{2}{*}{0.4521} & 1050,1030 & $\begin{array}{l}\text { Cellulose C-OH } \\
\text { (Mascarenhas et al. 2000) }\end{array}$ \\
\hline & & & 1060 and 1035 & $\begin{array}{l}\text { C-O vibrations of } \\
\text { cellulose(Corredor et al. } \\
\text { 2008) }\end{array}$ \\
\hline $\mathbf{N}$ & 927 & 0.6252 & $\begin{array}{l}1106,1045,994, \\
926,852\end{array}$ & $\begin{array}{l}\text { Major glycerol absorption } \\
\text { peaks(Petibois et al. 2002) }\end{array}$ \\
\hline $\mathbf{L}$ & 855 & 0.6697 & 915,840 & $\begin{array}{l}\alpha \text {-D Glucose (Mascarenhas } \\
\text { et al. 2000) \&'(Tul'chinsky } \\
\text { et al. 1976) }\end{array}$ \\
\hline
\end{tabular}


Generally, FTIR as a semi-quantitative tool was useful in confirming most of the chemical components, previously identified using other methods, based on functional group absorbance. For example, peak "F" indicated the presence of proteins strong band of amide I and amide II. Functional group analysis results presented in Figure 2-5 \& Table 2-4 strongly confirms the presence of chemical components measured using other analytical wet chemistry techniques in this study. FTIR is also useful to follow changes in functional groups in solid samples as a result of conversion reactions, though we deemed this beyond the scope of this characterization study.

\subsubsection{Mass balance closure of DCS}

The overall mass closure, which totaled $101 \%$, was calculated by summing the results reported in this section for components analyzed on a dry solid basis. This included the following; ash (12\%), protein (8\%), amino acids (3\%), glycerol (33\%), lignin (ASL \& AIL-10\%), oxalic acid (1\%), succinic acid (1\%), lactic acid (4\%) acetate (1\%) and total carbohydrates $(28 \%)$. Figure 2-6 summarizes these results showing the various components.

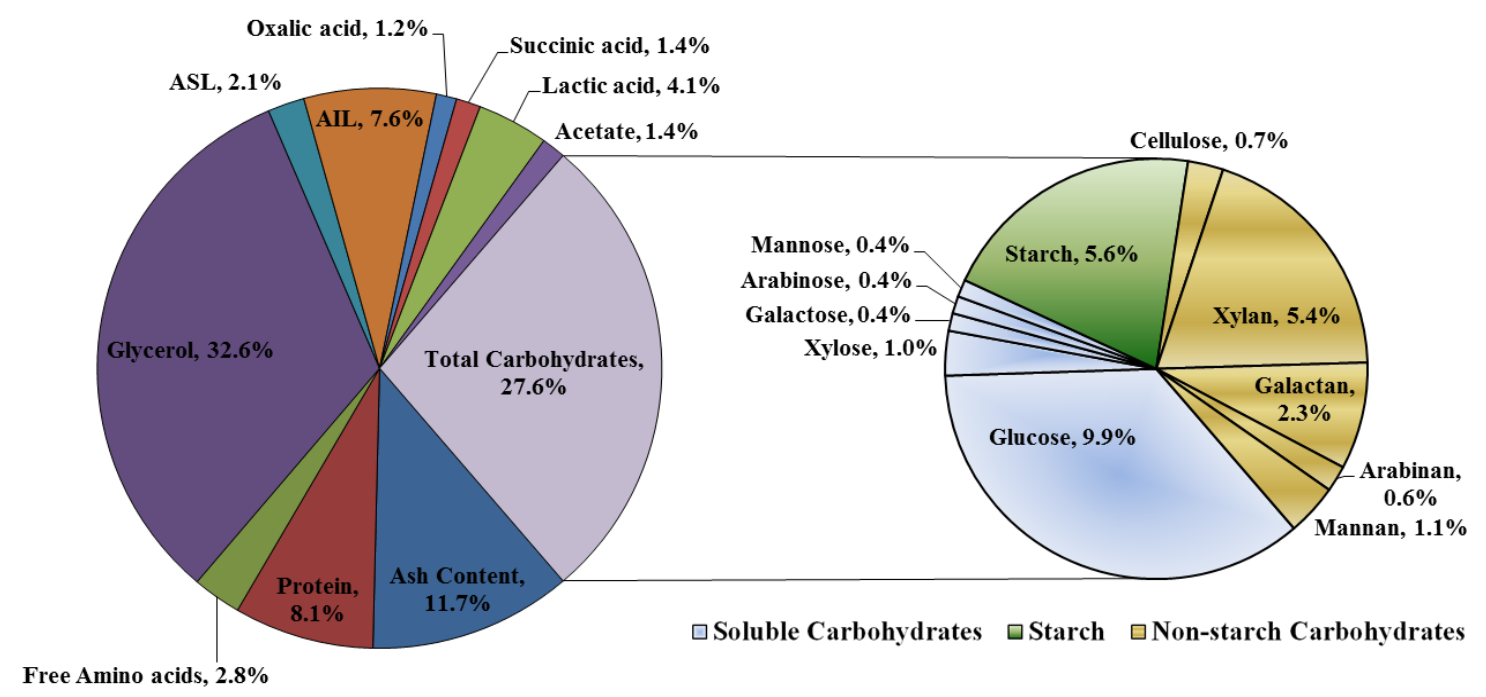

Figure 2-6 Summary of the compositional analysis result for oven-dried syrup

Process conditions such as elevated temperature and the presence of acids are capable of rendering hemicellulose and cellulose soluble (Harmsen et al. 2010). Acid pretreatment should be investigated as a potential conversion route for producing the 
sugar platform using DCS as the feedstock. Apart from the fact that a significant amount of soluble sugars of DCS is in solution ( $40 \mathrm{wt}$ percent of the total carbohydrates), dilute acid pretreatment may be advantageous given the prevalence of starch as compared to cellulose. In addition to acid hydrolysis, future work could also investigate milder process conditions through the use of cellulases and starch hydrolyzing enzymes. Ultimately, the cost and quantity of available feedstock (DCS), usable fermentable sugars, concentration of fermentation inhibitors and conversion yields will influence any intended use towards bio-based specialty chemical. The next section elaborates more on the potential of DCS as a feedstock for some bio-based chemicals.

\subsection{Potential yields from biorefining using syrup as a feedstock}

In this section, and using the characterization results from this study, we estimate the potential quantity of target chemical products that can be produced using DCS as a feedstock. Production of DCS averaged 59 million $\mathrm{kg}$ per month $(\sim 708$ million $\mathrm{kg}$ per year) in the U.S. (O'Brien 2010). A summary of our analysis is displayed in Table 2-5. Apart from ethanol, which was estimated using the theoretical yield calculator (DOE),(U.S. 2006) all other target bio-based chemicals (TBC) yields using fermentable carbohydrates were estimated using equation (9), where $\boldsymbol{X}$ represents yield of TBC on carbohydrate:

$\mathrm{TBC}(\mathrm{kg})=708 \times 10^{6} \frac{\mathrm{kg} \mathrm{syrup}}{\text { Year }} \times \frac{37.4}{100} \frac{\mathrm{kg} \text { syrup DM }}{\mathrm{kg} \text { syrup }} \times \frac{27}{100} \frac{\mathrm{kg} \text { carbohydrate }}{\mathrm{kg} \mathrm{syrup} \mathrm{DM} X}$ (9)

In the case of glycerol as a potential feedstock, the necessary adjustment was made by applying the ratio of $33 / 100$ in the place of $27 / 100$ in equation (9). The key highlight from this analysis is that DCS has a potential to meet current U.S. demand for succinic acid, and future research should investigate the feasibility of utilizing both fermentable sugars as well as glycerol for the production of succinic acid. Escherichia coli and Actinobacillus succinogenes strains have been successfully used for succinic acid production using glucose and glycerol as feedstock (Lennartsson 2005; Vlysidis et al. 2011). It was also interesting to note that even without any form of hydrolysis and based only on the concentration in DCS, histidine could be recovered (potential of 
$370,000 \mathrm{~kg}$ ) and could meet global demand of $360,000 \mathrm{~kg}$ (Ikeda 2003). From our analysis, DCS seem less promising to displace significant transportation fuels through production of ethanol and ABE (Acetone-Butanol-Ethanol). We recommend future research to investigate the feasibility of using DCS in a sugar platform approach as a feedstock for bio-based chemicals production.

Table 2-5 Potential yields of bio-based chemicals using DCS as a feedstock (M: Million \& T: Thousand)

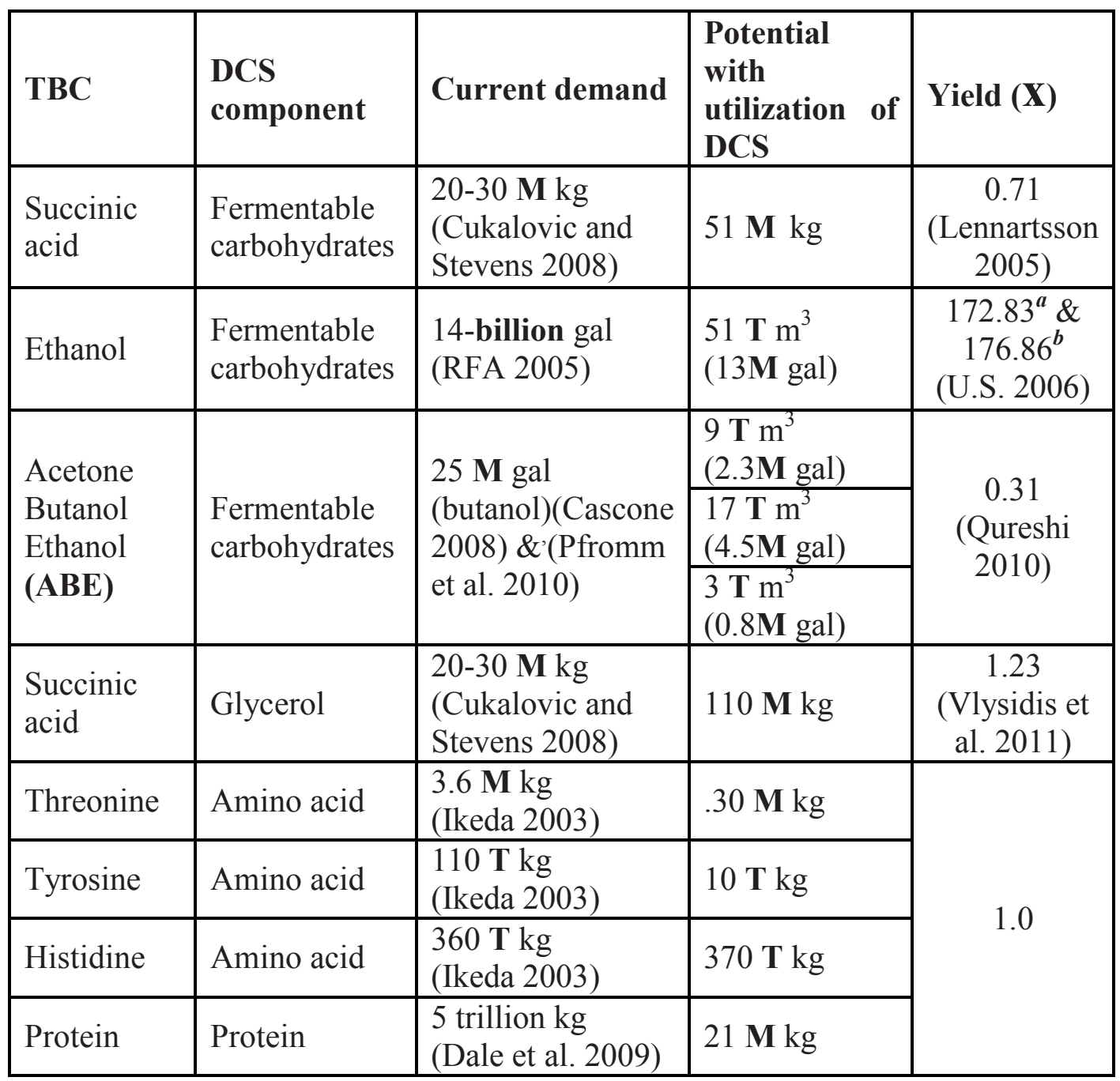

a.172. 83 gallons per dry ton of $\mathrm{C}_{6} \operatorname{sugar}\left(7.21 \times 10^{-4} \mathrm{~m}^{3}\right.$ of ethanol $/ \mathrm{kg} \mathrm{C}_{6}$ sugar $)$

${ }^{b}$.176. 86 gallons per dry ton of $\mathrm{C}_{5} \operatorname{sugar}\left(7.38 \times 10^{-4} \mathrm{~m}^{3}\right.$ of ethanol $/ \mathrm{kg} \mathrm{C}_{5}$ sugar $)$ 
Ultimately, detailed economic analyses considering feedstock cost, plant capacity, technology maturity, etc. will be required to analyze the profitability of using DCS as a bio-based feedstock. Furthermore, there are many other processing challenges to be addressed such as; toxicity / inhibitory levels of hydrolysate components that influence fermentation yields, product separation and recovery costs, scale-up, and system integration issues.

\subsection{Conclusions}

DCS is a co-product of the dry-grind corn ethanol process and no previous studies have investigated the potential utilization as a renewable feedstock for bio-based chemicals and products. In this study, DCS was analyzed for its physical and chemical characteristics. With total solids of $37.4 \%$ wt., a mass balance closure on all components of DCS was $101 \%$. Total carbohydrates (28\% of dry wt.) comprised of starch components $(6 \%)$, soluble carbohydrates $(12 \%)$ \& non-starch carbohydrates $(10 \%)$. Structural and non-structural bound hemicellulose components included; xylan $(6 \%)$, mannan $(1 \%)$, arabinan $(1 \%)$ and galatactan $(3 \%)$. The ash content comprised of $12 \%$ wt. DM basis while protein, glycerol and amino acids were $8 \%$ wt., $33 \%$, and 3\% wt. on DM basis, respectively. Syrup has good potential as a renewable feedstock for bio-chemicals production through either fermentation or separation of various compounds directly from the syrup. 


\subsection{References}

Belyea RL, Clevenger TE, Singh V, Tumbleson M, Rausch KD. 2006. Element concentrations of dry-grind corn-processing streams. Applied Biochemistry and Biotechnology 134:113-128.

Cascone R. 2008. Biobutanol: a replacement for bioethanol? In: Chemical Engineering Progress Special Edition Biofuels 104:S4-S9.

Corredor D, Sun X, Salazar J, Hohn K, Wang D. 2008. Enzymatic hydrolysis of soybean hulls using dilute acid and modified steam-explosion pretreatments. Journal of Biobased Materials and Bioenergy 2:43-50.

Cukalovic A, Stevens CV. 2008. Feasibility of production methods for succinic acid derivatives: a marriage of renewable resources and chemical technology. Biofuels, Bioproducts and Biorefining 2:505-529.

Dale BE, Allen MS, Laser M, Lynd LR. 2009. Protein feeds coproduction in biomass conversion to fuels and chemicals. Biofuels, Bioproducts and Biorefining 3:219-230.

Harmsen P, Huijgen W, López LMB, Bakker R. 2010. Literature review of physical and chemical pretreatment processes for lignocellulosic biomass. Wageningen UR, Food \& Biobased Research. No. 1184.

Henderson J, Ricker RD, Bidlingmeyer BA, Woodward C. 2000. Rapid, accurate, sensitive, and reproducible HPLC analysis of amino acids. Application bulletin 5980.

Ikeda M. 2003. Amino acid production processes. Microbial production of 1-amino acids 79:1-35.

Johnson DT, Taconi KA. 2007. The glycerin glut: Options for the value-added conversion of crude glycerol resulting from biodiesel production. Environmental Progress 26:338-348.

Kim Y, Mosier NS, Hendrickson R, Ezeji T, Blaschek H, Dien B, Cotta M, Dale B, Ladisch MR. 2008. Composition of corn dry-grind ethanol by-products: DDGS, wet cake, and thin stillage. Bioresource technology 99:5165-5176. 
Kim Y, Hendrickson R, Mosier NS, Ladisch MR, Bals B, Balan V, Dale BE, Dien BS, Cotta MA. 2010. Effect of compositional variability of distillers' grains on cellulosic ethanol production. Bioresource technology 101:5385-5393.

Laser M, Jin H, Jayawardhana K, Dale BE, Lynd LR. 2009. Projected mature technology scenarios for conversion of cellulosic biomass to ethanol with coproduction thermochemical fuels, power, and/or animal feed protein. Biofuels, Bioproducts and Biorefining 3:231-246.

Lennartsson A. 2005. Production of Succinic Acid by E. coli from Mixtures of Glucose and Fructose. Thesis work 2005. Lulea University of Technology, Div. Biochemical and Chemical Process Engineering.

Mascarenhas M, Dighton J, Arbuckle GA. 2000. Characterization of plant carbohydrates and changes in leaf carbohydrate chemistry due to chemical and enzymatic degradation measured by microscopic ATR FT-IR spectroscopy. Applied spectroscopy 54:681-686.

McKendry P. 2002. Energy production from biomass (part 1): overview of biomass. Bioresource technology 83:37-46.

Meislich H, Nechamkin. H., Sharefkin. J., , Schaum's Outline of Theory and Problems of Organic Chemistry (Schaum's Outline Series). Second ed.; McGraw-Hill: New York, 1999.

Menges F. 2011. Spekwin32- optical spectroscopy software. version 1.71.6, 201x ed.

Morey RV, Hatfield DL, Sears R, Tiffany D. 2006. Characterization of feed streams and emissions from biomass gasification/combustion at fuel ethanol plants. ASABE Meeting Paper(064180).

O'Brien D. 2010. Updated trends in U.S wet and dry corn milling production. Kansas State University.

Pandey K. 1999. A study of chemical structure of soft and hardwood and wood polymers by FTIR spectroscopy. Journal of applied polymer science 71:19691975.

Petibois C, Cazorla G, Déléris G. 2002. Triglycerides and glycerol concentration determinations using plasma FT-IR spectra. Applied spectroscopy 56:10-16. 
Pfromm PH, Amanor-Boadu V, Nelson R, Vadlani P, Madl R. 2010. Bio-butanol vs. bio-ethanol: A technical and economic assessment for corn and switchgrass fermented by yeast or Clostridium acetobutylicum. Biomass and Bioenergy 34:515-524.

Qureshi N. 2010. Agricultural residues and energy crops as potentially economical and novel substrates for microbial production of butanol (a biofuel).

Rausch K, Belyea R. 2006a. The future of coproducts from corn processing. Applied Biochemistry and Biotechnology 128:47-86.

Rausch KD, Belyea RL. 2005. Coproducts from bioprocessing of corn. ASAE Annual International Meeting(057041).

Rausch KD, Belyea RL. 2006b. The future of coproducts from corn processing. Applied Biochemistry and Biotechnology 128:47-86.

Reaney MJ, Jia Y, Shen J, Ratanaparlyanuch K. 2011. Recovery of multiple compounds and recyclable water from thin stillage. EP Patent 2,297,291.

RFA. 2005. Homegrown for the homeland: Ethanol industry outlook 2005.

Sannigrahi P, Ragauskas AJ, Tuskan GA. 2010. Poplar as a feedstock for biofuels: A review of compositional characteristics. Biofuels, Bioproducts and Biorefining 4:209-226.

Sigma-Aldrich. 2011. Bradford Reagent Technical Bulletin. No. RC,JDS,MAM 06/111.

Sluiter A, Sluiter J. 2005. Determination of Starch in Solid Biomass Samples by HPLC. Laboratory Analytical Procedure. NREL/TP-510-42624. National Renewable Energy Laboratory, Golden, Colorado.

Sluiter A, Hames B, Hyman D, Payne C, Ruiz R, Scarlata C, Sluiter J, Templeton D, Wolfe J. 2008a. Determination of total solids in biomass and total dissolved solids in liquid process samples. Laboratory Analytical Procedures, National Renewable Research Laboratory, Technical Report TP-510-42621, Golden, Co.

Sluiter A, Hames B, Ruiz R, Scarlata C, Sluiter J, Templeton D. 2008b. Determination of ash in biomass. Laboratory Analytical Procedures, National Renewable Research Laboratory, Technical Report TP-510-42622, Golden, Co. 
Sluiter A, Hames B, Ruiz R, Scarlata C, Sluiter J, Templeton D, Crocker D. 2008c. Determination of structural carbohydrates and lignin in biomass. Laboratory Analytical Procedure NREL/TP-510-426i8. National Renewable Energy Laboratory, Golden, Colorado.

Tharakan P, Volk T, Abrahamson L, White E. 2003. Energy feedstock characteristics of willow and hybrid poplar clones at harvest age. Biomass and Bioenergy 25:571-580.

Theerarattananoon K, Wu X, Staggenborg S, Propheter R, Madl R, Wang D. 2010. Evaluation and characterization of sorghum biomass as feedstock for sugar production. Transactions of the ASABE 53:509-525.

Tul'chinsky VM, Zurabyan SE, Asankozhoev KA, Kogan GA, Khorlin AY. 1976. Study of the infrared spectra of oligosaccharides in the region 1,000-40 cm-1. Carbohydrate research 51(1):1-8.

U.S. DoEEERE. 2006. (Biomass Program).Theoretical Ethanol Yield Calculator. Theoretical Ethanol Yield Calculator. .

United States. Dept. of Energy. 2011. US Billion-Ton Update: Biomass Supply for a Bioenergy and Bioproducts Industry. Perlack, R.D., Stokes, B.J. (Leads). Oak Ridge National Laboratory.

Vlysidis A, Binns M, Webb C, Theodoropoulos C. 2011. Glycerol utilisation for the production of chemicals: Conversion to succinic acid, a combined experimental and computational study. Biochemical Engineering Journal 58-59:1-11.

Werpy T, Petersen G, Aden A, Bozell J, Holladay J, White J, Manheim A, Eliot D, Lasure L, Jones S. 2004. Top Value Added Chemicals From Biomass. Volume 1-Results of Screening for Potential Candidates From Sugars and Synthesis Gas. DTIC Document.

Wilkie AC, Riedesel KJ, Owens JM. 2000. Stillage characterization and anaerobic treatment of ethanol stillage from conventional and cellulosic feedstocks. Biomass and Bioenergy 19:63-102. 
Xu F, Sun J, Liu C, Sun R. 2006. Comparative study of alkali-and acidic organic solvent-soluble hemicellulosic polysaccharides from sugarcane bagasse. Carbohydrate research 341:253-261.

Zarcinas B, Cartwright B, Spouncer L. 1987. Nitric acid digestion and multi-element analysis of plant material by inductively coupled plasma spectrometry. Communications in Soil Science \& Plant Analysis 18(1):131-146. 


\section{Chapter 3 \\ 3 Optimization of the Dilute Acid and Enzymatic Pretreatment of Defatted Syrup from a Corn Ethanol Dry Mill $^{2}$}

\subsection{Introduction}

Lignocellulosic biomass refers to plants and plant derived-organic material that contain cellulose, hemicellulose, and lignin as major components (de Wild et al. 2011). Considered the most abundant biopolymer on Earth, lignocellulosic biomass constitutes $50 \%$ of the world's biomass with an annual production of 10-50 billion tonnes (Claassen et al. 1999). Cellulose and hemicellulose are both potential sources of fermentable sugars. Unlike hemicellulose, which can be hydrolyzed under mild acid or alkaline conditions, cellulose is more resistant (Harmsen et al. 2010) and requires specialized enzymes or very high acid concentrations to de-polymerize to yield glucose.

Pretreatment involves the conversion of lignocellulosic biomass from its native form, in which it is recalcitrant to cellulase enzyme systems, into a form for which cellulose hydrolysis is much more effective (Zheng et al. 2009). The primary goals of pretreatment are (Brodeur et al. 2011) ; (i) production of highly digestible solids that enhances glucose yields during enzyme hydrolysis, (ii) avoiding the degradation of sugars (mainly pentoses) including those derived from hemicellulose, (iii) minimizing the formation of inhibitors of subsequent fermentation steps, (iv) recovery of lignin for conversion into bioenergy or valuable co-products, and (v) to be cost effective by operating in reactors of moderate size and by minimizing heat and power requirements.

2 This chapter will be submitted to Biomass and Bioenergy for publication. Citation: Adom, F., Fan, J., Davis, J., Taylor, A., Shonnard, D. (2012). Optimization of the Dilute Acid and Enzymatic Pretreatment of Defatted Syrup from a Corn Ethanol Dry Mill. Biomass and Bioenergy. 
A generalized classification of biomass pretreatment methods include; physical, physicochemical, chemical, and biological. Physical pretreatment involves the breakdown of biomass size and crystallinity through milling or grinding to enhance subsequent hydrolysis by improving mass transfer characteristics from reduction in particle size. Energy requirement for this pretreatment method is high and the overall process is expensive (Sun and Cheng 2002). Physicochemical pretreatment includes a majority of pretreatment technologies including: steam pretreatment, liquid hot water pretreatment, wet oxidation pretreatment, ammonia fiber / freeze explosion, ammonia recycle percolation, aqueous ammonia pretreatment and Organosolv pretreatment (Agbor et al. 2011). Generally, this pretreatment method utilizes conditions and compounds capable of affecting the physical and chemical properties of biomass.

Chemical pretreatment involves the use of chemicals through the initiation of chemical reactions to disrupt biomass structure (Harmsen et al. 2010). Acids, alkali, organic solvents, and ionic liquids have been reported to have significant effect on native lignocellulosic materials (Agbor et al. 2011). Both weak and strong acids have been reported for the pretreatment procedure. Two categories of weak acid hydrolysis (Harmsen et al. 2010) are; (i) high temperature and continuous flow for low-solids loading ( $\mathrm{T}>160^{\circ} \mathrm{C}, 5-10 \mathrm{wt} \%$ substrate concentration) and (ii) Low temperature and batch process for high-solids loading $\left(\mathrm{T} \leq 160^{\circ} \mathrm{C}, 10-40 \mathrm{wt} \%\right.$. substrate concentration). The method (i) is more suitable for low lignin containing biomass. The use of strong acid is a less desirable approach given the comparatively higher corrosive nature and the need to recycle acids in order to lower cost (Harmsen et al. 2010; Agbor et al. 2011).

Pretreatment processes are capital intensive and are estimated to be about $20 \%$ of the total cost of the biorefinery (Kootstra et al. 2009). The primary economic drivers of pretreatment costs are; yield of both five and six carbon sugars, solids concentration, enzyme loading and hemicelullase activity (Eggeman and Elander 2005). Careful optimization of lab scale pretreatment process taking into account various processing 
variables is essential to making its integration into the biorefinery concept economical. Biological pretreatment uses microorganisms (mainly fungi) to degrade lignin, hemicellulose and polyphenols but leave the cellulose intact (Sun and Cheng 2002; Agbor et al. 2011). White and soft-rot fungi and brown-rot fungi uses have been reported (Lee 1997; Sun and Cheng 2002). Slow rate of biological pretreatment, the requirement of careful growth conditions and the large amount of space for biological pretreatment have made this approach unattractive from an industrial perspective (Agbor et al. 2011).

In Chapter 2 was presented a detailed characterization study on defatted corn syrup (DCS) with an overall mass balance closure of about $101 \mathrm{wt} \%$. It was recommended to further study hydrolysis of DCS via acid pretreatment and cellulase application. It was further estimated that approximately $27 \mathrm{wt} \%$ on dry solid basis of the syrup is attributable to carbohydrates comprising of the following; (i) soluble carbohydrates (ii) starch and (iii) non-starch carbohydrates (cellulose, xylan, galactan, mannan \& arabinan). The primary goal of this chapter's research is to optimize the production of sugars using DCS via dilute sulfuric acid hydrolysis and enzymatic saccharification using cellulase enzymes. The sugar platform can then serve as a source of feedstock for the production of higher value bio-based chemical products such as succinic acids and polymer products (Werpy et al. 2004).

\subsection{Materials and methods}

\subsubsection{Hydrolysis scheme and experimental matrix}

The hydrolysis experiments involved dilute sulfuric acid $\left(\mathrm{H}_{2} \mathrm{SO}_{4}\right)$ pretreatment of the DCS followed by enzymatic hydrolysis. The experimental matrix was comprised of six experiment sets with different reaction times. Table 3-1 summarizes the set of experiments conducted. For example, in experimental set 1, DCS was pretreated with varying dilute acid concentrations $(0,1, \& 2 \mathrm{wt} \%)$ for 1 minute (in an autoclave) at $121^{\circ} \mathrm{C}$ with subsequent enzymatic hydrolysis for the following reaction times; 0,24 , 48 , and 72 hours at $50^{\circ} \mathrm{C}$ (in an incubator). The reaction time (0) refers to sampling of 
the hydrolysate right after adding the cellulase enzymes. The solid loading of biomass was kept at $10 \mathrm{wt} \%$ for all pretreatment experiments conducted while the enzymatic hydrolysis experiments were conducted at approximately $2 \%$ solids.

Table 3-1 Experimental matrix for dilute acid hydrolysis (10\% solids) and enzymatic saccharification ( $\sim 2 \%$ solids) of DCS

\begin{tabular}{|c|c|c|c|}
\hline $\begin{array}{l}\text { Experiment } \\
\text { Set }\end{array}$ & $\begin{array}{l}\text { Dilute Acid Pretreatment } \\
\text { (Minutes, Temperature) }\end{array}$ & $\begin{array}{l}\text { Acid } \\
\text { Concentrations }\end{array}$ & $\begin{array}{l}\text { Enzymatic } \\
\text { Hydrolysis }\end{array}$ \\
\hline 1 & $1 \min , \quad 121^{\circ} \mathrm{C}$ & \multirow{6}{*}{$0,1, \& 2 w t . \%$} & \multirow{6}{*}{$\begin{array}{l}\text { 0hr, } 24 \mathrm{hrs}, 48 \mathrm{hrs}, \\
72 \mathrm{hrs}, 50^{\circ} \mathrm{C}\end{array}$} \\
\hline 2 & $30 \mathrm{~min}, 121^{\circ} \mathrm{C}$ & & \\
\hline 3 & $45 \mathrm{~min}, 121^{\circ} \mathrm{C}$ & & \\
\hline 4 & $60 \mathrm{~min}, 121^{\circ} \mathrm{C}$ & & \\
\hline 5 & $75 \mathrm{~min}, 121^{\circ} \mathrm{C}$ & & \\
\hline 6 & $90 \mathrm{~min}, 121^{\circ} \mathrm{C}$ & & \\
\hline
\end{tabular}

\subsubsection{Materials}

The feedstock (DCS) used in this study was received from a dry-grind corn mill ethanol facility in a $500 \mathrm{ml}$ centrifuge flask. DCS was stored in a refrigerator at $5^{\circ} \mathrm{C}$ prior to any analysis. Reagent carbohydrates: $\mathrm{D}(+)$ Glucose; $\mathrm{D}(+)$ Xylose; $\mathrm{D}(+)$ Arabinose; $\mathrm{D}(+)$ Cellobiose; $\mathrm{D}(+)$ Galactose); and the fermentation inhibitors hydroxymethylfurfural (HMF) and furfural were purchased from Sigma Chemical Company (St. Louis, MO). Sulfuric acid (96 wt\%) and $\mathrm{NaOH}$ pellets were purchased from Fisher Scientific (Pittsburgh, PA). The cellulase enzyme formulation used for this study was Accellerase $1500^{\circ}$ from Genencor $囚$. Other materials used in enzymatic hydrolysis include sodium citrate buffer for $\mathrm{pH}$ stabilization, tetracycline and cycloheximide, which were all purchased from Sigma Chemical Company.

\subsubsection{Equipment}

An autoclave (New Burnswick Scientific AC-48) was used for the pretreatment experiment for controlling the temperature and time of reaction. A $14 \mathrm{ml}$ Ace ${ }^{\circledR}$ glass reactor (Ace Glass Inc., 8648-124) equipped with a PTFE seal was used as the reaction 
vessel. Enzymatic saccharification reactions were conducted in an incubator (Lab-Line Orbit Environ Shaker) at $50^{\circ} \mathrm{C}$. A combination of litmus paper and electronic $\mathrm{pH}$ meter (Accumet ${ }^{\circledR} \mathrm{pH}$ Electrode) were used for monitoring $\mathrm{pH}$ of solutions. Finally, High Perfomance Liquid Chromatography-HPLC (Agilent 1200 series) was used for sugar detection. The sugar concentrations were measured by the use of a refractive-index detector and furfural and HMF were measured with a diode-array detector, combined with suitable calibration of the detectors using known standards.

\subsubsection{Characterization of soluble sugars and inhibitors}

Using HPLC, the concentrations of soluble carbohydrates (cellobiose, xylose, glucose, galactose, mannose, arabinose) and fermentation inhibitors (furfural and HMF) were quantified prior to hydrolysis. To $1 \mathrm{~g}$ of syrup, distilled water $(4 \mathrm{~g})$ was added to prepare a $5 \mathrm{x}$ dilution. To ensure a uniform mixture, the solution was swirled using a votex mixer. Using a membrane filter purchased from VWR (Polycarbonate membrane filter, $25 \mathrm{~mm}$ dia., $0.2 \mu \mathrm{m}$ pore size), the solution was filtered into clear a HPLC vial for sugar analysis in the HPLC using an Aminex HPX-87P column (Bio-Rad). Filtered distilled water was used as the mobile phase at a flow rate of $0.6 \mathrm{ml}$ minute ${ }^{-1}$ and the column temperature was set to $80^{\circ} \mathrm{C}$. Duplicate samples were analyzed.

\subsubsection{Dilute acid pretreatment (DAP) procedure (First pretreatment stage)}

The dilute acid hydrolysis experiments were conducted according to the National Renewable Energy Laboratory (NREL) protocol (Sluiter et al. 2008) with slight modification (Figure A-1). 10g of the DCS sample was first added in each $100 \mathrm{ml}$ beaker, and then each syrup sample was diluted with $10 \mathrm{wt} \% \mathrm{H}_{2} \mathrm{SO}_{4}$ and distilled $\mathrm{H}_{2} \mathrm{O}$ to designated acid concentration of 0,1 and $2 \mathrm{wt} \%$ and to a total solid level of $10 \mathrm{wt} \%$. The diluted syrup solutions were transferred into the Ace ${ }^{\circledR}$ glass reactors for autoclaving. The autoclave time (temperature at $121^{\circ} \mathrm{C}$ ) was varied from 1 to 90 minutes to evaluate the impact of different pretreatment times on sugar recovery performance. These reaction times do not include the periods of normal autoclave heat up and cool down (to $80^{\circ} \mathrm{C}$ when contents were removed). After the DAP, $5 \mathrm{ml}$ of well-mixed dilute acid hydrolysate $(\mathrm{DAH})$ was transferred from each Ace ${ }^{\circledR}$ bottle for 
subsequent enzymatic hydrolysis and approximately $2.5 \mathrm{ml}$ of the remaining hydrolysate was subjected to another acid hydrolysis for the oligomer analysis.

\subsubsection{Oligomer analysis (Second pretreatment stage)}

The oligomer analysis procedure was adopted from the NREL laboratory analytical procedures (LAP) protocol (Sluiter et al. 2008). Approximately $2.5 \mathrm{ml}$ of the remaining hydrolysate was filtered through $0.2 \mu \mathrm{m}$ membrane into $1.5 \mathrm{ml}$ micro centrifuge vial (VWR) to collect $1 \mathrm{ml}$ DAH filtrate for the oligomer analysis. The acid concentration of filtrate in centrifuge vial was then brought to $4 \mathrm{wt} \%$. by adding different required volumes of $96 \mathrm{wt} \% \mathrm{H}_{2} \mathrm{SO}_{4}$ followed by autoclaving for another 60 minutes at $121^{\circ} \mathrm{C}$ to hydrolyze oligomer components to monomer sugars. $1 \mathrm{ml}$ of the retrieved hydrolysate after autoclaving were neutralized to $5-8 \mathrm{pH}$ range using $10 \mathrm{~N} \mathrm{NaOH}$, and filtered using $0.2 \mu \mathrm{m}$ membrane into HPLC vials for sugar analysis. Duplicate samples were analyzed. A "sugar recovery" standard of known sugar concentration was subjected to the same autoclave procedures as above and a sugar recovery factor was applied as per the NREL LAP (Sluiter et al. 2008) to calculate the oligomeric sugar concentrations in the samples.

\subsubsection{Enzymatic hydrolysis (EH)}

Five $\mathrm{ml}$ of the well-mixed DAH sample (after first pretreatment stage) was transferred into a $50 \mathrm{ml}$ Erlenmeyer flask, and then the hydrolyzate was adjusted to $\mathrm{pH} 5 \mathrm{using}$ $10 \mathrm{~N} \mathrm{NaOH}$. This was followed by the addition of the following: $1.5 \mathrm{ml}$ of $1 \mathrm{M}$ sodium citrate buffer to stabilize the $\mathrm{pH}, 120 \mu \mathrm{l}$ tetracycline $\left(10 \mathrm{mg} \mathrm{ml}^{-1}\right.$ in $70 \mathrm{vol} \%$ ethanol) and $90 \mu \mathrm{l}$ cycloheximide $\left(10 \mathrm{mg} \mathrm{ml}^{-1}\right.$ in $\left.\mathrm{H}_{2} \mathrm{O}\right)$ to all flasks as antimicrobial agents. The flasks were covered with parafilm and thin aluminum foil and allowed to equilibrate in an incubator for one hour at $50^{\circ} \mathrm{C}$. After one hour, dosages of the enzymes $(75 \mu \mathrm{l}$ Accellerase ${ }^{\circledR} 1500$ and $15 \mu$ of Accellerase ${ }^{\circledR}$ XY) and pre-warmed $\left(50^{\circ} \mathrm{C}\right)$ distilled water were added into the flask until the total volume was $30 \mathrm{ml}$. These enzyme dosages were in accordance with the recommended optimum dosage levels by Genencor ${ }^{\circledR}(0.25 \mathrm{ml}$ per gram of biomass). The $\mathrm{pH}$ meter was used to ensure a $\mathrm{pH}$ range of 4.5-5 prior to the addition of enzymes. After 0, 24, 48 and 72 hours, duplicate 
samples were drawn using pipette for HPLC analysis. The approach is similar to the NREL LAP protocol (Selig et al. 2008).

\subsection{Results}

All reported final concentrations have been "back calculated" to the syrup by accounting for all dilution factors (e.g., acids, bases, distilled $\mathrm{H}_{2} \mathrm{O}$, and antibiotics). Concentrations for enzyme blank for all experiments using Accellerase ${ }^{\circledR} 1500$ and XY were also accounted.

\subsubsection{Results for soluble carbohydrates and inhibitors in DCS}

Soluble carbohydrate analysis results (prior to any hydrolysis) obtained for DCS are as follows: cellobiose $\left[15.8( \pm 1.7) \mathrm{mg} \mathrm{ml}^{-1}\right]$, glucose $\left[11.4( \pm 0.1) \mathrm{mg} \mathrm{ml}^{-1}\right]$, xylose $[1.7$ $\left.( \pm 0.02) \mathrm{mg} \mathrm{ml}^{-1}\right]$, galactose $\left[1.0( \pm 0.03) \mathrm{mg} \mathrm{ml}^{-1}\right]$, arabinose $\left[2.0( \pm 0.1) \mathrm{mg} \mathrm{ml}^{-1}\right]$, and mannose $\left[2( \pm 0.6) \mathrm{mg} \mathrm{ml}^{-1}\right]$. In addition, furfural and HMF were measured to be 0.22 $( \pm 0.02)$ and $0.04( \pm 0.01) \mathrm{mg} \mathrm{ml}^{-1}$, respectively. Total monomer sugars (TMS), which is the sum of glucose, xylose, galactose, arabinose, and mannose concentration, was approximately $18 \mathrm{mg} \mathrm{ml}^{-1}$. DCS sample used for this hydrolysis experiment contained $28 \%$ dry solids and $12 \mathrm{wt} \%$ ash in dry solids (Figure A-2).

\subsubsection{Results for experiment set 1}

\subsubsection{Dilute acid pretreatment \& oligomer analysis - 1 minute}

Figure 3-1 shows the monomer sugar concentrations after 1 minute DAP (first stage pretreatment) and oligomer analysis (second stage pretreatment) for DCS solutions of 0,1 , and $2 \mathrm{wt} \%$ acid concentrations. The deep blue, red, and green represents the first pretreatment stage for 0,1 and $2 \mathrm{wt} \%$ acid concentrated hydrolysate, respectively, while the lighter shades represent the net monomer sugar increase after oligomer analysis. While the duration of time at target temperature of $121^{\circ} \mathrm{C}$ is only 1 minute, the time spent heating up from room temperature to $121^{\circ} \mathrm{C}$ (about 1 hour) and cooling down to $80^{\circ} \mathrm{C}$ prior to opening up the autoclave (about 0.5 hour) must be kept in mind. This will affect the overall hydrolysis reaction time and subsequently the total monomer sugars and inhibitors generated over time. 
Cellobiose concentration increased because of the breakdown of more polymers into oligomers, due to increasing acid intensity. The relatively short hydrolysis reaction time (1 minute) was not enough to further degrade the cellobiose into its glucose monomer units as was observed in other experiment sets. Glucose concentration peaked at around $23 \mathrm{mg} \mathrm{ml}^{-1}$ with the $2 \mathrm{wt} \%$ acid concentrated DCS after the first pretreatment stage. Overall, the TMS concentration was $13.4,16.3$ and $36 \mathrm{mg} \mathrm{ml}^{-1}$ for 0, 1 and $2 \mathrm{wt} \%$ acid sample, respectively, after the first pretreatment stage (1 minute). A two-fold (2x) increase in TMS was observed when comparing $2 \mathrm{wt} \%$ acid sample $\left(36 \mathrm{mg} \mathrm{ml}^{-1}\right.$ ) with the initially present soluble carbohydrates (see section 3.3.1).

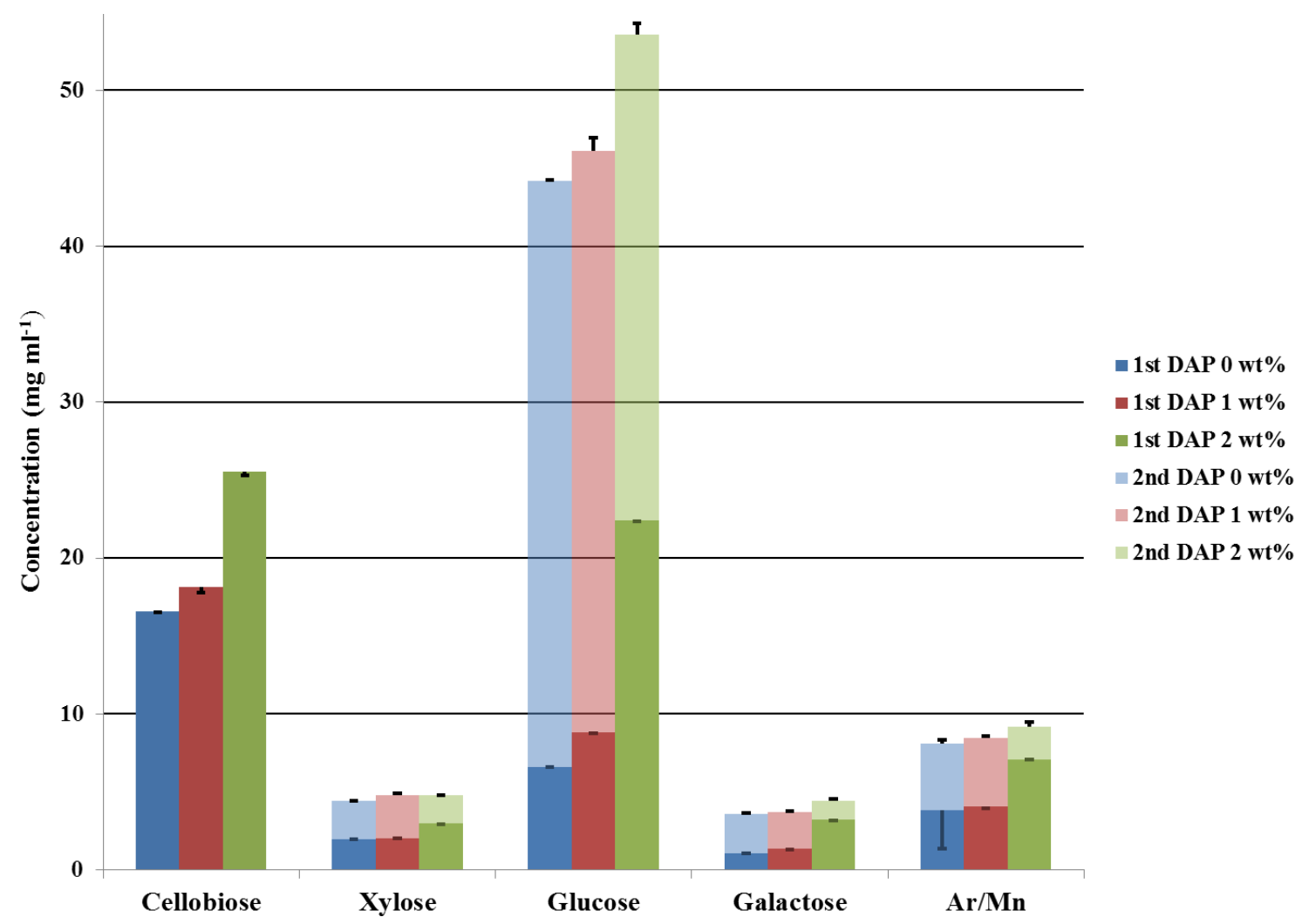

Figure 3-1 Average carbohydrates (cellobiose, xylose, glucose, galactose, mannose \& mannose) sugar concentration trend after 1 minute DAP (first \& second pretreatment stage)

Figure 3-1 shows the net increase in monomer sugars after oligomer analysis for a previously pretreated DCS at 1 minute. The net increase in monomer sugar 
concentrations (after the "sugar recovery" factor) after oligomer analysis (see Figure 31) was comparatively higher for both 0 and $1 \mathrm{wt} \%$ acid concentrated samples. On average, an approximate net increase of $37 \mathrm{mg} \mathrm{ml}^{-1}$ of glucose were measured for both 0 and $1 \mathrm{wt} \%$ acid concentration with only about $31 \mathrm{mg} \mathrm{ml}^{-1}$ detected for the $2 \mathrm{wt} \%$ acid concentrated DCS. Another observation (Figure 3-1) is that the monomer sugar (xylose, galactose, arabinose and mannose) concentrations for 0 \& 1 wt $\%$ acidconcencetrated hydrolysate doubled after oligomer analysis. TMS (first stage dilute acid hydrolysis + oligomer analysis) were estimated to be 60,63 and $70 \mathrm{mg} \mathrm{ml}^{-1}$ for 0 , 1 and $2 \mathrm{wt} \%$ acid concentrated samples respectively (Figure A-3). Glucose accounted for $71-78 \%$ of the TMS (first stage dilute acid hydrolysis + oligomer analysis) indicating its dominance over other monomer sugars.

\subsubsection{Enzymatic hydrolysis - 1 minute DAH}

In Table 3-2, results for monomer sugars, cellobiose, furfural and HMF measured for DCS $(0,1$ and $2 \mathrm{wt} \%$ acid concentrations) pretreated for 1 minute with subsequent EH at different incubation times are displayed. The general trend is an increase in TMS and decrease in cellobiose concentration over increasing reaction time. The $\mathrm{t}=0 \mathrm{hr}$ TMS results are slightly higher than those shown in Figure 3-1 presumable due to the effect of adding enzymes. Glucose concentrations increased $(\sim 2 \mathrm{x})$ with a corresponding decrease in cellobiose within the first 24 hour incubation period, an indication that most of the EH occurs within this reaction time. On average, about $17.5 \mathrm{mg} \mathrm{ml}^{-1}$ increase in glucose concentrations was observed within the first 24 hours in all cases. Higher acid concentrations resulted in comparatively higher TMS concentrations over increasing reaction time, indicating the effectiveness of the acid catalyst.

Additionally, higher acid concentrations resulted in relatively higher concentrations of inhibitors (Figure A-4). Inhibitors concentrations after DAP (first stage pretreatment), specifically for the $2 \mathrm{wt} \%$ acid concentrated DCS sample were high, 0.62 and $0.22 \mathrm{mg}$ $\mathrm{ml}^{-1}$ for furfural and HMF respectively. These unusually high concentrations detected may be artifacts of the HPLC analysis for this one experiment set. During EH, 
concentrations of HMF remain fairly constant or decreases slightly over time as a result of volatilization from the reaction flask.

Table 3-2 Average (and Standard Deviations) TMS, furfural and HMF concentrations $\left(\mathrm{mg} \mathrm{ml}^{-1}\right)$ for Enzymatic Hydrolysis on 1 minute DAH Samples

\begin{tabular}{|l|c|c|c|c|c|c|c|c|c|}
\hline $\begin{array}{l}\text { Enzymatic } \\
\text { Hydrolys ate } \\
\text { sample }\end{array}$ & $\begin{array}{c}\text { Time } \\
\text { (hours) }\end{array}$ & Cellobiose & Xylose & Glucose & Galactose & Ar/Mn & HMF & Furfural & TMS \\
\hline & $\mathbf{0}$ & $12.4( \pm 5.7)$ & $2.0( \pm 1.4)$ & $16.4( \pm 5.75)$ & $0.9( \pm 0.61)$ & $1.6( \pm 1.0)$ & $0.1( \pm 0.0)$ & $0.1( \pm 0.01)$ & $19.4( \pm 10.4)$ \\
$\mathbf{0 \%}$ wt. Acid- & $\mathbf{2 4}$ & $5.4( \pm 0.2)$ & $3.5( \pm 0.4)$ & $38.2( \pm 1.08)$ & $2.0( \pm 0.22)$ & $2.4( \pm 0.42)$ & $0.2( \pm 0.01)$ & $0.03( \pm 0.0)$ & $46.1( \pm 2.0)$ \\
$(\mathbf{1}$ min, DAH) & $\mathbf{4 8}$ & $3.0( \pm 0.1)$ & $3.2( \pm 0.1)$ & $40.0( \pm 1.02)$ & $1.8( \pm 0.05)$ & $5.6( \pm 0.18)$ & $0.2( \pm 0.01)$ & $0.03( \pm 0.0)$ & $50.7( \pm 1.3)$ \\
& $\mathbf{7 2}$ & $3.2( \pm 0.4)$ & $3.3( \pm 0.0)$ & $41.2( \pm 0.43)$ & $1.5( \pm 0.07)$ & $5.2( \pm 0.21)$ & $0.2( \pm 0.01)$ & $0.03( \pm 0.0)$ & $51.2( \pm 0.15)$ \\
\hline & $\mathbf{0}$ & $20.2( \pm 0.3)$ & $2.8( \pm 0.02)$ & $23.1( \pm 0.73)$ & $1.3( \pm 0.02)$ & $3.6( \pm 0.02)$ & $0.21( \pm 0.0)$ & $0.21( \pm 0.0)$ & $30.8( \pm 0.75)$ \\
$\mathbf{1 \%}$ wt. Acid- & $\mathbf{2 4}$ & $6.0( \pm 0.6)$ & $4.1( \pm 0.1)$ & $39.3( \pm 0.01)$ & $2.2( \pm 0.09)$ & $6.4( \pm 0.67)$ & $0.2( \pm 0.0)$ & $0.03( \pm 0.0)$ & $52.0( \pm 0.86)$ \\
$(\mathbf{1}$ min, DAH) & $\mathbf{4 8}$ & $4.9( \pm 0.19)$ & $4.1( \pm 0.2)$ & $41.3( \pm 1.10)$ & $2.1( \pm 0.08)$ & $6.8( \pm 0.11)$ & $0.2( \pm 0.0)$ & $0.03( \pm 0.0)$ & $54.3( \pm 1.49)$ \\
& $\mathbf{7 2}$ & $3.8( \pm 0.04)$ & $4.3( \pm 0.1)$ & $43.1( \pm 0.49)$ & $1.9( \pm 0.03)$ & $6.5( \pm 0.01)$ & $0.2( \pm 0.01)$ & $0.03( \pm 0.0)$ & $55.8( \pm 0.58)$ \\
\hline & $\mathbf{0}$ & $11.4( \pm 1.2)$ & $3.7( \pm 0.0)$ & $26.7( \pm 0.11)$ & $2.3( \pm 0.06)$ & $3.8( \pm 0.09)$ & $0.2( \pm 0.01)$ & $0.2( \pm 0.01)$ & $36.6( \pm 0.25)$ \\
$\mathbf{2 \%}$ wt. Acid- & $\mathbf{2 4}$ & $9.7( \pm 0.3)$ & $4.2( \pm 0.1)$ & $40.6( \pm 0.15)$ & $2.7( \pm 0.02)$ & $6.3( \pm 0.02)$ & $0.2( \pm 0.01)$ & $0.04( \pm 0.0)$ & $53.9( \pm 0.24)$ \\
$\mathbf{( 1 ~ m i n , ~ D A H )}$ & $\mathbf{4 8}$ & $5.0( \pm 0.3)$ & $4.4( \pm 0.1)$ & $43.0( \pm 0.57)$ & $2.8( \pm 0.05)$ & $6.3( \pm 0.15)$ & $0.2( \pm 0.0)$ & $0.04( \pm 0.0)$ & $56.5( \pm 0.83)$ \\
& $\mathbf{7 2}$ & $6.4( \pm 0.3)$ & $4.6( \pm 0.0)$ & $43.8( \pm 0.52)$ & $2.6( \pm 0.01)$ & $6.0( \pm 0.07)$ & $0.2( \pm 0.01)$ & $0.04( \pm 0.0)$ & $57.0( \pm 0.58)$ \\
\hline
\end{tabular}

\subsubsection{Results for experiment set 2}

\subsubsection{Dilute acid pretreatment \& oligomer analysis - 30 minutes}

Figure 3-2 displays the results of monomer sugar concentrations after 30 minutes of DAP (first \& second stage pretreatment) for 0,1 and $2 \mathrm{wt} \%$ acid concentrated samples.

Worth noting is the cellobiose trend, which peaks around $26 \mathrm{mg} \mathrm{ml}^{-1}$ at $1 \mathrm{wt} \%$ acid concentration followed by degradation drop to $11 \mathrm{mg} \mathrm{ml}^{-1}$ at $2 \%$ acid. The extended reaction time (30 minutes) and the $1 \mathrm{wt} \%$ acid concentrated DCS are effective in hydrolyzing more oligomers into cellobiose and subsequent degradation into glucose especially for the $2 \mathrm{wt} \%$ hydrolysate. For all sugars, there is less oligomer remaining in solution for the $30 \mathrm{~min}$. reaction period for all acid levels than for the $1 \mathrm{~min}$. results shown in Figure 3-1.

When comparing only glucose concentrations for the first stage pretreatment for 1 and 30 minutes, 7, 9 and $23 \mathrm{mg} \mathrm{ml}^{-1}$ were measured for 0,1 and $2 \mathrm{wt} \%$ acid concentration for 1 minute, respectively (see Figure 3-1). For 30 minutes, we measured 7, 18 and 41 $\mathrm{mg} \mathrm{ml}^{-1}$ for 0,1 and $2 \mathrm{wt} \%$ acid concentrated sample (see Figure 3-2) respectively. The doubling of the glucose concentration indicates the effectiveness of increasing acid 
catalyst concentration with increasing reaction time. Reaction temperature $\left(121^{\circ} \mathrm{C}\right)$ coupled with increasing reaction time (30 minutes) was not effective in degrading the carbohydrate component into monomer sugars for the $0 \%$ acid concentrated sample. Finally, TMS were estimated to be $12.4,27.1$ and $52.7 \mathrm{mg} \mathrm{ml}^{-1}$ respectively for the 0,1 and $2 \mathrm{wt} \%$ acid DCS (first stage pretreatment, 30 minutes).

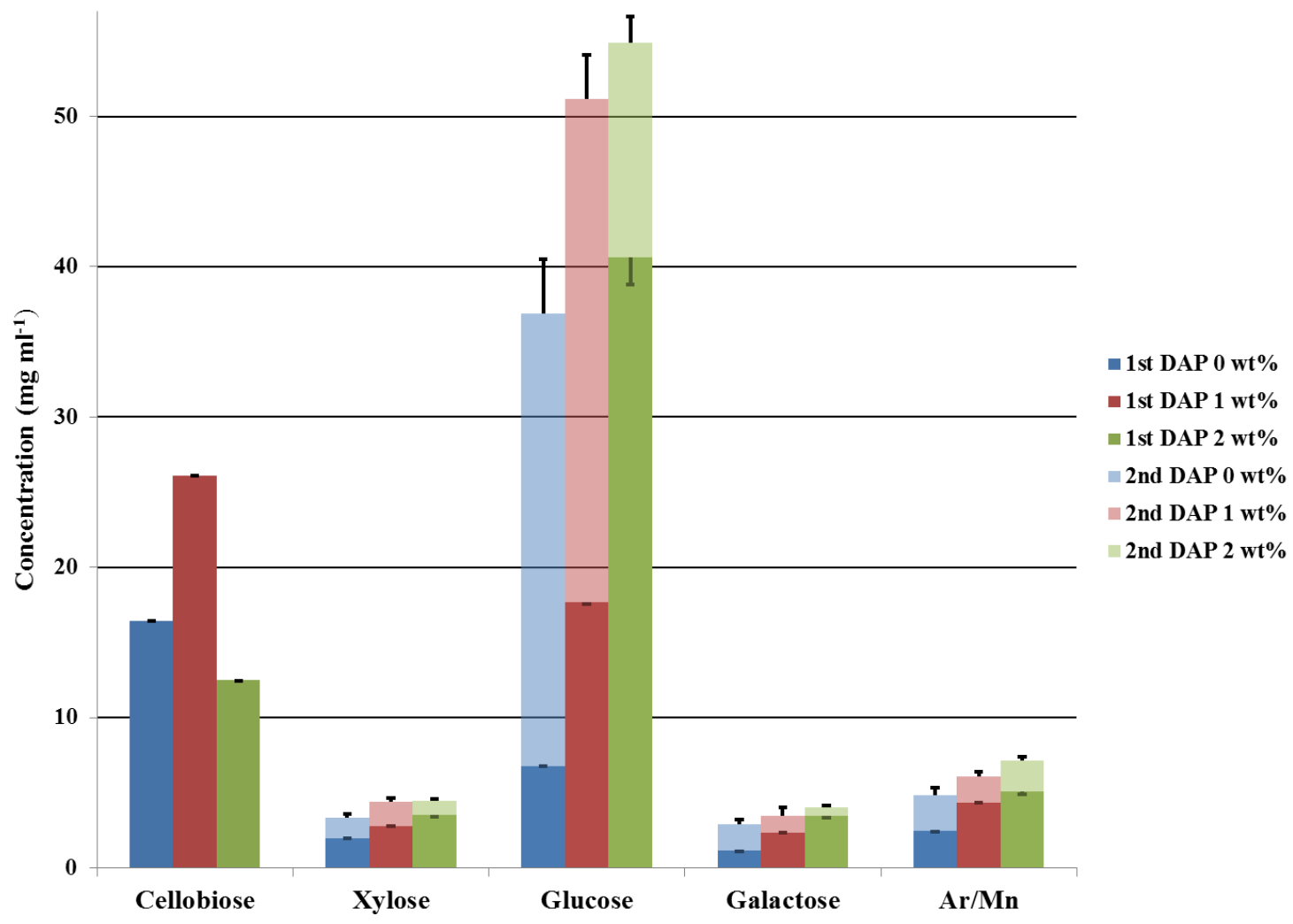

Figure 3-2 Average carbohydrates (cellobiose, xylose, glucose, galactose, mannose \& mannose) sugar concentration trend after 30 minutes DAP (first \& second pretreatment stage)

The light color shades in Figure 3-2, indicate the net increase in monomer sugars during oligomer analysis (30 minutes DAP) at different acid concentrations. Net glucose concentrations of approximately 30 and $33 \mathrm{mg} \mathrm{ml}^{-1}$ were estimated from the oligomer analysis for 0 and $1 \mathrm{wt} \%$ samples respectively. Using glucose concentration from the first pretreatment as the basis (see Figure 3-2) indicates an increase by a factor of about 4 and 2 for 0 and $1 \mathrm{wt} \%$. acid concentrated DCS respectively when glucose results from oligomer analysis are considered. The $2 \mathrm{wt} \%$ acid hydolyzed sample 
yielded only $14 \mathrm{mg} \mathrm{ml}^{-1}$ of net glucose after oligomer analysis, as this may indicate that the first hydrolysis step was effective in hydrolyzing most of the glucan component of DCS. TMS (first stage hydrolysis + oligomer analysis) was estimated to be 48, 65 and $69 \mathrm{mg} \mathrm{ml}^{-1}$ for 0,1 and $2 \mathrm{wt} \%$ acid DCS, respectively (see Figure A-5).

\subsubsection{Enzymatic hydrolysis - 30 minutes DAH}

Table 3-3 summarizes the results of EH for 30 minutes pretreated DCS. TMS increased with acid concentration over increasing reaction time though this trend was not significant for the $2 \mathrm{wt} \%$ acid concentrated DCS. These observations also indicate that the $2 \mathrm{wt} \%$ acid concentration was effective in the first stage pretreatment. HMF and furfural concentrations for 1 and $2 \mathrm{wt} \%$ acid concentrated samples for the first stage acid pretreatment [(DAP) - see Figure A-6] seems to be unusually low compared to the 0 hour incubation period. However, concentrations decreased overtime due to volatilization and remain relatively constant. The highest conentrations were detected at the 0 hour incubation time for $2 \mathrm{wt} \%$ acid concentrated DCS at, 0.2 and $1.2 \mathrm{mg} \mathrm{ml}^{-1}$ of HMF and furfural respectively.

Table 3-3 Average TMS, furfural and HMF concentrations $\left(\mathrm{mg} \mathrm{ml}^{-1}\right)$ for EH on 30

\begin{tabular}{|l|c|c|c|c|c|c|c|c|c|}
\hline $\begin{array}{l}\text { Enzymatic } \\
\text { Hydrolys ate } \\
\text { sample }\end{array}$ & $\begin{array}{c}\text { Time } \\
\text { (hours) }\end{array}$ & Cellobiose & Xylose & Glucose & Galactose & Ar/Mn & HMF & Furfural & TMS \\
\hline & $\mathbf{0}$ & $12.4( \pm 5.7)$ & $2.0( \pm 1.4)$ & $16.4( \pm 5.75)$ & $0.9( \pm 0.61)$ & $1.6( \pm 1.0)$ & $0.1( \pm 0.0)$ & $0.1( \pm 0.01)$ & $19.4( \pm 10.4)$ \\
$\mathbf{0 \%}$ wt. Acid- & $\mathbf{2 4}$ & $5.4( \pm 0.2)$ & $3.5( \pm 0.4)$ & $38.2( \pm 1.08)$ & $2.0( \pm 0.22)$ & $2.4( \pm 0.42)$ & $0.2( \pm 0.01)$ & $0.03( \pm 0.0)$ & $46.1( \pm 2.0)$ \\
$\mathbf{( 1 ~ m i n , ~ D A H ) ~}$ & $\mathbf{4 8}$ & $3.0( \pm 0.1)$ & $3.2( \pm 0.1)$ & $40.0( \pm 1.02)$ & $1.8( \pm 0.05)$ & $5.6( \pm 0.18)$ & $0.2( \pm 0.01)$ & $0.03( \pm 0.0)$ & $50.7( \pm 1.3)$ \\
& $\mathbf{7 2}$ & $3.2( \pm 0.4)$ & $3.3( \pm 0.0)$ & $41.2( \pm 0.43)$ & $1.5( \pm 0.07)$ & $5.2( \pm 0.21)$ & $0.2( \pm 0.01)$ & $0.03( \pm 0.0)$ & $51.2( \pm 0.15)$ \\
\hline & $\mathbf{0}$ & $20.2( \pm 0.3)$ & $2.8( \pm 0.02)$ & $23.1( \pm 0.73)$ & $1.3( \pm 0.02)$ & $3.6( \pm 0.02)$ & $0.21( \pm 0.0)$ & $0.21( \pm 0.0)$ & $30.8( \pm 0.75)$ \\
$\mathbf{1 \%}$ wt. Acid- & $\mathbf{2 4}$ & $6.0( \pm 0.6)$ & $4.1( \pm 0.1)$ & $39.3( \pm 0.01)$ & $2.2( \pm 0.09)$ & $6.4( \pm 0.67)$ & $0.2( \pm 0.0)$ & $0.03( \pm 0.0)$ & $52.0( \pm 0.86)$ \\
$\mathbf{( 1 ~}$ min, DAH) & $\mathbf{4 8}$ & $4.9( \pm 0.19)$ & $4.1( \pm 0.2)$ & $41.3( \pm 1.10)$ & $2.1( \pm 0.08)$ & $6.8( \pm 0.11)$ & $0.2( \pm 0.0)$ & $0.03( \pm 0.0)$ & $54.3( \pm 1.49)$ \\
& $\mathbf{7 2}$ & $3.8( \pm 0.04)$ & $4.3( \pm 0.1)$ & $43.1( \pm 0.49)$ & $1.9( \pm 0.03)$ & $6.5( \pm 0.01)$ & $0.2( \pm 0.01)$ & $0.03( \pm 0.0)$ & $55.8( \pm 0.58)$ \\
\hline & $\mathbf{0}$ & $11.4( \pm 1.2)$ & $3.7( \pm 0.0)$ & $26.7( \pm 0.11)$ & $2.3( \pm 0.06)$ & $3.8( \pm 0.09)$ & $0.2( \pm 0.01)$ & $0.2( \pm 0.01)$ & $36.6( \pm 0.25)$ \\
$\mathbf{2 \%}$ wt. Acid- & $\mathbf{2 4}$ & $9.7( \pm 0.3)$ & $4.2( \pm 0.1)$ & $40.6( \pm 0.15)$ & $2.7( \pm 0.02)$ & $6.3( \pm 0.02)$ & $0.2( \pm 0.01)$ & $0.04( \pm 0.0)$ & $53.9( \pm 0.24)$ \\
$\mathbf{( 1 ~ m i n , ~ D A H )}$ & $\mathbf{4 8}$ & $5.0( \pm 0.3)$ & $4.4( \pm 0.1)$ & $43.0( \pm 0.57)$ & $2.8( \pm 0.05)$ & $6.3( \pm 0.15)$ & $0.2( \pm 0.0)$ & $0.04( \pm 0.0)$ & $56.5( \pm 0.83)$ \\
& $\mathbf{7 2}$ & $6.4( \pm 0.3)$ & $4.6( \pm 0.0)$ & $43.8( \pm 0.52)$ & $2.6( \pm 0.01)$ & $6.0( \pm 0.07)$ & $0.2( \pm 0.01)$ & $0.04( \pm 0.0)$ & $57.0( \pm 0.58)$ \\
\hline
\end{tabular}

\subsubsection{Results for experiment set 3}

\subsubsection{Dilute acid pretreatment \& oligomer analysis - 45 minutes}


Result of the DAP (first \& second stage pretreatment) for 45 minutes is displayed in Figure 3-3. In a similar trend as before, cellobiose increased to about $28 \mathrm{mg} \mathrm{ml}^{-1}$ for 1 $\mathrm{wt} \%$ acid concentrated DCS and decreased to about $11 \mathrm{mg} \mathrm{ml}^{-1}$ (about $17 \mathrm{mg} \mathrm{ml}^{-1}$ degraded) in the $2 \mathrm{wt} \%$ samples. Glucose concentrations after the first pretreatment stage were measured as 6,18 and $52 \mathrm{mg} \mathrm{ml}^{-1}$ for 0,1 and $2 \mathrm{wt} \%$ acid concentrated sample (see Figure 3-3). Comparing with glucose concentrations after first pretreatment stage for 30 minutes $\left(7,18\right.$ and $41 \mathrm{mg} \mathrm{ml}^{-1}$ for 0,1 and $2 \mathrm{wt} \%$ acid) in section 3.3.3.1 indicates that approximately $11 \mathrm{mg} \mathrm{ml}^{-1}$ of additional glucose was generated for $2 \mathrm{wt} \%$ acid sample. In the case of $0 \& 1 \mathrm{wt} \%$ acid samples there was no significant increase. All other monomer sugars (xylose, mannose, arabinnose and galactose) follow the stepwise increase in concentration with increasing acid concentration as observed for other experiment sets.

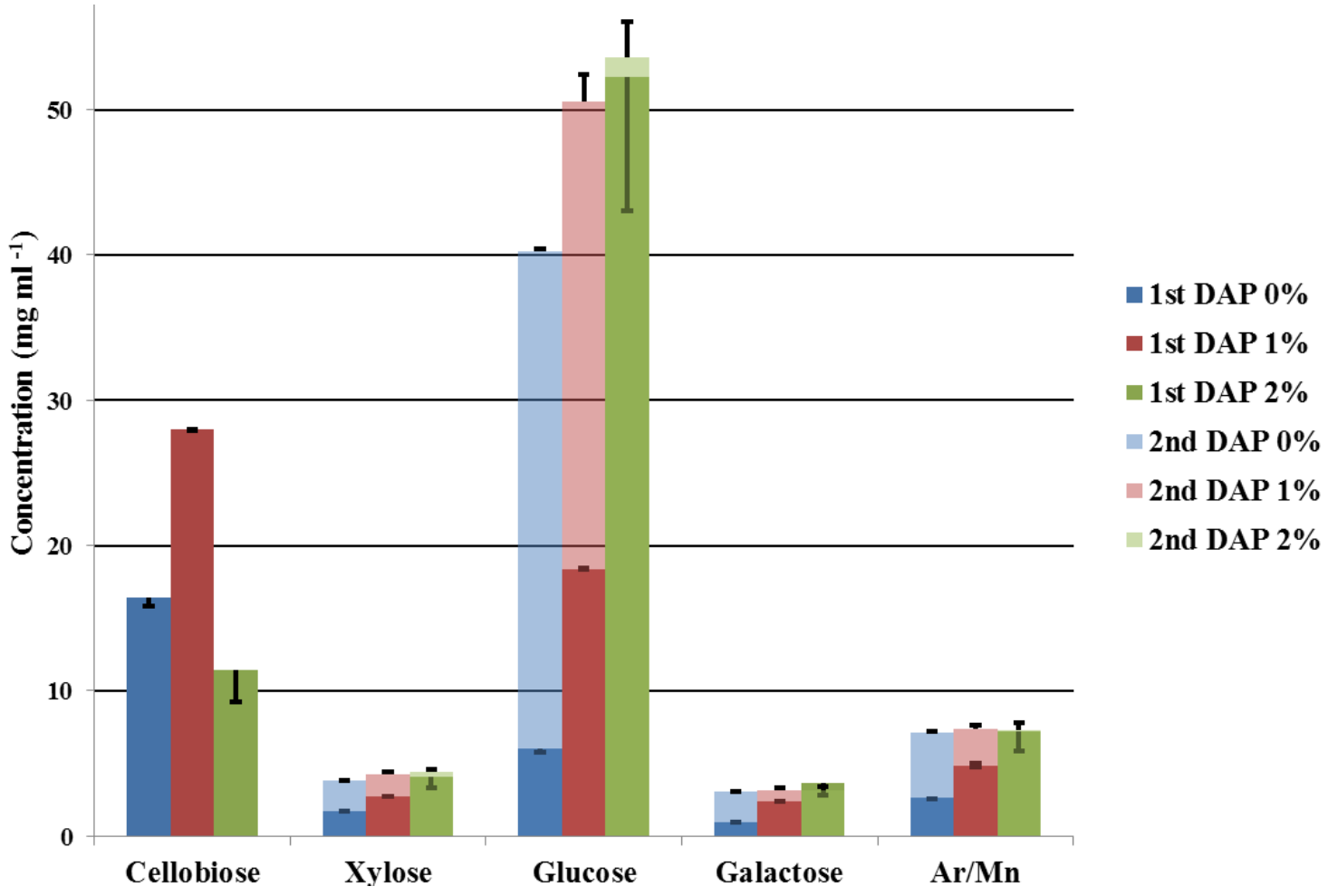

Figure 3-3 Average carbohydrates (cellobiose, xylose, glucose, galactose, mannose \& mannose) sugar concentration trend after 45 minutes DAP (first \& second pretreatment stage) 
Finally, TMS were measured to be 11, 28 and $67 \mathrm{mg}$ ml-1 respectively for the 0,1 and $2 \mathrm{wt} \%$ acid DCS (first stage pretreatment, 45 minutes). Even though the TMS concentration in the $2 \mathrm{wt} \%$ acid concentrated DCS was the highest observed so far for all first stage acid pretreatment, there was a high level of uncertainty (67 $\pm 12 \mathrm{mg} \mathrm{ml}-$ 1).

Figure 3-3 also shows oligomer analysis of 0, 1 and $2 \mathrm{wt} \%$ acid concentrated DCS initially acid pretreated for 45 minutes. The net increase of glucose concentrations measured after oligomer analysis were 34,32 and $1.43 \mathrm{mg} \mathrm{ml}^{-1}$ for 0,1 and $2 \mathrm{wt} \%$ acid concentrated DCS. We observed a decreasing trend in the net increase of glucose concentration with increasing initial pretreatment time after oligomer analysis $(2 \mathrm{wt} \%$ acid concentrated DCS): $31 \mathrm{mg} \mathrm{ml}^{-1}$ (see Figure 3-1, for 1 minute), $14 \mathrm{mg} \mathrm{m}^{-1}$ (see Figure 3-2, for 30 minute) and $1.43 \mathrm{mg} \mathrm{ml}^{-1}$ (see Figure 3-3, for 45 minutes). We also observed degradation of galactose sugars $\left(<1 \mathrm{mg} \mathrm{ml}^{-1}\right)$ for $2 \mathrm{wt} \%$ acid concentrated sample (see Figure 3-3). Net increases in TMS were significant for both 0 and $1 \mathrm{wt} \%$ acid hydrolysates. Unlike 1 and 30 minutes oligomer analysis (see Figures 3-1 \& 3-2) where we observed 35 and $17 \mathrm{mg} \mathrm{ml}^{-1}$ (net glucose concentration) for $2 \mathrm{wt} \%$ acid concentrated DCS, a rather low yield $\left(1.3 \mathrm{mg} \mathrm{ml}^{-1}\right)$ for 45 minutes oligomer analysis (see Figure 3-3) was observed in addition to galactose $\left(<1 \mathrm{mg} \mathrm{ml}^{-1}\right)$ degradation. The TMS for both the first stage acid pretreatment and oligomer analysis were estimated to be $54.2,65.4$ and $68.5 \mathrm{mg} \mathrm{ml}^{-1}$ (Figure A-7).

\subsubsection{Enzymatic hydrolysis - 45 minutes DAH}

Table 3-4 shows the general trend of increasing TMS and a corresponding decrease in cellobiose concentrations over time for 45 minutes DAH. Glucose concentrations were the most dominant for all hydrolysate analyzed (see Table 3-4). Arabinose/manose (Ar/Mn), HMF and furfural remain approximately constant over time. From Table 3-4, it is indicative that higher acid concentration results in increase in TMS. HMF and Furfural for EH averaged $0.13( \pm 0.05)$ and $0.2( \pm 0.04) \mathrm{mg} \mathrm{ml}^{-1}$ respectively (see Figure A-8). 
Table 3-4 Average TMS, furfural and HMF concentrations $\left(\mathrm{mg} \mathrm{ml}^{-1}\right)$ for $\mathrm{EH}$ on 45 minutes DAH

\begin{tabular}{|l|c|c|c|c|c|c|c|c|c|}
\hline $\begin{array}{l}\text { Enzymatic } \\
\text { Hydrolysate } \\
\text { sample }\end{array}$ & $\begin{array}{c}\text { Time } \\
\text { (hours) }\end{array}$ & Cellobiose & Xylose & Glucose & Galactose & Ar/Mn & HMF & Furfural & TMS \\
\hline & $\mathbf{0}$ & $6.0( \pm 0.0)$ & $1.9( \pm 0.07)$ & $25.9( \pm 1.17)$ & $2.1( \pm 0.09)$ & $1.1( \pm 1.63)$ & $0.1( \pm 0.01)$ & $0.5( \pm 0.05)$ & $31.0( \pm 2.9)$ \\
0\% wt. Acid- & $\mathbf{2 4}$ & $5.6( \pm 0.15)$ & $3.6( \pm 0.01)$ & $39.1( \pm 0.5)$ & $1.9( \pm 0.11)$ & $3.2( \pm 0.10)$ & $0.2( \pm 0.003)$ & $0.04( \pm 0.0)$ & $47.8( \pm 0.7)$ \\
$\mathbf{( 3 0}$ min, DAH) & $\mathbf{4 8}$ & $3.4( \pm 0.03)$ & $3.6( \pm 0.14)$ & $42.2( \pm 0.49)$ & $1.9( \pm 0.08)$ & $5.9( \pm 0.27)$ & $0.2( \pm 0.01)$ & $0.04( \pm 0.001)$ & $53.7( \pm 1.0)$ \\
& $\mathbf{7 2}$ & $3.5( \pm 0.12)$ & $3.7( \pm 0.06)$ & $42.7( \pm 0.31)$ & $1.7( \pm 0.04)$ & $5.3( \pm 0.50)$ & $0.2( \pm 0.02)$ & $0.04( \pm 0.0)$ & $53.4( \pm 0.84)$ \\
\hline & $\mathbf{0}$ & $5.6( \pm 0.0)$ & $2.6( \pm 0.08)$ & $30.3( \pm 0.48)$ & $3.5( \pm 0.06)$ & $6.0( \pm 3.08)$ & $0.2( \pm 0.01)$ & $1.1( \pm 0.03)$ & $42.5( \pm 2.6)$ \\
$\mathbf{1 \%}$ wt. Acid- & $\mathbf{2 4}$ & $7.0( \pm 0.24)$ & $5.2( \pm 0.12)$ & $42.5( \pm 0.80)$ & $3.3( \pm 0.01)$ & $5.2( \pm 0.0)$ & $0.3( \pm 0.002)$ & $0.05( \pm 0.002)$ & $56.2( \pm 0.9)$ \\
$\mathbf{( 3 0}$ min, DAH) & $\mathbf{4 8}$ & $3.3( \pm 1.15)$ & $3.3( \pm 1.84)$ & $35.8( \pm 14.5)$ & $2.4( \pm 0.9)$ & $5.7( \pm 1.66)$ & $0.2( \pm 0.08)$ & $0.04( \pm 0.02)$ & $47.2( \pm 18.9)$ \\
& $\mathbf{7 2}$ & $4.2( \pm 0.1)$ & $4.8( \pm 0.12)$ & $47.2( \pm 0.97)$ & $2.8( \pm 0.07)$ & $6.7( \pm 0.52)$ & $0.3( \pm 0.01)$ & $0.05( \pm 0.001)$ & $61.5( \pm 1.7)$ \\
\hline & $\mathbf{0}$ & $5.9( \pm 0.13)$ & $2.7( \pm 0.0)$ & $42.3( \pm 0.31)$ & $4.5( \pm 0.03)$ & $10.6( \pm 0.47)$ & $0.2( \pm 0.002)$ & $1.8( \pm 0.04)$ & $60.1( \pm 0.8)$ \\
$\mathbf{2 \%}$ wt. Acid- & $\mathbf{2 4}$ & $4.1( \pm 0.17)$ & $5.3( \pm 0.02)$ & $49.4( \pm 1.52)$ & $5.0( \pm 0.01)$ & $7.0( \pm 0.08)$ & $0.4( \pm 0.02)$ & $0.09( \pm 0.002)$ & $66.7( \pm 1.6)$ \\
$\mathbf{( 3 0}$ min, DAH) & $\mathbf{4 8}$ & $6.0( \pm 0.27)$ & $4.3( \pm 0.11)$ & $48.8( \pm 1.06)$ & $4.5( \pm 0.06)$ & $7.1( \pm 0.11)$ & $0.4( \pm 0.01)$ & $0.09( \pm 0.001)$ & $64.7( \pm 1.3)$ \\
& $\mathbf{7 2}$ & $3.8( \pm 0.12)$ & $4.3( \pm 0.17)$ & $50.2( \pm 2.0)$ & $4.0( \pm 0.11)$ & $6.7( \pm 0.25)$ & $0.3( \pm 0.01)$ & $0.09( \pm 0.003)$ & $65.3( \pm 2.5)$ \\
\hline
\end{tabular}

\subsubsection{Results for experiment set 4}

\subsubsection{Dilute acid pretreatment \& oligomer analysis - 60 minutes}

Results of first \& second stage DAP for 60 minutes are displayed in Figure 3-4. As previously observed, cellobiose increased from $18 \mathrm{mg} \mathrm{ml}^{-1}$ for $0 \mathrm{wt} \%$ acid concentrated sample peaking at $27 \mathrm{mg} \mathrm{ml}^{-1}(1 \mathrm{wt} \%$ acid) followed by subsequent degradation to 10 $\mathrm{mg} \mathrm{ml}^{-1}$ for $2 \mathrm{wt} \%$ acid concentrated sample. (see Figure $3-4$ ).

The glucose concentration after first pretreatment stage was measured to be 6.8, 22 and $49 \mathrm{mg} \mathrm{ml}^{-1}$ for 0,1 and $2 \mathrm{wt} \%$ acid concentrated sample (see Figure 3-4). Comparing with glucose concentration for the first pretreatment after 45 minutes $(6,18$ and $52 \mathrm{mg}$ $\mathrm{ml}^{-1}$ for 0,1 and $2 \mathrm{wt} \%$ acid concentrated sample, see section 3.3.4.1) indicates a slight improvement for $1 \mathrm{wt} \%$ acid concentrated sample after 60 minutes DAP. Finally, TMS were estimated to be $13.6,36$ and $66 \mathrm{mg} \mathrm{ml}^{-1}$ respectively for the 0,1 and $2 \mathrm{wt} \%$ acid DCS (first stage pretreatment, 60 minutes). Even though TMS of $2 \mathrm{wt} \%$ acid concentrated DCS for 45 minutes (see Figure 3-3) was $67( \pm 12) \mathrm{mg} \mathrm{ml}^{-1}$ as opposed to $66( \pm 2) \mathrm{mg} \mathrm{ml}^{-1}$ for the 60 minutes (see Figure 3-4), the high level of uncertainty for the former makes the 60 minute result a more confident choice. 


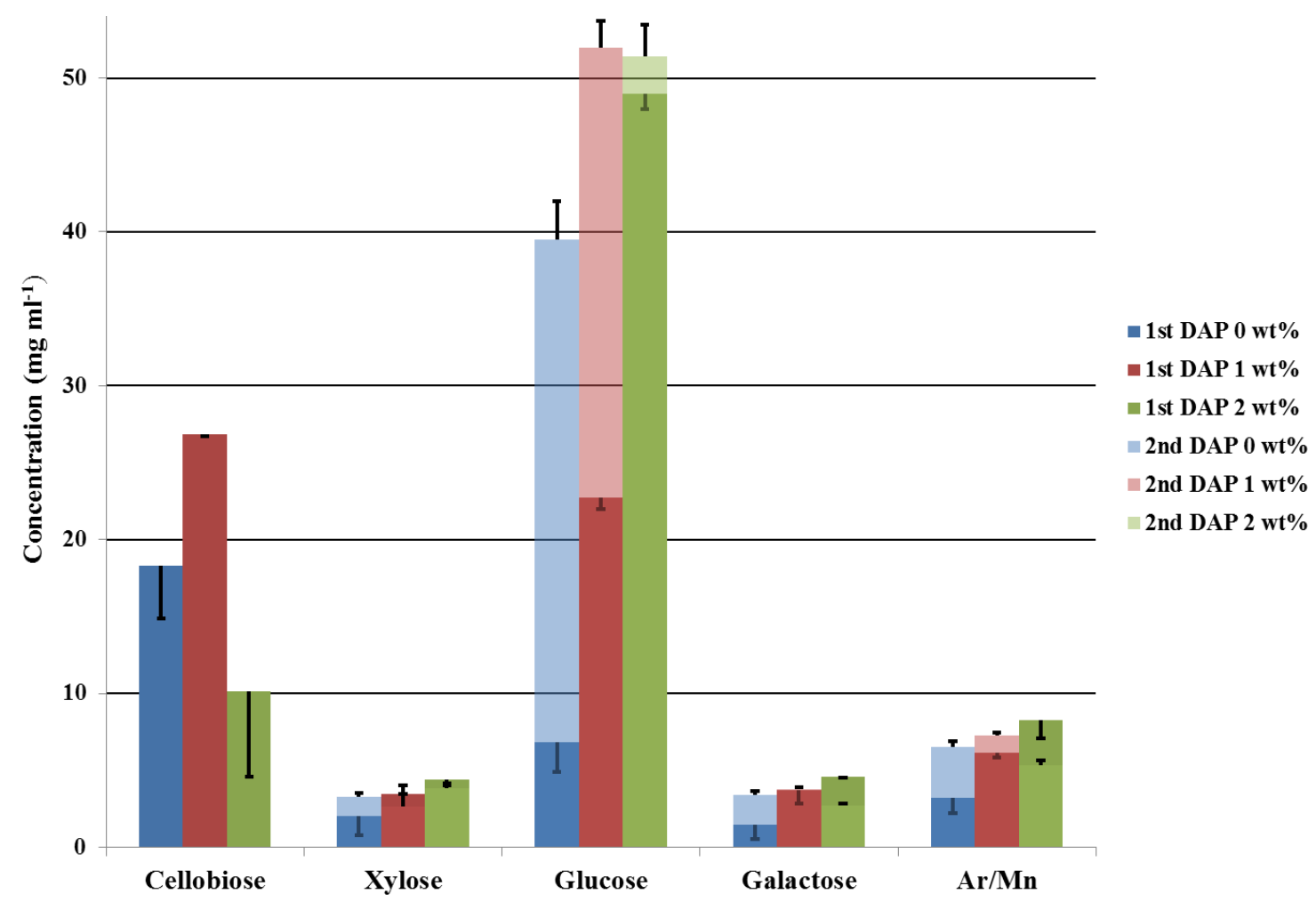

Figure 3-4 Average carbohydrates (cellobiose, xylose, glucose, galactose, mannose \& mannose) sugar concentration trend after 60 minutes DAP (first \& second pretreatment stage)

The net increase in monomer sugars due to 60 minutes oligomer analysis is also displayed in Figure 3-4. The increase in glucose concentrations measured after oligomer analysis were 32, 29 and $2.4 \mathrm{mg} \mathrm{ml}^{-1}$ for 0,1 and $2 \mathrm{wt} \%$ acid concentrated DCS as shown in Figure 3-4 indicating the effectiveness of the first pretreatment stage in the case of $2 \mathrm{wt} \%$ acid sample. Apart from glucose, all other monomer sugars (xylose, galactose, arabinose and mannose) degraded in the $2 \mathrm{wt} \%$ acid hydrolysate (concentration became lower). Glucose once again showed significant net increase especially for $0 \& 1 \mathrm{wt} \%$ acid concentrated DCS, an indication that the first hydrolysis stage was not effective in hydrolyzing the glucan component in DCS. Finally, TMS for both the first stage acid pretreatment and oligomer analysis combined was estimated to be 52.7, 65.6 and $65.7 \mathrm{mg} \mathrm{ml}^{-1}$ (see Figure A-9).

\subsubsection{Enzymatic hydrolysis - 60 minutes DAH}


Table 3-5 shows the TMS, furfural and HMF concentrations after varying times of EH (60 minutes first stage DAH). A trend of increasing xylose, glucose and galactose production over time was observed. Glucose is the dominant sugar, and it showed the largest increase in the first 24 hours of $\mathrm{EH}(0 \mathrm{wt} \%$ acid concentrated DCS $)$. Arabinose/manose, HMF and furfural remained approximately constant over time, and cellobiose showed a decreasing trend over time with none detected in some cases. Results for inhibitors (HMF and Furfural) concentrations generated for the 60 minutes hydrolysis scheme fluctuate with no clear pattern, they were all below $0.3 \mathrm{mg} \mathrm{ml}^{-1}$ (see Figure A-10).

Table 3-5 Average TMS, furfural and HMF concentrations $\left(\mathrm{mg} \mathrm{ml}^{-1}\right)$ for $\mathrm{EH}$ on 60 minutes DAH

\begin{tabular}{|l|c|c|c|c|c|c|c|c|c|}
\hline Components & $\begin{array}{c}\text { Time } \\
\text { (hours) }\end{array}$ & Cellobiose & Xylose & Glucose & Galactose & Ar/Mn & HMF & Furfural & TMS \\
\hline & $\mathbf{0}$ & $19.0( \pm 1.9)$ & $2.0( \pm 0.9)$ & $17.3( \pm 0.9)$ & $0.6( \pm 0.6)$ & $2.3( \pm 0.5)$ & $0.1( \pm 0.0)$ & $0.1( \pm 0.0)$ & $22.2( \pm 2.9)$ \\
0\% wt. Acid- & $\mathbf{2 4}$ & $9.1( \pm 0.0)$ & $2.2( \pm 0.0)$ & $32.3( \pm 0.3)$ & $0.5( \pm 0.0)$ & $2.2( \pm 0.0)$ & $0.1( \pm 0.0)$ & $0.1( \pm 0.0)$ & $37.3( \pm 0.2)$ \\
$(\mathbf{6 0}$ min, DAH) & $\mathbf{4 8}$ & $3.1( \pm 0.1)$ & $3.2( \pm 0.0)$ & $40.8( \pm 0.2)$ & $0.9( \pm 0.4)$ & $2.8( \pm 0.8)$ & $0.1( \pm 0.0)$ & $0.2( \pm 0.0)$ & $47.8( \pm 1.4)$ \\
& $\mathbf{7 2}$ & $( \pm 0.0)$ & $3.7( \pm 1.2)$ & $44.8( \pm 0.2)$ & $2.6( \pm 2.8)$ & $2.9( \pm 0.7)$ & $0.1( \pm 0.0)$ & $0.1( \pm 0.0)$ & $53.9( \pm 4.9)$ \\
\hline & $\mathbf{0}$ & $9.7( \pm 0.2)$ & $3.4( \pm 0.3)$ & $29.6( \pm 0.8)$ & $2.2( \pm 0.1)$ & $4.2( \pm 0.2)$ & $0.1( \pm 0.0)$ & $0.2( \pm 0.0)$ & $39.4( \pm 1.3)$ \\
& $\mathbf{2 4}$ & $9.4( \pm 0.0)$ & $2.8( \pm 0.3)$ & $40.7( \pm 1.1)$ & $1.2( \pm 0.5)$ & $3.3( \pm 0.4)$ & $0.1( \pm 0.0)$ & $0.2( \pm 0.0)$ & $48.0( \pm 0.2)$ \\
$\mathbf{1 \%}$ wt. Acid- & $\mathbf{4 8}$ & $2.9( \pm 0.9)$ & $3.4( \pm 0.4)$ & $48.9( \pm 7.0)$ & $1.7( \pm 0.7)$ & $4.0( \pm 0.9)$ & $0.2( \pm 0.1)$ & $0.2( \pm 0.0)$ & $58.0( \pm 9.1)$ \\
$\mathbf{6 0}$ min, DAH) & $\mathbf{7 2}$ & $( \pm 0.0)$ & $4.3( \pm 0.1)$ & $47.4( \pm 0.9)$ & $3.0( \pm 0.0)$ & $4.6( \pm 0.2)$ & $0.1( \pm 0.0)$ & $0.2( \pm 0.0)$ & $59.2( \pm 0.8)$ \\
\hline & $\mathbf{0}$ & $6.7( \pm 0.3)$ & $3.9( \pm 0.2)$ & $48.7( \pm 0.7)$ & $2.8( \pm 0.1)$ & $5.2( \pm 0.1)$ & $0.2( \pm 0.0)$ & $0.2( \pm 0.0)$ & $60.7( \pm 1.0)$ \\
& $\mathbf{2 4}$ & $( \pm 0.0)$ & $3.8( \pm 0.0)$ & $51.9( \pm 0.3)$ & $3.0( \pm 0.0)$ & $5.6( \pm 0.1)$ & $0.2( \pm 0.0)$ & $0.2( \pm 0.0)$ & $64.3( \pm 0.5)$ \\
$\mathbf{2 \%}$ wt. Acid- & $\mathbf{4 8}$ & $( \pm 0.0)$ & $4.1( \pm 0.3)$ & $49.6( \pm 4.9)$ & $2.9( \pm 0.4)$ & $5.4( \pm 0.8)$ & $0.2( \pm 0.1)$ & $0.2( \pm 0.0)$ & $62.0( \pm 5.8)$ \\
$\mathbf{6 0}$ min, DAH) & $\mathbf{7 2}$ & $( \pm 0.0)$ & $3.3( \pm 0.0)$ & $53.3( \pm 0.0)$ & $3.1( \pm 0.1)$ & $5.2( \pm 0.1)$ & $0.2( \pm 0.0)$ & $0.2( \pm 0.0)$ & $64.9( \pm 0.2)$ \\
\hline
\end{tabular}

\subsubsection{Results for experiment set 5}

\subsubsection{Dilute acid pretreatment - 75 minutes}

Sugar concentrations measured after 75 minutes of dilute acid hydrolysis (first \& second stage pretreatment) are shown in Figure 3-5. Cellobiose increased from $15 \mathrm{mg}$ $\mathrm{ml}^{-1}\left(0 \mathrm{wt} \%\right.$ acid concentrated sample) peaking at $27 \mathrm{mg} \mathrm{ml}^{-1}(1 \mathrm{wt} \%$ acid concentrated sample). It further degraded due to increased acid catalyst concentration and reaction time to $6 \mathrm{mg} \mathrm{ml}^{-1}$ (2 $\mathrm{wt} \%$ acid) as shown in Figure 3-5. 
Glucose concentration after the first acid pretreatment stage was 6,23 and $51 \mathrm{mg} \mathrm{ml}^{-1}$ for 0,1 and $2 \mathrm{wt} \%$ acid concentrated sample (see Figure 3-5) for 75 minutes. There was no significant increase in monomer sugars especially (glucose) when compared to the previous hydrolysis stage at 60 minutes (see section 3.3.5.1). TMS were estimated to be $11.5,34.0$ and $65.2 \mathrm{mg} \mathrm{ml}^{-1}$ for 0,1 and $2 \mathrm{wt} \%$ acid concentrated DCS respectively, slightly lower compared to 60 minutes first stage pretreatment (see Figure 3-4). After 75 minutes, little monomer sugars were generated for the second stage acid pretreatment.

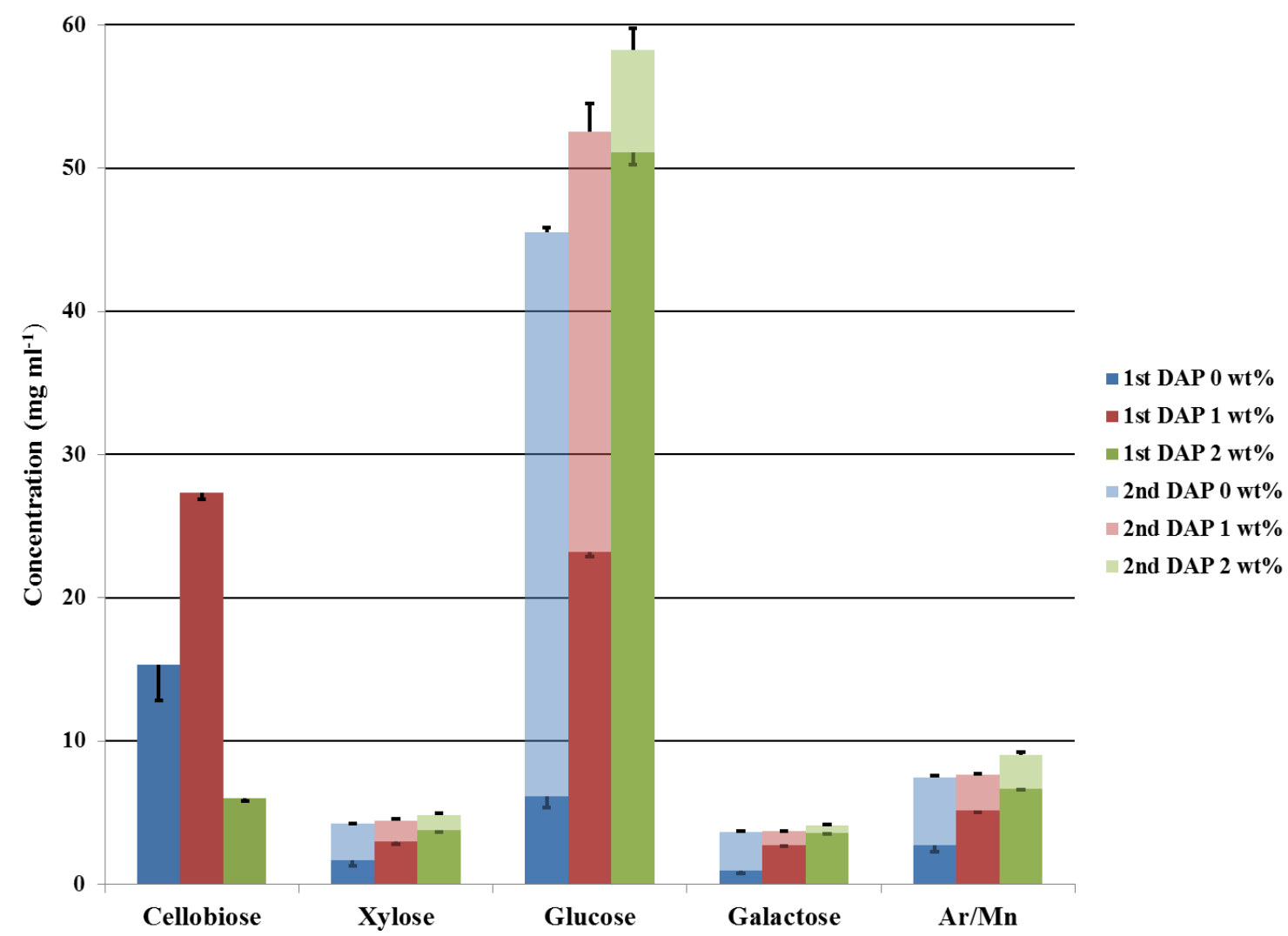

Figure 3-5 Average carbohydrates (cellobiose, xylose, glucose, galactose, mannose \& arabinose) sugar concentration trend after 75 minutes DAP (first \& second pretreatment stage)

The net increase in monomer sugars due to oligomer analysis of hydolysate previously subjected to 75 minutes DAP (first stage) is also shown in Figure 3-5. Interestingly, 
there was no degradation of monomer sugars for 75 minutes oligomer analysis, as observed for the 60 minutes (section 3.3.5.1). The TMS for both hydrolysis (first stage pretreatment + oligomer analysis) is displayed in Figure A-11, 60.8, 68.3 and $74.8 \mathrm{mg}$ $\mathrm{ml}^{-1}$ of TMS were measured for 0,1 and $2 \mathrm{wt} \%$ acid DCS respectively.

\subsubsection{Enzymatic hydrolysis - 75 minutes DAH}

Table 3-6 shows the results for monomer sugar and inhibitors concentrations for samples treated for 75 minutes with 0,1 and $2 \mathrm{wt} \%$ DAP (first stage) respectively followed by varying times of EH. The general trend, which is similar to previous experiments, shows a sharp increase in glucose concentration within the first 24 hour incubation period, especially for $0 \mathrm{wt} \%$ acid DCS, with a simultaneous decline in cellobiose. When comparing the three acid treatment intensities, the results indicated that nearly all concentrations are higher at higher acid concentrations. Slightly higher concentrations of inhibitors were observed for 75 minutes DAH (see Figure A-12) compared to 60 minutes (see Figure A-10). After the first stage DAP, inhibitor concentration for $2 \mathrm{wt} \%$ acid content remains constant over time after a slight increase during the first 24 hour incubation period.

Table 3-6 Average TMS, furfural and HMF concentrations ( $\mathrm{mg} \mathrm{ml}^{-1}$ ) for $\mathrm{EH}$ on 75 minutes DAH

\begin{tabular}{|l|c|c|c|c|c|c|c|c|c|}
\hline Components & $\begin{array}{c}\text { Time } \\
\text { (hours) }\end{array}$ & Cellobiose & Xylose & Glucose & Galactose & Ar/Mn & HMF & Furfural & TMS \\
\hline & $\mathbf{0}$ & $18.4( \pm 0.8)$ & $2.0( \pm 0.0)$ & $20.5( \pm 0.3)$ & $0.8( \pm 0.0)$ & $2.9( \pm 0.0)$ & $0.1( \pm 0.0)$ & $0.1( \pm 0.0)$ & $26.2( \pm 0.3)$ \\
0\% wt. Acid- & $\mathbf{2 4}$ & $5.6( \pm 0.1)$ & $2.6( \pm 0.0)$ & $37.7( \pm 0.0)$ & $0.9( \pm 0.0)$ & $2.8( \pm 0.0)$ & $0.2( \pm 0.0)$ & $0.2( \pm 0.0)$ & $43.9( \pm 0.1)$ \\
(75 min, DAH) & $\mathbf{4 8}$ & $3.4( \pm 0.1)$ & $3.0( \pm 0.1)$ & $40.8( \pm 0.1)$ & $1.0( \pm 0.0)$ & $2.9( \pm 0.0)$ & $0.1( \pm 0.0)$ & $0.2( \pm 0.0)$ & $47.8( \pm 0.0)$ \\
& $\mathbf{7 2}$ & $2.6( \pm 0.2)$ & $3.2( \pm 0.0)$ & $40.7( \pm 0.3)$ & $1.0( \pm 0.0)$ & $2.7( \pm 0.0)$ & $0.1( \pm 0.0)$ & $0.2( \pm 0.0)$ & $47.6( \pm 0.4)$ \\
\hline & $\mathbf{0}$ & $12.0( \pm 0.2)$ & $3.0( \pm 0.1)$ & $29.2( \pm 0.6)$ & $2.3( \pm 0.0)$ & $4.4( \pm 0.1)$ & $0.2( \pm 0.0)$ & $0.3( \pm 0.0)$ & $38.9( \pm 0.8)$ \\
& $\mathbf{2 4}$ & $5.7( \pm 0.0)$ & $3.6( \pm 0.1)$ & $43.6( \pm 0.5)$ & $2.3( \pm 0.0)$ & $4.4( \pm 0.1)$ & $0.2( \pm 0.0)$ & $0.3( \pm 0.0)$ & $54.0( \pm 0.6)$ \\
$\mathbf{( 7 5}$ min, DAH) & $\mathbf{4 8}$ & $3.9( \pm 0.1)$ & $4.0( \pm 0.1)$ & $46.3( \pm 0.9)$ & $2.5( \pm 0.1)$ & $4.4( \pm 0.1)$ & $0.1( \pm 0.0)$ & $0.3( \pm 0.0)$ & $57.2( \pm 1.1)$ \\
& $\mathbf{7 2}$ & $3.2( \pm 0.0)$ & $4.1( \pm 0.1)$ & $45.9( \pm 0.9)$ & $2.5( \pm 0.0)$ & $4.3( \pm 0.1)$ & $0.1( \pm 0.0)$ & $0.3( \pm 0.0)$ & $56.8( \pm 1.0)$ \\
\hline & $\mathbf{0}$ & $4.3( \pm 0.1)$ & $3.3( \pm 0.0)$ & $49.8( \pm 0.4)$ & $2.9( \pm 0.1)$ & $5.4( \pm 0.0)$ & $0.3( \pm 0.0)$ & $0.3( \pm 0.0)$ & $61.3( \pm 0.3)$ \\
$\mathbf{2 \%}$ wt. Acid- & $\mathbf{2 4}$ & $1.4( \pm 0.1)$ & $3.5( \pm 0.1)$ & $53.3( \pm 0.6)$ & $2.9( \pm 0.1)$ & $5.4( \pm 0.1)$ & $0.3( \pm 0.0)$ & $0.3( \pm 0.0)$ & $65.1( \pm 0.9)$ \\
$(\mathbf{7 5}$ min, DAH) & $\mathbf{4 8}$ & $1.3( \pm 0.0)$ & $3.7( \pm 0.0)$ & $53.6( \pm 0.1)$ & $3.0( \pm 0.1)$ & $5.5( \pm 0.1)$ & $0.2( \pm 0.0)$ & $0.3( \pm 0.0)$ & $65.7( \pm 0.3)$ \\
& $\mathbf{7 2}$ & $1.3( \pm 0.0)$ & $3.6( \pm 0.0)$ & $52.8( \pm 0.1)$ & $3.0( \pm 0.0)$ & $5.3( \pm 0.1)$ & $0.2( \pm 0.0)$ & $0.3( \pm 0.0)$ & $64.7( \pm 0.0)$ \\
\hline
\end{tabular}

\subsubsection{Results for experiment set 7}

\subsubsection{Dilute acid pretreatment - 90 minutes}


Figure 3-6 summarizes both the first \& second stage acid pretreatment results of DCS for 90 minutes. There is a general increase in monomer sugar concentrations with increasing acid concentration. As previously observed, while the $1 \mathrm{wt} \%$ acid content tends to breakdown more polymers into oligomers, the $2 \mathrm{wt} \%$ is effective in further hydrolyzing cellobiose into glucose units hence a corresponding decrease in concentration of cellobiose (see Figure 3-6).

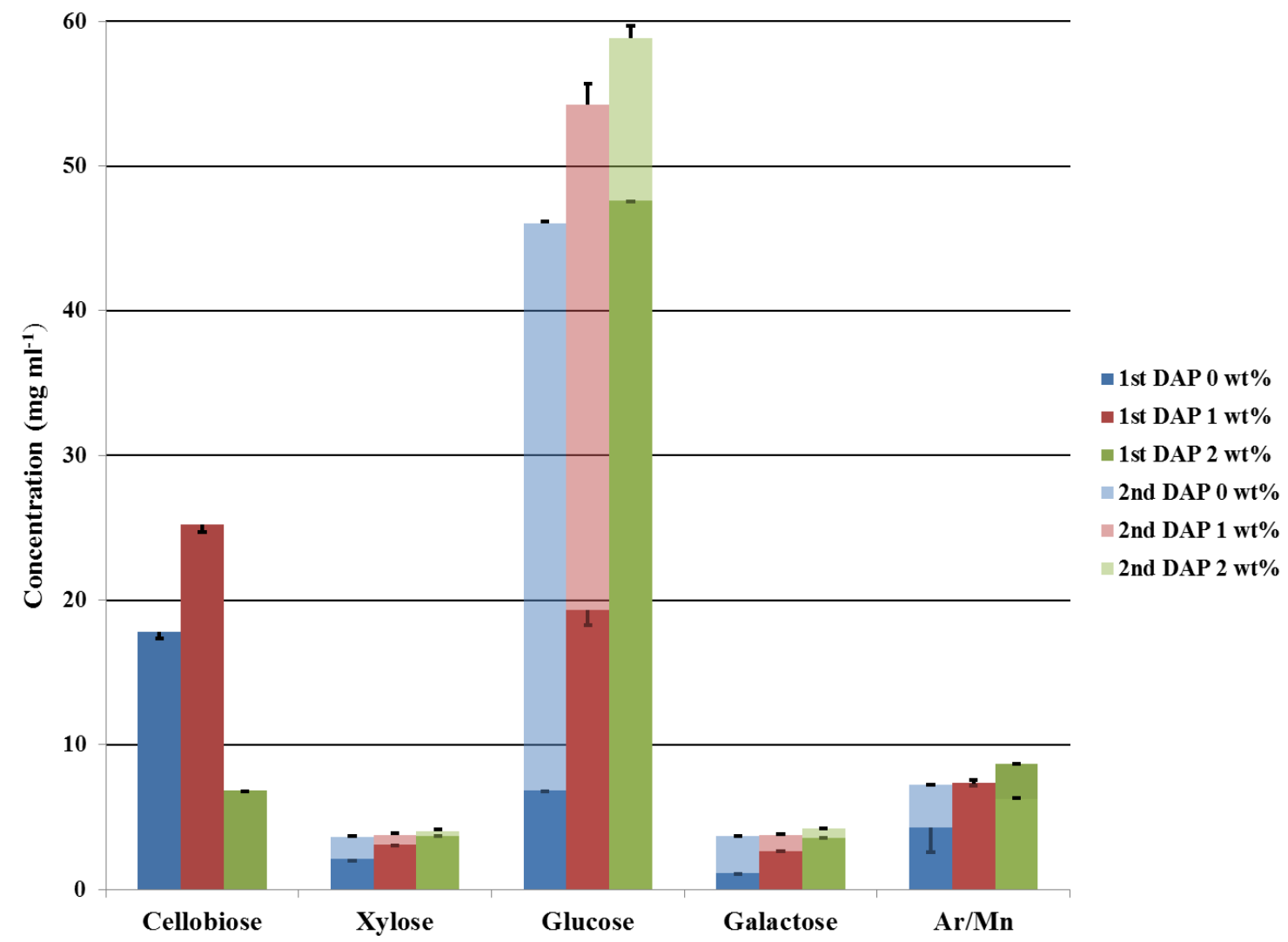

Figure 3-6 Average carbohydrates (cellobiose, xylose, glucose, galactose, mannose \& mannose) sugar concentration trend after 90 minutes DAP (first \& second pretreatment stage)

Glucose concentrations after the first pretreatment stage (90 minutes) were 7, 19 and 48 $\mathrm{mg} \mathrm{ml}^{-1}$ for 0,1 and $2 \mathrm{wt} \%$ acid concentrated DCS respectively. Comparing these results to glucose concentrations after first stage pretreatment for 60 and 75 minutes (see Figures 3-4 \& 3-5) indicates no increase for 0 and $2 \mathrm{wt} \%$ acid concentrated 
samples but further decline in the $1 \mathrm{wt} \%$ acid concentrated sample. TMS after first stage pretreatment was $14.3,32.4$ and $63.6 \mathrm{mg} \mathrm{ml}^{-1}$ for 0,1 and $2 \mathrm{wt} \%$ acid concentrated DCS respectively with glucose being the highest as observed in all experiments for the first stage acid pretreatment (see Figure 3-6).

In the oligomer analysis results for 90 minutes DAP (see Figure 3-6), more monomer sugars were detected in the 0 and $1 \mathrm{wt} \%$ DCS generating a total of 46 and $37 \mathrm{mg} \mathrm{ml}^{-1}$ (net increase) of TMS respectively. Glucose concentrations increased and peaked at approximately $39 \mathrm{mg} \mathrm{ml}^{-1}$ for $0 \mathrm{wt} \%$ acid concentrated DCS. The TMS for the two pretreatment stages (first acid hydrolysis + oligomer analysis) were estimated to be $60.5,69.0$ and $74.3 \mathrm{mg} \mathrm{ml}^{-1}$ (Figure A-13).

\subsubsection{Enzymatic hydrolysis - 90 minutes DAH}

Table 3-7 summarizes the sugar, furfural and HMF concentrations for samples pretreated for 90 minutes with 0,1 and $2 \mathrm{wt} \%$ wt. acid and subsequent $\mathrm{EH}$ at varying reaction times. A similar trend of increasing xylose, glucose and galactose over time was observed.

Table 3-7 Average TMS, furfural and HMF concentrations ( $\mathrm{mg} \mathrm{ml}^{-1}$ ) for EH on 90 minutes DAH

\begin{tabular}{|c|c|c|c|c|c|c|c|c|c|}
\hline Components & $\begin{array}{c}\text { Time } \\
\text { (hours) }\end{array}$ & Cellobiose & Xylose & Glucose & Galactose & $\mathbf{A r} / \mathbf{M n}$ & HMF & Furfural & TMS \\
\hline \multirow{4}{*}{$\begin{array}{l}\text { 0\% wt. } \\
\text { Acid, } 90 \text { min } \\
\text { DAH }\end{array}$} & 0 & $18.1( \pm 0.2)$ & $2.2( \pm 0.5)$ & 11.1( & 1.1 & $8.7( \pm 4.1)$ & $0.1( \pm 0.0)$ & $0.1( \pm 0.0)$ & $23.1( \pm 3.4)$ \\
\hline & 24 & $4.9( \pm 0.3)$ & $2.9( \pm 0.6)$ & $39.1( \pm 1.0)$ & $1.6( \pm 0.4)$ & $3.0( \pm 0.1)$ & $0.1( \pm 0.0)$ & $0.1( \pm 0.1)$ & $46.8( \pm 2.1)$ \\
\hline & 48 & $2.8( \pm 0.0)$ & $2.9( \pm 0.0)$ & $41.2( \pm 0.5)$ & $1.6( \pm 0.0)$ & $3.2( \pm 0.0)$ & $0.08( \pm 0.0)$ & $0.1( \pm 0.0)$ & $48.8( \pm 0.5)$ \\
\hline & 72 & $3.1( \pm 0.1)$ & $3.8( \pm 0.1)$ & $42.3( \pm 0.1)$ & $1.3( \pm 0.1)$ & $3.3( \pm 0.2)$ & $0.08( \pm 0.0)$ & $0.1( \pm 0.0)$ & $50.7( \pm 0.3)$ \\
\hline \multirow{4}{*}{$\begin{array}{l}1 \% \text { wt. } \\
\text { Acid, } 90 \text { min } \\
\text { DAH }\end{array}$} & 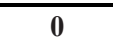 & $25.5( \pm 0.9)$ & $2.7( \pm 0.2)$ & $23.9( \pm 0.2)$ & $2.2( \pm 0.0)$ & $9.3( \pm 0.2)$ & $0.1( \pm 0.0)$ & $0.2( \pm 0.1)$ & $35.4( \pm 0.0)$ \\
\hline & 24 & & $3.3( \pm 0.1)$ & $44.8( \pm 1.1)$ & $2.9( \pm 0.3)$ & $4.3( \pm 0.3)$ & $0.2( \pm 0.0)$ & $0.3( \pm 0.0)$ & 55.4 \\
\hline & 48 & $6.6( \pm 0.3)$ & $6.4( \pm 0.9)$ & $48.5( \pm 1.9)$ & $4.2( \pm 0.8)$ & $5.9( \pm 0.5)$ & $0.2( \pm 0.1)$ & $0.2( \pm 0.1)$ & $65.1( \pm 4.1)$ \\
\hline & 72 & $( \pm 0.0)$ & $4.5( \pm 0.8)$ & $51.3( \pm 4.6)$ & $3.1( \pm 0.2)$ & $5.4( \pm 0.2)$ & $0.2( \pm 0.1)$ & $0.3( \pm 0.0)$ & $64.4( \pm 3.9)$ \\
\hline \multirow{4}{*}{$\begin{array}{l}2 \% \text { wt. } \\
\text { Acid, } 90 \text { min } \\
\text { DAH }\end{array}$} & 0 & $6.6( \pm 0.5)$ & $3.3( \pm 0.1)$ & $46.6( \pm 0.5)$ & $3.6( \pm 0.2)$ & $10.9( \pm 0.2)$ & $0.2( \pm 0.0)$ & $0.3( \pm 0.0)$ & $61.2( \pm 0.0)$ \\
\hline & 24 & $1.1( \pm 0.0)$ & $3.2( \pm 0.0)$ & $53.4( \pm 0.1)$ & $3.3( \pm 0.0)$ & $5.3( \pm 0.0)$ & $0.4( \pm 0.0)$ & $0.4( \pm 0.0)$ & $65.2( \pm 0.1)$ \\
\hline & 48 & $4.3( \pm 0.5)$ & $4.5( \pm 0.2)$ & $53.1( \pm 0.4)$ & $3.7( \pm 1.0)$ & $5.8( \pm 0.6)$ & $0.1( \pm 0.0)$ & $0.4( \pm 0.0)$ & $67.2( \pm 2.2)$ \\
\hline & 72 & $( \pm 0.0)$ & $4.1( \pm 0.2)$ & $48.7( \pm 4.7)$ & $2.7( \pm 0.5)$ & $4.9( \pm 0.8)$ & $0.2( \pm 0.1)$ & $0.2( \pm 0.0)$ & $60.5( \pm 5.8)$ \\
\hline
\end{tabular}

Glucose is the dominant sugar once again, and it shows the largest increase within the first 24 hours of enzymatic hydrolysis, with little increase after 24 hours. Inhibitors 
generated for the 90 minutes hydrolysis scheme are shown in Figure A-14. Comparatively, slightly higher concentrations were measured with 0.37 (HMF) and $0.40 \mathrm{mg} \mathrm{ml}^{-1}$ (furfural) estimated as the highest for $2 \mathrm{wt} \%$ acid concentrated DCS for the first 24 hour incubation period. HMF and furfural concentrations decreased over time after the 72 hour incubation period due to volatilization.

\subsection{Discussion}

The average total carbohydrate (starch, soluble sugars \& cellulose) content of DCS is $27 \mathrm{wt} \%$ on a dry solid basis. The maximum theoretical yield assuming total hydrolysis (i.e., 100\% solubilization of carbohydrate component in DCS into monomer sugars) was estimated to be $76 \mathrm{mg} \mathrm{ml}^{-1}$ (see Appendix A for detailed calculations).

First stage acid pretreatment: Figure A-16 summarizes the effect of residence time on the TMS yields (first stage acid pretreatment) at various acid concentrations $(0,1 \&$ $2 \mathrm{wt} \%$ ). The effect of $0 \mathrm{wt} \%$ acid on the yield of TMS overtime generally was very low, the highest yield observed was $14 \mathrm{mg} \mathrm{ml}^{-1}$ for both 60 and 90 minutes, representing $18 \%(=14 / 76)$ of the theoretical TMS yield. Clearly, the application of temperature alone over increasing reaction time was not effective in degrading the polymeric component of the carbohydrates in DCS into monomer sugars. Apart from 1 minute DAP (first stage pretreatment), TMS yield increased two fold (2x.) with the application of $1 \mathrm{wt} \%$ acid concentration, peaking at 60 minutes with a reported yield of $36 \mathrm{mg} \mathrm{ml}^{-1}$ (Figure A-16). This represents only $47 \%$ of the theoretically available carbohydrates, a clear indication of the effectiveness of the presence of acid catalyst as compared to the $0 \mathrm{wt} \%$ acid concentrated DCS. The TMS yield continues to increase with the application of $2 \mathrm{wt} \%$ acid. Estimated yields at $2 \mathrm{wt} \%$ acid concentration for 45 and 60 minutes were $67(87 \%)$ and $66(86 \%) \mathrm{mg} \mathrm{ml}^{-1}$ respectively, in parenthesis are

the theoretical yields. However, the high level of uncertainty associated with the glucose peak at 45 minutes (Figure 3-3) makes 60 minutes a better option for reaction time. The high acid concentration requirement for increase in TMS is due to the high ash content (alkaline in nature) which continues to neutralize the effect of the acid catalyst. The signature for 1 and $2 \mathrm{wt} \%$ acid concentrated hydrolysate was very similar 
(Figure A-16), there was an increase in concentrations of TMS overtime, peaking around $45 \& 60$ minutes and consequently experiencing a decline in TMS due to the degradation of monomer sugars into inhibitory products over extended reaction time. The key highlight from the first stage pretreatment is that, $2 \mathrm{wt} \%$ acid concentrated DCS was the most effective in hydrolyzing the carbohydrates into monomer sugars, especially for 45 and 60 minutes. This is most likely because the bulk of the carbohydrate components comprise of starch, soluble monomer sugars and non-starch components (xylan, mannan, galactan, mannan, \& cellulose)(Adom et al. 2012). Apart from cellulose, all other components are easily susceptible to degradation in the presence of acid catalyst at elevated temperatures.

Oligomer analysis (second stage acid pretreatment): The application of the second stage acid pretreatment (oligomer analysis) in principle should be capable of hydrolyzing all the carbohydrates into monomer sugars. This however can increase the concentration of inhibitors due to the increase in acid concentration and consequently affect TMS yield. From an industrial perspective, it is not attractive because the increase in acid requirement adversely affects pretreatment reactors and subsequently results in increase cost of maintaining reactors. The key highlights of the oligomer hydrolysis is that, $2 \mathrm{wt} \%$ acid concentrated samples pretreated initially at 75 and 90 minutes [see Figures A-11 and A-13] followed by oligomer analysis yielded 75 (97\%) and $74(96 \%) \mathrm{mg} \mathrm{ml}^{-1}$ of TMS. This represents near full recovery of the TMS, there was however, a comparatively high concentrations of inhibitors observed most likely due to the increased acid concentration and extended reaction time. Second stage pretreatment was most effective for $0 \mathrm{wt} \%$ acid concentrated in terms of TMS yield (during DAP) but less effective for 1 and $2 \mathrm{wt} \%$ acid concentrated DCS (especially for $2 \mathrm{wt} \%)$.

Enyzmatic hydrolysis: A summary of the enzymatic hydrolysis results for the different acid concentrations versus time are displayed in Figures A-17, A-18 \& A-19. In almost all cases, increase in monomer sugars occurs simultaneously with decreasing cellobiose concentrations, a clear indication of the effectiveness of the cellulase 
enzymes. It was also observed that enzymes were predominantly active within the first 24 hour incubation period resulting in drastic increase in concentrations of monomer sugars especially for glucose. Another observation was that, while cellulase enzymes were most efficient in hydrolyzing $0 \mathrm{wt} \%$ acid pretreated DCS, since the first stage acid pretreatment were comparatively efficient for the 1 and $2 \%$ acid pretreated DCS samples. We also observed from the various experimental results that extended reaction times and reaction temperature were not effective for $0 \mathrm{wt} \%$ hydrolysate for the first stage acid pretreatment. TMS increased by a factor of four in all cases for $0 \mathrm{wt} \%$ acid concentrated DCS subjected to EH (see Tables A-1 \& Figure A-20) after 72 hours of incubation time. Enzymes were less efficient in hydrolyzing both 1 and $2 \mathrm{wt} \%$ acid concentrated samples (see Tables A-2 and A-3; Figures A-21 and A-22) probably because a significant portion of the carbohydrate component has been hydrolysed after the first stage pretreatment. TMS increased by a factor of 2 and 1 after 72 hours EH for 1 and $2 \mathrm{wt} \%$ acid pretreated samples respectively, confirming the hypothesis that increasing acid concentration (especially $2 \%$ ) was efficient in hydrolyzing the carbohydrate component.

Inhibitors: The concentrations of HMF and furfural generated over time during the first stage acid pretreatment are displayed (Figure A-23). Furfural shows unusually high concentrations for $2 \%$ wt. acid at 1 minute, $0.6 \mathrm{mg} \mathrm{ml}^{-1}$ was the highest concentration observed. The next highest level of furfural was at $1 \mathrm{wt} \%$ acid concentration and 30 minutes, estimated at $0.38 \mathrm{mg} \mathrm{ml}^{-1}$. Also, the highest observed HMF concentration was $0.25 \mathrm{mg} \mathrm{ml}^{-1}$ at 45 minutes. We compared these estimated inhibitors generated after the first pretreatment stage (Figure A-23) to various acceptable level of inhibitor concentrations for a strain of E.coli anf three different types of yeast (Tables A-4). It can be inferred that levels of inhibitors generated in these experiments are below inhibitory levels likely to affect the efficiency of fermentation with E.coli into biobased chemicals.

\subsection{Conclusions}


In our choice of optimal condition, our goal was to identify the condition that maximizes yield of total monomer sugars within the shortest possible time as well as producing low concentrations of inhibitors. Avoidance of the application of enzyme will be ideal if at all possible given the significant portion of the costs associated with bio-based chemical production. From our analysis, we observed that contribution of cellulase enzymes to the TMS yield was not so significant. With high level of certainty, we determined that the first stage acid pretreatment for 60 minutes at $2 \mathrm{wt} \%$ acid was efficient in producing approximately $86 \%$ of the theoretically available carbohydrates with acceptable low inhibitory level.

\subsection{References}

Adom F, Fan J, Davis J, Dunn P, Shonnard D. 2012. Compositional Analysis of Defatted Syrup from a Corn Ethanol Dry Mill as a Feedstock for Bio-Based Products. Journal of agricultural and food chemistry (in revisions).

Agbor VB, Cicek N, Sparling R, Berlin A, Levin DB. 2011. Biomass pretreatment: fundamentals toward application. Biotechnology advances 29(6):675-685.

Brodeur G, Yau E, Badal K, Collier J, Ramachandran K, Ramakrishnan S. 2011. Chemical and Physicochemical Pretreatment of Lignocellulosic Biomass: A Review. Enzyme research 2011.

Claassen P, Van Lier J, Lopez Contreras A, Van Niel E, Sijtsma L, Stams A, De Vries S, Weusthuis R. 1999. Utilisation of biomass for the supply of energy carriers. Applied Microbiology and Biotechnology 52(6):741-755.

de Wild P, Reith H, Heeres E. 2011. Biomass pyrolysis for chemicals. Biofuels 2(2):185-208.

Eggeman T, Elander RT. 2005. Process and economic analysis of pretreatment technologies. Bioresource technology 96(18):2019-2025.

Harmsen P, Huijgen W, López LMB, Bakker R. 2010. Literature review of physical and chemical pretreatment processes for lignocellulosic biomass. Wageningen UR, Food \& Biobased Research. No. 1184. 
Kootstra AMJ, Beeftink HH, Scott EL, Sanders JPM. 2009. Comparison of dilute mineral and organic acid pretreatment for enzymatic hydrolysis of wheat straw. Biochemical Engineering Journal 46(2):126-131.

Lee J. 1997. Biological conversion of lignocellulosic biomass to ethanol. Journal of biotechnology 56(1):1-24.

Selig M, Weiss N, Ji Y. 2008. Enzymatic saccharification of lignocellulosic biomass. Golden, CO: National Renewable Energy Laboratory; 8 p. Report No.: NREL/TP-510-42629.

Sluiter A, Hames B, Ruiz R, Scarlata C, Sluiter J, Templeton D. 2008. Determination of sugars, byproducts, and degradation products in liquid fraction process samples. Golden, CO: National Renewable Energy Laboratory;14 p. Report No.: NREL/TP-510-42623.

Sun Y, Cheng J. 2002. Hydrolysis of lignocellulosic materials for ethanol production: a review. Bioresource technology 83(1):1-11.

Werpy T, Petersen G, Aden A, Bozell J, Holladay J, White J, Manheim A, Eliot D, Lasure L, Jones S. 2004. Top Value Added Chemicals From Biomass. Volume 1-Results of Screening for Potential Candidates From Sugars and Synthesis Gas. DTIC Document.

Zheng Y, Pan Z, Zhang R. 2009. Overview of biomass pretreatment for cellulosic ethanol production. International Journal of Agricultural and Biological Engineering 2(3):51-68. 


\section{Chapter 4 \\ 4 Optimization of the Protein Hydrolysis Scheme of Defatted Syrup from a Corn Ethanol Dry Mill Facility ${ }^{3}$}

\subsection{Introduction}

As the building blocks of life, amino acids have long played an important role in human, animal nutrition and health maintenance (Leuchtenberger et al. 2005; Bercovicil and Fuller 2008). Amino acids have applications such as animal feed additives (lysine, methionine, threonine and tryptophan), flavor enhancers (monosodium glutamate, serine, aspartic acid) and as specialty nutrients in the medical field. Contributing the largest share by weight (56\%) of the total amino acids sold globally, animal feed additives were estimated at approximately $\$ 4.5$ billion in terms of the market volume in 2004 (Leuchtenberger et al. 2005). Protein hydrolysis into constituent amino acids has applications in areas such as biochemistry, food science, microbiology, clinical studies, food industries, and diagnostic studies. Amino acid analysis (AAA) involves breaking down of protein to free the peptides/amino acids followed by quantitative measurements using chromatographic instruments. Here, a summary of literature review findings in relations to protein hydrolysis are discussed with emphasis on the following; i) types of protein hydrolysis (ii) enzymatic hydrolysis and the different types of proteases and (iii) separation, detection techniques and quantification of amino acids.

Protein hydrolysis can be classified into two major groups as chemical and enzymatic (Fountoulakis and Lahm 1998). Each hydrolysis route has been widely reported in the literature (Ozols 1990; I. Davidson 1997; Irvine 1997; Fountoulakis and Lahm 1998; Smith 2003) highlighting advantages and disadvantages. Factors such as temperature,

3 This chapter will be submitted to Biofuels, Bioproducts and Biorefining for publication. Citation: Adom, F., Dunn, P., Ruccins, S., Shonnard, D. (2012). Optimization of the Protein Hydrolysis Scheme of Defatted Syrup from a Corn Ethanol Dry Mill Facility. Biofuels, Bioproducts and Biorefining. 
reaction time, hydrolysis agent and additives affect the completeness of protein hydrolysis reactions (Fountoulakis and Lahm 1998). Due to its convenience, acid hydrolysis is the most commonly used method and two types have been reported; liquid- and gas-phase mode (Fountoulakis and Lahm 1998). In the liquid-phase mode, samples are dried to prevent the dilution of acid by water prior hydrolysis and subsequently hydrolyzed in a tube at $110^{\circ} \mathrm{C}$ for 24 hours (Fountoulakis and Lahm 1998). Vapor-phase mode hydrolysis involves the use of acid vapor to hydrolyze the dried samples in hydrolysis solution under an inert atmosphere; it is suitable when only smaller quantities of sample are available. Vapor phase hydrolysis is also conducted around $110^{\circ} \mathrm{C}$ for a 24 hour period with the advantage of reducing contamination of sample due to the use of acid reagent (Fountoulakis and Lahm 1998).

Typical acid hydrolysis reagents reported in the literature included $\mathrm{HCl}$, (Badadani et al. 2007) methanesulfonic acid, (Malmer and Schroeder 1990) toluenesulfonic acid, HCl-propionic acid, and mercaptoethanesulfonic acid (Fountoulakis and Lahm 1998). One advantage of methanesulfonic acid is that it allows for the determination of tryptophan and methionine sulfoxide, which are usually destroyed during the conventional hydrolysis with $\mathrm{HCl}$ (Fountoulakis and Lahm 1998). Liquid-phase mode hydrolysis has some setbacks however, because asparagine and glutamine are completely hydrolyzed to aspartic and glutamic acids but tryptophan and cysteine are destroyed. Vapor-phase mode hydrolysis though relatively fast, presents the danger of exploding of vials due to high-pressure requirement (Ian Davidson and O'Connor 2008).

Alkaline hydrolysis requires the use of a basic medium for the hydrolysis to proceed. The stable nature of tryptophan in a basic medium makes this approach suitable for its determination (Fountoulakis and Lahm 1998). This type of hydrolysis specifically uses aqueous solutions of $\mathrm{NaOH}$ or $\mathrm{KOH}$ to degrade proteins into peptides and amino acids. The use of heat at elevated temperatures of approximately $150^{\circ} \mathrm{C}$ accelerates the hydrolytic process (Thacker 2004). Apart from tryptophan determination, alkaline 
hydrolysis has been used to determine phosphoamino acids (e.g., phosphohistidine), sulfated tyrosine and also for the release of phosphate from phosphor-serinyl and threonyl residues (Fountoulakis and Lahm 1998). There are also reported drawbacks associated with the use of alkaline hydrolysis approach such as the complete destruction of some amino acids, e.g. arginine, asparagine, glutamine, and serine. Additionally, other amino acids become racemized (Thacker 2004).

A number of studies (Pickering and Newton 1990; Fountoulakis and Lahm 1998; Weiss et al. 1998) report on the use of microwave radiation-induced hydrolysis. This method of hydrolysis is usually conducted in a specially designed pressurized apparatus with the transfer of energy microwave radiation. This form of hydrolysis can be conducted in either the liquid- or the gas-phase with hydrolysis reagent such as $\mathrm{HCl}$ and methanesulfonic acid (Fountoulakis and Lahm 1998). Complete hydrolysis can be attained from 30-45 minutes depending on the mode of hydrolysis being used. While the process is rapid, conditions required for hydrolysis are extreme increasing the dangers of exploding vials (Davidson and O'Connor 2008).

Enzymatic hydrolysis requires the use of proteases to catalyze the amide or peptide bond during hydrolysis of protein or peptide substrates. One major advantage of enzymatic hydrolysis is that it allows for the quantification of asparagine and glutamine (Fountoulakis and Lahm 1998). There are many types of proteases available for conducting enzymatic hydrolysis. We reviewed the literature and identified studies that reported on various proteases using different substrates under different hydrolysis conditions. This included the following; Alcalase, Pepsin, Trypsin, Protamax, Papain and Favourzyme (Mota et al. 2004; Claver and Zhou 2005). Like other hydrolysis methods, the proteolytic activity is affected by factors such as temperature, $\mathrm{pH}$ range and the enzyme dosages. It was clear from our review the superiority of Alcalase enzyme in hydrolyzing a wide range of protein residues resulting in completion of total protein degradation. For this study on DCS, the two major methods of hydrolysis were applied (acid and enzymatic hydrolysis). 
Protein hydrolysis is subsequently followed by separation, detection and quantification of amino acids. Different separation techniques exist; however pre-column derivatization has gained prominence over the post -column derivatization because of the ability to use a broader range of reagents (Sigma-Aldrich). An example is the precolumn o-phthaladehyde (OPA) followed by reverse-phase HPLC separation with fluorometric detection or diode array. Pre-column (dimethylamino) azobenzenesulfonyl chloride (DABS-CL) followed by reversed-phase HPLC separation with visible light detection is another example. Other available techniques include pre-column 9fluorenylmethylchloroformate (FMO-CI), precolumn phenylisothiocyanate (PITC) and post-column ninhydrin detection (Fürst et al. 1990).

Defatted corn syrup (DCS) from a dry mill facility has been characterized in this dissertation to identify both the chemical and physical components in a previous chapter and study (Adom et al. 2012a). The fermentable carbohydrate component has also been optimize to release fermentable sugars through dilute acid pretreatment and enzymatic saccharification (Adom et al. 2012b). This study aims to study the combined effect of hydrolysis reaction time, temperature, and ratio of enzyme to substrate ratio to develop hydrolysis process that optimizes the amount of usable amino acids available in DCS.

\subsection{Materials and methods}

\subsubsection{Protein hydrolysis scheme and experimental matrix}

Protein content and free amino acids in DCS prior to hydrolysis have been reported in a previous chapter (2) and study (Adom et al. 2012a). Free amino acids characterization was subsequently followed by the development of hydrolysis pathways to investigate the release of amino acids. Figure 4-1 summarizes hydrolysis pathways. Pathway 1 (DAP-Dilute Acid Pretreatment) investigated the amount of amino acids recovered from protein at the previously determined optimum condition reported for dilute acid and enzymatic saccharification of DCS (Adom et al. 2012a). In pathway 2, we investigated DAP followed by subsequent protein hydrolysis using 3 different types of 
proteases namely; Pronase E (Sigma-Aldrich), Protex 6L (Genencor $\left.{ }^{\circledR}\right)$, and Trypsin $\left(\right.$ Sigma-Aldrich ${ }^{\circledR}$ ). Pathway 3 investigated a separate standalone experiment on both the recovery of monomeric fermentable sugars and amino acids on the hydrolysis of biomass in DCS without any prior pretreatment. Alcalase (Calbiochem), Pronase E, Protex 6L, and Trypsin were used to investigate the recovery of amino acids. In the case of FS, the enzymes used included Accellerase $1500^{\circledR}$, Accellerase $\mathrm{XY}^{\circledR}$ (Genencor,USA), $\alpha$-amylase (Sigma, St. Louis, MI, USA) and amyloglucosidase (Sigma, St. Louis, MI, USA). This experiment was necessary because the results obtained served as a basis for designing the experiments for hydrolysis pathway 4 . Finally, in hydrolysis pathway 4, simultaneous hydrolysis using both cellulases (Accellerase 1500 and XY) and a protease (Protex 6L) was investigated to quantify the release of both FS and amino acids in the same hydrolysis solution. The subsequent sections explain into more details the experiment matrixes and methods used in this study.

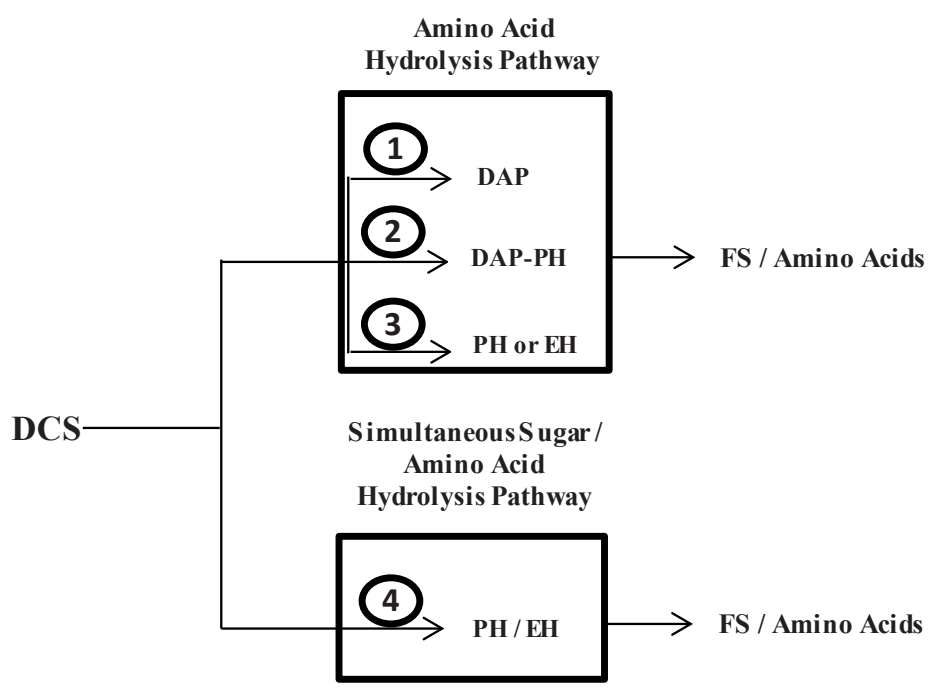

Figure 4-1 Hydrolysis pathways for the release of fermentable sugars and amino acids (DAP: dilute acid pretreatment, EH: enzymatic hydrolysis of cellulose, PH: Protein hydrolysis, FS: Fermentable Sugars)

\subsubsection{Amino acid analysis of crude DCS}

Characterization of free amino acids and proteins in DCS prior to protein hydrolysis was conducted previously on the crude DCS and results have been reported (Adom et 
al. 2012a). Briefly, DCS samples were diluted (3x dilution), centrifuged and filtered (VWR, polycarbonate membrane filter, $25 \mathrm{~mm}$ dia., $0.2 \mu \mathrm{m}$ pore size) into separate High Pressure Liquid Chromatography (HPLC) sample vials. Samples were analyzed in the HPLC according to the amino acid analysis procedures outlined section 2.7. Protein content analyses were conducted using the Bradford assay (Sigma-Aldrich 2011).

\subsubsection{Hydrolysis pathway 1: Experiment description of amino acid hydrolysis using DAP}

Two hydrolysate solutions namely "A" and "B" were prepared. Briefly, a 10g sample of DCS was diluted with distilled water $(20 \mathrm{ml})$ and sulfuric acid $(6.9 \mathrm{ml})$ to bring the acid concentration to $2 \mathrm{wt} \%$ and total solid loading in solution to $10 \mathrm{wt} \%$ [see Figure B1, (Adom et al. 2012b)]. The unpretreated defatted corn syrup (UPDCS) was analyzed for amino acids prior to autoclaving using the HPLC by transferring $1 \mathrm{ml}$ into $1.5 \mathrm{ml}$ centrifuge vials. The $\mathrm{pH}$ of UPDCS was then adjusted with $10 \mathrm{~N} \mathrm{NaOH}$ into the range of 6-8 (i.e. the suitable $\mathrm{pH}$ range for separation of amino acids on the Zorbax Eclipse Column) and centrifuged for 25 minutes at 10,000 RPM. Using a $0.2 \mu \mathrm{m}$ membrane

filters, the supernatant was filtered into HPLC vials and analyzed in the HPLC for amino acids. Another $2 \mathrm{wt} \%$ acid concentrated DCS solutions for "A" and "B" was prepared and transferred into the glass reactors according to the conditions described above (see Figure B-1). After the DAP for 1 hour, the pretreated defatted corn syrup (PDCS) was adjusted to a $\mathrm{pH}$ range of 6-8 and treated in the same manner as UPDCS prior to analysis in the HPLC. Duplicate samples of hydrolyzates "A" and "B" were all analyzed for amino acid concentrations, which were back calculated to account for all dilution factors (e.g. acids, bases, and distilled $\mathrm{H}_{2} \mathrm{O}$ ).

\subsubsection{Hydrolysis pathway 2: Experiment description of DAP followed by protein hydrolysis using proteases}

The experiment matrix for hydrolysis pathway 2 comprised of four experiment sets (see Table 4-1) with different reaction times. A number of factors such as extreme heat, $\mathrm{pH}$ and the presence of heavy metals could result in denaturation of protein. DCS as a 
co-product of the dry corn mill facility undergoes a lot of processing which are likely to denature the proteins in DCS. Three proteases, Pronase E, Protex 6L and Trypsin, were chosen because of their ability to hydrolyze both native and denatured proteins (Haurowitz et al. 1945; Genencor 2011). Phosphate buffer was chosen because it had the required buffering range $(\mathrm{pH} 5.8-8)$ needed for the optimal performance of the proteases. $5 \mathrm{ml}$ of well-mixed PDCS (see Figure B-1) were measured into 8 different labeled $50 \mathrm{ml}$ Erlenmeyer flasks and diluted with $23.2 \mathrm{ml}$ of distilled water. The solution was neutralized by adding $10 \mathrm{~N} \mathrm{NaOH}$ until $\mathrm{pH} 6$ or 7 . This was followed by the addition of $1.5 \mathrm{ml}$ of $0.2 \mathrm{M}$ phosphate buffer to stabilize the $\mathrm{pH}$. The flasks were covered with parafilm and aluminum foil and allowed to equilibrate in an incubator for one hour at $34^{\circ} \mathrm{C}$. The control solutions were prepared in the same manner without the addition of any proteases (see Figure B-2).

Table 4-1 Experiment matrix for protein hydrolysis scheme: pathway 2

\begin{tabular}{|c|l|l|l|}
\hline $\begin{array}{c}\text { Experiment } \\
\text { Sets }\end{array}$ & $\begin{array}{l}\text { Hydrolysis } \\
\text { Solution }\end{array}$ & $\begin{array}{l}\text { pH } \\
\text { Investigated }\end{array}$ & $\begin{array}{l}\text { Enzymatic Hydrolysis Reaction } \\
\text { times (Temperature) }\end{array}$ \\
\hline 1 & Control & 6,7 & $1 \mathrm{~min}, 2 \mathrm{hrs}, 3 \mathrm{hrs}, 5 \mathrm{hrs}, 34^{\circ} \mathrm{C}$ \\
\hline 2 & Pronase & 6,7 & $1 \mathrm{~min}, 2 \mathrm{hrs}, 3 \mathrm{hrs}, 5 \mathrm{hrs}, 34^{\circ} \mathrm{C}$ \\
\hline 3 & Trypsin & 6,7 & $1 \mathrm{~min}, 2 \mathrm{hrs}, 3 \mathrm{hrs}, 5 \mathrm{hrs}, 34^{\circ} \mathrm{C}$ \\
\hline 4 & Protex 6L & 6,7 & $1 \mathrm{~min}, 2 \mathrm{hrs}, 3 \mathrm{hrs}, 5 \mathrm{hrs}, 34^{\circ} \mathrm{C}$ \\
\hline
\end{tabular}

After one hour, dosages of the enzymes $(\sim 300 \mu \mathrm{l})$ were added into the flask to make $1 \%$ [(V/V)-enzyme added] of the total hydrolysis solution. The $\mathrm{pH}$ meter was used to ensure the solution had a $\mathrm{pH} 6$ or 7 before putting them back in the incubator for protein hydrolysis. After $1 \mathrm{~min}, 2$ hours and 5 hours, samples were drawn (duplicates) using micropipette into labeled $1.5 \mathrm{ml}$ centrifuge vials. This was followed by enzyme inactivation by heating the centrifuge vials containing sampled hydrolyzates in a water bath at $90^{\circ} \mathrm{C}$ for 15 minutes. The vials were then centrifuged for 25 minutes at 10,000 RPM and filtered with a $0.2 \mu \mathrm{m}$ filter membranes into HPLC vials for amino acid analysis. 


\subsubsection{Hydrolysis pathway 3: Experiment description of amino acid hydrolysis on unpretreated DCS using proteases, cellulases, $\alpha$-amylase and amyloglucosidase}

The experimental matrix for hydrolysis pathway 3 comprised of seven experiment sets. Process variables investigated included: $\mathrm{pH}$, enzyme dosages, temperature, and reaction time. Table 4-2 below summarizes the experimental matrix used in these sets of experiments.

Table 4-2 Experiment matrix for protein hydrolysis scheme of unpretreated DCS (10\% wt. DCS): Pathway $3 . \mathrm{H}=\operatorname{High}(1.5 \mathrm{v} / \mathrm{w}), \mathrm{M}=\operatorname{Medium}(1.0 \mathrm{v} / \mathrm{w}), \mathrm{L}=\operatorname{Low}(0.5 \mathrm{v} / \mathrm{w})$ (Volume of enzyme solution / weight of protein hydrolysate solution)

\begin{tabular}{|c|c|c|c|c|c|c|}
\hline $\begin{array}{c}\text { Experiment } \\
\text { Sets }\end{array}$ & Enzyme & pH & Buffer & $\begin{array}{c}\begin{array}{c}\text { Enzyme } \\
\text { dosage }\end{array} \\
\end{array}$ & $\begin{array}{c}\text { Hydrolysis } \\
\text { Temperature }\end{array}$ & $\begin{array}{c}\text { Reaction } \\
\text { times }\end{array}$ \\
\hline 1 & Alcalase & $\begin{array}{l}7,8 \& \\
9\end{array}$ & Tris & $\begin{array}{c}\mathrm{H}, \mathrm{M} \& \\
\mathrm{~L}\end{array}$ & $45 \& 55^{\circ} \mathrm{C}$ & \multirow{7}{*}{$\begin{array}{l}1 \mathrm{hr}, 2 \mathrm{hrs}, \\
3 \mathrm{hrs}, 5 \mathrm{hrs}, \\
24 \mathrm{hrs} \& \\
48 \mathrm{hrs}\end{array}$} \\
\hline 2 & Pronase E & $6 \& 7$ & Phosphate & $\mathrm{H}$ & $34^{\circ} \mathrm{C}$ & \\
\hline 3 & Trypsin & $6 \& 7$ & Phosphate & $\mathrm{H}$ & $34^{\circ} \mathrm{C}$ & \\
\hline 4 & Protex 6L & $6 \& 7$ & Phosphate & $\mathrm{H}$ & $34^{\circ} \mathrm{C}$ & \\
\hline 5 & $\begin{array}{l}\text { Accellerase } \\
1500 \& X Y\end{array}$ & 6 & Phosphate & $\mathrm{H}$ & $40^{\circ} \mathrm{C}$ & \\
\hline 6 & Amylase & 6 & Phosphate & $\mathrm{H}$ & $40^{\circ} \mathrm{C}$ & \\
\hline 7 & $\begin{array}{l}\text { Amylase \& } \\
\text { AMG }\end{array}$ & 6 & Phosphate & $\mathrm{H}$ & $40^{\circ} \mathrm{C}$ & \\
\hline
\end{tabular}

In experiment sets 1 through to 4, proteases (Alcalase, Pronase E, Protex 6L and Trypsin) were solely used to investigate amino acid production on the sample (on an as- received basis) without any form of pretreatment. In experiment sets 5 through to 7 , cellulases, $\alpha$-amylase and AMG were used to investigate sugar recoveries over time. These sets of experiments as previously stated were necessary in designing experiments in hydrolysis pathway 4.

Experiment set 1: At the sample preparation and conditioning stage, $10 \mathrm{~g}$ of the DCS was measured using an electronic weighing balance and transferred into a $50 \mathrm{ml}$ 
beaker. $18 \mathrm{ml}$ of distilled water were added to the DCS. In this experiment, amino acid

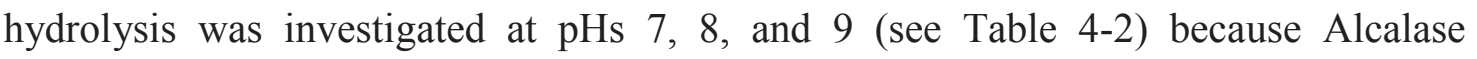
proteolytic activity increases and remains fairly stable within this $\mathrm{pH}$ range. After the addition of distilled water, $10 \mathrm{~N} \mathrm{NaOH}$ was added to the DCS solution using a micropipette to adjust the solution to the required $\mathrm{pH}$. $1.5 \mathrm{ml}$ of the $0.1 \mathrm{M}$ Tris buffer were then added to stabilize the $\mathrm{pH}$ and the flask was covered with parafilm and aluminum foil and allowed to equilibrate in an incubator for one hour at $45^{\circ} \mathrm{C}$ or $55^{\circ} \mathrm{C}$.

The choice of enzyme loading was investigated at 3 different loading levels as shown in Table 4-2. They are high, medium and low enzyme loading. The high enzyme loading ratio of $1.5 \% \mathrm{v} / \mathrm{w}$ (volume of enzyme solution / weight of protein hydrolysate solution), which was approximately $428 \mu \mathrm{l}$ alcalse enzyme solution. The medium and low were 1 and $0.5 \% \mathrm{v} / \mathrm{w}$ respectively representing approximately 284 and $141 \mu \mathrm{l}$ alcalse enzyme solution. Hydrolysates were transferred at various reaction times into centrifuge vials for AAA in the HPLC. After AAA, sampled hydrolyzates were swirled in a water bath at $90^{\circ} \mathrm{C}$ for 15 minutes to inactivate enzyme activity. After the enzyme inactivation stage, the hydrolysates were centrifuged for 25 minutes at 10,000 RPM followed by the filtration of supernatant into a labeled HPLC vial using $0.2 \mu \mathrm{m}$ membrane filter for AAA at room temperature.

Experiment sets 2, 3 \& 4: In experiment sets 2, 3 and 4, three proteases were used; Pronase E, Protex 6L and Trypsin. Additionally, phosphate buffer was chosen because it had a buffering range of 5.8-8, which was ideal for the $\mathrm{pH}$ of this experiment. Similar to experiment set $1,10 \mathrm{~g}$ of DCS was measured into a $50 \mathrm{ml}$ beaker and $18 \mathrm{ml}$ of distilled water was then added and followed with $\mathrm{pH}$ neutralization to 6 and 7 with $10 \mathrm{~N} \mathrm{NaOH}$. $1.5 \mathrm{ml}$ of $0.2 \mathrm{M}$ phosphate buffer was added to stabilize $\mathrm{pH}$ and the hydrolysis solution was allowed to equilibrate at $34^{\circ} \mathrm{C}$ for 1 hour prior to the addition of proteases. Dosages of the enzymes $(\sim 300 \mu \mathrm{l})$ were added into the flask to make $1 \%(\mathrm{v} / \mathrm{v})$ of the total solution. The same procedure for enzyme inactivation, centrifugation and 
filtration processes previously described above was applied to hydrolysates prior to AAA in the HPLC.

Experiment sets 5, 6 \& 7: $10 \mathrm{~g}$ of DCS was measured into a 50ml Erlenmeyer flask and neutralized by adding approximately $380 \mu \mathrm{l}$ of $10 \mathrm{~N} \mathrm{NaOH}$ to adjust $\mathrm{pH}$ to 6 . This was followed by the addition of $1 \mathrm{ml}$ of $0.2 \mathrm{M}$ phosphate buffer at $\mathrm{pH} 6$ to stabilize the $\mathrm{pH}$ of the hydrolysis solution. $370 \mu \mathrm{l}$ tetracycline $(10 \mathrm{mg} / \mathrm{ml} \mathrm{in} 70 \% \mathrm{EtOH})$ and 280 $\mu \mathrm{l}$ cycloheximide $\left(10 \mathrm{mg} / \mathrm{ml}\right.$ in $\left.\mathrm{H}_{2} \mathrm{O}\right)$ were added to all hydrolysis flasks. The flasks were covered with parafilm and aluminum foil and allowed to equilibrate in an incubator for one hour at $34^{\circ} \mathrm{C}$.

After one hour, dosages of the enzymes and pre-warmed $\left(34^{\circ} \mathrm{C}\right)$ distilled water were added into the flasks until the total volume was $37 \mathrm{ml}$. Enzyme dosages were added as follows; $925 \mu \mathrm{l}$ and $46 \mu \mathrm{l}$ of accellerase 1500 and XY based on the recommended dosages by Genecor ${ }^{\circledR}$ in experiment set 5 (see Table 4-2). In experimental set 6, $137 \mu$ l of amylase was added, while $137 \mu \mathrm{l}$ each of amylase and AMG was added in experiment set 7 . The $\mathrm{pH}$ meter was used to ensure the solution had a $\mathrm{pH} \sim 6$ before putting them back in the incubator for enzymatic hydrolysis. After $1 \mathrm{~min}, 24,48$ and 72 hours, samples were drawn using micropipette for HPLC analysis.

\subsubsection{Hydrolysis pathway 4: Experiment description of amino acid hydrolysis using protease \& cellulases (Simultaneous Hydrolysis)}

A combination of Accellerase 1500, XY and Protex 6L were used to investigate the simultaneous production of sugar and amino acids at $34^{\circ} \mathrm{C}$ for 24 hours. Protex $6 \mathrm{~L}$ was chosen because compared to other proteases used in this study, it had a very wide range of temperature activity from $25-70^{\circ} \mathrm{C}$ (Genencor 2011). Two hydrolysis solutions were prepared, with both having highest enzyme dosage of cellulases, i.e., Accellerase 1500 and XY, however the loading of Protex was varied from $1 \%$ and $2 \%(\mathrm{v} / \mathrm{v})$ enzyme dosage of the total solution.

To $10 \mathrm{~g}$ of DCS measured into a $50 \mathrm{ml}$ Erlenmeyer flask, approximately $380 \mu \mathrm{l}$ of $10 \mathrm{~N}$ $\mathrm{NaOH}$ was used to adjust $\mathrm{pH}$ to 6 . This was followed by the addition of the following: 
$1 \mathrm{ml} 0.2 \mathrm{M}$ phosphate buffer at $\mathrm{pH} 6,370 \mu \mathrm{l}$ tetracycline $(10 \mathrm{mg} / \mathrm{ml}$ in $70 \% \mathrm{EtOH})$ and $280 \mu \mathrm{l}$ cycloheximide $\left(10 \mathrm{mg} / \mathrm{ml}\right.$ in $\left.\mathrm{H}_{2} \mathrm{O}\right)$. After covering the hydrolysis flask with parafilm and aluminum foil, the flask was allowed to equilibrate for one hour at $34^{\circ} \mathrm{C}$ before enzyme loading. After one hour, dosages of the enzymes and pre-warmed $\left(34^{\circ} \mathrm{C}\right)$ distilled water were added into the flask until the total volume was $38 \mathrm{ml}(10 \%$ $\mathrm{w} / \mathrm{w}$ DCS in solution). Enzyme dosages were added as follows; $925 \mu \mathrm{l}$ and $46 \mu \mathrm{l}$ of Accellerase 1500 and XY. For 1\% (v/v) and 2\% (v/v) Protex solution $380 \mu \mathrm{l}$ and $760 \mu \mathrm{l}$ Protex 6L enzyme solution were added in addition to the cellulases (Accellerase 1500 and $\mathrm{XY}$ ) respectively. The $\mathrm{pH}$ meter was used to ensure the hydrolysis solutions had a $\mathrm{pH} \sim 6$ before putting them back in the incubator for protein hydrolysis to proceed. After 1 min, 6, 12 and 24 hours, samples were drawn using micropipette for HPLC analysis prior to enzyme inactivation at $90^{\circ} \mathrm{C}$ as previously described. After analysis with the Aminex HPX-87P column (Bio-Rad Life Sciences, Hercules, CA) for monomer sugars concentrations, the HPLC column was replaced with a Zorbax Eclipse column, $4.6 \times 150 \times 5 \mu \mathrm{m}$ for AAA and the hydrolysates were rerun.

\subsubsection{HPLC analysis of amino acids}

AAA protocol by Agilent Technology was adopted for this study (Henderson et al. 2000). This is an analytical technique with automated derivatization using ophthalaldehyde (OPA) for primary amino acids and 9-fluorenylmethyl chloroformate (FMOC) for secondary amino acids. Two mobile phases were used in the gradient elution, mobile phase "A" comprised of $40 \mathrm{mM} \mathrm{Na}_{2} \mathrm{PHO}_{4}$ adjusted to $\mathrm{pH}$ of 7.8 while mobile phase " $\mathrm{B}$ " was a mixture of acetonitrile, methanol and water $(45: 45: 10, \mathrm{v} / \mathrm{v} / \mathrm{v})$.

Prepared amino acids standards were separated on the Zorbax Eclipse column $(4.6 \times 150 \times 5 \mu \mathrm{m})$ at temperature of $40^{\circ} \mathrm{C}$ for calibration purposes. All other analytes were analyzed in a similar manner.

\subsection{Results and discussion}

In addition to "back calculating" all final concentrations by accounting for all dilution factors (e.g. acids, bases, distilled $\mathrm{H}_{2} \mathrm{O}$, antibiotics, and enzymes), concentrations for 
enzyme blank for all experiments using Alcalase, Pronase E, Protex 6L and Trypsin were also accounted (see Table B-1 through to B-8).

\subsubsection{Results for protein content and free amino acid analysis of crude DCS}

Protein concentrations in DCS ranged from $5-7 \mathrm{mg} / \mathrm{ml}$ representing 7-9 wt $\%$ of syrup on a dry basis. The average protein concentration was $6.06( \pm 0.85) \mathrm{mg} / \mathrm{ml}$ of proteins representing $8 \mathrm{wt} \%( \pm 0.6 \%)$ of DCS on a dry basis (Adom et al. 2012a). Amino acid profile of DCS is displayed in Figure 4-2 and was measured to be $3.51( \pm 0.24)$ and $3.38( \pm 0.35) \mathrm{mg} / \mathrm{ml}$ for DCS samples obtained at different times from the corporate sponsor and analyzed in the year 2011 and 2010 respectively. It was estimated that the free amino acids in DCS were approximately $3.45 \%( \pm 0.3 \%)$ wt. on a dry basis by averaging all samples (2010 \& 2011), (Adom et al. 2012a).

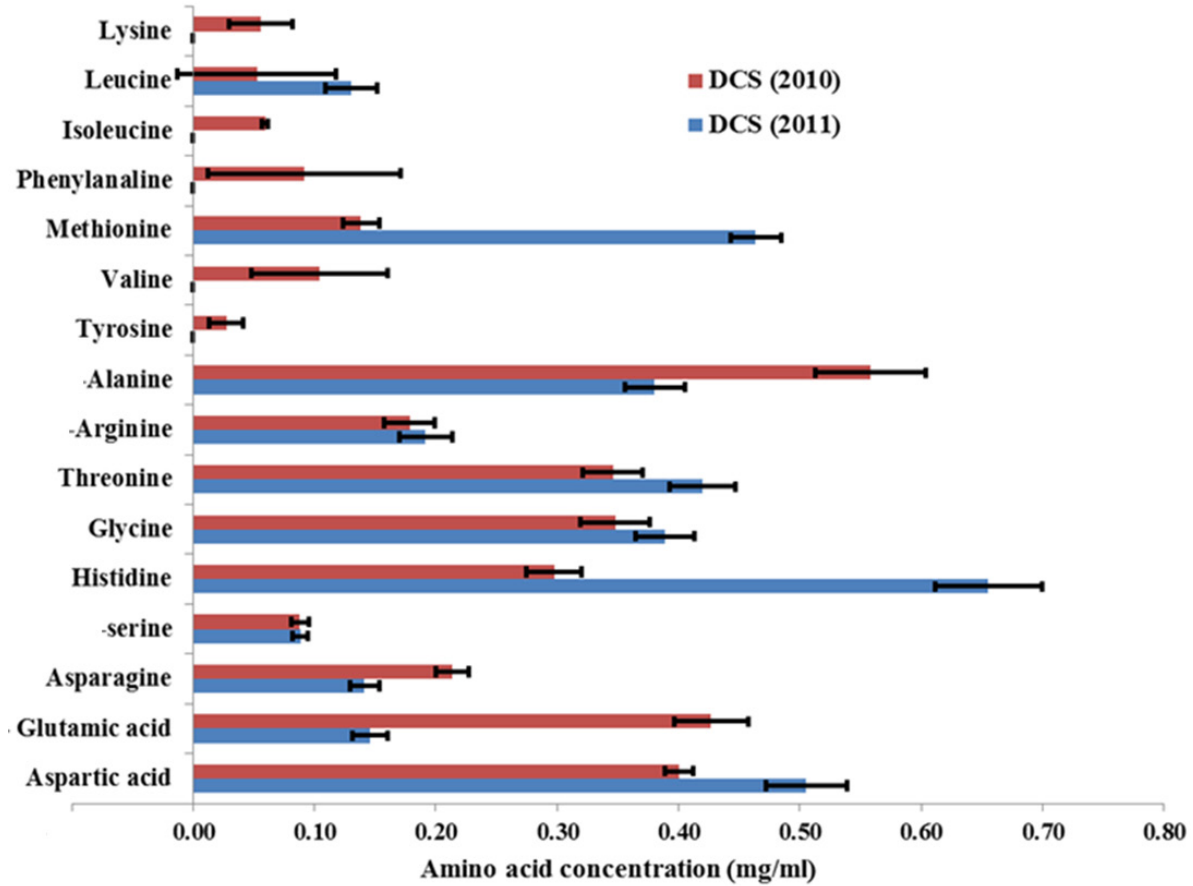

Figure 4-2 Average amino acid concentrations for DCS received in year 2010 and 2011 [Standard deviation of duplicate samples (Adom et al. 2012a)]

Taking into account the free amino acids $(\sim 3.4 \mathrm{mg} / \mathrm{ml})$ and the available proteins $(\sim 7-$ $9 \mathrm{mg} / \mathrm{ml}$ ), a total of about $\sim 10-12 \mathrm{mg} / \mathrm{ml}$ was estimated to be the maximum theoretical 
yield assuming $100 \%$ conversion of protein to total amino acids in DCS. Apart from some differences between samples analyzed in $2011 \& 2012$, there were also some differences between samples analyzed within the same year considering the error bars (see Figure 4-2). For example while tyrosine was present in 2010, it was not in the 2011 sample. The reasoning behind this observation was not clear; however, we think the cultivation practices of corn in addition to various processing techniques prior getting DCS could influence the amino acid profile.

\subsubsection{Results for hydrolysis pathway 1: Amino acid analysis using DAP}

Table 4-3 summarizes the total amino acid yields using DAP $\left(2 \%\right.$ acid, $\left.121^{\circ} \mathrm{C}, 60 \mathrm{~min}\right)$ for hydrolysis pathway 1. Yields generally averaged around $8.2( \pm 0.4) \mathrm{mg} / \mathrm{ml}$ corresponding to $82-68 \%$ [ $=8.2$ ( $(10$ or 12$)]$ of the theoretically available amino acids. Figure 4-3 displays the amino acid profile results for UPDCS (before DAP) and PDCS (after DAP). As previously described in section 4.2.3, two hydrolyzates "A" and "B" were prepared for pretreatment in the autoclave and each hydrolyzate was sampled in duplicates before and after the DAP autoclaving process for AAA. Clearly, the addition of $\mathrm{H}_{2} \mathrm{SO}_{4} 2 \mathrm{wt} \%$ even before pretreating at $121^{\circ} \mathrm{C}$ for 60 minutes in the autoclave liberates approximately $2 \mathrm{mg} / \mathrm{ml}$ of additional amino acids. This was estimated by subtracting the concentration of free amino acid in the crude sample (see Figure 4-2) from amino acid concentration of hydrolyzates $\mathrm{A}$ and $\mathrm{B}$ before autoclaving. Specifically, total amino acid concentration for UPDCS was estimated to be 5.8 and $5.3 \mathrm{mg} / \mathrm{ml}$ for samples A and B respectively (see Figure 4-3).

Table 4-3 Summary of total amino acid recovery using hydrolysis pathway 1 (DAP)

\begin{tabular}{|l|c|}
\hline Samples & Amino Acid Concentration (mg /ml) \\
\hline $\mathrm{H}_{1} \mathrm{~A}$ & 7.8 \\
\hline $\mathrm{H}_{2} \mathrm{~A}$ (duplicate) & 8.5 \\
\hline $\mathrm{H}_{1} \mathrm{~B}$ & 8.2 \\
\hline $\mathrm{H}_{2} \mathrm{~B}$ (duplicate) & 7.8 \\
\hline
\end{tabular}

After dilute acid pretreatment in the autoclave, total amino acid concentrations increased to approximately $7.8-8.5 \mathrm{mg} / \mathrm{ml}$ (see Figure 4-3). Specifically, aspartic acid 
and glutamic acid concentrations in UPDCS averaged around 0.6 and $0.4 \mathrm{mg} / \mathrm{ml}$ respectively. Both aspartic acid and glutamic acid increased to approximately $2(\sim 3 \mathrm{x})$ and $1(\sim 2 \mathrm{x}) \mathrm{mg} / \mathrm{ml}$ in all hyrolyzate samples. Taking into account the margin of error, serine remained stable without any major degradation for both hydrolyzates.

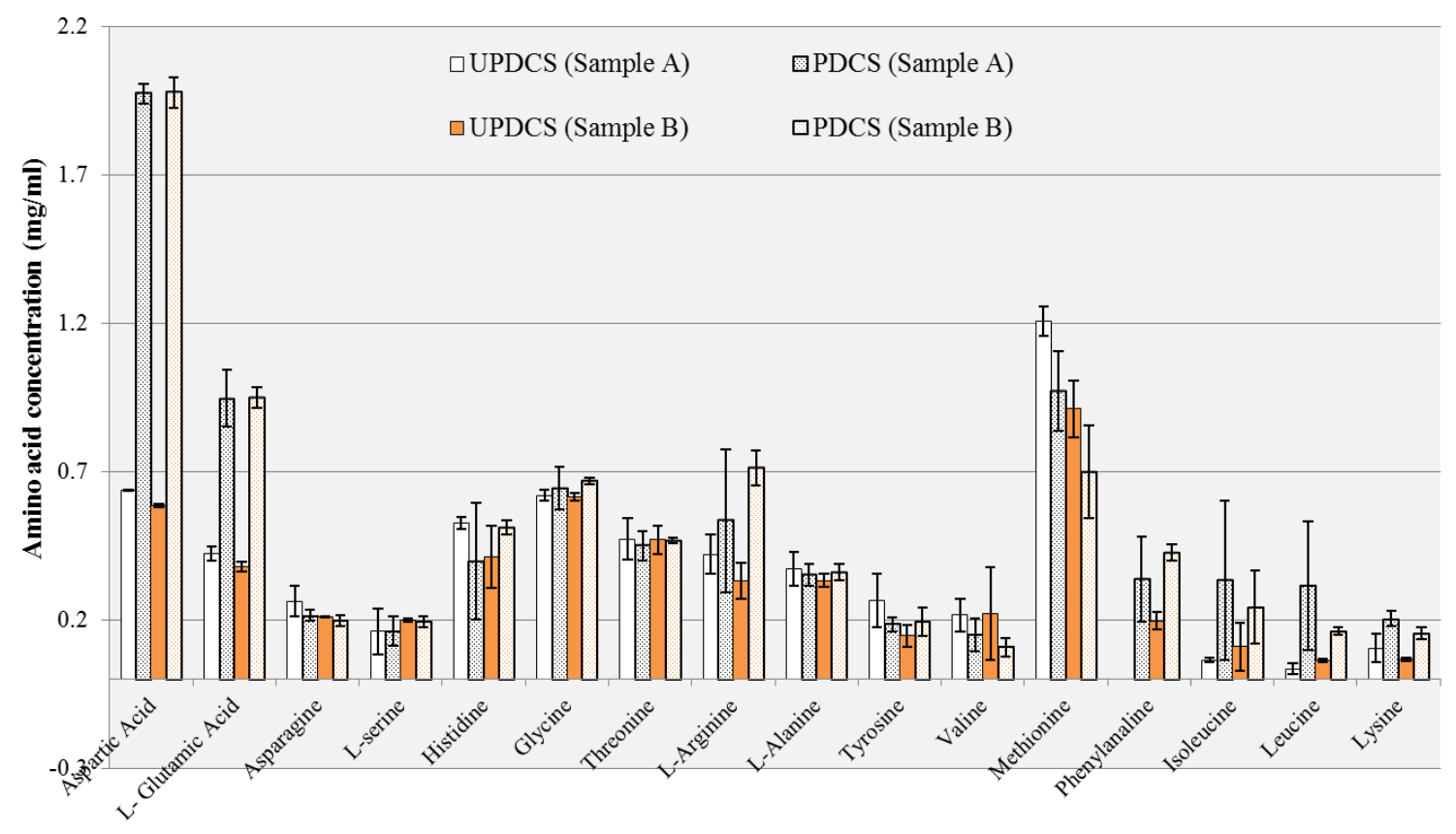

Figure 4-3 Amino acid analysis of hydrolyzate "A \& B" before (UPDCS) and after (PDCS) dilute acid pretreatment. (Standard deviation of duplicate samples)

\subsubsection{Results for hydrolysis pathway 2: DAP followed by protein hydrolysis using proteases}

Table 4-4 summarizes the average results from replicates and including standard deviations obtained for amino acid hydrolysis of DCS using pathway 2. Total amino acid concentration of the control remained fairly constant and with some degradation observed after 5-hour hydrolysis for both solutions ( $\mathrm{pH} 7$ and 6). For both control $\mathrm{pH} 7$ $\& 6$, about $25 \%$ of aspartic acid was degraded after the 5 hour period of hydrolysis, this was not observed in any of the protease inoculated solutions. Other amino acids like glutamic acid, serine, glycine, threonine, arginine and isoleucine remained fairly constant with little or no degradation over the hydrolysis time for both control solutions pH 6 and 7 (see Figure B-3 and B-4). Another interesting observation was the total 
degradation of asparagine and lysine after the 5 hours hydrolysis period for both solutions. Apart from aspartic acid, degradation of alanine, tyrosine and phenylalanine were relatively small ranging from $2-5 \%$ (recovery for 1 minute used as basis for comparison).

Table 4-4 Summary of results for hydrolysis pathway 2: amino acid analysis of dilute acid pretreated syrup followed by protease hydrolysis

\begin{tabular}{|l|l|c|c|}
\hline \multirow{2}{*}{\multicolumn{1}{|c|}{ Enzyme \& pH }} & \multicolumn{3}{|c|}{$\begin{array}{c}\text { Reaction times \& total amino acid } \\
\text { concentrations (mg / ml) }\end{array}$} \\
\cline { 2 - 4 } & \multicolumn{1}{|c|}{ min } & 2 hrs & 5 hrs \\
\hline Control-pH 7 & $7.5( \pm 0.14)$ & $7.6( \pm 0.23)$ & $6.5( \pm 0.25)$ \\
\hline Control- pH 6 & $7.5( \pm 0.29)$ & $8.4( \pm 0.53)$ & $6.5( \pm 0.11)$ \\
\hline Pronase E-pH 7 & $8.0( \pm 0.20)$ & $9.1( \pm 0.03)$ & $9.5( \pm 0.50)$ \\
\hline Pronase E-pH 6 & $10.0( \pm 0.10)$ & $9.0( \pm 1.22)$ & $10.7( \pm 0.07)$ \\
\hline Protex 6L -pH 7 & $11.2( \pm 1.21)$ & $11.1( \pm 0.32)$ & $9.6( \pm 0.31)$ \\
\hline Protex 6L-pH 6 & $10.4( \pm 0.29)$ & $9.3( \pm 0.89)$ & $13.5( \pm 0.28)$ \\
\hline Trypsin pH 7 & $8.6( \pm 0.14)$ & $8.0( \pm 0.33)$ & $9.5( \pm 0.13)$ \\
\hline Trypsin pH 6 & $7.9( \pm 0.07)$ & $8.0( \pm 0.08)$ & $9.4( \pm 0.29)$ \\
\hline
\end{tabular}

Pronase and Protex results are generally high, however all these reported results accounts for any concentration of any free amino acids in the enzyme solutions. Additionally, there were cases where we observed more that $100 \%$ amino acid production after hydrolysis. We think this is probably due to water of hydration for amino acids.

Hydrolysis with Pronase E at pH 7 and 6 yielded 9.5 (95-79\%) and 10.7 (100-89\%) mg / $\mathrm{ml}$ of total amino acids respectively (see Table 4-4). For Pronase E. hydrolysis solution conditioned at $\mathrm{pH} \mathrm{7,} \mathrm{the} \mathrm{following} \mathrm{amino} \mathrm{acid} \mathrm{concentrations} \mathrm{increased} \mathrm{over}$ time: histidine, glycine, arginine, valine, methionine, phenylalanine and isoleucine (see Figure B-5). The highest increase was isoleucine and leucine which increased about a factor of 8 and 2 respectively. All the other amino acids increased by factor of 1 . Surprisingly, some degradation was observed for aspartic acid, glutamic acid, asparagine, serine, alanine and tyrosine. Aspartic acid was the least degraded $(\sim 1 \%$ 
loss) with total degradation of tyrosine after the 5 hour hydrolysis period. In a previous study (Fountoulakis and Lahm 1998), the authors reported complete hydrolysis of asparagine and glutamine to aspartic acid and glutamic acid via conventional acidic hydrolysis of a protein substrate. They also reported partial degradation of tyrosine, serine and threonine. It is therefore most likely that these observed degradations are as a result of the initial acid pretreatment step. A similar trend was observed for hydrolysis solution conditioned at $\mathrm{pH} 6$ with some degradation of valine and methionine (see Figure B-6).

Results for individual amino acid recovery over time using Protex 6L are presented in Figure B-7 and B-8. Aspartic acid, histidine, arginine, and leucine all increased in concentration over time depending on the $\mathrm{pH}$ of the enzyme solution. The highest increase observed was histidine which increased by a factor of 4 for hydrolysis solution conditioned at a $\mathrm{pH}$ of 7 and about a factor of 10 for hydrolysis solution of $\mathrm{pH} 6$ after the 5 hour reaction time. Asparagine increased by a factor of 3 in hydrolysis solution of pH 6 after 5 hours but the concentration remained fairly constant in hydrolysis solution of $\mathrm{pH} 7$ taking into account the magnitude of error bars. Some amino acids also degraded over time; these included glycine, threonine, tyrosine, valine, methionine and phenylalanine. Degradation ranged from 33-77\% loss in amino acid concentration depending on the $\mathrm{pH}$ of the solution. Final reported yields after 5 hours were 9.62 (100$96 \%$ ) and $13.51(112 \%)$ for $\mathrm{pH} 7$ and 6 respectively (see Table 4-4).

Figure B-9 and B-10 summarizes amino acid trends over time due to hydrolysis by trypsin. For both pH 7 \& 6 hydrolysis solutions, amino acid concentrations of aspartic acid, glutamic acid, arginine, tyrosine, valine, methionine, isoleucine and leucine increased. The highest gain was observed for arginine and threonine that increased by a factor of 2 and 3 respectively for hydrolysis solution conditioned at $\mathrm{pH} 7$ after 5 hours. Leucine also increased by a factor of 5 for hydrolysis solution at pH 6 after 5 hours of hydrolysis. Alanine, phenylalanine and lysine all exhibited some loss with total loss of 
lysine in hydrolysis solution at $\mathrm{pH}$ 7. Final reported yields after 5 hours were 9.5 (95$79 \%$ ) and 9.4 (94-78\%) for $\mathrm{pH} 7$ and 6 respectively (see Table 4-4).

\subsubsection{Results for hydrolysis pathway 3: Hydrolysis of unpretreated DCS using proteases, cellulases, $\alpha$-Amylase and AMG}

This sections reports on amino acid recovery for hydrolysis pathway 3 over time for experiment sets 1 through to 4 (see section 4.2.5) where proteases (Alcalase, Pronase E, Protex 6L and Trypsin) were solely used on DCS without any form of pretreatment. Results for experimental sets 5 through to 7 (see section 4.2.5) where cellulases, $\alpha$ amylase and AMG were applied to investigate sugar, recoveries over time are also reported.

\subsubsection{Results for hydrolysis pathway 3 : Alcalase $\operatorname{at}^{\circ} \mathrm{C}$ and $55^{\circ} \mathrm{C}$}

Table 4-5 summarizes the results obtained from hydrolysis of DCS with Alcalase enzyme. The effect of enzyme loading and temperature on early amino acid production (1 min) shows higher concentrations with higher loading and temperature. The effect of time on amino acid production shows increased amino acid concentrations with increasing time. The effect of $\mathrm{pH}$ on either initial production or ultimate increase in amino acid concentration exhibits no clear trend.

Surprisingly, the highest amino acid concentrations at $48 \mathrm{hr}$ are from hydrolysis reactions at $45^{\circ} \mathrm{C}$. Production of amino acids from the protein fraction of DCS ranges between $60-100 \%$ depending on reaction conditions, and therefore Alcalase ${ }^{\circledR}$ hydrolysis appears to be an effective means for production of amino acids from unpretreated DCS.

Alcalase hydrolysis at $\mathrm{pH} 7\left(55^{\circ} \mathrm{C}\right)$ yielded $9.62,9.87$, and $8.92 \mathrm{mg} / \mathrm{ml}$ of total amino acids after 48 hours for high, medium and low enzyme loadings, respectively. These results correspond to a theoretical amino acid yields of $96-80 \%, 98-82 \%$ and $89-74 \%$ for high, medium and low enzyme loading, respectively and were generally high comparatively. 
Table 4-5 Summary of results for hydrolysis pathway 3: Amino acid analysis of DCS using Alcalase without DAP at temperatures of $45 \& 55^{\circ} \mathrm{C}$.

\begin{tabular}{|c|c|c|c|c|c|c|}
\hline \multirow{2}{*}{$\begin{array}{l}\text { Enzyme, } \\
\text { pH, \& T }\end{array}$} & \multicolumn{6}{|c|}{ Reaction times \& amino acid concentrations (mg / ml) } \\
\hline & $1 \mathrm{hr}$ & 2 hrs & 3 hrs & 5 hrs & $24 \mathrm{hrs}$ & 48 hrs \\
\hline H-pH 7-55 ${ }^{\circ} \mathrm{C}$ & 7.28 & 8.18 & 8.83 & 9.64 & 8.47 & 9.62 \\
\hline M-pH 7-55 ${ }^{\circ} \mathrm{C}$ & 7.89 & 8.03 & 7.88 & 7.73 & 7.75 & 9.87 \\
\hline L-pH $7-55^{\circ} \mathrm{C}$ & 6.34 & 6.35 & 6.48 & 6.61 & 7.82 & 8.92 \\
\hline H-pH 8-55 ${ }^{\circ} \mathrm{C}$ & 6.68 & 6.96 & 6.35 & 9.07 & 9.50 & 9.62 \\
\hline M-pH 8-55 ${ }^{\circ} \mathrm{C}$ & 6.68 & 6.37 & 8.99 & 8.39 & 9.44 & 8.60 \\
\hline L-pH 8-55 ${ }^{\circ} \mathrm{C}$ & 6.17 & 6.33 & 6.70 & 7.35 & 7.97 & 7.22 \\
\hline H-pH 9-55 ${ }^{\circ} \mathrm{C}$ & 7.31 & 7.66 & 8.17 & 8.03 & 8.73 & 9.21 \\
\hline M-pH 9-55 ${ }^{\circ} \mathrm{C}$ & 6.11 & 7.32 & 8.32 & 8.42 & 9.60 & 11.03 \\
\hline L-pH 9-55 ${ }^{\circ} \mathrm{C}$ & 5.92 & 8.63 & 7.80 & 8.31 & 7.82 & 10.14 \\
\hline H-pH 7-45 ${ }^{\circ} \mathrm{C}$ & 5.84 & 6.42 & 6.59 & 6.51 & 8.81 & 10.20 \\
\hline M-pH $7-45^{\circ} \mathrm{C}$ & 4.97 & 5.49 & 5.80 & 6.32 & 8.45 & 11.73 \\
\hline L-pH $7-45^{\circ} \mathrm{C}$ & 4.69 & 4.90 & 4.90 & 5.39 & 9.44 & 10.67 \\
\hline H-pH 8-45 ${ }^{\circ} \mathrm{C}$ & 5.89 & 7.38 & 7.20 & 7.45 & 9.28 & 8.13 \\
\hline M-pH 8-45 ${ }^{\circ} \mathrm{C}$ & 5.33 & 6.23 & 6.31 & 5.59 & 9.32 & 9.01 \\
\hline L-pH 8-45 ${ }^{\circ} \mathrm{C}$ & 5.13 & 5.49 & 5.42 & 6.22 & 7.97 & 7.22 \\
\hline H-pH 9-45 ${ }^{\circ} \mathrm{C}$ & 5.33 & 5.72 & 7.36 & 7.79 & 8.69 & 10.67 \\
\hline M-pH9-45 ${ }^{\circ} \mathrm{C}$ & 5.13 & 5.24 & 5.93 & 7.56 & 8.40 & 11.60 \\
\hline L-pH 9-45 ${ }^{\circ} \mathrm{C}$ & 4.05 & 5.43 & 5.30 & 5.16 & 7.74 & 9.39 \\
\hline
\end{tabular}

\subsubsection{Results for hydrolysis pathway 3: Pronase, Protex and Trypsin at $34^{\circ} \mathrm{C}$}

Results for a standalone experiments using proteases (Trypsin, Pronase E, and Protex 6L) on the DCS without any pretreatment at $34^{\circ} \mathrm{C}$ are reported in this section. The process variables investigated included the following; $\mathrm{pH}(6 \& 7)$, temperature $\left(34^{\circ} \mathrm{C}\right)$ and hydrolysis reaction time up to 48 hours [( 1 minute, 2, 5, 24 and 48 hours), see section 4.2.5]. Table 4-6 summarizes the hydrolysis results obtained from these experiments.

Total amino acid concentrations for the controls at pH 6 and 7 appear to remain fairly constant, with some fluctuations that are bounded by the standard deviation error bounds, over the 48 hour hydrolysis reaction time, indicating that little to no hydrolysis occurred in the absence of enzymes. However, when comparing amino acid concentrations (Control) reported in Table 4-6 with that of the crude sample on an as received basis $(\sim 3.5 \mathrm{mg} / \mathrm{ml}$-see section 4.3 .1$)$ is indicative that the neutralization step 
of the hydrolysis solution liberates some amino acids. Concentrations reported in Table 4-6 (Control $\mathrm{pH}$ 7) are approximately 43-71\% higher than total amino acid concentrations of crude DCS.

Table 4-6 Summary of results for hydrolysis pathway 3: Amino acid analysis of syrup without DAP using Pronase, Protex and Trypsin at low temperature $\left(34^{\circ} \mathrm{C}\right)$. Control contains no enzymes. Standard deviation of duplicate samples in parenthesis

\begin{tabular}{|l|c|c|c|c|c|}
\hline \multirow{2}{*}{$\begin{array}{c}\text { Enzyme \& } \\
\text { pH }\end{array}$} & \multicolumn{5}{|c|}{ Reaction Times \& Amino Acid Concentrations (mg / ml) } \\
\cline { 2 - 6 } & $\mathbf{1}$ minute & $\mathbf{2 ~ h r s}$ & $\mathbf{5}$ hrs & $\mathbf{2 4}$ hrs & $\mathbf{4 8}$ hrs \\
\hline Control-pH 7 & $5.28(0.07)$ & $5.88(0.93)$ & $4.92(0.81)$ & $4.50(0.11)$ & $4.72(0.10)$ \\
\hline Control-pH 6 & $6.82(0.49)$ & $5.88(1.01)$ & $4.92(0.17)$ & $4.25(0.28)$ & $6.88(0.10)$ \\
\hline Pronase-pH 7 & $6.14(0.99)$ & $7.03(1.03)$ & $6.73(1.39)$ & $5.39(0.73)$ & $6.60(1.25)$ \\
\hline Pronase-pH 6 & $7.54(0.12)$ & $4.59(0.02)$ & $6.54(0.91)$ & $6.72(0.66)$ & $5.50(0.08)$ \\
\hline Protex-pH 7 & $5.13(0.01)$ & $5.19(0.01)$ & $6.63(0.33)$ & $8.82(0.19)$ & $12.47(0.07)$ \\
\hline Protex-pH 6 & $5.78(0.35)$ & $6.55(0.41)$ & $5.51(0.13)$ & $6.12(0.32)$ & $9.91(0.26)$ \\
\hline Trypsin pH 7 & $4.14(0.11)$ & $3.98(0.04)$ & $4.51(0.21)$ & $4.92(0.14)$ & $6.19(0.14)$ \\
\hline Trypsin pH 6 & $4.12(1.32)$ & $4.08(1.03)$ & $4.73(1.39)$ & $5.64(0.73)$ & $6.09(0.66)$ \\
\hline
\end{tabular}

Yields reported for hydrolysis solutions at $\mathrm{pH} 7$ and 6 using Pronase E. were generally low (see Table 4-6). Total amino acid concentrations for solution $\mathrm{pH} 7$ peaked at 2 hours yielding approximately $7 \mathrm{mg} / \mathrm{ml}$ representing approximately $70-58 \%$ of theoretically available amino acids. Total amino acid concentration of hydrolysis solution degraded slightly over time giving a final yield of $6.60 \mathrm{mg} / \mathrm{ml}$ after 48 hours. Similarly, for hydrolysis solution of $\mathrm{pH} 6$, total amino acid concentration at 1 minute was quantified to be approximately $7.5 \mathrm{mg} / \mathrm{ml}$. This concentration reduced over time to a total of $5.5(55-46 \%) \mathrm{mg} / \mathrm{ml}$ after 48 hours.

Hydrolysis solution of pH 7 using Protex 6L showed a gradual rise in total amino acid concentration over time peaking after 48 hours with total amino acid yields of 12.5 $\mathrm{mg} / \mathrm{ml}$ (see Table 4-6). This represents more than 100\% yield in the theoretically available amino acids. Similarly, for hydrolysis solution of pH 6 using Protex 6L, total amino acid recovery over time was a steady rise after 5 hours as can be seen in Table 46. This concentration peaked after 48 hours yielding approximately $10 \mathrm{mg} / \mathrm{ml}$ of total 
amino acid concentrations representing about $100-83 \%$ of the theoretically available amino acids in DCS.

Comparatively, the reported yields for the use of Trypsin were low (see Table 4-6). For both hydrolysis solutions of $\mathrm{pH} 6$ and 7, recovery increased steadily over time peaking after 48 hours. Total yields were quantified to be 6.20 and $6.10 \mathrm{mg} / \mathrm{ml}$ of total amino acids for solutions of $\mathrm{pH} 7$ and 6 respectively. The use of Trypsin yielded approximately $51-62 \%$ of the theoretically available amino acids and was comparatively less effective. The key highlight from this study was the efficiency of Protex 6L ( $\mathrm{pH} \mathrm{7)}$ in bringing into completeness the protein hydrolysis reaction ultimately achieving $100 \%$ of the theoretically available amino acids.

\subsubsection{Results for hydrolysis pathway 3: Sugar analysis using Accellerase 1500 and $\mathrm{XY}, \alpha$-Amylase and a combination of $\alpha$-Amylase and $\mathrm{AMG}\left(40^{\circ} \mathrm{C}\right)$}

Figure 4-4 shows the general trend of total monomer sugar production over 72 hours for hydrolysis at $\mathrm{pH}$ 6. Characterization of the total monomer sugars for unpretreated DCS ranged from 21-23 mg/ml. Control and $\alpha$-amylase hydrolysis solutions behaved very similar, with total monomer sugar concentrations ranging between 41-43 mg/ml over the 72 hour period of hydrolysis (see Figure 4-4). These results are an indication that Amylase by itself is not effective in hydrolyzing the starch and other carbohydrate components of DCS.

Hydrolysis reaction containing a combination of Accellerase 1500/XY exhibited increased total monomer sugar concentrations and peaked at 24 hours with 64.50 $\mathrm{mg} / \mathrm{ml}$. Thereafter to 48 hours, concentration started to decrease rapidly after 48 hours. The total monomer sugar concentration for enzyme solution containing a combination of $\alpha$-amylase / AMG increased slowly but peaked at 72 hours yielding a total of 63.05 $\mathrm{mg} / \mathrm{ml}$. In addition to $\alpha$-amylase, $\mathrm{AMG}$ was required to complete the hydrolysis by further converting maltodextrins into monomer sugars. Finally, concentrations of HMF for all solutions ranged from $0.03-0.30 \mathrm{mg} / \mathrm{ml}$ while that of furfural ranged from 0.17 $0.32 \mathrm{mg} / \mathrm{ml}$ (see Figure B-9). 


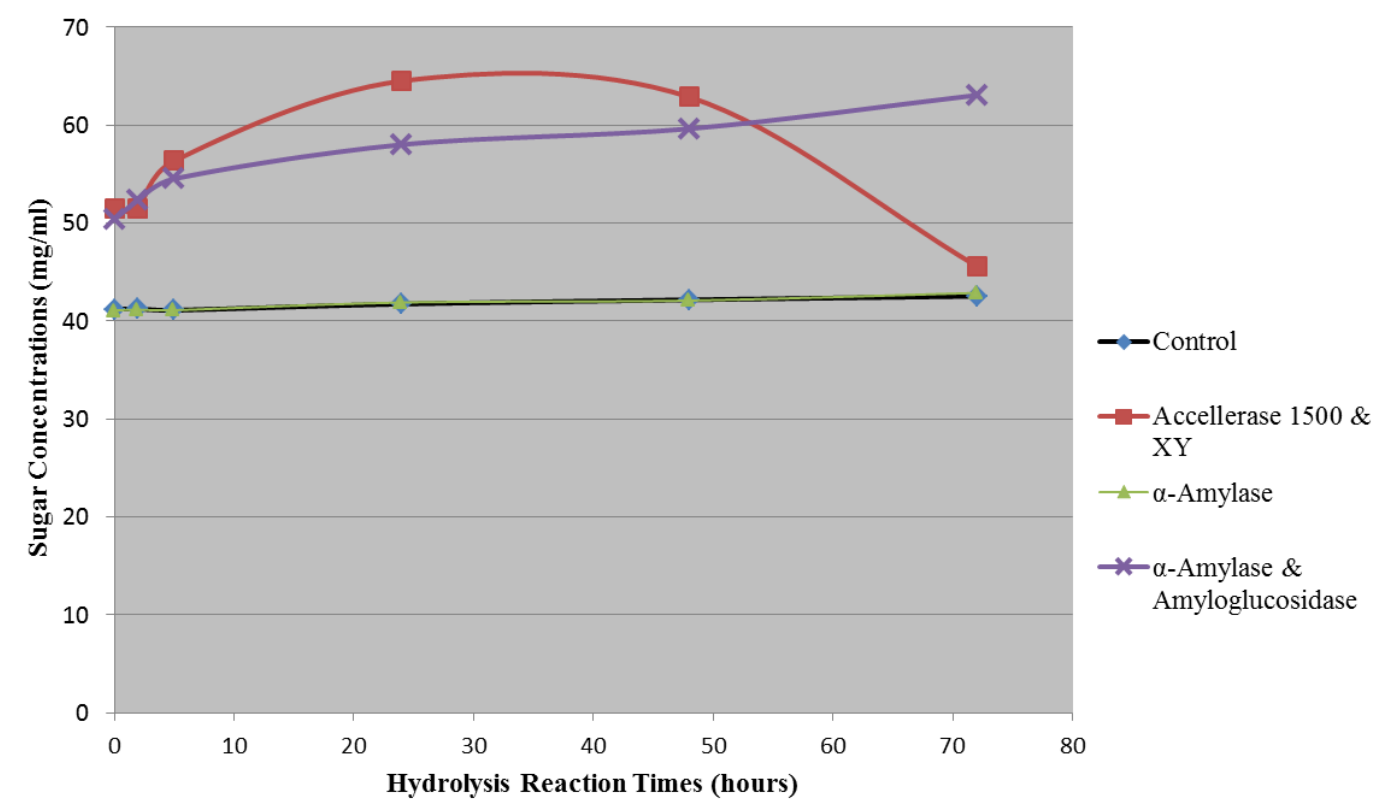

Figure 4-4 Total monomer sugar recovery using a combination of Accellerase 1500 / $\mathrm{XY}, \alpha$-amylase / AMG and $\alpha$-amylase alone

\subsubsection{Results for hydrolysis pathway 4: Simultaneous hydrolysis of unpretreated DCS using Protease (Protex 6L) \& Cellulases (Accellerase 1500 and XY)}

Figure 4-5 shows the results obtained from the simultaneous hydrolysis of unpretreated DCS using Protex 6L, Accellerase 1500 and XY. Total monomer sugar concentrations for the control solution remained stable over the 24 hour hydrolysis period. Total sugar yields of hydrolysis solution containing 1\% Protex increased steadily over time peaking after the 24 hour period at $56 \mathrm{mg} / \mathrm{ml}$. A similar trend was observed for hydrolysis solution containing $2 \%$ of Protex. These quantified total monomer sugars presented in Figure 4-5 were relatively small compared to the standalone hydrolysis of unpretreated DCS solution using just Accellerase 1500 and XY (see Figure 4-4) where total monomer sugars peaked at 24 hours yielding $63 \mathrm{mg} / \mathrm{ml}$. 


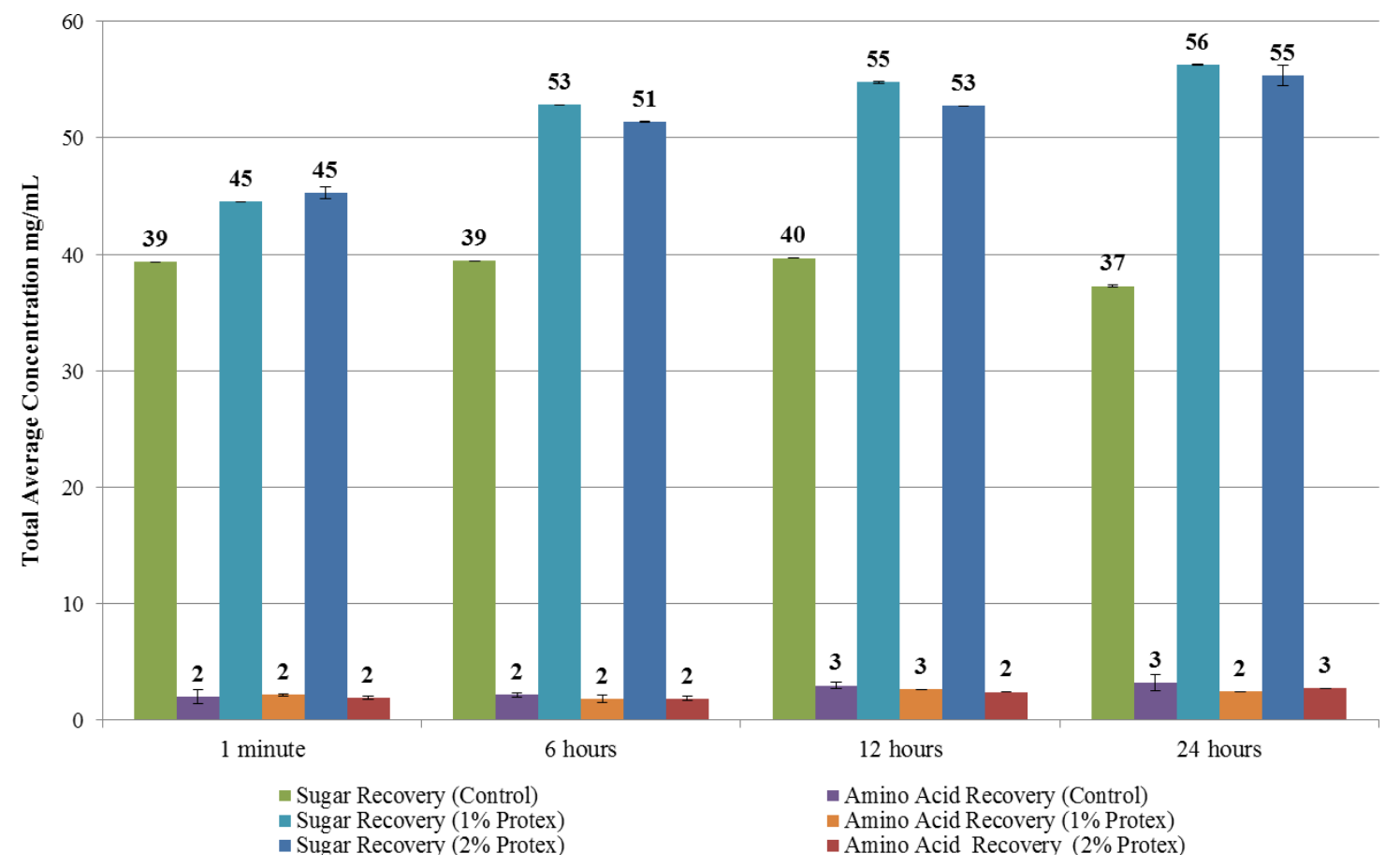

Figure 4-5 Total monomer sugar and amino acid recovery using a combination of Protex 6L and Accellerase 1500 / XY for simultaneous hydrolysis

No increase in total amino acid concentrations was observed for both 1 and 2\% Protex enzymatic hydrolysis solutions. Control solution compares closely to the amino acid analysis of DCS on as received basis (see Section 4.3.1). The use of protease and cellulases together seem to have a significant effect the proteolytic activity of Protex $6 \mathrm{~L}$ and hence was not effective in the protein hydrolysis. Total amino acid concentration for 1 and $2 \%(\mathrm{v} / \mathrm{v})$ loaded enzymatic hydrolysis solutions ranged between $2-3 \mathrm{mg} / \mathrm{ml}$ representing only $18-27 \%$ of the theoretically available amino acids in DCS biomass.

\subsection{Conclusions \& recommendations}

The goal of this research was to study the combined effect of hydrolysis reaction time, temperature, and ratio of enzyme to substrate ratio to develop hydrolysis process that optimizes the amount of usable amino acids available in DCS. Hydrolysis pathway 1, which is DAP alone at "optimum carbohydrate hydrolysis conditions (60 min, 2\% acid)" yielded $68-82 \%$ of the theoretically available amino acids. Hydrolysis pathway 
2, which is DAP of syrup followed by subsequent protease hydrolysis was also investigated using Trypsin, Pronase E (streptomyces griseus) and Protex 6L. Overall, reported yields ranged from 100-78\% of the theoretically available amino acids ( $\mathrm{pH} 6$ \& 7). For this pathway, Pronase E at $\mathrm{pH} 7$ resulted in the highest yield of $10.7 \mathrm{mg} / \mathrm{ml}$ (100-89\%) of total amino acids. Hydrolysis pathway 3 which was a standalone experiment using proteases Trypsin, Pronase E (Streptomyces griseus) and Protex 6L on the unpretreated DCS reported yields ranging from $46-100 \%$ of the theoretically available amino acids. Protex at $\mathrm{pH} 7$ yielded a total amino acid concentrations of 12.5 $\mathrm{mg} / \mathrm{ml}(100 \%$ yield) which was the highest for pathway 3. Pathway 4 (simultaneous hydrolysis with cellulase and protex) generally reported the lowest yields for both amino acids and total monomer sugars. Total amino acid concentration for 1 and $2 \%$ (v/v) loaded enzymatic hydrolysis solutions ranged between $2-3 \mathrm{mg} / \mathrm{ml}$ representing only $18-27 \%$ of the theoretically available amino acids in DCS biomass. Apart from hydrolysis pathway 4 , varying hydrolysis reaction times, investigated temperature and various enzyme loadings resulted in nearly quantitative recovery of amino acids from the protein contained in DCS. Since different alternate pathways could result in quantitative recovery of amino acids, a techno-economic analysis taking into account these routes will be important to help understand the economic impacts of these hydrolysis routes. This research topic is covered in Chapter 5. 


\subsection{References}

Adom F, Fan J, Davis J, Dunn P, Shonnard D. 2012a. Compositional Analysis of Defatted Syrup from a Corn Ethanol Dry Mill as a Feedstock for Bio-Based Products. Journal of agricultural and food chemistry (in revisions).

Adom F, Fan J, Davis J, Taylor A, Shonnard D. 2012b. Optimization of the Dilute Acid and Enzymatic Pretreatment of Defatted Syrup from a Corn Ethanol Dry Mill. . Biomass and Bioenergy in revisions.

Badadani M, Babu SVS, Shetty KT. 2007. Dinitrophenyl derivatization of imino acids, spectral characteristics and HPLC analysis: application in urinary peptidederived hydroxyproline and proline assay. Annals of clinical biochemistry 44(2):164-172.

Bercovicil D, Fuller MF. 2008. 6 Industrial amino acids in nonruminant animal nutrition. Biotechnology in Animal Feeds and Animal Feeding:93.

Claver IP, Zhou H. 2005. Enzymatic hydrolysis of defatted wheat germ by proteases and the effect on the functional properties of resulting protein hydrolysates. Journal of food biochemistry 29(1):13-26.

Davidson I. 1997. Hydrolysis of samples for amino acid analysis. Methods in molecular biology (Clifton, NJ) 64:119.

Davidson I, O'Connor P, Amino Acid Analysis Molecular Biomethods Handbook. Walker JM, Rapley R, Eds. Humana Press: 2008; pp 793-808.

Fountoulakis M, Lahm HW. 1998. Hydrolysis and amino acid composition analysis of proteins. Journal of Chromatography A 826(2):109-134.

Fürst P, Pollack L, Graser T, Godel H, Stehle P. 1990. Appraisal of four pre-column derivatization methods for the high-performance liquid chromatographic determination of free amino acids in biological materials. Journal of Chromatography A 499:557-569.

Genencor. 2011. Protex 6L Bacterial Alkaline Protease. REV0301 1654 PRO44AX $02: 2$.

Haurowitz F, Tunca M, Schwerin P, Göksu V. 1945. The action of trypsin on native and denatured proteins. Journal of Biological Chemistry 157(2):621-625. 
Henderson J, Ricker RD, Bidlingmeyer BA, Woodward C. 2000. Rapid, accurate, sensitive, and reproducible HPLC analysis of amino acids. Application bulletin 5980.

Irvine GB. 1997. Amino acid analysis. Precolumn derivatization methods. Methods in molecular biology (Clifton, NJ) 64:131.

Leuchtenberger W, Huthmacher K, Drauz K. 2005. Biotechnological production of amino acids and derivatives: current status and prospects. Applied Microbiology and Biotechnology 69(1):1-8.

Malmer MF, Schroeder LA. 1990. Amino acid anslysis by high-performance liquid chromatography with methanesulfonic acid hydrolysis and 9fluorenylmethylchloroformate derivatization. Journal of Chromatography A 514:227-239.

Mota M, Ferreira I, Oliveira M, Rocha C, Teixeira J, Torres D, Gonçalves M. 2004. Enzymatic hydrolysis of whey protein concentrates: Peptide HPLC profiles. Journal of liquid chromatography \& related technologies 27(16):2625-2639.

Ozols J. 1990. [44] Amino acid analysis. Methods in enzymology 182:587-601.

Pickering MV, Newton P. 1990. Amino acid hydrolysis: old problems, new solutions. LC-GC 8(10).

Peptide Analysis [Internet]. [updated cited.

Sigma-Aldrich. 2011. Bradford Reagent Technical Bulletin. No. RC, JDS,MAM 06/11-1.

Smith BJ, Protein sequencing protocols. Springer: 2003; Vol. 211.

Thacker H. 2004. Alkaline hydrolysis. Carcass disposal: A comprehensive review. National Agricultural Biosecurity Center, Kansas State University.

Weiss M, Manneberg M, Juranville JF, Lahm HW, Fountoulakis M. 1998. Effect of the hydrolysis method on the determination of the amino acid composition of proteins. Journal of Chromatography A 795(2):263-275. 


\section{Chapter 5}

\section{Modeling of Dilute Acid Pretreatment Process using Defatted Corn Syrup as Feedstock: Techno-economic Analysis and Life Cycle Assessment ${ }^{4}$}

\subsection{Introduction}

Defatted corn syrup (DCS) from a dry corn mill facility is a processed residue from the dry corn mill facility. Production of DCS averaged 59 million kg per month $(\sim 708$ million $\mathrm{kg}$ per year) in the U.S. (O'Brien 2010) and is expected to increase given the continuous expansion of the dry-grind mill facility across the U.S. Rich in carbohydrates and amino acids, DCS has potential as a feedstock for bio-products. Currently, it is dried and added to distillers dried grains with solubles (DDGS) as a feed additive. DCS as a complex process residue consisting of various soluble and nonsoluble carbohydrate polymers making it ideal feedstock for bioproducts via the biochemical conversion route and subsequent fermentation to value-added products (Adom et al. 2012b). Separate studies (Adom et al. 2012a; Adom et al. 2012c) investigating the combined effect of hydrolysis reaction time, temperature, and ratio of enzyme to substrate ratio to develop hydrolysis process that optimizes the amount of usable fermentable sugars and amino acids using DCS have been conducted. This developed platform can serve as a building block for high value chemicals such as lactic acid, glycerol, and amino acids (lysine, aspartic acid, etc.).

The aim of this work was to investigate the economic feasibility of an industrial process of the sugar and amino acid platform from DCS via dilute acid pretreatment. This constructed model will serve as a platform for the investigation of specific

\footnotetext{
${ }^{4}$ This chapter will be submitted to Industrial \& Engineering Chemistry Research for publication. Citation: Adom, F., Rogers, T., Shonnard, D. (2012). Modeling of dilute acid pretreatment process using defatted corn syrup as feedstock: Techno-economic analysis and life cycle assessment. Industrial \& Engineering Chemistry Research
} 
bioproduct using the sugar and amino acid platform while considering additional downstream processes in future research analyses. The process was simulated using Aspen Plus ${ }^{\circledR}$ (Aspen Technologies, Cambridge, MA, USA) based on experimental data in the lab. Originally developed for the Department of Energy (DOE) by the Massachusetts Institute of Technology in 1987, Aspen Plus is capable of solving steady state material and energy balances, calculating phase equilibria, and estimating physical properties for thousands of chemical compounds as well as capital costs of equipment (Jayawardhana and Walsum 2004). Process simulation procedures primarily involve; defining chemical components, selecting the thermodynamic model, choosing proper operating conditions (flow rate, temperature, pressure, etc.) (Fasahati and Liu 2012). Physical properties selection is important, and the successful implementation of a process design starts with selecting the appropriate physical property method (Carlson 1996). For example, GRAYSON is recommended for hydrogen components and Peng Robingson is useful for gas processing coupled with binary parameters (Peris Serrano 2012). The Non-random, Two Liquids (NRTL) property method is capable of estimating the vapor-liquid phase equilibria by using the binary interaction coefficients for chemical components and has been mostly adopted for biomass pretreatment processes (Aden and Foust 2009; Humbird and Aden 2009; Kazi et al. 2010). Specific study objectives for this chapter are enumerated below:

- Development of a process design for the production of the both the sugar and amino acid platform via dilute acid pretreatment

- A preliminary cost analysis to estimate the initial capital cost and operating cost of this facility using Aspen Plus Economic Analyzer

- A greenhouse gas analysis to understand the environmental impact of this facility

\subsection{Methods}

\subsubsection{Process description}

A plant with a total capacity of processing $27,329 \mathrm{~kg} / \mathrm{hr}$ (wet basis) $[\sim 10,240 \mathrm{~kg} / \mathrm{hr}$ (dry basis)] of DCS is simulated. The Non-random, Two Liquids (NRTL) property method 
was selected for this process design. Assuming a plant uptime of 80\% (7000 hours per year), the cost component of the analysis is simulated using Aspen Process Economic Analyzer ${ }^{\circledR}$.

\subsubsection{Feed composition of DCS}

DCS broadly comprise of: (i) Fermentable carbohydrates \& Lignin (35 wt\%) (ii) Protein \& Amino acids (10.9 wt\%) (iii) Organic acids, glycerol \& Ash (52 wt\%). Table 5-1 summarizes the DCS composition and their corresponding flow rates on an hourly basis used in this process design.

Table 5-1 Summary of the DCS composition and their corresponding flow rates on an hourly basis used. (FAA: Fermentable amino acids, FS: Fermentable sugars, SA:

Succinic acid, AIL Acid insoluble lignin, and ASL: Acid soluble lignin)

\begin{tabular}{|c|c|c|c|c|c|c|c|c|}
\hline FAA & $\begin{array}{l}\text { Flow } \\
\text { rate } \\
(\mathrm{kg} / \mathrm{hr})\end{array}$ & $\begin{array}{l}\% \text { Dry } \\
\text { basis }\end{array}$ & $\begin{array}{l}\text { FS and } \\
\text { Lignin }\end{array}$ & $\begin{array}{l}\text { Flow } \\
\text { rate } \\
(\mathrm{kg} / \mathrm{hr})\end{array}$ & $\begin{array}{l}\% \\
\text { Dry } \\
\text { basis }\end{array}$ & Others & $\begin{array}{l}\text { Flow } \\
\text { rate } \\
(\mathrm{kg} / \mathrm{hr})\end{array}$ & $\begin{array}{l}\% \\
\text { Dry } \\
\text { basis }\end{array}$ \\
\hline Aspartic acid & 37 & 0.004 & Cellulose & 71 & 0.007 & Ash & 1,185 & 0.117 \\
\hline Glutamic acid & 23 & 0.002 & Xylan & 547 & 0.054 & Glycerol & 3,302 & 0.326 \\
\hline Asparagine & 14 & 0.001 & Galactan & 233 & 0.023 & Oxalic acid & 122 & 0.012 \\
\hline Serine & 7 & 0.001 & Arabinan & 61 & 0.006 & SA & 142 & 0.014 \\
\hline Histidine & 39 & 0.004 & Mannan & 111 & 0.011 & Lactic acid & 415 & 0.041 \\
\hline Glycine & 30 & 0.003 & Glucose & 1003 & 0.099 & Acetate & 142 & 0.014 \\
\hline Threonine & 31 & 0.003 & Xylose & 101 & 0.01 & & & \\
\hline Arginine & 15 & 0.002 & Galactose & 41 & 0.004 & & & \\
\hline Alanine & 38 & 0.004 & Arabinose & 41 & 0.004 & & & \\
\hline Tyrosine & 1 & 0.0001 & Mannose & 41 & 0.004 & & & \\
\hline Valine & 4 & 0.0004 & Starch & 567 & 0.056 & & & \\
\hline Methionine & 24 & 0.002 & ASL & 213 & 0.021 & & & \\
\hline Phenylalanine & 4 & 0.0004 & AIL & 770 & 0.076 & & & \\
\hline Iso-leucine & 2 & 0.0002 & & & & & & \\
\hline Leucine & 7 & 0.001 & & & & & & \\
\hline Lysine & 2 & 0.0002 & & & & & & \\
\hline Protein & 821 & 0.081 & & & & & & \\
\hline Total & 1,101 & 0.109 & & 3,799 & 0.375 & & 5,308 & 0.524 \\
\hline
\end{tabular}




\subsubsection{Process description}

Figure 5-1 shows a process flow diagram for the pretreatment design process. The pretreatment section comprise of 3 key subsections namely (i) DCS viscosity reduction and preheating section (ii) Dilute acid pretreatment and flash cooling section and (iii) Neutralization and unreacted residues separation section. For approximately $27,329 \mathrm{~kg} / \mathrm{hr}$ (wet basis), $74,661 \mathrm{~kg} / \mathrm{hr}$ of $\mathrm{H}_{2} \mathrm{O}$ and $209 \mathrm{~kg} / \mathrm{hr}$ of $98 \mathrm{wt} \% \mathrm{H}_{2} \mathrm{SO}_{4}$ is required to bring the solution to $10 \mathrm{wt} \%$ solid loadings and $2 \mathrm{wt} \%$ acid concentration.

DCS viscosity reduction and preheating section: Pretreatment proceeds (see Figure $5-1)$ by mixing (MIXER-1) DCS with a water stream $(24,887 \mathrm{~kg} / \mathrm{hr}$ ) to reduce viscosity of DCS for subsequent transfer of stream (S-1) to the pretreatment reactor (RSTOIC-1) via a centrifugal pump. Both streams (water \& DCS) have pressure and temperature of $1 \mathrm{~atm}$ and $25^{\circ} \mathrm{C}$. Positive displacement and special effect types such as venture eductors are used but by far the most common type of slurry pump is the centrifugal pump (Warman International 1994). Assuming 85\% pump efficiency and power requirement of 3728 Watts or 5 horsepower (Lardy G 2004) for a centrifugal slurry pump (PUMP-1), Aspen Plus ${ }^{\circledR}$ was run to estimate parameters such as net positive suction height, brake power, and the pressure of outlet of stream (S-2). A mixing valve (VALVE-1) to regulate the amount of dilute DCS stream (S-3) going into the preheater (PREHEAT1) operating at an adiabatic flash with no pressure drop was used. DCS solution (S-3) is preheated to $60^{\circ} \mathrm{C}$ with an incoming low-pressure steam (STEAM-1) at $2.96 \mathrm{~atm}$ and $134^{\circ} \mathrm{C}$ (Towler and Sinnott 2012). Using the design specification capability in Aspen Plus ${ }^{\circledR}$, STEAM-1 was varied between 1000-3000 using the following design specification expressions; Spec (S1), Target (60) and Tolerance (0.001). Aspen Plus ${ }^{\circledR}$ estimated 2,574 kg/hr of low-pressure steam (LPS) required to reach the $60^{\circ} \mathrm{C}$ target temperature in the preheater (PREHEAT1), this was used in this model. Preheated stream (S-4) is subsequently pumped to the dilute acid pretreatment and flash cooling section. 
Dilute acid pretreatment and flash cooling section: The preheated stream (S-4) with biomass solid loadings of approximately $20 \mathrm{wt} \%$ is pumped (PUMP-2) to the pretreatment reactor (RSTOIC-1) prior to mixing with another LPS (STEAM-2) and $98 \mathrm{wt} \% \mathrm{H}_{2} \mathrm{SO}_{4}$. Given the pretreatment reactor conditions (see Table 5-2) in the RSTOIC-1, it was estimated that approximately $47,558 \mathrm{~kg} / \mathrm{hr}$ of LP steam (STEAM-2) is required to bring total solid loadings in stream (S-7) to $10 \mathrm{wt} \%$. RSTOIC-1 is used because of the unavailability of kinetic data for the pretreatment reactions.

Table 5-2 Pretreatment Reactor Conditions (RSTOIC-1) (Adom et al. 2012c)

\begin{tabular}{|l|l|}
\hline Processing Variables & Conditions \\
\hline Sulfuric acid loading & $2 \mathrm{wt} \%$ \\
\hline Residence Time & 60 minutes \\
\hline Temperature & $121^{\circ} \mathrm{C}$ \\
\hline Total solids loading & $10 \mathrm{wt} \%$ \\
\hline
\end{tabular}

However, experimentally validated conversion yields measured and reported in chapters 3 and 4 of this dissertation were used (see Table 5-3). DCS optimization focusing on protein degradation into amino acids reported $82-68 \%$ (Average $=75 \%$ ) of theoretical amino acids liberated at the pretreatment reactor conditions (see Table 5-4). A protein model $\left(\mathrm{CH}_{1.99} \mathrm{O}_{0.61} \mathrm{~N}_{0.32} \mathrm{~S}_{0.01}\right)$ in addition to a protein degradation hydrolysis reaction model was developed based on the reported amino acid yields at the pretreatment condition using a mass balance approach (see Table C-1 and C-2). This was necessary to model protein degradation at the pretreatment conditions reported in Table 5-2. Aspen Plus ${ }^{\circledR}$ model was initially run by inputting the reactions (see Table 53 ) in RSTOIC-1 assuming a heat duty (0 kWhr) and pressure (2.96 atm). This initial run estimated the RSTOIC-1 reactor conditions to be approximately $135^{\circ} \mathrm{C}$. Design specification was therefore necessary to achieve the specified reactor conditions of $121^{\circ} \mathrm{C}$. 
Design specification analysis was implemented in Aspen Plus ${ }^{\circledR}$ by estimating the required pressure in RSTOIC-1 to achieve the target temperature $\left(121^{\circ} \mathrm{C}\right)$. The following design specification expressions; Spec (S2), Target (121) and Tolerance (0.001) were used to estimate the required pressure in RSTOIC-1 to achieve the target temperature. Manipulated variable (pressure in RSTOIC-1) specified in Aspen Plus ${ }^{\circledR}$ ranged from 1 to $5 \mathrm{~atm}$. Aspen Plus ${ }^{\circledR}$ calculated the required pressure $(1.95 \mathrm{~atm})$ to reach the $121{ }^{\circ} \mathrm{C}$ reaction conditions, and this was used in our process design. The final unit operation in this section is the application of a flash tank (FLASH-1) to flash cool $\left(110^{\circ} \mathrm{C}\right)$ the slurry $(\mathrm{S}-8)$ to volatilize some inhibitors like HMF, furfural and acetic acid into volatile organic compounds (VOC's). The carbohydrate and amino acid rich stream (S-10) is sent to the neutralization and unreacted residues separation section for further detoxification.

Table 5-3 Pretreatment Hydrolysis Reactions (Refer to list of abbreviations for the meaning of 3-letter amino acid)

\begin{tabular}{|c|c|c|}
\hline Reaction & Reactant & Conversion \\
\hline $\mathrm{H}_{2} \mathrm{O}+$ Xylan (Cisolid) --> Xylose & Xylan & $90 \%$ \\
\hline $\mathrm{H}_{2} \mathrm{O}+$ Galactan (Cisolid) --> Galactose & Galactan & $85.0 \%$ \\
\hline Xylan (Cisolid) --> Furfural $+2 \mathrm{H}_{2} \mathrm{O}$ & Xylan & $0.05 \%$ \\
\hline Mannan (Cisolid) --> $\mathrm{HMF}+2 \mathrm{H}_{2} \mathrm{O}$ & Mannan & $15.7 \%$ \\
\hline Arabinan (Cisolid) --> $2 \mathrm{H}_{2} \mathrm{O}+$ Furfural & Arabinan & $0.6 \%$ \\
\hline Starch (Cisolid) $+\mathrm{H}_{2} \mathrm{O}-->2$ Glucose & Starch & $100 \%$ \\
\hline Acetate (Cisolid) --> Acetic acid & Acetate & $100 \%$ \\
\hline Lignin (Cisolid) --> Soluble lignin & Lignin & $50 \%$ \\
\hline $\mathrm{H}_{2} \mathrm{O}+$ Mannan (Cisolid) --> Mannose & Mannan & $60 \%$ \\
\hline $\mathrm{H}_{2} \mathrm{O}+$ Arabinan (Cisolid) --> Arabinose & Arabinan & $49.5 \%$ \\
\hline Galactan (Cisolid) --> HMF $+2 \mathrm{H}_{2} \mathrm{O}$ & Galactan & $1 \%$ \\
\hline Cellulose (Cisolid) $+\mathrm{H}_{2} \mathrm{O}-->$ Glucose & Cellulose & $100 \%$ \\
\hline $\begin{array}{l}\text { PROTEIN(Cisolid) }+.09138 \mathrm{H}_{2} \mathrm{O}-->.24 \\
\mathrm{ASP}+.12 \mathrm{GLU}+.03 \mathrm{ASN}+.02 \mathrm{SER}+.06 \\
\mathrm{HIS}+.08 \mathrm{GLY}+.06 \mathrm{THR}+.06 \mathrm{ARG}+.04 \\
\mathrm{ALA}+.02 \mathrm{TYR}+.02 \mathrm{VAL}+.1 \mathrm{MET}+.05 \\
\mathrm{PHE}+.04 \mathrm{ILE}+.03 \mathrm{LEU}+.02 \mathrm{LYS}\end{array}$ & Protein & $75 \%$ \\
\hline
\end{tabular}



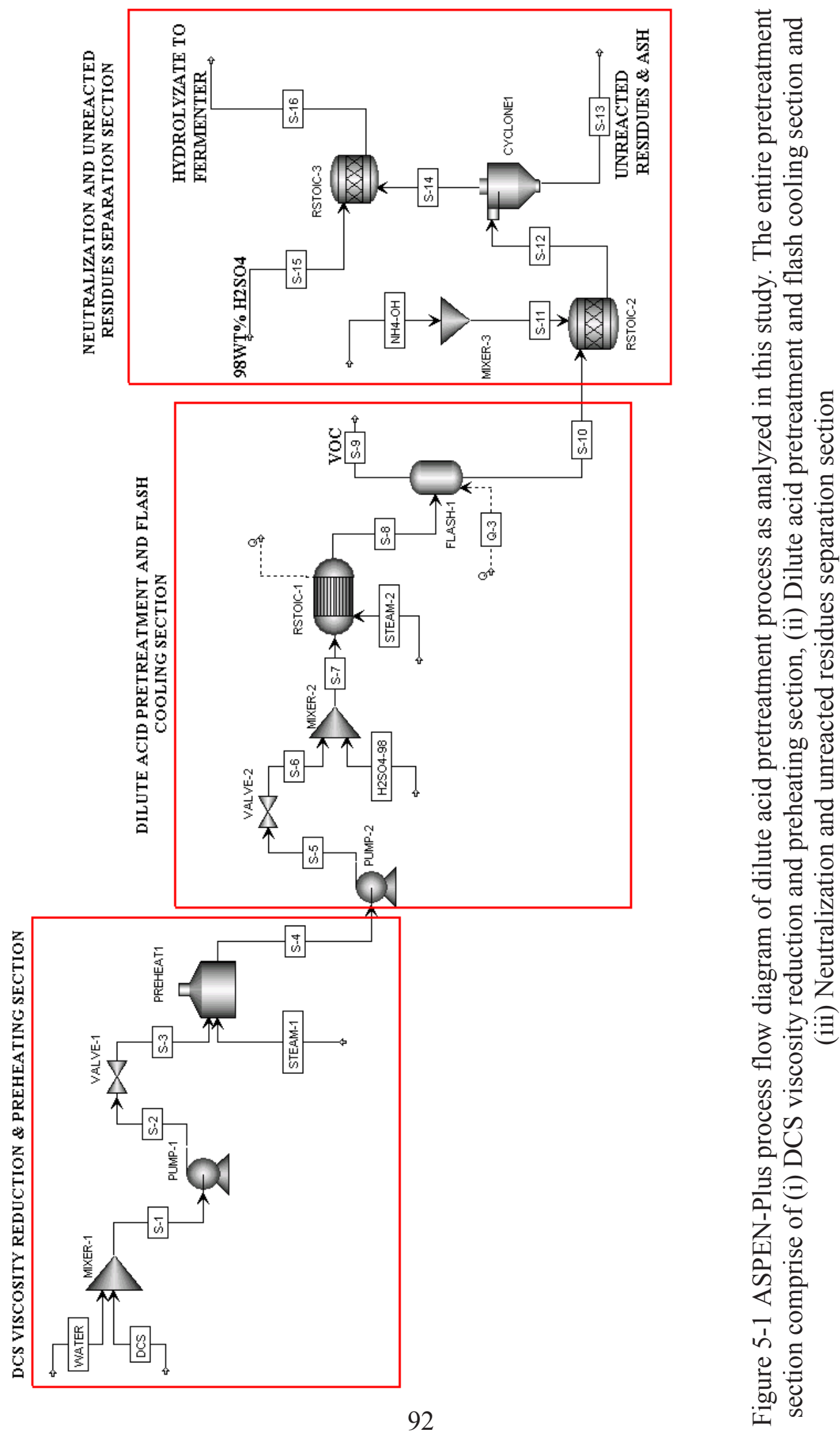
Neutralization and unreacted residues separation section: Though more expensive than lime, reduction in both sugar loss and overall capital cost make the use of ammonia a more attractive neutralizer (Jennings and Schell 2011). Ammonia loading of $4.8 \mathrm{~g} / 1$ of hydrolysate (Humbird and Aden 2009) was assumed for the neutralization of acetic acid and $\mathrm{H}_{2} \mathrm{SO}_{4}$ into ammonium acetate $\left(\mathrm{C}_{2} \mathrm{H}_{3} \mathrm{O}_{2} \mathrm{NH}_{4}\right)$ and ammonium sulfate $\left[\left(\mathrm{NH}_{4}\right)_{2} \mathrm{SO}_{4}\right]$ respectively. The neutralized slurry $(\mathrm{S}-12)$ is run through a cylone (CYCLONE1) to separate the unreacted residues (S-13) from the liquid hydrolyzate (S12). Stream (S-14) which is the hydrolyzate containing excess $\mathrm{NH}_{3}$ is further neutralized with $98 \mathrm{wt} \% \mathrm{H}_{2} \mathrm{SO}_{4}$ to subsequently precipitate more $\left(\mathrm{NH}_{4}\right)_{2} \mathrm{SO}_{4}$ prior to fermentation. Design specification analysis was used to estimate the amount of $98 \mathrm{wt} \%$ $\mathrm{H}_{2} \mathrm{SO}_{4}(5580.134 \mathrm{~kg} / \mathrm{hr})$ required to have less than $0.1 \mathrm{~kg} / \mathrm{hr}$ of $\mathrm{NH}_{3}$ in the STREAM16 (hydrolyzate to fermenter). Operation conditions of the unit operations for the entire pretreatment section are summarized in Table 5-4.

Table 5-4 Parameters used for modeling the process flow diagram

\begin{tabular}{|l|l|}
\hline Unit Operation & Modeling Parameters used \\
\hline $\begin{array}{l}\text { Mixers } \\
\text { Mixer-1 \& 2) }\end{array}$ & $\begin{array}{l}\text { Valid phases specified; Liquid \& Vapor phase. No outlet } \\
\text { pressure was specified allowing mixer to use minimum } \\
\text { pressure from the inlet streams to determine outlet stream } \\
\text { conditions. }\end{array}$ \\
\hline $\begin{array}{l}\text { Pumps } \\
(\text { Pump-1 \& 2) }\end{array}$ & $\begin{array}{l}\text { Efficiency: } 85 \% \\
\text { Power required : 3.7 kWh }\end{array}$ \\
\hline $\begin{array}{l}\text { Valves } \\
(\text { Valves } 1 \& 2)\end{array}$ & $\begin{array}{l}\text { Adiabatic flash with zero pressure drop used to estimate } \\
\text { outlet stream temperature and phase conditions }\end{array}$ \\
\hline $\begin{array}{l}\text { Reactor } \\
(\text { RSTOIC 1,2 \& 3) }\end{array}$ & $\begin{array}{l}\text { RSTOIC 1: Pressure } 1.95 \text { atm, Heat duty: } 0 \mathrm{~kW} \\
\text { RSTOIC 2 \& 3: Pressure } 1.37 \text { atm, Heat duty: } 0 \mathrm{~kW}\end{array}$ \\
\hline Flash tank (Flash-1) & Temperature: $110^{\circ} \mathrm{C}$, modeled as adiabatic flash \\
\hline $\begin{array}{l}\text { Cyclone } \\
\text { (CYCLONE1) }\end{array}$ & $\begin{array}{l}\text { MIXED (Split fraction : } 1) \\
\text { CISOLID (Split fraction: } 0.01)\end{array}$ \\
\hline
\end{tabular}

\subsection{Process simulation and economic calculations}


Aspen Plus was used to conduct rigorous material and energy balance calculations by choosing equipment models, specifying key input flow rates and allowing the software to determine resultant stream composition and energy flow. Standard Aspen Plus inhouse databank lacks the physical properties of typical lignocellulosic biomass components. Thermodynamic database for components such as cellulose, lignin, xylose, etc were obtained from an NREL technical report (Wooley and Putsche 1996).

Using Aspen Plus Economic Analyzer ${ }^{\circledR}$ (APEA) version 7.3, the capital cost of equipment such as pumps, reactors, vessels, cyclones, mixers and valves were estimated. The cost basis for this version of APEA is first quarter of 2010. APEA has the capability of analyzing the cost of other auxiliary equipment such as piping, electrical equipment, instrumentation, etc., all these cost components were included in the final cost analysis. Results from the Aspen Plus ${ }^{\circledR}$ simulation file for the mass and energy balances were used by APEA for sizing calculations and subsequent mapping of equipment. The stoichiometric reactors in this process were all considered agitated tanks with enclosed jackets.

For this cost analysis, startup and construction period of 2 years, in addition to a plant life of 15 years, was assumed. Annual maintenance and insurance expenditures were assumed to be $2 \%$ and $1 \%$ of FCI respectively. Assuming that 10 persons operate the plant, we further assumed default labor wage in Aspen Plus Economic Analyzer (\$20/operator and \$35/supervisor) for this analysis. Since plant, location has not been determined; this figure has been reported to be enough to cover labor expenses in Europe and USA (Sassner et al, 2008; Lohrasbi et al, 2010). 30\% taxation rate has been reported to be reasonable for most places and hence assumed for this model (Lohrasbi et al, 2010). Finally, a straight-line depreciation method and 5\% salvage value of the initial fixed capital cost was assumed for this process economic evaluation. Table 5-5 summarizes the additional cost elements used in the evaluation of this processing facility. 
Table 5-5 Cost of raw materials and utilities used in process simulation

\begin{tabular}{|l|l|l|}
\hline Inputs & Price & Unit (Source) \\
\hline Raw material (DCS) & 0.01 & $\$ / \mathrm{kg}$ (Agri-Energy 2012) \\
\hline Sulfuric acid & 0.17 & $\$ / \mathrm{kg}$ (Lohrasbi et al. 2010) \\
\hline Ammonia & 0.33 & $\$ / \mathrm{kg}$ (Wingren et al. 2003) \\
\hline Steam & 0.0013 & $\$ / 1 \mathrm{~b}$ (Jayawardhana and Walsum 2004) \\
\hline Electricity & 0.05 & $\$ / \mathrm{kWhr}$ (Lohrasbi et al. 2010) \\
\hline Maintenance & 2 & $\%$ of fixed capital \\
\hline Insurance & 1 & $\%$ of fixed capital \\
\hline
\end{tabular}

\subsection{Greenhouse gas analysis of the dilute acid pretreatment processing facility}

A GHG analysis was conducted on this processing facility to estimate the overall greenhouse gas emissions on an annual basis. The environmental impact (GHG) was analyzed by identifying the input requirements for this process facility. A key assumption is that DCS has no environmental burden and is treated as "waste" given the fact that it is a low value product in the market. Other key inputs included in this analysis are; 98 wt\% $\mathrm{H}_{2} \mathrm{SO}_{4}(5789 \mathrm{~kg} / \mathrm{hr}), \mathrm{NH}_{4} \mathrm{OH}(6.830 \mathrm{~kg} / \mathrm{hr})$, electricity $(7.46$ $\mathrm{kWh})$, steam $(50,132 \mathrm{~kg} / \mathrm{hr})$ and water $(24,882 \mathrm{~kg} / \mathrm{hr})$. Using the global warming potential method $\left(\mathrm{CO}_{2}=1, \mathrm{CH}_{4}=25, \mathrm{~N}_{2} \mathrm{O}=298\right)$ in SimaPro ${ }^{\circledR}$, the emission factors of the corresponding inputs were identified and applied on these inputs. Specifically, the following emission factors from SimaPro ${ }^{\circledR}$ were used for this analysis: sulfuric acid, liquid, at plant/RER S (0.123), Ammonia, steam reforming, liquid, at plant/RER S (1.91), Water, completely softened, at plant/RER $S\left(2.43 \times 10^{-5}\right)$ and Steam, for chemical processes, at plant/RER S (0.234) all on a basis of $\mathrm{kgCO}_{2}$ equivalent (e) / $\mathrm{kg}$ of input. Emision factor for Electricity, U.S. national grid $\left(0.823 \mathrm{kgCO}_{2} \mathrm{e} / \mathrm{kWh}\right)$ from Adom et al. (2012d) was used.

\subsection{Results and discussion}

\subsubsection{Mass and energy balances for process simulation in Aspen Plus ${ }^{\circledR}$}


Table 5-6 summarizes the composition of streams for hydrolyzate to fermenter (S-16) and unreacted residues stream (S-13) for this simulated processing facility. Generally, the stream (S-16) is rich in both carbohydrates and amino acids. Glucose production is approximately $1,697 \mathrm{~kg} / \mathrm{hr}$ while glycerol is $3,338 \mathrm{~kg} / \mathrm{hr}$. This stream $(\mathrm{S}-16)$ subsequently goes into the fermentation section for the fermentation process to produce high value products. The two major energy intensive unit operations were the preheater (PREHEAT-1) and pretreatment reactor (RSTOIC-1). Overall steam demand amounted to $50,100 \mathrm{~kg} / \mathrm{hr}(351,000,000 \mathrm{~kg} / \mathrm{yr})$.

Table 5-6 Composition of streams for hydrolyzate to fermenter (S-16) and unreacted residues (S-13) [GLU-ACID: Glutamic Acid and ASP-ACID: Aspartic Acid]

\begin{tabular}{|c|c|c|c|c|c|}
\hline \multirow{2}{*}{ Components } & \multicolumn{2}{|c|}{ Mass Flow kg/hr } & \multirow{2}{*}{ Components } & \multicolumn{2}{|c|}{ Mass Flow kg/hr } \\
\hline & S-13 & S-16 & & S-13 & S-16 \\
\hline $\mathrm{H}_{2} \mathrm{O}$ & - & 48,326 & XYLAN & 52 & - \\
\hline GLUCOSE & - & 1,697 & ARABINAN & 30 & - \\
\hline GALACTOS & - & 263 & LIGNIN & 385 & - \\
\hline MANNOSE & - & 116 & ACETATE & - & - \\
\hline XYLOSE & - & 668 & ASH & 1,186 & - \\
\hline ARABINOS & - & 76 & LYSINE & - & 13 \\
\hline LIGNIN-SOLUBLE & - & 604 & LEUCINE & - & 22 \\
\hline HMF & - & 42 & I-LEUCIN & - & 21 \\
\hline FURFURAL & - & 0 & PHENYLAL & - & 24 \\
\hline ACETIC ACID & - & - & METHIONI & - & 87 \\
\hline LACTIC ACID & - & 417 & VALINE & - & 13 \\
\hline XYLITOL & - & - & TYROSINE & - & 10 \\
\hline GLYCEROL & - & 3,338 & ALANINE & - & 63 \\
\hline SUCCINIC ACID & - & 143 & ARGININE & - & 3 \\
\hline OXALIC ACID & - & 123 & THREONIN & - & 54 \\
\hline $\mathrm{NH}_{3}$ & - & - & GLYCINE & - & 96 \\
\hline $\mathrm{H}_{2} \mathrm{SO}_{4}$ & - & - & HISTIDIN & - & 86 \\
\hline $\mathrm{NH}_{4} \mathrm{SO}_{4}$ & 278 & - & SERINE & - & 22 \\
\hline $\mathrm{NH}_{4} \mathrm{ACETATE}$ & 112 & - & ASPARAGINE & - & 36 \\
\hline CELLULOSE & - & - & GLU-ACID & - & 100 \\
\hline GALACTAN & 33 & - & ASP-ACID & - & 211 \\
\hline MANNAN & 27 & - & PROTEIN & 205 & - \\
\hline Total Flow kg/hr & 596 & $\mathbf{5 5 , 0 7 7}$ & & 2,322 & 861 \\
\hline
\end{tabular}




\subsubsection{Results for economic analysis}

Table 5-7 summarizes the total cost components of the facility under investigation. From this analysis, raw materials and plant operational cost were the most significant. The most expensive streams were identified to be (see Figure 5-1); STEAM-2 (1,048 \$/hr), S-15 (98wt\% $\left.\mathrm{H}_{2} \mathrm{SO}_{4}-967 \$ / \mathrm{hr}\right)$, DCS (274 \$/hr) and $\mathrm{NH}_{4} \mathrm{OH}$ stream (67 \$/hr). Future analysis should investigate the potential of regulating the ammonia content in the hydrolysis stream to serve as a source of nitrogen during fermentation to value added products.

In another study (Jayawardhana and Walsum 2004), the authors reported the capital cost of a facility using $\mathrm{H}_{2} \mathrm{SO}_{4}$ as the main catalyst to be $\$ 5,847,005$. In our study, operating cost is particularly high because of the high requirement of steam, sulfuric acid and ammonia for neutralization, however because of the minimization of sugar loss this is expected to improve overall process economics depending on target bioproduct (e.g. succinic acid, lysine, and aspartic acid).

Table 5-7 Summary of results from economic analysis from Aspen Plus ${ }^{\circledR}$ (United States Dollars: USD)

\begin{tabular}{|l|l|}
\hline Name & Summary \\
\hline Total Capital Cost [USD] & $4,700,000$ \\
\hline Total Operating Cost [USD/Year] & $22,100,000$ \\
\hline Total Raw Materials Cost [USD/Year] & $19,300,000$ \\
\hline Total Utilities Cost [USD/Year] & 70,200 \\
\hline
\end{tabular}

Finally, Figure 5-2 summarizes the direct cost for all the unit operations assembled for the process facility. The direct cost comprises of equipment cost and auxilliary equipment as well as the building requirements associated with process and installation (Wingren et al. 2003). The three stoichiometric reactors were the largest cost component contributing approximately $62 \%$ towards total direct cost for all unit 
operations combined. The next major contributors were the cyclone (CYCLONE1), flash vessel (FLASH-1), and preheater (PREHEAT1) contributing approximately 13\%, $11 \%$ and $9 \%$ towards the direct cost respectively. For detailed cost analysis for each unit operation, see Figures C-1 through to C-7.

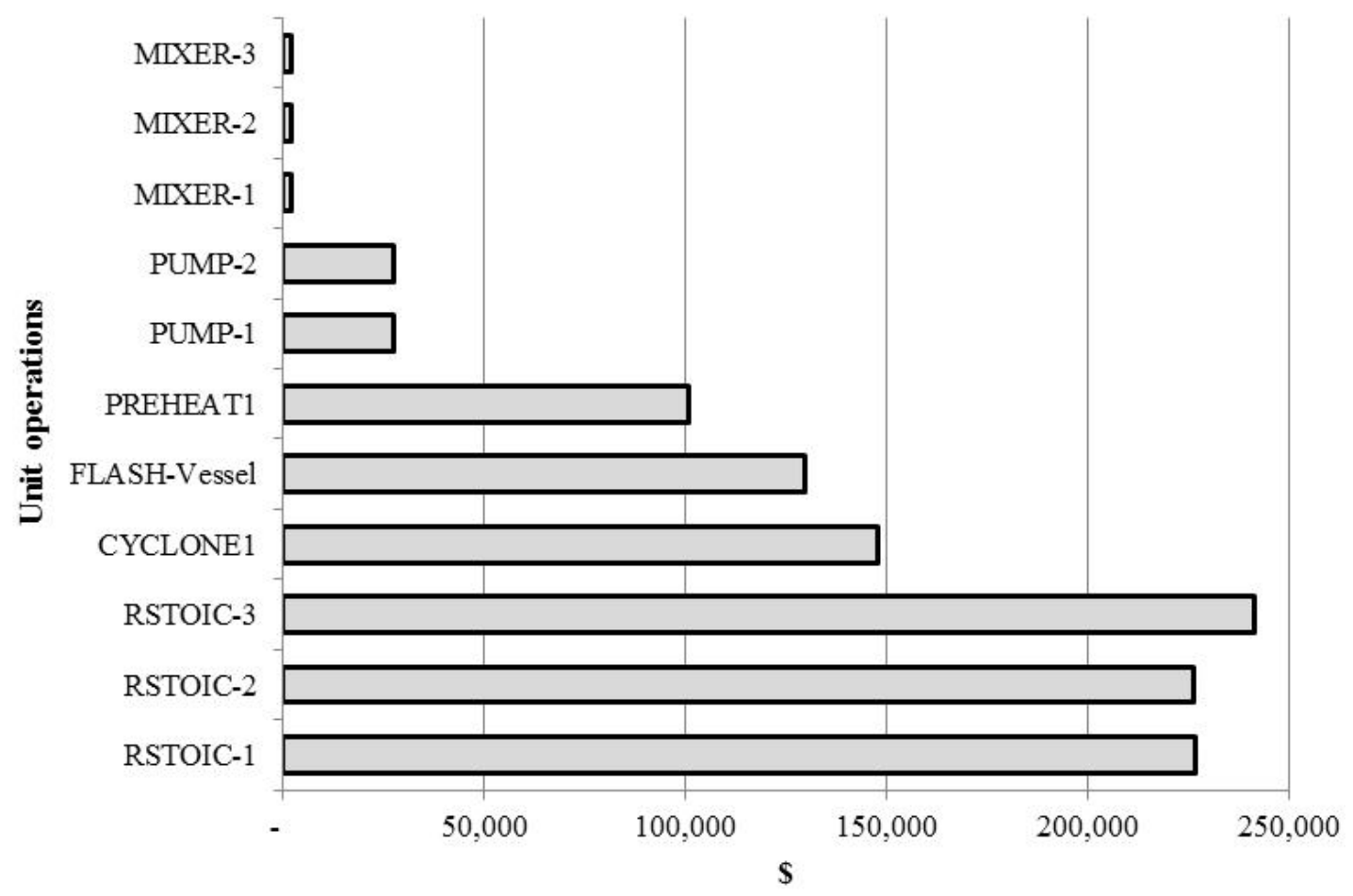

Figure 5-2 Summary of cost components for all equipment used in this facility

Results from the mass balance of this constructed process facility indicate that $2,844 \mathrm{~kg}$ fermentable carbohydrates/hr (see Figure 5-6) could be potentially available for fermentation. Fermentable carbohydrate here refers to all the monomer sugars (glucose, xylose, galactose, arabinose and mannose). Assuming the reported yield of 0.71 for succinic acid (Lennartsson. 2005) it was calculated that approximately, $2004 \mathrm{~kg}$ succinic acid per hour could be theoretically produced after fermentation. Taking into account total plant uptime, capital and operataion cost, about 14,000,000 kg of succinic acid could be produced at a cost of $0.5 \$ / \mathrm{kg}$ succinic acid. 
Wholesale price of succinic acid varies significantly ranging from $2-25 \$ / \mathrm{kg}$ (Alibaba, 2012) depending on grade and intended use. Additional detailed economic analysis such as fermentation, product recovery and purification is required to fully understand the overall cost per production of succinic acid using DCS. However, the high level estimated value of $0.5 \$ / \mathrm{kg}$ succinic acid is promising in terms of making a biorefinery using DCS as a feedstock potentially profitable and attractive.

\subsubsection{GHG results}

Table 5-8 summarizes the GHG impact of this processing facility. Overall, this facility will emit approximately 114,000,000 $\mathrm{kgCO}_{2} \mathrm{e} / \mathrm{yr}\left(114,000 \mathrm{MT} \mathrm{CO}_{2} \mathrm{e} / \mathrm{yr}\right)$. The 2 key drivers were identified to be steam and ammonia contributing 72 and $24 \%$ towards GHG emission respectively. All other inputs contribution with the exception of ammonia and steam to GHG were approximately $4 \%$.

Table 5-8 Summary of GHG results from carbon footprint analysis

\begin{tabular}{|l|l|}
\hline Input data & KgCO \\
\hline $\mathrm{H}_{2} \mathrm{e} / \mathbf{y r}$ \\
\hline $\mathrm{NH}_{4} \mathrm{OH}\left(\mathrm{NH}_{3}\right.$ gas) & $4,980,000$ \\
$\mathrm{NH}_{4} \mathrm{OH}($ Water $)$ & $27,200,000$ \\
\hline Electricity & 815 \\
\hline Steam & 43,000 \\
\hline Water & $82,100,000$ \\
\hline Total & 4,000 \\
\hline
\end{tabular}

\subsection{Conclusions \& recommendations}

The key objectives of this PhD research work are (i) Development of a process design for the production of the both the sugar and amino acid platform via dilute acid pretreatment (ii) A preliminary cost analysis to estimate the initial capital cost and operating cost of this facility using Aspen Plus Economic Analyzer ${ }^{\circledR}$ and (iii) A greenhouse gas analysis to understand the environmental impact of this facility. A conceptual process design has been constructed to produce the carbohydrate and amino acid rich stream. The initial capital cost was estimated to be $\$ 4,700,000$ with 
substantial operational $(\$ 22,100,000)$ and raw material cost $(\$ 19,300,000)$ on an annual basis. This is mainly attributable to the high steam and $98 \mathrm{wt} \% \mathrm{H}_{2} \mathrm{SO}_{4}$ requirement. Finally, GHG emissions from this facility were estimated to be $114,000,000 \mathrm{kgCO}_{2} \mathrm{e} / \mathrm{yr}$ (114,000 MT $\left.\mathrm{CO}_{2} \mathrm{e} / \mathrm{yr}\right)$ with steam and ammonia contributing 72 and 24\% while all other inputs contributed $4 \%$ or less.

\subsection{References}

Alibaba, 2012.Available at: http://www.alibaba.com/showroom/succinic-acid.html Aden A, Foust T. 2009. Technoeconomic analysis of the dilute sulfuric acid and enzymatic hydrolysis process for the conversion of corn stover to ethanol. Cellulose 16(4):535-545.

Adom F, Dunn P, Ruccins S, Shonnard D. 2012a. Optimization of the Protein Hydrolysis Scheme of Defatted Syrup from a Corn Ethanol Dry Mill Facility. Biofuels, Bioproducts and Biorefining (in revisions).

Adom F, Fan J, Davis J, Dunn P, Shonnard D. 2012b. Compositional Analysis of Defatted Syrup from a Corn Ethanol Dry Mill as a Feedstock for Bio-Based Products. Journal of agricultural and food chemistry (in revisions).

Adom F, Fan J, Davis J, Taylor A, Shonnard D. 2012c. Optimization of the Dilute Acid and Enzymatic Pretreatment of Defatted Syrup from a Corn Ethanol Dry Mill. . Biomass and Bioenergy in revisions.

Adom F, Maes A, Workman C, Clayton-Nierderman Z, Thoma G, Shonnard D. 2012d. Regional carbon footprint analysis of dairy feeds for milk production in the USA. The International Journal of Life Cycle Assessment 17(5):520-534.

Agri-Energy. 2012. [updated cited. Available from: http://www.commonwealthagrienergy.com/pricing.

Carlson EC. 1996. Don't gamble with physical properties for simulations. Chemical Engineering Progress 92(10):35-46.

Fasahati P, Liu JJ. 2012. Process simulation of bioethanol production from brown algae. Cellulose 6:6. 
Humbird D, Aden A, Biochemical production of ethanol from corn stover: 2008 state of technology model. National Renewable Energy Laboratory: 2009.

Jayawardhana K, Peter Van Walsum G. 2004. Modeling of carbonic acid pretreatment process using ASPEN-plus R. Applied Biochemistry and Biotechnology 115(1):1087-1102.

Jennings EW, Schell DJ. 2011. Conditioning of dilute-acid pretreated corn stover hydrolysate liquors by treatment with lime or ammonium hydroxide to improve conversion of sugars to ethanol. Bioresource technology 102(2):1240-1245.

Kazi FK, Fortman JA, Anex RP, Hsu DD, Aden A, Dutta A, Kothandaraman G. 2010. Techno-economic comparison of process technologies for biochemical ethanol production from corn stover. Fuel 89:S20-S28.

Lardy G. 2004. Handling Liquid Feed Commodities. NDSU Extension Service. NDSU Department of Animal and Range Sciences.

Lennartsson A. 2005. Production of Succinic Acid by E. coli from Mixtures of Glucose and Fructose. Thesis work 2005. Lulea University of Technology, Div. Biochemical and Chemical Process Engineering.

Lohrasbi M, Pourbafrani M, Niklasson C, Taherzadeh MJ. 2010. Process design and economic analysis of a citrus waste biorefinery with biofuels and limonene as products. Bioresource technology 101(19):7382-7388.

O'Brien D. 2010. Updated trends in U.S wet and dry corn milling production. Kansas State University.

Peris Serrano R. 2012. Biogas Process Simulation using Aspen Plus [Masters]. University of Southern Denmark.

Sassner P, Galbe M, Zacchi G. 2008. Techno-economic evaluation of bioethanol production from three different lignocellulosic materials. Biomass and Bioenergy 32(5):422-430.

Towler G, Sinnott RK, Chemical engineering design: principles, practice and economics of plant and process design. Butterworth-Heinemann: 2012.

Warman International I. Warman Slurry Pumping Handbook [Internet]. 1994. 
Wingren A, Galbe M, Zacchi G. 2008. Techno-Economic Evaluation of Producing Ethanol from Softwood: Comparison of SSF and SHF and Identification of Bottlenecks. Biotechnology progress 19(4):1109-1117.

Wooley RJ, Putsche V, Development of an ASPEN PLUS physical property database for biofuels components. National Renewable Energy Laboratory Golden, CO: 1996. 


\section{Chapter 6}

\section{Regional Carbon Footprint Analysis of Dairy Feeds for Milk Production in the United States 5}

\subsection{Introduction}

The issue of environmental sustainability has become a prominent factor in decisionmaking for industries in addressing environmental challenges, such as global climate change. The United States (U.S.) dairy industry inaugurated a study to analyze greenhouse gas (GHG) emissions from milk production in the U.S. The U.S. dairy milk supply chain can be divided into the following major stages: (a) feed production, (b) milk production, (c) milk delivery to processor, (d) processing, (e) packaging, (f) distribution, (g) retail activities, (h) milk consumption, and (i) disposal. In a comprehensive report, within which this article is a part, each stage was analyzed independently and combined to provide the carbon footprint for the dairy supply chain (Thoma et al. 2012). This article here focuses on the production of dairy feed in the U.S. using sources of data at the level of individual states and then aggregates that information into five dairy regions.

While there have been a number of life cycle assessment (LCA) studies on crops in Europe, there have been relatively few in the U.S. The Ecoinvent ${ }^{\mathrm{TM}}$ (PRé Consultants 2006) database contains many food and forage crop inventory profiles, but these are from European data sources. Hayashi et al. (2006) reviewed the progress of LCA studies in Europe for areas like renewable energy, animal production, and horticulture. In the U.S., there were several LCA studies conducted on single crops such as

\footnotetext{
${ }^{5}$ This chapter has been published as an article in International Journal of Life Cycle Assessment. Figure D-1 shows copyright clearance allowing for use in dissertation. Citation: Adom, F., Maes, A., Workman, C., Clayton-Nierderman, Z., Thoma, G., \& Shonnard, D. (2012). Regional carbon footprint analysis of dairy feeds for milk production in the USA. The International Journal of Life Cycle Assessment, 17(5), 520-534. doi: 10.1007/s11367-012-0386-y
} 
switchgrass, soybeans, and corn associated with bioenergy product analyses, including studies by Kim et al. (2009 a, b), Spatari et al. (2005) Landis et al. (2007), Shapouri et al. (2003), Sheehan et al.(1998), Pradhan et al. (2009) and Rotz et al. (2010). A review of this literature indicated that no previous LCAs considered a large number of crops and dairy feeds, and therefore, our study fills an important gap in the U.S. with respect to updated analyses for agricultural crops and other dairy feeds.

\subsection{Life cycle assessment methodology}

\subsubsection{Dairy feeds, goal, and scope}

In this study, ISO protocols were followed and all GHG emissions were expressed as equivalent emissions of carbon dioxide $\left(\mathrm{CO}_{2} \mathrm{e}\right.$.). Commonly used feeds for U.S. dairy production were identified based on a recent literature source (Mowrey and Spain 1999) and information obtained from a nationwide dairy producer survey regarding the composition of dairy feeds (and other related topics) [(Thoma et al. 2012) - see Tables D-1 through to Table D-10 and Figures D-2 through to D-5)]. Over 5,000 surveys were sent to dairy farmers through their Co-ops from January to May 2009 and a second mailing was conducted in June 2009. Of those surveyed, 531 responded. The main relevancy of this survey to this carbon footprint study was the identification of commonly used dairy feeds in the U.S. Responses from the dairy farmer survey and the collection of other crop data were organized on the basis of five regions as shown in Figure 6-1. The definition of dairy milk production regions was done through consultation with dairy experts (Thoma et al. 2012). The basis for selection of these regions was a combination of production practices and climatic conditions. There are over 130 distinct dairy feedstuffs included in the results of that survey.

Goal: The main goal of this study was to determine the carbon footprint from the cultivation and harvesting of U.S. dairy feeds on a basis of $1 \mathrm{~kg}$ of feed harvested or produced in units of grams $\mathrm{CO}_{2}$ equivalents $\left(\mathrm{gCO}_{2} \mathrm{e}\right) / \mathrm{kg}$ of dry feed. An additional goal was to identify dairy feed inputs with the highest environmental impact to serve as a source of information for improvement in production and as a benchmark against which progress can be measured in the dairy industry. 
Scope: The scope was a cradle-to-farm gate analysis. In this article, we report on grain, forage crops, and other co-products e.g., dried distillers grains with soluble (DDGS) and soybean meal for which inventory data were available from U.S. government and university extension sources. In this study, we did not consider all of the 130 or so dairy feeds identified in the survey by Thoma et al. (2012). Table 6-1 shows the three major categories of dairy feeds considered in this study, including grain crops, forage crops, and co-products. This study includes application of inorganic fertilizers, effects of crop residues, manure application, crop protection chemicals, and energy inputs required for cultivation and harvesting. According to the study by Landis et al. (2007), seed production comprised less than 1\% of GHG emissions for corn and soybean.

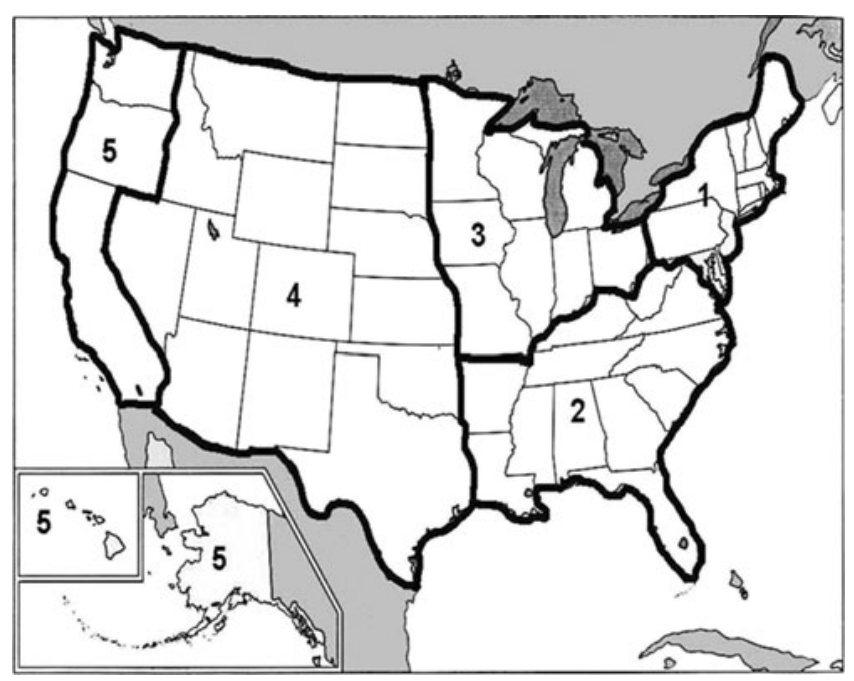

Figure 6-1 Dairy production regions used for this study

This result was generalized for all dairy feeds analyzed in this study by assuming all associated inputs for seed production were below cutoff criteria, and hence were excluded. Also, the scope of this carbon footprint analysis does not include incidental effects such as emissions from employee travel to or from the farm. Infrastructure elements, such as construction of buildings and farm equipment, were also excluded.

\subsubsection{Functional unit}


The functional unit for this carbon footprint study was $1 \mathrm{~kg}$ of dairy feed (grains, forage crops, and other co-products) harvested or processed on dry matter basis.

Table 6-1 Dairy feeds analyzed in this study. Shown in parenthesis are the percentage moisture content for all feed analyzed in this study (NDSU 2011)

\begin{tabular}{|l|l|l|}
\hline Grain Crops & Forage Crops & Co-products \\
\hline & Alfalfa hay (16\%) & \\
Oats (14\%) & Alfalfa silage (16\%) & \\
Soybean (13\%) & Forage mix (16\%) & DDGS, dry mill (10\%) \\
Corn silage (65\%) & Grain mix (15\%) & DDGS, wet mill (60\%) \\
Corn grain (15.5\%) & Grass hay (16\%) & Soybean meal (11\%) \\
Winter wheat (13.5\%) & $\begin{array}{l}\text { Grass pasture (16\%) } \\
\text { Grass silage (16\%) }\end{array}$ & \\
\hline
\end{tabular}

\subsubsection{Geographical boundaries}

The geographical context of this carbon footprint study is the U.S. for dairy feeds grown and produced in the U.S.

\subsubsection{Allocation procedure}

Most dairy feeds produced no co-products, but for certain feeds, it was not possible to avoid allocation. For those feeds, allocations based on market value were used, as shown in Table 6-2. Section 6.3.1 explains the basis for allocation of nitrogen $(\mathrm{N})$ inputs to corn and corn silage. Sections 6.3.1.1 and 6.3.1.2 explain in more detail the economic allocation to soybean oil and meal as well as wet and dried distillers grains with solubles. Five-year average commodity cost data from Illinois were used for economic allocation of soybean oil and meal, which was assumed to be representative of the national commodity market (USDA-IL 2010). Also, mass allocation based on a 5-year average yield provided by the National Oilseeds Processing Association was used for testing scenario cases, while economic allocation was adopted as the base case. Economic and mass allocation values for dried distillers grains with solubles from the thesis by Kodera (2007) were used in this study. 


\subsubsection{Inputs versus inventory data and possible limitations}

Inputs such as fertilizer and fuel used for each crop production system were obtained from U.S. government sources and the U.S. literature. Inventory data underlying those inputs are largely from the Ecoinvent ${ }^{\mathrm{TM}}$ database (PRé Consultants 2006), which mostly represents European production. This presents a possible limitation to this study. However, European inventory data, while not geographically relevant, are technologically relevant for the inputs used in this U.S. study because both U.S. and European production uses modern technology. In addition, inventory data for many study inputs are simply not available yet based on U.S. production.

Table 6-2 Summary of allocation ratios and types used in this study

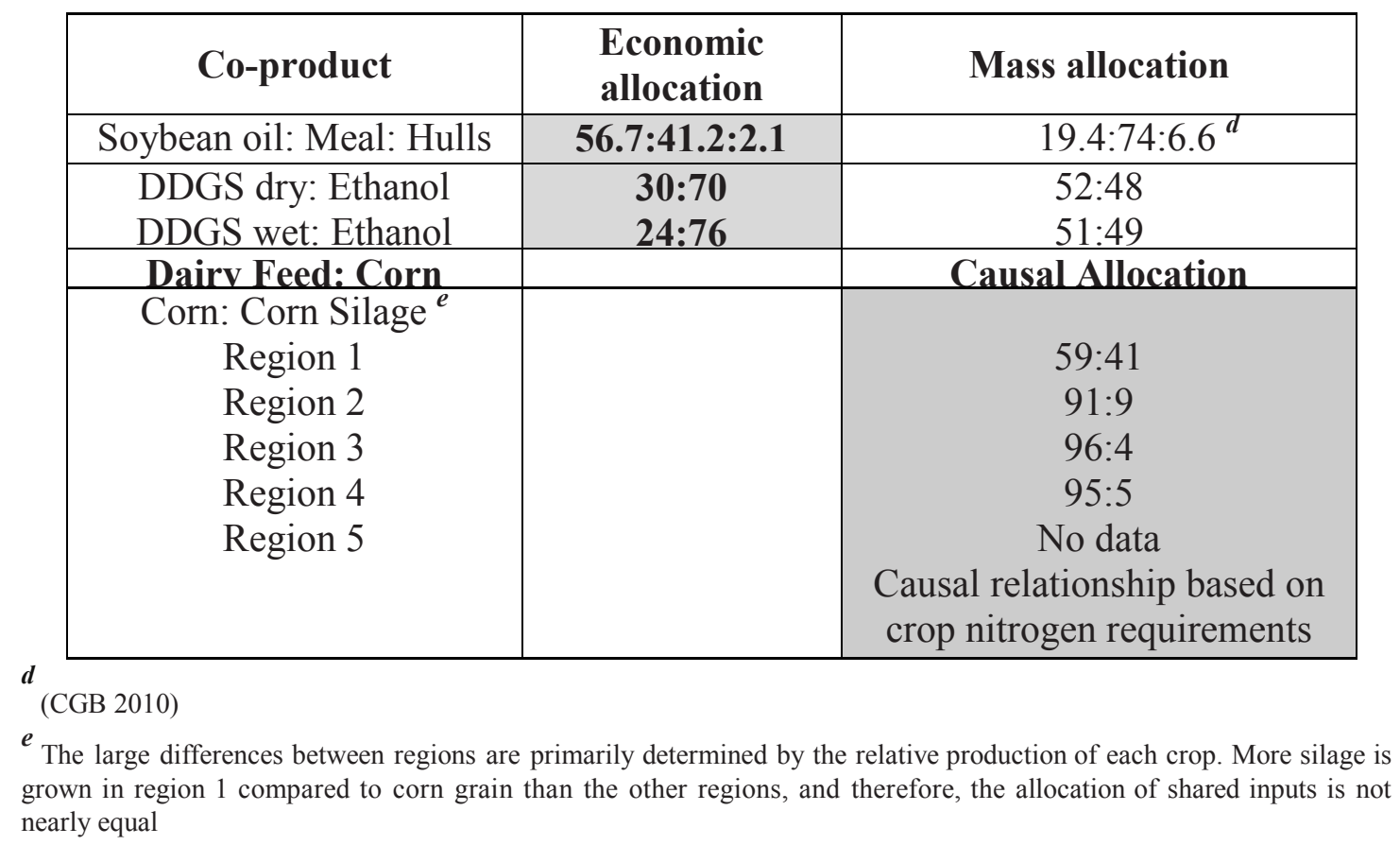

\subsection{Life cycle inventory analysis}

A life cycle diagram describing the key inputs for each crop production system is shown in Figure 6-2. The major inputs included: inorganic and organic fertilizer application on the farm, agrochemicals used to control pests, and farm energy use. Lime application on the farm was considered for some of the crops where data were 
available as well as effects of crop residues on direct and indirect nitrous oxide $\left(\mathrm{N}_{2} \mathrm{O}\right)$ emissions. Energy use included gasoline, diesel, liquefied petroleum gas (LPG), natural gas, and electricity. GHG emissions for this analysis included: carbon dioxide $\left(\mathrm{CO}_{2}\right)$, methane $\left(\mathrm{CH}_{4}\right), \mathrm{N}_{2} \mathrm{O}$, solvents, and refrigerants. Solvents and refrigerants were not directly included as system inputs, rather these were incorporated by the use of Ecoinvent ${ }^{\mathrm{TM}}$ ecoprofiles (PRé Consultants 2006) for the various crop inputs. $\mathrm{N}_{2} \mathrm{O}$ emissions from nitrogen fertilizer application for the degradation of crop residues and manure application were accounted for using guidelines (IPCC 2006) for national GHG inventories (tier 1).

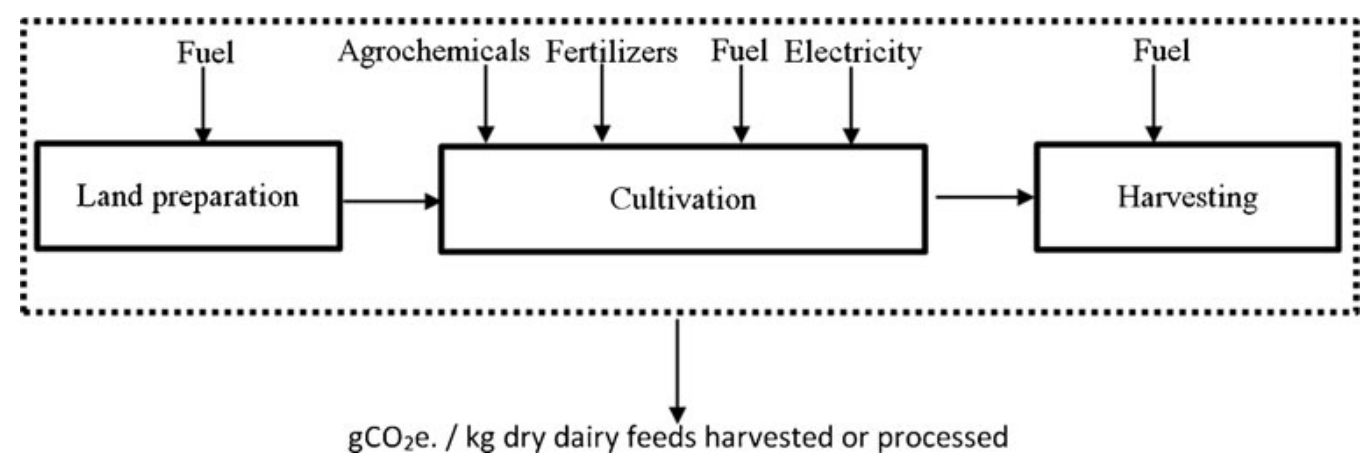

Figure 6-2 Life cycle diagram for the cultivation and harvesting of dairy feed crops. Dotted lines represent the system boundary considered in this carbon footprint analysis

\subsubsection{Production inputs and inventory for grains: corn, oats, soybeans, and winter wheat}

Every year, the U.S. Department of Agriculture (USDA) National Agricultural Statistical Service (NASS) conducts hundreds of farm surveys on cropping practice, chemical use, farm costs, and income. It is usually structured in a three-phase annual survey with specific goals. Phase I screens various farms for commodities and for potential inclusion in phases II and III, and this is done usually on a state-by-state basis. Phase II collects data on chemicals, fertilizer, and pesticides and has only one collection mode-personal interviews via-face-to-face contact. Phase III focuses on detailed economic information about the agricultural operation and the operator's household. Response rate from farmers has been highest for phase II with an average 
response rate of $80 \%$ from 2002 to 2006 and an average sample size of 5,465 (National Research Council 2008).

Table 6-3 summarizes the major crop databases and sources of the dairy grain crops. The USDA NASS databases were the primary source of crop production data for this study. Specific data obtained on a state-by-state basis included area harvested, yield, and total production. Average values for the harvested acres, yield, and production over the 5-year production period (2004-2008) were calculated and used. Annual crop production data for soybean, oats, wheat, corn grain, and silage for the 5-year period were obtained from the crop production summary reports from (USDA NASS 2007a; USDA NASS 2009). Tables D-11 through to D-17 shows the computational spreadsheets of the major crops discussed here (USDA NASS 2006).

Mac Donald et al. (2009) established that about 5\% of U.S. cropland receives animal manure, with corn land receiving over half of this applied manure. The percentage of planted acres receiving manure (manure share) was highest for corn and oats, being $11.6 \%$ and $9 \%$, respectively. For all other grain crops, this area percentage for manure was approximately $1 \%$ or less. Therefore, we assume that only corn and oats receive manure as a fertilizer supplement. Dairy production regions needing supplementation with manure were identified by estimating the growth nitrogen requirements to meet crop production yields and comparing these with reported inorganic nitrogen inputs from the USDA NASS databases. The following sections explain in more details how the manure inputs were determined.

Corn: Combined corn and silage input data for fertilizer and chemical application rates were obtained for states in regions $1,2,3$, and 4 , but no data were reported for region 5. USDA NASS database reported separate productivity data for corn grain and silage. Agrochemical chemical input data such as inorganic fertilizers and herbicides were reported for combined corn and silage land area. Productivity data indicated that region 5 contributed less than $1 \%$ toward the total corn production in the U.S. The 
authors (Mac Donald et al. 2009) in their report on manure usage for fertilizer estimated that 408 million $\mathrm{kg}$ of manure nitrogen was applied to corn grain and silage in the U.S. in 2007. The USDA NASS data for nitrogen application rates do not include manure contributions. In addition, the reported inorganic $\mathrm{N}$ application rates do not meet known crop requirements of approximately $0.54 \mathrm{~kg} \mathrm{~N} / \mathrm{bushel}(\mathrm{bu})$ for corn grain and $5.19 \mathrm{~kg} \mathrm{~N} / \mathrm{mt}$ for silage as defined by numerous crop production budgets. The amount of manure $\mathrm{N}$ required to reach the crop requirement was determined on a state-by-state basis using this equation: manure $\mathbf{N}=$ corn $\mathbf{N}$ growth requirement synthetic $\mathbf{N}$ fertilizer application - residual $\mathbf{N}$ following rotation with soybeans.

Using crop budgets for a corn-soybean rotation, it was estimated that approximately $23 \mathrm{~kg} \mathrm{~N} / \mathrm{ac}$ was supplied in soybean residue (MSU 2010). The organic $\mathrm{N}$ from manure was applied in a manner to force the total $\mathrm{N}$ per crop to match the growth requirements mentioned above. Using a causal allocation based on the crop nitrogen requirements for both grain and silage, other crop inputs were allocated. Table 6-2 shows the allocation ratios used in this model for the various dairy production regions. Using this method, the total manure nitrogen applied to corn was approximately matched to the reported annual application rate of 408 million $\mathrm{kg}$ within a $4 \%$ margin. Specific inputs (e.g., lime) for the various crops are further explained in subsequent sections.

Soybeans In the case of soybeans, the USDA NASS (2009a, 2007 a, b) had data such as quantity of inorganic fertilizer used, area harvested, crop productivity, chemical use, and other information for states in regions 2, 3, and 4. Soybean energy inputs and lime application rate data were obtained from another study Sheehan et al. (1998) and Pradhan et al. (2009), respectively. Inorganic nitrogen input data from USDA NASS (2007b) were included, while manure inputs were not because Mac Donald et al. (2009) reported a manure share of approximately 1\% of acres for soybean. Section 6.3.1.1 provides the sources of inventory data for the soybean meal-oil. The average of the carbon footprint in regions 2, 3, and 4 was used to represent regions 1 and 5 for which there were no data available. 
Table 6-3 Crop databases and data sources for dairy grains

\begin{tabular}{|l|l|}
\hline \multicolumn{2}{|c|}{ Summary of Crop inventory and data source } \\
\hline Soybean \& Soybean meal & \multicolumn{1}{l|}{ Data Sources: } \\
Area harvested /production data & USDA NASS (2009a, 2007a) \\
Fertilizer and agrochemical inputs & USDA NASS (2007b) \\
Lime input & Pradhan et al. (2009) \\
\hline Oats & \\
Area harvested /production data & USDA NASS (2009a, 2007a) \\
Fertilizer and agrochemical inputs & USDA NASS (2006) \\
Lime input & Pradhan et al. (2009) \\
Energy inputs & Dartt and Schwab (2001) \\
\hline $\begin{array}{l}\text { Wheat } \\
\text { Area harvested /production data } \\
\text { Fertilizer and agrochemical inputs } \\
\text { Energy inputs }\end{array}$ & USDA NASS (2009a, 2007a) \\
\hline $\begin{array}{l}\text { Corn } \\
\text { Area harvested /production data }\end{array}$ & Piringer and Steinberg (2006) \\
\hline Fertilizer and agrochemical inputs \\
Energy inputs & USDA NASS (2009a, 2007a) \\
\hline & USDA NASS (2006) \\
Dhapouri et al. (2002)
\end{tabular}

Oats The primary source of data for fertilizer and chemical inputs for oats was from USDA NASS (2006). However, no input data (e.g., inorganic fertilizer and crop protection chemical) were reported for the states in region 2, and this is due to its relatively low oats productivity ( $5 \%$ of oats production). Due to the unavailability of input data for lime application for oat-producing states, the national average lime application rate for soybeans was assumed for the oats analysis (extension documents validated this estimate). Based on the $\mathrm{N}$ requirement recommendation of $0.5 \mathrm{~kg} \mathrm{~N} / \mathrm{bu}$ and $40 \mathrm{~kg} \mathrm{~N} / \mathrm{ac}$ (Beegle 1997), NASS reported inorganic $\mathrm{N}$ input data for dairy production regions 1 and 3 were low, requiring supplementation with manure. The reported inorganic $\mathrm{N}$ input data for regions 4 and 5 were sufficient to meet $\mathrm{N}$ requirement of oats. An estimated $20 \mathrm{~kg} \mathrm{~N} / \mathrm{ac}$ of additional $\mathrm{N}$ from manure meets the reported yields, and this was applied to regions 1 and 3 on a state-by-state basis. This 
method does not take into account any nitrogen credit from prior rotation unlike in the case of manure GHG impact estimation for corn. Section 6.3.5 provides the details on energy inputs. Finally, due to lack of data for region 2, the inventory for this region was estimated by averaging regions $1,3,4$, and 5 .

Winter wheat This study focused on winter wheat because it accounts for $70 \%$ to $80 \%$ of the total wheat produced in the U.S. (USDA NASS 2009b) as compared to other types like durum and spring wheat. Productivity data were obtained from USDA NASS (2009a, 2007a); however, no data were available for the energy inputs on a state-to-state basis. Energy estimates for the production of wheat in the U.S. on a per hectare basis was obtained from Piringer and Steinberg (2006) for the wheat analysis. Manure impact was not considered for wheat primarily because it has less than $1 \%$ of acres applied with manure Mac Donald et al. (2009).

For all crops, input data for fuel and electricity consumption on the farm for crop production were obtained from the technical literature, state agricultural extension services, the U.S. Department of Energy, the USDA, and other academic institutions (see Table 6-3). There are three regional interconnection grids in the U.S., namely, Eastern Interconnection, Western Interconnection, and the Electric Reliability Council of Texas Interconnection. GHG emission factors (in $\mathrm{gCO}_{2} \mathrm{e} / \mathrm{kWh}$ ) were constructed using Ecoinvent ${ }^{\mathrm{TM}}$ unit processes (PRé Consultants 2006) based on regional fuel mixes. Additionally, pre-combustion emissions and the transmission and distribution losses were included in the emission factor using regional interconnection grid data reported by (Deru and Torcellini 2007). Section 6.3.5 of this article explains in more detail the assumptions and data sources for the specific crops for which energy input data were not available.

\subsubsection{Soybean meal-oil-hull allocation}

In the soybean meal analysis, additional processes were considered including transporting soybean to the crusher and crushing to recover oil and meal. The impact of transporting soybean to the crusher was estimated as well as the impact of crushing 
with the use of data obtained from a separate study Sheehan et al. (1998), Pradhan et al. (2009) and Pollak (2010). The crushing and extraction energy required were updated based on a more recent study Pradhan et al. (2009). Allocation to meal and oil were based on economic value of the co-products from price data averaged over 20042008. The primary data source for prices was from Illinois, but is expected to be representative of the national commodity markets during the time period (USDA-IL 2010). Soybean meal allocation factors are shown in Table 6-2.

\subsubsection{Dried distillers grains with solubles}

Articles from the technical literature representing work done by LCA experts with corn ethanol and DDGS were used in this analysis. A thesis by Kodera (2007) performed a review of the effects of allocation method on LCA impacts of corn ethanol production by the dry milling process, for example, mass, energy, and value allocation as well as system expansion. Based on the allocation factor summary in this thesis and another study Kim and Dale (2002), an allocation of the GHG burdens for corn ethanol production was made to DDGS in our model. As shown in Table 6-4, allocation factors varied widely and this resulted in some uncertainty for DDGS carbon footprint analysis. The DDGS GHG emissions values in this table were obtained using the allocation factors shown combined with GHG emissions for corn ethanol from three studies (Wang 2001; Shapouri et al. 2003; Hill et al. 2006) and DDGS production data from Hill et al. (2006). Detailed analysis of wet mill and dry mill DDGS can be found in Tables D-16 and D-17.

\subsubsection{Production inputs and inventory for forage crops: alfalfa, alfalfa silage, grass hay, grass pasture, and grass silage}

To estimate the inventory for cattle forage production, crop production budgets produced by state agriculture extension specialists were collected and used as the primary source of input data. These budgets estimated the inputs needed to produce alfalfa, grass hay, silage, and pasture. These are not actual production records, but estimates prepared by agricultural extension agents with detailed knowledge of agronomic conditions in specific states. For this analysis, inventory data on fuel, 
electricity, fertilizers, soil amendments (N, P, K, sulfur, boron, and lime), and crop protection chemicals were used. When only purchase price for inputs was given, price was converted to quantity using information from budgets published on the same year that provided both price and quantity for the inputs in question. Pesticide application rates varied widely, depending on the type of pesticide. For budgets where only estimated pesticide purchase price was provided, available cost data were used to convert to quantities (Schnitkey 2004). Mac Donald et al. (2009) reported that 6.9\% (manure share) of hay and pasture land received manure as fertilizer. Because the budgets used to create the unit processes for these forage feeds report recommended total organic and inorganic nitrogen application rates together, it was assumed that $6.9 \%$ of the fertilizer applied was in the form of manure. In several cases, budgets provided total quantity of fertilizer, but did not specify the percentage breakdown for each. In this case, a ratio of 20:40:40 NPK for alfalfa was chosen, as it is a nitrogen fixer. For grass, we used 50:25:25.

Some budgets included custom costs for contracted services such as tilling, planting, or harvesting rather than providing explicit input estimates for each of these processes. Using figures from MSU Extension (MSU 2010) that showed custom costs per acre and fuel cost per acre for different practices, it was found that $16 \%$ of custom costs for tillage went to fuel, $12 \%$ to planting, $18 \%$ to fertilizers, and $18 \%$ of harvesting costs went to fuel. Over a 5-year period, a typical field is tilled and planted once, fertilized five times and harvested twice per year $(10 \times)$; thus each practice was weighted by these estimated rates, giving tillage and planting a value of 1 , fertilizing a value of 5 , and harvesting a value of 10 . As a result, a weighted average of $18 \%$ of custom costs was attributed to the consumption of diesel fuel.

There is a large difference in diesel use for hay, silage, and pasture. Most states provided budgets for hay, but fewer for pasture or silage. Using those few states that provided diesel use data for both (primarily regions 2 and 3), the average difference in diesel used to harvest hay or silage per short ton of crop was calculated. We assumed 
the dry matter yield was equivalent for pasture, hay, or silage. The only difference was harvesting and hauling. After finding the mean diesel use for hay for each region, we added $\sim 1$ gal per dry short ton of crop if harvested as silage and subtracted $\sim 3$ gal if kept as pasture.

Table 6-4 Allocation factors and GHG intensity of DDGS (See Tables D-16 and D-17)

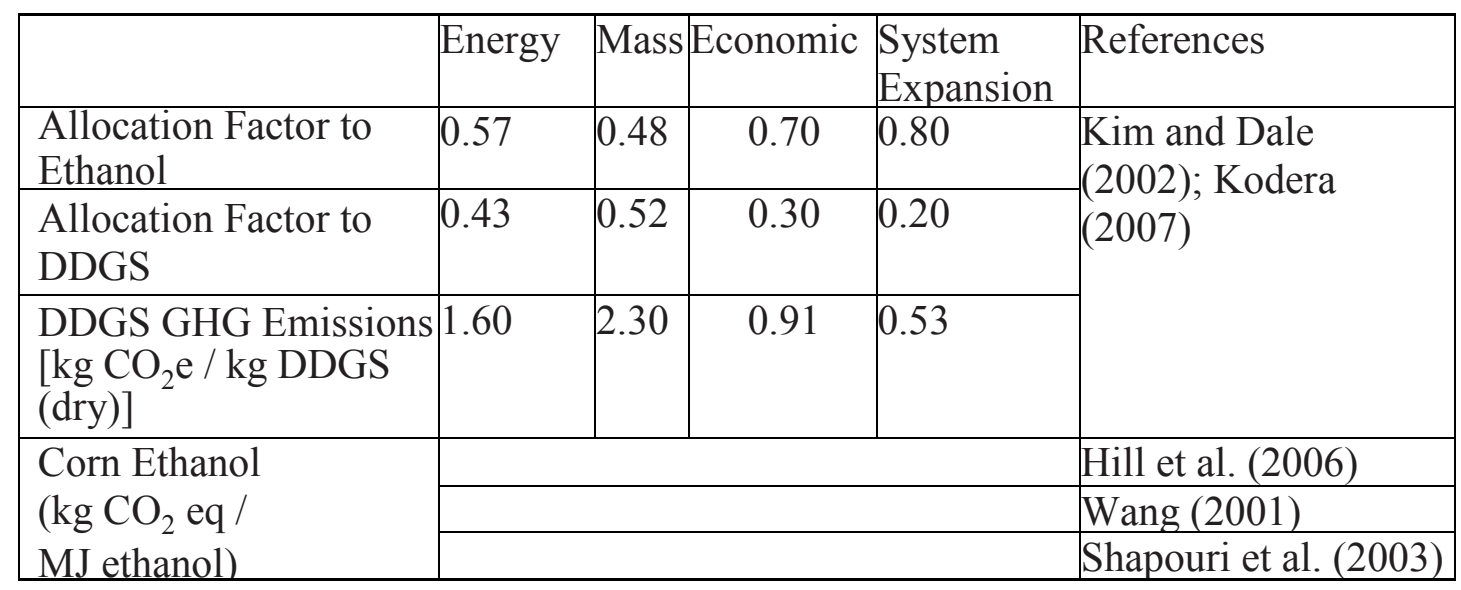

\subsubsection{Direct/indirect $\mathrm{N}_{2} \mathrm{O}$ emissions}

The (IPCC 2006) tier 1 method was used to calculate direct and indirect $\mathrm{N}_{2} \mathrm{O}$ emissions from managed soils for inputs such as synthetic and manure $\mathrm{N}$ fertilizer, $\mathrm{N}$ in crop residues (above and below ground residues) as well as $\mathrm{CO}_{2}$ released by lime and urea-containing fertilizer. Direct $\mathrm{N}_{2} \mathrm{O}$ release was estimated as $1 \%$ of $\mathrm{N}$ applied to soil released as $\mathrm{N}$ in $\mathrm{N}_{2} \mathrm{O}$. For indirect $\mathrm{N}_{2} \mathrm{O}$ emissions, two major pathways were included. The first is the volatilization of $\mathrm{N}$ as $\mathrm{NH}_{3}$ and oxides of $\mathrm{N}$ at a rate of $10 \%$ of applied $\mathrm{N}$, and redeposition of these gases on water bodies where $\mathrm{N}_{2} \mathrm{O}-\mathrm{N}$ is emitted at a rate of $1 \%$ of the redeposited $\mathrm{N}$. Leaching and runoff is the second pathway with a default leaching factor of $30 \%$ of applied $\mathrm{N}$ and an emission factor for $\mathrm{N}_{2} \mathrm{O}-\mathrm{N}$ of $0.75 \%$ of leached $\mathrm{N}$. When urea $\left(\mathrm{CO}\left(\mathrm{NH}_{2}\right)_{2}\right)$ is applied, it can be converted to ions like ammonium $\left(\mathrm{NH}_{4}{ }^{+}\right)$and bicarbonate $\left(\mathrm{HCO}_{3}{ }^{-}\right)$in the presence of urease enzymes and release $\mathrm{CO}_{2}$. GHG emission from lime application is dealt with in Section 6.3.6. In this study, dinitrogen monoxide $\left(\mathrm{N}_{2} \mathrm{O}\right)$ emissions for manure application is a 
combination of direct and indirect mechanisms as discussed above (see Tables D-18, D-19 and D-20) including emissions from manure management systems (MMS).

The USDA NASS database does provide $\mathrm{N}$ fertilizer input data for crops (see Table 63); however, this database does not indicate the type of nitrogen fertilizer applied to crops. The production of different nitrogen fertilizers results in very different quantities of GHG emissions from their production. Therefore, an average US nitrogen fertilizer production profile was created for this study. Data on fertilizer consumption in the U.S. from the period of 2004-2007 was obtained and used to create the synthetic $\mathrm{N}$ ecoprofile for this analysis (see Tables D-21 and D-22). One of the $\mathrm{N}$ fertilizers, nitrogen solutions, was comprised of urea (35\%), ammonium nitrate (40\%), and water (25\%) (Dyno Nobel Inc ; Vitosh 1996).

For phosphorus fertilizer, a similar approach as for $\mathrm{N}$ fertilizer was taken by basing the mixture of phosphate fertilizers in proportion to their U.S. production (USDA ERS 2009) as reported in Table D-23. Potassium and sulfur fertilizers as well as lime were treated similarly.

\subsubsection{Crop protection chemicals}

Insecticides, herbicides, and fungicides applied on the farm were considered in our analysis. In cases where the ecoprofile of a pesticide was not found in the Ecoinvent ${ }^{\mathrm{TM}}$ database in SimaPro 7.1@ (PRé Consultants 2006), the chemical class was used. For instance, tebupirimphos which was not directly listed in the Ecoinvent ${ }^{\mathrm{TM}}$ database belongs to the organophosphorous class of compounds (PAN Pesticides Database 2009) and this was the ecoprofile used in our model. Rate of crop protection chemical application for soybean and winter wheat were all obtained from USDA NASS (2007b) while that of corn and oats were obtained from USDA NASS (2006). Forage crop protection data were obtained from state extension budgets as mentioned earlier.

\subsubsection{On-farm energy}


This analysis accounted for the following energy inputs on the farm: electricity, gasoline, diesel, LPG, and natural gas. Due to the lack of energy input information in the USDA NASS database, other sources were used to fill in the required data for the crop analysis. Energy input data for forage energy were from state extension documents as mentioned previously. Soybean energy input data were obtained from Sheehan et al.(1998) and represented 14 soybean-producing states, which together accounted for about $86 \%$ of the soybean produced in the U.S. Additionally, energy input data for corn producing states were obtained from Shapouri et al.(2003) and represented about $80 \%$ of corn produced in the U.S. In the case of oats, data for diesel use were obtained from Dartt and Schwab (2001). Due to lack of data on gasoline consumption for oats cultivation and harvesting, it was assumed that gasoline consumption was equal to one third of diesel consumption, based on diesel and gasoline inputs for other field crops, for example corn and soybeans. To fill data gaps, LPG and electricity inputs for corn and soybean were then averaged on a regional basis and used as an estimate for oats. Energy estimates for production of wheat in the USA on a per hectare basis was obtained from another study Piringer and Steinberg (2006).

\subsubsection{Lime application}

Lime application rates for soybean were obtained from Pradhan et al. (2009. In the case of oats, the national average of lime application rate for soybeans was assumed, which in our study (358 lb lime/acre) falls within the recommended range from two budgets that were obtained from KSU (2003) and Crozier et al. (2004). Lime application data for corn grain and silage were estimated using a crop production budget (MSU 2010). While data on lime application rate were not available for wheat production, it appeared that lime was seldom used. For example, only $9 \%$ of wheat land area has ever been treated with lime based on a 1997 survey by USDA (Heimlich 2003). According to a U.S. Geological Survey (USGS 2007) approximately 10.8 billion and 32 million $\mathrm{kg}$ of limestone and quicklime were applied in the U.S. agricultural sector, respectively. As a result, every kilogram of an average U.S. lime 
comprises $0.997 \mathrm{~kg} \mathrm{CaCO}_{3}$ and $0.003 \mathrm{~kg}$ of $\mathrm{CaO}$. Final $\mathrm{GHG}$ intensity of lime accounts for both the production and its application on the field. Due to the on-farm application of calcium carbonate to acidic soils, $\mathrm{CO}_{2}$ is released, which was accounted for in this study using the emission factor from the IPCC (2006) (see Section 6.3.8 for emission factor).

\subsubsection{Crop residue effects on direct/indirect $\mathrm{N}_{2} \mathrm{O}$ emissions}

In this study, the 2006 IPCC guidelines for national GHG inventories (tier 1) was used to account for the $\mathrm{N}_{2} \mathrm{O}$ emissions from the degradation of crop residues above and below ground. The average regional yields for various dairy feeds were converted on a dry weight basis to obtain a kilogram dry crop per harvested area. In addition, other parameters like the $\mathrm{N}$ content and weight of dry matter residue above and below ground allowed for the final estimation of kilogram $\mathrm{N}$ above and below ground of crop residue per kilogram of crop harvested. Tables D-24 through to D-28 shows the detailed analysis of $\mathrm{N}_{2} \mathrm{O}$ emissions of crop residues.

\subsubsection{Emission factors for fertilizer, crop protection chemicals, and energy input}

The emission factors are shown in Table 6-5 for the production and use of various fertilizers, lime, and energy inputs. Emission factors for pesticides are listed in the Tables D-29 through to D-32.

Table 6-5 Emission Factors for Farm Input: Fertilizer, agro-chemical and energy

\begin{tabular}{|c|c|c|c|c|}
\hline Farm & \multicolumn{3}{|r|}{ Emission Factors } & Sources \\
\hline \multirow[t]{2}{*}{ : } & $\mathrm{N}$ & $\begin{array}{l}3.871 \\
0.633 \\
6.205\end{array}$ & $\begin{array}{l}\mathrm{kg} \mathrm{CO} \mathrm{CO}_{2} \text { eq/kg N in U.S mix N fertilizer } \\
\text { due to manufacturing of } \mathrm{N} \text { fertilizer } \\
\mathrm{kg} \mathrm{CO} \mathrm{CO}_{2} \text { eq/kg N in U.S urea in U.S mix of } \\
\mathrm{N} \text { fertilizer due to field emissions } \mathrm{CO}_{2} \\
\mathrm{~kg} \mathrm{CO} \mathrm{CO}_{2} \text { eq/ } / \mathrm{kg} \mathrm{N} \text { in U.S mix of } \mathrm{N} \text { fertilizer } \\
\text { due to direct and indirect } \mathrm{N}_{2} \mathrm{O} \text { field emissions }\end{array}$ & $\begin{array}{l}\text { USDA ERS } \\
\text { IPCC (2006) } \\
\text { EcoInvent } \\
\text { database } \\
\text { (SimaPro) }\end{array}$ \\
\hline & $\bar{P}$ & 3.028 & $\begin{array}{l}\mathrm{kg} \mathrm{CO} \mathrm{CO}_{2} \mathrm{eq} / \mathrm{kg} \text { P in U.S mix P fertilizer due } \\
\text { to manufacturing of P fertilizer (applied as P) }\end{array}$ & $\begin{array}{l}\text { USDA ERS } \\
\text { EcoInvent } \\
\text { database } \\
\text { (SimaPro) }\end{array}$ \\
\hline
\end{tabular}




\begin{tabular}{|c|c|c|c|c|}
\hline & \multicolumn{2}{|r|}{ K } & $\begin{array}{l}0.573 \mathrm{~kg} \mathrm{CO}_{2} \mathrm{eq} / \mathrm{kg} \mathrm{K} \text { in U.S mix K fertilizer due to } \\
\text { manufacturing of K fertilizer }\end{array}$ & $\begin{array}{l}\text { USDA ERS } \\
\text { EcoInvent } \\
\text { database } \\
\text { (SimaPro) }\end{array}$ \\
\hline & & $\mathrm{S}$ & $3.855 \mathrm{~kg} \mathrm{CO}_{2} \mathrm{eq} / \mathrm{kg} \mathrm{S}$ in fertilizer & $\begin{array}{l}\text { EcoInvent } \\
\text { database } \\
\text { (SimaPro) }\end{array}$ \\
\hline 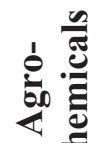 & & Lime & $\begin{array}{l}0.0158 \mathrm{~kg} \mathrm{CO}_{2} \mathrm{eq} / \mathrm{kg} \mathrm{lime} \text { due to manufacturing } \\
0.4400 \mathrm{~kg} \mathrm{CO}_{2} / \mathrm{kg} \mathrm{CaCO}_{3} \text { due to application on farm }\end{array}$ & $\begin{array}{l}\text { USGS } \\
(2007)^{g}\end{array}$ \\
\hline \multirow{9}{*}{ 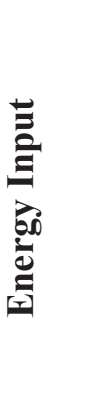 } & \multirow{4}{*}{$\underset{\Xi}{\Xi}$} & Gasoline & $10.96 \mathrm{~kg} \mathrm{CO}_{2}$ eq./gallon & \multirow{4}{*}{$\begin{array}{l}\text { Deru \& } \\
\text { Torcellini } \\
(2007) \\
\text { SEIT (2006) }\end{array}$} \\
\hline & & Diesel & $11.89 \mathrm{~kg} \mathrm{CO}_{2}$ eq./gallon & \\
\hline & & $\mathrm{LPG}^{\mathbf{h}}$ & $7.66 \mathrm{~kg} \mathrm{CO}_{2}$ eq./gallon & \\
\hline & & $\mathrm{NG}^{\mathrm{i}}$ & $7.72 \mathrm{~kg} \mathrm{CO}{ }_{2}$ eq. $/ \mathrm{CCF}$ & \\
\hline & \multirow{5}{*}{ 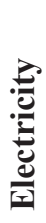 } & U.S Region & $\mathrm{kg} \mathrm{CO} \mathrm{Cq}_{2} / \mathrm{kWh}$ & Sources \\
\hline & & U.S Avg ${ }^{j}$ & 0.823 & \multirow{4}{*}{$\begin{array}{l}\text { Deru \& } \\
\text { Torcellini } \\
\text { (2007) }\end{array}$} \\
\hline & & Eastern & 0.867 & \\
\hline & & Western & 0.653 & \\
\hline & & ERCOT & 0.928 & \\
\hline
\end{tabular}

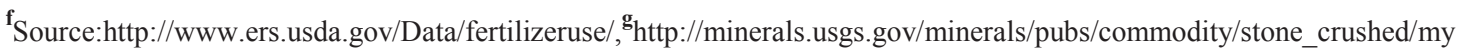
b1-2007-stonc.xls \& http://minerals.usgs.gov/minerals/pubs/commodity/lime/myb1-2007-lime.xls, ${ }^{\text {LPG: Liquefied }}$ Petroleum Gas, ERCOT: Electric Reliability Council of Texas, ${ }^{\mathbf{i}} \mathrm{NG}$ : Natural Gas, ${ }^{\mathbf{j}}$ Avg: Average

\subsubsection{Data quality}

The pedigree matrix derived from Frischknecht et al. (2007) was used to assess the quality of data, primarily fertilizer and other $\mathrm{N}_{2} \mathrm{O}$ emissions, crop protection chemicals, and energy inputs. Six characteristics of data quality were included: reliability, completeness, temporal correlation, geographic correlation, further technological correlation, and sample size. This was done by assigning a set of scores from 1 to 5 after a careful analysis of each data source (see Tables D-33 through to D-44). Using some basic uncertainty $\left(\mathrm{U}_{7}\right)$ factors provided in Table 7.2 of Frischknecht et al. (2007) and assessing the data sources according to the six characteristics mentioned above, the square of geometric standard deviation $\left(\mathrm{SD}_{\mathrm{g} 95}\right)$ was calculated using the equation below $\left(\mathrm{SD}_{\mathrm{g} 95}\right)$ : For calculating $\mathrm{SD}_{\mathrm{g} 95}$

$$
S D_{g 95}=\sigma_{g}^{2}=\exp ^{\sqrt{\left[\ln \left(U_{1}\right)\right]^{2}+\left[\ln \left(U_{2}\right)\right]^{2}+\left[\ln \left(U_{3}\right)\right]^{2}+\left[\ln \left(U_{4}\right)\right]^{2}+\left[\ln \left(U_{5}\right)\right]^{2}+\left[\ln \left(U_{6}\right)\right]^{2}+\left[\ln \left(U_{7}\right)\right]^{2}}}
$$


where $U_{1}=$ uncertainty factor of reliability, $U_{2}=$ uncertainty factor of completeness, $U_{3}=$ uncertainty factor of temporal correlation, $U_{4}=$ uncertainty factor of geographic correlation, $U_{5}=$ uncertainty factor of other technological correlation, $U_{6}=$ uncertainty factor of sample size, and $\mathrm{U}_{7}=$ basic uncertainty factor.

By assuming a log-normal distribution of uncertainty, the estimated $\mathrm{SD}_{\mathrm{g} 95}$ was used to calculate an upper and a lower bound of the $95^{\text {th }}$ percentile confidence interval for the various dairy feeds on a national basis (Table 6-6). The geometric mean (in micrograms) was used to estimate the lower and upper bound $\left(\mathrm{gCO}_{2} \mathrm{e} / \mathrm{kg}\right.$ feed) using equations below (Frischknecht et al. 2007). Equations below were used for calculating the lower and upper bound values of carbon footprint.

$$
\text { Upperbound }=\mu_{g} \times \sigma_{g}^{2}
$$

$$
\text { Lowerbound }=\frac{\mu_{g}}{\sigma^{2}}
$$

\subsection{Life cycle greenhouse gas impact assessment and interpretation of results}

\subsubsection{General assumptions for life cycle impact analysis}

In estimating the carbon footprint, the $\mathrm{GHG}$ emissions were converted to $\mathrm{CO}_{2}$ equivalents using global warming potentials (GWP) in the "IPCC 2006 100a" method in SimaPro 7.1@ (PRé Consultants 2006); GWP is 1 for $\mathrm{CO}_{2}, 298$ for $\mathrm{N}_{2} \mathrm{O}$, and 25 for $\mathrm{CH}_{4}$ (Forster et al. 2007). The effects of other greenhouse gases emitted in minor amounts such as refrigerants, halons, and certain chlorinated solvents were also accounted for.

\subsubsection{Regional greenhouse gas emissions of dairy feeds}

Table 6-6 summarizes the regional GHG emissions of dairy feeds on a per dry kilogram basis. Careful examination of the table reveals that there is significant variability among the regions for several feeds. Nearly all of the highest values are associated with region 2, and this appears to be driven primarily by greater nitrogen 
and lime inputs. The exception is the production of oats in region 5, which is nearly double the lowest value. This is as a result of much higher application rates for $\mathrm{N}$ reported in California; approximately three times the rates applied in other areas. This is partially offset by larger yields; however, the yield is only 1.5 to 1.7 times that of other regions. Grass has a higher carbon footprint than other forage crops and nearly as high as corn grain. Regional results for each feed analyzed were combined to estimate the national carbon footprint (see Table 6-6). Overall, processed co-products like wet mill and dry mill DDGS and soybean meal show higher GHG emissions.

Results in Table 6-6 can be compared to recent literature values, though some of these studies occurred in different geographic contexts. Landis et al. (2007) modeled the agro-system material flows for U.S. corn and soybean by employing the greenhouse gases, regulated emissions, and energy use in transportation (GREET) model. The following results were obtained by Landis et al. (2007): 310-680 $\mathrm{gCO}_{2} \mathrm{e} / \mathrm{kg}$ of dry corn and $120-290 \mathrm{gCO}_{2} \mathrm{e} / \mathrm{kg}$ of dry soybean. The carbon footprint results for corn and soybean at the farm stage from GREET (2010) were 290 and $200 \mathrm{gCO}_{2} \mathrm{e} / \mathrm{kg}$ of dry crop, respectively. Two separate studies by Kim and Dale (2009a-40 counties in the U.S.) and Kim et al. (2009b-eight counties in the U.S.) estimated $360 \pm 100$ and $540 \pm 290 \mathrm{gCO}_{2} \mathrm{e} / \mathrm{kg}$ of dry corn grain, respectively, for U.S. corn-producing counties. In our study, the national carbon footprint of corn grain was estimated to be $390 \mathrm{gCO}_{2} \mathrm{e} / \mathrm{kg}$ of dry corn grain, with upper and lower bounds of 270 and $560 \mathrm{gCO}_{2} \mathrm{e} / \mathrm{kg}$ of dry corn grain. Additionally, a value of $300 \mathrm{gCO}_{2} \mathrm{e}$ was estimated for $1 \mathrm{~kg}$ dry corn at field using the United States Life Cycle Inventory database in SimaPro (PRé Consultants 2006). The GHG emissions of $1 \mathrm{~kg}$ corn silage at the farm gate for the Swiss production processes using Ecoinvent Database was $190 \mathrm{gCO}_{2} \mathrm{e} / \mathrm{kg}$ of dry corn silage, a value close to corn silage for our study in Table 6-6. A value of $620 \mathrm{gCO}_{2} \mathrm{e} / \mathrm{kg}$ dry soybean was obtained from the Denmark LCA food database in SimaPro (Denmark LCA Food 2011 and PRé Consultants 2009). Dalgaard et al. (2008), using the EDIP 97 database (a Danish LCA methodology) in SimaPro 
(PRé Consultants 2006), analyzed the GWP of $1 \mathrm{~kg}$ (dry) of soybean meal to be 721 $\mathrm{gCO}_{2} \mathrm{e}$ while Pelletier (2008) in the study of the environmental performance in the U.S. broiler poultry sector estimated $297 \mathrm{gCO}_{2} \mathrm{e}$.

Table 6-6 Cradle to farm gate carbon footprint results of commonly used feeds by region and on national basis ( $\mathrm{g} \mathrm{CO}_{2} \mathrm{e}$. / $\mathrm{kg}$ dry feed).

\begin{tabular}{|c|c|c|c|c|c|c|c|c|}
\hline & \multicolumn{5}{|c|}{ Production Region } & \multirow[b]{2}{*}{$\begin{array}{l}\text { Lower } \\
\text { bound }\end{array}$} & \multirow[b]{2}{*}{$\begin{array}{l}\text { Central } \\
\text { bound } \\
(\text { Geometric } \\
\text { mean) })^{\mathbf{k}}\end{array}$} & \multirow[b]{2}{*}{$\begin{array}{l}\text { Higher } \\
\text { bound }\end{array}$} \\
\hline & 1 & 2 & 3 & 4 & 5 & & & \\
\hline Alfalfa hay & 190 & 270 & 140 & 140 & 150 & 140 & 170 & 210 \\
\hline Alfalfa silage & 200 & 280 & 150 & 150 & 160 & 150 & 180 & 220 \\
\hline Corn grain & 360 & 440 & 370 & 440 & 400 & 270 & 390 & 560 \\
\hline Corn silage & 160 & 260 & 190 & 220 & 210 & 140 & 200 & 290 \\
\hline DDGS, dry mill & 910 & 910 & 910 & 910 & 910 & 590 & 910 & 1400 \\
\hline DDGS, wet mill & 670 & 670 & 670 & 670 & 670 & 430 & 670 & 1400 \\
\hline Forage mix & 160 & 260 & 140 & 140 & 150 & 130 & 160 & 200 \\
\hline Grain mix & 530 & 590 & 520 & 570 & 550 & 450 & 550 & 670 \\
\hline Grass hay & 300 & 470 & 280 & 270 & 330 & 260 & 320 & 390 \\
\hline Grass pasture & 240 & 410 & 250 & 220 & 280 & 130 & 270 & 560 \\
\hline Grass silage & 310 & 480 & 290 & 280 & 340 & 270 & 330 & 410 \\
\hline Oats & 800 & 800 & 580 & 1000 & 1140 & 580 & 850 & 1240 \\
\hline Soybean & 410 & 520 & 330 & 390 & 410 & 270 & 390 & 580 \\
\hline Soybean meal & 460 & 540 & 400 & 430 & 450 & 420 & 460 & 490 \\
\hline Winter wheat & 380 & 400 & 510 & 500 & 390 & 300 & 430 & 600 \\
\hline
\end{tabular}

For crops with data presented in bold, no data for production was available; the average of results from other regions was adopted. ${ }^{\mathbf{k}}$ The geometric mean represents the US national greenhouse gas profiles for the various dairy feed with their respective ranges (lower/upper bound) estimated using the square of geometric standard deviation.

Finally, another European study by Van der Werf et al. (2005) estimated the GHG emissions for the production of $1 \mathrm{~kg}$ of wheat and barley to be 375 and $400 \mathrm{gCO}_{2} \mathrm{e} / \mathrm{kg}$ of dry crop, respectively, while the Denmark LCA food database (PRé Consultants 2006) estimates 710 and $570 \mathrm{gCO}_{2} \mathrm{e}$ for $1 \mathrm{~kg}$ of dry wheat and oats, respectively. Taking into account the differences in modeling tools, study scope, and geographical context for the different studies, results from the literature are generally comparable to those obtained in this study. The following sections will display the results in more 122 
detail with regard to the relative importance of specific crop life cycle stages and inputs.

\subsubsection{Soybean}

Soybean showed a lower carbon footprint than some crops due to lower inorganic nitrogen fertilizer application, and this was largely due to the fact that it is a nitrogenfixing crop. However, significant contributors to the various regional results are: lime application, gasoline, diesel, and $\mathrm{N}_{2} \mathrm{O}$ emissions from soybean residues, as shown in Figure 6-3. Together, they contributed about $70-86 \%$ of the overall GHG emissions in each productive dairy region. Interesting was the relative impact of lime input on the overall regional footprints. Lime input data for regions 2 and 3 for the soybeanproducing states were relatively comprehensive $(60 \%$ and $100 \%$ of states reporting, respectively). For region 4, data for lime application were available for just two states out of the six soybean-producing states. Another probable reason could have been the acidic nature of soils in regions 2 and 3 requiring more lime to increase soil $\mathrm{pH}$ for plant growth.

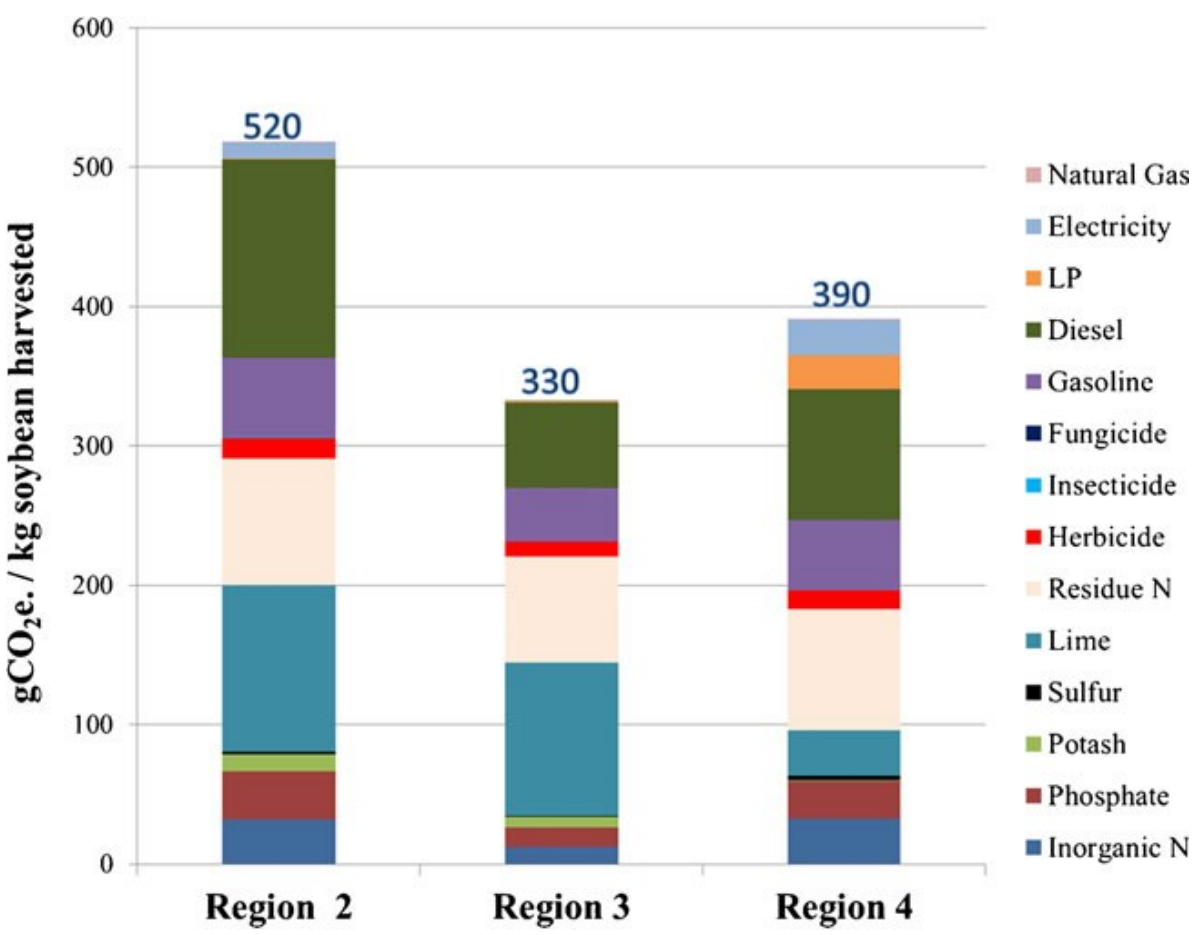

Figure 6-3 Carbon footprint profile of soybeans harvested in the U.S. 
Emissions of $\mathrm{N}_{2} \mathrm{O}$ from crop residues were large compared to $\mathrm{N}_{2} \mathrm{O}$ released from the application of $\mathrm{N}$ fertilizers for soybeans, a distinctly different feature compared to other crops. Approximately $65 \%$ of GHG emissions from $\mathrm{N}$ fertilizers were due to field application, with about 35\% from manufacture, as also seen from the data in Table 6-5. Although it was not exactly clear why the states in the midwest (region 3) used relatively lower amounts of diesel, one possible reason was the effect of the Midwest Clean Initiative Diesel (EPA, 2011) which encourages operational changes, technological improvements, and use of cleaner fuels for powering equipment. Finally, using the pedigree matrix, the standard deviation with $95 \%$ confidence interval for inorganic fertilizer, crop protection chemicals, and energy inputs was estimated to be $1.51,1.21$, and 1.57, respectively (see Table D-43).

\subsubsection{Oats}

The major contributors to the oats carbon footprint in the U.S. (Figure 6-4) were identified to be inorganic nitrogen and phosphate fertilizers, manure, lime application, diesel, and the impact of $\mathrm{N}_{2} \mathrm{O}$ emissions from oat residues, which together makes up approximately $72-92 \%$ of the overall footprint in each region.

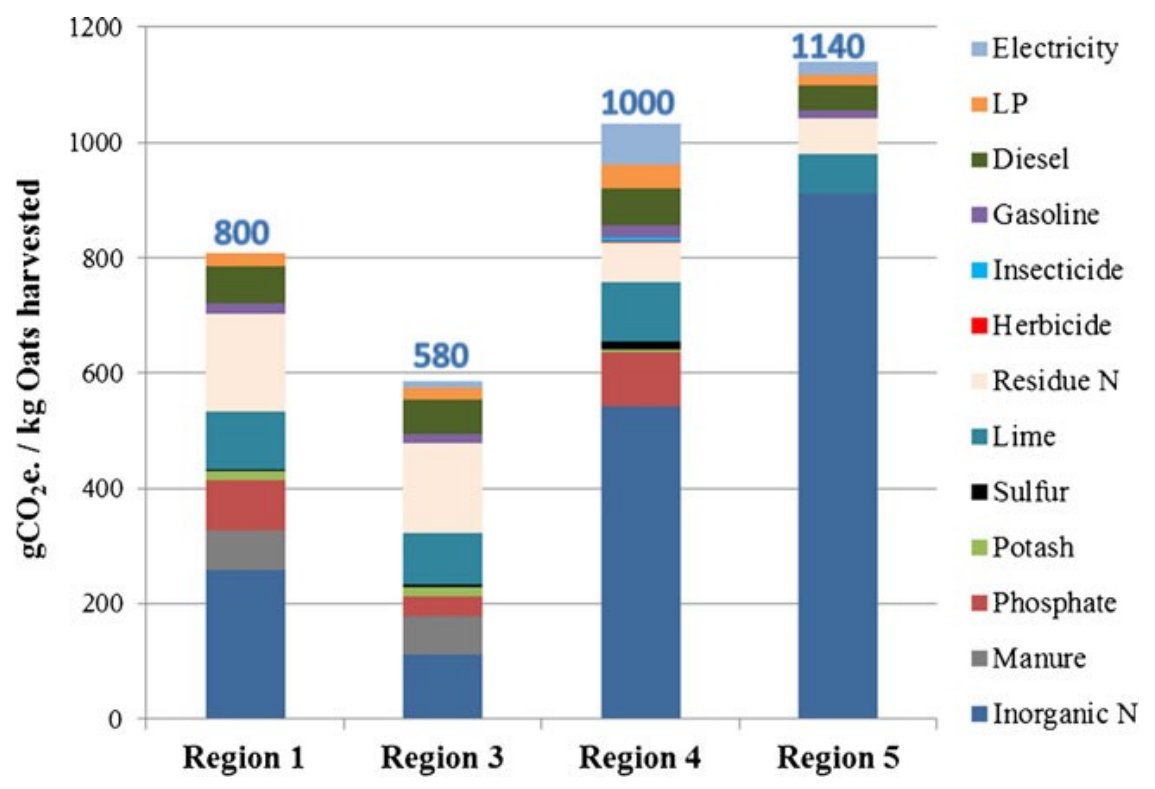

Figure 6-4 Carbon footprint profile of Oats harvested in the U.S 
The regional variation in carbon footprint was due to the impact of fertilizer application rate. For example, dairy region 5 shows an unusually high carbon footprint of $1,100 \mathrm{gCO}_{2} \mathrm{e} / \mathrm{kg}$ of oats harvested, due to high fertilizer $\mathrm{N}$ application. Furthermore, results from California in region 5 may not be representative of the other states in this region. About $65 \%$ of inorganic $\mathrm{N}$ fertilizer GHG emissions was from field application and 35\% was due to manufacture. The impact of crop residues remains fairly constant across the various regions for oats, contributing about $9 \%$ on national average towards the carbon footprints reported. However, the use of manure to supplement inorganic fertilizers in regions 1 and 3 contributed $21 \%$ and $26 \%$, respectively, towards the regional footprints. Finally, in the case of oats, the standard deviation with 95\% confidence for inorganic fertilizer, chemical protection, and energy inputs was estimated to be 1.51, 1.24, and 1.36, respectively (see Table D-43).

\subsubsection{Corn grain and silage}

Inorganic fertilizers, manure, phosphates, lime, diesel as well as the impacts of grain drying and $\mathrm{N}_{2} \mathrm{O}$ emissions due to residues contributed approximately $80-90 \%$ towards the regional carbon footprint of corn grain (see Figure 6-5).

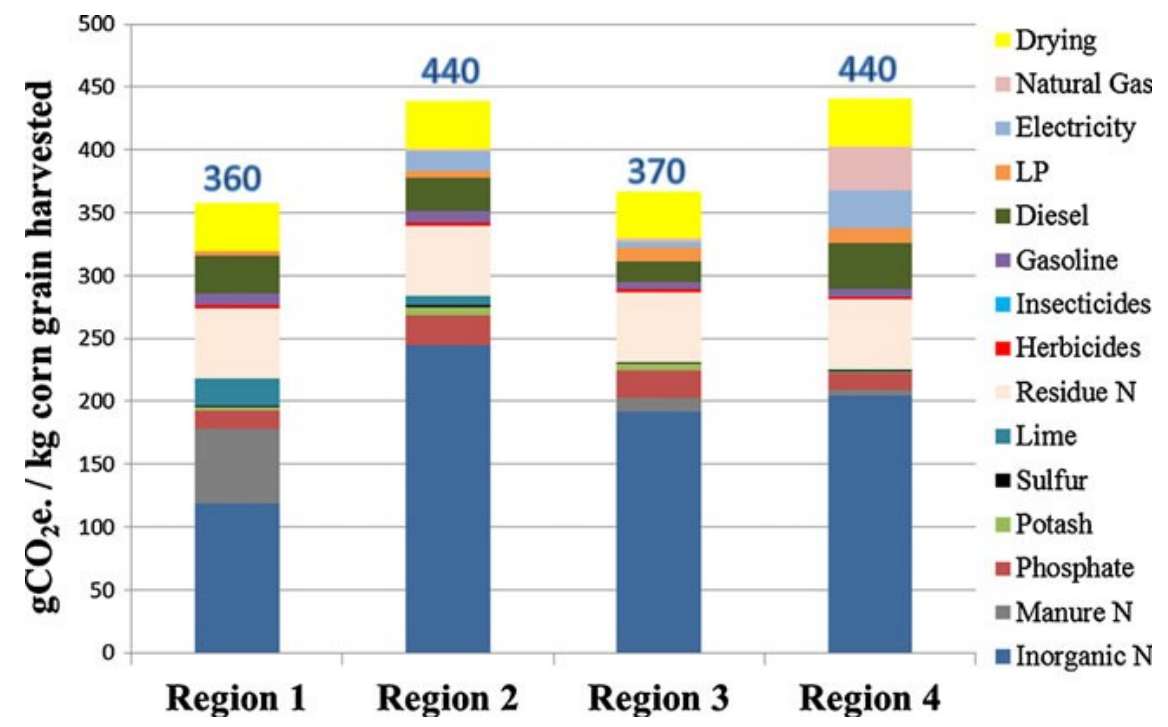

Figure 6-5 Carbon footprint profile of Corn grain harvested in the U.S

In the corn silage analysis in Figure 6-6, inorganic fertilizers, manure, phosphates, 
lime, diesel as well as the impacts of drying and $\mathrm{N}_{2} \mathrm{O}$ emissions due to residues contributed about $73-90 \%$ towards the corn silage footprint for each dairy region. The contribution of the MMS to the GHG emissions for both crops was small (always $<2 \%$ ). Generally, the GHG emissions for corn grain with respect to the various dairy regions were about two times greater than for the corn silage. The comparatively larger emissions for corn grain compared to silage were mainly due to the allocation method applied from Section 7.3.1, under "Corn". Figure 6-5 shows high contributions of inorganic fertilizer from region 2, as this is the reason why additional manure was not added to supplement plant growth in this region. Interestingly, Figure 6-6 shows a relatively high contribution for the use of natural gas for region 4 and this was primarily due to extremely high level of energy requirements from corn farms in Texas. In the final analysis, the standard deviation with $95 \%$ confidence for fertilizer, chemical protection, and energy inputs was estimated to be 1.51, 1.21, and 1.26, respectively, (see Table D-43) using the pedigree matrix.

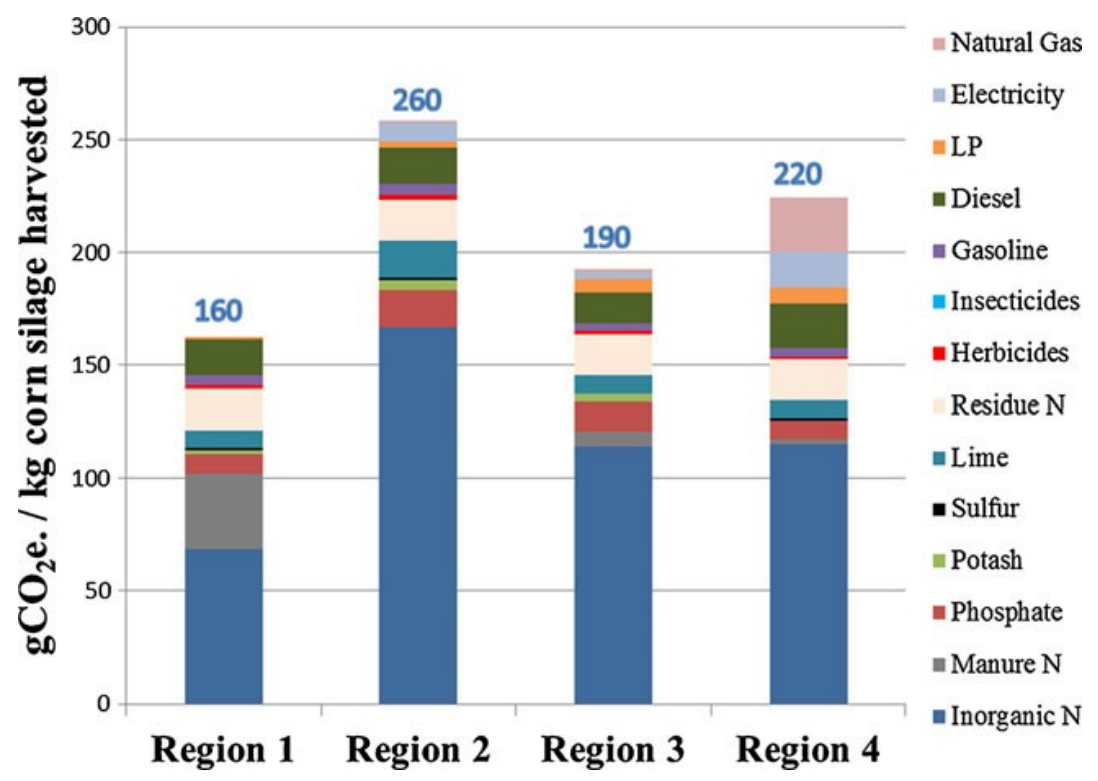

Figure 6-6 Carbon footprint profile of Corn silage harvested in the U.S.

\subsubsection{Winter wheat}


Regions 3 and 4 showed the highest carbon footprint (Figure 6-7), largely due to the high rate of application of inorganic nitrogen fertilizers by farmers. Inorganic nitrogen and phosphate fertilizers, diesel, and the impact of $\mathrm{N}_{2} \mathrm{O}$ releases contributed $93-95 \%$ of the overall GHG emissions in each dairy region. As in other crops, about $65 \%$ of inorganic $\mathrm{N}$ fertilizer GHG emissions was from field application and 35\% was due to fertilizer manufacture.

On the whole, the carbon footprints for all dairy feed crops analyzed in this study were within the range $160-1140 \mathrm{gCO}_{2} \mathrm{e} / \mathrm{kg}$ of dry feed. Various contributions of different farm inputs varied on a regional basis and this was mainly due to the different fertilizer, liming, and energy requirements depending on location, soil properties, and climate.

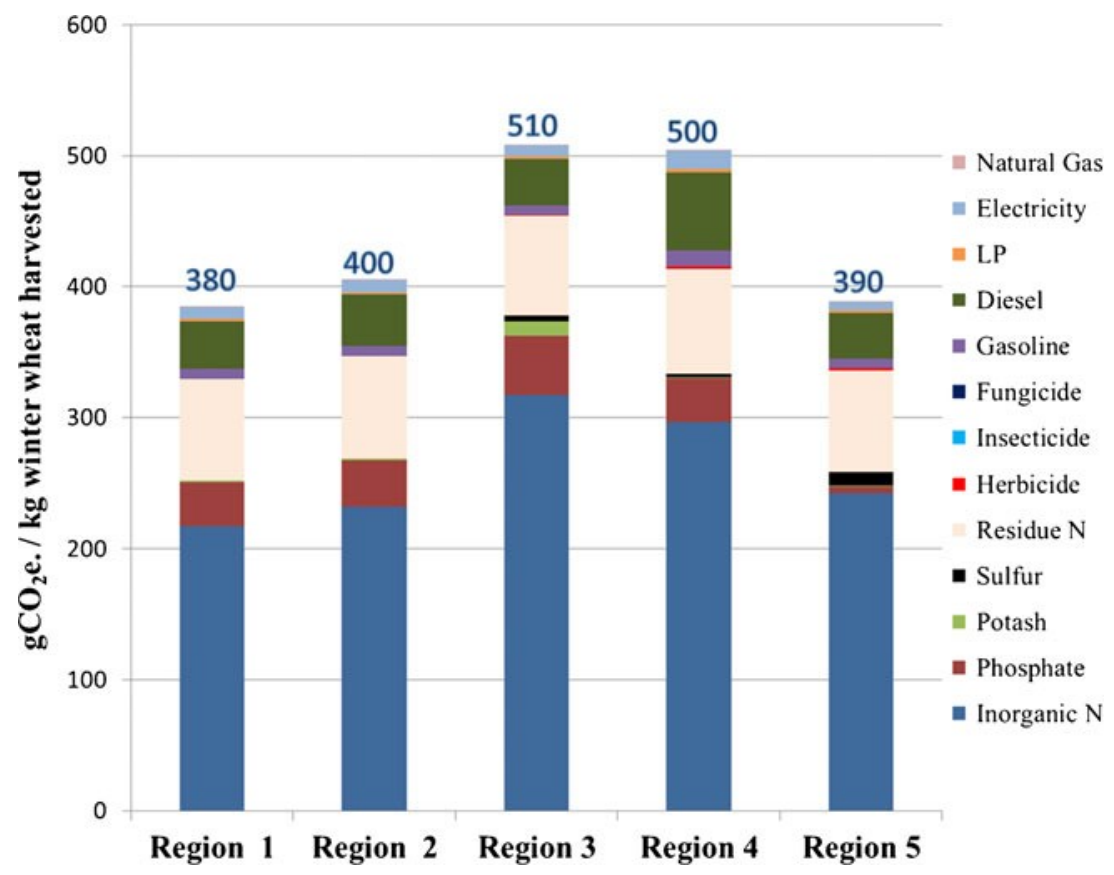

Figure 6-7 Carbon footprint profile of winter wheat harvested in the U.S

6.4.2.5 Forage crops: alfalfa hay, alfalfa silage, grass hay, grass pasture, and grass silage 
The major contributors towards the regional footprints for both alfalfa hay and silage were identified to be due to crop residue, phosphate, lime, diesel, and electricity. In all regions, these factors contributed between $80 \%$ and $90 \%$ toward the overall regional footprint. However, impacts due to the application of potash, boron, crop protection chemicals, and use of gasoline were minimal ranging between $4 \%$ and $14 \%$ toward the carbon footprint for both alfalfa hay and silage. Contributions to carbon (GHG) footprint due to the application of inorganic fertilizer for both alfalfa hay and silage was less than $10 \%$ in all dairy production regions for which input data were available, and this low result was not surprising given that alfalfa is a nitrogen-fixing crop.

Grass showed a higher carbon footprint than other forage crops and nearly as high as the corn grain. Grass typically requires less maintenance and inputs, but produces lower yields than many other crops. In addition, there is much higher variability and uncertainty in actual yield than for other commodity crops. Region 2, which has the highest carbon footprint for grass and hay production, also had higher fuel, lime, and nitrogen use based on the available budget information. In all the different types of grass analyzed, inorganic fertilizers were the major contributors ranging from $34 \%$ to as high as $90 \%$ toward the footprint in the case of grass pasture. Lime contributions were significant for regions 1,2 , and 3, ranging between $13 \%$ and $19 \%$ for all grasses analyzed, but under $10 \%$ for regions 4 and 5 . This reflects the acidic nature of soil in regions 1 to 3 .

Finally, the standard deviation with $95 \%$ confidence for all inputs of alfalfa and grass were both estimated to be 1.22 . Emission ranges varied significantly on a regional basis. The ranges reported in $\mathrm{gCO}_{2} \mathrm{e} / \mathrm{kg}$ dry forage feed were as follows: 140-270 (alfalfa hay), 150-280 (alfalfa silage), 270-470 (grass hay), 220-410 (grass pasture) and 280-410 (grass silage). The GHG emissions of $1 \mathrm{~kg}$ grass hay and silage at the farm gate for the Swiss production processes using Ecoinvent ${ }^{\mathrm{TM}}$ database (PRé Consultants 2009) were analyzed to be 180 and $220 \mathrm{gCO}_{2} \mathrm{e} / \mathrm{kg}$ of dry feed, 128 
respectively, and somewhat lower than our results.

\subsection{Conclusions and recommendations}

In this carbon footprint study, the main goal was to estimate the GHG emissions from the cultivation and harvesting of dairy feeds on a basis of one dry kilogram of dairy feed harvested or produced $\left(\mathrm{gCO}_{2} \mathrm{e} / \mathrm{kg}\right.$ of dry dairy feed). Table 6-6 shows the cradleto-farm gate carbon footprint results obtained for all dairy feeds analyzed in this study. There were large differences in GHG emissions among the different dairy crops, with corn silage showing the lowest, while oats and DDGS displayed the highest. This variability was largely driven by fertilizer and energy utilization intensity as shown in Figures: 6-3, 6-4, 6-5, 6-6, and 6-7. There was some variability in carbon footprint for any crop from region to region, driven by regional differences in energy and lime use, but this variability was smaller than inter-crop variability.

The highest contributor to carbon footprint was the on-farm application of inorganic $\mathrm{N}$ fertilizer except for the leguminous feeds, whereas the fertilizer input categories $\mathrm{P}, \mathrm{K}$, and $\mathrm{S}$ accounted for relatively small impacts for all crops. About $65 \%$ of inorganic $\mathrm{N}$ fertilizer GHG emissions was due to $\mathrm{N}_{2} \mathrm{O}$ release upon application, whereas 35\% was from fertilizer manufacture. $\mathrm{N}_{2} \mathrm{O}$ emission contribution from crop residues was also significant for most crops. With $\mathrm{N}$ fertilizer input being the largest contributor to GHG emissions, much effort should be targeted toward lowering emissions associated with their production and use on the farm. Additionally, the efficient transfer of knowledge to farmers with regards to fertilizer best management practices might help reduce emissions on the farm. The use of crop protection chemicals was not so significant however, and energy use impacts varied widely from region to region, likely due to differences in climate, energy conservation programs, and need for crop drying. Finally, on the energy front, there is the need to promote the use of safe and cleaner forms of energy to help reduce climate active GHG emissions associated with the energy input needed by farmers. 
This study highlights key crop inputs that are the drivers for emissions of greenhouse gases from the cradle-to-gate cultivation and harvesting for US dairy grain and forage crops. These crop results are equally applicable for uses other than dairy products; for example food production in general and bioenergy. Hopefully, these results will be useful for reducing GHG emissions by guiding efforts to modifying agricultural practices with respect to fertilizer application, use of manure, and energy consumption.

\subsection{References}

Beegle D (1997) Estimating manure application rates. Agronomy fact sheet 55. Available at: http://juniataccd.org/programs/NMP/agronomy55.pdf

CGB (2010) CGG Enterprise Inc. http://www.cgb.com/browse.asp?page0339. Accessed 23 Jan 2010

Crozier CR, Osmond DS, Dunphy EJ, Fisher L, Heiniger RW, Johnson SE, Jordan DL, Weisz R, Hardy DH (2004) Lime and fertilizer suggestions_-field, pasture, and hay crops. In 2012 North Carolina agricultural chemicals manual. The College of Agric. And Life Sci, North Carolina State Univ, Raleigh, p 40 Available: http://ipm.ncsu.edu/agchem/4-toc.pdf. Accessed 1 Dec 2010

Dalgaard R, Schmidt J, Halberg N, Christensen P, Thrane M, Pengue W (2008) LCA of soybean meal. Int J Life Cycle Assess 13:240-254

Dartt A, Schwab G (2001) Crops and livestock budgets estimates for Michigan. Agricultural economics report 609. Available at: http://www.aec.msu.edu/aecreports/budgets01.htm

Denmark LCA Food Database (2011). Available at http://www.lcafood.dk/products/crops/cashcrops.htm. Accessed 16 Jan 2011

Deru M, Torcellini P (2007) Source energy and emission factors for energy use in building, technical report NREL/TP-550-38617. Available at: http://www.nrel.gov/docs/fy07osti/38617.pdf 
Dyno Nobel Inc, MSDS (2010) Material safety data sheet, Dyno Nobel Inc. MSDS \# 1138. Available at: http://www.irmteam.com/Product_Sheets/MSDSdynonobel-UAN32.pdf

EPA (2011) Environmental Protect Agency. USA http://www.epa.gov/midwestcleandiesel/. Accessed 23 Feb 2011

Forster P, Ramaswamy V, Artaxo P, Berntsen T, Betts R, Fahey DW, Haywood J, Lean J, Lowe DC, Myhre G, Nganga J, Prinn R, Prinn G, Raga G, Schulz M, Van Dorland R (2007) Changes in atmospheric constituents and in radiative forcing. In: Solomon S, Qin Min D, Manning M, Chen Z, Marquis M, Averyt KB, Tignor M, Miller HL (eds) Climate change 2007: the physical science basis. Contribution of Working Group I to the Fourth Assessment Report of the Intergovernmental Panel on Climate Change. Cambridge University Press, Cambridge. Available at: http://www.ipcc.ch/pdf/assessmentreport/ar4/wg1/ar4-wg1-chapter2.pdf

Frischknecht R, Jungbluth N, Althaus HJ, Doka G, Heck T, Hellweg S, Hischier R, Nemecek T, Rebitzer G, Spielmann M, Wernet G (2007) Overview and methodology. Ecoinvent report no 1. Swiss Centre for Life Cycle Inventories, Dübendorf

GREET (2010) The greenhouse gases, regulated emissions, and energy use in transportation model. Argonne National Laboratory, U.S. Department of Energy. Available at: http://greet.es.anl.gov/main.Version 1.8d. Accessed 10 Jan 2011

Hayashi K, Gaillard G, Nemecek T (2006) Life cycle assessment of agricultural production systems: current issues and future perspectives. In: $\mathrm{Hu} \mathrm{SH}$, Bejosano-Gloria C (eds) Good agricultural practice (GAP) in Asia and Oceania. Food and Fertilizer Technology Center, Taipei, pp 98-110

Heimlich R (2003) Agricultural resources and environmental indicators.Agriculture handbook no. AH722. Washington, DC: USDA Economic Research Service. Available

at: 
http://www.ers.usda.gov/publications/arei/ah722/arei4_4/AREI4_4nutrientmgt. pdf

Hill J, Nelson E, Tilman D, Polasky S, Tiffany D (2006) Environmental, economic, energetic costs and benefits of biodiesel and ethanol biofuels. Proc Natl Acad Sci 103:1206-11210

IPCC (2006) Guidelines for national greenhouse gas inventories, prepared by the National Greenhouse Gas Inventories Programme. In: Eggleston H, Buendia L, Miwa K, Ngara Tand Tanabe K (eds). Available at: http://www.ipccnggip.iges.or.jp/public/2006gl/index. htm

Kim S, Dale B (2002) Allocation procedure in ethanol production system from corn grain: I. System expansion. Int J Life Cycle Assess 7:237-243

Kim S, Dale B (2009) Regional variations in greenhouse gas emissions of biobased products in the United States - corn-based ethanol and soybean oil. Int J Life Cycle Assess 14:540-546

Kim S, Dale B, Jenkins R (2009) Life cycle assessment of corn grain and corn stover in the United States. Int J Life Cycle Assess 14:160-174

Kodera K (2007) Analysis of allocation methods of bioethanol LCA, M.Sc. Thesis, CML, Leiden University, Netherlands, pp 23

KSU (2003) http://www.ksre.ksu.edu/library/crpsl2/mf2586.pdf. Accessed 1 Jan 2010

Landis E, Miller A, Theis L (2007) Life cycle of the corn-soybean agroecosystem for biobased production. Environ Sci Technol 41:1457-1464

MacDonald J, Ribaudo M, Livingston M, Beckman J, HuangW(2009) Manure use for fertilizer and for energy: report to congress. Administrative publication number: 037. Available at: http://www.ers.usda.gov/publications/ap/ap037/

Mowrey A, Spain N (1999) Results of a nationwide survey to determine feedstuffs fed to lactating dairy cows. J Dairy Sci 82:445-451

MSU (2010) Michigan State University Extension. https://www.msu.edu/user/steind/. Accessed 1 Jan 2010

National Research Council (2008) Understanding American agriculture: challenges for the agricultural resource management survey. Panel to review USDAs 132 
agricultural resource management survey. Committee on national statistics, division of behavioral and social sciences and education. The National Academies Press, Washington, DC

NDSU (North Dakota State University, USA) (1992) Fertilizing corn grain, popcorn, silage corn, and sweet corn. Available at: http://www.ag.ndsu.edu/pubs/plantsci/soilfert/sf722w.htm. Accessed 23Feb 2011

NDSU (North Dakota State University, USA) (2011). Equivalent weights of grains and oilseeds. Available at: http://www.ag.ndsu.edu/pubs/ageng/machine/ae945w.htm. Accessed 23 Jan 2011

PAN Pesticides Database (2009) Available at: http://www.pesticideinfo.org/Search_Chemicals.jsp. Accessed 1 Jan 2009

Pelletier N (2008) Environmental performance in the US broiler poultry sector: life cycle energy use and greenhouse gas, ozone depleting, acidifying and eutrophying emissions. Agric Syst 98:67-73

Piringer G, Steinberg LJ (2006) Reevaluation of energy use in wheat production in the United States. J Ind Ecol 10:149-167

Pollak J (2010) Data update of soybean and soy feedstocks production and life cycle assessment of soy-based products and petroleum based alternatives, peer reviewed final report. Omni Tech International and Four Elements Consulting. Available at: http://www.biodiesel.org/resources/reportsdatabase/reports/gen/20100201_GE N-422.pdf

Pradhan A, Shrestha S, Mc Aloon A, Yee W, Haas M, Duffield A,Shapouri H (2009) Energy life cycle assessment of soybean biodiesel.U.S. Department of Agriculture, Office of Energy Policy and New Uses. Agricultural economic report no. $845.10 / 2002$

PRé Consultants (2009) SimaPro 7.1 LCA software. http://www.pre.nl/. Accessed 1 Jan 2009 
Rotz CA, Montes F, Chianese DS (2010) The carbon footprint of dairy production systems through partial life cycle assessment. J Dairy Sci 93:1266-1282

Schnitkey G (2004) Estimated cost of crop production in Illinois. Farm business management handbook. Available at: www.farmdoc.illinois.edu/manage/enterprise_cost/2004_crop_budgets.pdf

Shapouri H, Duffield JA, Wang M (2002) The energy balance of corn ethanol: an update: U.S. Department of Agriculture, Office of Energy Policy and New Uses. Agricultural economic report no.813. 7/2002. Available at: http://www.transportation.anl.gov/pdfs/AF/265.pdf

Shapouri H, Duffield JA, Wang M (2003) The energy balance of corn ethanol revisited. U.S. Department of Agriculture, Office of Energy Policy and New Uses. Agricultural economic report number 813

Sheehan J, Camobreco V, Duffield JA, Graboski M, Shapouri H (1998) Life-cycle inventory of biodiesel and petroleum diesel for use in an urban bus. A joint study sponsored by U.S. Department of Agriculture and U.S. Department of Energy. NREL/SR-580-24089 Golden, CO: National Renewable Energy Laboratory. U.S. Department of Energy, 5/1998

Simplified Emission Inventory Tools - SEIT (2006). SEIT calculation workbook; v1.0. US Energy Information Administration, Washington, July 2006

Spatari S, Zhang Y, Maclean HL (2005) Life cycle assessment of switch and corn stover derived ethanol-fueled automobiles. Environ Sci Technol 39:9750-9758

Thoma G, Popp J, Shonnard D, Nutter D, Ulrich R, Matlock M, Kim D, Neiderman Z, East C, Adom F, Kemper N, (2012) Greenhouse gas emissions from production and consumption in the United States: A cradle-to-grave life cycle assessment circa. International Dairy Journal

(2012), http://dx.doi.org/10.1016/j.idairyj.2012.08.013

USDA NASS (2006) U.S. Department of Agriculture, National Agricultural Statistics Service. Agricultural chemical usage-field crops summary (2005). Available at: http://usda.mannlib.cornell.edu/usda/nass/AgriChemUsFC//2000s/2006/AgriCh emUsFC-05-17-2006.pdf 
USDA NASS (2007a) U.S. Department of Agriculture, National Agricultural Statistics Service. Crop production 2006 summary. U.S. Department of Agriculture, 11 Jan 2008. Available at: http://usda.mannlib.cornell.edu/usda/nass/CropProdSu//2000s/2007/CropProdS u-01-12-2007.pdf

USDA NASS (2007b) U.S. Department of Agriculture, National Agricultural Statistics Service. Agricultural chemical usage-field crops summary, 2006. Available at: http://usda.mannlib.cornell.edu/usda/nass/AgriChemUsFC//2000s/2007/AgriCh emUsFC-05-16-2007_revision.pdf

USDA ERS (Economic Research Service) (2009) U.S. fertilizer use and price. Available at: www.ers.usda.gov/Data/FertilizerUse. Accessed 1 Jan 2009

USDA NASS (U.S. Department of Agriculture, National Agricultural Statistics Service) (2009a) Crop production 2008 summary. U.S. Department of Agriculture, 11 January 2008.

http://usda.mannlib.cornell.edu/usda/nass/CropProdSu//2000s/2009/CropProdS u-01-12-2009.pdf

USDA NASS (2009b) U.S. Wheat classes. Available at: http://www.ers.usda.gov/briefing/wheat/background.htm. Accessed 14 Apr 2009

USDA-IL (2010) Illinois Department of Agriculture. Available at: http://www.agr.state.il.us/marketing/index.html. Accessed 23 Feb 2011

USGS (2007) United States Geological Survey 2007 available at: http://minerals.usgs.gov/minerals/pubs/commodity/stone_crushed/myb1-2007stonc.xls http://minerals.usgs.gov/minerals/pubs/commodity/lime/myb1-2007lime.xls

Van der Werf H, Petit J, Sanders J (2005) The environmental impacts of the production of concentrated feed: the case of pig feed in Bretagne. Agric Syst 83:153-177

Vitosh ML (1996) N-P-K fertilizers, Michigan State University Extension Bulletin. Available at: http://fieldcrop.msu.edu/sites/fieldcrop/files/E0896.pdf 
Wang M (2001) Development and use of GREET 1.6 fuel-cycle model for transportation fuels and vehicle technologies. Tech. Rep. ANL/ESD/TM-163, Argonne National Laboratory, Argonne, IL, 2001. Available at: www.transportation.anl.gov/pdfs/TA/153.pdf 


\section{Chapter 7 \\ 7 Carbon Footprint Analysis of Dairy Feed from a Mill in Michigan, U.S. ${ }^{6}$}

\subsection{Introduction}

Key business decisions should take into account environmentally-benign processes and products as a means of addressing environmental issues. It was on this premise that the U.S. dairy industry embarked on a project to study the GHG emissions from the production of milk in the U.S. dairy industry. Findings from this dairy study were presented in a report by Thoma et al. (2010). Subsequently, Thoma et al. (2012) reported nine major stages comprising the U.S. dairy industry as follows: i. feed production stage (cultivation of grain and forage crops and other mill feed ingredients plus mill operations and all transportation steps), ii. milk production, iii. delivery to processor; iv. processing, v. packaging, vi. distribution, vii. retail, viii. consumption and ix. disposal. Analyzing each stage separately and then combining all stages provided the carbon footprint of the U.S. dairy milk supply chain. The analysis reported here however required a carbon footprint study of a U.S. dairy feed mill as part of "i. feed production stage" listed above. Additionally, a detailed literature review by the authors revealed that no previous studies were found with regard to carbon footprint analysis of any animal feed mills in the U.S. Shaw et al. (1998)., investigating the development of emission factors for unloading grain and loading feed at mills for cattle feed yards. A recent global dairy sector GHG emissions life cycle assessment [LCA] (Gerber et al. 2010) compared impacts of fat- and proteincorrected milk production and processing for different countries and agricultural cultivation settings, but did not include an analysis of dairy feed mills. Therefore, our

${ }^{6}$ This chapter has been published as an article in International Dairy Journal. Figure E-1 shows copyright clearance from Elsevier. Citation: Adom, F., Workman, C., Thoma, G., Shonnard, D., Carbon Footprint Analysis of Dairy Feed from a Mill in Michigan, U.S., International Dairy Journal (2012), doi: 10.1016/j.idairyj.2012.09.008. 
study makes a contribution in understanding the GHG emissions of dairy feed mills and identifies major mill inputs contribution to the carbon footprint.

The American Feed Industry Association [AFIA], which represents the U.S. animal feed industry, is a trade association which estimates that approximately 3,000 feed mills exist in the U.S. and these mills produced between 107, 000 to 112,000 million $\mathrm{kg}$ of animal feed over the last ten years (Balal et al. 2008). The feed mill sector is a very important part of the agricultural industry for the U.S. from an economic perspective because the sector directly employs about 110,000 individuals and contributes approximately $\$ 35$ billion from feed sales towards the U.S. economy annually (International Feed Federation Industry, 2009). The mandatory reporting of GHG emissions proposed by the U.S. Environmental Protection Agency (USEPA) requires industrial facilities emitting more than 25 million $\mathrm{kg}$ of $\mathrm{CO}_{2}$ equivalents each year to report to the USEPA. This study calculates the magnitude of GHG emissions expected from a dairy feed mill, whose facilities have yet to be subject to such analysis in the U.S. Specific study goals are:

- Develop an LCA methodology applicable to the animal feed mill industry to accommodate a large number of inputs and activities associated with dairy mill operations, and

- Gain an understanding of the relative importance of milled dairy feed inputs and activities on the GHG emissions of the outputs of the mill (which are themselves inputs to dairy milk production) through the application of these developed methodologies.

\subsection{Materials and methods}

\subsubsection{Goal and scope definition}

This is an analysis of a single dairy feed mill including transport of milled dairy feed to various dairy farms in Michigan. The scope of this carbon footprint analysis did not include biogenic carbon removals and emissions, emissions from employee travel to 
or from the mill, the impacts of manufacturing the mill itself, and other passenger vehicles used on the milling premises.

- Goal. Estimation of GHGs emitted from feed mill operations on the basis of one kilogram of dairy feed output from the mill $\left(\mathrm{kg} \mathrm{CO}_{2}\right.$-eq $\mathrm{kg}^{-1}$ of milled dairy feed), including delivery to local dairy farms.

- $\quad$ Scope. The scope specifically included GHG emissions only (see Figure 7-1). The study authors acknowledge that different formulations for dairy feed are possible depending on animal age and other factors. Indeed, the mill under study produces custom formulation of dairy feeds for specific customers. However, this analysis was meant to determine the impacts of producing dairy feed averaged over a typical year, by extrapolating the data provided over an annual cycle.

\subsubsection{Audience}

This study was a subsystem of a larger study undertaken for the U.S. dairy industry sector, yet the results are relevant to animal feed mill industry sector, the general public and federal government agencies responsible for the regulation of emissions from industrial operations.

\subsubsection{Functional unit}

The functional unit was $1 \mathrm{~kg}$ of milled dairy feed at its exit moisture content (an average feed formulation for dairy animal nutrition at this mill).

\subsubsection{System boundaries}

System boundaries included production and transport of feed inputs (grain crops, processed feed components, nutrients and other additives, and energy use) to the mill, for milling of the feed ingredients, to the delivery of milled feed to dairy farms. Figure 7-1 shows a schematic diagram (red line indicates the system boundaries) for the stages considered in this analysis. The green ellipses represent the various inputs at each stage while the red rounded squares represent corresponding emissions. 


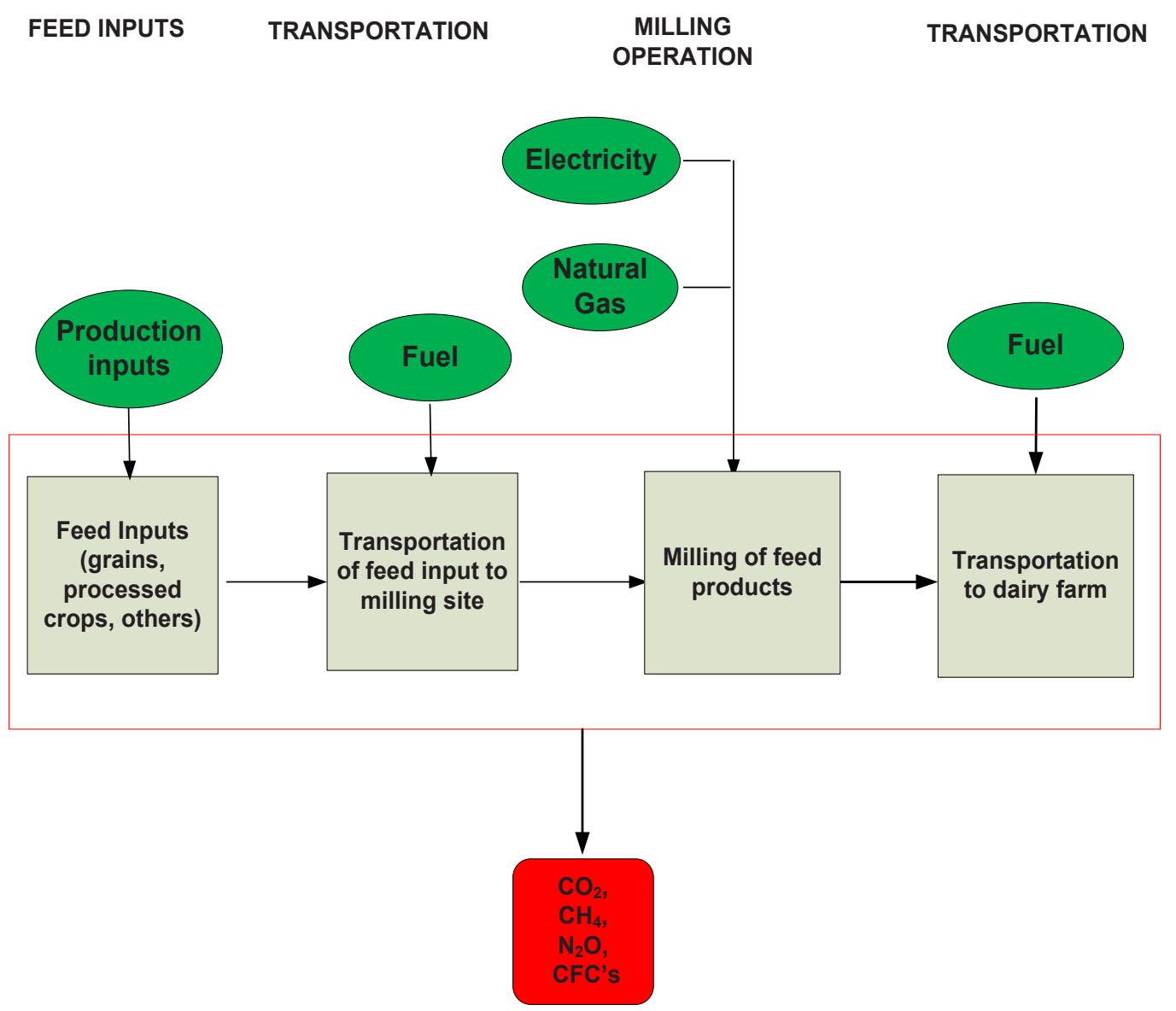

Figure 7-1 Schematic diagram of various stages for dairy feed mill carbon footprint analysis

To the extent possible, ecoinvent ${ }^{\mathrm{TM}}$ unit processes (PRé Consultants., 2009) have been used. The ecoinvent ${ }^{\mathrm{TM}}$ data are mostly based on European conditions, whereas the geographic context of our study was the U.S. This situation introduced a geographicrelevance conflict; however, technology relevance is still strong because both E.U. and U.S. manufacturers use modern production technology. For major crop and agricultural by-product inputs to this study, we have developed inventories based on our own research using U.S. data sources. There were many inputs for which unit processes were modeled using Open input-output (IO) data (Sustainability Consortium, 2011) and also some data were obtained from peer reviewed journal articles. Differences in system boundaries, particularly between input-output and process-based models will result in inconsistent system boundaries. This is because 
Open IO models in essence have no specific boundary cut-off criteria. However, in this study, a relatively small fraction of the mass of feed inputs to the mill has been modeled with the IO approach. The specific items for which IO data have been used are restricted to nutritional supplements for feed ingredients in category 3. Section 7.2.9.1 provides more details on the different categories of feed ingredients.

\subsubsection{Geographical boundaries}

This mill, located in the lower peninsula of Michigan, is the geographical context for this carbon footprint study. It is a modern milling site with the bulk of its milled animal feed being dairy feed. Results from this mill carbon footprint analysis may not be representative of other dairy feed mills in the U.S. However, in an attempt to model mills from other locations in the U.S., sensitivity analyses in section 7-4 of this article model GHG emissions of milled dairy feeds with a predominance of dry distillers grains and solubles (DDGS), soybean meal, and oats, respectively in separate scenarios.

\subsubsection{Allocation procedures}

The ISO guidelines were followed for co-product allocation in this carbon footprint study. Specifically, ISO standards 14040:14044 (ISO, 2006 a, b) and Sinden et al, (2008) recommend the avoidance of allocation by using system expansion. However, system expansion was not possible in our study given that LCA results are not currently available to credit the non-dairy feed products from this mill. Apart from this, it has been stated in section 7.2.2 that this study was a subsystem of a larger study (Thoma et al., 2012). In the overall study, economic and mass allocations were used, and hence to be consistent we used both of these allocation approaches. An economic allocation factor of 0.90 was used for milled dairy feed based on consultation with the mill manager who indicated that $90 \%$ of total mill revenue generated was attributable to the sale of dairy feed output. A mass allocation factor of 0.88 was used based on the fact that $88 \%$ of the mill outputs were dairy feed while the remaining outputs were non-dairy feed products. 


\subsubsection{Collection of input data}

Data collection efforts have been a combination of a survey instrument developed for the mill manager, internet searches (e.g., ISI, Google scholar, ProQuest, etc), peerreviewed journal articles, a mill site visit, and direct communication with the feed mill manager. Inputs such as types of feed, mass of each feed ingredient, transportation distances, as well as unit and total cost of feed ingredients were all obtained from the purchase history documents of the milling facility, provided by the mill manager. The next sections show how input data were collected and organized as well as some sensitivity analyses considered in this study.

\subsubsection{Developing a data collection spreadsheet (Survey)}

The life cycle inventory stage of this project required gathering input and output data for the milling operation. A survey instrument was created and used to collect data from the mill facility (see Appendix E). This survey instrument can broadly be categorized into three major sections. Questions in Table E-1 sought information on the various types of fuel used in the milling operations, types of feed produced aside from dairy feed, and the annual energy consumption for the milling processes. The main objective in Table E-2 of the survey instrument was to determine the kind and amount of feed that go into producing starter, lactating and dry feed for dairy cattle. In the transportation section, Table E-3, questions specifically targeted the transportation of feed inputs to the milling site, including modes of transportation, the kind of road vehicles used, and distances covered in transporting feed ingredients to the milling site. The data obtained was collected between March 1 and June 30, 2009. The feed mill manager confirmed that this dataset was representative of annual production.

\subsubsection{Organization of input data for carbon footprint analysis}

As identified in Figure 7-1, input data from this mill facility were organized for this carbon footprint analysis into feed ingredients, transport of feed ingredients to milling site, mill electricity and natural gas use, and milled product transportation.

\subsubsection{Categories of feed ingredients and sources of inventory data}


The feed ingredients were organized into three categories based on i. specific functions, ii. source of emission factors, and iii. environmental impact modeling approach. The total 4 month input of feed ingredients to the mill was approximately $9,683,000 \mathrm{~kg}$, and this was increased to an annual input (three-fold increase) in consultation with the feed mill manager. The mill manager confirmed that inputs equal to mill feed outputs. The first category of mill inputs was the majority of feed ingredients on a mass-input basis (Category 1). Inventory data for these ingredients were obtained primarily from unit processes in the ecoinvent ${ }^{\mathrm{TM}}$ database and also from the study by Adom et al., (2012). This first feed category was comprised mainly of soybean co-products, DDGS, and other high-mass inputs. Table 7-1 shows the individual feed components, their overall percentage contributions towards the feed mill inputs, and organizes these components into major feed types for which inventory data were available. Reported feed types in both tables 7-1 \& 7-2 were obtained from the purchase history document obtained from the feed mill manager. The percentage composition of the individual components making up the total 4 month input were estimated by dividing their individual masses $(\mathrm{kg})$ of feed types by the total $(9,683,000$ $\mathrm{kg})$. For this particular feed mill, soybean meal-type feed alone accounted for approximately $59 \%$ of the mill inputs while DDGS contributed close to $17 \%$. Category 1 of the feed ingredients contributed about $84 \%$ of the mill's total feed input by mass. Miller, Ramsey, \& Madsen (1988) and Siciliano-Jones, Socha, Tomlinson, \& DeFrain (2008) established that trace minerals such as $\mathrm{Zn}, \mathrm{Mn}, \mathrm{Cu}$, and Co plays a very important role in overall health of dairy animals. For example, these trace minerals help in protein synthesis, vitamin metabolism, formation of connective tissue, and immune function in animals. 
Table 7-1 Major feed inputs on a 4-month basis: soybean, dried distiller grain and other co-products (Category 1)

\begin{tabular}{|c|c|c|c|}
\hline FEED TYPE & $\begin{array}{c}\text { FEED INPUTS } \\
(\mathrm{T}=\text { TRUCK, } \mathrm{R}=\text { RAIL })\end{array}$ & $\begin{array}{l}\text { UNITS PURCHASED } \\
(1000 \mathrm{~kg})\end{array}$ & $\begin{array}{l}\text { PERCENTA } \\
\text { GE }\end{array}$ \\
\hline COTTONSEED & Fuzzy Cottonseed $(\mathrm{T})$ & 124 & $1.28 \%$ \\
\hline $\begin{array}{l}\text { DRIED DISTILLER } \\
\text { GRAIN (DDG) }\end{array}$ & $\begin{array}{l}\text { Corn Gluten Feed Bulk (T) } \\
\text { Distillers Bulk (T) } \\
\text { Corn Gluten Direct }(\mathrm{T}) \\
\text { Direct Distillers }(\mathrm{T})\end{array}$ & $\begin{array}{c}578 \\
843 \\
127 \\
89 \\
\end{array}$ & $\begin{array}{l}5.97 \% \\
8.70 \% \\
1.31 \% \\
0.91 \%\end{array}$ \\
\hline SOY MEAL & $\begin{array}{l}\text { Canola Meal }(\mathrm{T}) \\
\text { Heifer Concentrate 35\% (T) } \\
\text { Heifers Edge Direct }(\mathrm{T}) \\
\text { Soybean Meal 48\% Direct }(\mathrm{T}) \\
\text { Chief Beef Finisher 36 }(\mathrm{T}) \\
\text { Dairy Beef Finisher }(\mathrm{T}) \\
\text { Bran Meal 50\# }(\mathrm{T}) \\
\text { Bulk 48\% Soy 50\# }(\mathrm{T}) \\
\text { Heifers Edge Bulk }(\mathrm{T}) \\
\text { Soy Chlor 16 50\# (T) } \\
\text { Soy Plus Bulk 50\# (R) } \\
\text { Vita Soy Bulk (T) }\end{array}$ & $\begin{array}{c}304 \\
6 \\
27 \\
83 \\
25 \\
3 \\
0.05 \\
1,915 \\
46 \\
11 \\
3,271 \\
6 \\
\end{array}$ & $\begin{array}{c}3.14 \% \\
0.07 \% \\
0.28 \% \\
0.86 \% \\
0.26 \% \\
0.03 \% \\
0.0005 \% \\
19.78 \% \\
0.48 \% \\
0.11 \% \\
33.78 \% \\
0.06 \% \\
\end{array}$ \\
\hline SUGAR & $\begin{array}{l}\text { Dairy Sugar 38(T) } \\
\text { Dairy Sugar 38(T) }\end{array}$ & $\begin{array}{c}53 \\
8\end{array}$ & $\begin{array}{l}0.54 \% \\
0.08 \%\end{array}$ \\
\hline SOY HULLS & $\begin{array}{l}\text { Direct Soy Hulls }(\mathrm{T}) \\
\text { Direct Soy Plus }(\mathrm{T}) \\
\text { Soy Hulls Bulk }(\mathrm{T}) \\
\end{array}$ & $\begin{array}{c}22 \\
21 \\
189 \\
\end{array}$ & $\begin{array}{l}0.23 \% \\
0.22 \% \\
1.95 \% \\
\end{array}$ \\
\hline ANIMAL MEAL & $\begin{array}{l}\text { Blood Meal 50\# }(\mathrm{T}) \\
\text { Fish Meal 50\# }(\mathrm{T}) \\
\text { Pork and Bone Meal Bulk }(\mathrm{T})\end{array}$ & $\begin{array}{c}0.005 \\
4 \\
108 \\
\end{array}$ & $\begin{array}{c}0.0005 \% \\
0.04 \% \\
1.12 \% \\
\end{array}$ \\
\hline FAT & $\begin{array}{l}\text { A/V Blend Fat Bulk (T) } \\
\text { Choice White Grease Bulk (T) } \\
\text { Energy Booster } 100 \text { 50\# Bag }(\mathrm{T}) \\
\text { Megalac 50\# }(\mathrm{T})\end{array}$ & $\begin{array}{c}94 \\
79 \\
30 \\
2 \\
\end{array}$ & $\begin{array}{l}0.97 \% \\
0.82 \% \\
0.31 \% \\
0.02 \% \\
\end{array}$ \\
\hline MOLASSES & $\begin{array}{l}\text { Dry Molasses 50\# (T) } \\
\text { Liquid Molasses-Bulk }(\mathrm{T}) \\
\text { Molasses Tub-16\% }(\mathrm{T}) \\
\text { Molasses Tub-25\% (T) } \\
\text { Direct Molasses (T) } \\
\end{array}$ & $\begin{array}{c}7 \\
29 \\
1 \\
1 \\
5 \\
\end{array}$ & $\begin{array}{l}0.07 \% \\
0.30 \% \\
0.01 \% \\
0.01 \% \\
0.06 \% \\
\end{array}$ \\
\hline OATS & Rolled Oats 50\# $(\mathrm{T})$ & 2 & $0.02 \%$ \\
\hline UREA & Feed Urea Bag 50\# (T) & 41 & $0.43 \%$ \\
\hline WHEY & Dried Whey 50\# $(\mathrm{T})$ & 2 & $0.02 \%$ \\
\hline & & 8,158 & $84 \%$ \\
\hline
\end{tabular}

The second category of feed ingredients (see Table 7-2, Category 2) was comprised of mineral ingredients and other feed components, contributing approximately $12 \%$ by mass to the feed mill inputs. These are highly-processed feed ingredients. For 
example, dairy base mix (Hubbard Feeds, 2007) provides calcium, phosphorous, magnesium, and other trace minerals.

Table 7-2 Feed inputs on a 4-month basis: minerals and others (Category 2)

\begin{tabular}{|c|c|c|c|}
\hline FEED TYPE & $\begin{aligned} & \text { FEED INPUTS } \\
(\mathrm{T}= & \mathrm{TRUCK}, \mathrm{R}=\mathrm{RAIL})\end{aligned}$ & $\begin{array}{c}\text { UNITS } \\
\text { PURCHASED } \\
(1000 \mathrm{~kg})\end{array}$ & PERCENTAGE \\
\hline GYPSUM & Cal Sulfate Bag 50\# (T) & 27 & $0.276 \%$ \\
\hline LIME & Hydrated Lime 50\# BAG (T) & 2 & $0.019 \%$ \\
\hline LIMESTONE & $\begin{array}{l}\text { Cal Carb Bulk (T) } \\
\text { Cal Carb 50\# (T) } \\
\text { Dical Bag 50\# }(\mathrm{T})\end{array}$ & $\begin{array}{c}281 \\
13 \\
1\end{array}$ & $\begin{array}{l}2.903 \% \\
0.131 \% \\
0.009 \%\end{array}$ \\
\hline $\begin{array}{l}\text { MAGNESIUM } \\
\text { OXIDE }(\mathrm{MgO})\end{array}$ & Mag Oxide Bag 50\# (T) & 19 & $0.197 \%$ \\
\hline $\begin{array}{l}\text { MAGNESIUM } \\
\text { SULFATE }\left(\mathrm{MgSO}_{4}\right)\end{array}$ & Mag Sulfate 50\# Bag (T) & 4 & $0.044 \%$ \\
\hline $\begin{array}{l}\text { OTHER TRACE } \\
\text { MINERALS }\end{array}$ & $\begin{array}{l}\text { 24-12 Mineral 50\# (T) } \\
\text { Copper Sulfate -Fine 50\# (T) } \\
\text { Copper Sulfate-Cryb 50\# }(\mathrm{T}) \\
\text { Dairy Base Mix Bulk (T) } \\
\text { DCAD Plus-Potasm Carb 50\# (T) } \\
\text { Dical/Monocal Bulk (T) } \\
\text { Iodine 50 50\# (T) } \\
\text { Manganese Sulfate 50\# (T) } \\
\text { Propnos Mineral W/Altosiu (T) } \\
\text { Minerals Mixture }\end{array}$ & $\begin{array}{c}2 \\
2 \\
0.3 \\
85 \\
10 \\
49 \\
0.05 \\
2 \\
0.005 \\
38\end{array}$ & $\begin{array}{l}0.023 \% \\
0.019 \% \\
0.004 \% \\
0.879 \% \\
0.103 \% \\
0.505 \% \\
0.001 \% \\
0.019 \% \\
0.002 \% \\
0.392 \%\end{array}$ \\
\hline SALT $(\mathrm{NaCl})$ & $\begin{array}{l}\text { Mixing Salt Bag }(\mathrm{T}) \\
\text { Tm Blocks W/Sel }(\mathrm{T}) \\
\text { Tm Salt Bag }(\mathrm{T}) \\
\text { Mixing Salt Bulk }(\mathrm{T}) \\
\text { White Salt Blocks }(\mathrm{T}) \\
\text { White Salt } 50 \#(\mathrm{~T}) \\
\text { TM Blocks }(\mathrm{T}) \\
\end{array}$ & $\begin{array}{c}14 \\
4 \\
10 \\
136 \\
2 \\
2 \\
7 \\
\end{array}$ & $\begin{array}{l}0.149 \% \\
0.041 \% \\
0.103 \% \\
1.405 \% \\
0.026 \% \\
0.023 \% \\
0.072 \% \\
\end{array}$ \\
\hline SODA POWDER & $\begin{array}{l}\text { Bicarb Bulk (R) } \\
\text { Bicarb-Bag (T) }\end{array}$ & $\begin{array}{c}445 \\
9 \\
\end{array}$ & $\begin{array}{l}4.596 \% \\
0.090 \% \\
\end{array}$ \\
\hline & & 1,165 & $12 \%$ \\
\hline
\end{tabular}

The largest input to Category 2 ingredients was soda powder, contributing approximately $5 \%$ towards total feed mass. In addition to serving as a source of sodium, soda powder also offers buffering qualities that help stabilize rumen $\mathrm{pH}$ by reducing acid conditions. Finally, feed input labeled mineral mixture contributed less than $0.5 \%$ towards the feed milling input by weight even though it was comprised of 
41 different ingredients (Table E-4). These ingredients contain varying concentrations of trace minerals such as selenium, copper, zinc, among others, which were grouped and referred to as minerals mixture. Inventory data for Category 2 dairy feed inputs were obtained from ecoinvent ${ }^{\mathrm{TM}}$.

The third category for the feed mill inputs (Category 3) was comprised of 66 different components with much smaller amounts on a weight basis (see Table E-5). This category mainly included highly-processed ingredients like vitamins and amino acids such as lysine $98.5 \%$, methionine, aureomycin 50, among others. This category however contributed approximately $4 \%$ towards the mill inputs by mass. Inventory data for Category 3 dairy feed inputs were obtained from the Open IO database because the ecoprofiles for them were not available in ecoinvent ${ }^{\mathrm{TM}}$ or any other literature sources.

Open IO is a comprehensive analytical database developed and created by staff of the Applied Sustainability Center at the Walton College of Business, University of Arkansas for the Sustainability Consortium (2011). In analyzing feed inputs in Category 3, the economic sector most closely related to these mill input ingredients was identified as "other food manufacturing" (sector-311119) and was used to complete the inventory. This sector ecoprofile was imported into SimaPro and modified to remove the contribution of Category 1 and 2 inputs, and the outputs renormalized so that the relative contribution of all other sectors would be proportionally increased.

\subsubsection{Onsite energy}

For the energy analysis in this study, two major inputs were identified using data obtained from the mill operation survey: electricity and natural gas. The total electricity used $(\mathrm{kWh})$ for three electricity meters was obtained for an eleven month period (see Table 7-3). Electricity consumption averaged over the eleven month period was used as an estimate for the twelfth month to obtain the total annual electricity used. 
Table 7-3 Summary of electricity inventory data for milling site from 2008-2009

\begin{tabular}{|l|c|}
\hline \multicolumn{2}{|c|}{ Electricity (11 month.) } \\
\hline Meter \# & $\mathrm{kWh}$ \\
\hline 10988145 & 21,940 \\
\hline 7838695 & 42,514 \\
\hline 83157581 & 38,270 \\
\hline
\end{tabular}

In the case of natural gas, annual average for natural gas used at the site for 2007 and 2008 were used in the calculations. Data for natural gas inputs are presented in Table 7-4.

Table 7-4 Summary of natural gas inventory data for milling site from 2008-2009

Note: The ecoinvent profile used for natural gas is: Heat, natural gas, at boiler modulating $<100 \mathrm{~kW} /$ RER S. The emission factor for electricity assuming Michigan grid was modified according to the study by Deru \& Torcellini, 2007

\begin{tabular}{|c|c|}
\hline \multicolumn{2}{|c|}{ Natural Gas (1 year) } \\
\hline Year & Cubic meter $\left(\mathrm{m}^{3}\right)$ \\
\hline 2008 & 125,826 \\
\hline 2009 & 180,401 \\
\hline Total (Average) & 153,115 \\
\hline
\end{tabular}

\subsubsection{Transportation}

The goal for the transportation analysis was to model the GHG emissions of transportation of feed ingredients to the mill site as well as the milled products to the various local dairy farms. For this section of the analysis, the site manager provided the required data inputs for assessing both steps. Appendix E shows transportation data of all the feed ingredients input to the mill facility. These data included the miles traveled, amount transported, and transportation mode. Tables E-6, E-7 and E-8 show the transportation inputs in terms of miles travelled for feed ingredients in categories 1,2 and 3, respectively. Using this information, ecoinvent ${ }^{\mathrm{TM}}$ ecoprofiles most closely 
matching transport mode were used. A 16,257-32,514 kg European road transport ecoprofile and a U.S. freight train ecoprofile were selected from the ecoinvent ${ }^{\mathrm{TM}}$ database. The freight train emission factor used was $3.8 \times 10^{-5} \mathrm{~kg} \mathrm{CO}_{2}$-eq $(\mathrm{kg} \mathrm{km})^{-1}$, and multiplying this by the corresponding payload-distance $(\mathrm{kg} \mathrm{km})$ values for each ingredient, the total GHG emissions for each ingredient transported were estimated. Using a similar approach for a 16,257-32,514 $\mathrm{kg}$ capacity road transport, with emission factor of $1.7 \times 10^{-4} \mathrm{~kg} \mathrm{CO}_{2}$-eq $\left(\mathrm{kg} \mathrm{km}^{-1}\right.$, the GHG results were estimated for road transport of feed ingredients.

Inputs for the transportation of milled dairy feed products using the mill fleet of trucks to local dairy farms were provided by the mill manager in terms of the diesel use. These transport inputs are summarized in Table 7-5. Data covered the period January 2007 to August 2009; however, the average amount of diesel used for transportation in 2007 and 2008 was used in this analysis due to the incomplete data reported in 2009. Using diesel density of $840 \mathrm{~kg} \mathrm{~m}^{-3}$ and heating value of $42.8 \mathrm{MJ} \mathrm{kg}^{-1}$ of diesel (Edwards et al, 2006), the total mass (kg) as well as the total amount of energy (MJ) were estimated. Inventories of GHG emissions for production and combustion of diesel were obtained using the ecoinvent" profile "diesel, burned in diesel-electric generating set/GLO S" (90 $\left.\mathrm{gCO}_{2} \mathrm{MJ}^{-1}\right)$, which closely approximates diesel emissions from use in trucks.

Table 7-5 Summary fuel usage input data (average for 2007 and 2008) for road transport of milled feed product from mill to Michigan dairy farm

\begin{tabular}{|l|c|c|c|}
\hline \multicolumn{3}{|c|}{ Transportation Fuel Usage Input From Dairy Feed Mill to Dairy Farms } \\
\hline Date & Diesel $\left(\mathrm{m}^{3}\right)$ & Total Mass $(\mathrm{kg})$ & $\begin{array}{c}\text { Total Amount of } \\
\text { Energy } \\
\text { (Mega Joule- MJ) }\end{array}$ \\
\hline $1 / 1 / 2009-8 / 31 / 2009$ & 58.94 & 49,512 & $2,119,123$ \\
$1 / 1 / 2008-12 / 31 / 2008$ & 145.11 & 121,903 & $5,217,443$ \\
$1 / 1 / 2007-12 / 31 / 2007$ & 135.28 & 113,648 & $4,864,142$ \\
\hline Average $(2007-2008)$ & 140.19 & 117,776 & $5,040,792$ \\
\hline
\end{tabular}




\subsection{Life cycle impact assessment}

The IPCC GWP 100a method in SimaPro 7.3 was used to convert GHG inventory data into equivalent emissions of $\mathrm{CO}_{2}$. This method uses global warming potentials [GWPs] of 1 for $\mathrm{CO}_{2}, 25$ for $\mathrm{CH}_{4}$, and 298 for $\mathrm{N}_{2} \mathrm{O}$. In addition to these three greenhouse gases, the analysis included emissions of refrigerants and of other chemicals with high GWPs that were included in the inventory data from ecoinvent ${ }^{\mathrm{TM}}$ and the open IO model.

\subsubsection{Emission factors for GHG analysis}

Table 7-6 summarizes the GHG emission factors used in this mill analysis. The majority of GHG emission factors for inputs to the feed mill were obtained using ecoprofiles ${ }^{\mathrm{TM}}$ in the ecoinvent database or were generated from original crop inputs from another study (Adom et al., 2012). In the case of sugar and animal meal, emission factors for these inputs were obtained from LCA Food Database (Nielsen, Weidema, Dalgaard \& Halberg., 2003). Also, the emission factor for "other trace minerals" was a unit process comprising of all the commonly used minerals in feed input category 2. Emission factors used for electricity and natural gas from the ecoinvent ${ }^{\mathrm{TM}}$ database were $0.82 \mathrm{~kg} \mathrm{CO}_{2}$-eq $\mathrm{kWh}^{-1}$ assuming a Michigan grid mix and $0.075 \mathrm{~kg} \mathrm{CO}_{2}$-eq $\mathrm{MJ}^{-1}$ of natural gas.

Table 7-6 Emission factors and mill greenhouse gas analysis (MA: Mass allocation and EA: Economic Allocation)

\begin{tabular}{|c|c|c|c|}
\hline \multirow[b]{2}{*}{ Category 1} & \multicolumn{2}{|c|}{$\begin{array}{c}\text { Emission Factors } \\
\left(\mathrm{kgCO}_{2} \mathrm{eq} / \mathrm{kg} \text { feed }\right. \\
\text { input })\end{array}$} & \multirow[b]{2}{*}{ Source } \\
\hline & MA & EA & \\
\hline Cottonseed & 1.27 & 0.39 & $\begin{array}{l}\text { PRé Consultants (2009)- } \\
\text { Ecoinvent database } \\
\text { (Cotton seed, at regional } \\
\text { storehouse/US U) }\end{array}$ \\
\hline DDGS (Dry mill) & 2.30 & 0.91 & Adom et al., (2012) \\
\hline DDGS (Wet mill) & 2.21 & 0.67 & Adom et al., (2012) \\
\hline Soy meal & 0.54 & 0.41 & Adom et al., (2012) \\
\hline $\begin{array}{l}\text { Sugar (Cotton seed, at regional } \\
\text { storehouse/US U UA Dairy) }\end{array}$ & 0.51 & 0.51 & $\begin{array}{l}\text { Nielsen, Weidema, } \\
\text { Dalgaard \& Halberg } \\
\text { (2003) }\end{array}$ \\
\hline
\end{tabular}




\begin{tabular}{|c|c|c|c|}
\hline Soy hulls & 0.50 & 0.41 & Thoma et al, (2010) \\
\hline Animal meal & 0.07 & 0.07 & $\begin{array}{l}\text { Nielsen, Weidema, } \\
\text { Dalgaard \& Halberg } \\
\text { (2003) }\end{array}$ \\
\hline Fat (Tallow, at plant/CH U) & 0.66 & 0.66 & $\begin{array}{l}\text { PRé Consultants (2009)- } \\
\text { Ecoinvent database }\end{array}$ \\
\hline Molasses & 0.11 & 0.11 & $\begin{array}{l}\text { PRé Consultants (2009)- } \\
\text { Ecoinvent database }\end{array}$ \\
\hline Oats & 0.58 & 0.58 & Adom et al., (2012) \\
\hline $\begin{array}{l}\text { Urea } \\
\text { (Urea, as N, at regional storehouse/RER U) }\end{array}$ & 3.30 & 3.30 & $\begin{array}{l}\text { PRé Consultants (2009)- } \\
\text { Ecoinvent database }\end{array}$ \\
\hline Category 2 & MA & EA & Source \\
\hline Gypsum (Gypsum, mineral, at mine/CH U) & 0.002 & 0.002 & \multirow{8}{*}{$\begin{array}{l}\text { PRé Consultants (2009)- } \\
\text { EcoInvent database }\end{array}$} \\
\hline Lime (Lime, hydrated, loose, at plant/CH U) & 0.75 & 0.75 & \\
\hline $\begin{array}{l}\text { Limestone } \\
\text { (Limestone, milled, loose, at plant/CH U) }\end{array}$ & 0.013 & 0.013 & \\
\hline $\begin{array}{l}\text { Magnesium Oxide } \\
\text { (Magnesium oxide, at plant/RER U) }\end{array}$ & 1.05 & 1.05 & \\
\hline $\begin{array}{l}\text { Magnesium sulfate } \\
\text { (Magnesium sulphate, at plant/RER U) }\end{array}$ & 0.30 & 0.30 & \\
\hline $\begin{array}{l}\text { Other Trace Minerals } \\
\text { (Minerals mixture, at factory/US U) }\end{array}$ & 1.59 & 1.59 & \\
\hline $\begin{array}{l}\text { Sodium Chloride } \\
\text { (Sodium chloride, powder, at plant/RER U) }\end{array}$ & 0.18 & 0.18 & \\
\hline $\begin{array}{l}\text { Soda powder } \\
\text { ( Soda, powder, at plant/RER U) }\end{array}$ & 0.44 & 0.44 & \\
\hline Category 3 & MA & EA & Source \\
\hline Supplements & 1.07 & 1.07 & Open IO database \\
\hline
\end{tabular}

\subsection{Sensitivity analyses}

Sensitivity analyses were performed to compare three major scenarios to the base case study (the MI mill inputs). In the base case, soybean meal dominated the ingredients on a mass-input basis by contributing 59\% (wt.), while DDGS from dry corn mill facility contributed 17\% (wt.). In Scenario 1, we investigated the feed mill's GHG impacts when using DDGS from a wet corn mill facility as oppose to a dry mill, without changing the mass input contributions of any other feed inputs. Scenarios 2 and 3 investigated the impact of input grain crop type by modifying the major crop inputs. To investigate a DDGS dominant case, DDGS from a dry corn mill and soybean meal were assumed to contribute $59 \%$ and $17 \%$, respectively to the total feed input in scenario 2 (the inverse of the MI mill). In scenario 3, oats was assumed to contribute $42 \%$ and DDGS (from dry mill facility) and soybean meal were assumed to 
each contribute $17 \%$ to the total feed input on a mass-input basis. These scenarios reflect the geographical preferences for the feed inputs. For example, DDGS is likely to be dominant over soybean and soybean meal in regions with high production of DDGS such as Iowa (scenario 2). Scenario 3 is more relevant for regions where oats is more prevalent in the local grain-crop supply, such as North and South Dakota. In section 7-6 of this manuscript, results obtained from the various scenarios investigated are presented

\subsection{LCA results and discussion of base case}

\subsubsection{GHG impact of a dairy feed mill in Michigan, U.S.}

In Figure 7-2, the GHG footprint contributions of various inputs and activities for the base case study are presented. The pie charts compare the effect of allocation choice on the resultant carbon footprint for the mill output. For both mass and economic allocation [Figure 7-2(A) and 7-2(B)], the majority of the GHG footprint of the dairy feed mill products were due to the input crops and other major ingredients to the mill (Category 1 inputs contributed approximately $84 \%$ of mill inputs by mass). Depending on allocation used, 73 to $82 \%$ of the total feed mill's GHG footprint was attributable to feed inputs in category 1. Category 1 impact was lower $(73 \%)$ in the feed mill's GHG footprint when economic allocation was used. This was because the emission factors (Table 7-6) for co-products such as cottonseed, DDGS and soybean meal on economic allocation basis were smaller given the lower value of these co-products in the market compared to those estimated using a mass allocation.

The next largest category for GHG emissions were mineral ingredients (Category 2) which contributed approximately 6 to $9 \%$ to total mill carbon footprint (and $12 \%$ of total feed mass). The next largest category for GHG emissions were supplements (Category 3), which contributed 4 to $7 \%$ of the carbon footprint depending on allocation method (approximately 4\% of total feed mass). Category 3 feed input GHG impact was estimated using Open IO data, and thus has a different system boundary than other inputs, as discussed in section 2.1.3. 


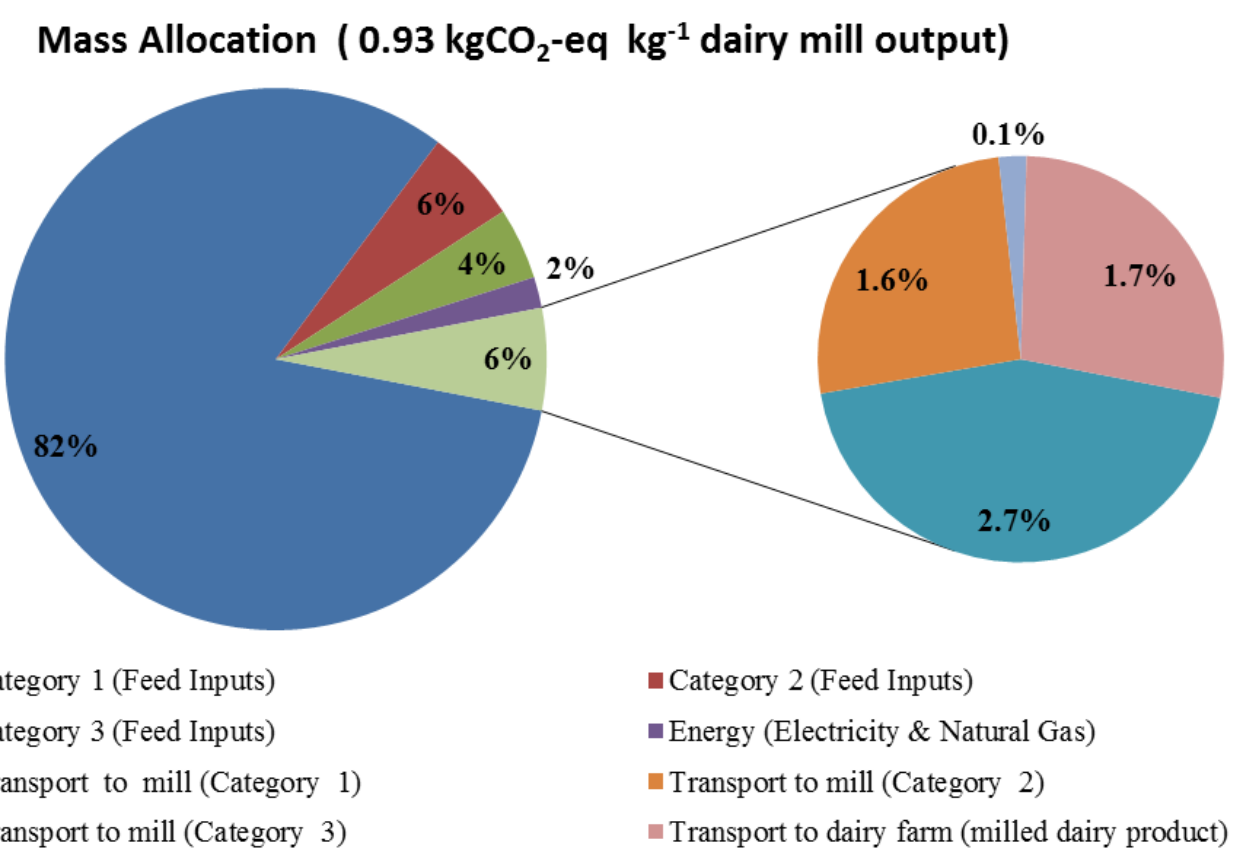

Figure 7-2 Relative contribution to GHG emissions of milled dairy feed (Base case analysis). Panel A Economic Allocation ( $0.62 \mathrm{kgCO}_{2}$-eq $\mathrm{kg}^{-1}$ dairy mill output)

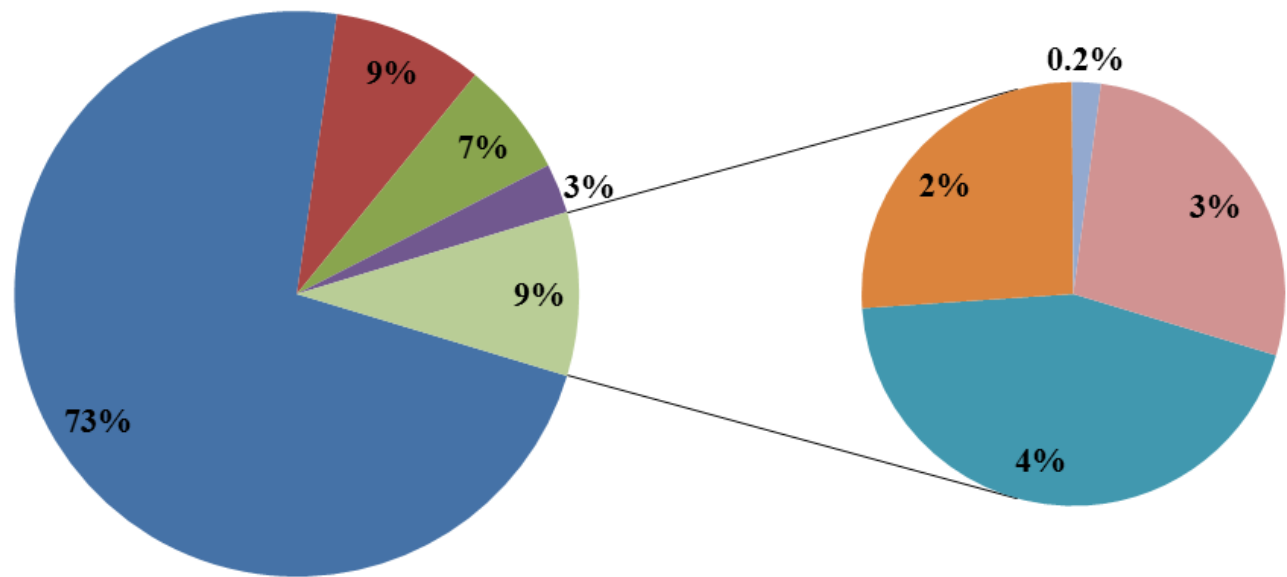

- Category 1 (Feed Inputs)

- Category 3 (Feed Inputs)

- Transport to mill (Category 1)

- Transport to mill (Category 3)
- Category 2 (Feed Inputs)

- Energy (Electricity \& Natural Gas)

- Transport to mill (Category 2)

- Transport to dairy farm (milled dairy product)

Figure 7-2 Relative contribution to GHG emissions of milled dairy feed (Base case analysis). Panel B 
Nonetheless, this larger GHG intensity (per unit mass of Category 3 input) was expected given that many of these inputs (e.g., amino acids) were subjected to much more processing compared to the major crop inputs (e.g., oats, soybean meal, DDGS).

An analysis of all unit processes contributing to the feed mill showed that the economic IO data represents about $4 \%$ of the total mill carbon footprint, and thus system boundary inconsistencies do not have substantial influence on the final GHG results. On-site energy consumption at the mill contributed only about 2 to $3 \%$ (see Figure 7-2) to the total GHG emissions depending on allocation, and natural gas for crop drying accounted for $80 \%$ of this energy impact. All transportation, both raw material delivery and distribution of the feed to local MI dairy farms, contributed approximately 6 to $9 \%$ of the footprint depending on allocation method, as shown in Figure 7-2. Section 7.5.2 provides details of the transportation impacts.

\subsubsection{Discussion of base case LCA results for annual emissions}

Category 1 feed inputs contributed approximately 19 and 11 million $\mathrm{kg} \mathrm{CO}_{2}$-eq year ${ }^{-1}$ for mass and economic allocation, respectively. This was due to high mass input rate and differences in emission factors based on economic and mass allocation as previously explained in section 7.3.1. Category 2 inputs contributed 1.3 and 1.4 million $\mathrm{kg} \mathrm{CO}_{2}$-eq year-1 for both allocation methods considered. Category 3 input contributions were approximately one million $\mathrm{kg} \mathrm{CO}_{2}$-eq $\mathrm{yr}^{-1}$ for both allocation methods considered. In the final analysis, the total GHG emission of all feed inputs of this milling site was estimated to be approximately 22 and 14 million $\mathrm{kg} \mathrm{CO}_{2}$-eq year ${ }^{-1}$ for mass and economic allocation, respectively.

A total of approximately 1.4 and 1.5 million $\mathrm{kg} \mathrm{CO}_{2}$-eq year ${ }^{-1}$ for mass and economic allocations, respectively, was the estimated GHG emissions due to fuel inputs associated with transportation. This accounted for GHG burdens due to transport of all feed ingredients to the milling site as well as the transportation of the processed dairy feed to various dairy farms. Figure 7-2 provides more details on the transportation 
impact. GHG burdens due to the transportation of feed ingredients to the milling site were about three times more than the impact due to the transport of milled dairy output to the various dairy farms. Transportation impact of feed ingredients (all feed categories) was estimated to be about one million $\mathrm{kg} \mathrm{CO}_{2}$-eq year ${ }^{-1}$ whereas transportation to various dairy farms was estimated to be $400,000 \mathrm{~kg} \mathrm{CO}_{2}$-eq year ${ }^{-1}$. The reason for this difference is that this milling site serves mainly the local market and is located at a distance close to customers whereas purchased mill inputs are transported much further.

Annual GHG emissions as a result of onsite energy use at this mill facility were approximately $450,000 \mathrm{~kg} \mathrm{CO}_{2}$-eq year ${ }^{-1}$ (economic allocation). Natural gas was the largest contributor, accounting for $80 \%$ of this annual total, with electricity consumption accounting for the remaining $20 \%$. Natural gas is used in drying corn grain, which arrives at the milling site with relatively high moisture content that is typical of a northern U.S. mill location. Mills in southern locations of the US generally receive corn that is of lower moisture content and hence tend to use much less energy in drying (based on communication with a mill manager).

Cradle-to-dairy farm GHG annual emissions were approximately 16 and 24 million $\mathrm{kg}$ $\mathrm{CO}_{2}$-eq $\mathrm{yr}^{-1}$ for the milled dairy feed product system including all inputs and transport activities using economic and mass allocations, respectively. When restricting the mill inputs to those directly consumed in mill operations, such as electricity, natural gas, and diesel fuel for transport of feed to dairy farms, annual milled dairy feed-related GHG emissions were much lower (860,000 $\mathrm{kg} \mathrm{CO}_{2}$-eq $\mathrm{yr}^{-1}$ using economic allocation). Total annual emissions from the MI feed mill, including dairy and non-dairy products are $860,000 / 0.90=950,000 \mathrm{~kg} \mathrm{CO}_{2}$-eq $\mathrm{yr}^{-1}$, where 0.90 is the economic allocation factor for this mill.

\subsection{Discussion of results from sensitivity analyses}


As described in section 7-4, sensitivity analyses were conducted to investigate three major scenarios for comparison with the base case GHG analysis. Figure 7-3 summarizes the GHG results estimated for all the scenarios considered. Figures E-2 through E-4 present GHG profile pie charts of the scenario results based on mass and economic allocations. In scenario 1, use of DDGS from a wet mill facility reduces the overall footprint of this mill by just 2 to $6 \%$ depending on allocation method (see Figure E-2). This is because the differences in emission factor values for DDGS from a wet mill relative to those from a dry mill were minor, especially for mass allocation (see Table 7-6).

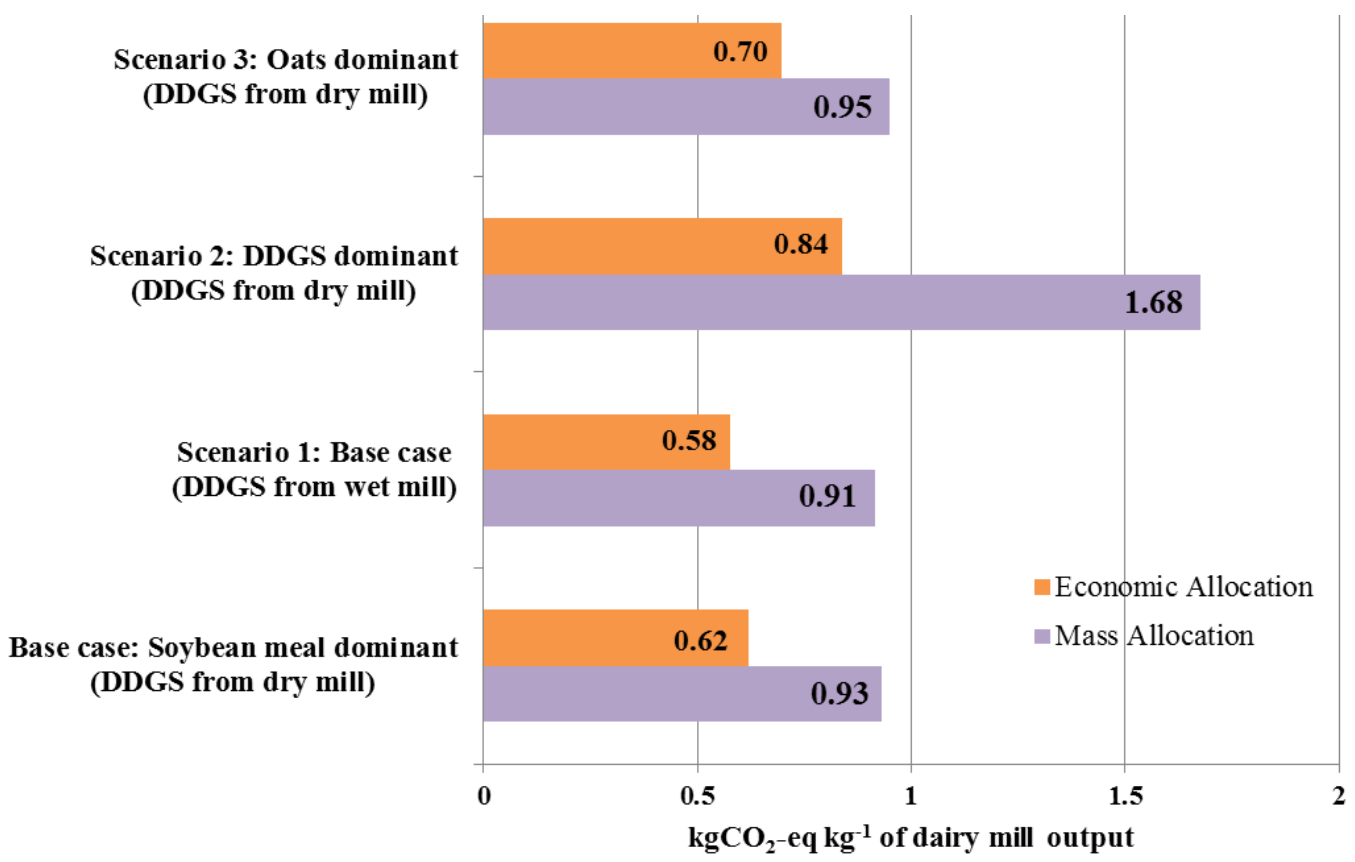

Figure 7-3 Sensitivity analysis of feed inputs to dairy feed mill greenhouse gas profile

Scenario 2, in which DDGS (from the dry mill facility) was considered to be dominant, resulted in a substantial increase in the mill GHG emission $\left(1.70 \mathrm{kgCO}_{2}\right.$-eq. $\mathrm{kg}^{-1}$ dairy mill output based on mass allocation) which was about two times that of the base case using a mass allocation (see Figure E-3). The feed mill GHG burdens increased by approximately $35 \%$, from 0.62 to $0.84 \mathrm{~kg} \mathrm{CO}_{2}-\mathrm{eq} \mathrm{kg}^{-1}$ dairy mill output, based on 
economic allocation. This was due to the relatively high emission factors for DDGS as opposed to soybean meal (See Table 7-6).

In scenario 3 (oats dominant), the GHG profiles for this mill were calculated to be 0.69 and $0.95 \mathrm{~kg} \mathrm{CO}$-eq. $\mathrm{kg}^{-1}$ dairy mill output for both economic and mass allocation, respectively (see Figure E-4). This resulted in a small increase relative to the base case of between 2 and $11 \%$ in the feed mill's GHG profile, depending on allocation method. This was not surprising given that the emission factor for oats reported in Table 6 is comparable to the base case in which soybean meal is the dominant feed ingredient.

These scenario analyses demonstrate that geographic differences in dairy feed mill GHG impacts can be substantial, especially for mill locations that predominantly process GHG-intense ingredients such as DDGS.

\subsection{Conclusions \& recommendations}

The goals of this carbon footprint study were to i. develop an LCA methodology applicable to the animal feed mill industry to accommodate a large number of inputs and activities associated with dairy mill operations, and ii. gain an understanding of the relative importance of milled dairy feed inputs and activities on the GHG emissions of the outputs of the mill (which are themselves inputs to dairy milk production) through the application of these developed methodologies. Our methods were able to accommodate a very large number of system inputs using a variety of inventory data sources, including existing databases, new LCA results for U.S. crops and agricultural co-products, and industry sector IO data on highly processed ingredients for which no ecoprofiles currently exist.

GHG emission values of 0.62 and $0.93 \mathrm{~kg} \mathrm{CO}_{2}$-eq $\mathrm{kg}^{-1}$ milled dairy feed were calculated based on economic and mass allocations, respectively. Overall, the highest contributors to the mill feed carbon footprint were agricultural co-product feed inputs (e.g., DDGS, soybean meal), contributing between 88 to $92 \%$ of the carbon footprint 
depending on the allocation method (see Figure 7-2). Mill energy use and transportation of mill inputs and of mill products together contributed 8 to $12 \%$. In the final analysis, this mill facility emits approximately 16 to 24 million $\mathrm{kg} \mathrm{CO}_{2}$-eq year ${ }^{-1}$ (depending on allocation method) assuming the study system boundary of cradle-todairy farm gate. Annual GHG emissions directly attributable to dairy and non-dairy feed mill activities, including on-site electricity use, process heat demands, and road transport of mill feed to local farms, totals $950,000 \mathrm{~kg} \mathrm{CO}_{2}$-eq $\mathrm{yr}^{-1}$. It is very clear from scenarios 2 and 3 that the type of feed crop greatly affects the feed mill GHG emissions. Crop inputs are likely to vary from U.S. region depending on local supply of feed crops.

This study is of a single dairy feed mill, and therefore further study is required to investigate location-specific differences in dairy feed mill inputs and resulting effects these differences have on GHG emissions for the mill feed products. Mill site energy consumption and transportation fuel emissions are under the control of mill operators.

Suggested measures to reduce dairy feed mill GHG emissions will center on the use of cleaner sources of electricity and low carbon fuels, such as biodiesel and renewable hydrocarbon diesel from biomass. It is also recommended that further studies be conducted to increase the mill sample size and to include several facilities from southern U.S. locations. Finally, given the large number of ingredients to the mill, we also recommend further studies of other highly processed supplements to help improve the accuracy of estimating the GHG burdens of milled dairy feeds.

\subsection{References}

F. Adom, A. Maes, C. Workman, Z. Clayton-Nierderman, G. Thoma, D. Shonnard. Regional carbon footprint analysis of dairy feeds for milk production in the USA. The International Journal of Life Cycle Assessment, 17 (5) (2012), pp. 520-534 http://dx.doi.org/10.1007/s11367-012-0386-y

Batal, A., Dale, N., Waller, J., Pettigrew, J. E., Hollis, G. R., Baker Hagler Jr., W. M. (2008). Feedstuffs 2009: Reference issue \& buyers guide. Minnetonka, MN, 
USA: Sarah Muirhead. URL

http://fdsmagissues.feedstuffs.com/fds/Reference_issue_2010/Reference_issue_ 2009/Section1_2008.pdf

British Standards Institute (BSI). (2008). Specification for the assessment of the life cycle greenhouse gas emissions of goods and services (PAS 2050: 2008). BSI.

Deru, M. P., \& Torcellini, P. A. (2007). Source energy and emission factors for energy use in buildings (NREL/TP-550-38617). Golden, CO, USA: National Renewable Energy Laboratory.

Edwards, R., Larive, J. F., Mahieu, V. \& Rouveirolles, P. (2006). Well-to-wheels analysis of future automotive fuels and powertrains in the European context: Well-to-wheels report Version $2 \mathrm{~b}$ [online report]. URL http://ies.jrc.ec.europa.eu.

Gerber, P., Vellinga, T., Opio, C., Henderson, B., \& Steinfeld, H. (2010). Greenhouse gas emissions from the dairy sector, a life cycle assessment. Rome: FAO Food and Agricultural Organisation of the United Nations Animal Production and Health Division.

Google Scholar. (2009). Google Scholar [Online search engine]. URL http://scholar.google.com/

Hubbard Feeds. (2007). Hubbards Feeds [WWW page]. URL http://www.hubbardfeeds.com/Default.aspx

International Feed Industry Federation, 2009

International Feed Industry Federation. (2009). International Feed Industry Federation Annual Report 2009. Brussels, Belgium: International Feed Industry Federation.

ISI. (2009). Web of Knowledge [online search engine]. URL http://apps.webofknowledge.com

ISO. (2006a). 14040: 2006 Environmental management-life cycle assessmentprinciples and framework. Geneva, Switzerland: ISO.

ISO. (2006b). 14044: 2006 Environmental management-life cycle assessmentrequirements and guidelines. Geneva, Switzerland: ISO. 
Miller, J.K., Ramsey, N., \& Madsen, F.C. (1988). The trace elements. In D.C. Church (Ed.), The ruminant animal-digestive physiology and nutrition (pp. 342-401). Englewood Cliffs, NJ, USA: Prentice-Hall.

Nielsen, P.H., Nielsen, N. A., Weidema, B.P., Dalgaard, R., \& Halberg, N. (2003). LCA food database [Online database]. URL www.lcafood.dk

PRé Consultants. (2009). SimaPro 7.1 LCA software [Computer software]. URL http://www.pre.nl/

ProQuest. (2009). ProQuest [online search engine] URL http://www.proquest.com/en$\mathrm{US} /$

B. Shaw, P. Buharivala, C. Parnell Jr., M. Demny Emission factors for grain receiving and feed loading operations at feed millsTransactions of the ASAE, 41 (3) (1998), pp. 757-765

J. Siciliano-Jones, M. Socha, D. Tomlinson, J. DeFrain Effect of trace mineral source on lactation performance, claw integrity, and fertility of dairy cattle Journal of Dairy Science, 91 (5) (2008), pp. 1985-1995

The Sustainability Consortium. (2011). Open-IO Version Beta 1.5 [Online database]. URL http://www.sustainabilityconsortium.org/open-io/

Thoma, G., Popp, J., Nutter, D., Shonnard, D., Ulrich, R., Matlock, M., Adom, F. (2010). Regional analysis of greenhouse gas emissions from milk production practices in the United States. Rosemont, IL, USA: Innovation Centre for US Dairy.http://www.usdairy.com/Public\%20Communication\%20Tools/USDairy_ Sustainability_Report_12-2010\%20(4).pdf

Thoma, G., Popp, J., Nutter, D., Shonnard, D., Ulrich, R., Matlock, M., Adom, F. (2012). Greenhouse gas emissions from milk production and consumption in the U.S.: A cradle to grave life cycle assessment. International Dairy Journal (2012). 


\section{Chapter 8}

\section{Summary, Conclusions, and Recommendations for Future Work}

\subsection{Summary and conclusions}

Compositional analysis of defatted syrup from a corn ethanol dry mill as a feedstock for bio-based products: DCS which is a co-product of the dry-grind corn ethanol process was analyzed for its physical and chemical characteristics. With total solids of $37.4 \%$ wt., a mass balance closure on all components of DCS was 101\%. Total carbohydrates ( $28 \%$ of dry wt.) comprised of starch components $(6 \%)$, soluble carbohydrates $(12 \%) \&$ non-starch carbohydrates (10\%). Structural and non-structural bound hemicellulose components included; xylan (6\%), mannan (1\%), arabinan (1\%) and galatactan (3\%). The ash content comprised of 12\% wt. DM basis while protein, glycerol and amino acids were 8\% wt., 33\%, and 3\% wt. on DM basis, respectively. Syrup has good potential as a renewable feedstock for bio-chemicals production through either fermentation or separation of various compounds directly from the syrup.

\section{Optimization of the dilute acid and enzymatic pretreatment of defatted syrup} from a corn ethanol dry mill: The sugar platform optimization using DCS investigated the use of different acid concentrations $(0,1 \& 2 \%)$ and subsequent enzymatic hydrolysis over a range of hydrolysis reaction time. Dilute acid pretreatment and enzymatic hydrolysis were conducted at $121^{\circ} \mathrm{C}$ and $50^{\circ} \mathrm{C}$ respectively. In our choice of optimal condition, our goal was to identify the condition that maximizes

yield of total monomer sugars within the shortest possible time as well as producing low concentrations of inhibitors. Avoidance of the application of enzyme will be ideal if at all possible given the significant portion of the costs associated with bio-based chemical production. From our analysis, we observed that contribution of cellulase enzymes to the TMS yield was not so significant. With high level of certainty, we determined that the first stage acid pretreatment for 60 minutes at $2 \%$ acid was efficient 
in producing approximately $86 \%$ of the theoretically available carbohydrates with acceptable low inhibitory level.

\section{Optimization of the protein hydrolysis scheme of defatted syrup from a corn} ethanol dry mill facility: The protein optimization experiments of my $\mathrm{Ph}$.D. research investigated the combined effect of hydrolysis reaction time, temperature, and ratio of enzyme to substrate ratio to develop hydrolysis process that optimizes the amount of usable amino acids available in DCS. Apart from hydrolysis pathway 4, experimental results show nearly quantitative recovery amino acids from the protein contained in DCS. Hydrolysis pathway 1, which is DAP alone at "optimum carbohydrate hydrolysis conditions (60 $\mathrm{min}, 2 \%$ acid)" yielded $82-68 \%$ of the theoretically available amino acids. Hydrolysis pathway 2, which is DAP of syrup followed by subsequent protease hydrolysis was also investigated using Trypsin, Pronase E (streptomyces griseus) and Protex 6L. Overall, reported yields ranged from 100-78\% of the theoretically available amino acids ( $\mathrm{pH} 6 \&$ 7). For this pathway, Pronase $\mathrm{E}$ at $\mathrm{pH} 7$ resulted in the highest yield of $10.7 \mathrm{mg} / \mathrm{ml}(100-89 \%)$ of total amino acids. Hydrolysis pathway 3 which was a standalone experiment using proteases Trypsin, Pronase E (streptomyces griseus) and Protex 6L on the unpretreated DCS reported yields ranging from 100-46\% of the theoretically available amino acids. Protex at $\mathrm{pH} 7$ yielded a total amino acid concentrations of $12.5 \mathrm{mg} / \mathrm{ml}(100 \%$ yield) which was the highest for pathway 3 . Pathway 4 (simultaneous hydrolysis with cellulase and protex) generally reported the lowest yields for both amino acids and total monomer sugars. Total amino acid concentration for 1 and $2 \%(\mathrm{v} / \mathrm{v})$ loaded enzymatic hydrolysis solutions ranged between $2-3 \mathrm{mg} / \mathrm{ml}$ representing only $18-27 \%$ of the theoretically available amino acids in DCS biomass.

\section{Modeling of dilute acid pretreatment process using defatted corn syrup as} feedstock: Techno-economic analysis \& life cycle assessment: A preliminary cost analysis to estimate the initial capital cost and operating cost of this facility using Aspen Plus Economic Analyzer ${ }^{\circledR}$ and (iii) A greenhouse gas analysis to understand the 
environmental impact of this facility. A conceptual process design has been constructed to produce the carbohydrate and amino acid rich stream. The initial capital cost was estimated to be $\$ 4,682,000$ with substantial operational $(\$ 22,100,000)$ and raw material cost $(\$ 19,300,000)$ on an annual basis. This is mainly attributable to the high steam and 98wt sulfuric acid requirement. Finally, GHG emissions from this facility was estimated to be $114,000,000 \mathrm{kgCO}_{2} \mathrm{e} / \mathrm{yr}\left(114,000 \mathrm{MT} \mathrm{CO}_{2} \mathrm{e} / \mathrm{yr}\right)$ with steam and ammonia contributing 72 and $24 \%$ while all other inputs contributed $4 \%$ or less.

\section{Regional carbon footprint analysis of dairy feeds for milk production in the} United States: The next objective of my Ph.D. research work is the LCA of dairy feeds in the U.S. The main goal was to estimate the GHG emissions from the cultivation and harvesting of dairy feeds on a basis of one dry kilogram of dairy feed harvested or produced $\left(\mathrm{gCO}_{2} \mathrm{e} / \mathrm{kg}\right.$ of dry dairy feed). There were large differences in GHG emissions among the different dairy crops, with corn silage showing the lowest, while oats and DDGS displayed the highest. This variability was largely driven by fertilizer and energy utilization intensity. There was also some variability in carbon footprint for any crop from region to region, driven by regional differences in energy and lime use, but this variability was smaller than inter-crop variability.

The highest contributor to carbon footprint was the on-farm application of inorganic $\mathrm{N}$ fertilizer except for the leguminous feeds, whereas the fertilizer input categories $\mathrm{P}, \mathrm{K}$, and $\mathrm{S}$ accounted for relatively small impacts for all crops. About $65 \%$ of inorganic $\mathrm{N}$ fertilizer GHG emissions was due to $\mathrm{N}_{2} \mathrm{O}$ release upon application, whereas 35\% was from fertilizer manufacture. $\mathrm{N}_{2} \mathrm{O}$ emission contribution from crop residues was also significant for most crops. With $\mathrm{N}$ fertilizer input being the largest contributor to GHG emissions, much effort should be targeted toward lowering emissions associated with their production and use on the farm. Additionally, the efficient transfer of knowledge to farmers with regards to fertilizer best management practices might help reduce emissions on the farm. The use of crop protection chemicals was not so significant 
however, and energy use impacts varied widely from region to region, likely due to differences in climate, energy conservation programs, and need for crop drying.

This study highlights key crop inputs that are the drivers for emissions of greenhouse gases from the cradle-to-gate cultivation and harvesting for US dairy grain and forage crops. These crop results are equally applicable for uses other than dairy products; for example food production in general and bioenergy.

Carbon footprint analysis of dairy feed from a mill in Michigan, U.S: The final objective of my Ph.D. research work was GHG analysis of a dairy feed mill. The goals of this carbon footprint study were to i. develop an LCA methodology applicable to the animal feed mill industry to accommodate a large number of inputs and activities associated with dairy mill operations, and ii. gain an understanding of the relative importance of milled dairy feed inputs and activities on the GHG emissions of the outputs of the mill (which are themselves inputs to dairy milk production) through the application of these developed methodologies. Our methods were able to accommodate a very large number of system inputs using a variety of inventory data sources, including existing databases, new LCA results for U.S. crops and agricultural coproducts, and industry sector IO data on highly processed ingredients for which no ecoprofiles currently exist.

GHG emission values of 0.62 and $0.93 \mathrm{~kg} \mathrm{CO}_{2}$-eq $\mathrm{kg}^{-1}$ milled dairy feed were calculated based on economic and mass allocations, respectively. Overall, the highest contributors to the mill feed carbon footprint were agricultural co-product feed inputs (e.g., DDGS, soybean meal), contributing between 88 to $92 \%$ of the carbon footprint depending on the allocation method. Mill energy use and transportation of mill inputs and of mill products together contributed 8 to $12 \%$. In the final analysis, this mill facility emits approximately 16 to 24 million $\mathrm{kg} \mathrm{CO}_{2}$-eq year ${ }^{-1}$ (depending on allocation method) assuming the study system boundary of cradle-to-dairy farm gate. Annual GHG emissions directly attributable to dairy and non-dairy feed mill activities, 
including on-site electricity use, process heat demands, and road transport of mill feed to local farms, totals $950,000 \mathrm{~kg} \mathrm{CO}_{2}$-eq $\mathrm{yr}^{-1}$. It is clear from the scenarios (2 and 3) investigated that the type of feed crop greatly affects the feed mill GHG emissions. Crop inputs are likely to vary from U.S. region depending on local supply of feed crops.

This study is of a single dairy feed mill, and therefore further study is required to investigate location-specific differences in dairy feed mill inputs and resulting effects these differences have on GHG emissions for the mill feed products. Mill site energy consumption and transportation fuel emissions are under the control of mill operators. Suggested measures to reduce dairy feed mill GHG emissions will center on the use of cleaner sources of electricity and low carbon fuels, such as biodiesel and renewable hydrocarbon diesel from biomass.

\subsection{Recommendations for future work}

All the optimization experiments (Chapters $3 \& 4$ ) focused on producing sugar and amino acid platform for subsequent production of value added products via fermentation. The glycerol glut on the marketed has stimulated research into using glycerol as a feedstock for bio-products. Future research work should investigate the potential of DCS in this regard given the significant amount of glycerol component. Specifically, the potential of using both the fermentable carbohydrates and glycerol component to simultaneous produce succinic acid is important and needs further investigation. Theoretically, they both can meet global demand for succinic acid (Chapter 2). Additionally, since different alternate pathways could result in quantitative recovery of amino acids, a techno-economic analysis taking into account these routes will be important to help understand the economic impacts of these hydrolysis routes.

The techno-economic analysis focused on just a previous determined optimum carbohydrate hydrolysis conditions (60 min, 2\% acid). Future research work should investigate other hydrolysis pathways like dilute acid pretreatment followed by protein hydrolysis or just the standalone scenario where only proteases were recovered. 
Current process design should be improved upon by investigating the effect of heat integration using heat exchangers heated hydrolysate streams from pretreatment reactor to preheat incoming DCS streams to the facility. This may help reduce cost of utilities. Finally, there is the need to investigate the potential combusting the unreacted residues as a source of heat and power generation to this facility.

The LCA on dairy feeds is a comprehensive GHG analysis of commonly used dairy feeds in the U.S. On the energy front, there is the need to promote the use of safe and cleaner forms of energy to help reduce climate active GHG emissions associated with the energy input needed by farmers. Also, there is the need to investigate other environmental impacts besides carbon footprint. For example, future studies should investigate impacts such as eutrophication, land use intensity, water use impact among others. Hopefully, results from the dairy feed LCA will be useful for reducing GHG emissions by guiding efforts to modifying agricultural practices with respect to fertilizer application, use of manure, and energy consumption.

For the mill GHG analysis, it is also recommended that further studies be conducted to increase the mill sample size and to include several facilities from southern U.S. locations. Finally, given the large number of ingredients to the mill, we also recommend further studies of other highly processed supplements to help improve the accuracy of estimating the GHG burdens of milled dairy feeds. 


\section{Appendix}

\section{Appendix A: Supplementary information for sugar platform optimization experiments}

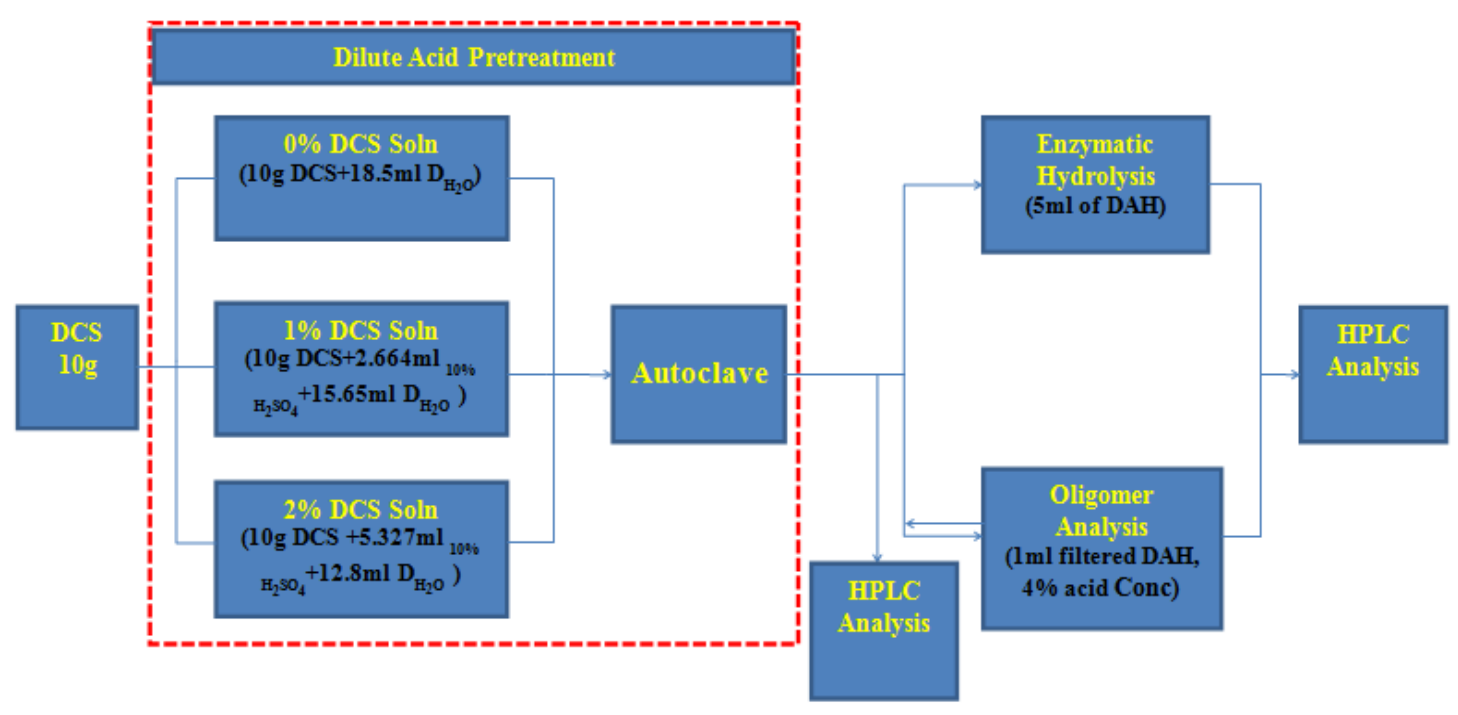

Figure A-1 Flow diagram of dilute acid hydrolysis and enzymatic saccharification of

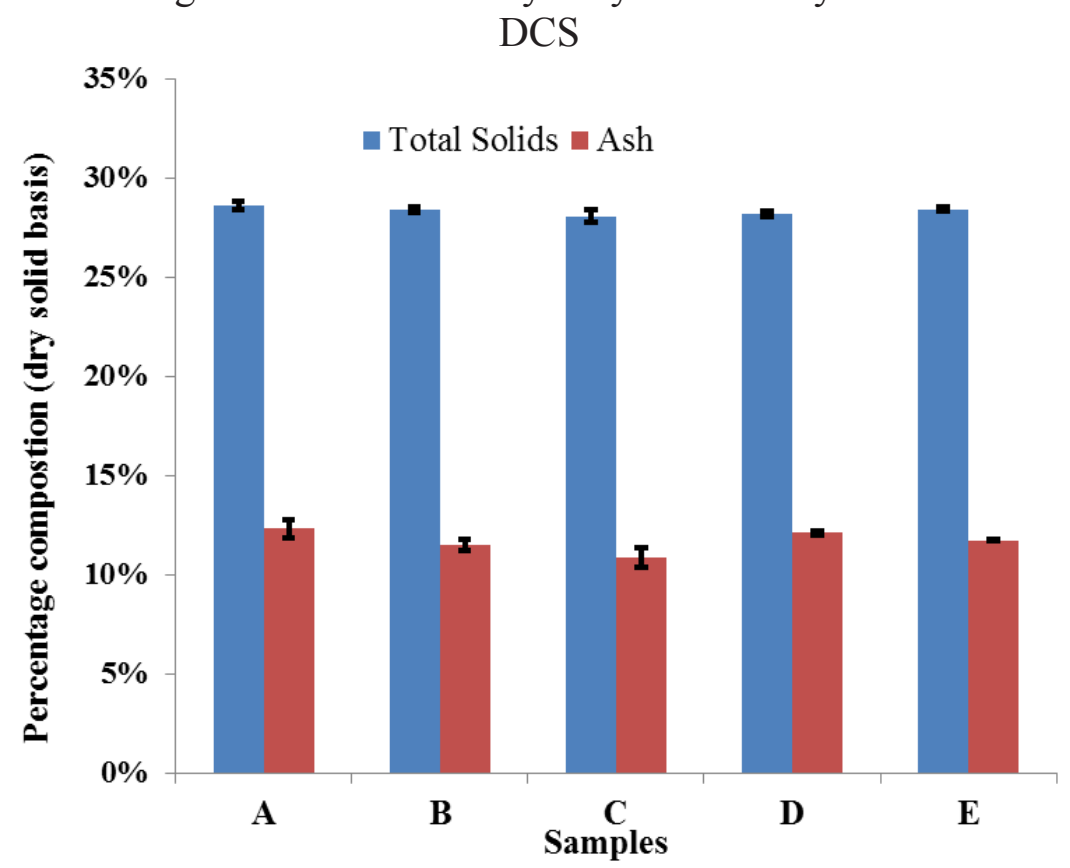

Figure A-2 Total Solids and Ash Content for DCS used for hydrolysis 


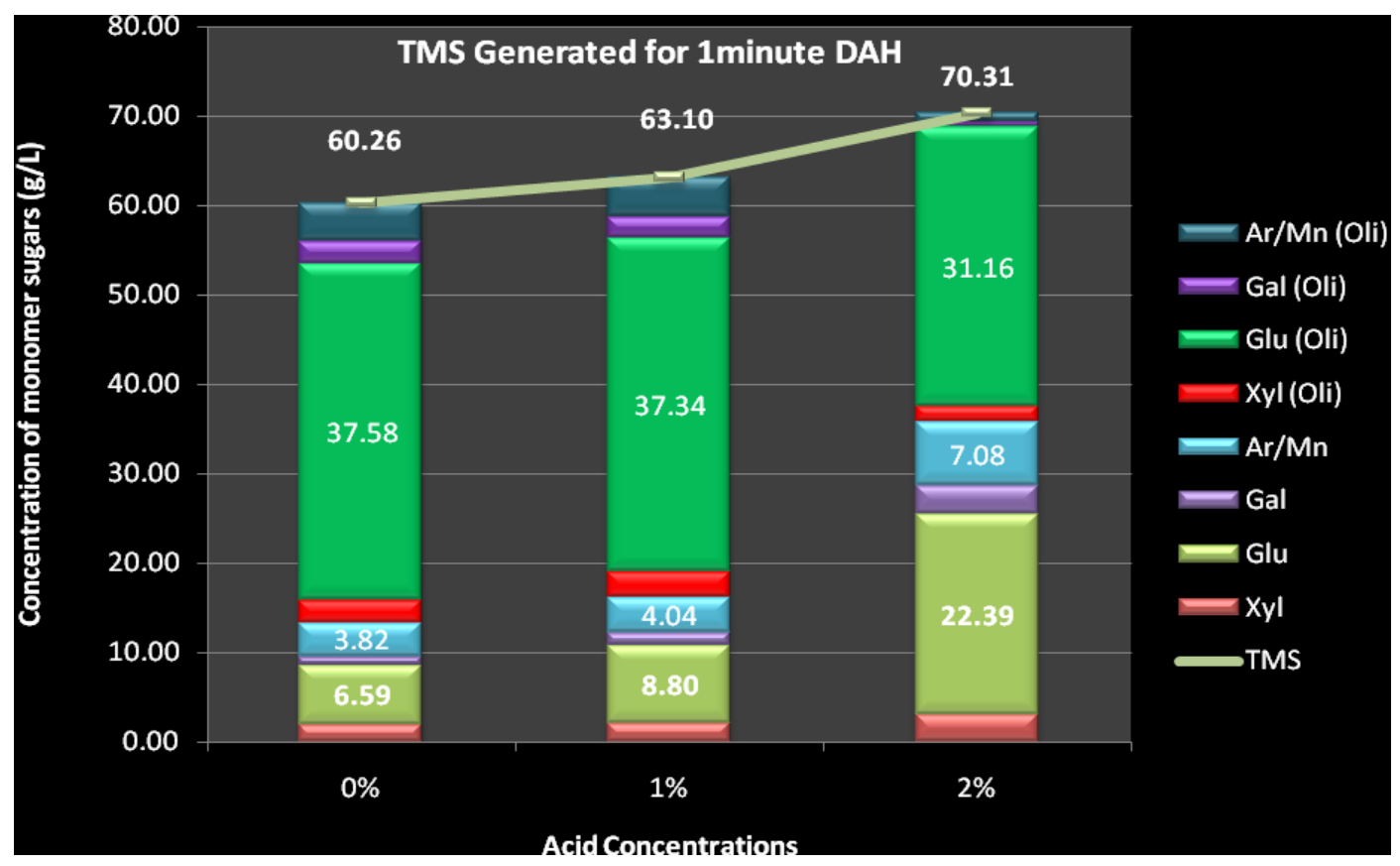

Figure A-3 TMS for 1-minute hydrolysis (first stage dilute acid hydrolysis +oligomer

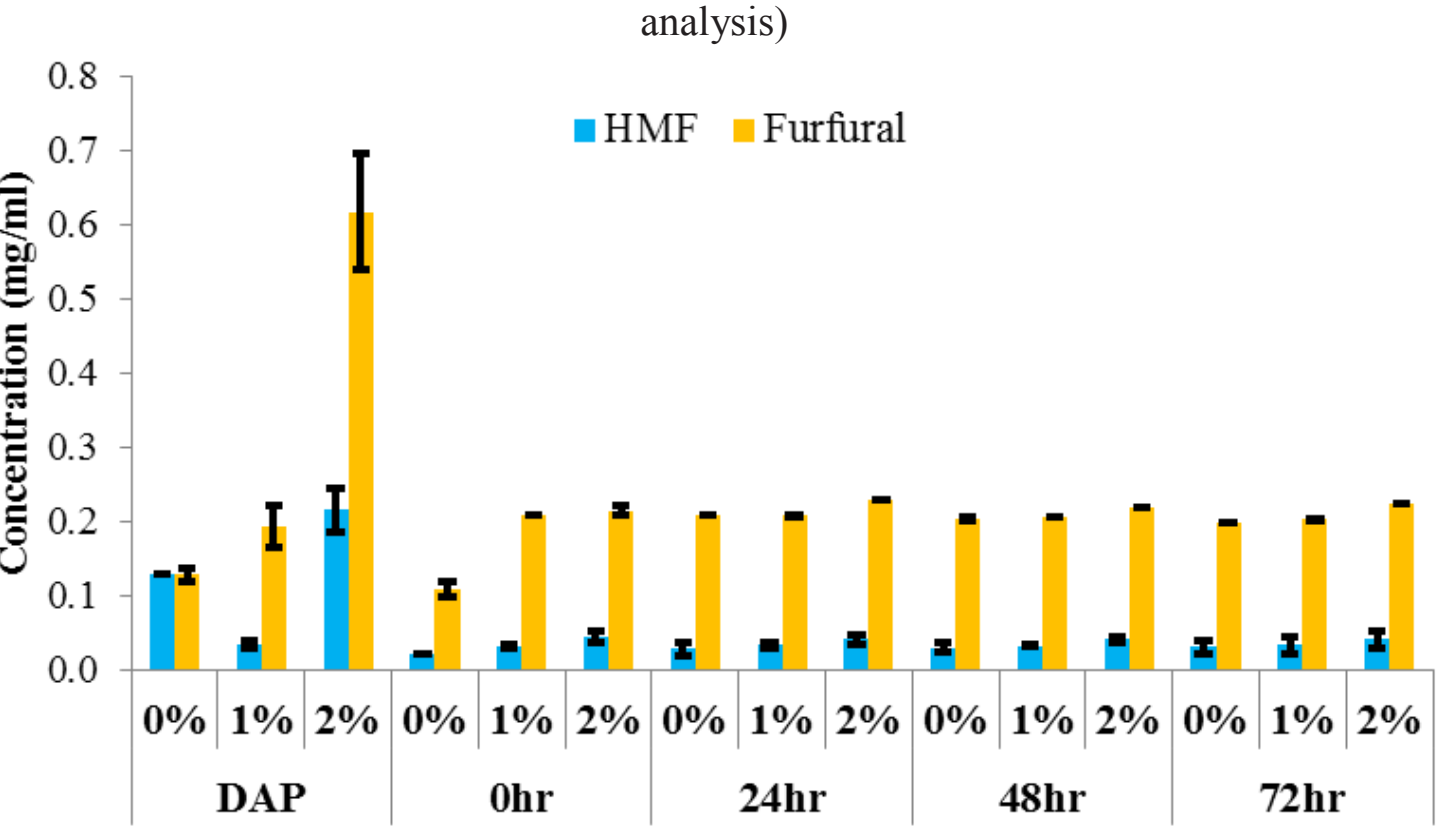

Figure A-4 Concentrations of inhibitors generated for 1 minute hydrolysis scheme 


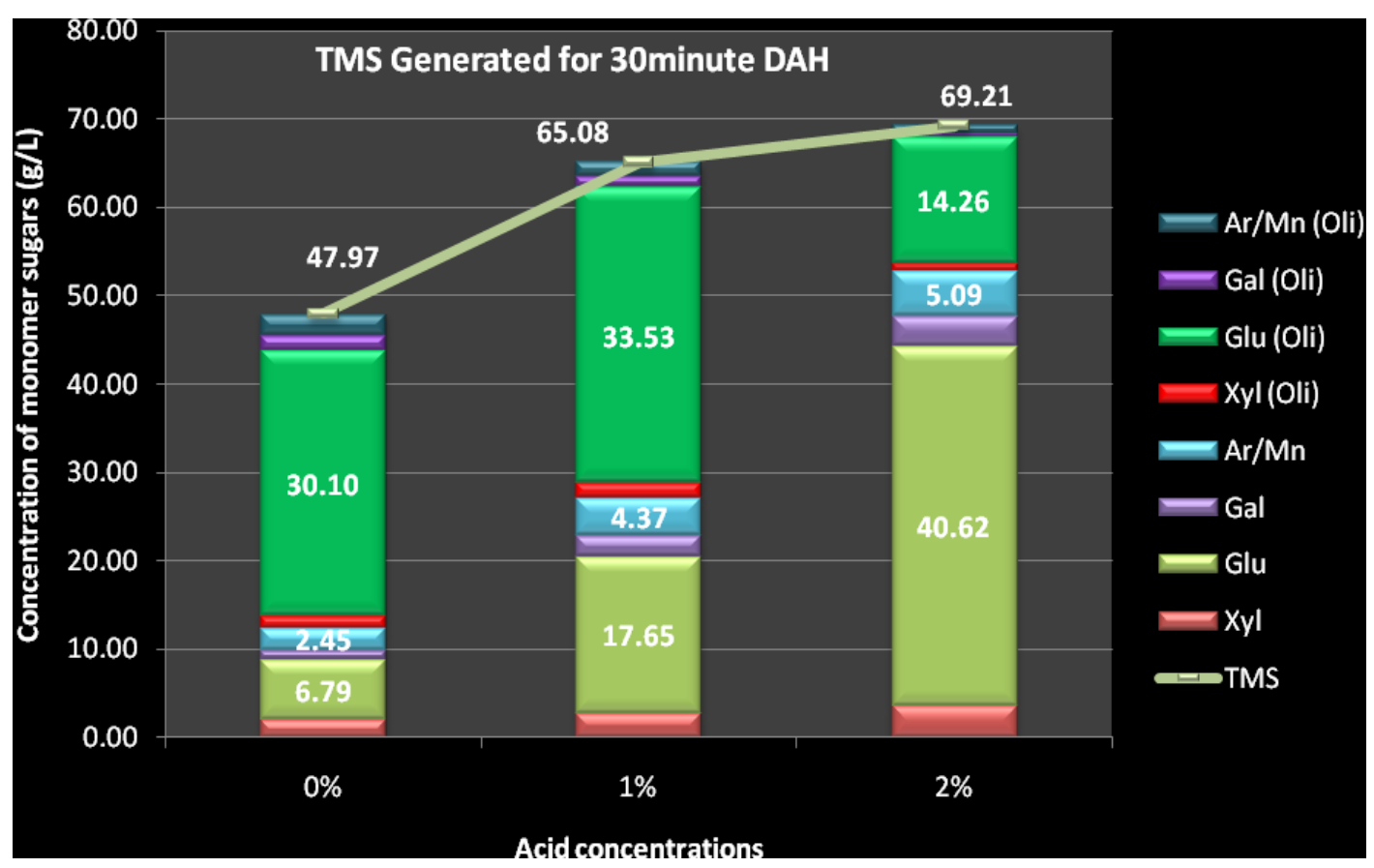

Figure A-5 TMS for 30-minute hydrolysis (first stage dilute acid hydrolysis +oligomer analysis)

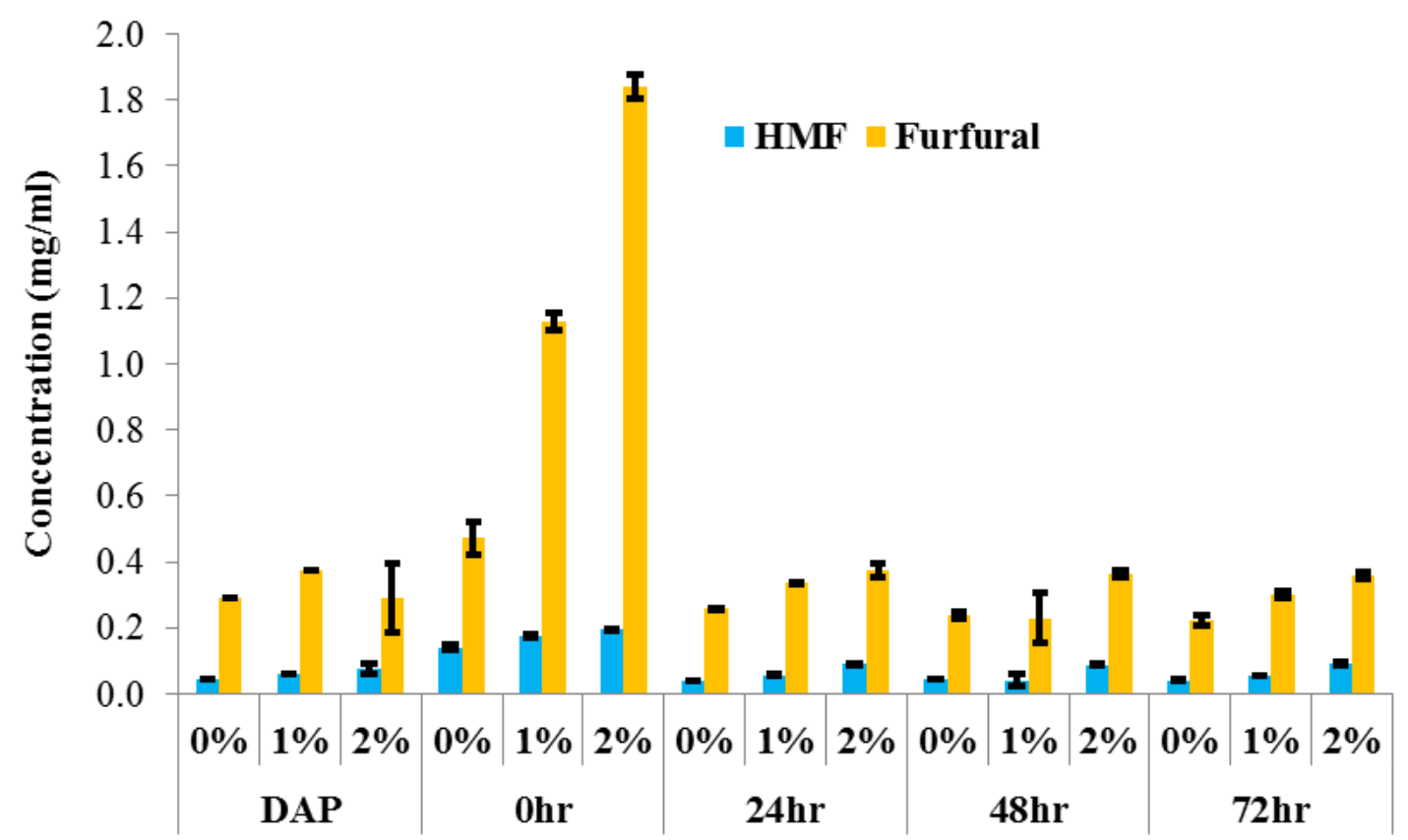

Figure A-6 Concentrations of inhibitors generated for 30 minutes hydrolysis scheme 


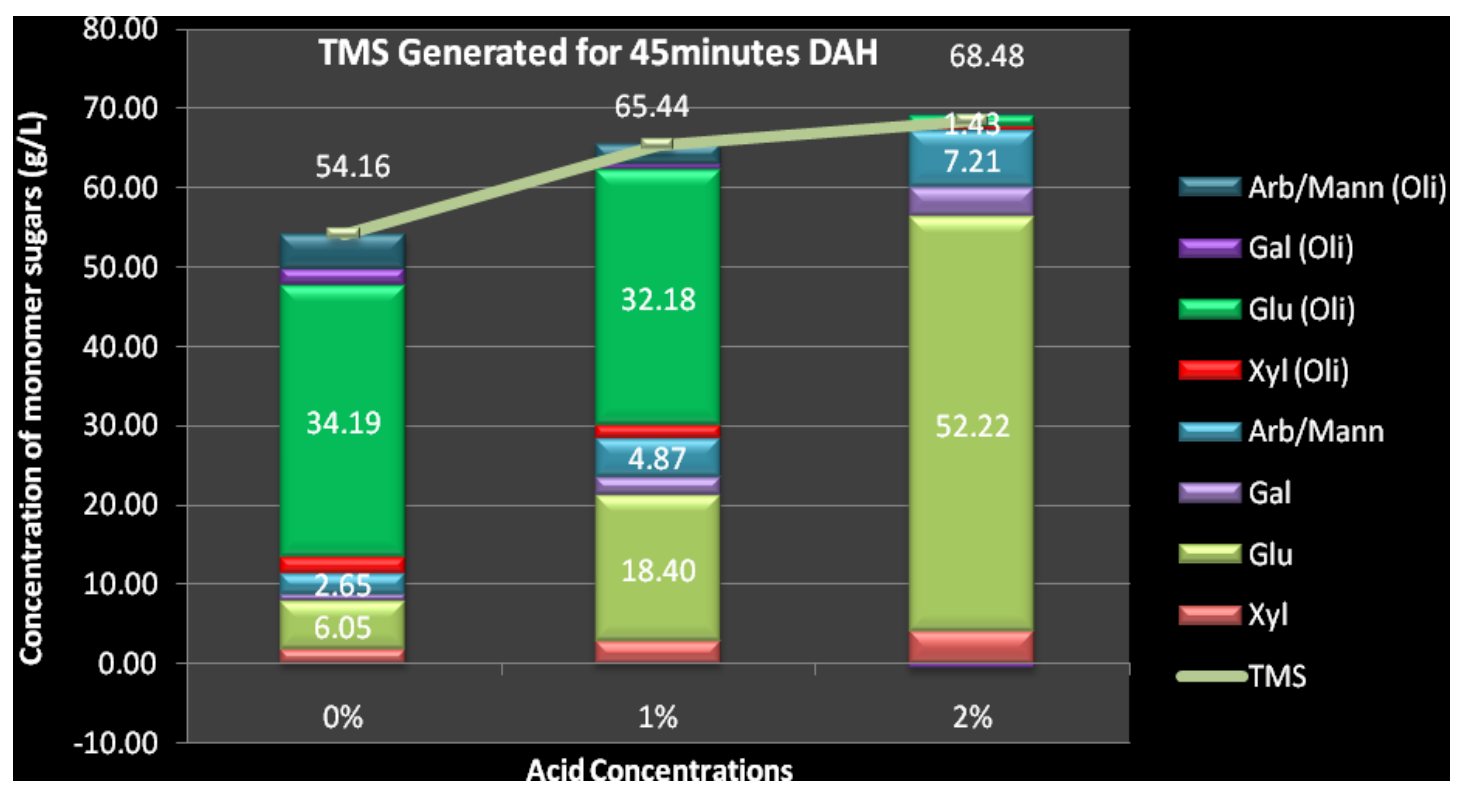

Figure A-7 TMS for 45-minute hydrolysis (first stage dilute acid hydrolysis +oligomer analysis)

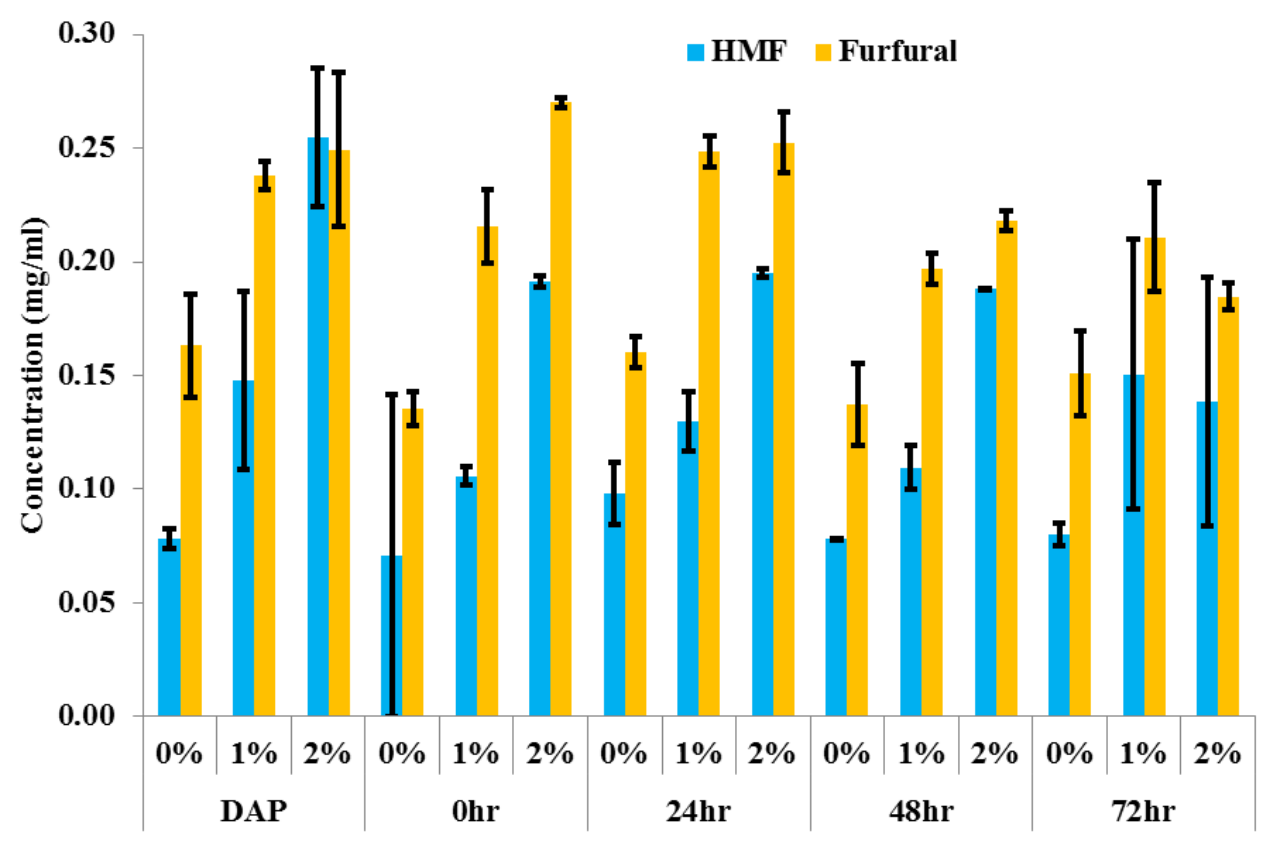

Figure A-8 Concentrations of inhibitors generated for 45 minutes hydrolysis scheme 


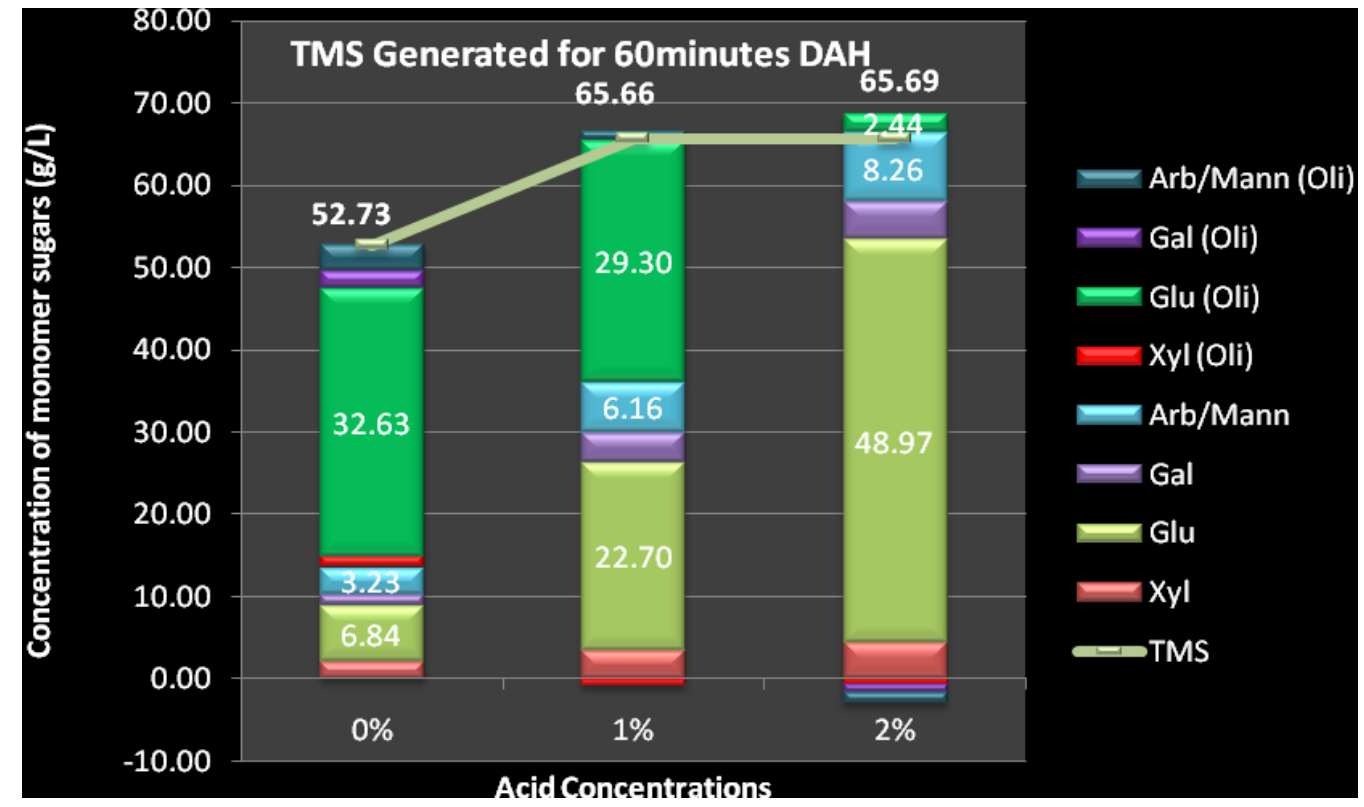

Figure A-9 TMS for 60-minute hydrolysis (first stage dilute acid hydrolysis +oligomer analysis)

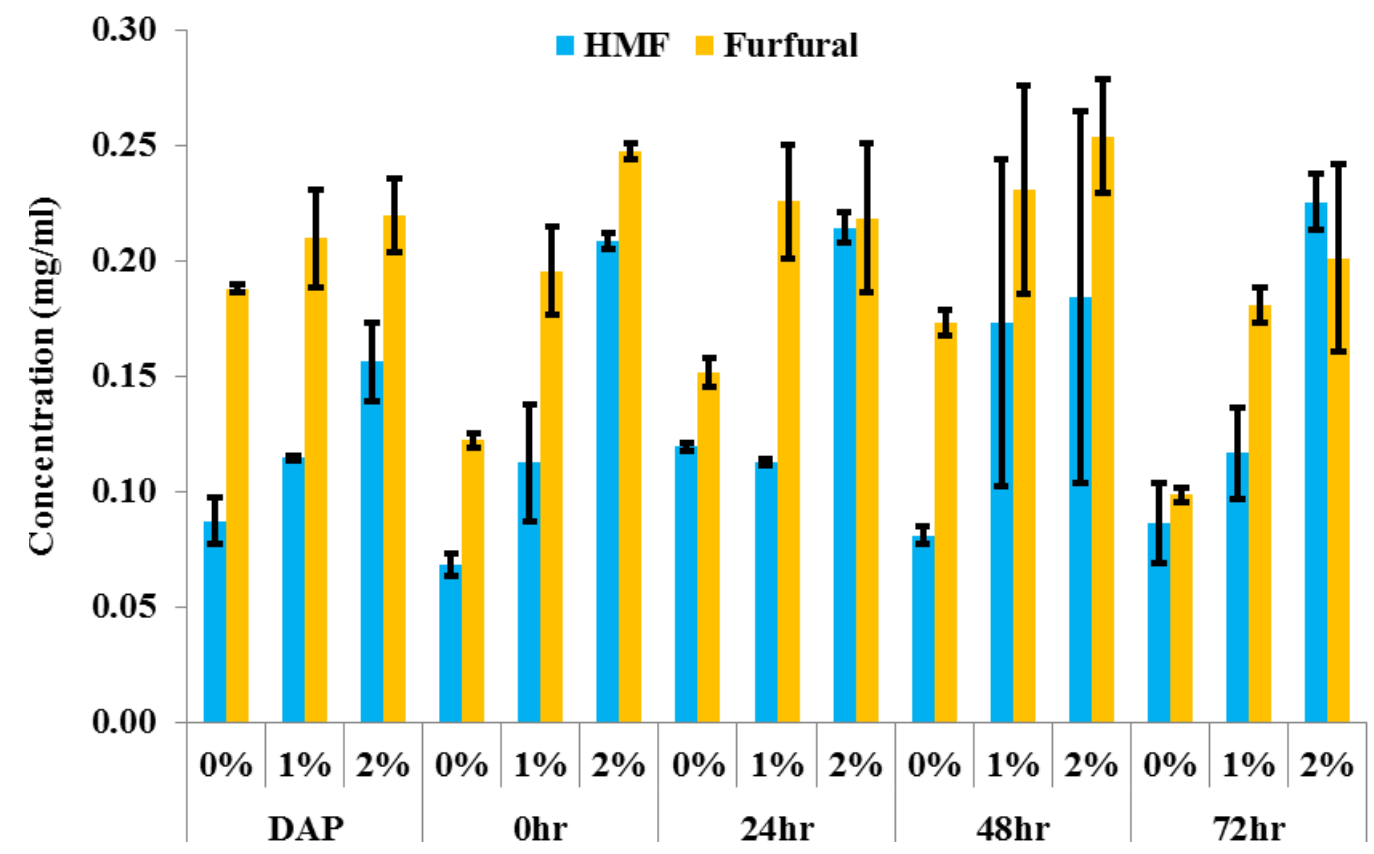

Figure A-10 Concentrations of inhibitors generated for 60 minutes hydrolysis scheme 


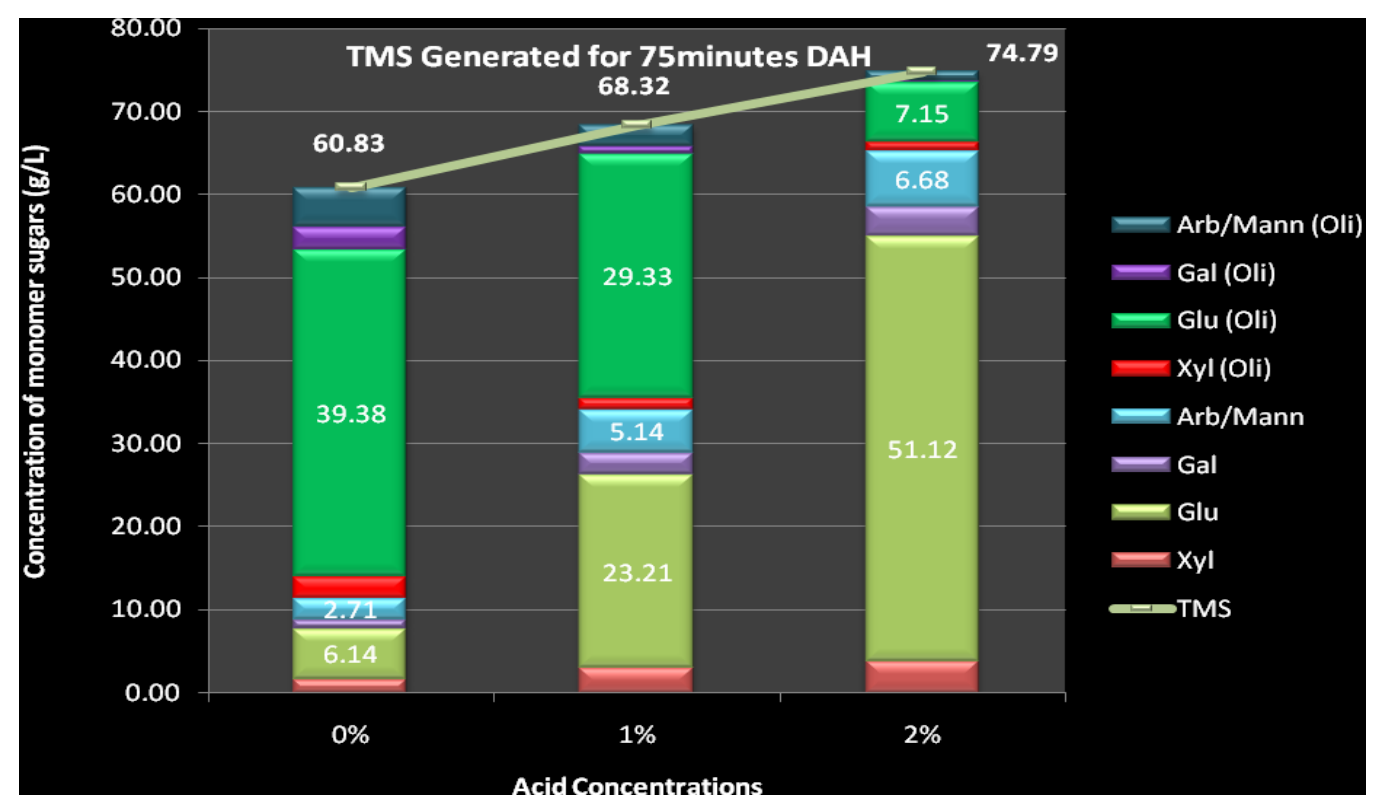

Figure A-11 TMS for 75-minute hydrolysis (first stage dilute acid hydrolysis +oligomer analysis)

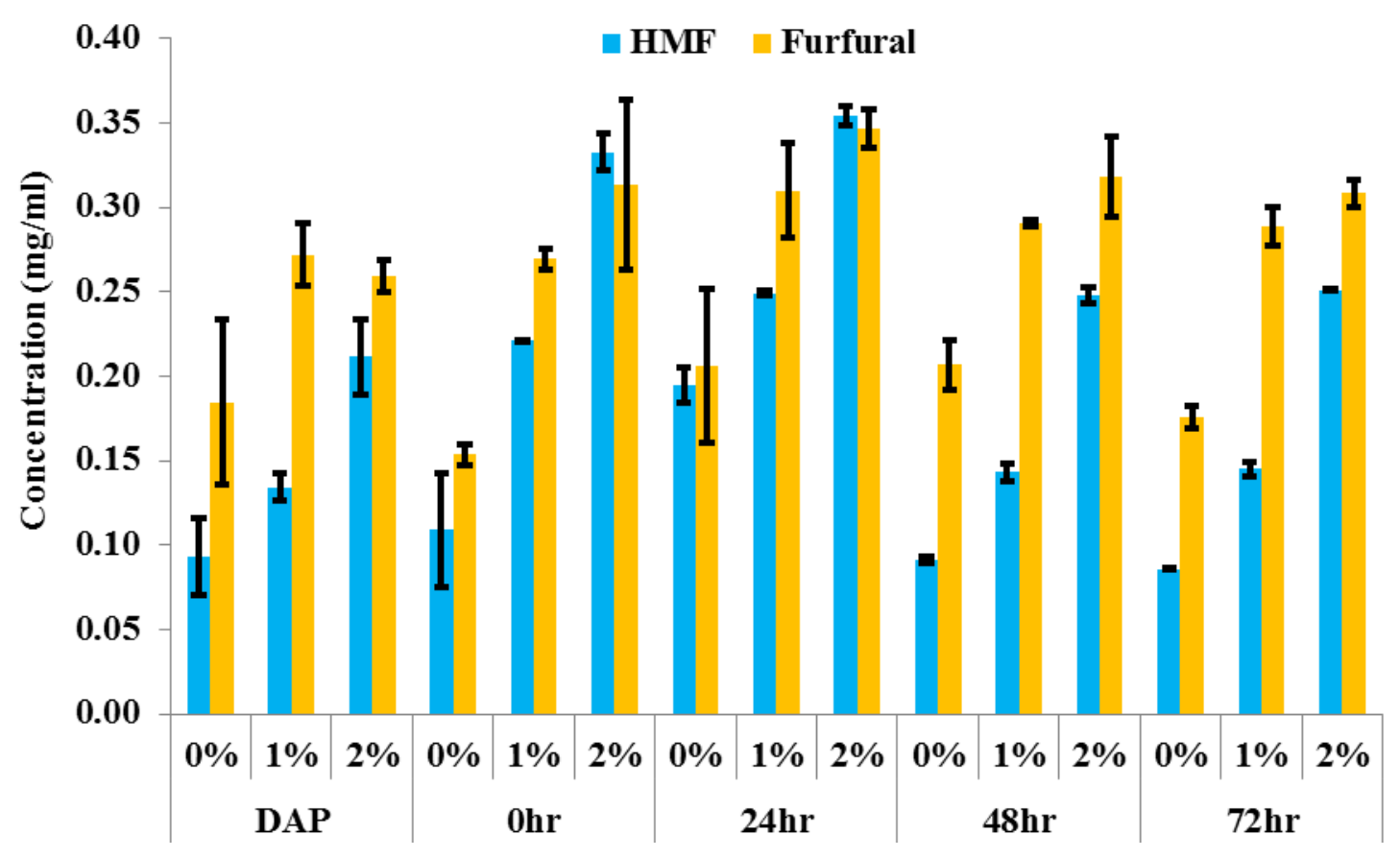

Figure A-12 Concentrations of inhibitors generated for 75-minute hydrolysis scheme 


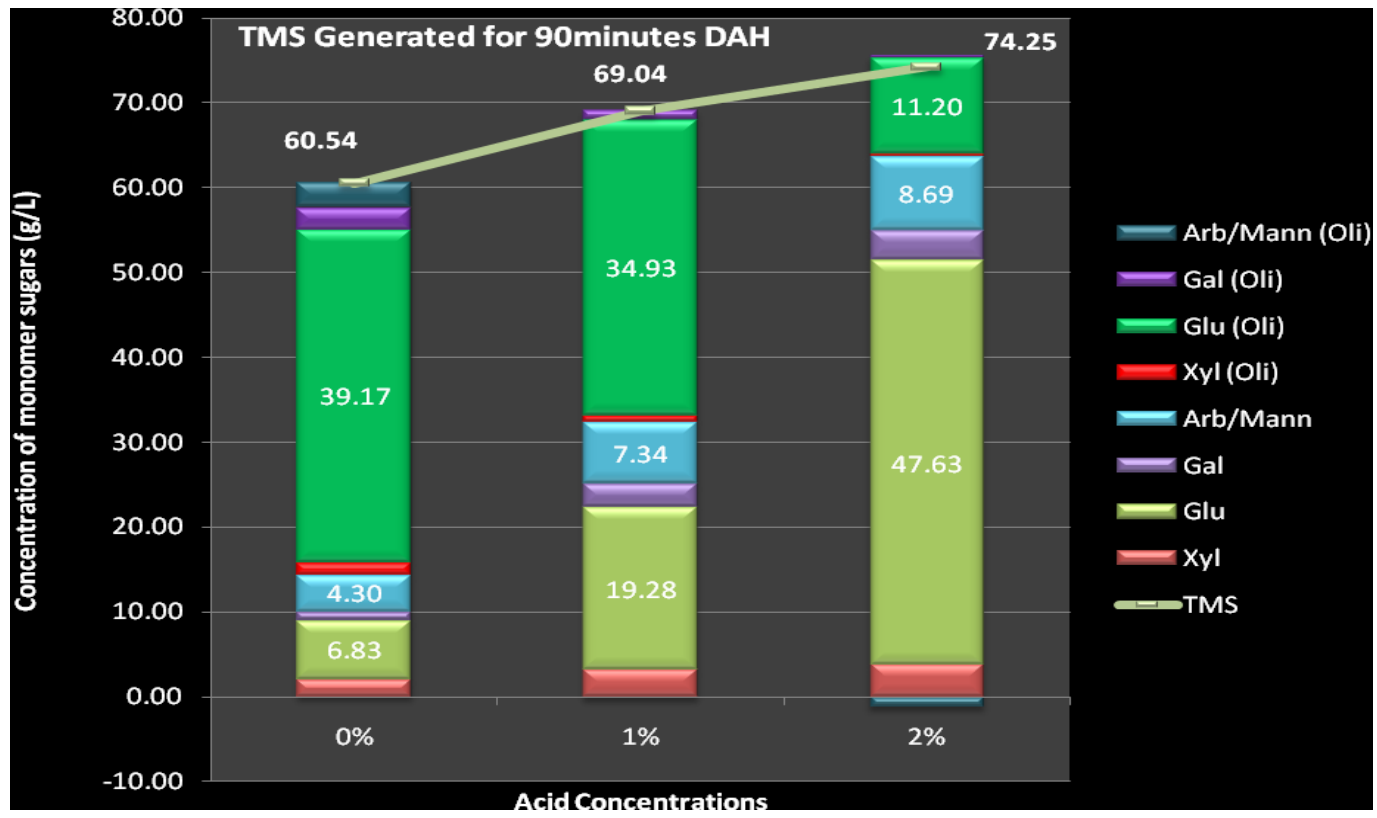

Figure A-13 TMS for 90-minute hydrolysis (first stage dilute acid hydrolysis +oligomer analysis)

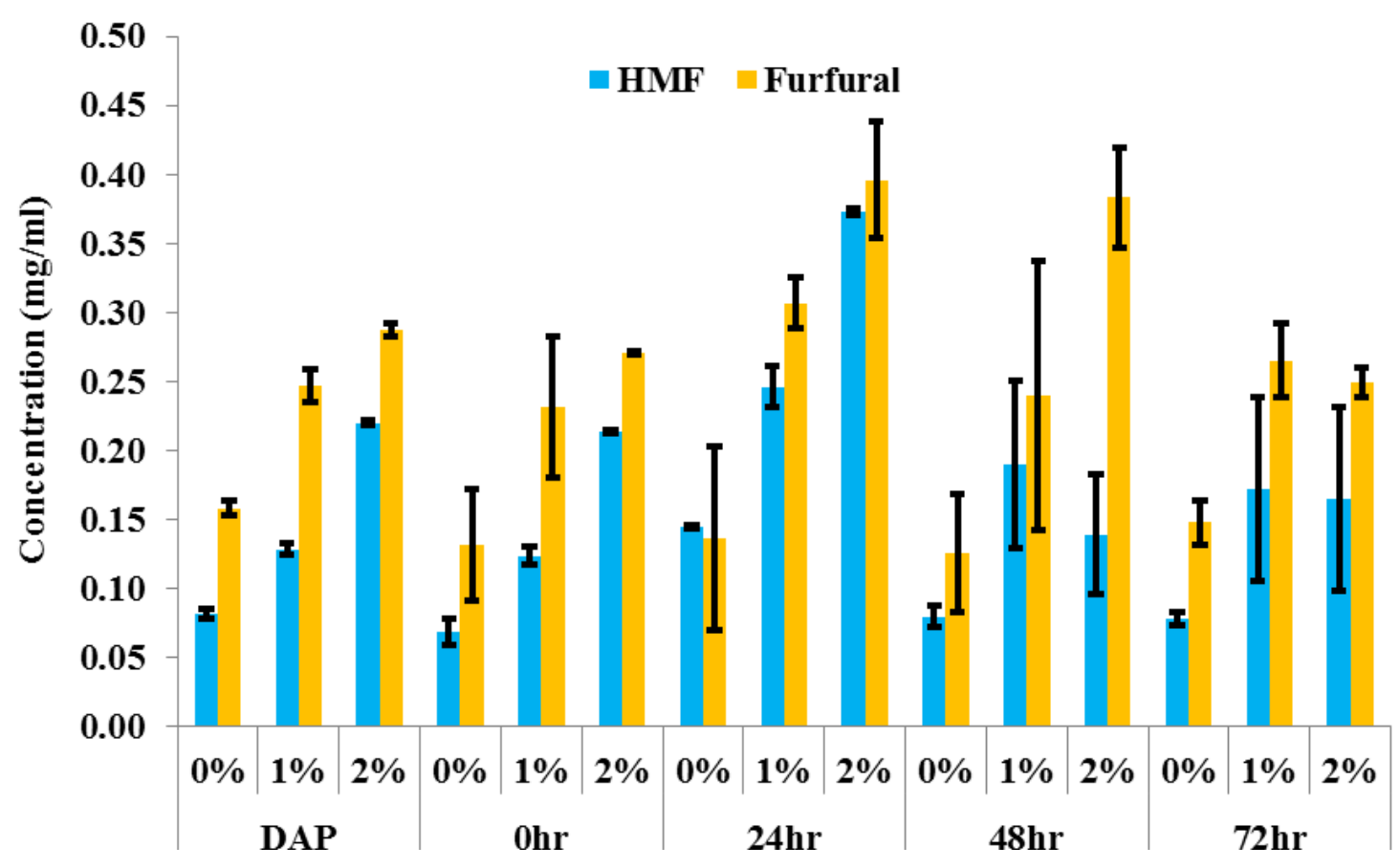

Figure A-14 Concentrations of inhibitors generated for 90 minute hydrolysis scheme 
In the another study (Adom et al. 2012), the authors estimated the average total carbohydrates to be be $[27 \%( \pm 5 \%)$ wt.]. Total carbohydrates comprised of the following; starch, soluble sugars (glucose, xylose, galactose, mannose, \& arabinose) and cellulose. Using the total carbohydrates, we estimated the maximum theoretical

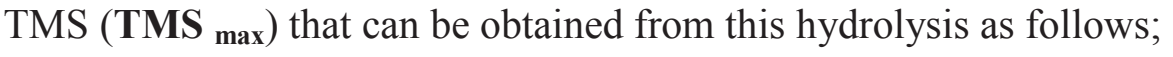

Weight of syrup used in hydrolysis $=10 \mathrm{~g}$, Total solids in DCS (Appendix A. Figure A-15) $=28 \%$ wt.

Total carbohydrates $=27 \%$ wt. (of total solids), Syrup density $=1000 \mathrm{mg} / \mathrm{ml}$

\section{TMS (max)}

$=\frac{10 \mathrm{~g} D C S \times 28 \%(\text { total solids }) \times 27 \%(\text { carbohydrates }) \times 1000 \mathrm{mg} / \mathrm{ml}}{10 \mathrm{ml} \mathrm{DCS}}$

$=76 \mathrm{mg} / \mathrm{ml}$

The maximum TMS expected (assuming all carbohydrates was hydrolyzed to monomer sugars) was estimated to be $76 \mathrm{mg} / \mathrm{ml}$.

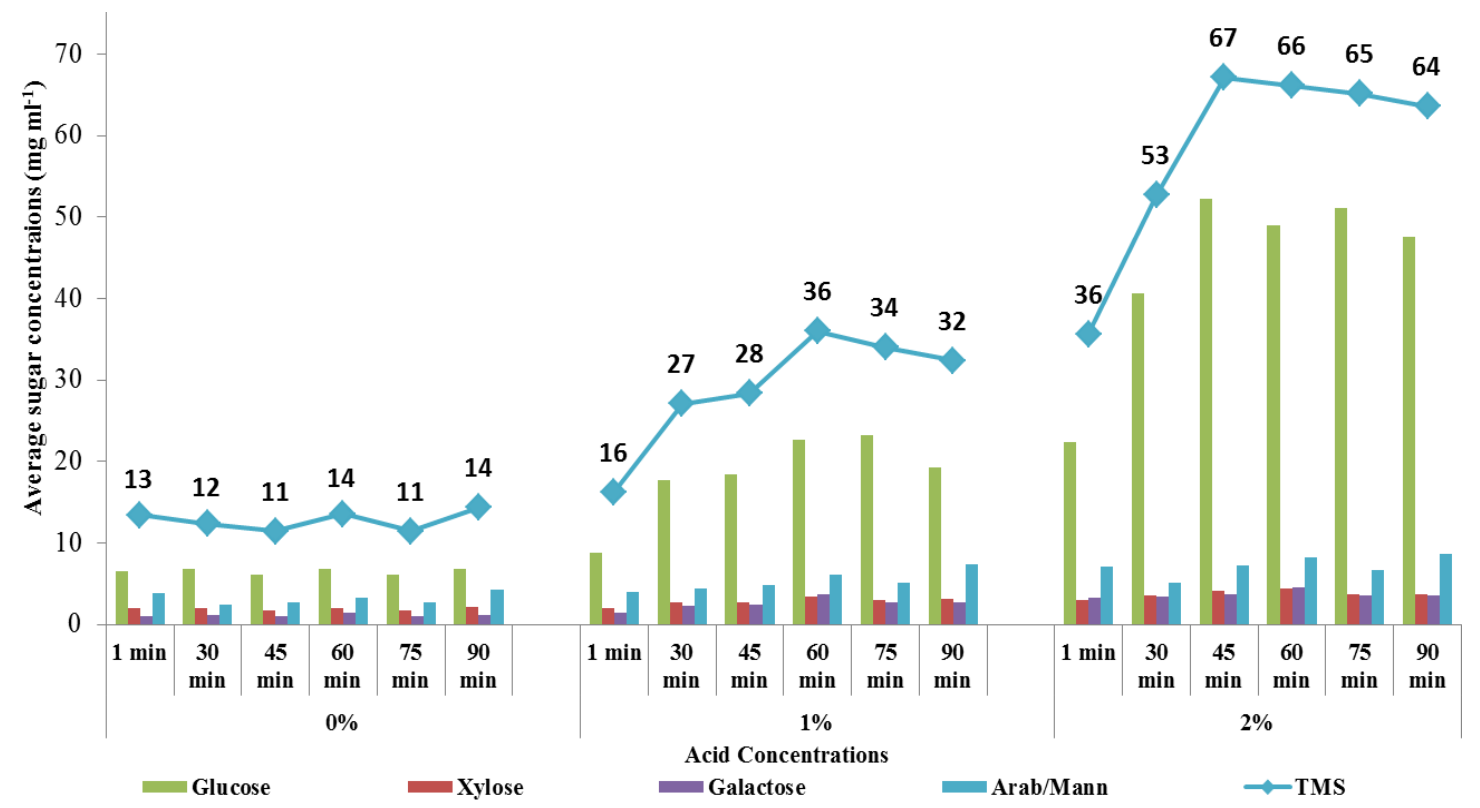

Figure A-16 Effect of time and $0,1 \& 2 \mathrm{wt} \%$ acid concentration on the yield of total monomer sugars (first stage acid pretreatment) 


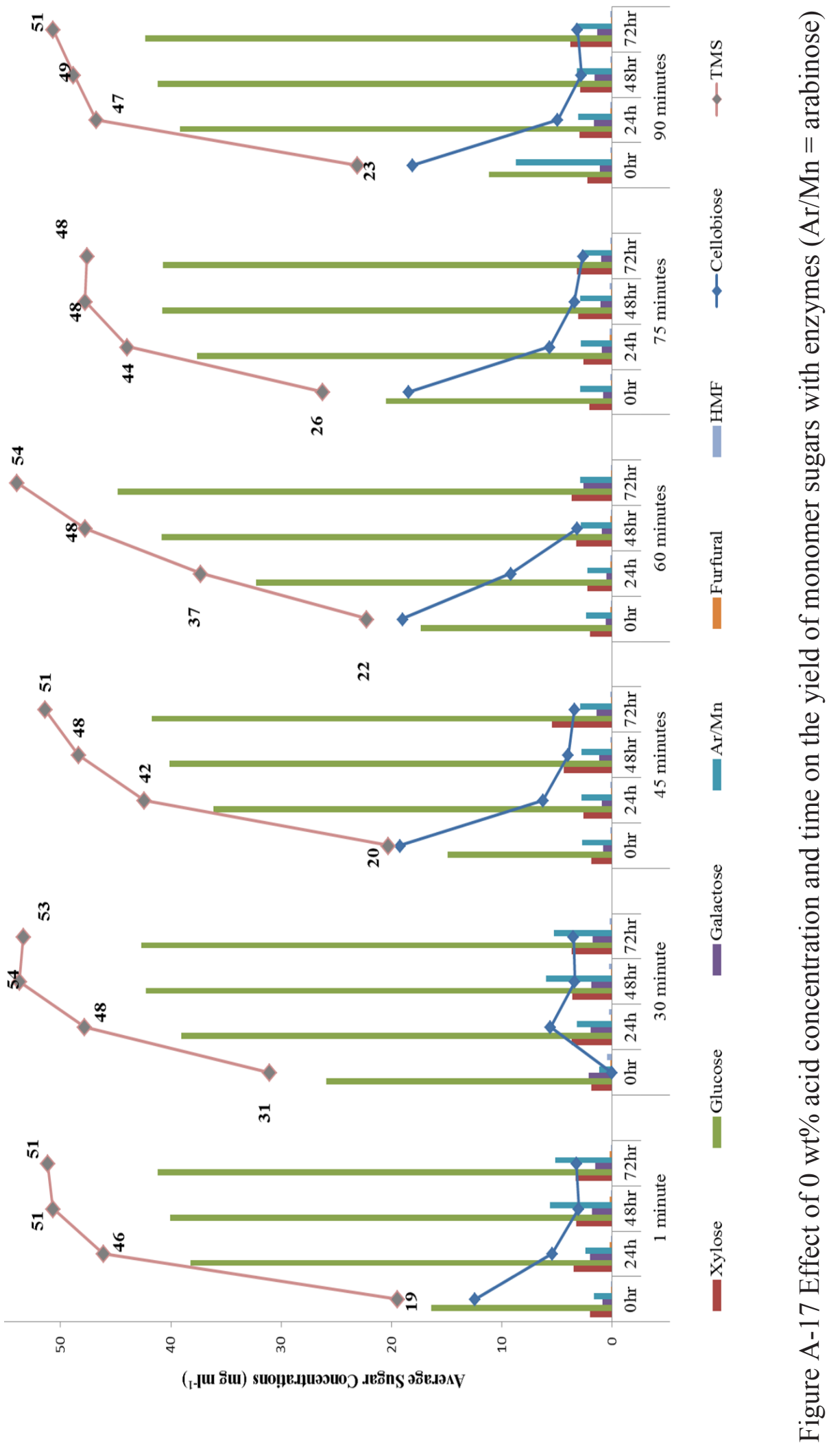




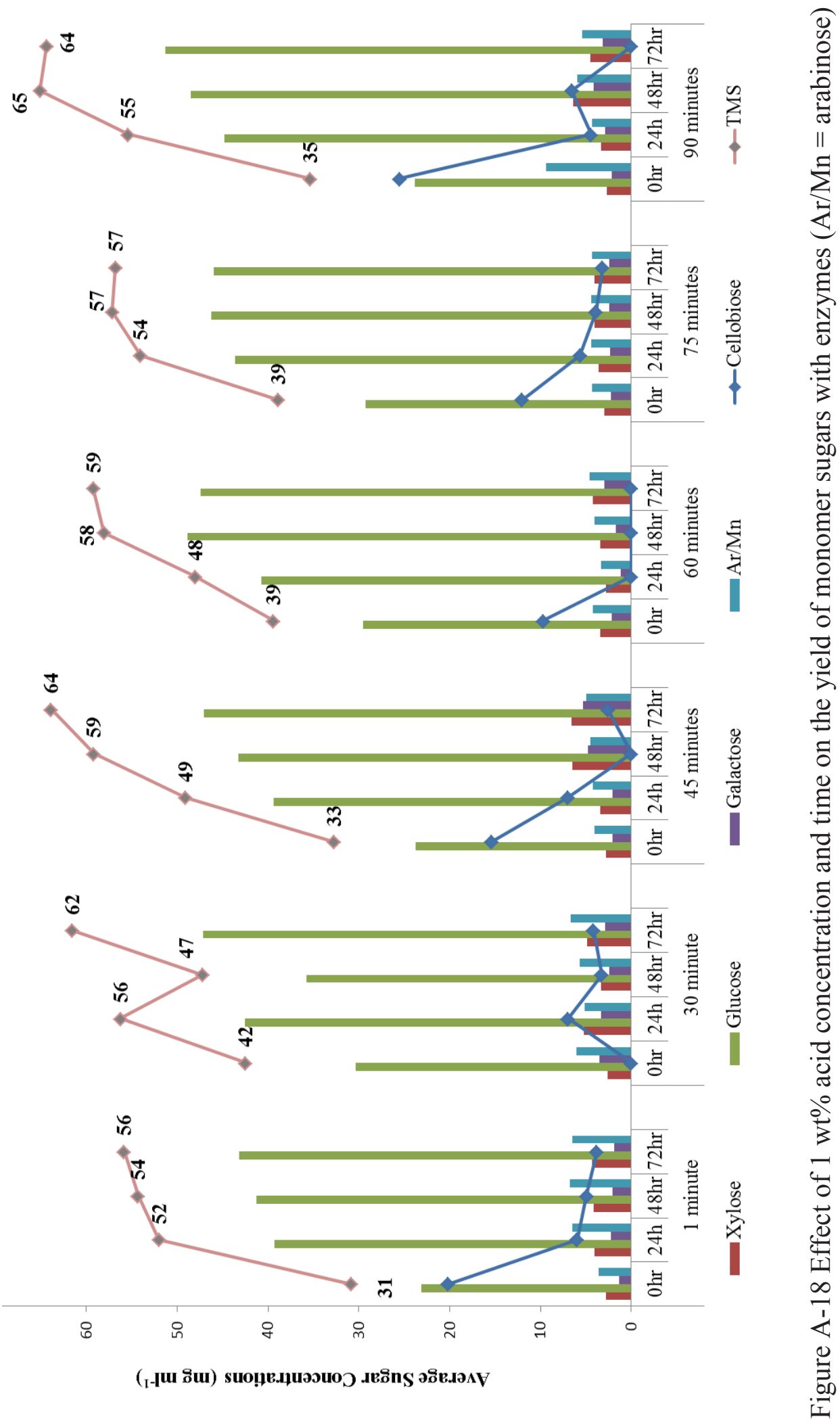




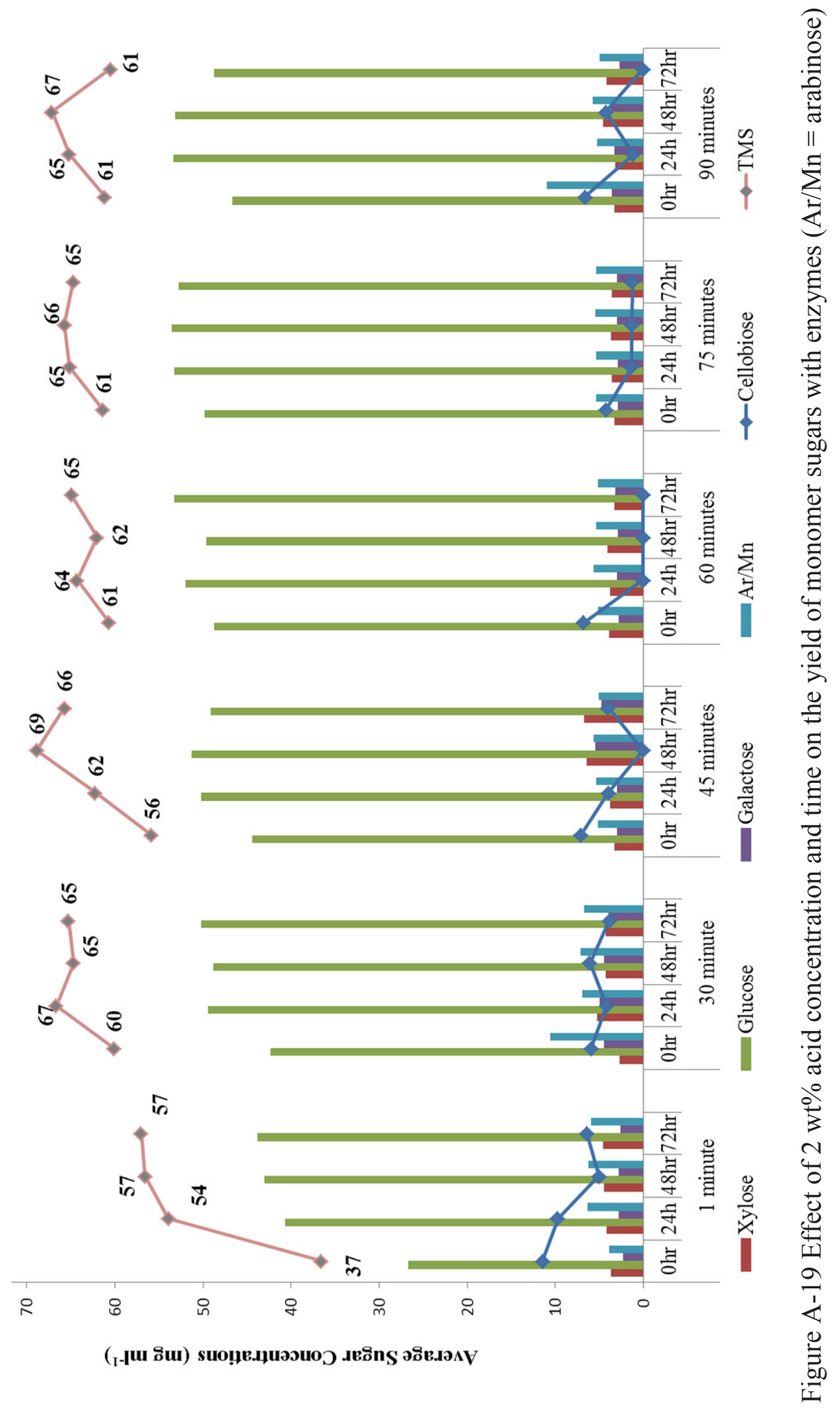


Table A-1 Comparison of DAP (first stage) with 72 hours EH for $0 \mathrm{wt} \%$ acid concentration [Min: Minute(s)]

\begin{tabular}{|l|l|l|l|l|l|l|}
\hline \multicolumn{7}{|c|}{$0 \mathrm{wt} \%$ (Total Sugars in $\mathrm{mg} \mathrm{m}^{-1}$ ) } \\
\hline Incubation time & $1 \mathrm{~min}$ & $30 \mathrm{~min}$ & $45 \mathrm{~min}$ & $60 \mathrm{~min}$ & $75 \mathrm{~min}$ & $90 \mathrm{~min}$ \\
\hline $0 \mathrm{hr}$ & 19.44 & 31.05 & 20.31 & 26.21 & 26.21 & 23.10 \\
$24 \mathrm{~h}$ & 46.12 & 47.80 & 42.39 & 43.94 & 43.94 & 46.78 \\
$48 \mathrm{hr}$ & 50.69 & 53.73 & 48.39 & 47.77 & 47.77 & 48.83 \\
$72 \mathrm{hr}$ EH & 51.17 & 55.00 & 51.40 & 54.00 & 47.59 & 50.71 \\
\hline TMS due to DAP $(0$ & & & & & & \\
wt\%)-First stage & & & & & & \\
hydrolysis & 13.40 & 12.36 & 11.44 & 13.55 & 11.46 & 14.32 \\
\hline $\begin{array}{l}\text { Factor of increase } \\
\text { after 72hr EH }\end{array}$ & 3.8 & 4.4 & 4.5 & 4.0 & 4.2 & 3.5 \\
\hline
\end{tabular}

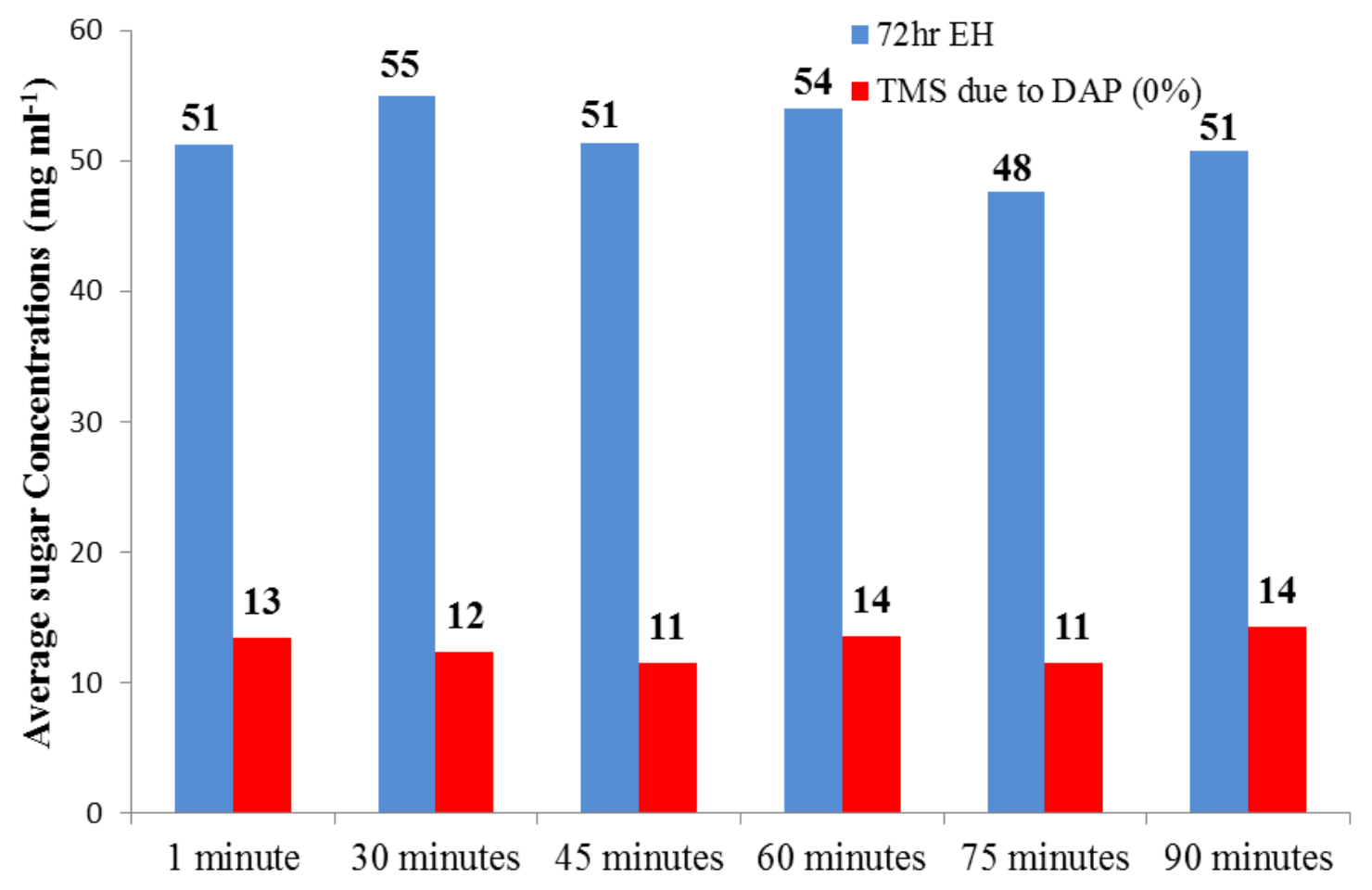

Figure A-20 Comparison of DAP (first stage) with 72 hours EH for $0 \mathrm{wt} \%$ acid concentration DCS 
Table A-2 Comparison of DAP (first stage) with 72 hours EH for $1 \mathrm{wt} \%$ acid concentration [Min: Minute(s)]

\begin{tabular}{|l|l|l|l|l|l|l|}
\hline \multicolumn{7}{|c|}{$1 \mathrm{wt}^{\%}$ (Total Sugars in $\mathrm{m} \mathrm{ml}^{-1}$ ) } \\
\hline $\begin{array}{l}\text { Incubation } \\
\text { time }\end{array}$ & $1 \mathrm{~min}$ & $30 \mathrm{~min}$ & $45 \mathrm{~min}$ & $60 \mathrm{~min}$ & $75 \mathrm{~min}$ & $90 \mathrm{~min}$ \\
\hline $0 \mathrm{hr}$ & 30.85 & 42.48 & 32.71 & 39.41 & 38.87 & 35.40 \\
$24 \mathrm{~h}$ & 52.03 & 56.26 & 49.05 & 48.05 & 54.04 & 55.38 \\
$48 \mathrm{hr}$ & 54.30 & 47.20 & 59.20 & 58.06 & 57.18 & 65.10 \\
$72 \mathrm{hr}$ & 55.85 & 61.53 & 63.91 & 59.25 & 56.82 & 64.39 \\
\hline TMS due to & & & & & & \\
DAP (1 wt\%) & 16.26 & 27.11 & 28.40 & 36.03 & 34.03 & 32.39 \\
\hline $\begin{array}{l}\text { Factor of } \\
\text { increase after }\end{array}$ & & & & & & \\
$72 \mathrm{hr}$ EH & 3.4 & 2.3 & 2.3 & 1.6 & 1.7 & 2.0 \\
\hline
\end{tabular}

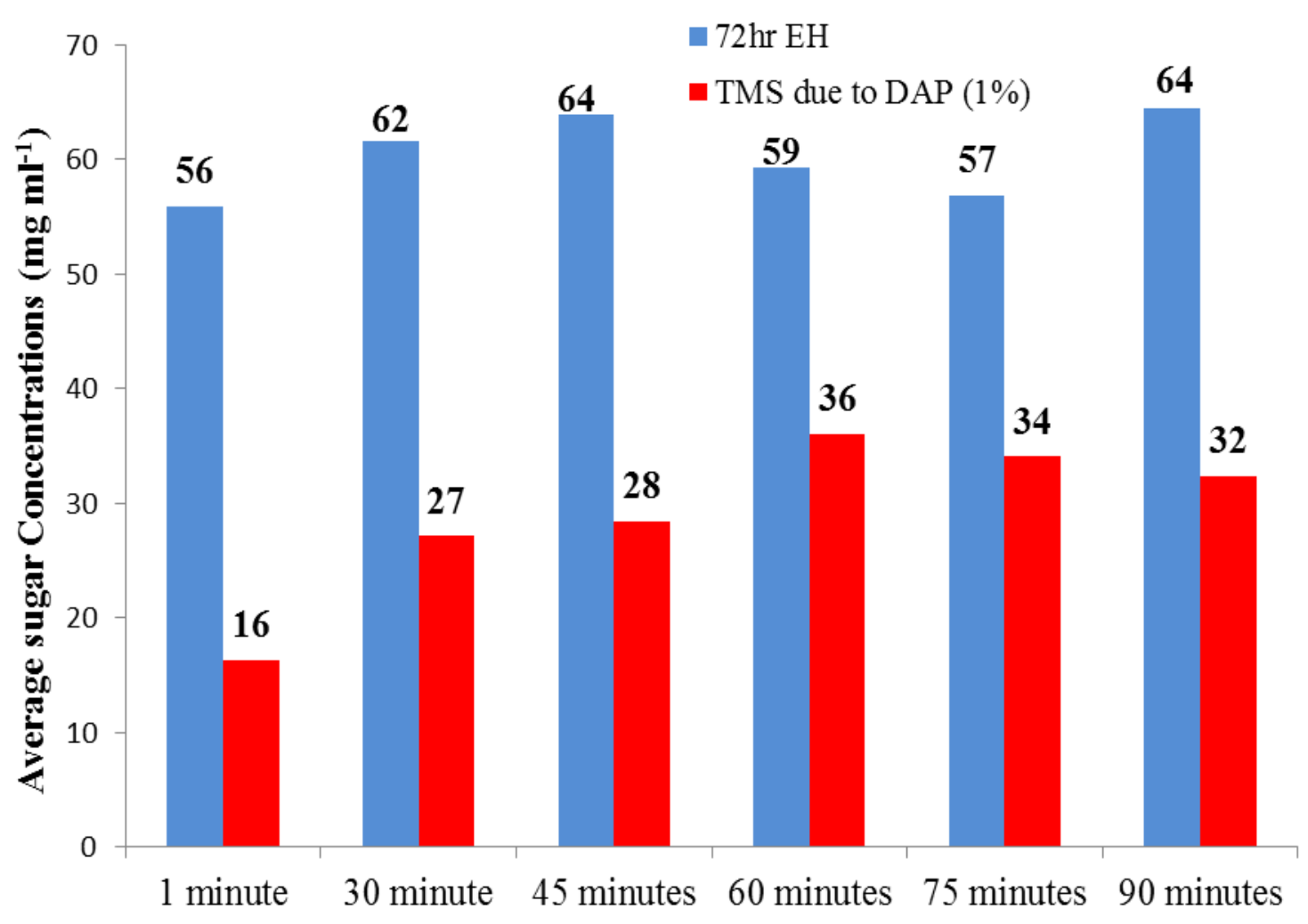

Figure A-21 Comparison of DAP (first stage) with 72 hours EH for $1 \mathrm{wt} \%$ acid concentration DCS 
Table A-3 Comparison of DAP (first stage) with 72 hours EH for $2 \mathrm{wt} \%$ acid concentration [Min: Minute(s)]

\begin{tabular}{|l|l|l|l|l|l|l|}
\hline \multicolumn{7}{|c|}{ 2 wt\% (Total Sugars in $\mathrm{mg} \mathrm{m}^{-1}$ ) } \\
\hline Incubation time & $1 \mathrm{~min}$ & $30 \mathrm{~min}$ & $45 \mathrm{~min}$ & $60 \mathrm{~min}$ & $75 \mathrm{~min}$ & $90 \mathrm{~min}$ \\
\hline $0 \mathrm{hr}$ & 36.60 & 60.13 & 55.82 & 60.67 & 61.35 & 61.17 \\
$24 \mathrm{~h}$ & 53.95 & 66.67 & 62.23 & 64.32 & 65.13 & 65.18 \\
$48 \mathrm{hr}$ & 56.56 & 64.67 & 68.89 & 62.02 & 65.73 & 67.18 \\
$72 \mathrm{hr}$ & 57.03 & 65.31 & 65.74 & 64.95 & 64.74 & 60.53 \\
\hline & & & & & & \\
$(2 \mathrm{wS}$ due to DAP & 35.65 & 52.70 & 67.19 & 66.20 & 65.15 & 63.61 \\
\hline & & & & & & \\
Factor of increase & 1.6 & 1.2 & 1.2 & 1.0 & 1.0 & 0.9 \\
after 72hr EH & & & & & & \\
\hline
\end{tabular}

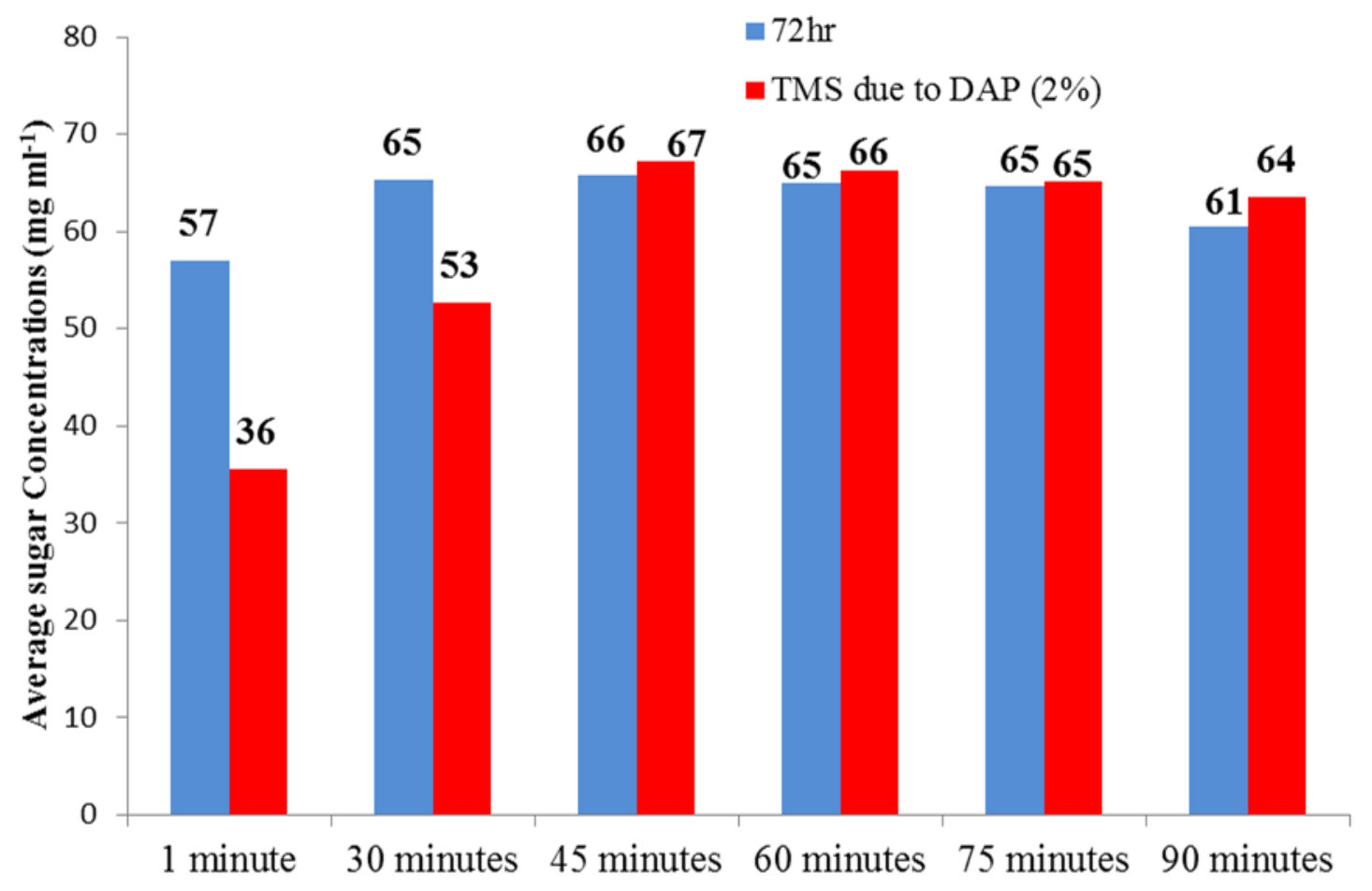

Figure A-22 Comparison of DAP (first stage) with 72 hours EH for $2 \mathrm{wt} \%$ acid concentration DCS 


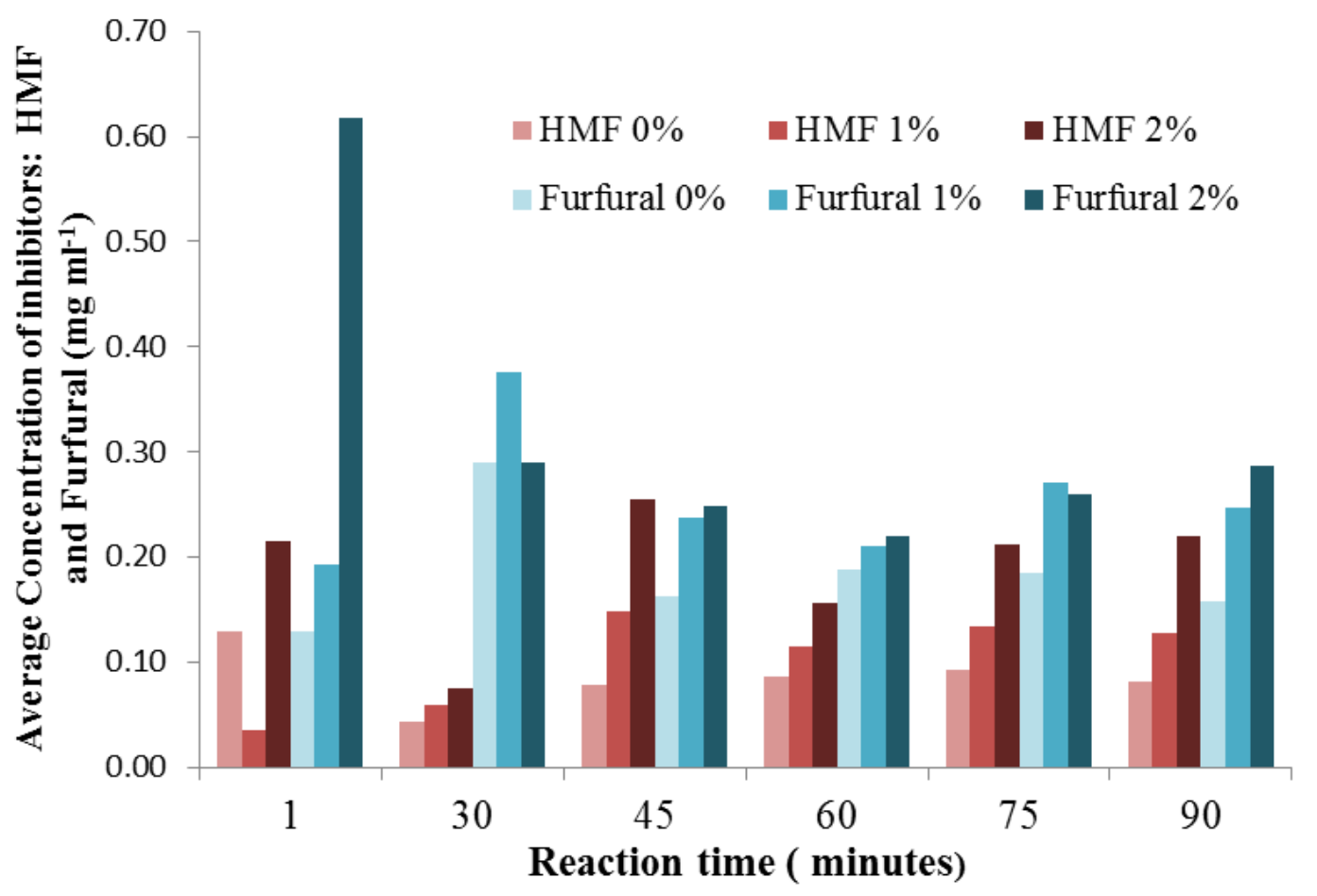

Figure A-23 The concentrations of HMF and Furfural generated overtime

Table A-4 Inhibitory concentrations of furfural and HMF for three types of yeast and E. coli $\mathrm{KO} 11$

\begin{tabular}{|c|c|c|}
\hline Organism & $\begin{array}{l}\text { Furfural } \\
\left(\mathrm{mg} \mathrm{ml}^{-1}\right)\end{array}$ & $\begin{array}{c}\text { 5-HMF } \\
\left(\mathrm{mg} \mathrm{ml}^{-1}\right)\end{array}$ \\
\hline Pichia stipitis & $\begin{array}{c}\text { 2.0-2.5 (Delgenes } \\
\text { et al. 1996) }\end{array}$ & $\begin{array}{c}5.0 \text { (Delgenes et } \\
\text { al. 1996) }\end{array}$ \\
\hline Kluveromyces marxianus & $\begin{array}{c}\text { 2.0-2.5 (Oliva et } \\
\text { al. 2003) }\end{array}$ & $\begin{array}{c}\text { 4.0- } 4.2 \text { (Oliva et } \\
\text { al. 2003) }\end{array}$ \\
\hline Pachysolen tannophilus & $\begin{array}{c}\text { 0.35-0.7 (Almeida } \\
\text { et al. 2009) }\end{array}$ & $\mathrm{n} / \mathrm{a}$ \\
\hline Escherichia coli KO11 & $\begin{array}{c}3.5 \text { (Zaldivar et al. } \\
1999)\end{array}$ & $\begin{array}{c}4.0 \text { (Zaldivar et } \\
\text { al. 1999) }\end{array}$ \\
\hline
\end{tabular}


Almeida JRM, Bertilsson M, Gorwa-Grauslund MF, Gorsich S, Lidén G. 2009. Metabolic effects of furaldehydes and impacts on biotechnological processes. Applied Microbiology and Biotechnology 82(4):625-638.

Delgenes J, Moletta R, Navarro J. 1996. Effects of lignocellulose degradation products on ethanol fermentations of glucose and xylose by Saccharomyces cerevisiae, Zymomonas mobilis, Pichia stipitis, and Candida shehatae. Enzyme and microbial technology 19(3):220-225.

Oliva JM, Saez F, Ballesteros I, Gonzalez A, Negro MJ, Manzanares P, Ballesteros M. 2003. Effect of lignocellulosic degradation compounds from steam explosion pretreatment on ethanol fermentation by thermotolerant yeast Kluyveromyces marxianus. Applied Biochemistry and Biotechnology 105(1):14.153-1

Zaldivar J, Martinez A, Ingram LO. 1999. Effect of selected aldehydes on the growth and fermentation of ethanologenic Escherichia coli. Biotechnology and bioengineering 65(1):24-33. 


\section{Appendix B: Supplementary information for protein platform optimization experiments}

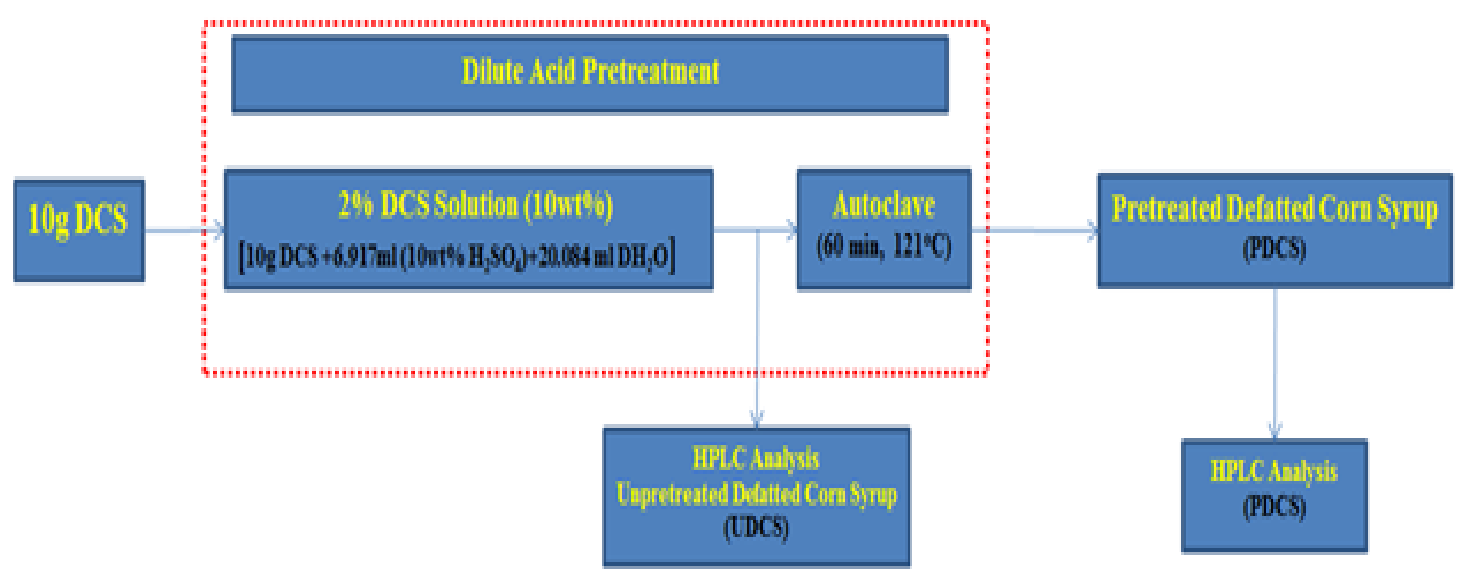

Figure B-1 Flow diagram of dilute acid hydrolysis at optimum conditions
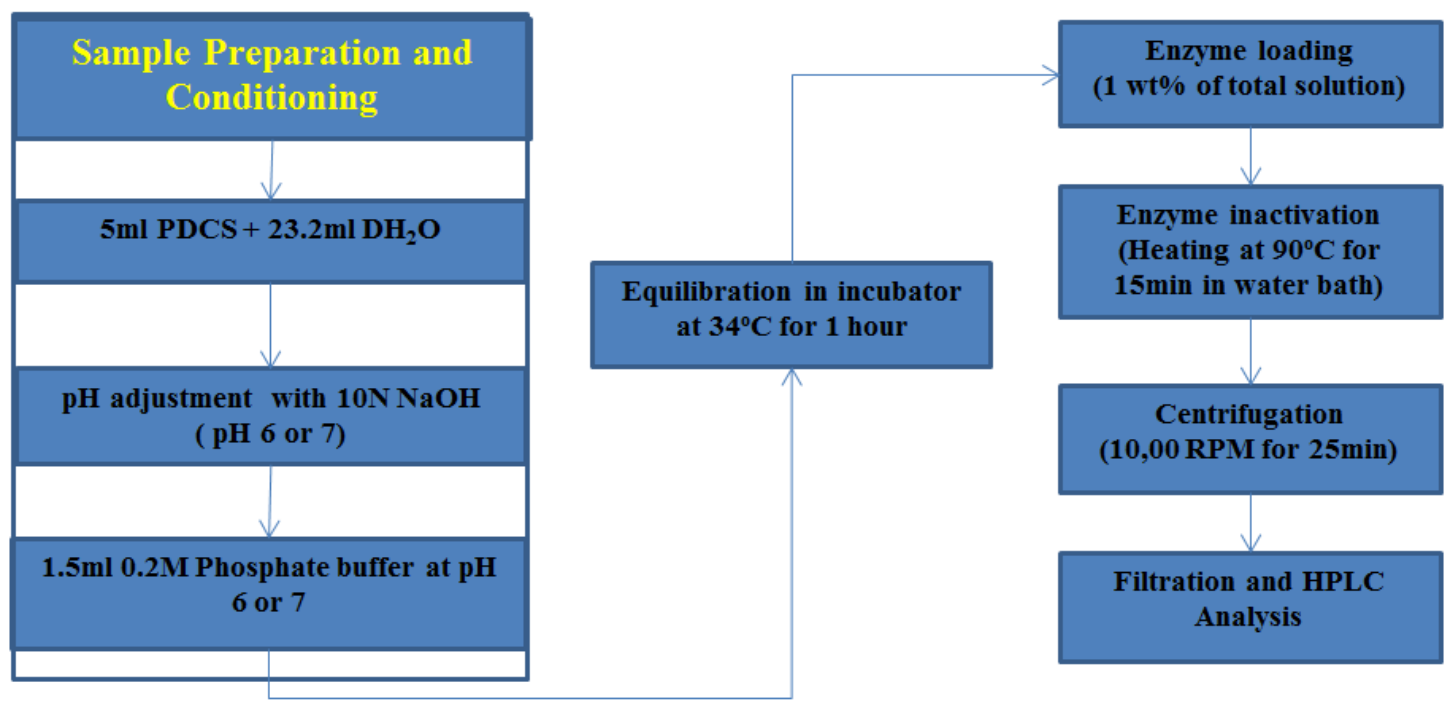

Figure B-2 Flow diagram for dilute acid pretreatment followed by protein hydrolysis using proteases (Hydrolysis Pathway 2) 
Table B-1 Amino acid concentrations of enzyme blanks (Pathway 2)

\begin{tabular}{|c|c|c|c|}
\hline \multicolumn{4}{|c|}{ Pronase E, Protex $6 \mathrm{~L}$ and Trypsin $\left(34^{\circ} \mathrm{C}\right)$} \\
\hline Hydrolysis pathn & 2-pH 7 & Hydrolysis pathn & 2-pH 6 \\
\hline Amino acids & $\begin{array}{l}\text { Amino acid } \\
\text { concentrations }\end{array}$ & Amino acids & $\begin{array}{l}\text { Amino acid } \\
\text { concentrations }\end{array}$ \\
\hline $\begin{array}{l}\text { Aspartic Acid } \\
\text { L- Glutamic Acid } \\
\text { Asparagine } \\
\text { L-serine } \\
\text { Histidine } \\
\text { Glycine } \\
\text { Threonine } \\
\text { L-Arginine } \\
\text { L-Alanine } \\
\text { Tyrosine } \\
\text { Valine } \\
\text { Methionine } \\
\text { Phenylanaline } \\
\text { Isoleucine } \\
\text { Leucine } \\
\text { Lysine }\end{array}$ & 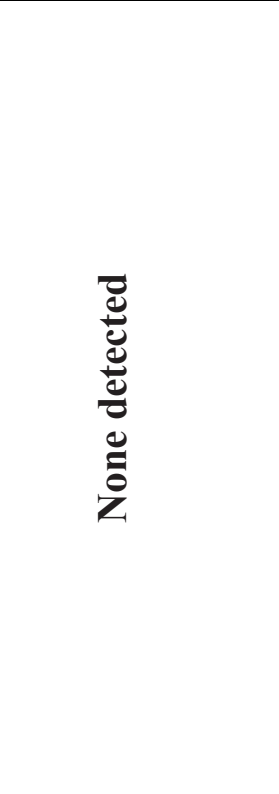 & $\begin{array}{l}\text { Aspartic Acid } \\
\text { L- Glutamic Acid } \\
\text { Asparagine } \\
\text { L-serine } \\
\text { Histidine } \\
\text { Glycine } \\
\text { Threonine } \\
\text { L-Arginine } \\
\text { L-Alanine } \\
\text { Tyrosine } \\
\text { Valine } \\
\text { Methionine } \\
\text { Phenylanaline } \\
\text { Isoleucine } \\
\text { Leucine } \\
\text { Lysine }\end{array}$ & 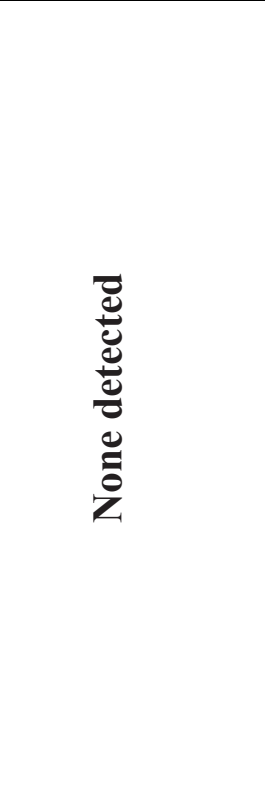 \\
\hline
\end{tabular}

NB: Enzyme blank for all hydrolysis solutions comprised of all reagents (e.g. distilled water, base, tetracycline, etc ) except for the protease or cellulase enzyme.

Table B-2 Amino acid concentrations of enzyme blanks (Pathway 3) experimental set 1

\begin{tabular}{|l|c|c|}
\hline \multicolumn{3}{|c|}{ Enzyme Blank (Alcalase ${ }^{\circledR}$ ) } \\
\hline Blank & Retention Time & Peak Area \\
\hline pH 7,8,9 H & Serine & 202.50 \\
pH 7,8,9 M & Serine & 198.60 \\
pH 7,8,9 L & Serine & 195.23 \\
\hline
\end{tabular}


Table B-3 Amino acid concentrations of enzyme blanks (Pathway 3) experimental sets 2, $3 \& 4$

\begin{tabular}{|c|c|c|c|}
\hline \multicolumn{4}{|c|}{ Enzyme Blank for Hydrolysis Pathway 3} \\
\hline \multicolumn{4}{|c|}{ Pronase E, Protex 6L and Trypsin } \\
\hline \multicolumn{2}{|c|}{$\begin{array}{c}\text { Hydrolysis Pathway 3-pH } 7 \\
\left(34^{\circ} \mathrm{C}\right)\end{array}$} & \multicolumn{2}{|c|}{$\begin{array}{c}\text { Hydrolysis Pathway 2-pH } 6 \\
\left(34^{\circ} \mathrm{C}\right)\end{array}$} \\
\hline $\begin{array}{l}\text { Amino Acid } \\
\text { Concentration }\end{array}$ & Concentration & $\begin{array}{l}\text { Amino Acid } \\
\text { Concentration }\end{array}$ & Concentration \\
\hline $\begin{array}{l}\text { Aspartic Acid } \\
\text { L- Glutamic } \\
\text { Acid } \\
\text { Asparagine } \\
\text { L-serine } \\
\text { Histidine } \\
\text { Glycine } \\
\text { Threonine } \\
\text { L-Arginine } \\
\text { L-Alanine } \\
\text { Tyrosine } \\
\text { Valine } \\
\text { Methionine } \\
\text { Phenylanaline } \\
\text { Isoleucine } \\
\text { Leucine } \\
\text { Lysine }\end{array}$ & 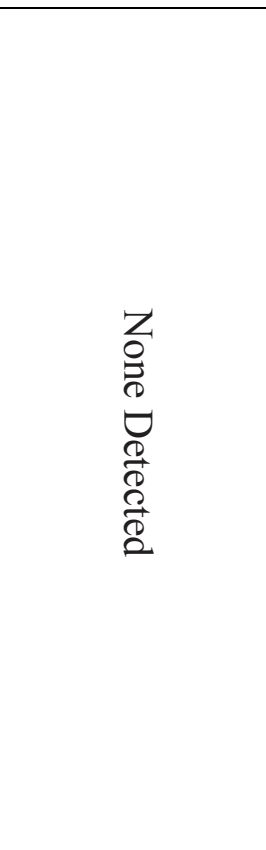 & $\begin{array}{l}\text { Aspartic Acid } \\
\text { L- Glutamic } \\
\text { Acid } \\
\text { Asparagine } \\
\text { L-serine } \\
\text { Histidine } \\
\text { Glycine } \\
\text { Threonine } \\
\text { L-Arginine } \\
\text { L-Alanine } \\
\text { Tyrosine } \\
\text { Valine } \\
\text { Methionine } \\
\text { Phenylanaline } \\
\text { Isoleucine } \\
\text { Leucine } \\
\text { Lysine }\end{array}$ & 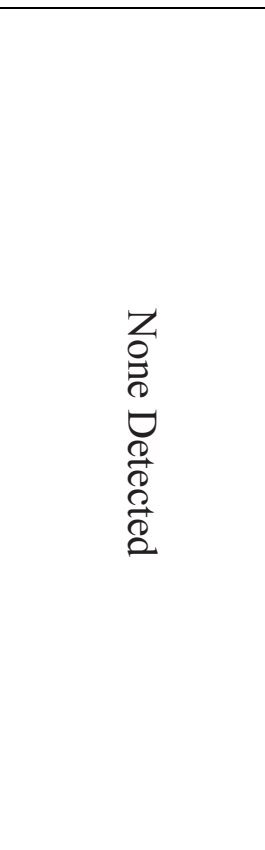 \\
\hline
\end{tabular}


Table B-4 Amino acid concentrations of enzyme blanks (Pathway 3) experimental sets 5, $6 \& 7$ (ND: None detected)

\begin{tabular}{|c|c|c|c|}
\hline Sugars/HMF/Furfural & $\begin{array}{c}\text { Accellerase } \\
1500: \\
\text { Peak area } \\
\text { (nRIU*S) }\end{array}$ & $\begin{array}{l}\text { Amylase } \\
\text { Peak area } \\
\left(\mathrm{nRIU}{ }^{*} \mathrm{~S}\right)\end{array}$ & $\begin{array}{l}\text { Amylase } \\
\text { \& AMG } \\
\text { Peak area } \\
\text { (nRIU*S) }\end{array}$ \\
\hline Cellobiose & ND & \multirow{8}{*}{ ND } & ND \\
\hline Glucose & 25546.8 & & $5.68 \mathrm{E}+04$ \\
\hline Xylose & \multirow{6}{*}{ ND } & & \multirow{6}{*}{ ND } \\
\hline Galactose & & & \\
\hline Arab & & & \\
\hline Mann & & & \\
\hline $\mathrm{HMF}$ & & & \\
\hline Furfural & & & \\
\hline
\end{tabular}

Table B-5 Amino acid concentrations of enzyme blanks (Pathway 4): 1\% v/v Protex 6L

\begin{tabular}{|clc|}
\hline \multicolumn{3}{|c|}{ Enzyme Blank for Hydrolysis Pathway 4 } \\
\hline \multicolumn{3}{|c|}{$\mathbf{1 \%}$ \%/v Protex 6L } \\
\hline \# Peaks & Name of AA & mg/ml \\
\hline 1 & Aspartic Acid & 0.04 \\
2 & L- Glutamic Acid & 0.05 \\
3 & Asparagine & 0.02 \\
4 & L-serine & 0.01 \\
5 & Histidine & 0.00 \\
6 & Glycine & 0.00 \\
7 & Threonine & 0.00 \\
8 & L-Arginine & 0.02 \\
9 & L-Alanine & 0.04 \\
10 & Tyrosine & 0.01 \\
11 & Valine & 0.00 \\
12 & Methionine & 0.00 \\
13 & Phenylanaline & 0.08 \\
14 & Isoleucine & 0.00 \\
15 & Leucine & 0.06 \\
16 & Lysine & 0.00 \\
\hline
\end{tabular}


Table B-6 Amino acid concentrations of enzyme blanks (Pathway 4): 2\% v/v Protex 6L

\begin{tabular}{|c|c|c|}
\hline \multicolumn{3}{|c|}{ Enzyme Blank for Hydrolysis Pathway 4} \\
\hline \multicolumn{3}{|c|}{$2 \%$ v/v Protex 6L } \\
\hline \multicolumn{3}{|c|}{ Hydrolysis Pathway 2-pH $6\left(40^{\circ} \mathrm{C}\right)$} \\
\hline \# Peaks & $\begin{array}{l}\text { Amino Acic } \\
\text { Component }\end{array}$ & $(\mathrm{mg} / \mathrm{ml})$ \\
\hline 1 & $\begin{array}{l}\text { Aspartic Acid } \\
\text { L-Glutamic }\end{array}$ & 0.03 \\
\hline 2 & Acid & 0.05 \\
\hline 3 & Asparagine & 0.02 \\
\hline 4 & L-serine & 0.02 \\
\hline 5 & Histidine & 0.00 \\
\hline 6 & Glycine & 0.01 \\
\hline 7 & Threonine & 0.01 \\
\hline 8 & L-Arginine & 0.03 \\
\hline 9 & L-Alanine & 0.05 \\
\hline 10 & Tyrosine & 0.02 \\
\hline 11 & Valine & 0.00 \\
\hline 12 & Methionine & 0.00 \\
\hline 13 & Phenylanaline & 0.00 \\
\hline 14 & Isoleucine & 0.02 \\
\hline 15 & Leucine & 0.09 \\
\hline 16 & Lysine & 0.00 \\
\hline
\end{tabular}


Table B-7 Sugar concentrations of enzyme blanks (Pathway 4): 1\% v/v Protex 6L

\begin{tabular}{|c|c|c|}
\hline \multicolumn{3}{|c|}{ Enzyme Blank for Hydrolysis Pathway 4} \\
\hline \multicolumn{3}{|l|}{$1 \%$ v/v Protex 6L } \\
\hline \multicolumn{3}{|l|}{ Hydrolysis Pathway 2-pH $6\left(40^{\circ} \mathrm{C}\right)$} \\
\hline Sugars/HMF/Furfural & $\begin{array}{l}\text { Peak area } \\
(\mathrm{nRIU} * \mathrm{~S})\end{array}$ & $\mathbf{m g} / \mathbf{m l}$ \\
\hline Cellobiose & ND & 0 \\
\hline Glucose & 24851.1 & 0.635 \\
\hline Xylose & & 0 \\
\hline Galactose & & 0 \\
\hline Arab & & 0 \\
\hline Mann & & 0 \\
\hline $\mathrm{HMF}$ & & 0 \\
\hline Furfural & ND & 0 \\
\hline $\begin{array}{l}\text { Total Sugar }=\text { Glucose }+ \text { Xylose }+ \text { Galactose }+ \\
\text { Arabinose }+ \text { Mannose }=\end{array}$ & & 0.635 \\
\hline
\end{tabular}

Table B-8 Sugar concentrations of enzyme blanks (Pathway 4): 2\% v/v Protex 6L

\begin{tabular}{|c|c|c|}
\hline \multicolumn{3}{|c|}{ Enzyme Blank for Hydrolysis Pathway 4} \\
\hline \multicolumn{3}{|c|}{$2 \%$ v/v Protex 6L } \\
\hline \multicolumn{3}{|c|}{ Hydrolysis Pathway 2-pH $6\left(40^{\circ} \mathrm{C}\right)$} \\
\hline Sugars/HMF/Furfural & Peak area (nRIU*S) & $\begin{array}{c}\text { Dilution } \\
\text { Factor } \\
(\mathrm{DF}=3.8)- \\
\mathrm{mg} / \mathrm{ml}\end{array}$ \\
\hline Cellobiose & ND & 0 \\
\hline Glucose & 23424.4 & 0.598 \\
\hline Xylose & & 0 \\
\hline Galactose & & 0 \\
\hline Arab & & 0 \\
\hline Mann & & 0 \\
\hline $\mathrm{HMF}$ & & 0 \\
\hline Furfural & ND & 0 \\
\hline $\begin{array}{l}\text { Total Sugar }=\text { Glucose }+ \text { Xylo } \\
\text { Mannose }=\end{array}$ & lactose + Arabinose + & 0.598 \\
\hline
\end{tabular}


Table B-9 HMF and Furfural concentrations for hydrolysis pathway 3

\begin{tabular}{|c|c|c|c|c|c|c|c|}
\hline \multirow{2}{*}{$\begin{array}{l}\text { Hydrolysis } \\
\text { solution }\end{array}$} & \multirow[t]{2}{*}{ Inhibitors } & \multicolumn{2}{|l|}{1 minute } & \multicolumn{2}{|l|}{2 hours } & \multicolumn{2}{|l|}{5 hours } \\
\hline & & $\begin{array}{l}\text { Conc } \\
\text { (mg/ml) }\end{array}$ & Std Dev & $\begin{array}{l}\text { Conc } \\
\text { (mg/ml) }\end{array}$ & Std Dev & $\begin{array}{l}\text { Conc } \\
(\mathrm{mg} / \mathrm{ml})\end{array}$ & $\begin{array}{l}\text { Std } \\
\text { Dev }\end{array}$ \\
\hline \multirow[t]{2}{*}{ Control } & HMF & 0.26 & 0.0143 & 0.25 & 0.00001 & 0.25 & 0.00211 \\
\hline & Furfural & 0.25 & 0.0019 & 0.28 & 0.0007 & 0.27 & 0.0008 \\
\hline \multirow[t]{2}{*}{ Accellerase } & HMF & 0.25 & 0.0040 & 0.26 & 0.0001 & 0.26 & 0.0004 \\
\hline & Furfural & 0.24 & 0.0012 & 0.27 & 0.0002 & 0.27 & 0.0003 \\
\hline \multirow[t]{2}{*}{ Amylase } & $\mathrm{HMF}$ & 0.26 & 0.0046 & 0.27 & 0.0007 & 0.26 & 0.0097 \\
\hline & Furfural & 0.28 & 0.0004 & 0.28 & 0.0012 & 0.28 & 0.0041 \\
\hline \multirow{2}{*}{$\begin{array}{l}\text { Amylase } \\
\text { and AMG }\end{array}$} & HMF & 0.30 & 0.000 & 0.30 & 0.0035 & 0.28 & 0.0333 \\
\hline & Furfural & 0.32 & 0.002 & 0.32 & 0.0019 & 0.31 & 0.0104 \\
\hline \multirow{2}{*}{$\begin{array}{l}\text { Hydrolysis } \\
\text { solution }\end{array}$} & \multirow[t]{2}{*}{ Inhibitors } & \multicolumn{2}{|l|}{24 hours } & \multicolumn{2}{|l|}{48 hours } & \multicolumn{2}{|l|}{72 hours } \\
\hline & & $\begin{array}{l}\text { Conc } \\
(\mathrm{mg} / \mathrm{ml})\end{array}$ & Std Dev & $\begin{array}{l}\text { Conc } \\
(\mathrm{mg} / \mathrm{ml})\end{array}$ & Std Dev & $\begin{array}{l}\text { Conc } \\
(\mathrm{mg} / \mathrm{ml})\end{array}$ & $\begin{array}{l}\text { Std } \\
\text { Dev }\end{array}$ \\
\hline \multirow[t]{2}{*}{ Control } & HMF & 0.20 & 0.0147 & 0.01 & 0.0172 & 0.18 & 0.1213 \\
\hline & Furfural & 0.26 & 0.0063 & 0.17 & 0.0089 & 0.25 & 0.0391 \\
\hline \multirow[t]{2}{*}{ Accellerase } & HMF & 0.25 & 0.0593 & 0.24 & 0.0000 & 0.25 & 0.0000 \\
\hline & Furfural & 0.26 & 0.0185 & 0.26 & 0.0023 & 0.23 & 0.0405 \\
\hline \multirow[t]{2}{*}{ Amylase } & HMF & 0.47 & 0.0808 & 0.47 & 0.0130 & 0.47 & 0.0130 \\
\hline & Furfural & 0.32 & 0.0215 & 0.18 & 0.0060 & 0.17 & 0.0019 \\
\hline \multirow{2}{*}{$\begin{array}{l}\text { Amylase } \\
\text { and AMG }\end{array}$} & HMF & 0.24 & 0.099 & 0.10 & 0.018 & 0.03 & 0.000 \\
\hline & Furfural & 0.31 & 0.054 & 0.22 & 0.007 & 0.20 & 0.007 \\
\hline
\end{tabular}




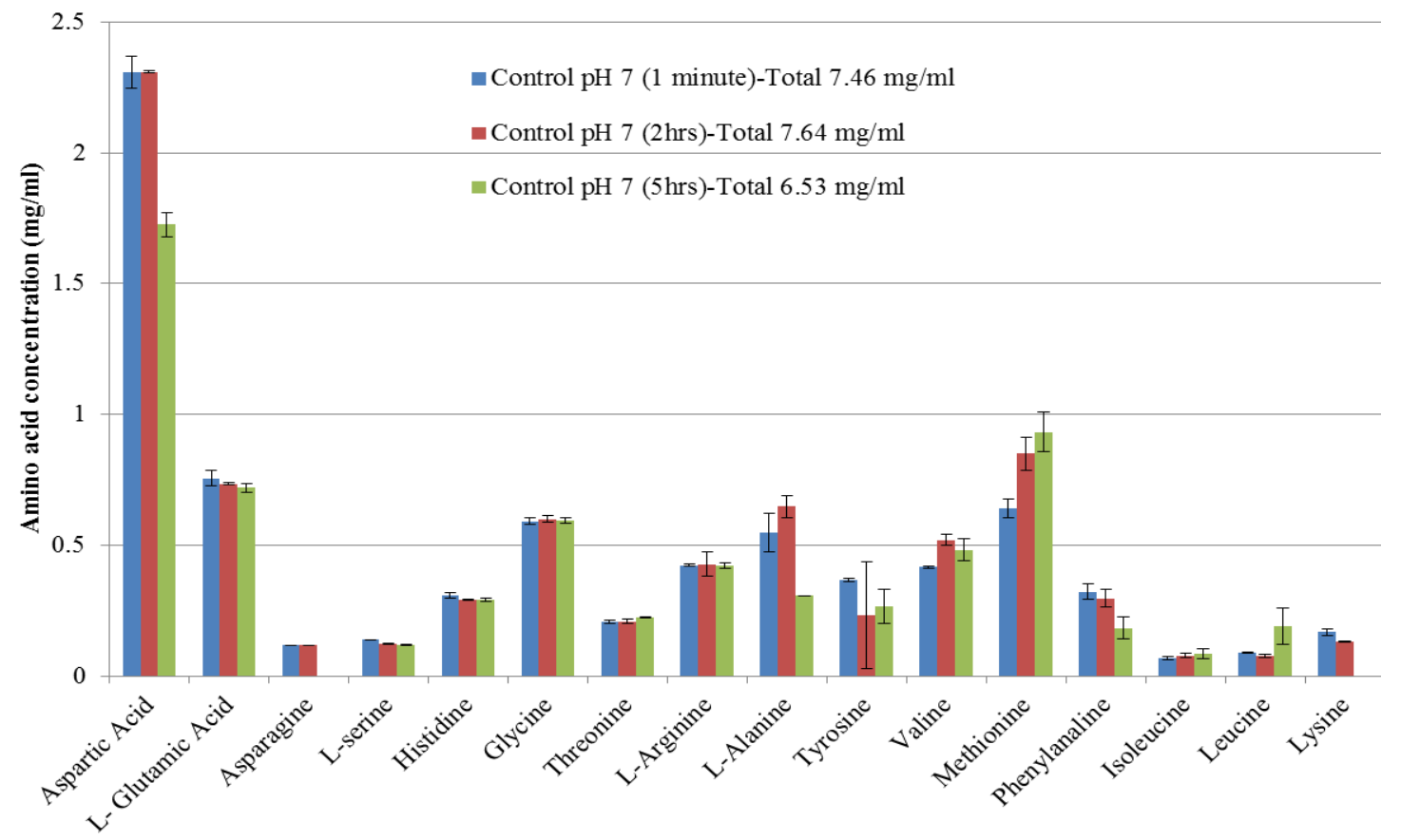

Figure B-3 Results for Hydrolysis Pathway 2: DAP followed by protein hydrolysis using proteases

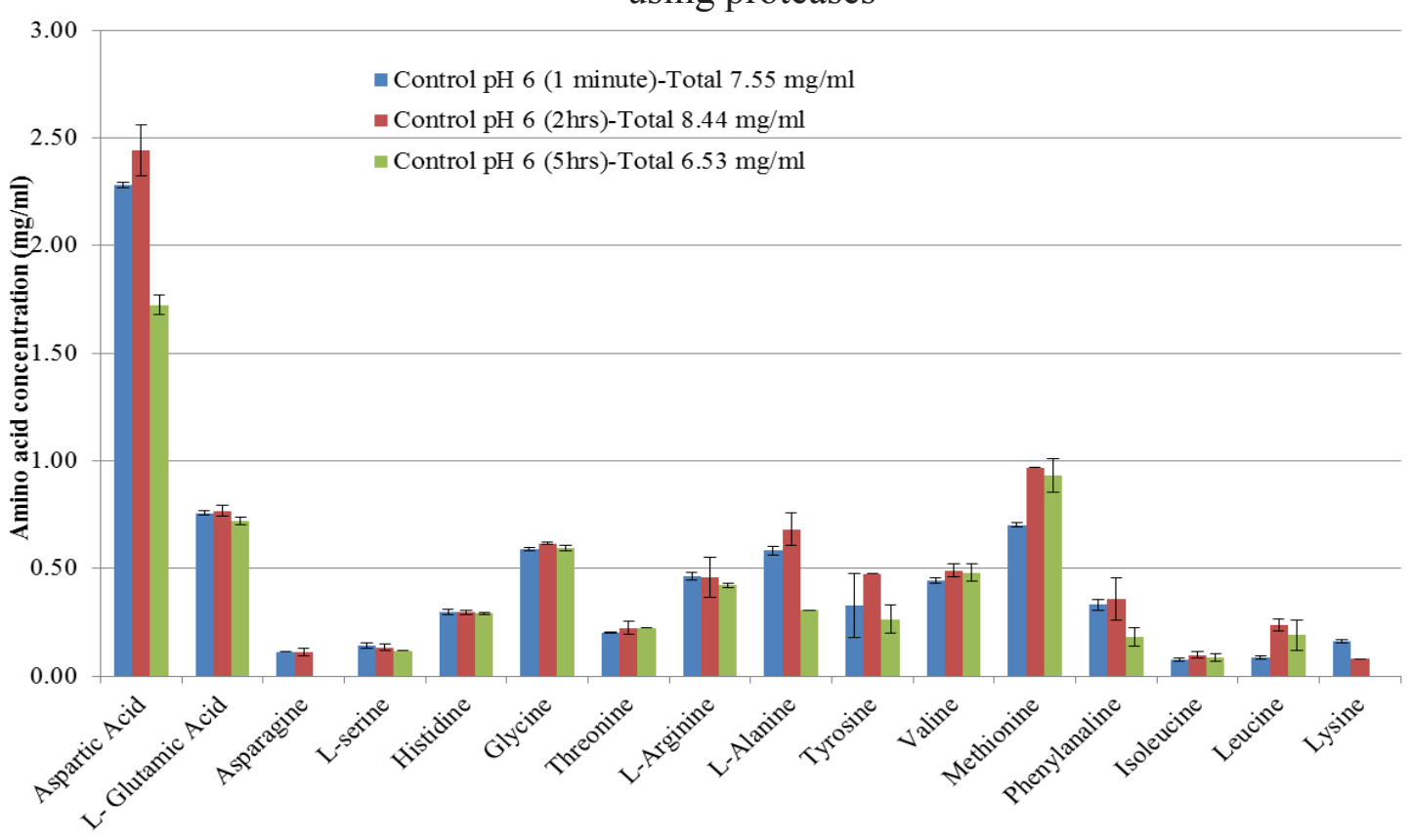

Figure B-4 Amino acid hydrolysis trends of individual amino acids for control pH 6 


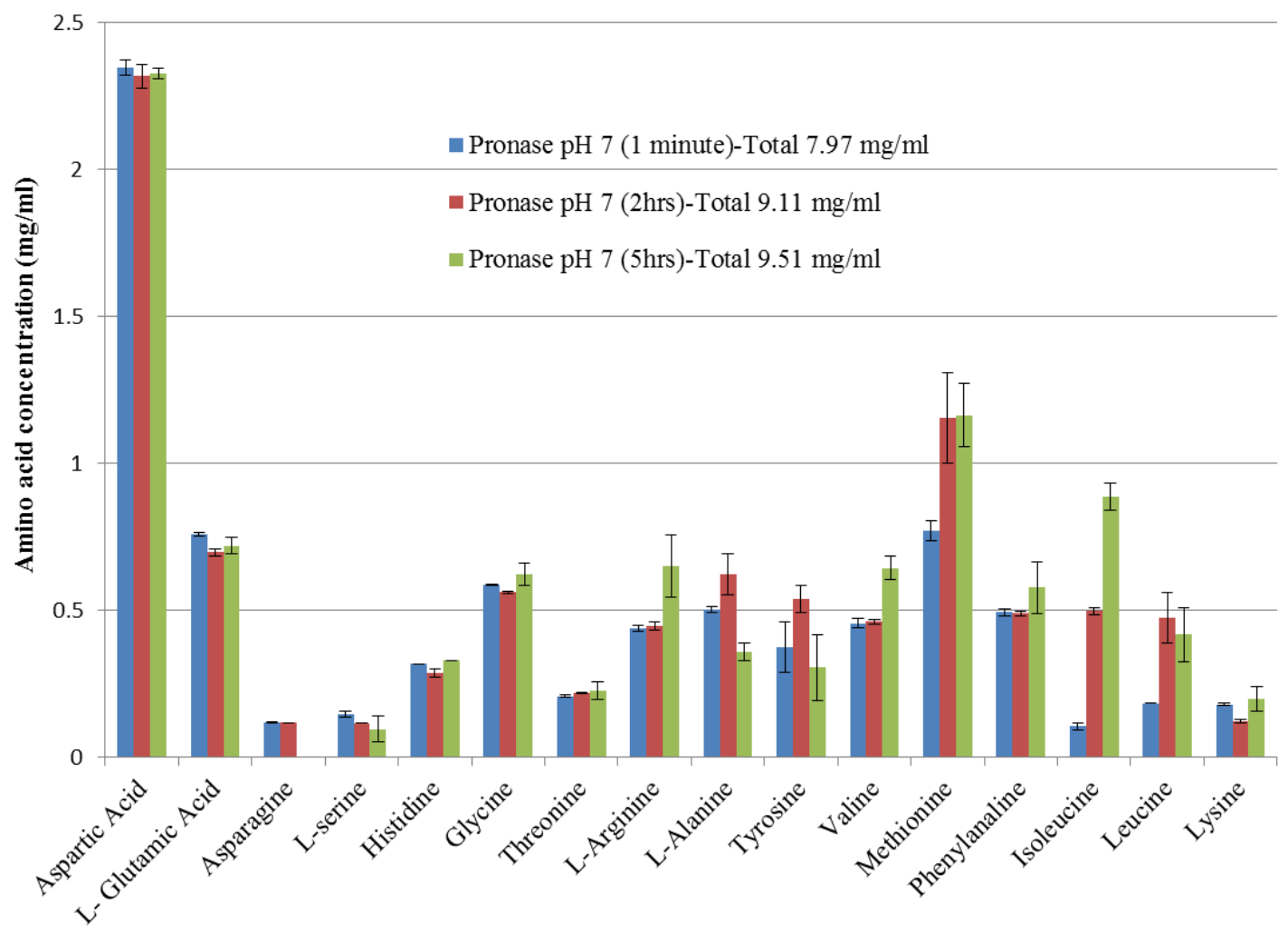

Figure B-5 Amino acid hydrolysis trends of individual amino acids for Pronase $\mathrm{pH} 7$

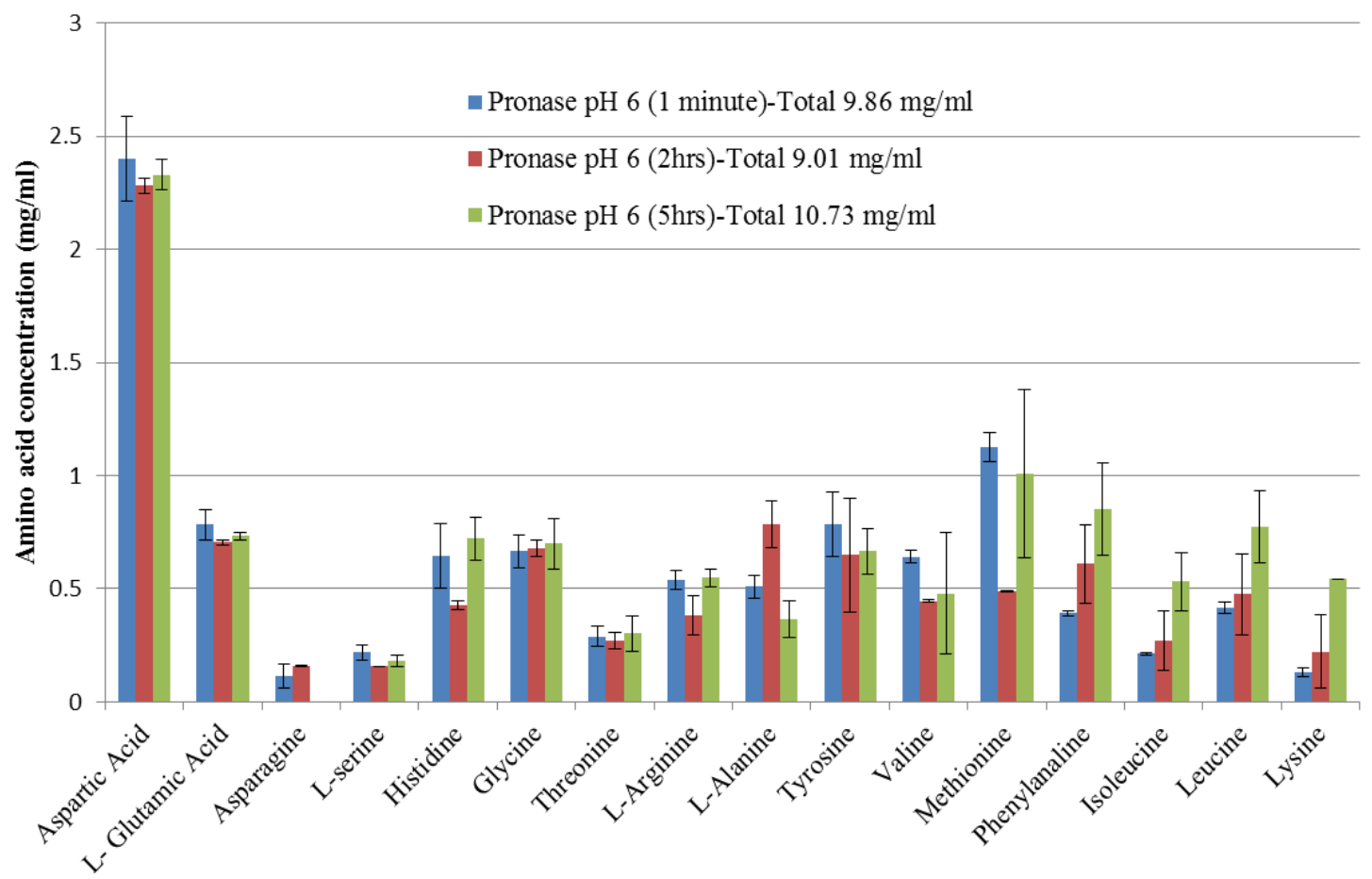

Figure B-6 Amino acid hydrolysis trends of individual amino acids for Pronase $\mathrm{pH} 6$ 


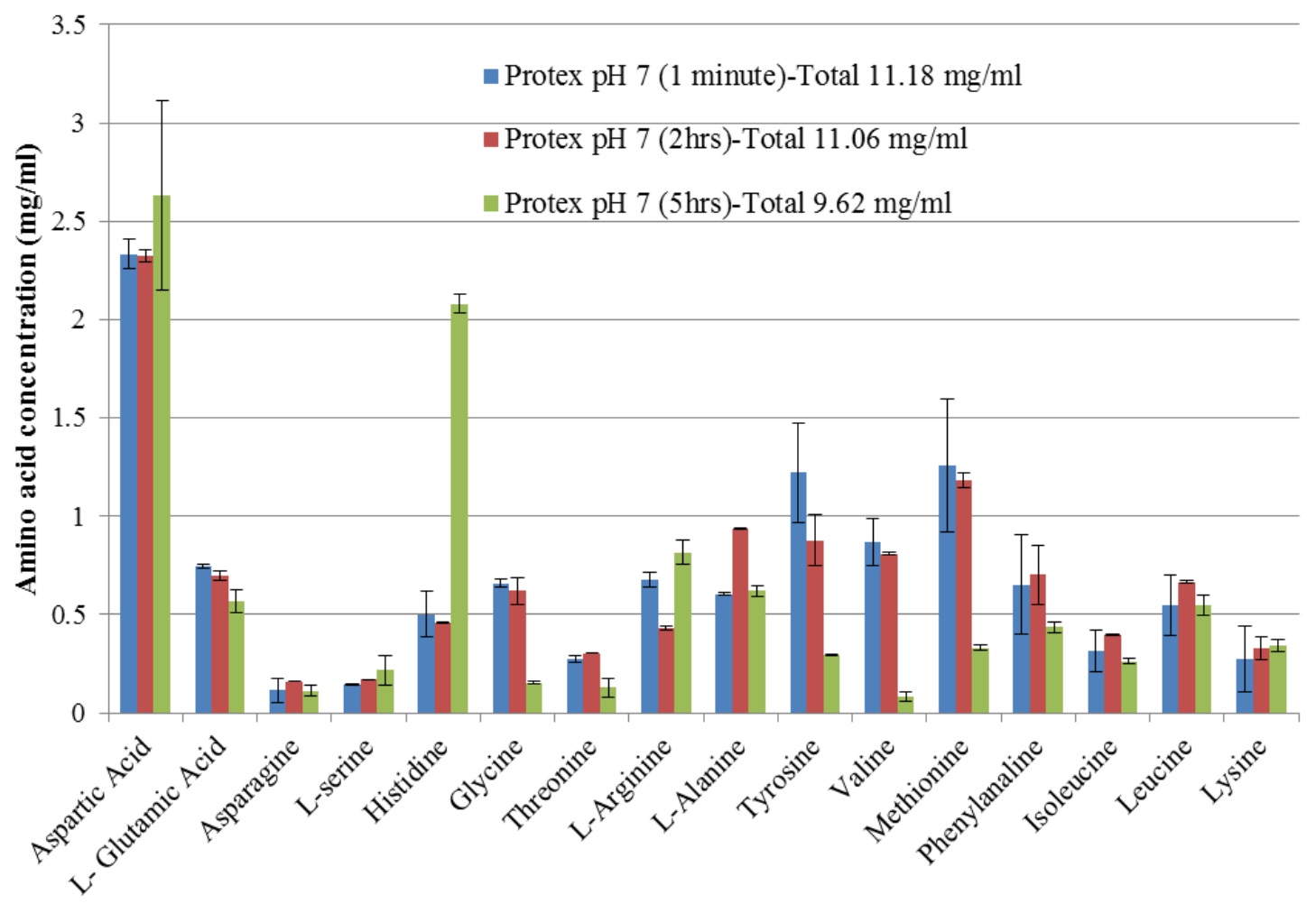

Figure B-7 Amino acid hydrolysis trends of individual amino acids for Protex pH 7

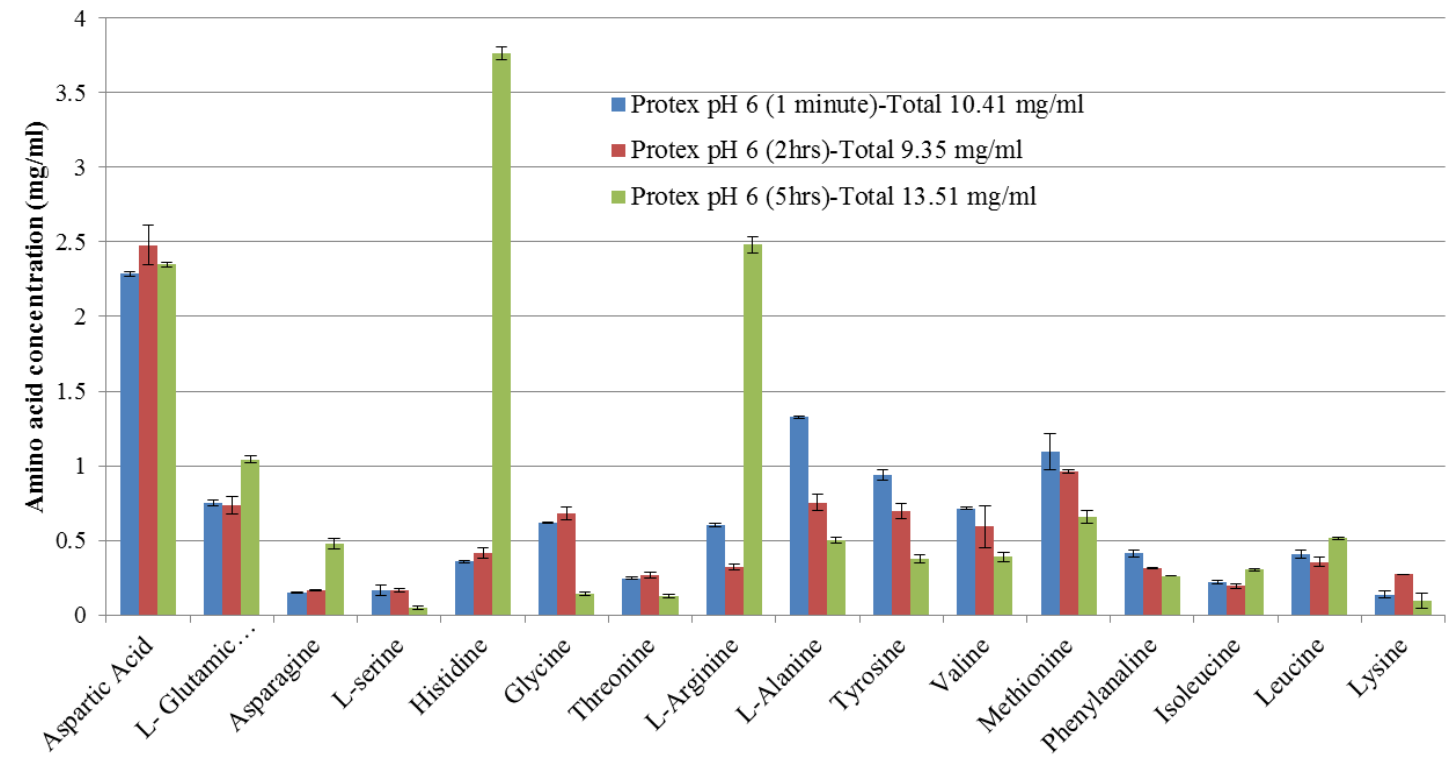

Figure B-8 Amino acid hydrolysis trends of individual amino acids for Protex pH 6 


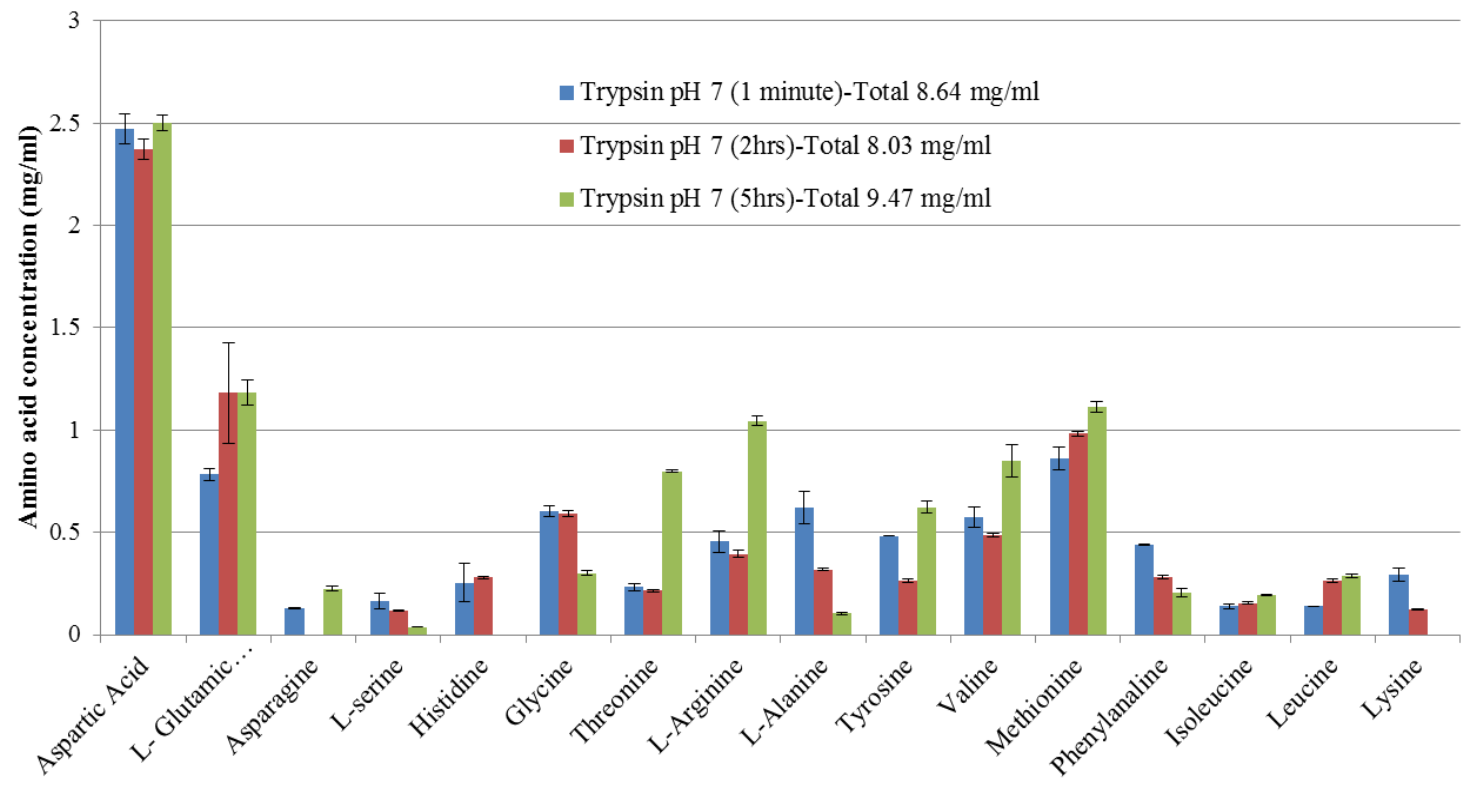

Figure B-9 Amino acid hydrolysis trends of individual amino acids for Trypsin $\mathrm{pH} 7$

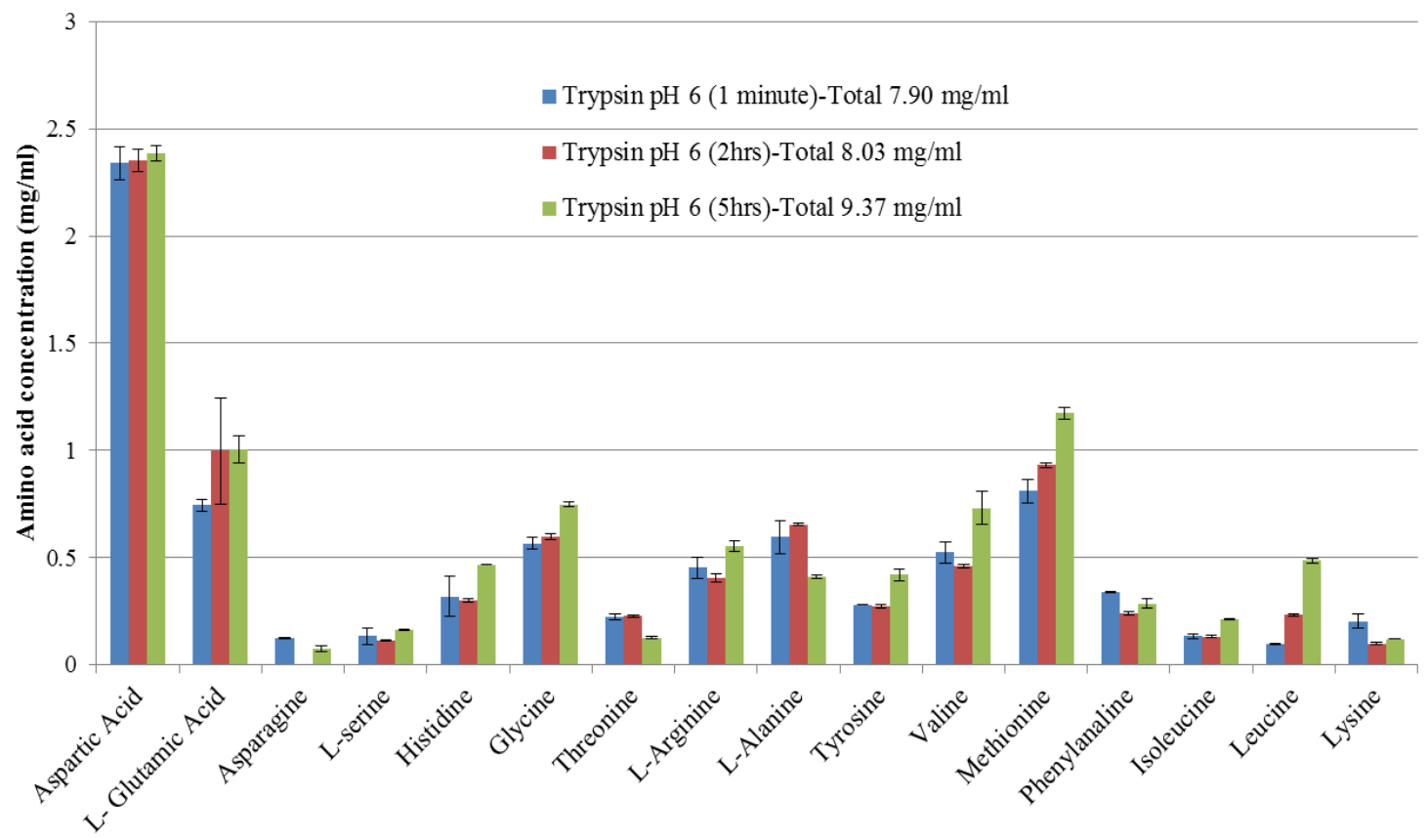

Figure B-10 Amino acid hydrolysis trends of individual amino acids for Trypsin $\mathrm{pH} 6$ 


\section{Appendix C: Supplementary information for modeling of dilute acid pretreatment process using defatted corn syrup as feedstock.}

Table C-1: Reactant components and chemical formular for protein model

\begin{tabular}{|lllll|}
\hline \multicolumn{5}{|c|}{ Reactants } \\
\hline \#Mole & Component & Formular & MW $\begin{array}{l}\text { (\#Mole* } \\
\text { MW) } \\
\text { (amount in } \\
\text { solution, g) }\end{array}$ \\
1 & Protein & $\mathbf{C H}_{\mathbf{1 . 9 9}} \mathbf{O}_{\mathbf{0 . 6 1}} \mathbf{N}_{\mathbf{0 . 3 2}} \mathbf{S}_{\mathbf{0 . 0 1}}$ & 28.55 & 28.55 \\
0.09 & $\mathrm{H}_{2} \mathrm{O}$ & $\mathbf{H}_{\mathbf{2}} \mathbf{O}$ & 18 & 1.6 \\
0 & Acid catalyst & $\mathbf{H}_{\mathbf{2}} \mathbf{S O}_{\mathbf{4}}$ & 0 & 0 \\
& Total & & & $\mathbf{3 0 . 1 9}$ \\
\hline
\end{tabular}

Table C-2 Product components and chemical formular for protein model

\begin{tabular}{|c|c|c|c|c|}
\hline \multicolumn{5}{|c|}{ Products } \\
\hline \#Mole & Component & Formular & MW & $\begin{array}{l}\text { (\#Mole* MW) } \\
\text { (amount in } \\
\text { solution, g) }\end{array}$ \\
\hline 0.24 & Aspartic acid & $\mathrm{CH}_{1.75} \mathrm{ON}_{0.25}$ & 33.25 & 7.98 \\
\hline 0.12 & Glutamic acid & $\mathrm{CH}_{1.8} \mathrm{O}_{0.8} \mathrm{~N}_{0.2}$ & 29.4 & 3.528 \\
\hline 0.03 & Asparagine & $\mathrm{CH}_{2} \mathbf{O}_{0.75} \mathbf{N}_{0.5}$ & 33.0 & 0.99 \\
\hline 0.02 & Serine & $\mathrm{CH}_{2.33} \mathrm{ON}_{0.33}$ & 34.95 & 0.699 \\
\hline 0.06 & Histidine & $\mathbf{C H}_{2} \mathbf{O}_{0.75} \mathbf{N}_{0.7}$ & 35.8 & 2.148 \\
\hline 0.08 & Glycine & $\mathbf{C H}_{2.5} \mathbf{O N}_{0.5}$ & 37.5 & 3 \\
\hline 0.06 & Threonine & $\mathrm{CH}_{2.25} \mathrm{O}_{0.75} \mathbf{N}_{0.75}$ & 36.75 & 2.205 \\
\hline 0.06 & Arginine & $\mathrm{CH}_{2.33} \mathrm{O}_{0.67} \mathbf{N}_{0.33}$ & 29.67 & 1.7802 \\
\hline 0.04 & Alanine & $\mathrm{CH}_{2.33} \mathrm{O}_{0.67} \mathbf{N}_{0.33}$ & 29.67 & 1.1868 \\
\hline 0.02 & Tyrosine & $\mathrm{CH}_{1.22} \mathrm{O}_{0.33} \mathrm{~N}_{0.11}$ & 20.04 & 0.4008 \\
\hline 0.02 & Valine & $\mathrm{CH}_{2.2} \mathrm{O}_{0.4} \mathbf{N}_{0.2}$ & 23.42 & 0.4684 \\
\hline 0.1 & Methionine & $\mathrm{CH}_{1.22} \mathrm{O}_{0.4} \mathbf{N}_{0.2} \mathrm{~S}_{0.2}$ & 28.82 & 2.882 \\
\hline 0.05 & Phenylalanine & $\mathrm{CH}_{1.22} \mathrm{O}_{0.22} \mathrm{~N}_{0.11}$ & 18.28 & 0.914 \\
\hline 0.04 & Isoleucine & $\mathrm{CH}_{2.17} \mathrm{O}_{0.33} \mathrm{~N}_{0.17}$ & 21.83 & 0.8732 \\
\hline 0.03 & Leucine & $\mathrm{CH}_{2.17} \mathrm{O}_{0.33} \mathrm{~N}_{0.17}$ & 21.83 & 0.6549 \\
\hline 0.02 & $\begin{array}{l}\text { Lysine } \\
\text { Total }\end{array}$ & $\mathrm{CH}_{2.33} \mathrm{O}_{0.33} \mathrm{~N}_{0.33}$ & 24.23 & $\begin{array}{l}0.4846 \\
\mathbf{3 0 . 1 9}\end{array}$ \\
\hline
\end{tabular}




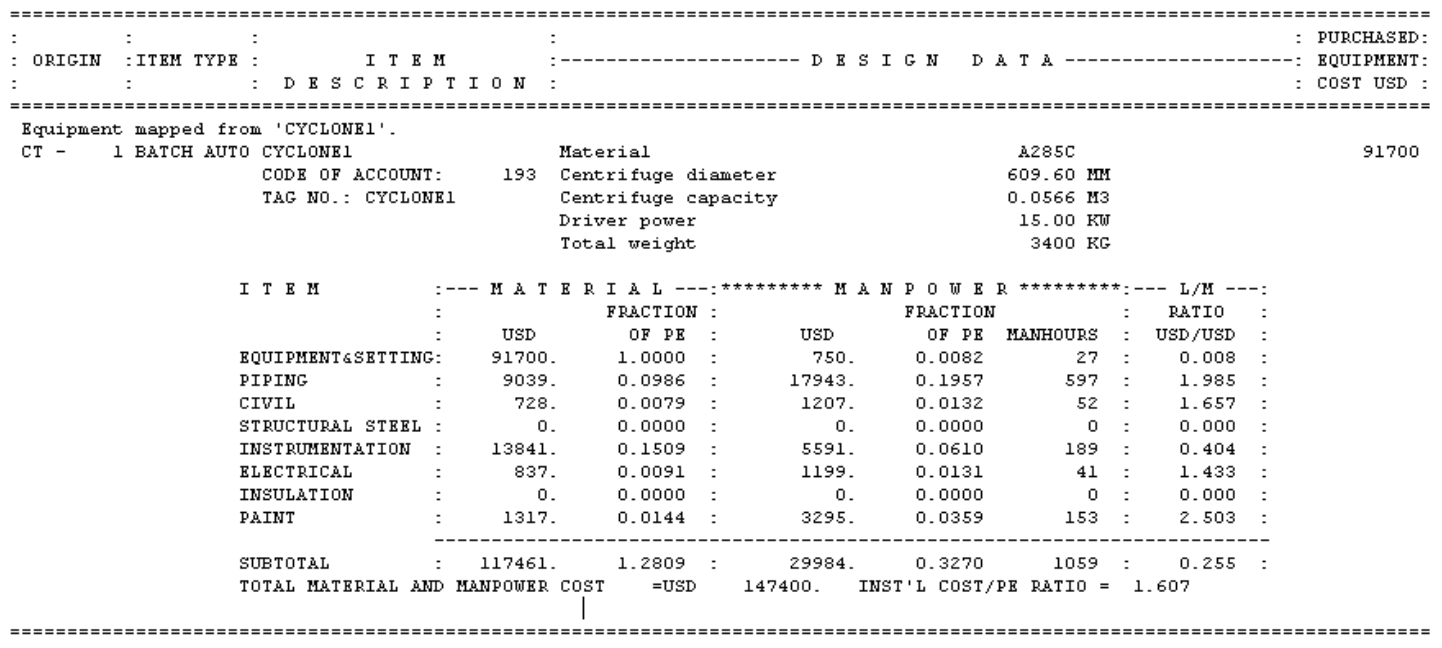

Figure C-1 Detailed cost analysis of unit operation: Cyclone

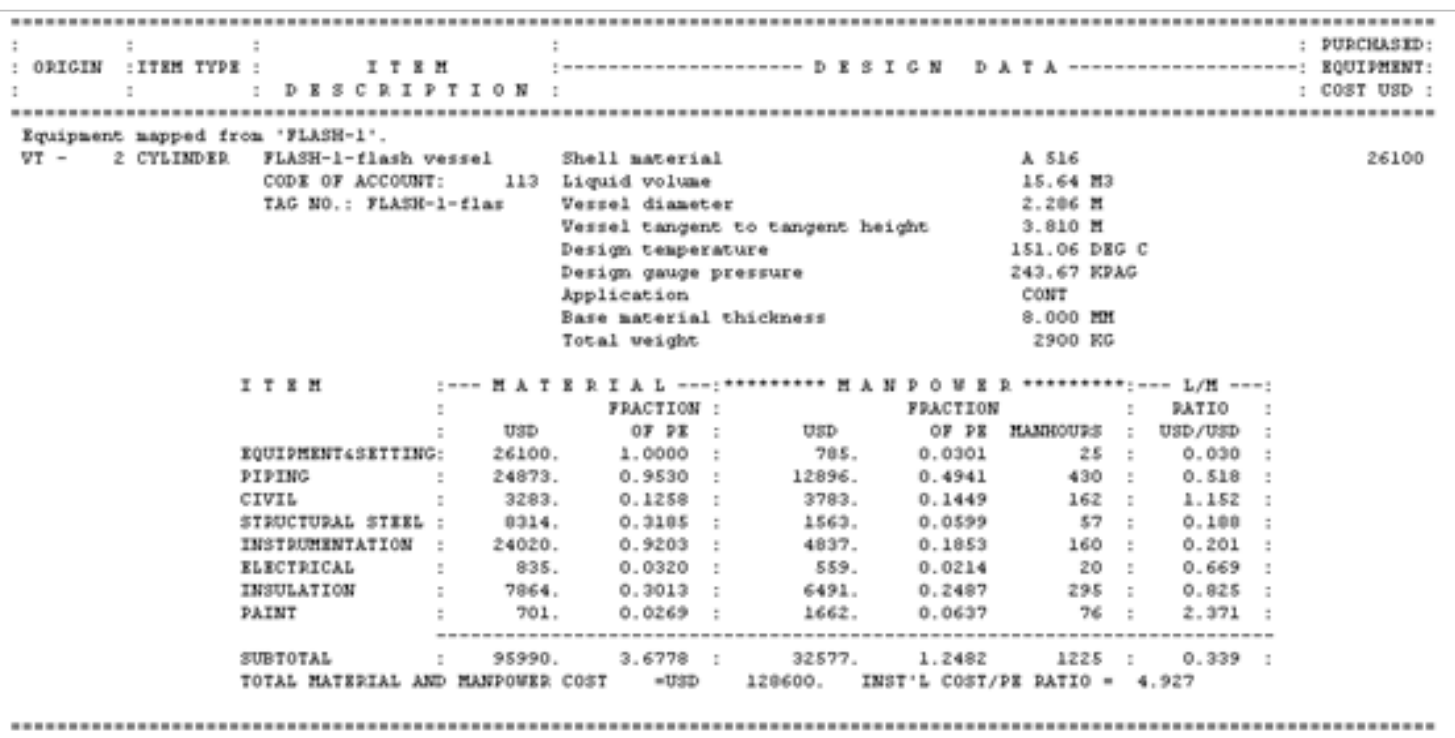

Figure C-2 Detailed cost analysis of unit operation: Flash tank 


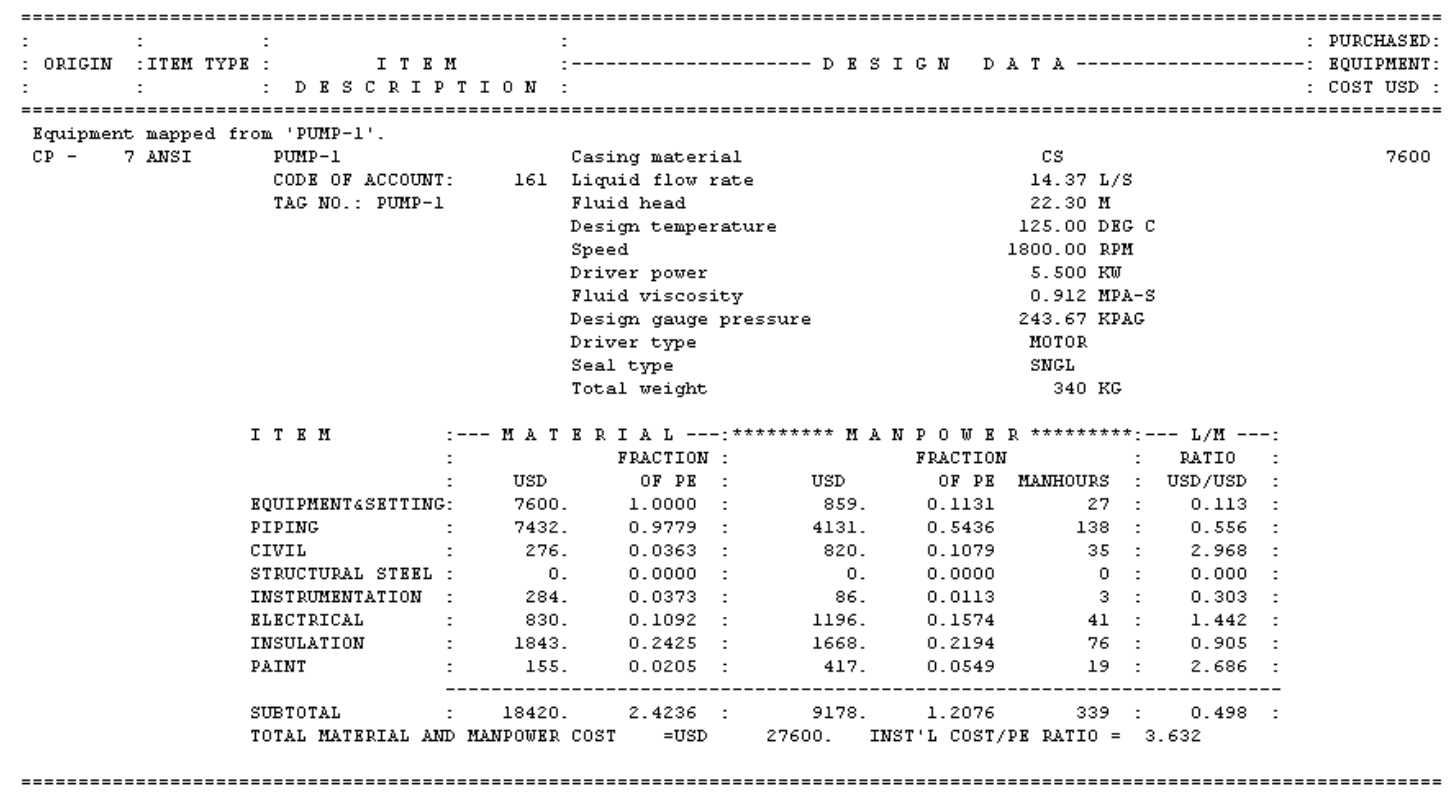

Figure C-3 Detailed cost analysis of unit operation: Pump-1

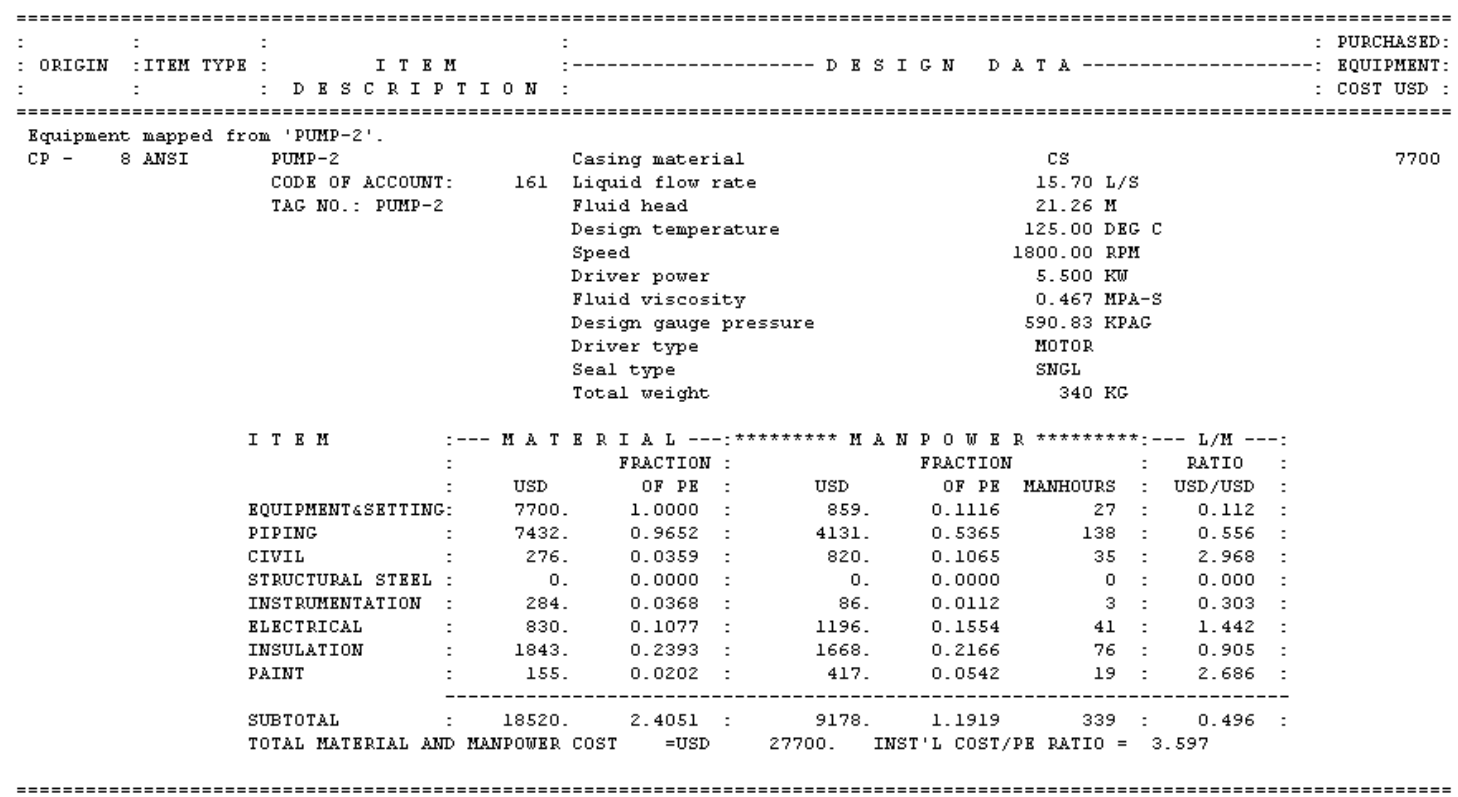

Figure C-4 Detailed cost analysis of unit operation: Pump-2 


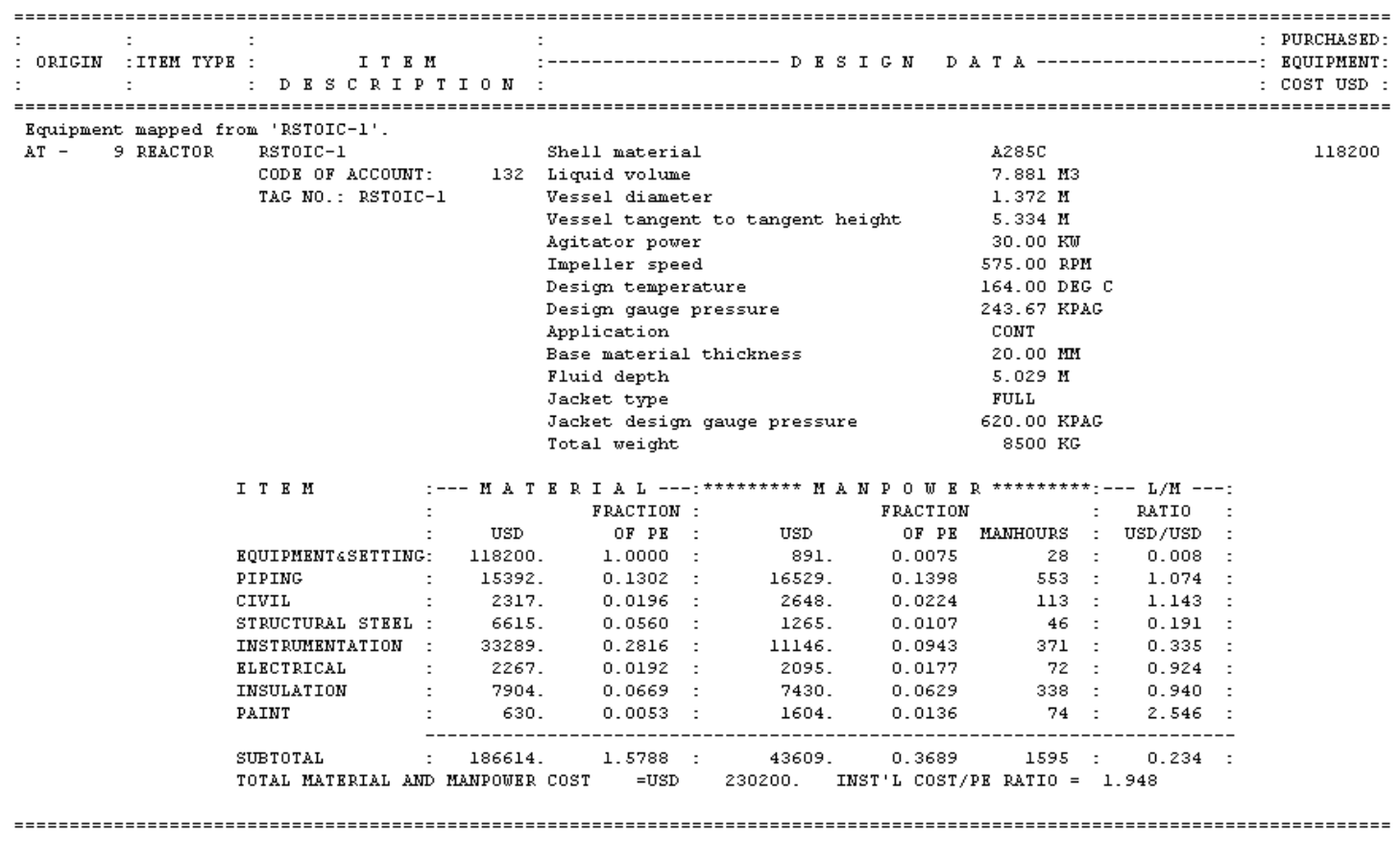

Figure C-5 Detailed cost analysis of unit operation: RSTOIC-1

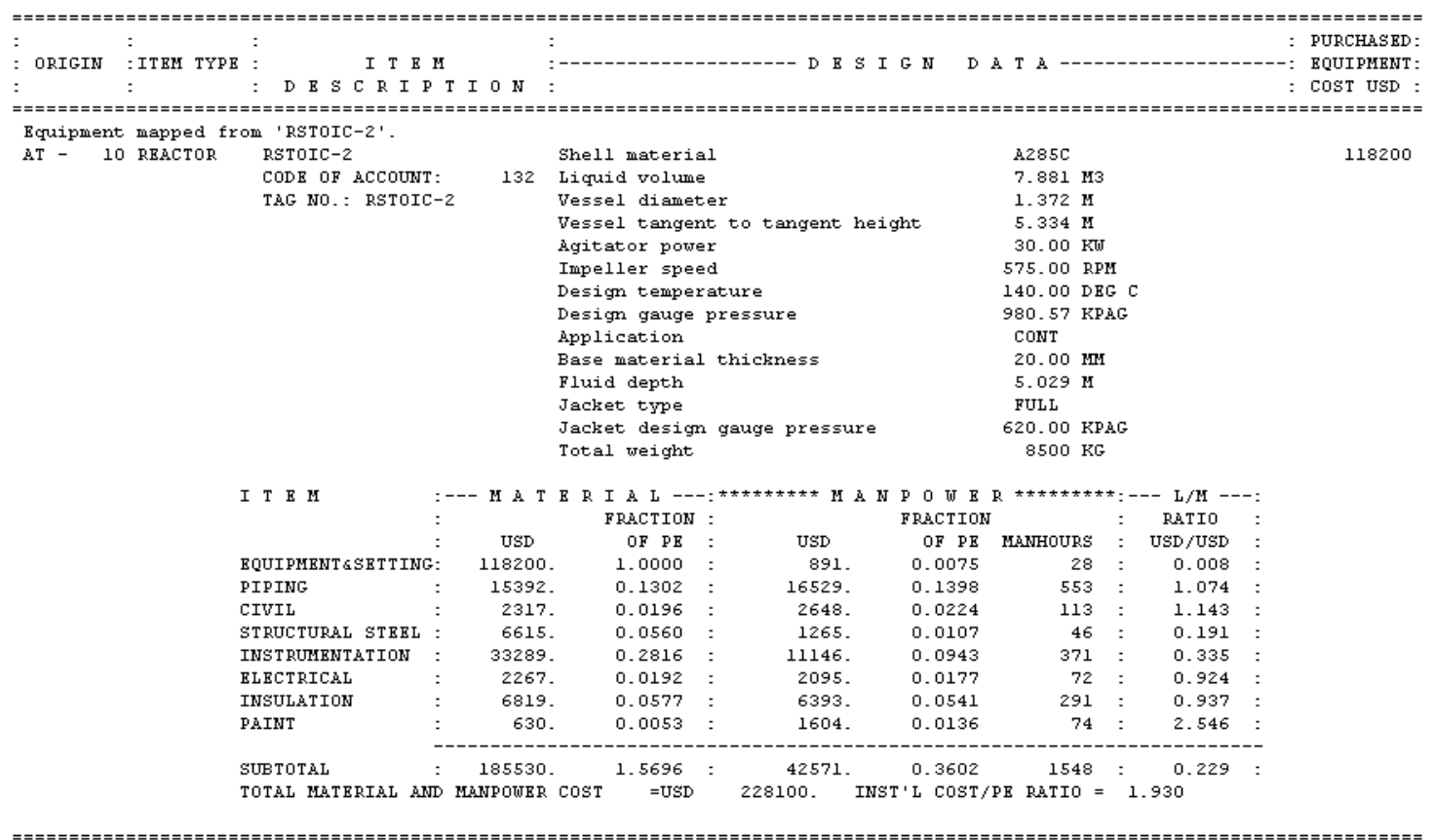

Figure C-6 Detailed cost analysis of unit operation: RSTOIC-2 


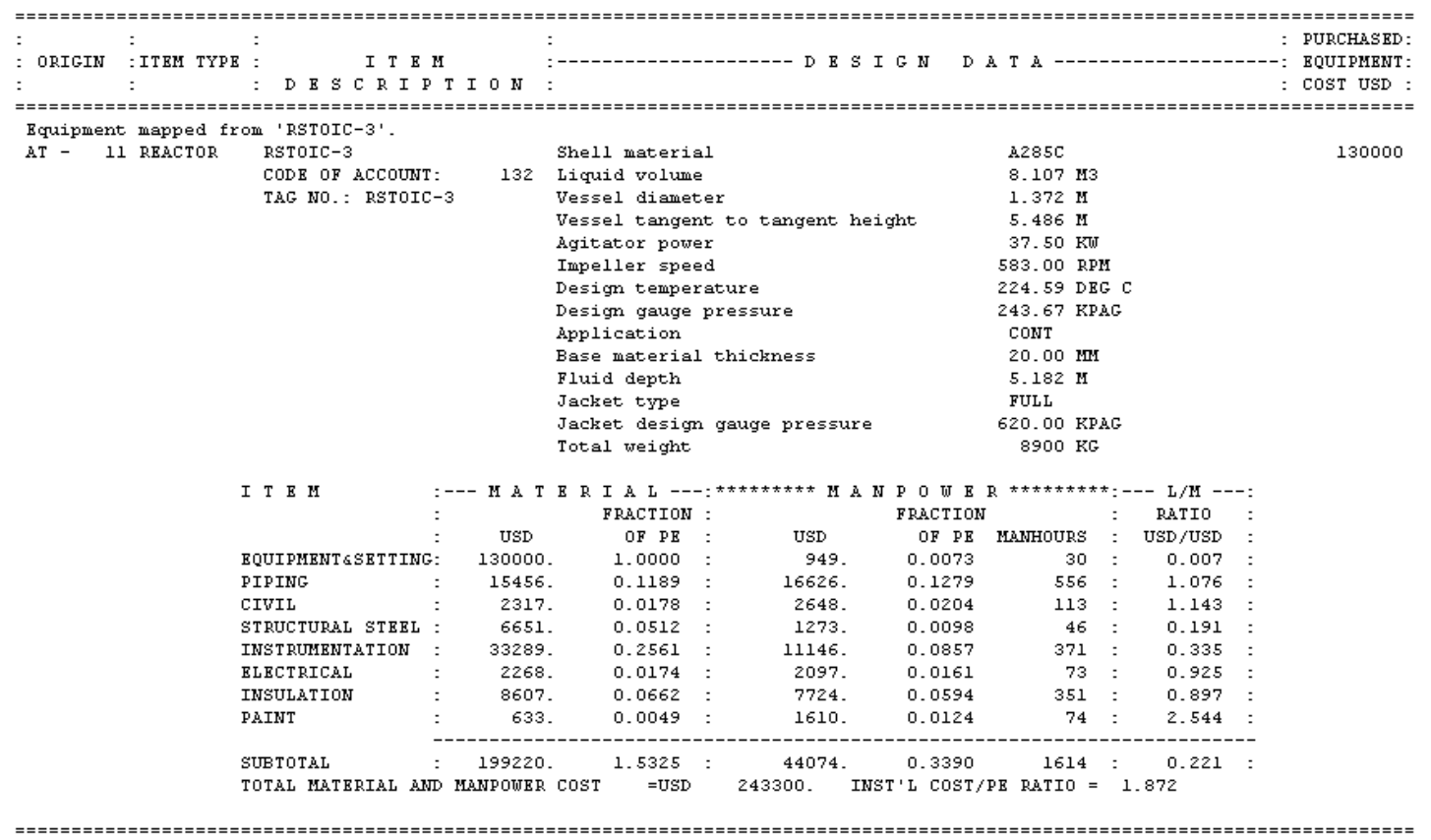

Figure C-7 Detailed cost analysis of unit operation: RSTOIC-3 


\section{Appendix D: Supplementary information for regional carbon footprint analysis of dairy feeds for milk production in the USA}

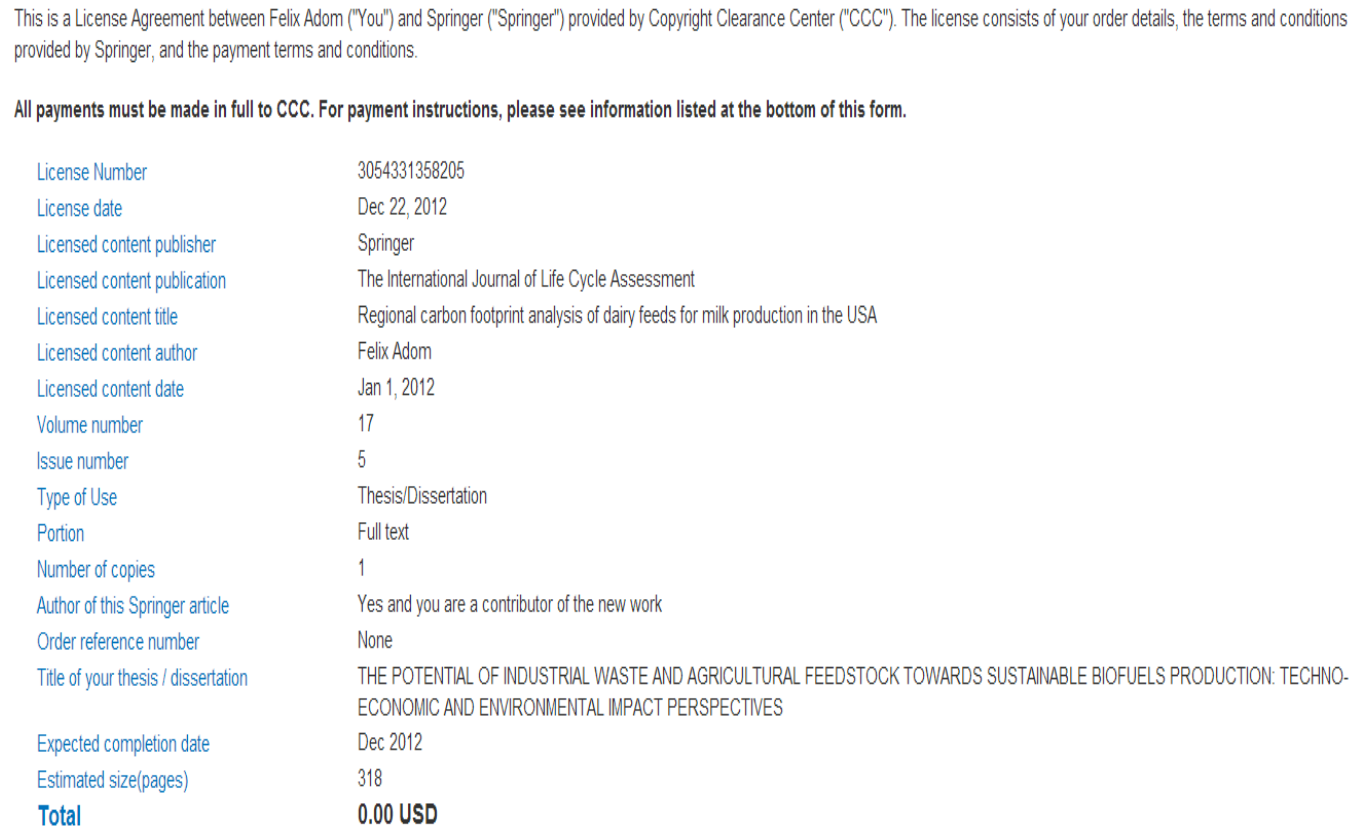

Figure D-1: Copyright clearance from Springer

Figure D-1 above applies to chapter 6 including all supplementary materials in Appendix-D 
Table D-1 Region 1 Grazing season average ration (All values reported as pounds of dry matter intake per day)

\begin{tabular}{|c|c|c|c|c|c|c|c|c|}
\hline Feed & Calves & Open Heifers & Bred Heifers & Springers & First Calf Heifers & Lactating & Dry \\
\hline alfalfa hay & 0.26 & 1.46 & 1.12 & 2.08 & 1.87 & 2.12 & 1.74 \\
\hline alfalfa silage & 0.95 & 5.28 & 7.93 & 3.36 & 7.39 & 6.86 & 4.48 \\
\hline canola meal & 0.00 & 0.00 & 0.15 & 0.14 & 0.97 & 0.96 & 0.00 \\
\hline corn & 0.08 & 0.45 & 0.09 & 1.56 & 5.37 & 5.86 & 0.29 \\
\hline corn silage & 0.76 & 4.26 & 7.47 & 10.78 & 16.03 & 17.04 & 12.27 \\
\hline corn, hm & 0.01 & 0.08 & 0.08 & 0.05 & 1.24 & 1.13 & 0.14 \\
\hline ddg, dry & 0.03 & 0.15 & 0.54 & 0.57 & 1.14 & 1.14 & 0.44 \\
\hline grain mix & 0.15 & 0.84 & 0.08 & 0.49 & 3.89 & 3.90 & 0.85 \\
\hline grass hay & 0.06 & 0.31 & 0.89 & 1.57 & 0.09 & 0.09 & 1.80 \\
\hline grass silage & 0.01 & 0.03 & 0.34 & 1.86 & 0.22 & 0.39 & 0.67 \\
\hline oat silage & 0.00 & 0.01 & 0.46 & 0.00 & & & 0.00 \\
\hline protein mix & 0.03 & 0.19 & 0.09 & 0.48 & 3.09 & 2.81 & 0.18 \\
\hline soybean meal & 0.03 & 0.19 & 0.08 & 0.62 & 1.31 & 1.48 & 0.75 \\
\hline supplement & 0.08 & 0.42 & 0.45 & 1.24 & 1.94 & 2.38 & 1.04 \\
\hline wheat silage & 0.15 & 0.81 & 0.72 & & & 0.40 & 2.36 \\
\hline wheat straw & & & 0.12 & 2.01 & 0.11 & 0.17 & \\
\hline
\end{tabular}

Table D-2 Region 1 Non-grazing season average ration (All values reported as pounds of dry matter intake per day)

\begin{tabular}{|c|c|c|c|c|c|c|c|}
\hline Feed & Calves & Open Heifers & Bred Heifers & Springers & First Calf Heifers & Lactating & Dry \\
\hline alfalfa hay & 1.15 & 0.48 & 0.72 & 0.96 & 3.42 & 3.15 & 0.09 \\
\hline alfalfa silage & & 0.54 & 0.24 & 0.65 & 0.45 & 0.37 & 0.10 \\
\hline corn silage & 0.96 & 1.32 & 1.00 & 2.66 & 1.83 & 2.50 & 0.24 \\
\hline corn, hm & 0.05 & & 0.11 & 0.07 & 1.96 & 1.97 & \\
\hline grain mix & 0.33 & 0.31 & 0.18 & 0.58 & 2.75 & 2.76 & 0.06 \\
\hline pasture & 20.02 & 8.74 & 17.28 & 17.72 & 25.18 & 26.09 & 1.57 \\
\hline $\mathrm{pmr}$ & 0.15 & & & 1.20 & 1.14 & 1.89 & \\
\hline soy hulls & 0.07 & 0.02 & 0.01 & 0.25 & 1.14 & 0.61 & 0.00 \\
\hline soybean meal & 0.20 & 0.77 & 0.16 & 0.65 & 0.89 & 1.07 & 0.14 \\
\hline supplement & 1.12 & 0.56 & 0.31 & 0.63 & 2.05 & 2.32 & 0.10 \\
\hline
\end{tabular}


Table D-3 Region 2 Grazing season average ration (All values reported as pounds of dry matter intake per day)

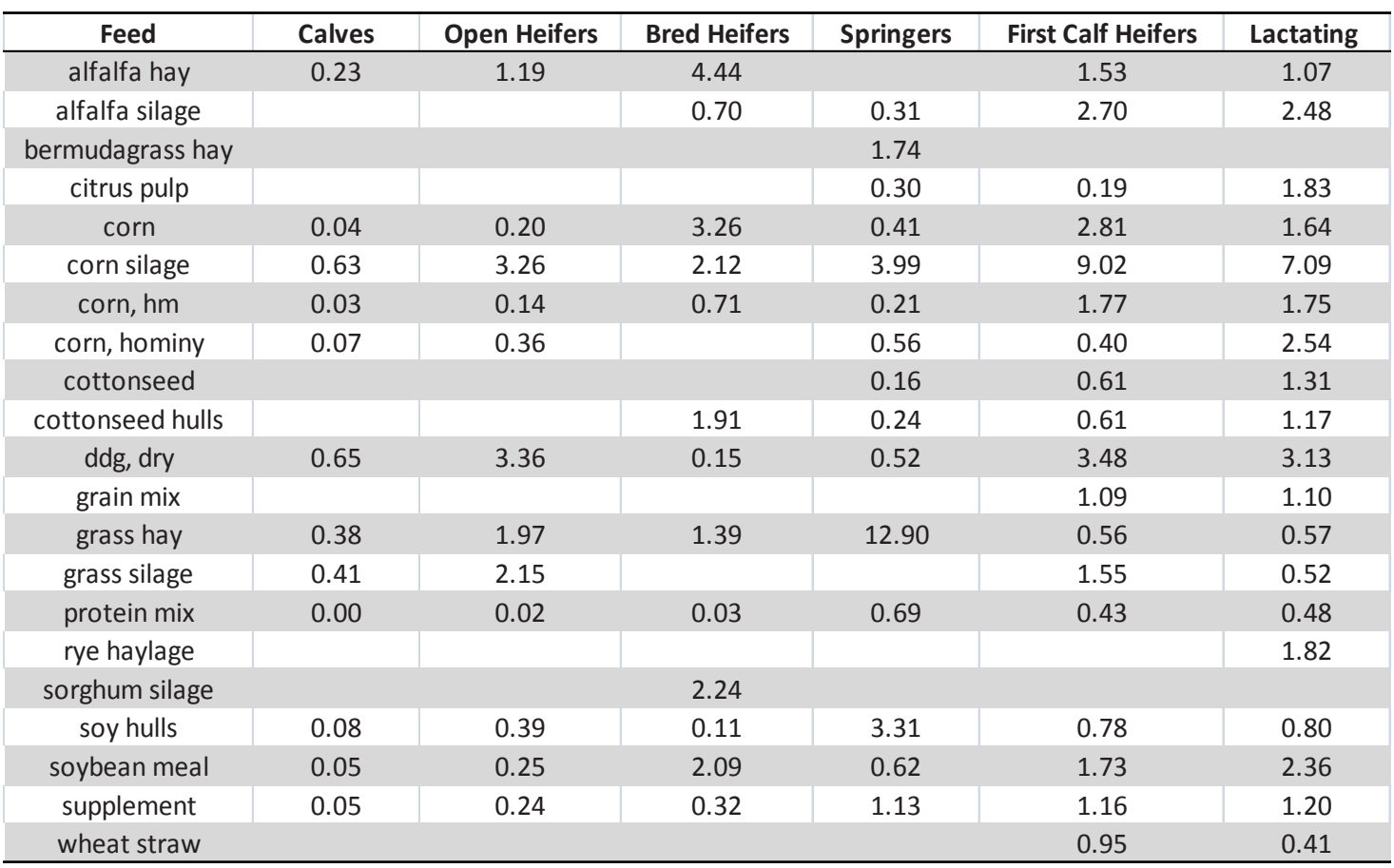

Table D-4 Region 2 Non-grazing season average ration (All values reported as pounds of dry matter intake per day)

\begin{tabular}{|c|c|c|c|c|c|c|}
\hline Feed & Calves & Open Heifers & Bred Heifers & Springers & First Calf Heifers & Lactating \\
\hline citrus pulp & 1.98 & 1.32 & 1.56 & 2.77 & 4.86 & 4.46 \\
\hline corn & 0.72 & 0.56 & 2.05 & 1.26 & 2.40 & 2.95 \\
\hline corn, hominy & & 0.59 & & & 1.32 & 1.74 \\
\hline cottonseed & & & & & 2.80 & 2.37 \\
\hline cottonseed hulls & 0.57 & 0.38 & & 0.79 & 1.21 & 1.21 \\
\hline ddg, dry & 1.11 & 1.04 & 0.48 & 1.10 & 1.50 & 2.45 \\
\hline grain mix & & 0.08 & & & 0.94 & 0.73 \\
\hline grass hay & 1.30 & 1.83 & 5.72 & 0.91 & 0.88 & 0.62 \\
\hline pasture & 15.35 & 6.01 & 7.73 & 17.46 & 10.45 & 12.16 \\
\hline soy hulls & 0.39 & 0.63 & 0.06 & 0.27 & 2.04 & 1.44 \\
\hline soybean meal & 1.46 & 0.83 & 1.35 & 1.85 & 2.48 & 2.44 \\
\hline supplement & 0.59 & 0.27 & 0.54 & 0.69 & 0.50 & 0.71 \\
\hline
\end{tabular}


Table D-5 Region 3 Grazing season average ration (All values reported as pounds of dry matter intake per day)

\begin{tabular}{|c|c|c|c|c|c|c|}
\hline Feed & Calves & Open Heifers & Bred Heifers & Springers & First Calf Heifers & Lactating \\
\hline alfalfa hay & 0.37 & 2.19 & 1.61 & 0.71 & 1.56 & 1.45 \\
\hline alfalfa silage & 0.67 & 3.89 & 4.40 & 1.45 & 8.54 & 9.35 \\
\hline corn & 0.12 & 0.72 & 0.04 & 0.81 & 6.89 & 6.64 \\
\hline corn gluten feed & 0.05 & 0.28 & 0.62 & 0.97 & 2.04 & 2.21 \\
\hline corn silage & 0.76 & 4.44 & 7.70 & 10.26 & 15.31 & 16.26 \\
\hline corn, hm & 0.05 & 0.29 & 0.05 & 0.43 & 2.57 & 3.31 \\
\hline ddg, dry & 0.06 & 0.36 & 0.46 & 0.91 & 1.66 & 1.24 \\
\hline grain mix & 0.09 & 0.53 & 0.18 & 0.27 & 1.02 & 0.95 \\
\hline grass hay & 0.21 & 1.20 & 0.98 & 1.42 & 0.11 & 0.22 \\
\hline oat silage & 0.01 & 0.08 & 0.46 & & & 3.22 \\
\hline protein mix & 0.03 & 0.15 & 0.75 & 1.25 & 1.70 & 1.83 \\
\hline soybean meal & 0.04 & 0.25 & 0.71 & 1.29 & 0.92 & 1.00 \\
\hline soybean, roasted & 0.00 & 0.01 & 0.00 & 0.02 & 2.24 & 2.48 \\
\hline supplement & 0.08 & 0.45 & 0.74 & 1.57 & 0.69 & 0.71 \\
\hline wheat straw & 0.06 & 0.34 & 3.12 & 5.18 & & \\
\hline
\end{tabular}

Table D-6 Region 3 Non-grazing season average ration (All values reported as pounds of dry matter intake per day)

\begin{tabular}{|c|c|c|c|c|c|c|}
\hline Feed & Calves & Open Heifers & Bred Heifers & Springers & First Calf Heifers & Lactating \\
\hline alfalfa hay & 0.83 & 0.07 & 0.07 & 0.40 & 0.55 & 0.62 \\
\hline corn & 1.02 & 0.43 & 0.39 & 0.34 & 3.94 & 3.52 \\
\hline $\begin{array}{c}\text { corn gluten feed } \\
\text { corn silage }\end{array}$ & 3.22 & & 0.05 & & 1.31 & 1.43 \\
\hline $\begin{array}{c}\text { corn, hm } \\
\text { cottonseed }\end{array}$ & & 1.06 & 0.26 & 0.62 & 0.36 \\
\hline ddg, dry & & 0.72 & 0.67 & & 4.84 & 5.74 \\
\hline grain mix & 1.07 & & & & 1.89 & 2.03 \\
\hline pasture & 21.01 & 12.82 & 18.54 & 18.65 & 3.61 & 3.28 \\
\hline protein mix & & 0.12 & 0.11 & 0.03 & 0.99 & 1.77 \\
\hline soybean meal & & 0.12 & 0.02 & 1.11 & 0.91 & 1.44 \\
\hline supplement & 0.19 & 0.16 & 0.28 & 0.84 & 1.34 & 0.80 \\
\hline
\end{tabular}


Table D-7 Region 4 Grazing season average ration (All values reported as pounds of dry matter intake per day)

\begin{tabular}{|c|c|c|c|c|c|c|}
\hline Feed & Calves & Open Heifers & Bred Heifers & Springers & First Calf Heifers & Lactating \\
\hline alfalfa hay & 0.81 & 5.51 & 5.74 & 6.88 & 10.29 & 10.11 \\
\hline alfalfa silage & 0.26 & 1.75 & 3.53 & 1.08 & 6.24 & 5.91 \\
\hline barley & & & & 1.01 & 1.83 & 2.57 \\
\hline bermudagrass hay & 0.01 & 0.06 & 0.26 & 0.27 & & \\
\hline canola meal & 0.02 & 0.14 & 0.13 & 0.49 & 0.84 & 1.17 \\
\hline corn & 0.06 & 0.41 & 0.14 & 2.37 & 5.15 & 5.62 \\
\hline corn gluten feed & 0.14 & 0.95 & 0.67 & 0.29 & 0.77 & 0.75 \\
\hline corn silage & 0.24 & 1.65 & 1.46 & 7.21 & 9.70 & 10.13 \\
\hline corn steep liquor & 0.08 & 0.55 & 0.66 & & & \\
\hline corn, hm & 0.01 & 0.06 & 0.01 & 0.28 & 2.86 & 2.73 \\
\hline cotton gin trash & 0.13 & 0.86 & 1.62 & & & 0.13 \\
\hline cottonseed & & & 0.03 & 0.64 & 2.49 & 2.65 \\
\hline ddg, dry & 0.13 & 0.90 & 0.96 & 0.42 & 2.57 & 2.58 \\
\hline grain mix & 0.00 & 0.01 & 0.01 & 0.19 & 0.72 & 1.07 \\
\hline grass hay & 0.12 & 0.83 & 1.03 & 2.14 & 0.02 & 0.10 \\
\hline molasses & 0.01 & 0.04 & 0.13 & 0.16 & 1.00 & 0.85 \\
\hline oat hay & & & 0.75 & 0.19 & & \\
\hline oat silage & 0.06 & 0.39 & 2.35 & 0.01 & & \\
\hline oat straw & 0.07 & 0.46 & & & & \\
\hline protein mix & 0.00 & 0.00 & 0.34 & 0.58 & 1.44 & 1.22 \\
\hline ryegrass silage & 0.05 & 0.32 & 0.30 & & 0.42 & 0.41 \\
\hline sorghum silage & 0.23 & 1.58 & 1.82 & 0.77 & 0.76 & 0.61 \\
\hline soybean meal & 0.00 & 0.01 & 0.01 & 0.37 & 0.82 & 0.51 \\
\hline sudangrass hay & 0.01 & 0.05 & 0.13 & 0.10 & & \\
\hline supplement & 0.04 & 0.26 & 0.30 & 1.48 & 1.31 & 2.28 \\
\hline wheat hay & & & 0.33 & 0.23 & 0.18 & 0.12 \\
\hline wheat straw & 0.14 & 0.92 & 0.33 & 0.90 & 0.15 & 0.08 \\
\hline
\end{tabular}

Table D-8 Region 4 Non-grazing season average ration (All values reported as pounds of dry matter intake per day)

\begin{tabular}{|c|c|c|c|c|c|c|}
\hline Feed & Calves & Open Heifers & Bred Heifers & Springers & First Calf Heifers & Lactating \\
\hline alfalfa hay & 1.73 & 1.37 & 0.50 & & 3.66 & 2.07 \\
\hline alfalfa silage & & & & & 4.58 & 2.56 \\
\hline barley & & 6.27 & 6.53 & & & \\
\hline corn & 0.82 & 0.14 & 0.27 & 4.02 & 8.43 & 13.50 \\
\hline corn gluten feed & & 0.56 & 0.24 & & & \\
\hline corn silage & 1.15 & 0.92 & 0.28 & & 4.42 & 2.47 \\
\hline cotton gin trash & & 1.16 & 0.93 & & & \\
\hline ddg, dry & 0.68 & 0.04 & 0.24 & 0.01 & 2.35 & 1.55 \\
\hline pasture & 26.28 & 6.95 & 12.69 & 21.98 & 15.57 & 23.05 \\
\hline protein mix & 0.03 & 0.01 & & 0.04 & 1.62 & 2.14 \\
\hline sorghum grain & 0.14 & 0.01 & 0.24 & & 4.87 & \\
\hline soybean meal & 0.14 & 0.01 & 0.01 & 0.15 & 0.72 & 2.14 \\
\hline soybean, extrudec & 0.12 & & & & 2.44 & 1.36 \\
\hline supplement & 0.32 & 0.28 & 0.41 & 1.87 & 0.91 & 0.76 \\
\hline wheat hay & & & 0.73 & & & \\
\hline
\end{tabular}


Table D-9 Region 5 Grazing season average ration (All values reported as pounds of dry matter intake per day)

\begin{tabular}{|c|c|c|c|c|c|c|}
\hline Feed & Calves & Open Heifers & Bred Heifers & Springers & First Calf Heifers & Lactating \\
\hline alfalfa hay & 0.50 & 2.60 & 3.52 & 4.85 & 7.68 & 7.74 \\
\hline alfalfa silage & 0.01 & 0.03 & 0.82 & 0.07 & 0.88 & 0.87 \\
\hline almond hulls & 0.11 & 0.60 & 1.45 & 0.39 & 2.44 & 2.87 \\
\hline barley & & & & & 0.54 & 0.66 \\
\hline canola meal & 0.09 & 0.47 & 0.61 & 0.54 & 2.64 & 2.26 \\
\hline citrus pulp & 0.07 & 0.36 & 0.34 & & 0.46 & 0.49 \\
\hline corn & 0.21 & 1.09 & 0.11 & 2.53 & 5.00 & 5.91 \\
\hline \multicolumn{7}{|l|}{ corn dust } \\
\hline corn gluten feed & & & 0.27 & 0.54 & 1.27 & 1.35 \\
\hline corn screenings & & & & & 0.81 & 0.12 \\
\hline corn silage & 0.35 & 1.83 & 1.91 & 8.58 & 8.71 & 8.98 \\
\hline corn stover & 0.01 & 0.04 & 0.45 & & & \\
\hline \multicolumn{5}{|l|}{ corn, hominy } & 0.55 & 0.44 \\
\hline cottonseed & & & & 0.20 & 0.92 & 1.00 \\
\hline ddg, dry & 0.13 & 0.71 & 0.44 & 0.84 & 3.59 & 3.19 \\
\hline grain mix & 0.07 & 0.34 & 0.07 & 0.47 & 1.12 & 1.55 \\
\hline grape pomace & 0.01 & 0.05 & 0.82 & & & \\
\hline grass hay & & & 0.32 & 0.04 & 0.18 & 0.06 \\
\hline oat hay & 0.13 & 0.70 & 1.22 & 1.51 & 0.35 & 0.33 \\
\hline oat silage & 0.23 & 1.20 & 2.17 & 0.21 & & 0.24 \\
\hline \multicolumn{7}{|l|}{ pea silage } \\
\hline soybean meal & 0.02 & 0.10 & 0.03 & 0.20 & 0.37 & 0.64 \\
\hline sugar & 0.02 & 0.13 & 0.26 & & 0.09 & 0.16 \\
\hline supplement & 0.11 & 0.56 & 0.33 & 2.63 & 1.32 & 2.59 \\
\hline wheat hay & & & & 0.45 & 0.03 & \\
\hline wheat midds & 0.06 & 0.32 & & & 0.16 & 0.14 \\
\hline \multicolumn{4}{|l|}{ wheat mill run } & 0.33 & 0.92 & 0.66 \\
\hline wheat silage & 0.28 & 1.46 & 2.37 & 0.43 & 0.48 & 0.53 \\
\hline wheat straw & 0.19 & 1.00 & 1.83 & 0.25 & 0.21 & 0.17 \\
\hline whey & & & 0.01 & & 0.80 & 0.85 \\
\hline
\end{tabular}

Table D-10 Region 5 Non-grazing season average ration (All values reported as pounds of dry matter intake per day)

\begin{tabular}{|c|c|c|c|c|c|c|}
\hline Feed & Calves & Open Heifers & Bred Heifers & Springers & First Calf Heifers & Lactating \\
\hline grain mix & \multicolumn{7}{c}{} & 1.20 & 2.90 & 6.53 \\
pasture & 5.12 & 4.60 & 10.34 & 5.87 & 20.50 & 19.00 \\
pmr & 22.39 & 9.00 & 9.00 & 17.98 & 18.13 & 18.25 \\
\hline
\end{tabular}




\section{Section D: Animal Feedstuffs and Grazing Practices}

D1. Please print (or ask your nutritionist to provide) and attach all of your fed rations for each of the following animal classes during both grazing and non-grazing seasons. Please write the animal class name (see list below) and "non-grazing season" or "grazing season" on each attached ration. If you cannot provide detalls of your ration, please attach feed composition information (feed tags) and label with each antmal class/season.

Please list the average number of head in each animal class, corresponding to the ratlons (or feed composttions). Note: The numbers may be the same across non-grazing and grazing seasons.

\begin{tabular}{|l|l|l|}
\hline Animal Class & Non-Graxing Season & Grazing Season \\
\hline Newborn Galves & head & head \\
\hline Open Heifers & head & head \\
\hline Bred Heifers & head & head \\
\hline Springers and Close-ups & head & head \\
\hline First-Calf Heifers & head & head \\
\hline Mature Cows & head & head \\
\hline Dry Cows & head & head \\
\hline
\end{tabular}

D2. Do the rations you printed for question D1 above include the pounds per day fed to each class of antmal on etther an as-fed or dry-matter basts (DMI)?

$\square$ yes (skip to question D4) $\quad \square$ no (continue with question D3)

D3. For each ration, indieate how many pounds were fed dally to each class of animal. Do not include forage consumed while grazing, which is covered in another question. Indicate below whether you are reporting rations on an as-fed basis or a dry-matter basis. In the table on the following page, if you have more than one ration to report per antmal class, use a separate line in each box for each ration, and be sure to name the ration. If you need more space, attach a separate sheet or use the space at the end of sectlon D.

As-Fed v. Dry-Matter Rations: Rations contain water, whether they are concentrate feedstufffs or forages. As-fed means the feed or forage as it is fed to animals, induding the moisture content. Dry-matter intake (DMD) is the feed on a moisture-free basis. Use whichever format is easiest, but indicate which you are using:

$\square$ as-fed basis

$\square$ dry-matter (DMI) basis

Dairy Producer Life Cycle Assessment Survey [11]

Figure D-2 Dairy producer life cycle assessment survey and How-To guide (a) 
Dairy Producer Life Cycle Assessment Survey

\begin{tabular}{|c|c|c|}
\hline Animal Cass & $\begin{array}{l}\text { Non-Graving Season Rations } \\
\text { (lbs per day per animal dass) }\end{array}$ & $\begin{array}{l}\text { Grazing Season Ration } \\
\text { (Ibs per day per animal dass) }\end{array}$ \\
\hline $\begin{array}{l}\text { Newborn Calver (0-3 months) } \\
\text { Please describe milk and milk } \\
\text { replacer feeding regimes } \\
\text { (amounts given and units) }\end{array}$ & & \\
\hline $\begin{array}{l}\text { Newborn Calves (0-3 months) } \\
\text { Feed rations (not milk or millk } \\
\text { replacer) }\end{array}$ & (lbs/day) & (lbs/day) \\
\hline Open Heifers & (lbs/day) & (lbs/day) \\
\hline Bred Heifers & (lbs/day) & (lbs/day) \\
\hline Springers and Close-ups & (lbs/day) & (lbs/day) \\
\hline First-Galf Heifers & (lbs/day) & (lbs/day) \\
\hline Mature Cows & (lbs/day) & (lbs/day) \\
\hline Dry Cows & (lbs/day) & (lbs/day) \\
\hline
\end{tabular}

D4. In 2008 did you feed any agricultural byproducts (cottonseed, eltrus pulp, DDGs, etc.) that are not included in the rations you described/attached in questlons D1 through D3?

\section{$\square$ yes (continue with question D5) \\ $\square$ no (skip to question D6)}

D5. If you also fed agricultural by-products (cottonseed, cttrus pulp, DDGs, etc.) and they were NOT included in your fed rations described above, please describe the average by-product feeding regime for each class of animal here. Please list each average byproduct ration for each class of animal (In pounds per day) throughout the year. Attach additional paper (or use the space below question D8), if necessary.

Are you reporting pounds per day fed on an as-fed basts or dry-matter basts?

$\square$ as-fed basts

$\square$ dry-matter (DMI) basts

[12] Dainy Producer Life Cycle Assessment Survey

Figure D-3 Dairy producer life cycle assessment survey and How-To guide (b) 


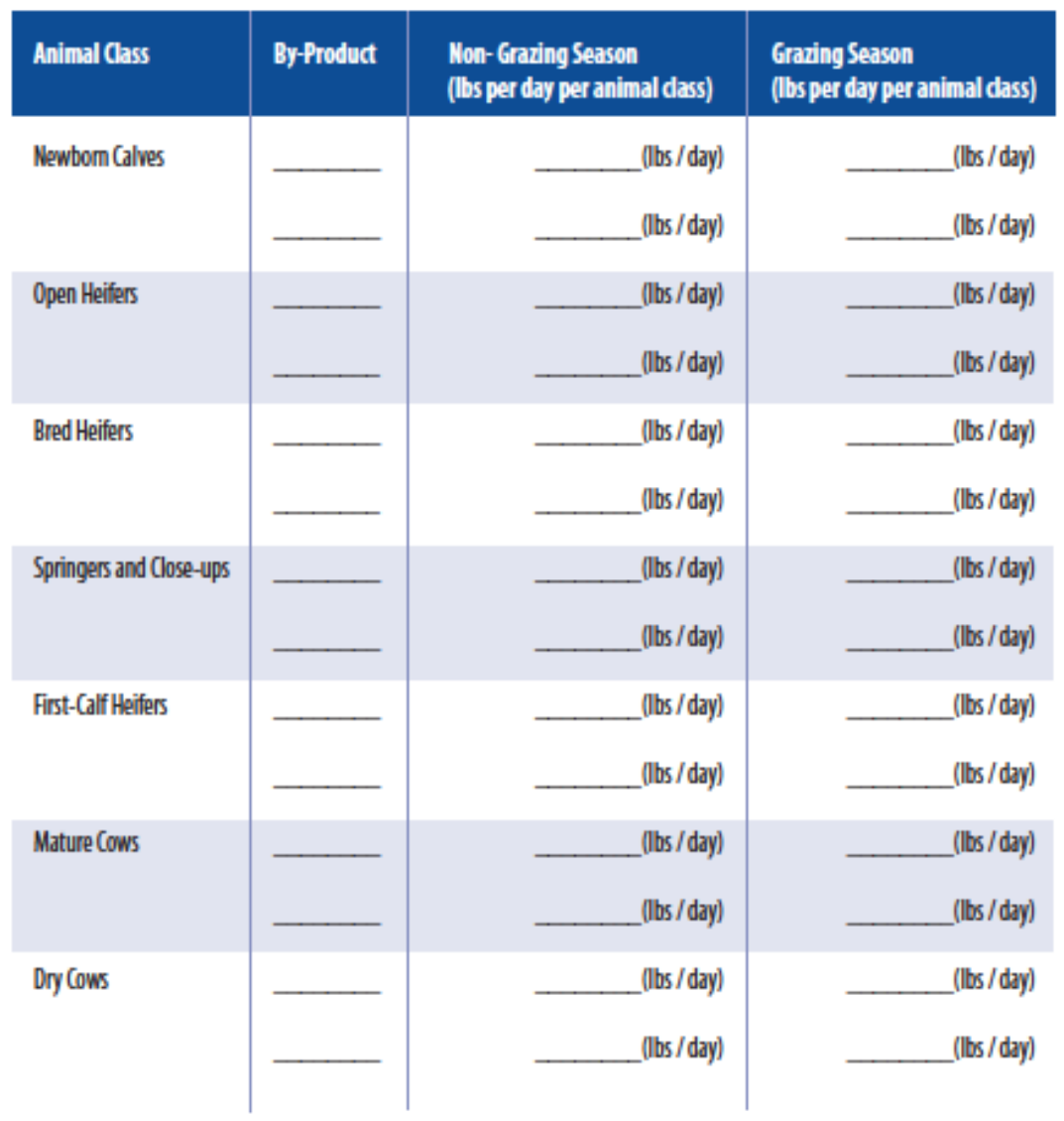

D6. In 2008 , how many acres were dedicated primarlly to grazing?

acres

If the answer to this question is zero (0), please move to question D8.

Dairy Producer Life Cyde Assessment Survey [13]

Figure D-4 Dairy producer life cycle assessment survey and How-To guide (c) 
D7. Please indicate with an $\mathrm{X}$ the months in 2008 during which your cattle were recetving the majortty of their forage intake from pasture. For example, If your cattle are kept on pasture all year, only check months during which your cattle are feeding on forage actually growing on the pasture. If you feed baled hay November through February, but no forage is being eaten off the pasture, do not check those months.

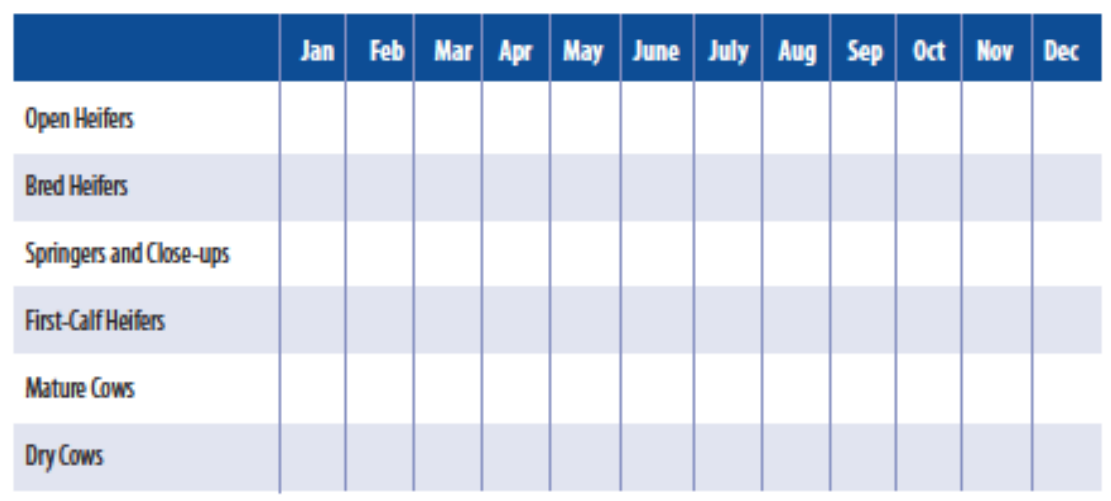

D8. Please list any addittonal detalls regarding your feeding regimen that could help us understand the attached feed information and/or how you fed your cattle in 2008.

[14] Dainy Producer Life Cycle Assessment Survey

Figure D-5 Dairy producer life cycle assessment survey and How-To guide (d) 


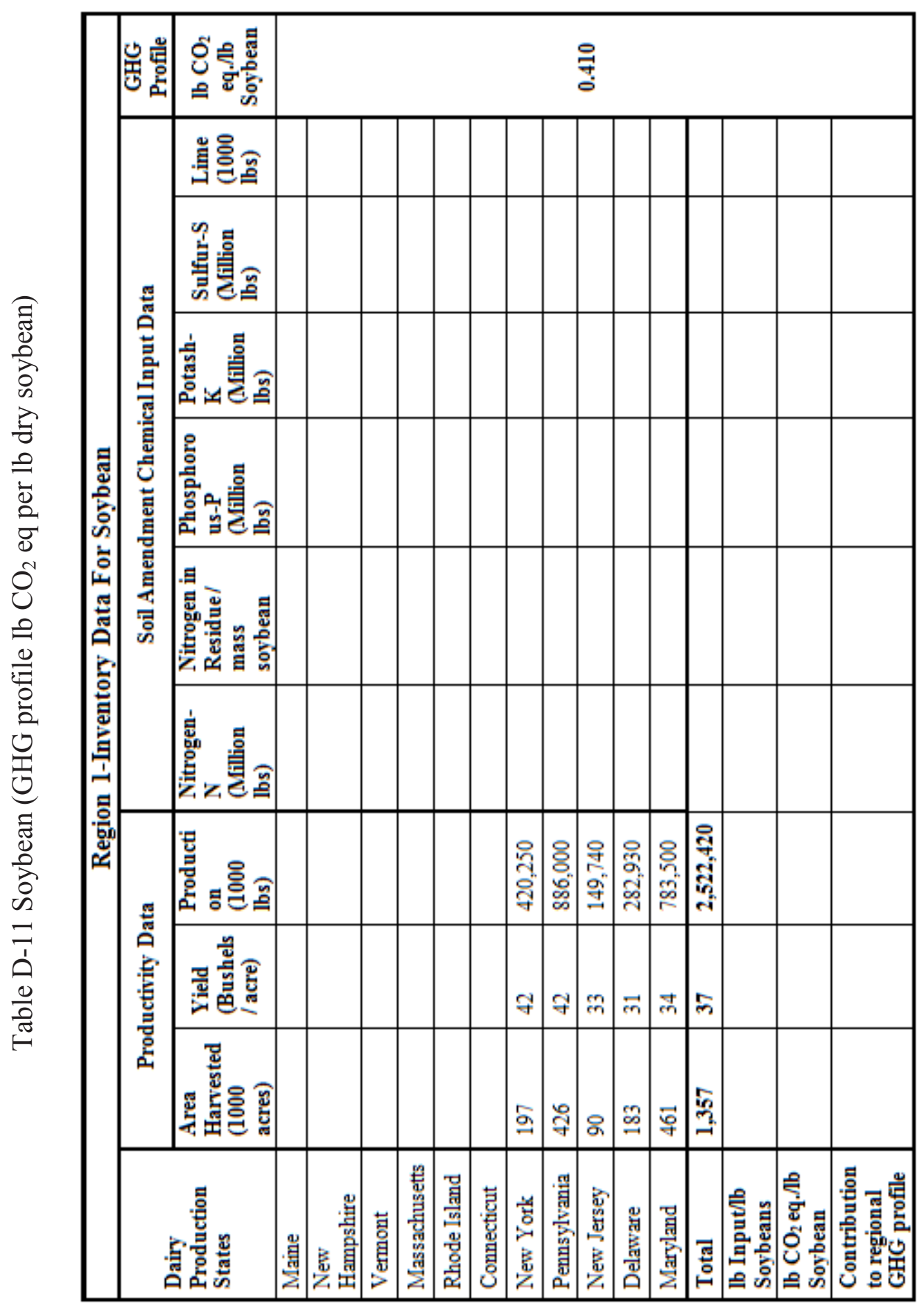




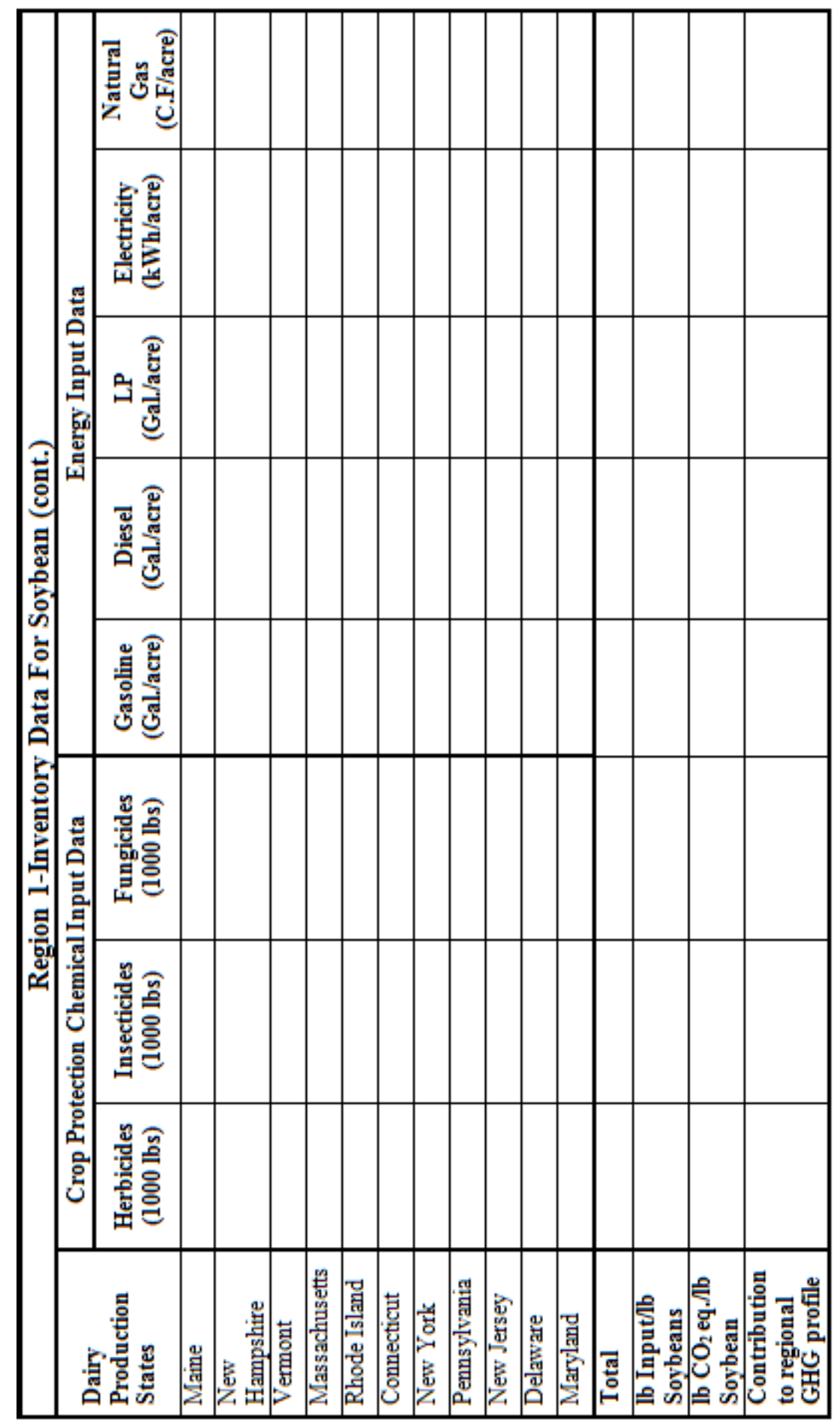




\begin{tabular}{|c|c|c|c|c|c|c|c|c|c|c|c|c|c|c|c|}
\hline 屈 & 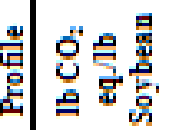 & \multicolumn{14}{|c|}{ 苗 } \\
\hline \multirow{6}{*}{ (2) } & 氮 & 赵 & & $\begin{array}{l}\overrightarrow{7} \\
0 \\
\vdots \\
\vdots \\
\vdots \\
1\end{array}$ & 管 & & & & & & & 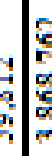 & 응 & ' & జ̊ี \\
\hline & 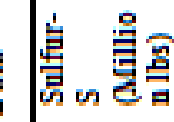 & & & $\rightarrow$ & & & & & & & & - & . & 홍 & 훙 \\
\hline & 总兽合 & $\because$ & $\%$ & $:$ & $\vec{n}$ & & & & & 8 & s. & . & $\frac{2}{3}$ & 잉 & జٌ \\
\hline & 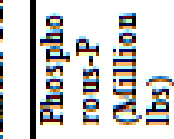 & & $m$ & वి & 워 & & & & & & & $E$ & ) & ఫั & : \\
\hline & 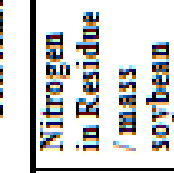 & & & & & & & & & & & & 올 & '。ㅇํ & : \\
\hline & 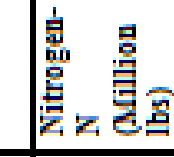 & & & 연 & 量 & & & & & & & $=$ & ': & 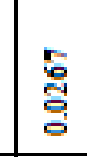 & : \\
\hline & 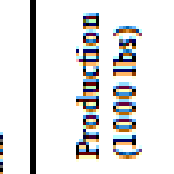 & 영응 & 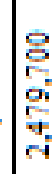 & 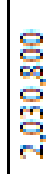 & 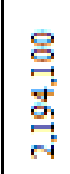 & 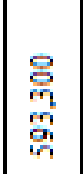 & 量 & 5 & & $\hat{\imath}$ & & : & & & \\
\hline & 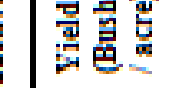 & 당 & 学 & 点 & 요 & 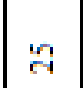 & $\approx$ & $\vec{m}$ & $1{ }^{\circ}$ & 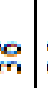 & n & 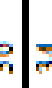 & & & \\
\hline & 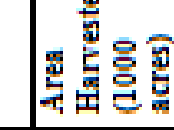 & $\cong$ & & 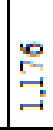 & 辛 & 후 & $\approx$ & & & & & 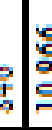 & & & \\
\hline & 总总善 & 善 & 䙳 & 苂 & 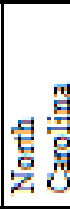 & 䄑影 & 严 & & & & & & 造最 & 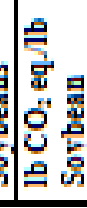 & 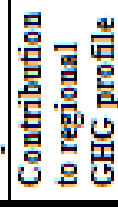 \\
\hline
\end{tabular}




\begin{tabular}{|c|c|c|c|c|c|c|c|c|c|c|c|c|c|}
\hline & 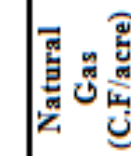 & & & & & & & & 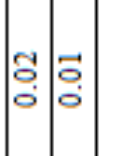 & & 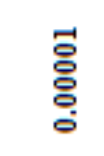 & 高 & 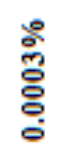 \\
\hline & 象 & & & & & $\stackrel{\infty}{\circ}$ & $\mid \begin{array}{l}\approx \\
\infty \\
\overrightarrow{\vec{\tau}} \\
\end{array}$ & & 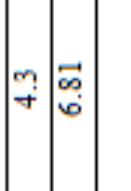 & & $\begin{array}{l}\stackrel{\leftrightarrow}{\%} \\
\stackrel{े}{0}\end{array}$ & 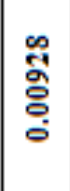 & $\begin{array}{l}\text { 今े } \\
\text { cे } \\
\text { c. }\end{array}$ \\
\hline$\sqrt{5}$ & 递 & & & & & $\overrightarrow{0}$ & 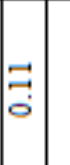 & 客 & 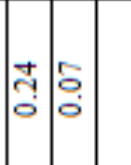 & & ஜัे & \begin{tabular}{|l|}
0 \\
0 \\
0 \\
0 \\
0
\end{tabular} & ؛े \\
\hline . & 包 & & & & & $\underset{\infty}{+}$ & 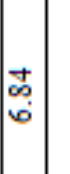 & 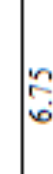 & 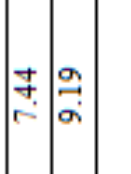 & & 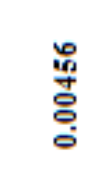 & 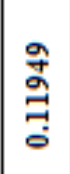 & 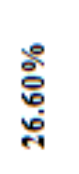 \\
\hline | & 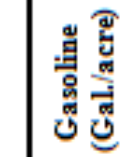 & & & & & $\begin{array}{l}n \\
\mathrm{r} \\
\mathrm{r}\end{array}$ & & & 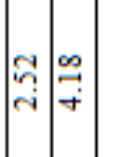 & & 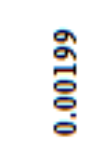 & \begin{tabular}{|c|}
0 \\
0 \\
0 \\
0 \\
0 \\
0 \\
0
\end{tabular} & $\begin{array}{l}\stackrel{8}{\circ} \\
\stackrel{9}{9}\end{array}$ \\
\hline 悹。 & 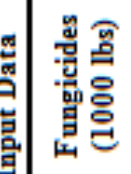 & & o: & & $\Xi$ & & & & স্লাঃ্ণ & ले & 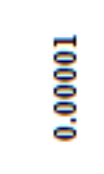 & \begin{tabular}{|c|} 
\\
\\
\\
0 \\
0
\end{tabular} & $\stackrel{\circ}{\stackrel{0}{0}}$ \\
\hline 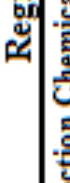 & 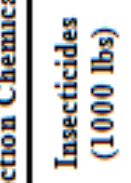 & $+a$ & $\rightarrow$ & & 이 & & & & $\therefore$ ஃ & م̂े & $\begin{array}{l}\text { पे } \\
\text { 잉 }\end{array}$ & 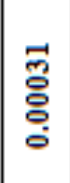 & 总 \\
\hline & 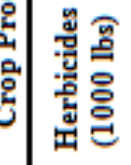 & 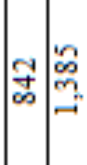 & $\mid$\begin{tabular}{l}
$\infty$ \\
$\vdots$ \\
$\vdots$ \\
\hdashline
\end{tabular} & & $\begin{array}{l}\text { 怘 } \\
\stackrel{-}{-}\end{array}$ & & & & 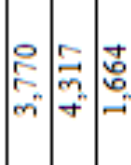 & $\mid$ & 。̊̀े & $\mid$\begin{tabular}{l}
$\overrightarrow{0}$ \\
\multirow{3}{1}{} \\
0 \\
0 \\
0
\end{tabular} & 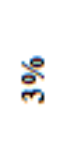 \\
\hline & 总 & 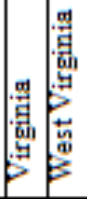 & 践 & & & 5 & & & 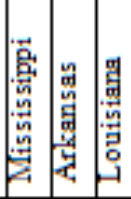 & & 兽 & 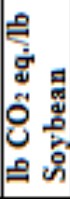 & 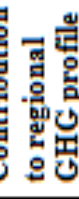 \\
\hline
\end{tabular}




\begin{tabular}{|c|c|c|c|c|c|c|c|c|c|c|c|}
\hline 栲总 & 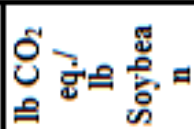 & & & & & & & & & & \\
\hline & 总 & 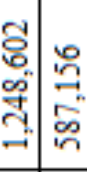 & 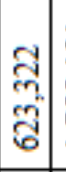 & 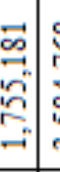 & & & J & 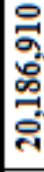 & ్ㅕㅇ & ఏే & 高 \\
\hline 䓀 & 害总总 & ב & ä & 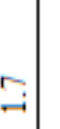 & & & 9 & $\overrightarrow{6}$ & สู่ & 免 & ్ํㅇ \\
\hline 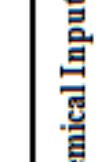 & 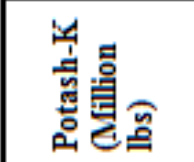 & ב & 8 & 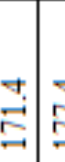 & & 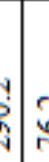 & 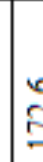 & 总 & 密 & 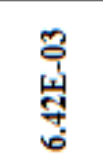 & ఫ్ํำ \\
\hline 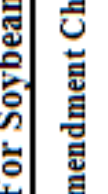 & 总 & $\mathscr{\Omega}$ & 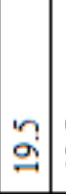 & '? & & 15 & & 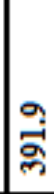 & 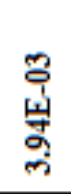 & 䓀 & 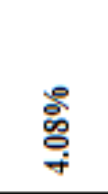 \\
\hline 秀 & 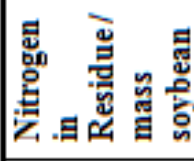 & & & & & & & & 岁 & 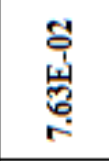 & 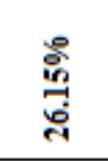 \\
\hline & 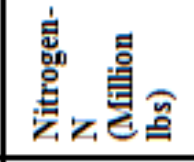 & $\underset{\sim}{\stackrel{*}{*}}$ & 要 & & & & & $0 \%$ & 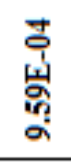 & 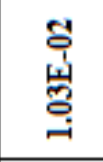 & 商 \\
\hline 跑 & 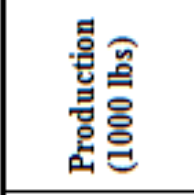 & 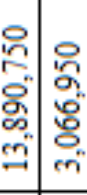 & 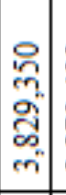 & 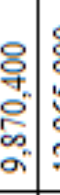 & & 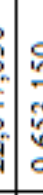 & & 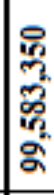 & & & \\
\hline 賞 & 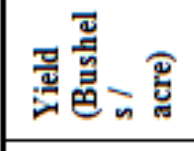 & 7 辛 & 아 & J & & 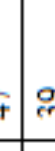 & in & $1 \%$ & & & \\
\hline g. & 总 & & -1 & & & & & & & & \\
\hline & 鄫 & 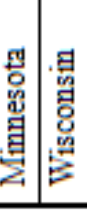 & 31 & & & & & & & 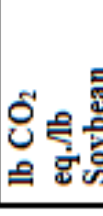 & 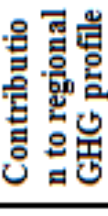 \\
\hline
\end{tabular}




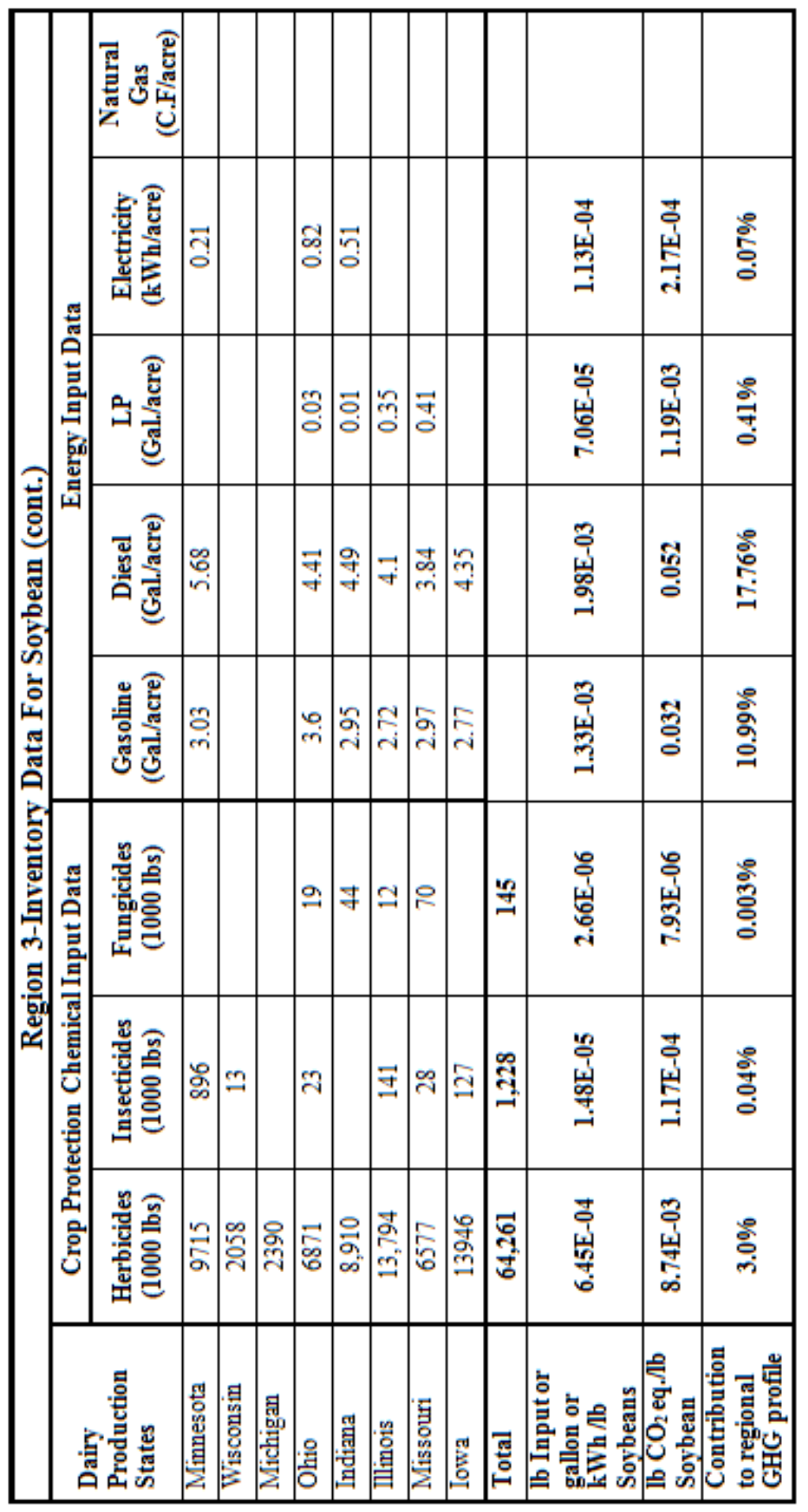




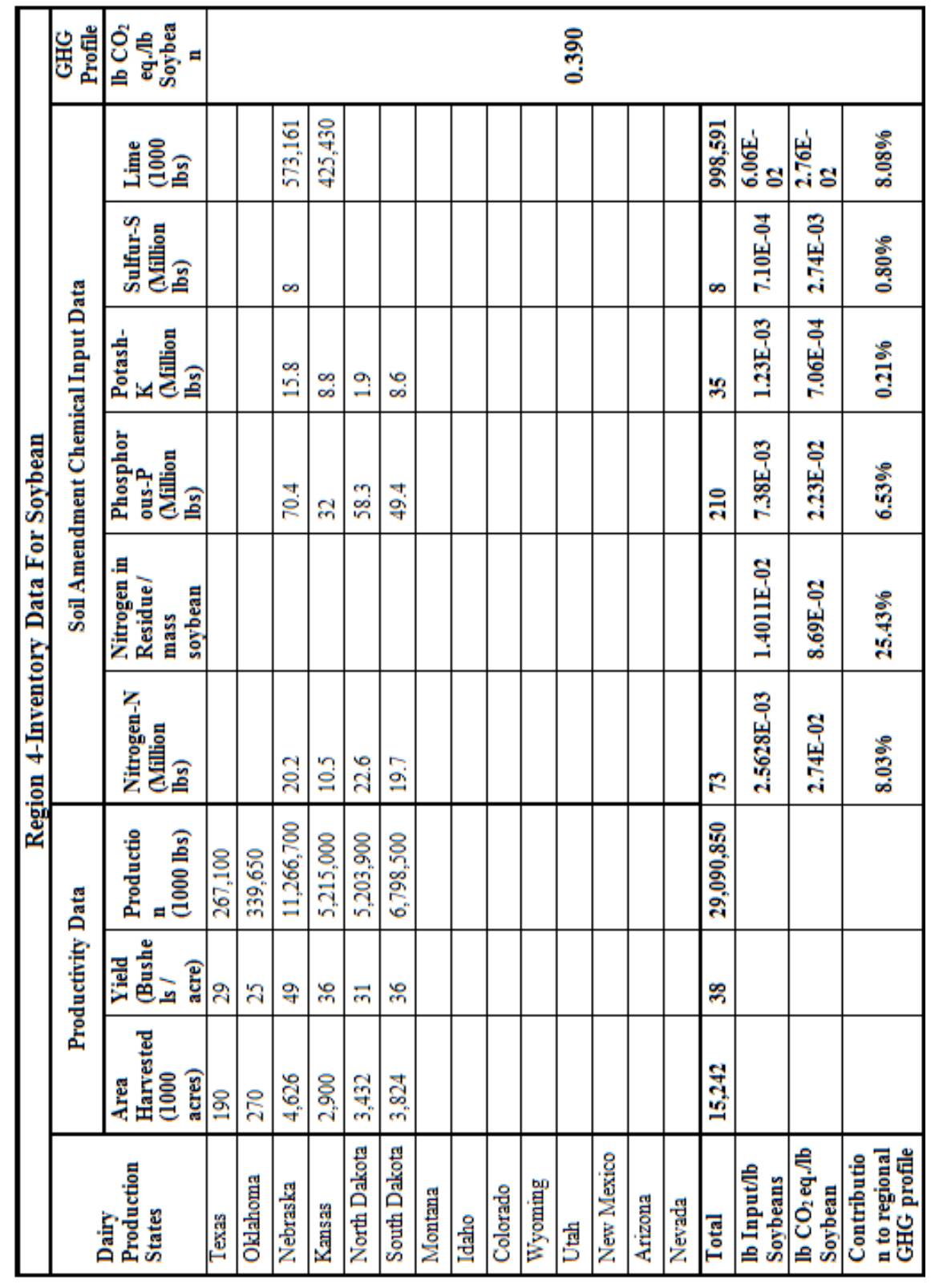




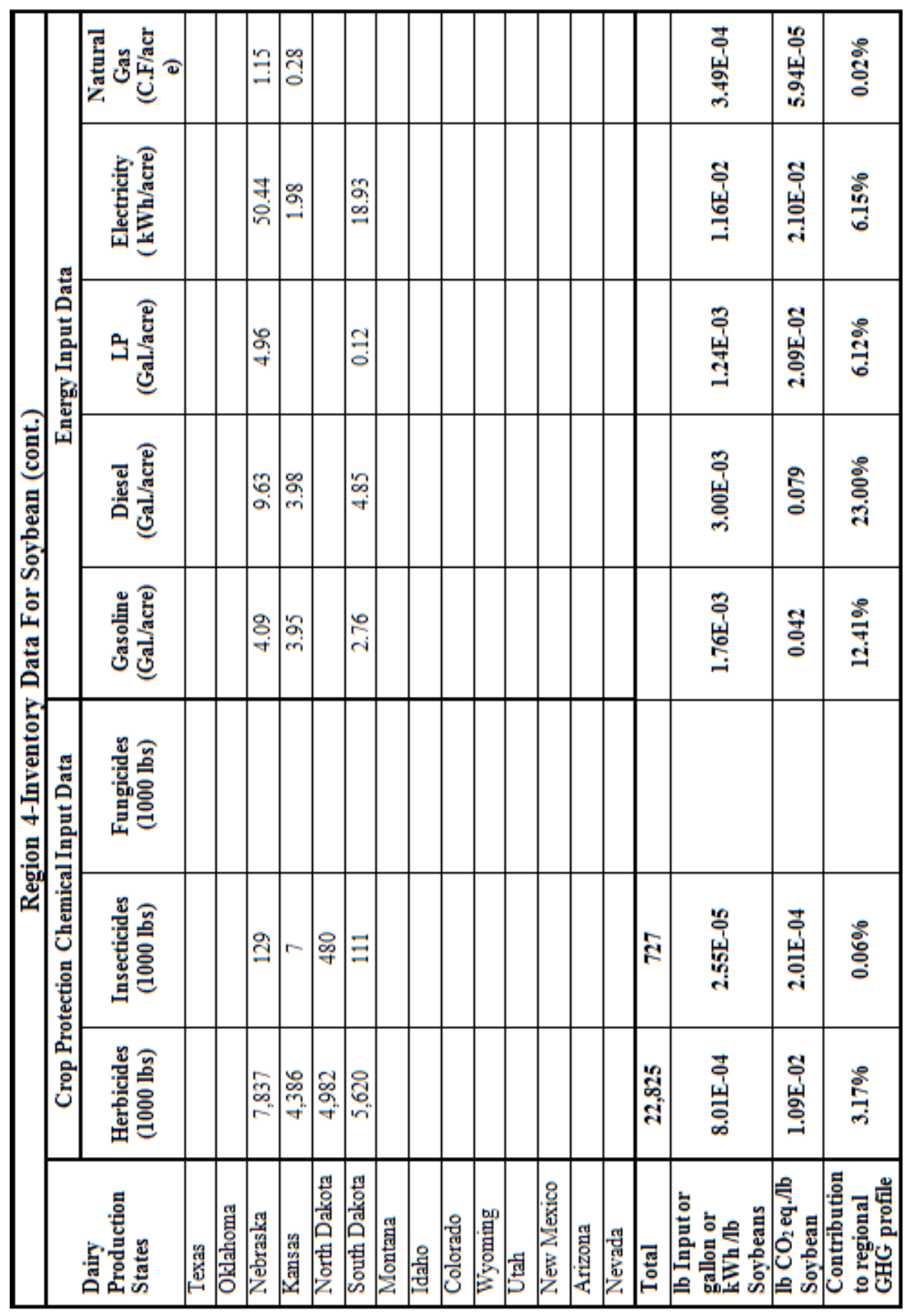




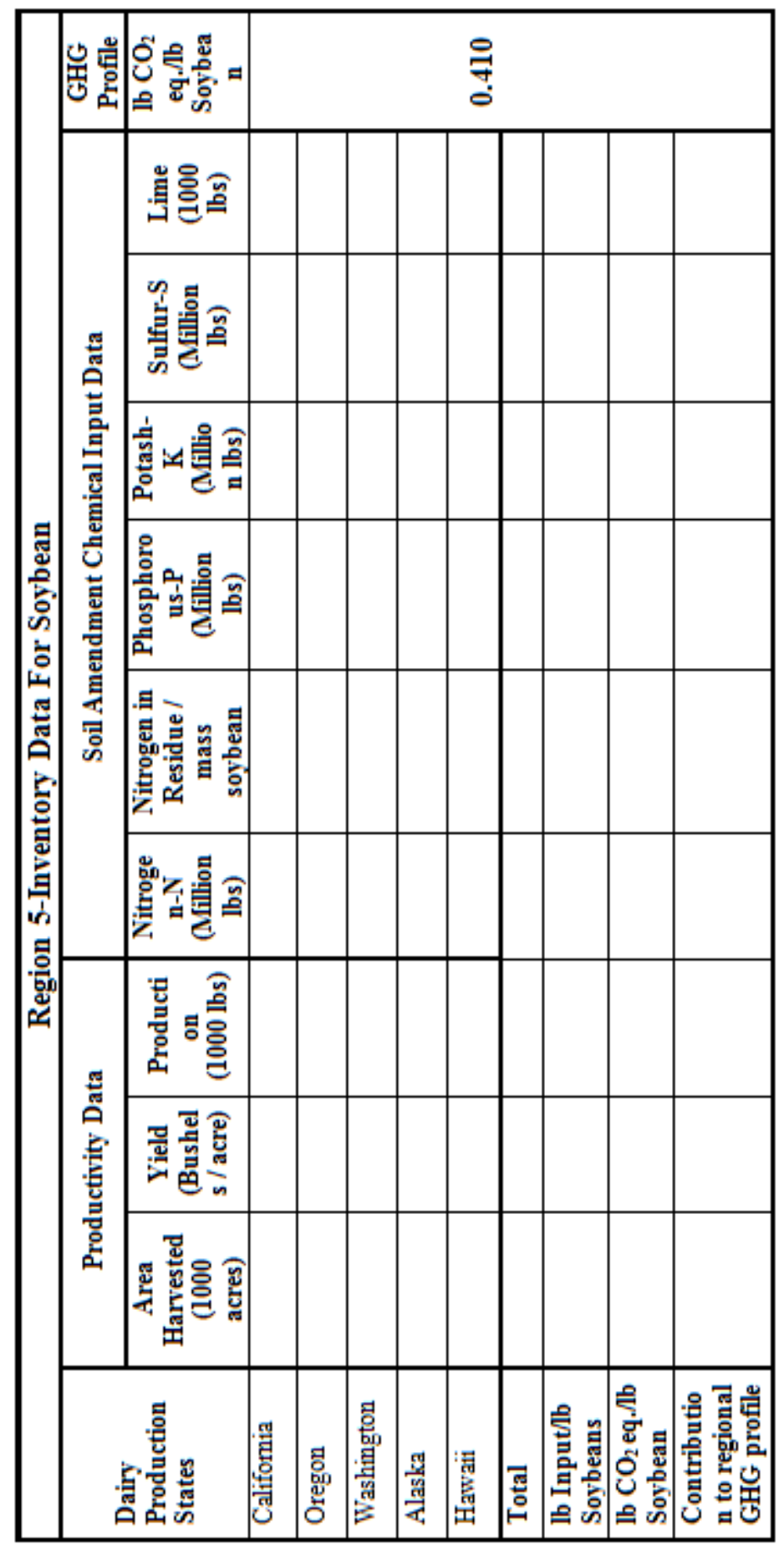




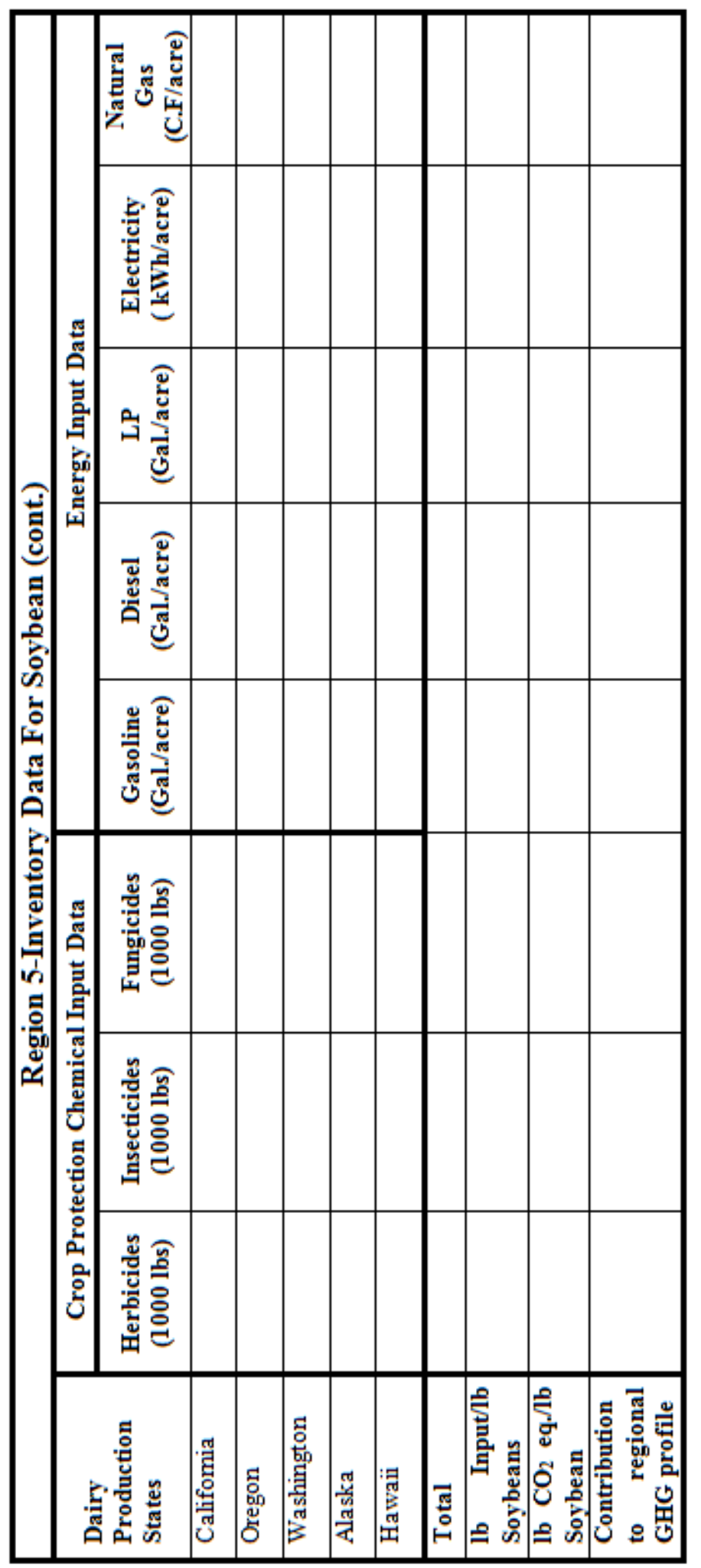




\begin{tabular}{|c|c|c|c|c|c|c|c|c|c|c|c|c|c|c|c|c|c|}
\hline & 选 & 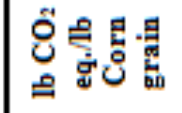 & \multicolumn{15}{|c|}{ है } \\
\hline \multirow{11}{*}{ 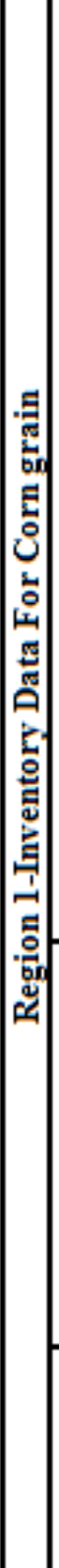 } & \multirow{7}{*}{ 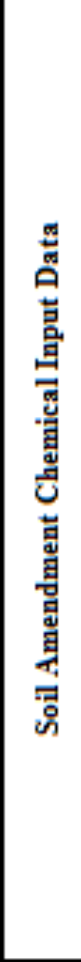 } & 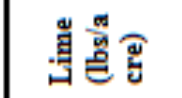 & & & & & & & in & in & & & & ఏ్తి & 蒿 & $\stackrel{\infty}{\Xi}$ & $\stackrel{\circ}{3}$ \\
\hline & & 点鼻合 & & & & & & & & $m$ & & & & m & 봉 & ஜ̊̀ & 灾 \\
\hline & & 融首合 & & & & & & & 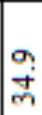 & 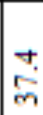 & & & & 1 & $\begin{array}{l}\text { 웅 } \\
\text { 웅 }\end{array}$ & $\begin{array}{l}\tilde{c} \\
\stackrel{8}{0} \\
\dot{0}\end{array}$ & 客 \\
\hline & & 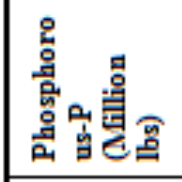 & & & & & & & m. & ? & & & & 2 & 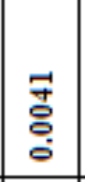 & $\begin{array}{l}\ddot{\theta} \\
\ddot{\sigma} \\
\dot{\sigma}\end{array}$ & $\begin{array}{l}\stackrel{8}{\circ} \\
\text { \& } \\
+\end{array}$ \\
\hline & & 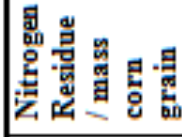 & & & & & & & & & & & & & 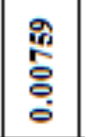 & $\begin{array}{l}\text { gे } \\
\stackrel{5}{0} \\
\stackrel{0}{0}\end{array}$ & 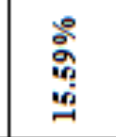 \\
\hline & & 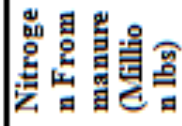 & & & & & & & డే & 16 & & & & 告 & $\begin{array}{l}\overrightarrow{0} \\
\stackrel{\circ}{\circ} \\
\stackrel{0}{0}\end{array}$ & $\begin{array}{l}\stackrel{0}{\circ} \\
\stackrel{6}{\circ} \\
\end{array}$ & 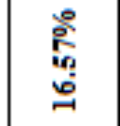 \\
\hline & & 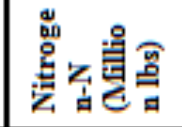 & & & & & & & త్ర & 方 & & & & E & $\begin{array}{l}\stackrel{+}{\circ} \\
\stackrel{\circ}{\circ}\end{array}$ & 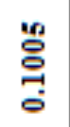 & 旁 \\
\hline & \multirow{3}{*}{ 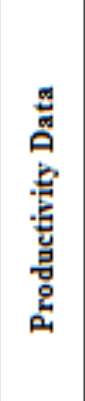 } & 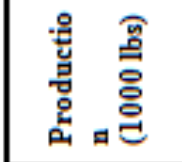 & & & & & & & 売 & 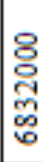 & 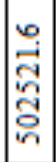 & 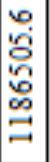 & 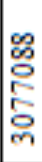 & 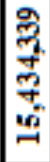 & & & \\
\hline & & 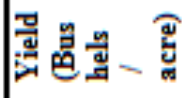 & & & & & & & 节 & $\begin{array}{c}\text { I } \\
\text { త్ }\end{array}$ & 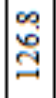 & 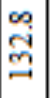 & 节 & తి & & & \\
\hline & & 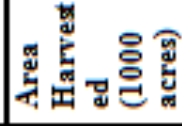 & & & & & & & స్ & 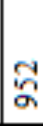 & $\stackrel{\infty}{\infty}$ & $\vec{\bullet}$ & ને & $\underset{3}{-1}$ & & & \\
\hline & & 总 & 貣 & 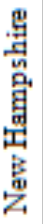 & 莧 & 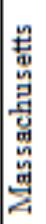 & $\begin{array}{l}\text { 昜 } \\
\text { 量 } \\
\text { : }\end{array}$ & 䲩 & 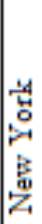 & 罯 & 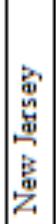 & 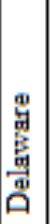 & 息 & 喿 & 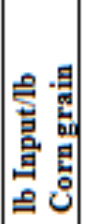 & 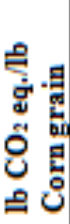 & 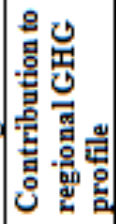 \\
\hline
\end{tabular}




\begin{tabular}{|c|c|c|c|c|c|c|c|c|c|c|c|c|c|c|c|c|}
\hline & & 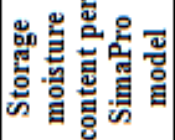 & & & & & & & & & & & & & 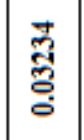 & $\begin{array}{l}\stackrel{8}{\circ} \\
\stackrel{\text { F }}{\ominus}\end{array}$ \\
\hline & & 局兽 & & & & & & & & & & & & & & 宮 \\
\hline$\exists$ & 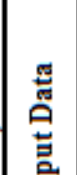 & 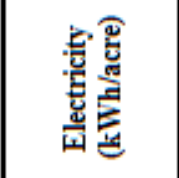 & & & & & & & & & & & & & & 융 \\
\hline 园 & 岀 & 总 & & & & & & & 苞 & $?$ & & & & 营 & ণ্ণ & $\begin{array}{l}\text { :े } \\
\text { o }\end{array}$ \\
\hline 苛 & & 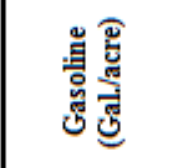 & & & & & & & $\overrightarrow{\mathrm{cr}}$ & $\stackrel{\circ}{-}$ & & & & 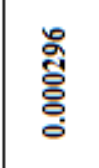 & $\begin{array}{l}\mathbb{E} \\
\stackrel{\circ}{\circ} \\
\stackrel{\circ}{0}\end{array}$ & 疍 \\
\hline 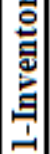 & & 局 & & & & & & & ટુ & '? & & & & $\begin{array}{l}\text { 吕 } \\
\text { ᄋ̆ } \\
\text { ᄋ }\end{array}$ & 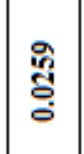 & 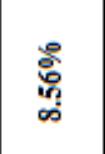 \\
\hline 히 & 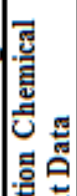 & 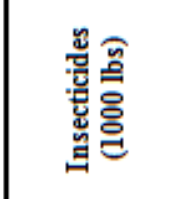 & & & & & & & & 吉 & & & $\stackrel{\vec{\sigma}}{二}$ & 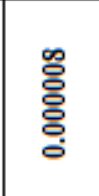 & 宮 & 웅 \\
\hline & 施 & 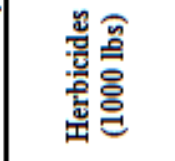 & & & & & & & & & & & $\begin{array}{l}\overrightarrow{6} \\
0 \\
0\end{array}$ & 突 & 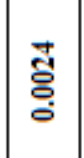 & 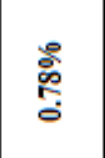 \\
\hline & & 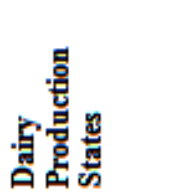 & ע & 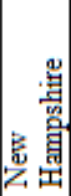 & 蒙 & 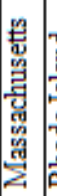 & 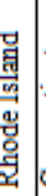 & 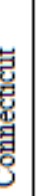 & 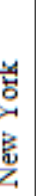 & & 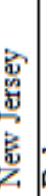 & 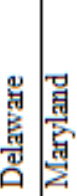 & 퐁 & 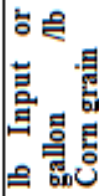 & 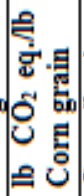 & 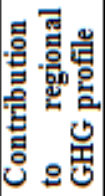 \\
\hline
\end{tabular}




\begin{tabular}{|c|c|c|c|c|c|c|c|c|c|}
\hline 俤总 & 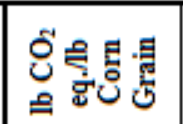 & & & 导 & 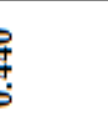 & & & & \\
\hline & 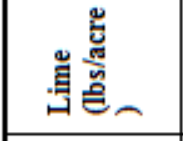 & & 웡요 & & & & s: & 产 & t: \\
\hline & 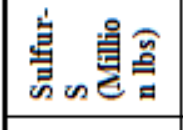 & & $=$ a & & & & 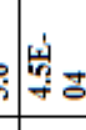 & 悹 & : \\
\hline 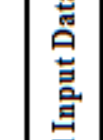 & 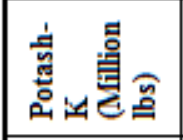 & & 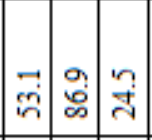 & & & $:$ & 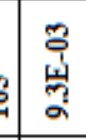 & : & $\stackrel{\circ}{\stackrel{9}{9}}$ \\
\hline 氞 & 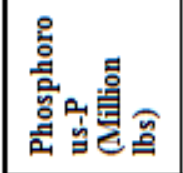 & & 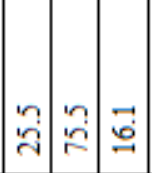 & & & $\Xi$ & 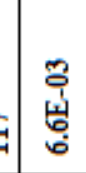 & 害 & 总 \\
\hline 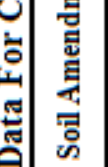 & 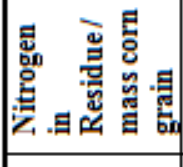 & & & & & & : & $\begin{array}{l}\text { F } \\
0 \\
0\end{array}$ & 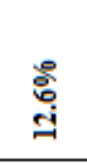 \\
\hline & 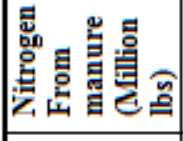 & & & & & & & & \\
\hline & 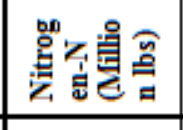 & & $\begin{array}{llll} & 0 \\
0\end{array}$ & & & & 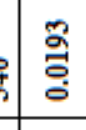 & 鉫 & $\frac{8}{70}$ \\
\hline 㟧 & 总高 & 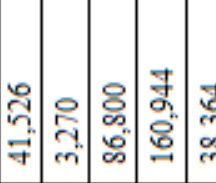 & 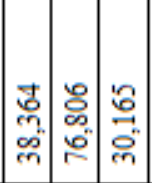 & 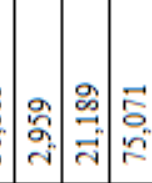 & 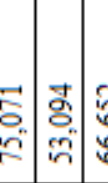 & 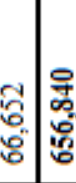 & & & \\
\hline 喜 & 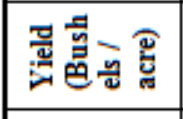 & 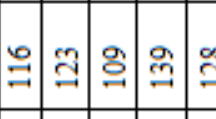 & 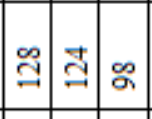 & $2 \%$ & 20 & I & & & \\
\hline & 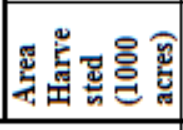 & 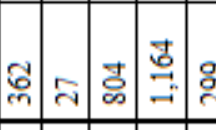 & 영 & 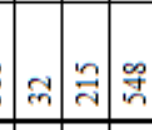 & 要: & 索 & & & \\
\hline & 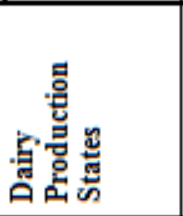 & 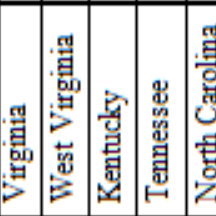 & 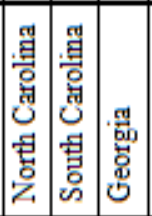 & & 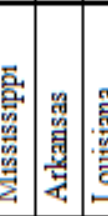 & & & ن & 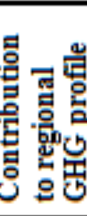 \\
\hline
\end{tabular}




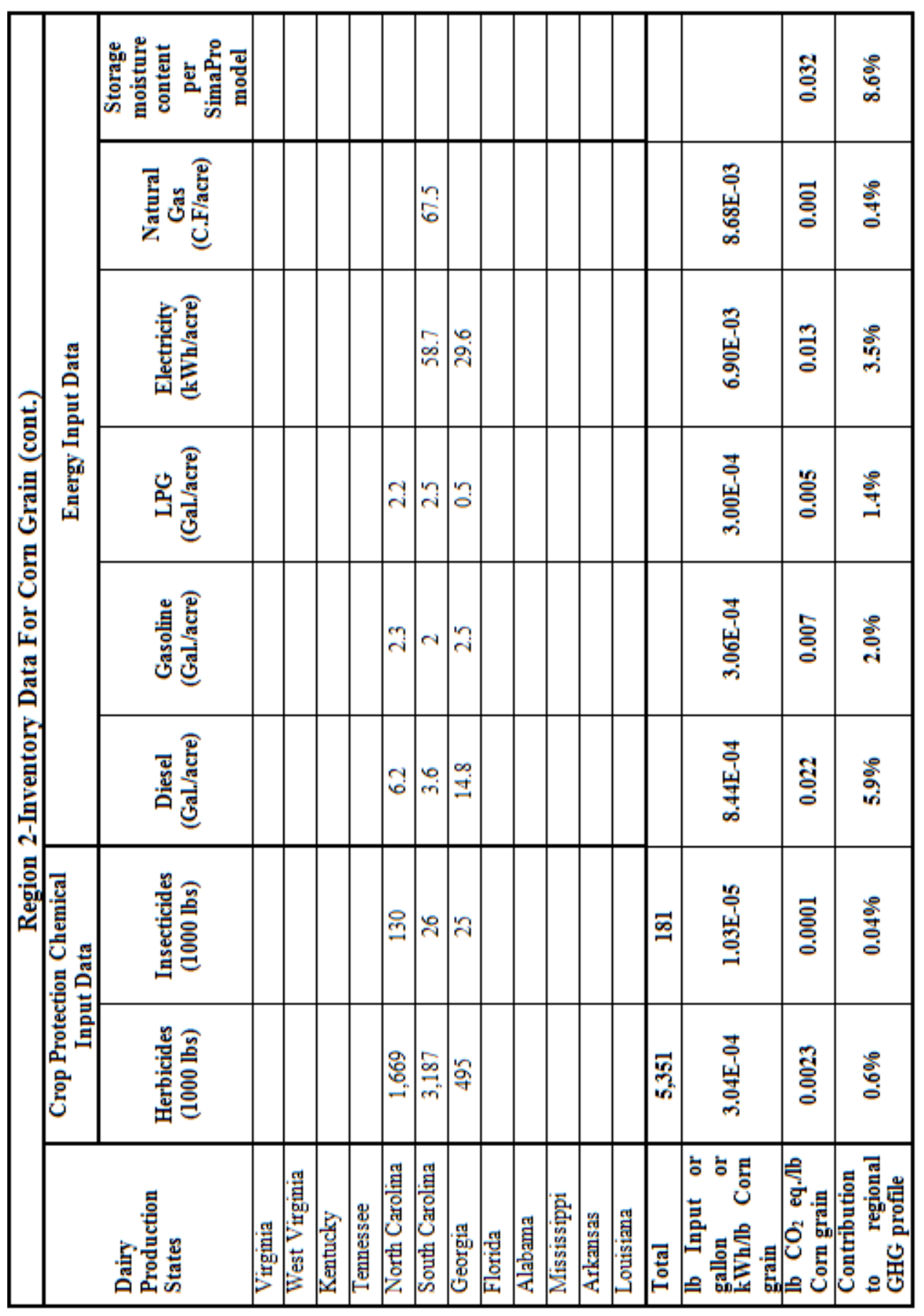




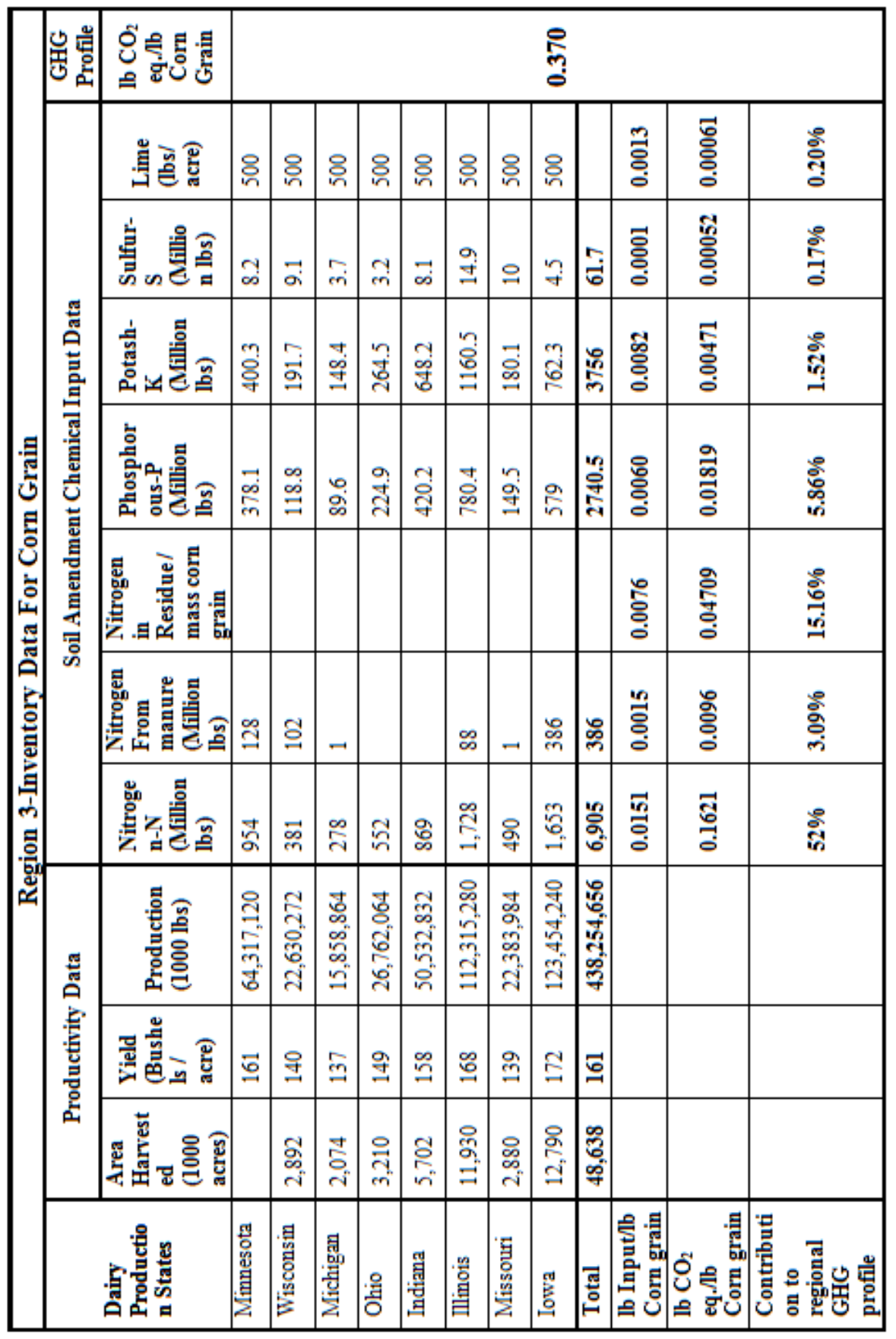




\begin{tabular}{|c|c|c|c|c|c|c|c|c|c|c|c|c|c|c|c|}
\hline & & 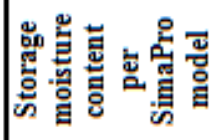 & & & & & & & & & & & & 今્' & ஓ \\
\hline & & 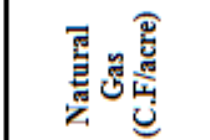 & 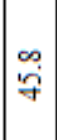 & $\Xi$ & है & & $\stackrel{\mathbb{3}}{\rightarrow}$ & 导 & $\begin{array}{l}9 \\
0 \\
0\end{array}$ & $\overrightarrow{\text { ते }}$ & & & 동 & 总 & 옹 \\
\hline & مّ & 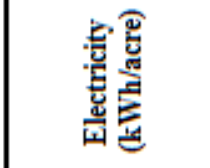 & \begin{tabular}{|l|l}
$\infty$ \\
\hdashline \\
\hdashline
\end{tabular} & $\because$ & 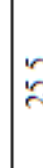 & & 으 & के & $\stackrel{\circ}{\circ}$ & 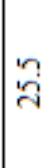 & $\mid \begin{array}{l}\infty \\
0 \\
0\end{array}$ & & 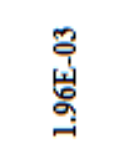 & 旁 & $\stackrel{\circ}{7}$ \\
\hline 园 & 缹 & 氖 & '? & 9 & ch & & $\begin{array}{l}0 \\
י \\
י\end{array}$ & ry & $\stackrel{\infty}{\mathrm{i}}$ & 官 & 곰 & & 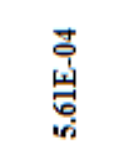 & 突 & $\begin{array}{l}\text { 今̊ } \\
\text { 울 }\end{array}$ \\
\hline | & & 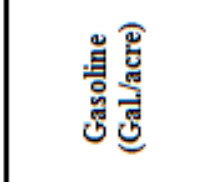 & 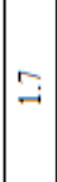 & $\stackrel{+}{-}$ & "s & & $\stackrel{\circ}{-}$ & $\vec{i}$ & $?$ & '? & $\stackrel{9}{I}$ & & 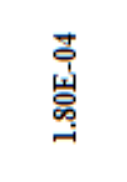 & 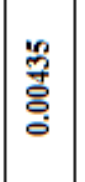 & $\stackrel{\text { ఃे }}{\stackrel{9}{+}}$ \\
\hline 总 & & 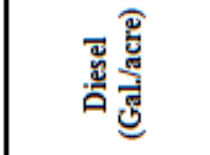 & 茫 & $\stackrel{+}{\sim}$ & ? & & 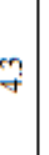 & $\begin{array}{l}\bullet \\
\dot{v}\end{array}$ & ri & in & $\begin{array}{l}0 \\
+\end{array}$ & & 总 & $\begin{array}{l}\text { 总 } \\
\text { 号 }\end{array}$ & $\underset{+}{\stackrel{5}{5}}$ \\
\hline & 死 & 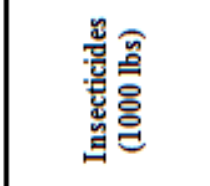 & $\stackrel{\Xi}{\vec{\lambda}}$ & $\stackrel{ \pm}{\leftrightarrows}$ & 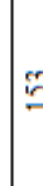 & & ते & Z & 学 & F & $\stackrel{\infty}{\infty}$ & 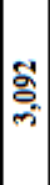 & 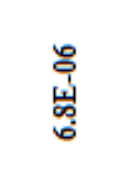 & 응 & 융 \\
\hline & 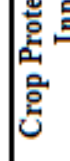 & 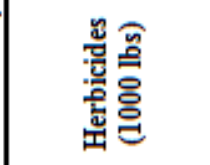 & \begin{tabular}{|l}
$\overrightarrow{5}$ \\
0 \\
0 \\
0
\end{tabular} & $\begin{array}{l}8 \\
\text { ? } \\
6\end{array}$ & 年 & & స్. & 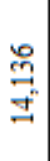 & $\begin{array}{l}8 \\
8 \\
\circ \\
\end{array}$ & 을 & 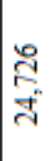 & 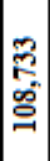 & $\begin{array}{l}\text { 孛 } \\
\text { 突 }\end{array}$ & 吕 & 害 \\
\hline & & 密总总 & 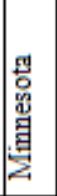 & 㠔 & 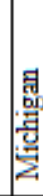 & 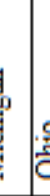 & & 蜝 & & 总 & 蹗 & ब्ञूँ & 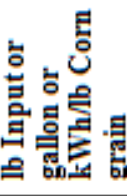 & 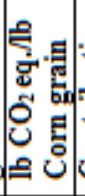 & 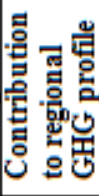 \\
\hline
\end{tabular}




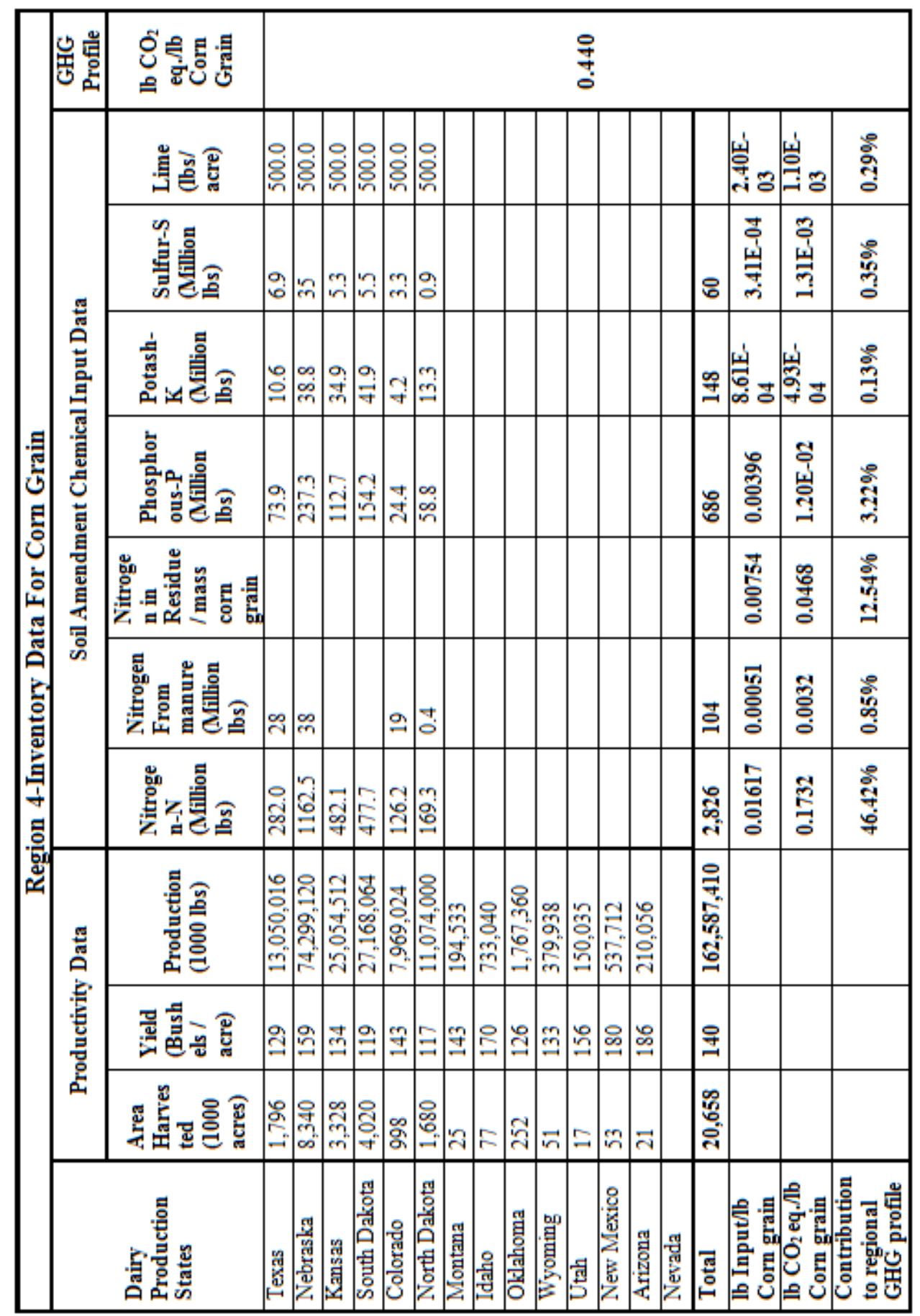




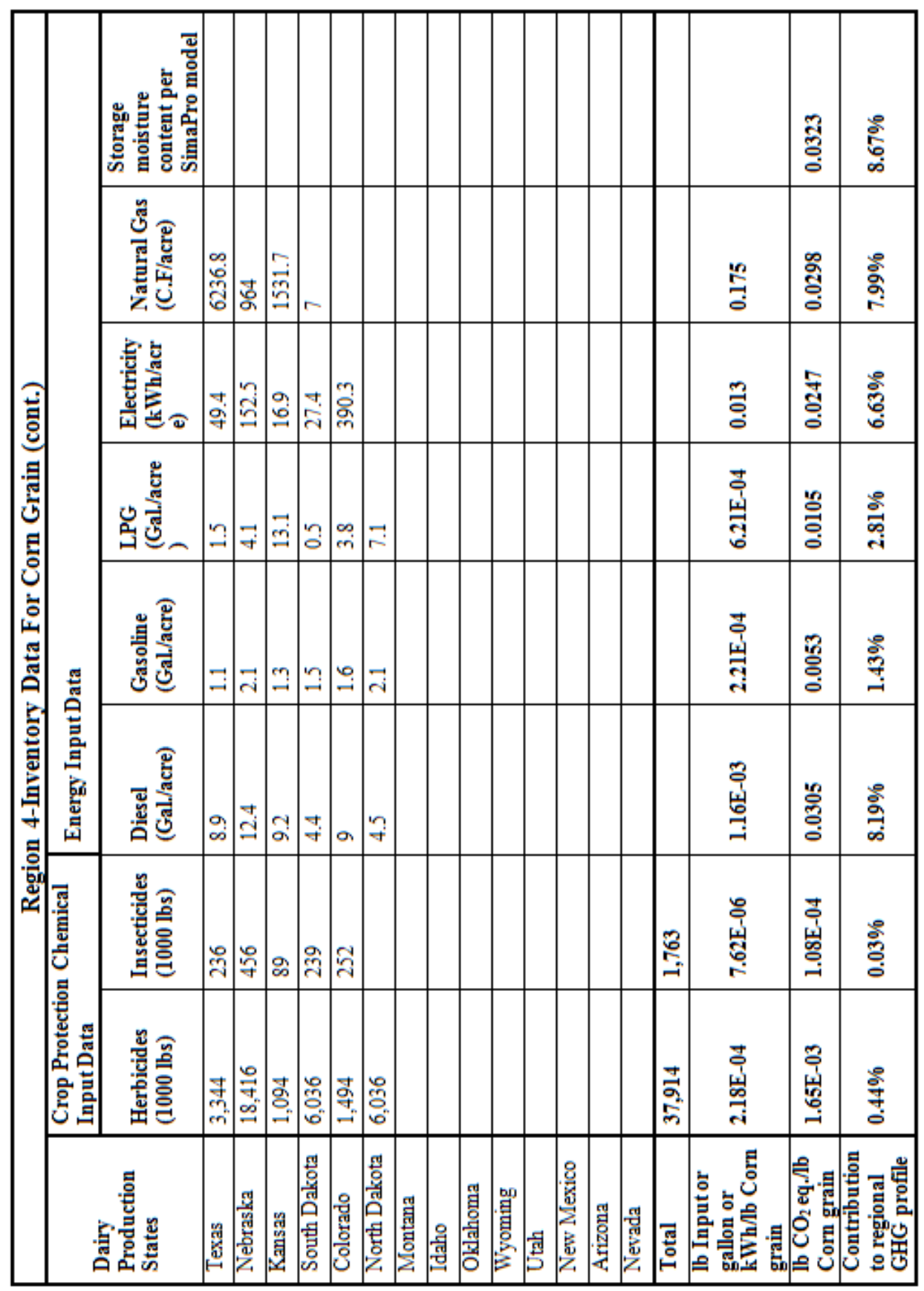




\begin{tabular}{|c|c|c|c|c|c|c|c|c|c|c|c|}
\hline \multirow{8}{*}{\multicolumn{2}{|c|}{ 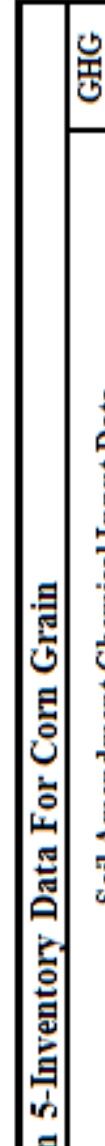 }} & \multirow{2}{*}{ 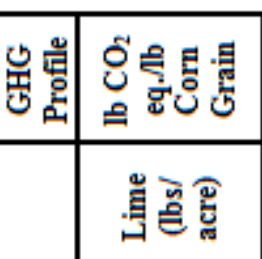 } & \multicolumn{9}{|c|}{ ঃ̊ } \\
\hline & & & & & & & & & & & \\
\hline & & 急的夏会 & & & & & & & & & \\
\hline & & 竞讦夏会 & & & & & & & & & \\
\hline & & 昜品最 & & & & & & & & & \\
\hline & & 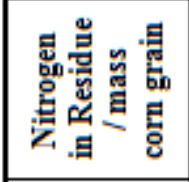 & & & & & & & & & \\
\hline & & 品塄兑昷合 & & & & & & & & & \\
\hline & 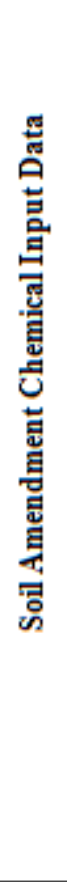 & 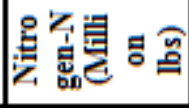 & & & & & & & & & \\
\hline & ฮึ & 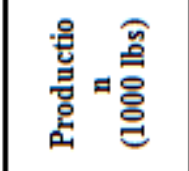 & & & & & & & & & \\
\hline & 点 & 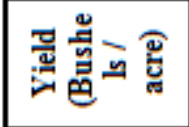 & & & & & & & & & \\
\hline & 号 & 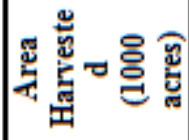 & & & & & & & & & \\
\hline & & 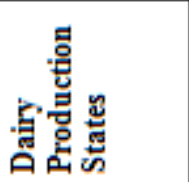 & 罡 & & 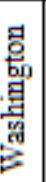 & 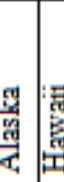 & 娄? & & 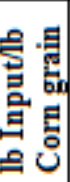 & 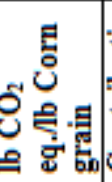 & 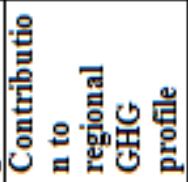 \\
\hline
\end{tabular}




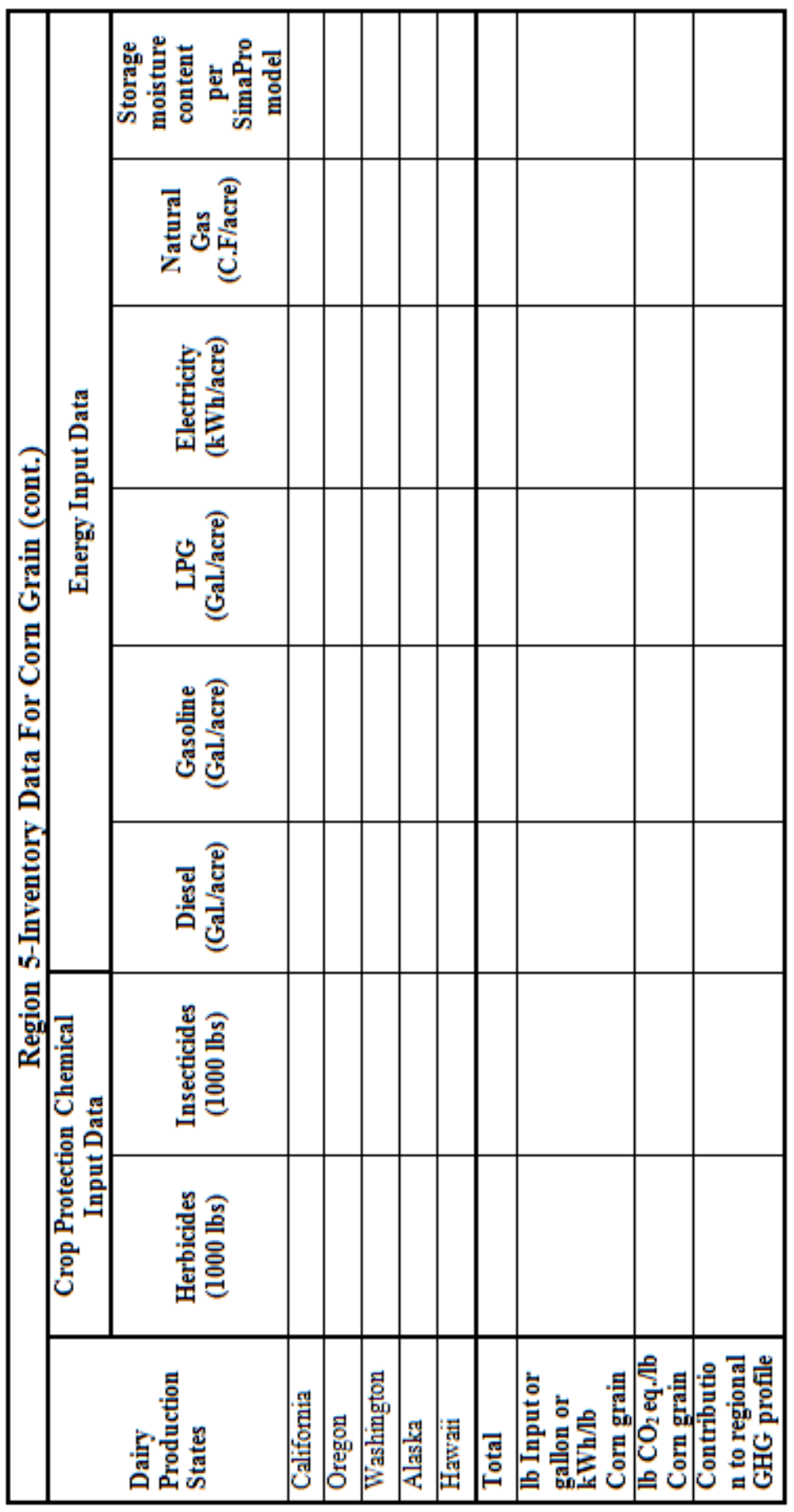




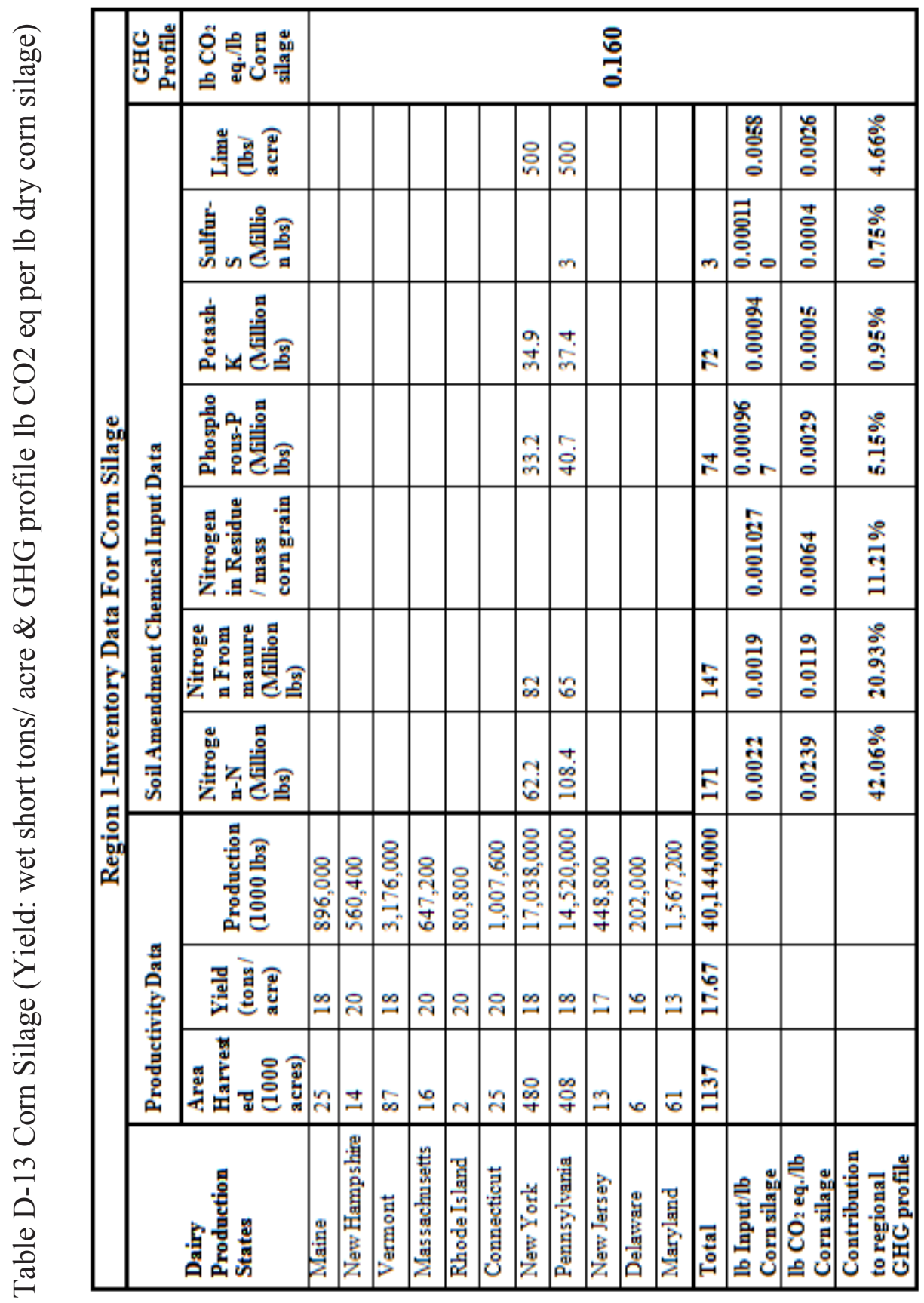




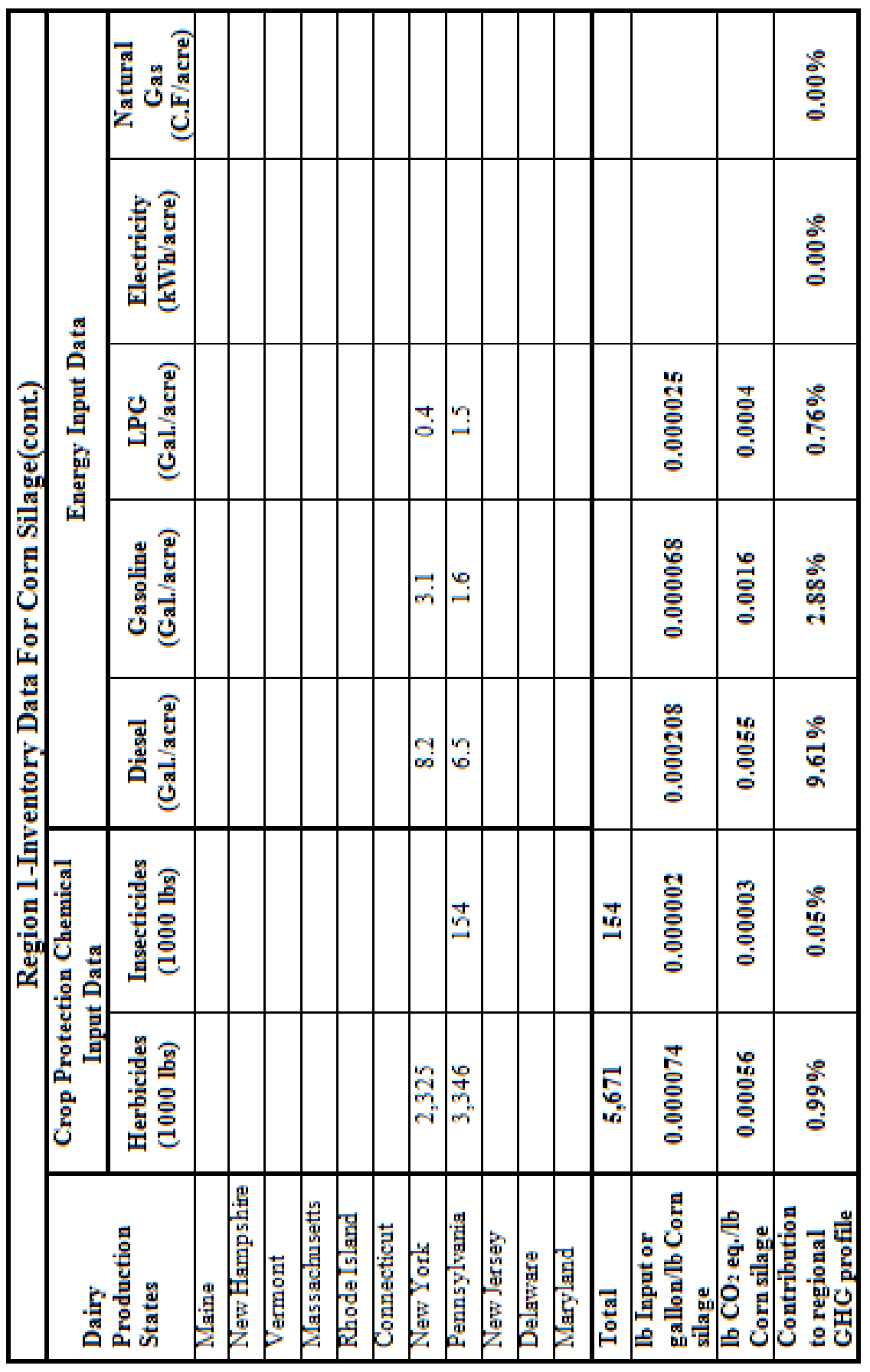




\begin{tabular}{|c|c|c|c|c|c|c|c|c|c|c|c|}
\hline 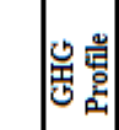 & 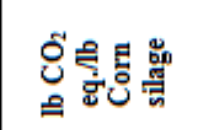 & & & & & :્ત્రీ & & & & & \\
\hline \multirow{7}{*}{ 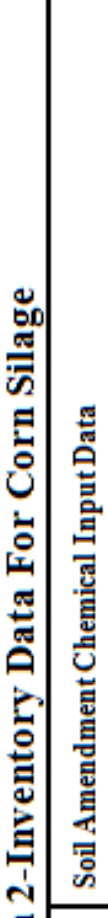 } & 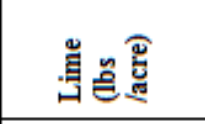 & & & 8 & & & & & 总 & : & $\stackrel{\circ}{\circ}$ \\
\hline & 急媳鿖 & & & & | & & & & : & 兽 & : \\
\hline & 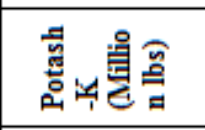 & & & (a) & 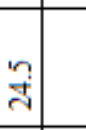 & & & & : & 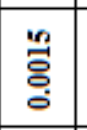 & 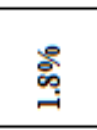 \\
\hline & 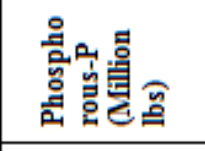 & & & & $\overrightarrow{\mathrm{s}}$ & & & & : & $\begin{array}{l}8 \\
\text { : } \\
: \\
\end{array}$ & : \\
\hline & 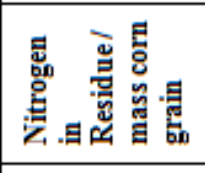 & & & & & & & & 总 & : & $\stackrel{\stackrel{\leftrightarrow}{:}}{:}$ \\
\hline & 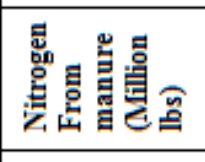 & & & & & & & & & & \\
\hline & 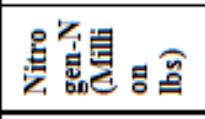 & & & : & & & & & 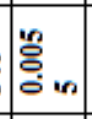 & 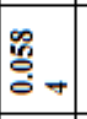 & 8ㅇ: \\
\hline & 总总 & 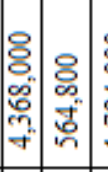 & 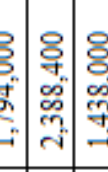 & 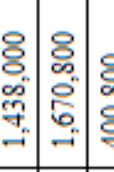 & 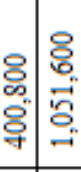 & & $\begin{array}{ll} & \\
8 \\
0\end{array}$ & 额 & & & \\
\hline 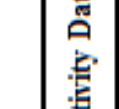 & 吾鵕 & $\Rightarrow \therefore$ & $\therefore$ & $\because=$ & $\Xi \cong$ & $\cong \pm$ & \pm & : & & & \\
\hline & 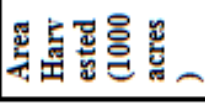 & 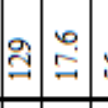 & & 7 赵 & 递 & $\Rightarrow \cong$ & tin & 㖕 & & & \\
\hline & 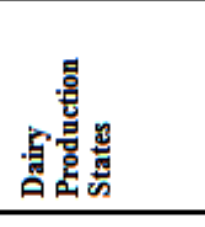 & 罯 & 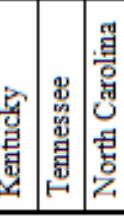 & 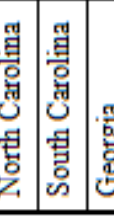 & 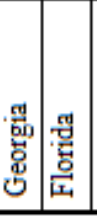 & & & & & & 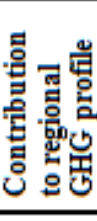 \\
\hline
\end{tabular}




\begin{tabular}{|c|c|c|c|c|c|c|c|c|c|c|c|c|c|c|c|c|c|c|}
\hline \multirow{5}{*}{\multicolumn{2}{|c|}{ 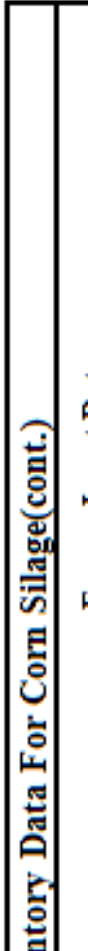 }} & 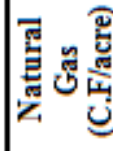 & & & & & & $\begin{array}{l}2 \\
6\end{array}$ & & & & & & & & 鰨 & $\begin{array}{l}\text { 홍 } \\
\text { ¿ }\end{array}$ & $\stackrel{ }{\stackrel{\circ}{\circ}}$ \\
\hline & & 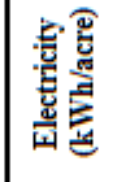 & & & & & & $\vec{\sim}$ & $\mid \begin{array}{l}0 \\
2 \\
2 \\
\end{array}$ & & & & & & & 曽 & $\begin{array}{l}\text { 今ั } \\
\text { ర్ }\end{array}$ & ஓ్ \\
\hline & & 氖 & & & & & I & ' & '? & & & & & & & $\begin{array}{l}\text { 웡 } \\
\text { 突 }\end{array}$ & 옹 & 今్ \\
\hline & & 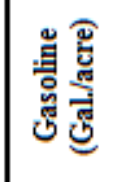 & & & & & $\ddot{\lambda}$ & N & 2 & & & & & & & 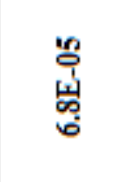 & 융 & 今్ \\
\hline & 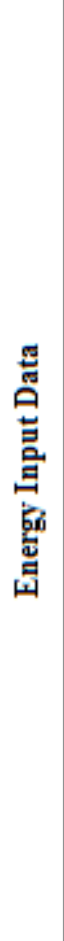 & 鸪 & & & & & ช్ & $\stackrel{\bullet}{r}$ & 舟 & & & & & & & $\begin{array}{l}\text { 总 } \\
\text { 岁 }\end{array}$ & 동 & 宮 \\
\hline 言 & 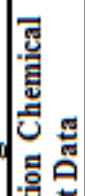 & 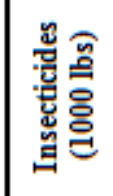 & & & & & 욤 & $\stackrel{ }{\circ}$ & 'ว & & & & & & 悉 & $\begin{array}{l}\text { 옹 } \\
\text { 봉 }\end{array}$ & 콩 & ㅇํㅇ \\
\hline & 总是 & 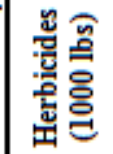 & & & & & $\underset{:}{\stackrel{8}{8}}$ & 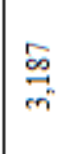 & 㞼 & & & & & & $\mid \begin{array}{l}\vec{n} \\
2 \\
\text { s. }\end{array}$ & $\begin{array}{l}\text { ஸे } \\
\text { 司 } \\
\text { ஸू }\end{array}$ & 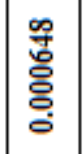 & 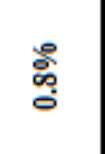 \\
\hline & & 总 & 罗 & 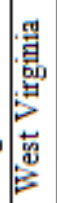 & 密 & 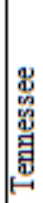 & 害悬 & 害 & \begin{tabular}{|l|l}
0 \\
$\vdots$ \\
0
\end{tabular} & 曾 & & 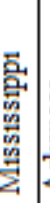 & & & 롱 & 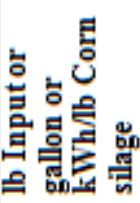 & 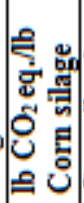 & 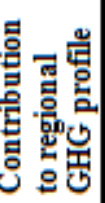 \\
\hline
\end{tabular}




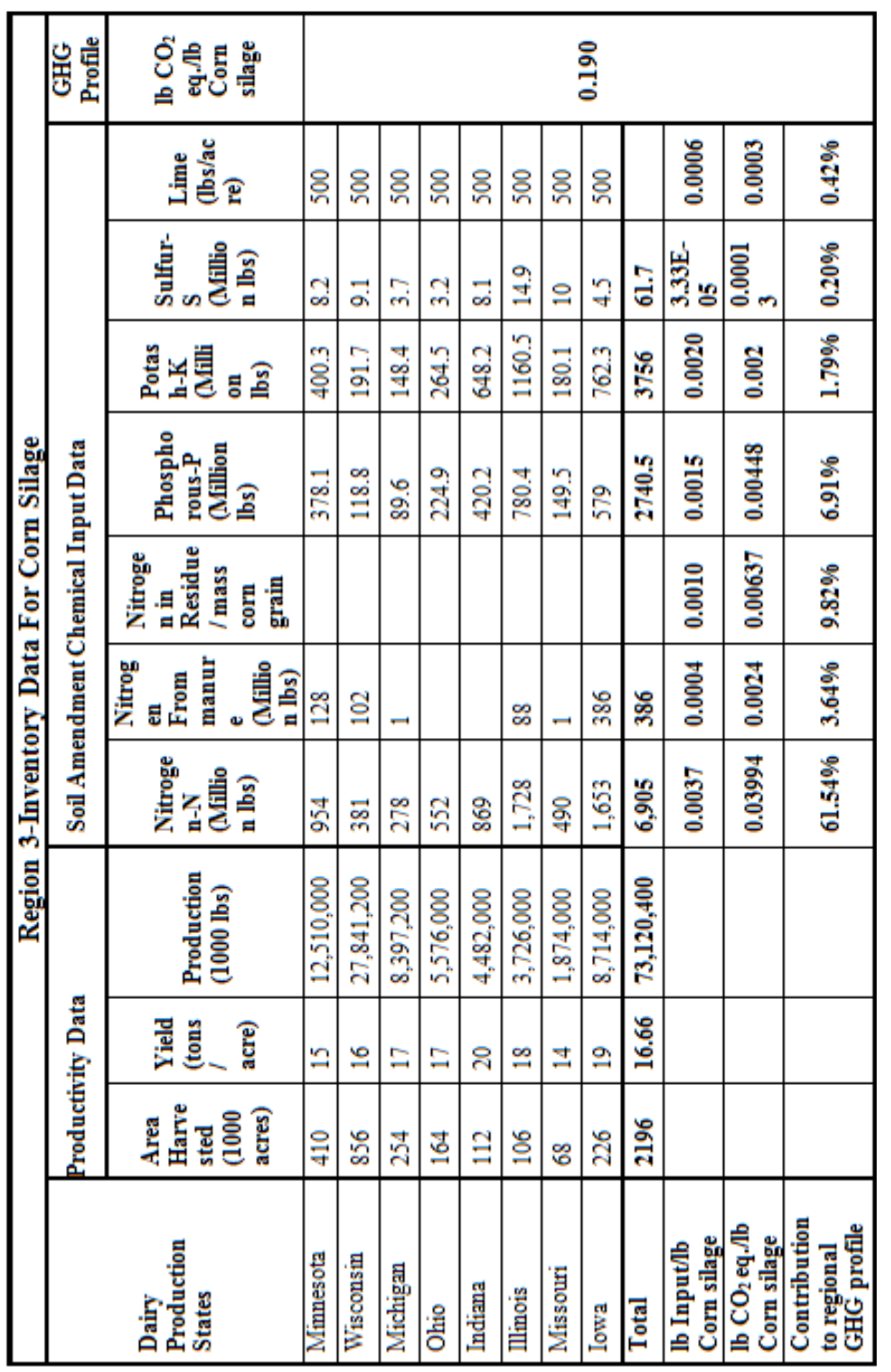




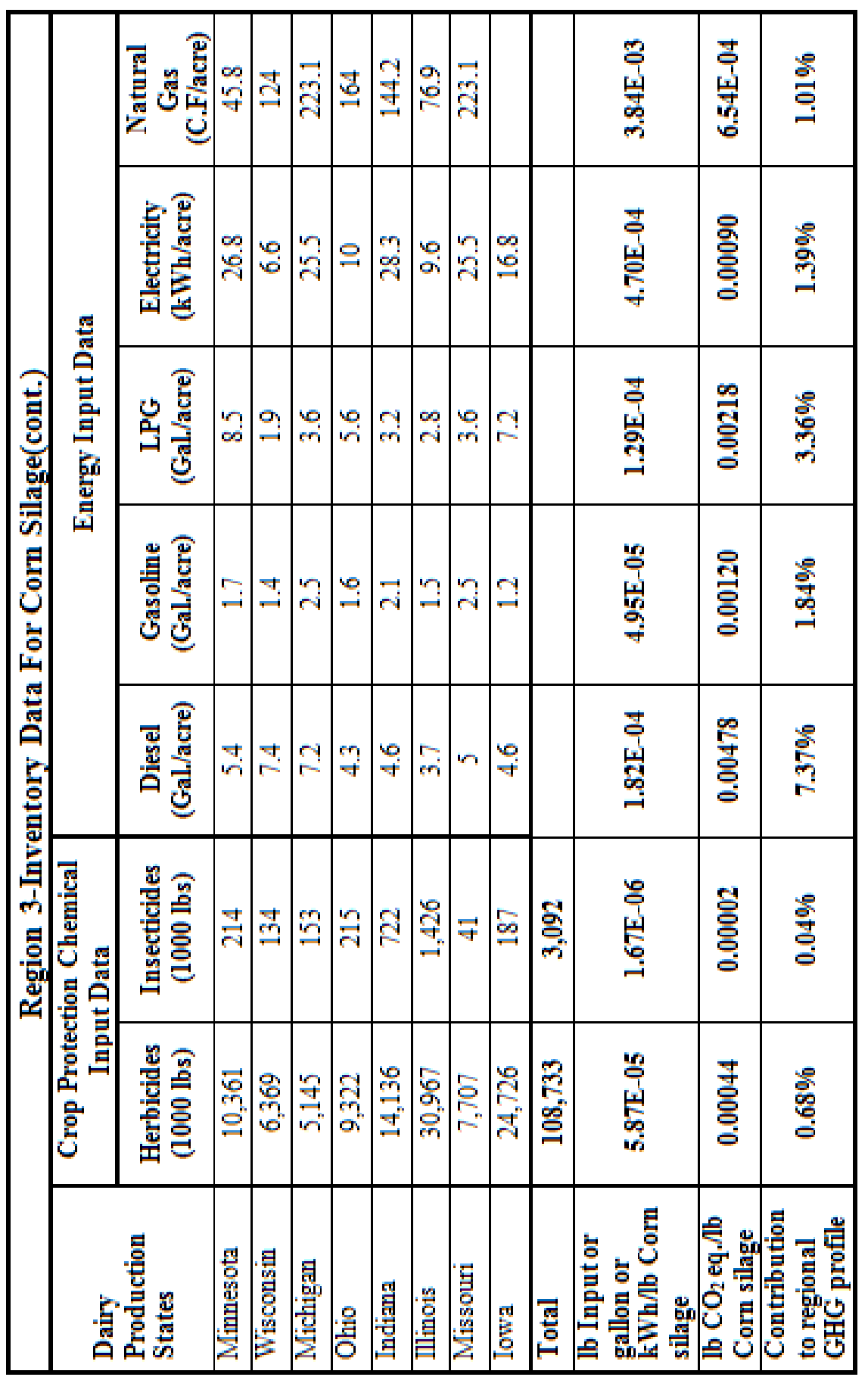




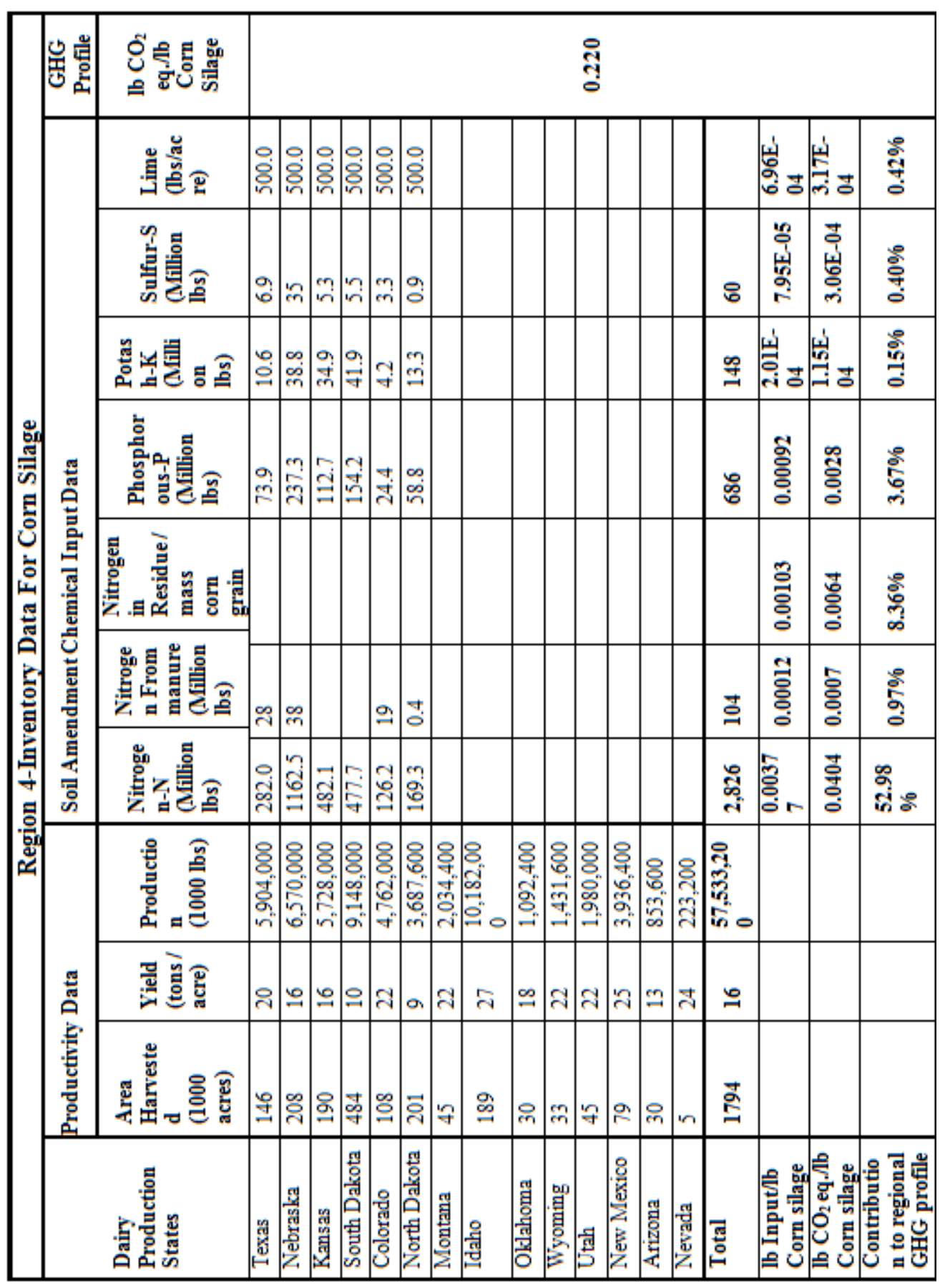




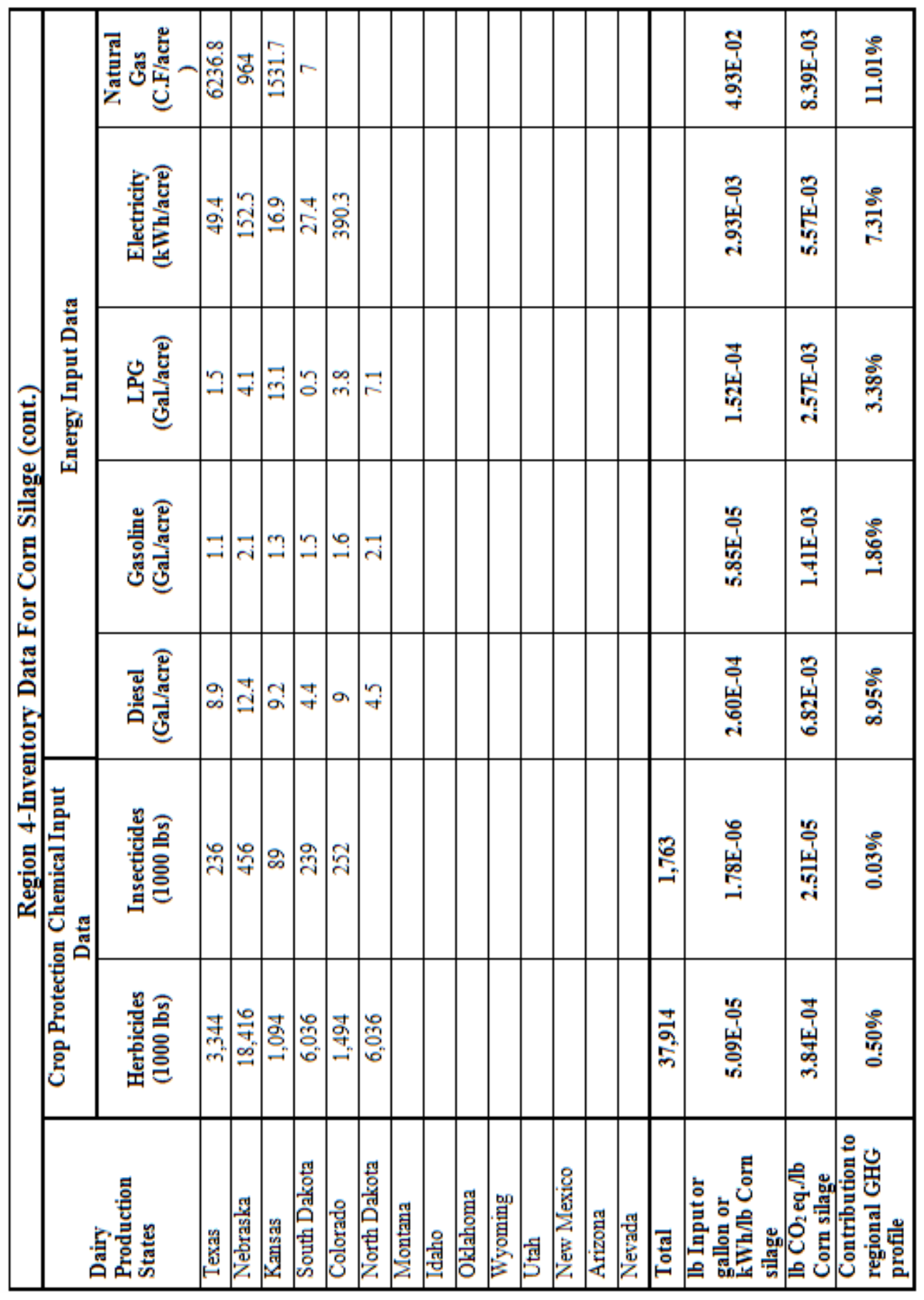




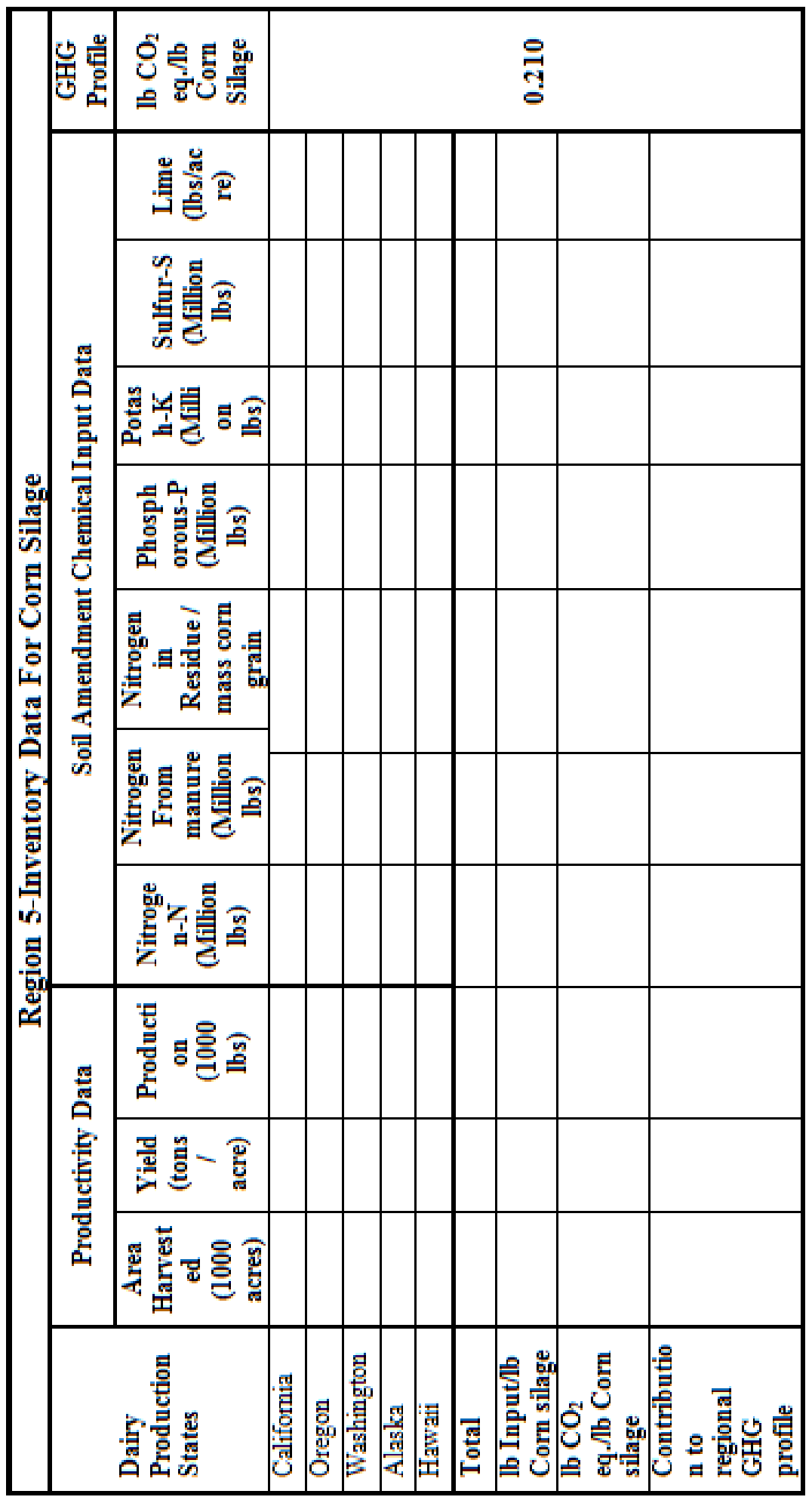




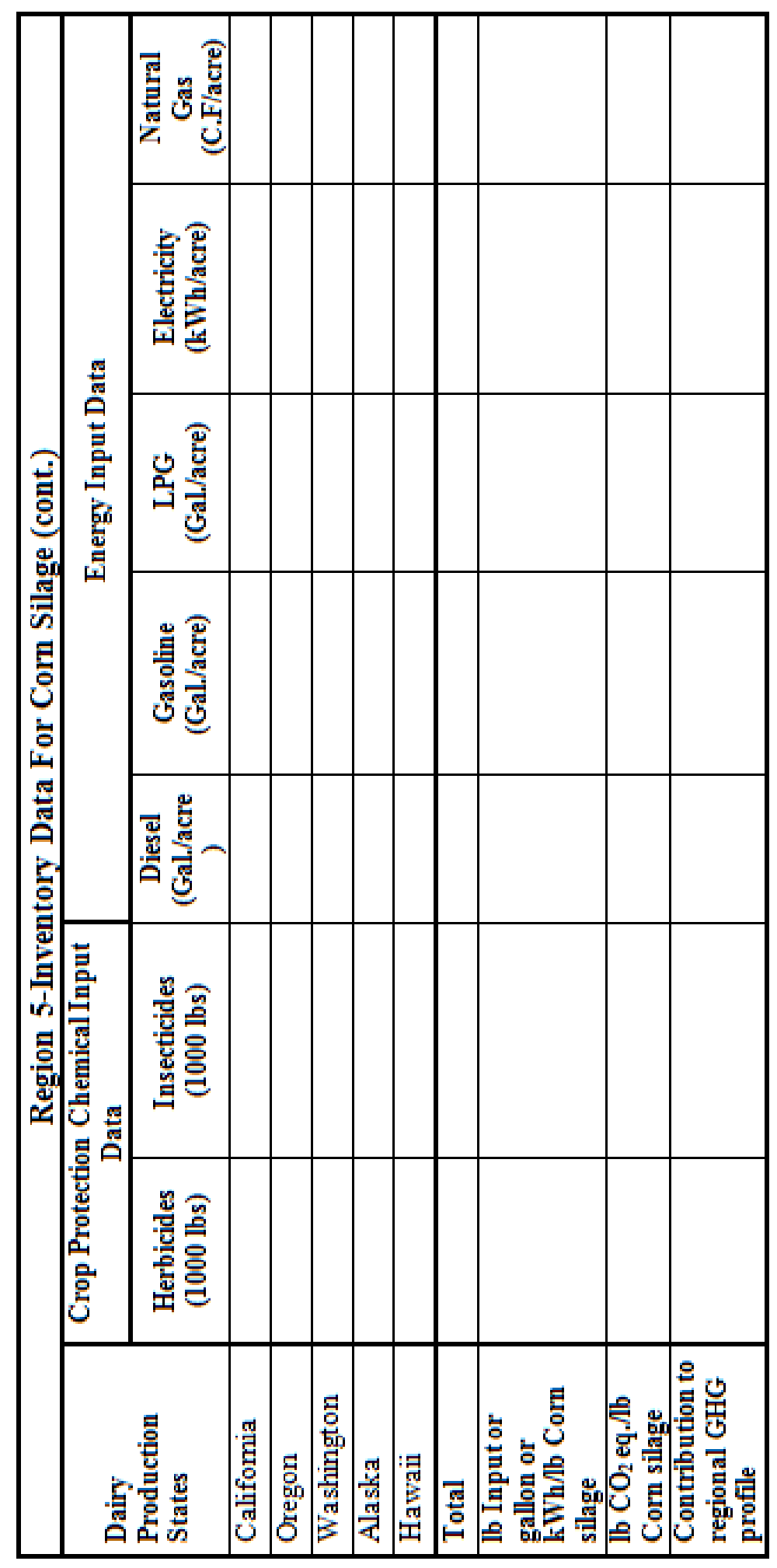




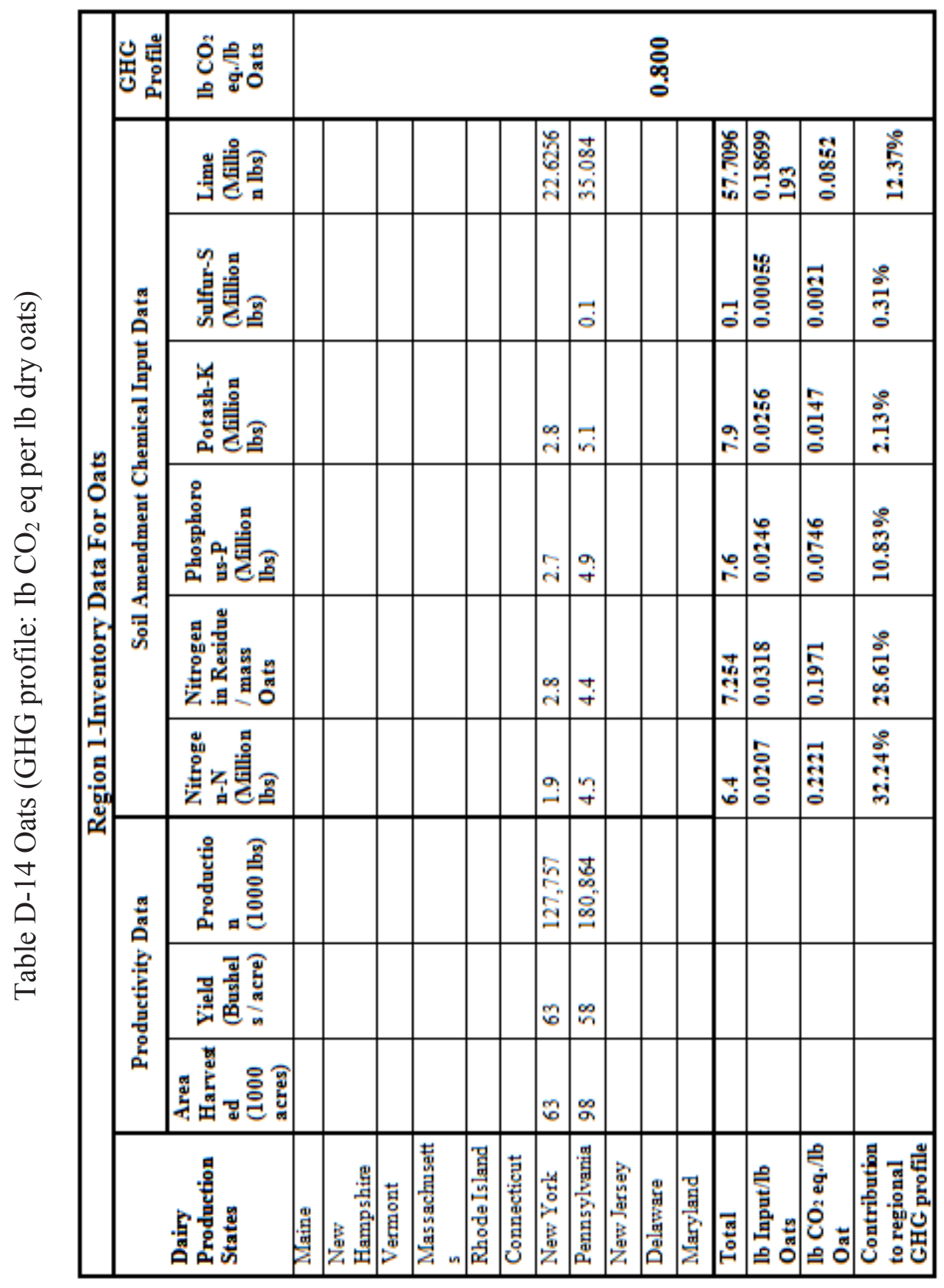




\begin{tabular}{|c|c|c|c|c|c|c|c|c|c|c|c|c|c|c|}
\hline & 意令 & & & & & & 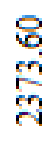 & $\begin{array}{l}\text { ô } \\
\text { ồ } \\
\text { of }\end{array}$ & & & 营 & & 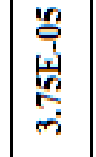 & $\begin{array}{l}\stackrel{\circ}{\circ} \\
\stackrel{0}{0}\end{array}$ \\
\hline & 䎋 & & & & & & 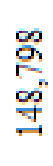 & 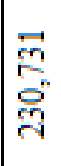 & & & $\begin{array}{l}\frac{9}{7} \\
\frac{9}{7} \\
\frac{9}{7}\end{array}$ & & 产 & ㅇํㅇ \\
\hline 苛 & 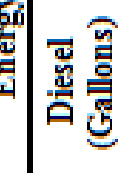 & & & & & & $\begin{array}{l}\text { ठे } \\
\text { ป̂. } \\
\text { ป̂. }\end{array}$ & $\begin{array}{l}8 \\
\delta \\
-j \\
\text { d }\end{array}$ & & 00 & 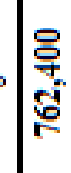 & & $\begin{array}{l}\stackrel{0}{0} \\
\stackrel{0}{0} \\
0\end{array}$ & ㅇํㅇ \\
\hline 일 & 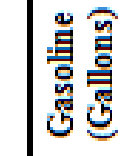 & & & & & & $\begin{array}{l}\text { 总 } \\
\text { ఫे }\end{array}$ & 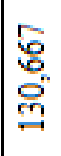 & & & 急 & & $\begin{array}{l}\stackrel{0}{0} \\
\stackrel{0}{0} \\
0\end{array}$ & 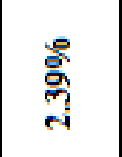 \\
\hline 闵 & 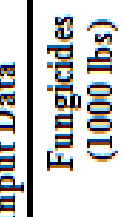 & & & & & & & & & & & & & \\
\hline 일 & 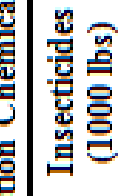 & & & & & & & & & & 0 & 0 & 0 & ఃे \\
\hline$i$ & 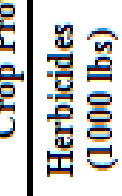 & & & & & & & 웡 & & & 8) & 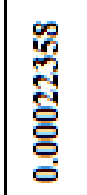 & 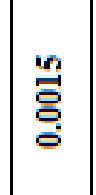 & 홍 \\
\hline & 量 & 䝮 & 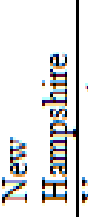 & 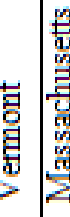 & 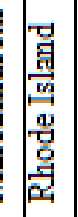 & 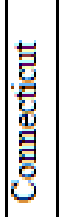 & $\begin{array}{l}\text { 폄 } \\
\text { 党 } \\
\text { 总 }\end{array}$ & 悬 & 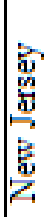 & 㻤 & 啥 & 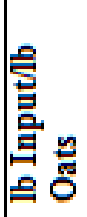 & 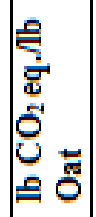 & 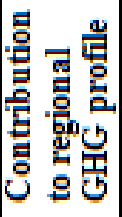 \\
\hline
\end{tabular}




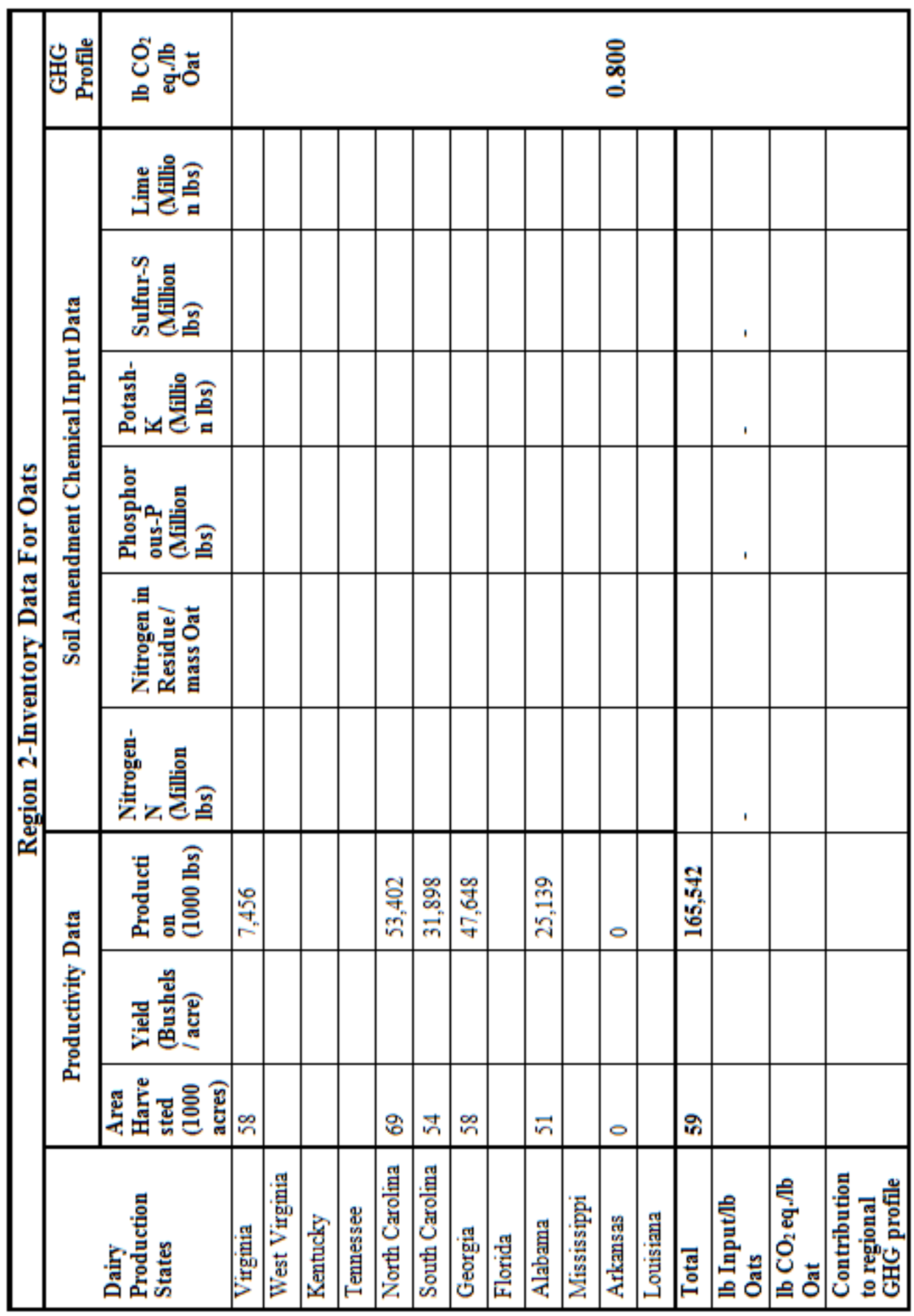




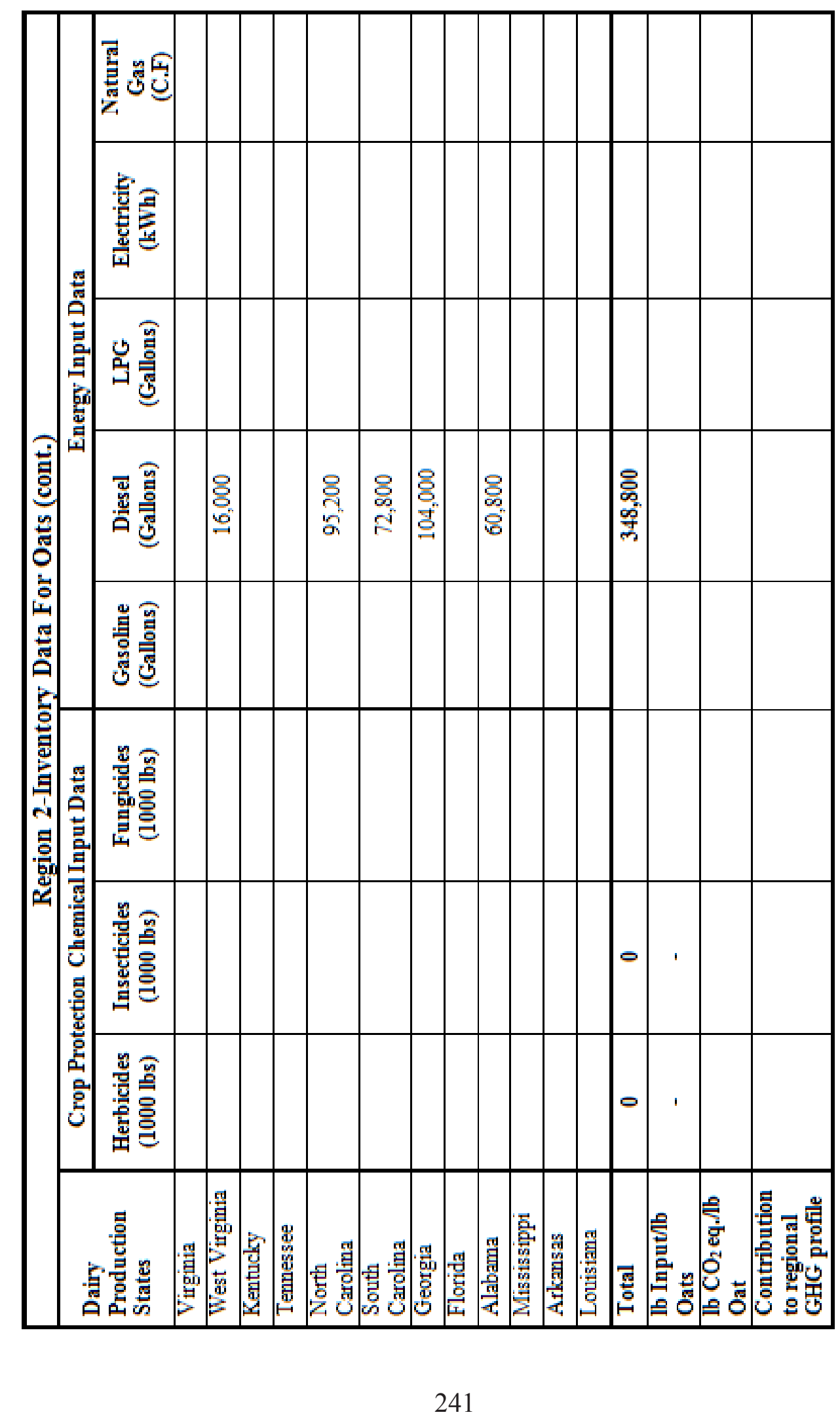




\begin{tabular}{|c|c|c|c|c|c|}
\hline 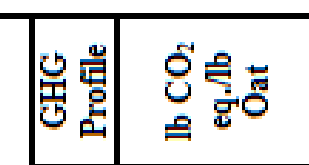 & & & 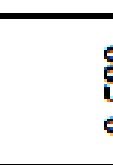 & & \\
\hline 掼曾兽 & 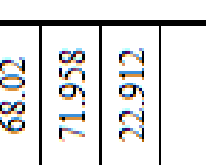 & $\frac{8}{2}+$ & 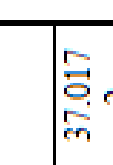 & 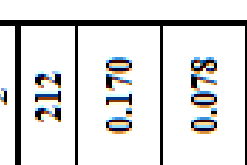 & $\frac{9}{9}: 8$ \\
\hline 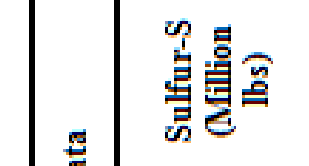 & & & & $\because \frac{1}{9}$ & 产 \\
\hline 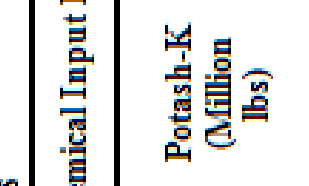 & & $=$ & & $\Rightarrow=\frac{g}{2}$ & 高 \\
\hline 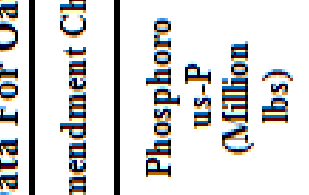 & & $:$ & & 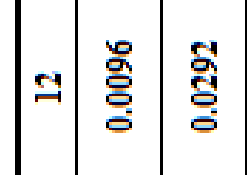 & 善 \\
\hline 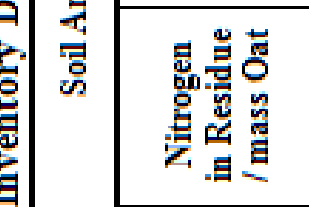 & $\therefore \approx$ & $\cong$ & 7 & 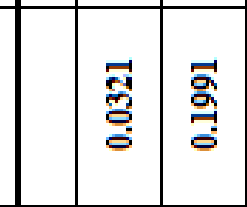 & 总 \\
\hline 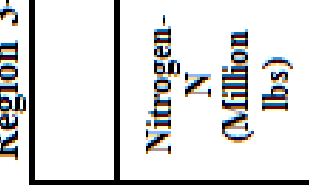 & & 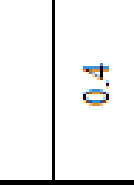 & 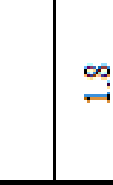 & 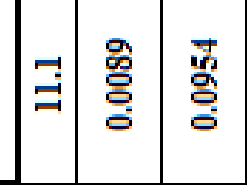 & 咅 \\
\hline 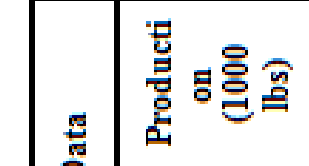 & & 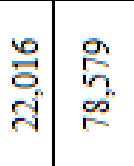 & 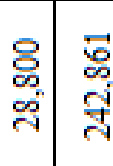 & & \\
\hline 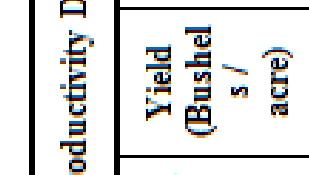 & 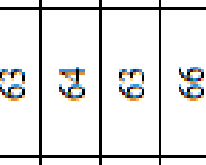 & $\approx$ & & $:$ & \\
\hline 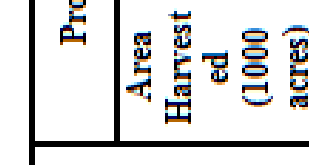 & 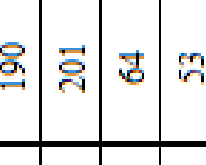 & \# & $=:$ & $:$ & \\
\hline 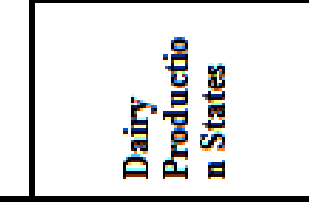 & 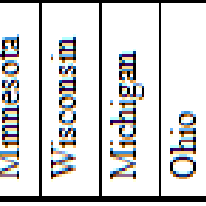 & 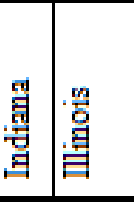 & & 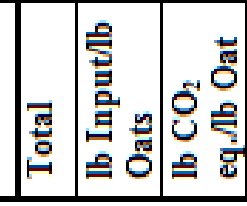 & 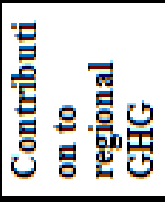 \\
\hline
\end{tabular}




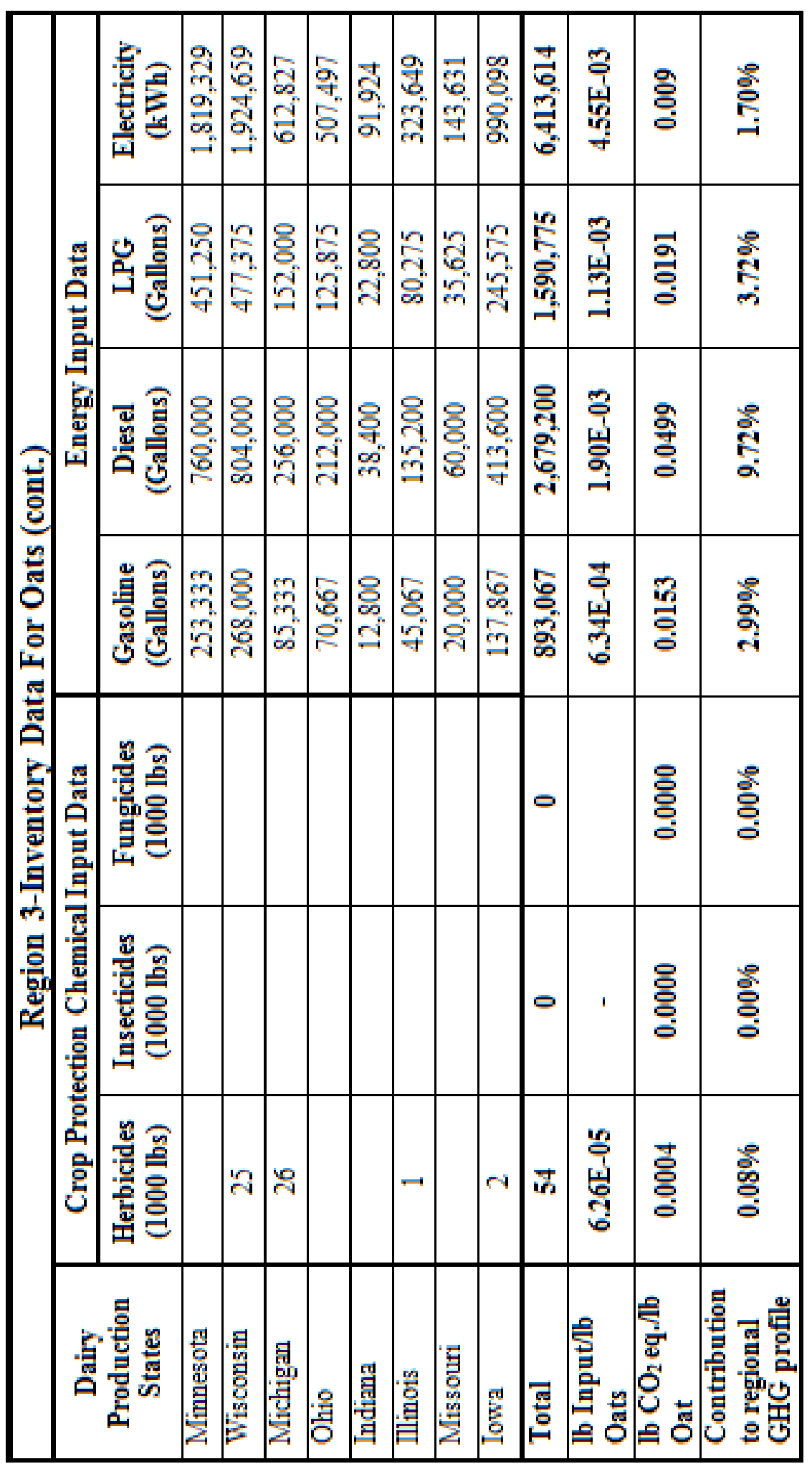




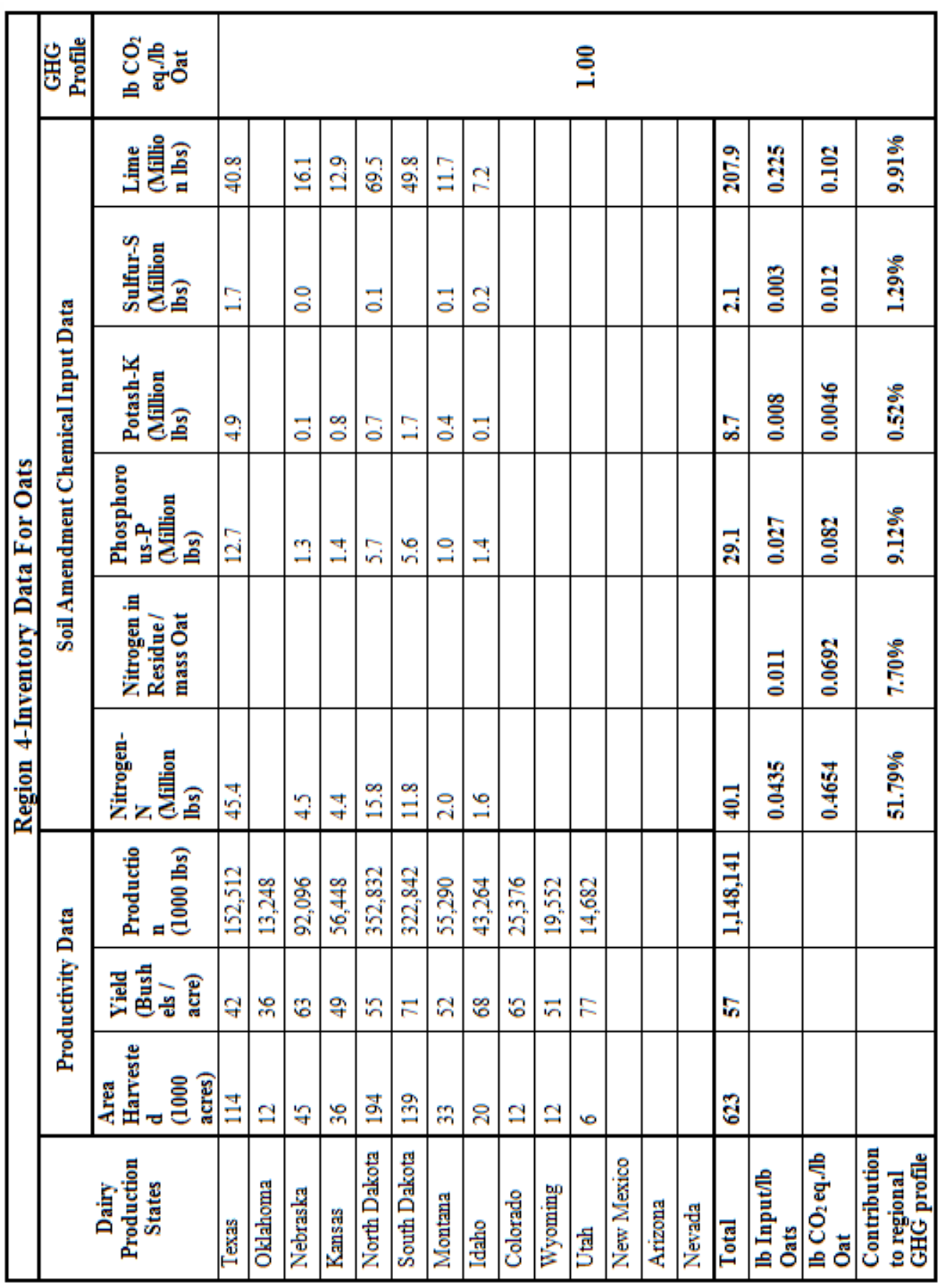




\begin{tabular}{|c|c|c|c|c|c|c|c|c|c|c|c|c|c|c|c|c|c|c|}
\hline & 尼 & & & & & & & & & & & & & & & & & \\
\hline & 密焉 & 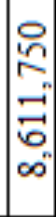 & $\begin{array}{l}\infty \\
\infty \\
\sim \\
0 \\
\infty \\
\infty\end{array}$ & $\begin{array}{l}n \\
\tilde{n} \\
\text { g. } \\
\text { m. } \\
\text { m. }\end{array}$ & 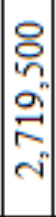 & $\begin{array}{l}m \\
0 \\
0 \\
2 \\
2 \\
0 \\
0 \\
\pm \\
\pm\end{array}$ & $\begin{array}{l}5 \\
\text { 2. } \\
8 \\
0 \\
0 \\
0\end{array}$ & 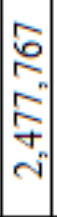 & $\begin{array}{l}m \\
\text { ma } \\
0 \\
0 \\
\\
-1\end{array}$ & 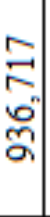 & 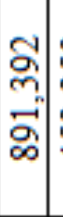 & 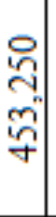 & & & 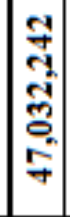 & & 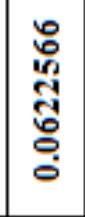 & 웅 \\
\hline & 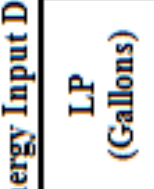 & 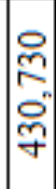 & $\begin{array}{l}\text { ปे } \\
\infty \\
\text { ஸे }\end{array}$ & 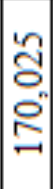 & $\begin{array}{l}\text { 옹 } \\
8 \\
\text { ㅇ. }\end{array}$ & $\begin{array}{l}\widehat{\widehat{g}} \\
\text { - } \\
\text { ñ }\end{array}$ & 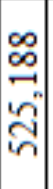 & 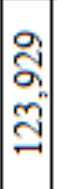 & $\begin{array}{l}6 \\
2 \\
2 \\
2\end{array}$ & $\begin{array}{l}\vec{n} \\
\infty \\
0 \\
0 \\
+0\end{array}$ & $\begin{array}{l} \pm \\
\stackrel{\infty}{n} \\
f^{f}\end{array}$ & $\begin{array}{l}\text { 이 } \\
\text { ㅇ. } \\
\text { ते }\end{array}$ & & & 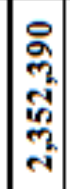 & & $\begin{array}{l}0 \\
0 \\
0 \\
0 \\
0 \\
0 \\
0\end{array}$ & $\begin{array}{l}\stackrel{\circ}{\circ} \\
\ddot{\infty} \\
\infty \\
\text { ’ }\end{array}$ \\
\hline 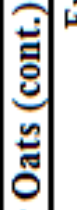 & 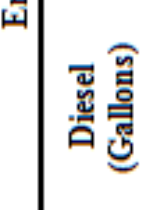 & $\begin{array}{l}8 \\
8 \\
\circ \\
\\
+\end{array}$ & 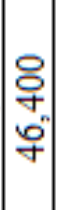 & $\begin{array}{l}8 \\
8 \\
8 \\
8 \\
0 \\
-\end{array}$ & $\begin{array}{l}8 \\
8 \\
7 \\
7\end{array}$ & $\begin{array}{l}8 \\
8 \\
0 \\
0 \\
2\end{array}$ & 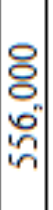 & 올 & 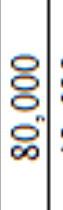 & $\begin{array}{l}\text { 이 } \\
\text { on } \\
\text { g. }\end{array}$ & 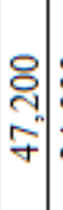 & $\begin{array}{l}8 \\
8 \\
\text { பn } \\
\text { | }\end{array}$ & & & 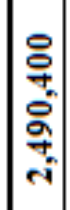 & & $\begin{array}{l}5 \\
0 \\
5 \\
0 \\
0 \\
0 \\
0 \\
0\end{array}$ & 울 \\
\hline 월 & 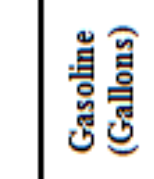 & $\begin{array}{l}\text { 8 } \\
8 \\
\text { กิ } \\
\end{array}$ & 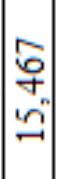 & 응 & $\begin{array}{c}8 \\
8 \\
8 \\
\infty \\
+\end{array}$ & $\begin{array}{l}6 \\
8 \\
\infty \\
\\
\end{array}$ & $\begin{array}{l}m \\
\\
\\
\\
\infty \\
=\end{array}$ & $\begin{array}{c}m \\
\tilde{r} \\
\tilde{y} \\
\bar{y}\end{array}$ & 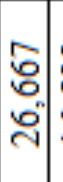 & $\begin{array}{l}\text { ñ } \\
\text { ñ } \\
0 \\
\end{array}$ & $\begin{array}{l}m \\
\\
\stackrel{n}{\sim}\end{array}$ & $\begin{array}{l}8 \\
\varnothing \\
\varnothing^{n}\end{array}$ & & & 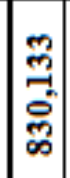 & & 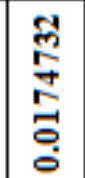 & $\stackrel{\circ}{\stackrel{3}{3}}$ \\
\hline 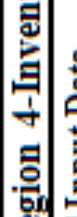 & 总苟会 & & & & & & & & & & & & & & & & & \\
\hline & 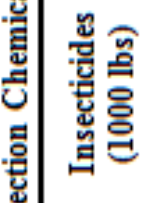 & m & & & & & & & & & & & & & $\begin{array}{c}0 \\
\dot{10} \\
\text { ஸे }\end{array}$ & 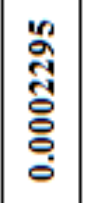 & 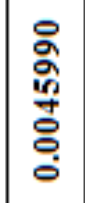 & $\stackrel{\circ}{\stackrel{2}{n}}$ \\
\hline & 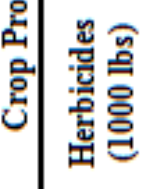 & $\infty$ & & $\nabla$ & $m$ & 6 & Nin & $\stackrel{\infty}{-\infty}$ & 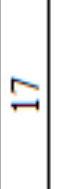 & & & & & & 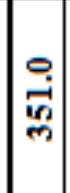 & 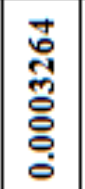 & 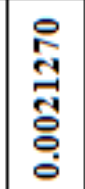 & ㅇํㄹ \\
\hline & 䓌䓌总 & 惫 & 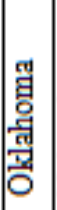 & & 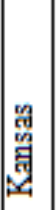 & 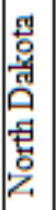 & 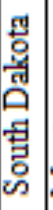 & 串 & 量 & 몸 & 恕 & 完 & 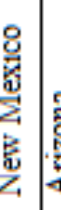 & 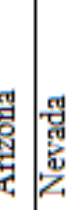 & 急 & 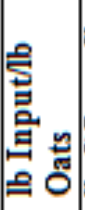 & 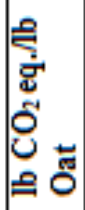 & 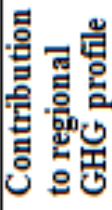 \\
\hline
\end{tabular}




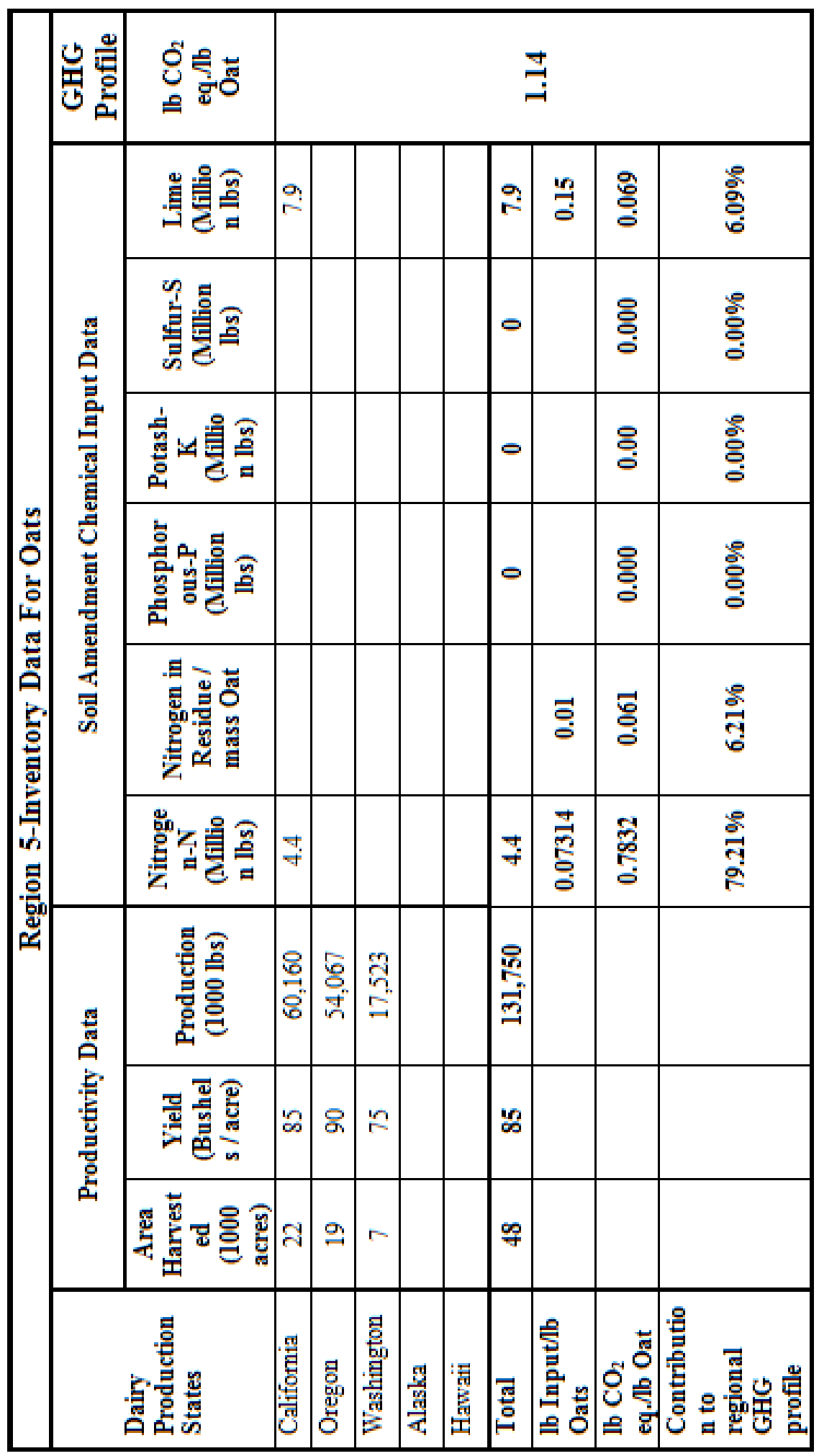




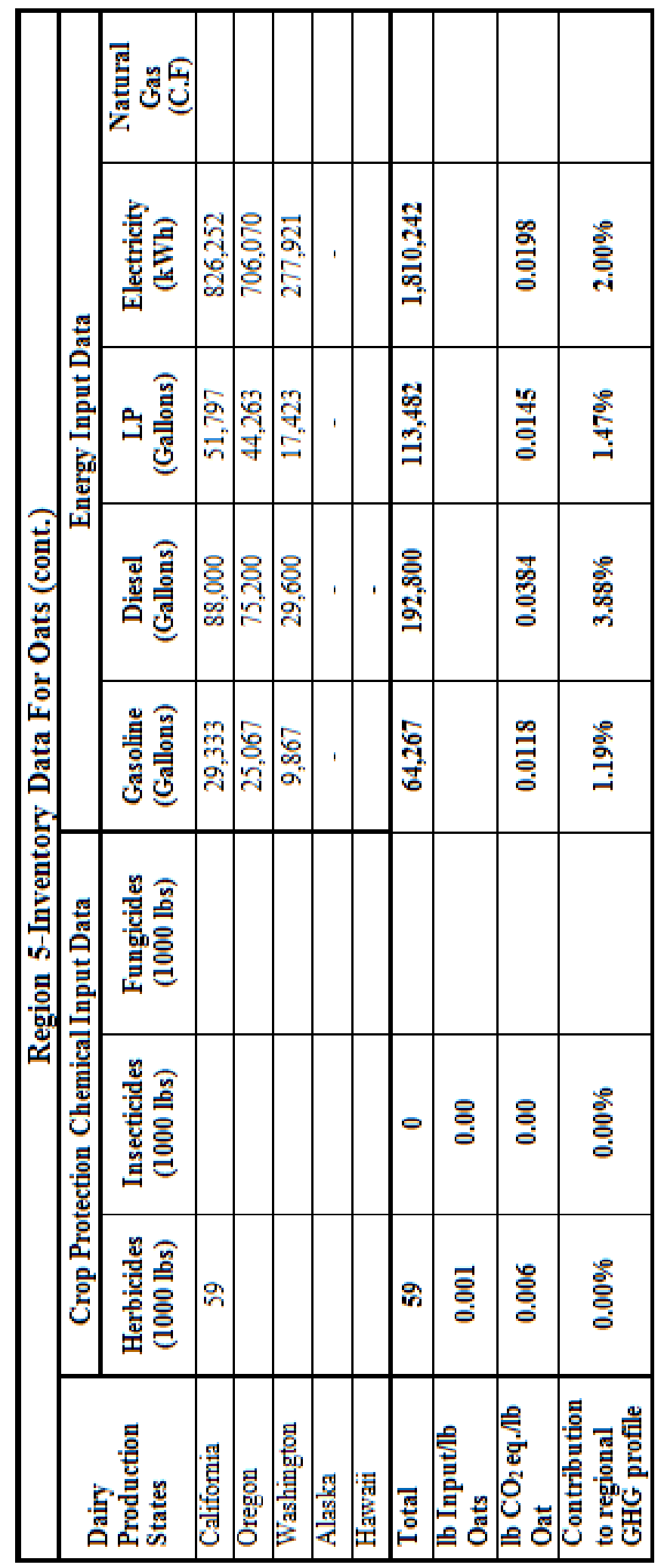




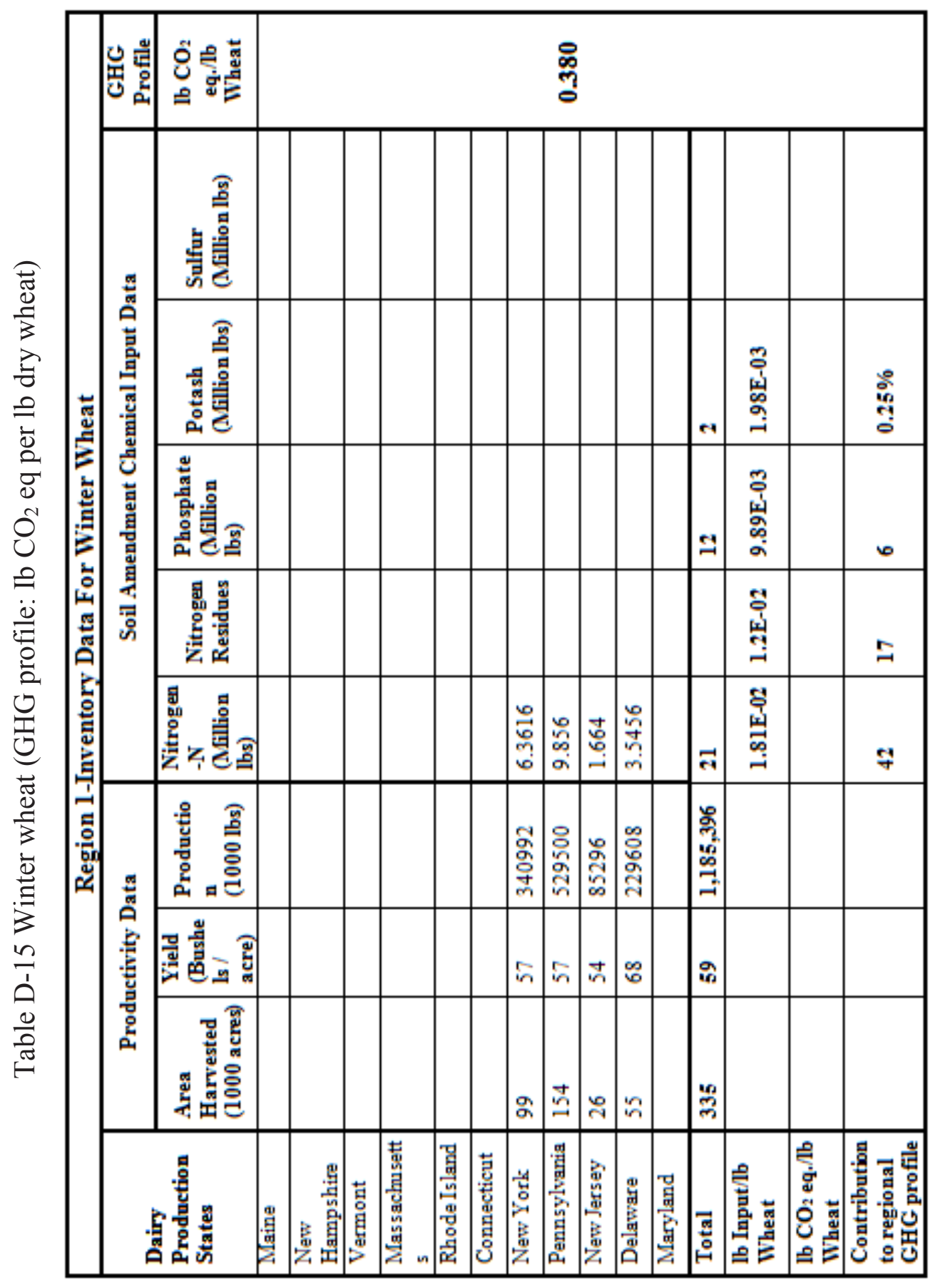




\begin{tabular}{|c|c|c|c|c|c|c|c|c|c|c|c|c|c|c|c|c|c|}
\hline & 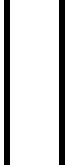 & 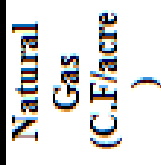 & & & & & & & 응 & 응 & 응 & 응 & & & 总 & 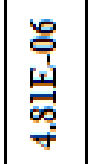 & 융 \\
\hline & 올 & 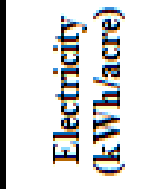 & & & & & & & 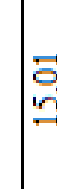 & 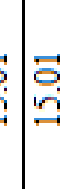 & 훙 & 훙 & & & $\begin{array}{l}\text { 仓े } \\
\text { 岑 } \\
\text { वे }\end{array}$ & 恣 & 웃 \\
\hline 켤 & 包 & 号 突 & & & & & & & 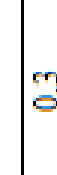 & $\stackrel{n}{0}$ & m? & ? & & & 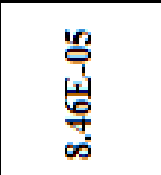 & 臨 & $\frac{\stackrel{8}{2}}{\stackrel{2}{6}}$ \\
\hline 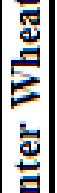 & |ำ & 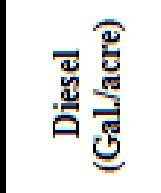 & & & & & & & 7 & $\vec{v}$ & $\underset{\forall}{\vec{y}}$ & 守 & & & 氺 & ક્' & $\stackrel{2}{2}$ \\
\hline 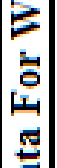 & 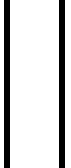 & $\begin{array}{l}\text { 总总。 } \\
\text { 岕导 }\end{array}$ & & & & & & & 운 & 을 & 을 & $\vec{\circ}$ & & & 志 & 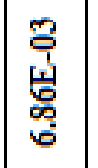 & 욤 \\
\hline 동. & 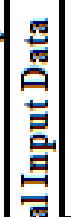 & 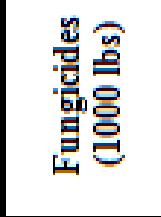 & & & & & & & & & & & & & & & \\
\hline 혐 & $\mid$ & 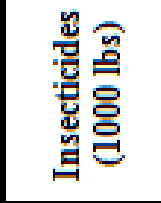 & & & & & & & & & & & & & & & \\
\hline & 일 & 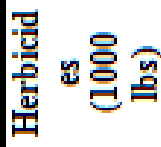 & & & & & & & & & & & & & & & \\
\hline & & 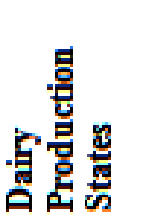 & 咅 & 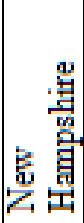 & 苛 & 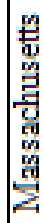 & 兽 & $\begin{array}{l}\mathrm{E} \\
\mathrm{E} \\
\mathrm{E} \\
\mathrm{L} \\
\mathrm{E}\end{array}$ & 竞 & 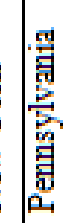 & 勇 & 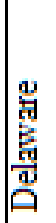 & 櫋 & 롱 & 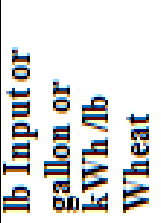 & 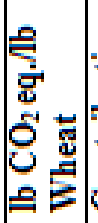 & 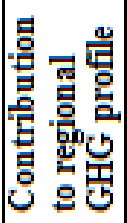 \\
\hline
\end{tabular}




\begin{tabular}{|c|c|c|c|c|c|c|c|c|c|c|c|c|c|c|c|}
\hline 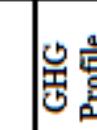 & 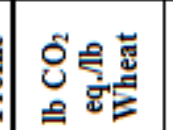 & & & & & & & & & & & & & & \\
\hline \multirow{5}{*}{ 赑 } & 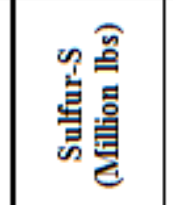 & & & & & & & & & & & & & & \\
\hline & 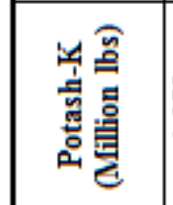 & $=7$ & d. & & 总 & 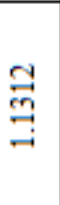 & $\exists$ & & & & & 2 & 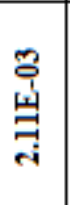 & : & कें \\
\hline & 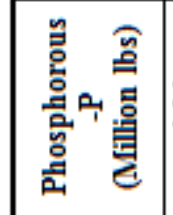 & $:$ & 9 & ¿ & 蛋 & 菅 & 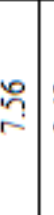 & & & 会 & & $\Phi$ & 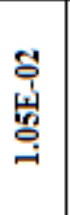 & 苛 & $\stackrel{\circ}{\circ}$ \\
\hline & 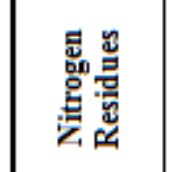 & & & & & & & & & & & & & E & ఃั \\
\hline & & 总 & $\begin{array}{l}\mathscr{\infty} \\
\stackrel{\mathscr{D}}{\mathrm{c}}\end{array}$ & ฮ & 黑 & 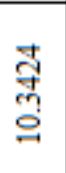 & 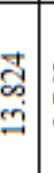 & & & & & $E$ & & 今్ & 高 \\
\hline \multirow{4}{*}{ 高 } & 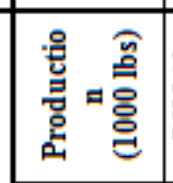 & ఫั) & 8. & 윯 & 品 & 卷落 & $g$ & & & & g & 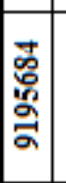 & & & \\
\hline & 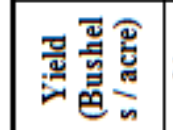 & t & $\sigma$ & in & in & io & & & & in & 8 & $\because$ & & & \\
\hline & 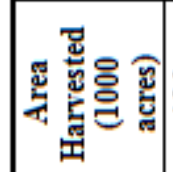 & & $q$ & \& & s & $\subseteq$ & & & & & & $\vec{E}$ & & & \\
\hline & 总 & 要 & 隐 & & & & & & & & & 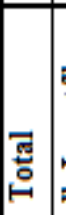 & & 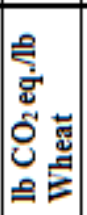 & 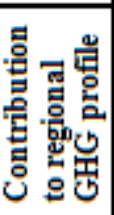 \\
\hline
\end{tabular}




\begin{tabular}{|c|c|c|c|c|c|c|c|c|c|c|c|c|c|c|c|c|c|c|}
\hline & . & 蛋兽密 & 응 & $\stackrel{9}{\circ}$ & 응 & 응 & $\stackrel{9}{\circ}$ & 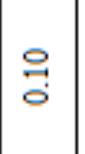 & 응 & 응 & 응 & 응 & 응 & 응 & & 总 & 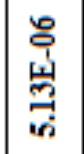 & 。유. \\
\hline & 용 & 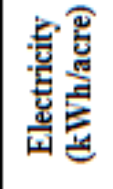 & $\begin{array}{l}\overrightarrow{0} \\
\vdots \\
\underline{2}\end{array}$ & $\begin{array}{l}\overrightarrow{0} \\
\vdots \\
0\end{array}$ & "뭉 & 음 & 훌 & 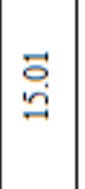 & \begin{tabular}{l}
$\overrightarrow{0}$ \\
0 \\
\hdashline
\end{tabular} & 웅 & $\begin{array}{l}\overrightarrow{0} \\
\text { 믈 }\end{array}$ & $\mid$\begin{tabular}{l}
$\overrightarrow{0}$ \\
$\vdots$ \\
\hdashline
\end{tabular} & $\begin{array}{l}\overrightarrow{0} \\
\stackrel{2}{a}\end{array}$ & \begin{tabular}{l}
$\overrightarrow{0}$ \\
\hdashline \\
\hdashline
\end{tabular} & & 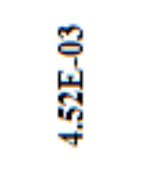 & 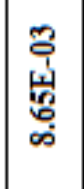 & స్ \\
\hline ㄱ․ㄹ. & 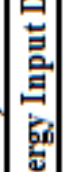 & 号兽 & $\dddot{m}$ & $?$ & $?$ & ? & ? & m & 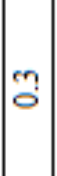 & ?a & $\dddot{m}$ & $\dddot{0}$ & $\tilde{o}$ & $\hat{m}$ & & 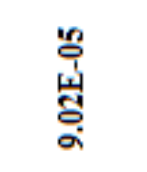 & 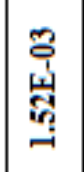 & 웡 \\
\hline | & 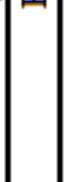 & 鸹 & $\begin{array}{l}\vec{y} \\
\dot{\vec{\tau}}\end{array}$ & $\vec{j}$ & $\overrightarrow{8}$ & 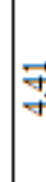 & 守 & $\underset{+}{\vec{f}}$ & $\vec{\nabla}$ & 守 & $\vec{f}$ & $\begin{array}{l}\vec{y} \\
\dot{v}\end{array}$ & $\vec{f}$ & 守 & & 密 & 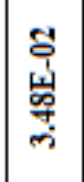 & 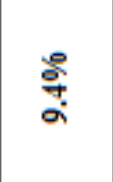 \\
\hline | & & 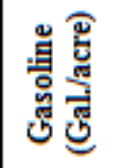 & $\mid \vec{i}$ & $\overrightarrow{-}$ & 음 & 흔 & $\stackrel{\overrightarrow{0}}{-}$ & $\stackrel{\overrightarrow{0}}{-}$ & 훔 & 훙 & 흠 & 훙 & 을 & 엄 & & 离 & 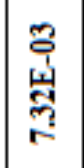 & 옹 \\
\hline 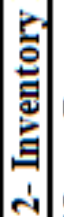 & 韋 & 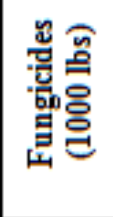 & & & & & & & & & & & & & & & & \\
\hline . & 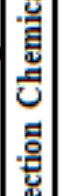 & 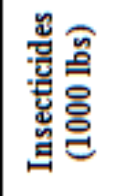 & & & & & & & & & & & & & & & & \\
\hline & $\mid$ & 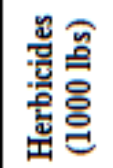 & & & & & & & & & & & & & & & & \\
\hline & 今. & 总 & 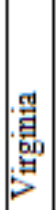 & 覃 & 福 & 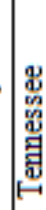 & 思高 & 容員 & 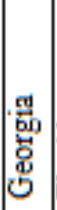 & 票 & 買 & 言 & 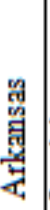 & 筧 & 롱. & 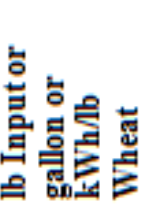 & 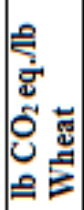 & 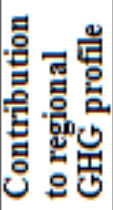 \\
\hline
\end{tabular}




\begin{tabular}{|c|c|c|c|c|c|c|c|c|c|c|c|}
\hline 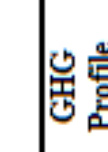 & 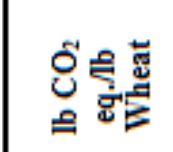 & \multicolumn{10}{|c|}{ ip } \\
\hline \multirow{5}{*}{ 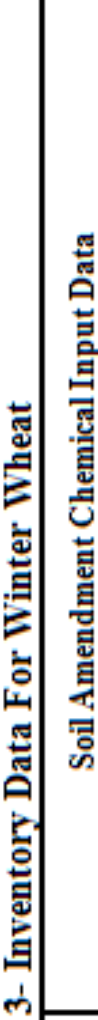 } & 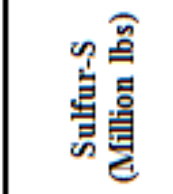 & & $m ?$ & & |c & $\stackrel{\infty}{-}$ & & $\approx$ & $\begin{array}{c}\stackrel{8}{0} \\
\text { 产 } \\
\text { - }\end{array}$ & 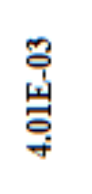 & $\stackrel{2}{2}$ \\
\hline & 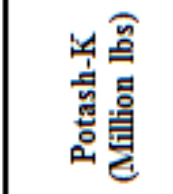 & & $\left|\begin{array}{l}9 \\
m \\
\tilde{m}\end{array}\right|$ & & $\%$ & $\mid$\begin{tabular}{l}
$\infty$ \\
\multirow{j}{*}{$\mid$}
\end{tabular} & & : & 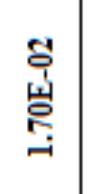 & 总 & ڤે \\
\hline & 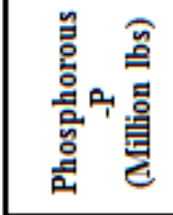 & & สี & & gو & 瓷 & & ta & 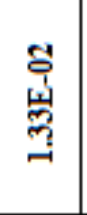 & 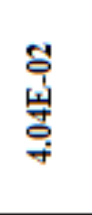 & ڤ̊ \\
\hline & 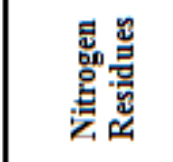 & & & & & & & & 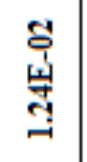 & E. & $\stackrel{8}{\stackrel{2}{2}}$ \\
\hline & 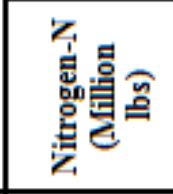 & & 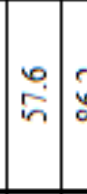 & 苂 & & 8 & & 毡 & 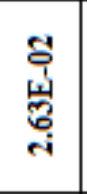 & 茖 & : \\
\hline \multirow{4}{*}{ 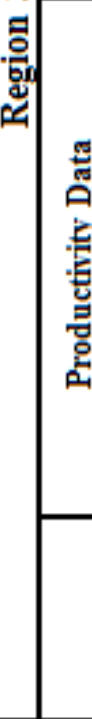 } & 㲋总 & 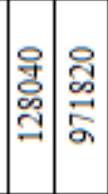 & 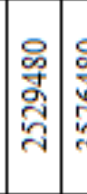 & 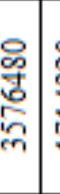 & : & 送 & & 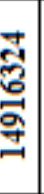 & & & \\
\hline & 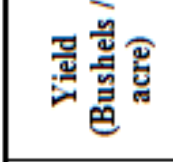 & f: & $5=$ & $:$ & $\bar{\sigma}$ & 음 & & 6 & & & \\
\hline & 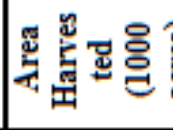 & 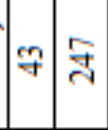 & ఫु & 8 & & & & & & & \\
\hline & 总 & 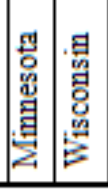 & & & & & & & & & \\
\hline
\end{tabular}




\begin{tabular}{|c|c|c|c|c|c|c|c|c|c|c|c|c|c|c|}
\hline & 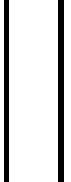 & 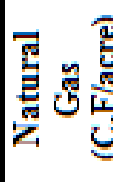 & & & 응 & 응 & & 응 & 응 & & & $\begin{array}{l}\text { 㝵 } \\
\text { 突 } \\
\text { i }\end{array}$ & 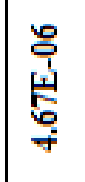 & $\begin{array}{l}\stackrel{8}{8} \\
\text { 융 }\end{array}$ \\
\hline & 영 & 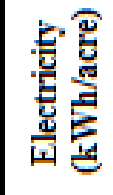 & & & 总 & $\mid$\begin{tabular}{l}
$\overrightarrow{0}$ \\
$\vdots$ \\
\hdashline
\end{tabular} & & $\mid \begin{array}{l}\overrightarrow{0} \\
\stackrel{1}{\varrho}\end{array}$ & $\mid$\begin{tabular}{l}
$\overrightarrow{0}$ \\
$\vdots$ \\
\hdashline
\end{tabular} & & & $\begin{array}{l}\text { 突 } \\
\text { 孛 } \\
\text { 子 }\end{array}$ & $\begin{array}{l}\text { 管 } \\
\text { 点 } \\
\text { م }\end{array}$ & 욕 \\
\hline 일 & 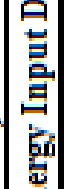 & 엽 兽 & & & ફি & ફি & & 오 & ల్ల & & & 总 & $\begin{array}{l}\text { \% } \\
\text { 鸟 }\end{array}$ & స్ \\
\hline : & (19 & 怘 & & & $\begin{array}{l}\vec{\theta} \\
\dot{\theta}\end{array}$ & $\begin{array}{l}\vec{y} \\
\dot{v}\end{array}$ & & $\begin{array}{l}\vec{\theta} \\
\dot{v}\end{array}$ & $\begin{array}{l}\vec{y} \\
\dot{v}\end{array}$ & & & 官 & 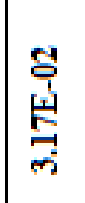 & 움 \\
\hline $\mid$ & & 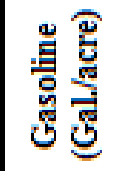 & & & $\vec{\sigma}$ & $\vec{\sigma}$ & & $\stackrel{\overrightarrow{0}}{-}$ & $\overrightarrow{0}$ & & & $\begin{array}{l}\text { 후 } \\
\text { 붕 } \\
\text { 어 }\end{array}$ & 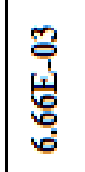 & 学 \\
\hline 昰 & 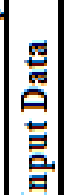 & 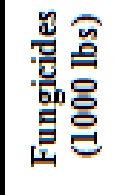 & & & $\approx$ & & & $n$ & 으 & & స & 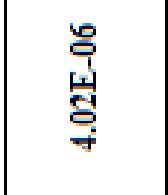 & $\begin{array}{l}\text { 옹 } \\
\text { 맄 } \\
\text { iㅗ }\end{array}$ & $\begin{array}{l}\text { 今̊ } \\
\text { 융 }\end{array}$ \\
\hline 형. & 章 & 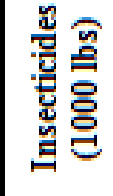 & & & & & & & $\Xi$ & & I & 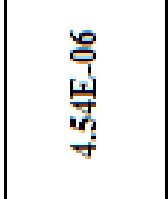 & 동 & $\begin{array}{l}\text { 용 } \\
\text { ర్̊̆ } \\
\text { ర్ }\end{array}$ \\
\hline & 竞 & 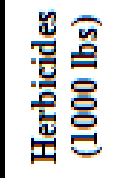 & & & 导 & 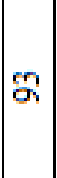 & & (이 & 㝵 & & గ్ల & 옹 & $\begin{array}{l}\text { 훙 } \\
\text { 홍 } \\
\text { ले }\end{array}$ & 옹 \\
\hline & & 总莺 & 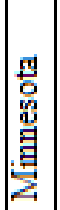 & 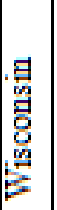 & 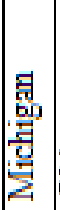 & 용 & 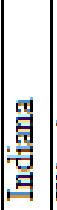 & 哭 & 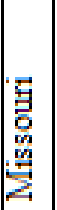 & 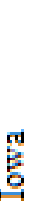 & | ㅎّㅇ & 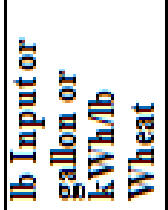 & 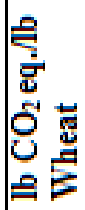 & 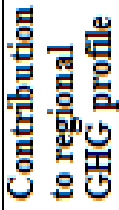 \\
\hline
\end{tabular}




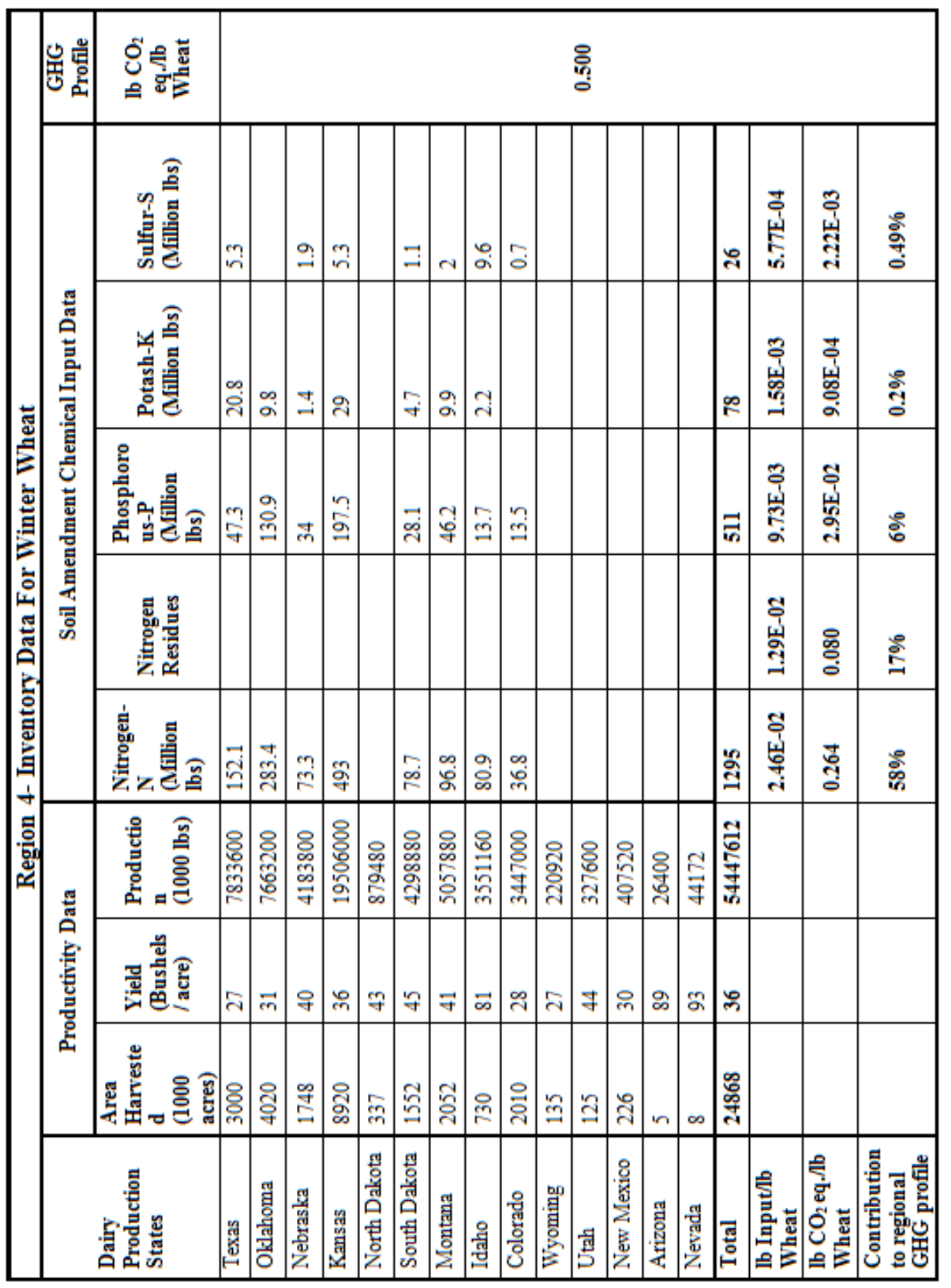




\begin{tabular}{|c|c|c|c|c|c|c|c|c|c|c|c|c|c|c|c|c|c|c|}
\hline & & 晃氙 & & 음 & $\because$ 으 & 으 & 을 & $\because$ & 윽 & 읍 & 음 & & & & & $\begin{array}{l}\text { 우 } \\
\text { 窎 } \\
7\end{array}$ & 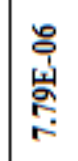 & ఫ్రి \\
\hline & 옵 & 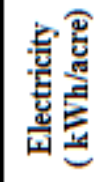 & 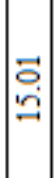 & \begin{tabular}{l}
$\overrightarrow{0}$ \\
\hdashline \\
\hdashline
\end{tabular} & 总 & $\mid$\begin{tabular}{c}
$\overrightarrow{0}$ \\
$\vdots$ \\
\hdashline
\end{tabular} & 总 & $\left|\begin{array}{l}\overrightarrow{0} \\
. \\
\hdashline\end{array}\right|$ & $\begin{array}{l}\vec{\partial} \\
\stackrel{2}{a}\end{array}$ & 宫 & $\mid$\begin{tabular}{l}
$\overrightarrow{0}$ \\
\hdashline \\
\hdashline
\end{tabular} & & & & & 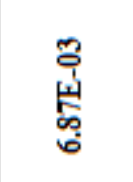 & 突 & 今్ \\
\hline 형 & 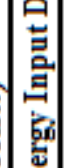 & 업 兽 & 유 & 위 & 위 & 위 & 위 & প্লি & 유. & 유 & 위 & & & & & 总 & 总 & $\stackrel{\circ}{\circ}$ \\
\hline 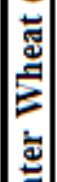 & 5 & 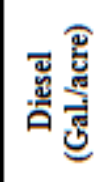 & $\underset{\vec{f}}{\vec{\tau}}$ & $\begin{array}{l}\vec{y} \\
\vec{v}\end{array}$ & Fे & $\vec{q}$ & $\vec{q}$ & $\begin{array}{l}\vec{z} \\
\vec{f}\end{array}$ & $\vec{F}$ & $\underset{f}{\vec{f}}$ & 守 & & & & & 올 & 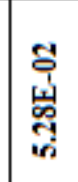 & ๕ั \\
\hline 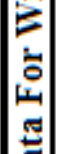 & & 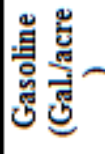 & $\overrightarrow{-}$ & 울 & $\overrightarrow{-}$ & $\overrightarrow{0}$ & $\mid \overrightarrow{0}$ & $\stackrel{\overrightarrow{0}}{-}$ & $\stackrel{\overrightarrow{0}}{-}$ & $\stackrel{\vec{\sigma}}{-}$ & $\overrightarrow{-}$ & & & & & 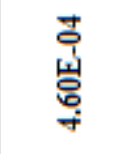 & 客 & సి \\
\hline 氞 & 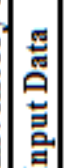 & 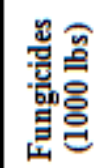 & & & $\infty$ & & & $\vec{A}$ & & $\mathrm{~m}$ & & & & & m & $\begin{array}{l}\text { o } \\
0 \\
0 \\
01 \\
\end{array}$ & $\begin{array}{l}\stackrel{10}{0} \\
0 \\
0 \\
\\
-1\end{array}$ & $\begin{array}{l}\text { 웅 } \\
\text { 웅 }\end{array}$ \\
\hline 题 & 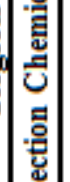 & 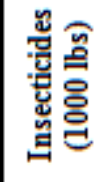 & S & 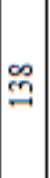 & & & & & & & & & & & శ్ & 脶 & 홍 & 웡 \\
\hline & 章 & 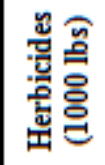 & 总 & 古 & ন্লে & 迆 & & 总 & $\mid \begin{array}{l}\frac{2}{2} \\
\text { กิ }\end{array}$ & 疍 & $\stackrel{\infty}{\circ}$ & & & & క్ & 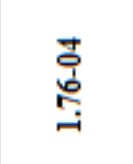 & 宮 & 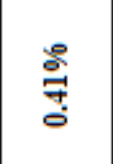 \\
\hline & & 量 & 哭 & $\begin{array}{l}\text { 音 } \\
\text { 章 } \\
\text { 공 }\end{array}$ & 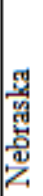 & 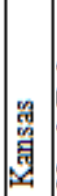 & 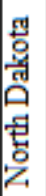 & 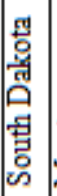 & 賏 & & 鸪 & 照 & 惫 & 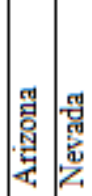 & 롱 & 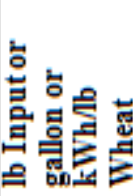 & 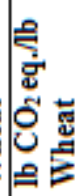 & 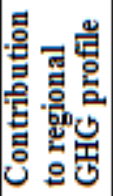 \\
\hline
\end{tabular}




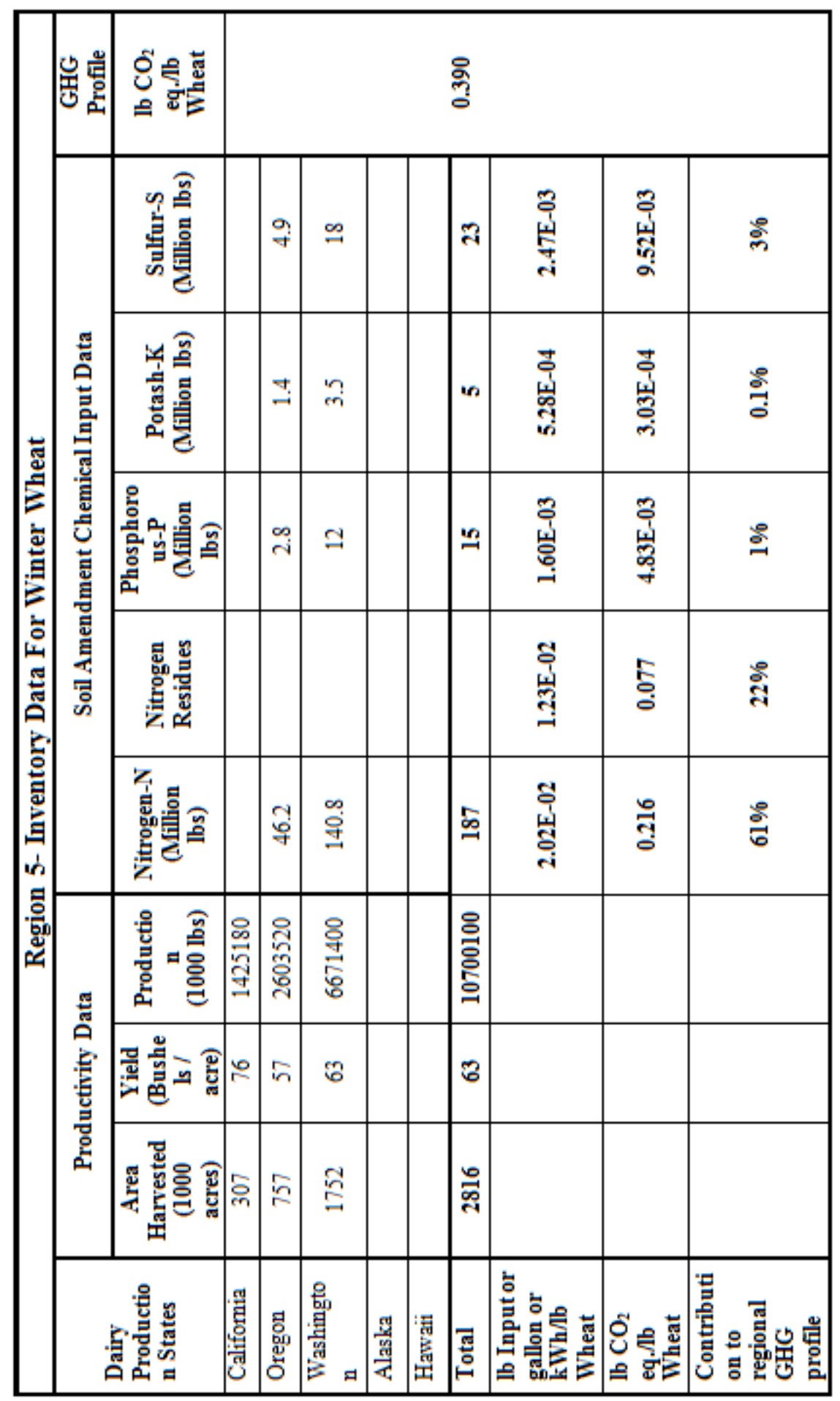




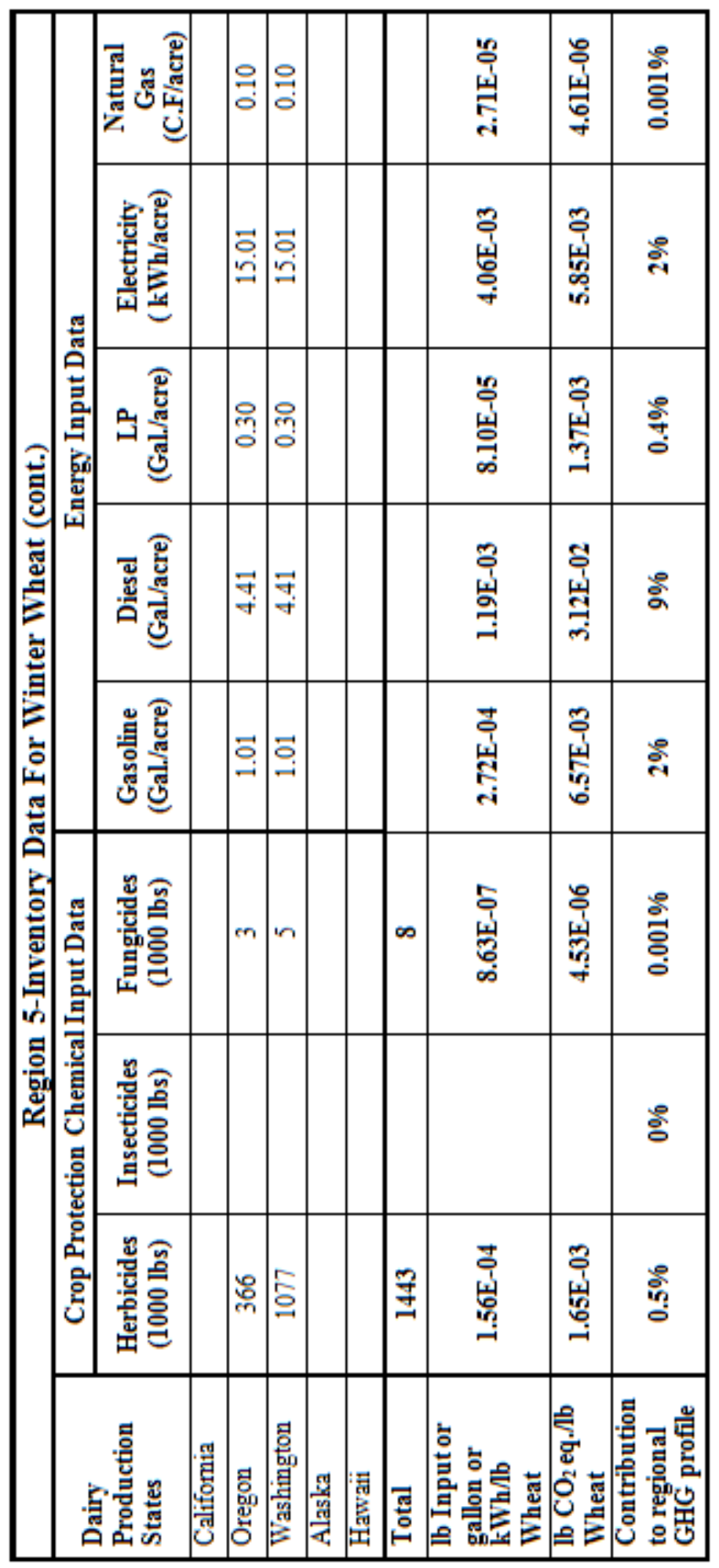


Table D-16 Wet mill / Dry mill dried distillers grains with solubles (DDGS)

\begin{tabular}{|c|c|c|c|c|c|}
\hline & Energy & Mass & Value & $\begin{array}{c}\text { System } \\
\text { Expansion }\end{array}$ & References \\
\hline $\begin{array}{l}\text { Allocation to Corn Ethanol } \\
\text { (Wet mill) }\end{array}$ & 0.61 & 0.49 & 0.76 & 0.8 & \multirow[t]{2}{*}{ Kim. S., Dale. B. E., (2002) } \\
\hline \begin{tabular}{|l|} 
Allocation to Corn Ethanol \\
(Dry mill)
\end{tabular} & 0.57 & 0.48 & 0.7 & 0.8 & \\
\hline Allocation to DDGS (Wet mill) & 0.39 & 0.51 & 0.24 & 0.2 & \multirow{2}{*}{$\begin{array}{l}\text { Estimated from corn and } \\
\text { ethanol allocation }\end{array}$} \\
\hline Allocation to DDGS (Dry mill) & 0.43 & 0.52 & 0.3 & 0.2 & \\
\hline \multirow{3}{*}{ Corn Ethanol } & \multicolumn{4}{|c|}{$0.0849 \mathrm{~kg} \mathrm{CO} \mathrm{Cq}_{2} / \mathrm{MJ} \mathrm{EtOH}$} & Hill, Tillman et al. PNAS 2006 \\
\hline & \multicolumn{4}{|c|}{$0.07 \mathrm{~kg} \mathrm{CO}_{2} \mathrm{eq} / \mathrm{MJ} \mathrm{EtOH}$} & $\begin{array}{l}\text { Wang, M. GREET } 1.6 \text { report, } \\
2001\end{array}$ \\
\hline & \multicolumn{4}{|c|}{$0.062 \mathrm{~kg} \mathrm{CO} 2$ eq / MJ EtOH } & Shapouri et al. 2003 \\
\hline \multicolumn{5}{|c|}{$0.914 \mathrm{~kg}$ dry DDGS / kg corn ethanol } & $\begin{array}{l}\text { Hill, Tillman et al. PNAS } 2006 \\
\text { Table } 9\end{array}$ \\
\hline \multicolumn{5}{|l|}{$26.8 \mathrm{MJ} / \mathrm{kg}$ ethanol } & $\begin{array}{l}\text { CONCAWE WTT Appendix } 1 \\
\text { pg } 11 .\end{array}$ \\
\hline
\end{tabular}

Table D-17 GHG emissions on basis of $\mathrm{kgCO}_{2} \mathrm{e} / \mathrm{MJ}$ Ethanol

\begin{tabular}{|c|c|c|c|c|}
\hline & \multicolumn{4}{|c|}{ GHG Emissions $\mathrm{kg} \mathrm{CO}_{2} \mathrm{eq} / \mathrm{MJ}$ Ethanol } \\
\hline & Energy & Mass & Value & System \\
\hline \multirow{3}{*}{ DDGS (WET MILL) } & 0.054 & 0.088 & 0.027 & 0.021 \\
\hline & 0.045 & 0.073 & 0.022 & 0.018 \\
\hline & 0.040 & 0.065 & 0.020 & 0.016 \\
\hline \multirow{3}{*}{ DDGS (DRY MILL) } & 0.064 & 0.092 & 0.036 & 0.021 \\
\hline & 0.053 & 0.076 & 0.030 & 0.018 \\
\hline & 0.047 & 0.067 & 0.027 & 0.016 \\
\hline \multicolumn{3}{|c|}{ Wet Mill, DDGS GHG Emissions } & $\begin{array}{l}2.2065 \\
1.3554 \\
0.6695 \\
0.5300 \\
\end{array}$ & $\begin{array}{l}\mathrm{kg} \mathrm{CO} \mathrm{CO}_{2} \text { eq / kg dry DDGS -Mass } \\
\mathrm{kg} \mathrm{CO}_{2} \text { eq / kg dry DDGS -Energy } \\
\mathrm{kg} \mathrm{CO}_{2} \text { eq / kg dry DDGS -Value } \\
\mathrm{kg} \mathrm{CO}_{2} \text { eq / kg dry DDGS -System }\end{array}$ \\
\hline \multicolumn{3}{|c|}{ Dry Mill, DDGS GHG Emissions } & $\begin{array}{l}2.2966 \\
1.5993 \\
0.9086 \\
0.5300\end{array}$ & $\begin{array}{l}\mathrm{kg} \mathrm{CO}_{2} \text { eq / kg dry DDGS -Mass } \\
\mathrm{kg} \mathrm{CO}_{2} \text { eq / kg dry DDGS -Energy } \\
\mathrm{kg} \mathrm{CO}_{2} \text { eq / kg dry DDGS -Value } \\
\mathrm{kg} \mathrm{CO}_{2} \text { eq / kg dry DDGS -System }\end{array}$ \\
\hline
\end{tabular}




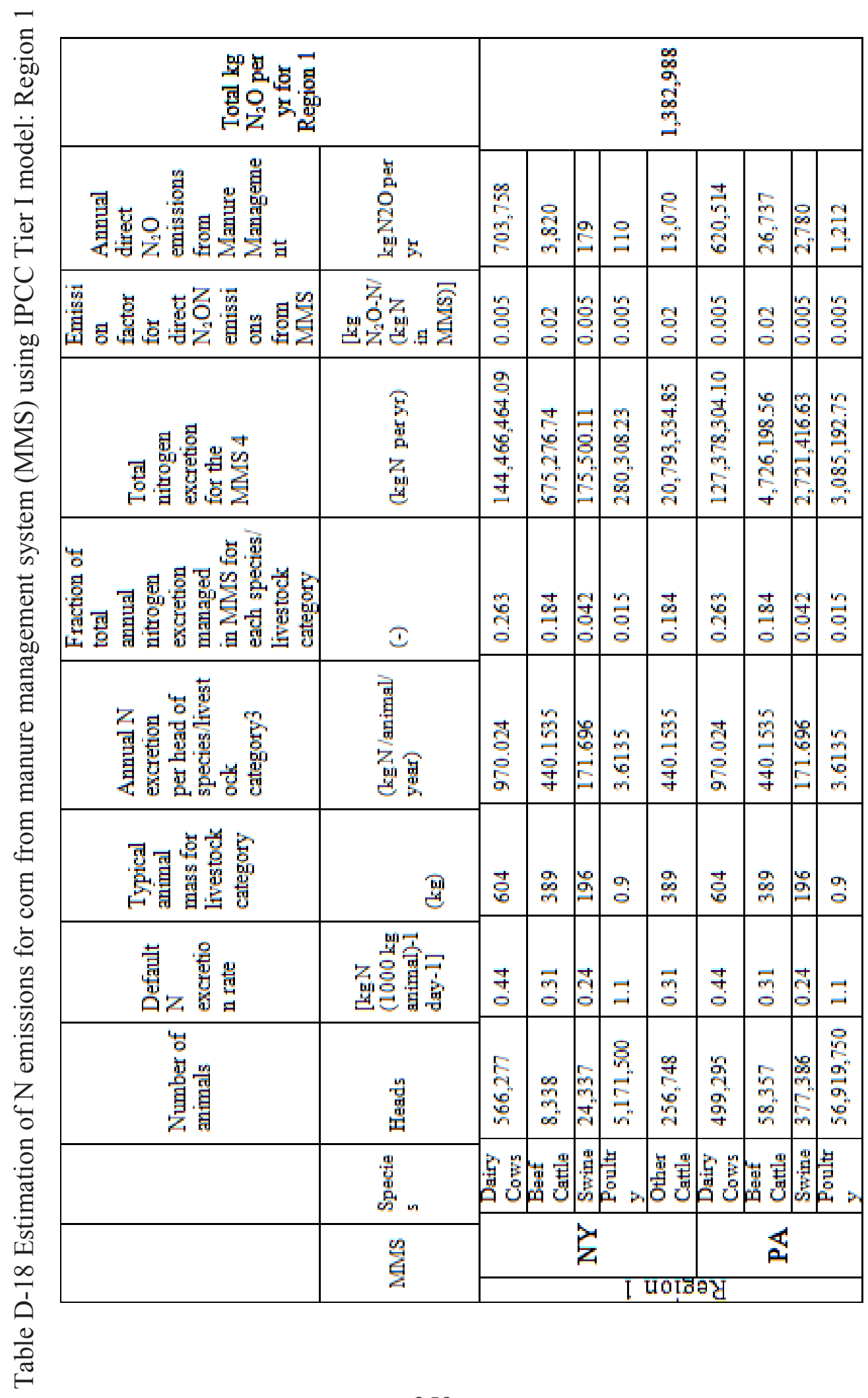




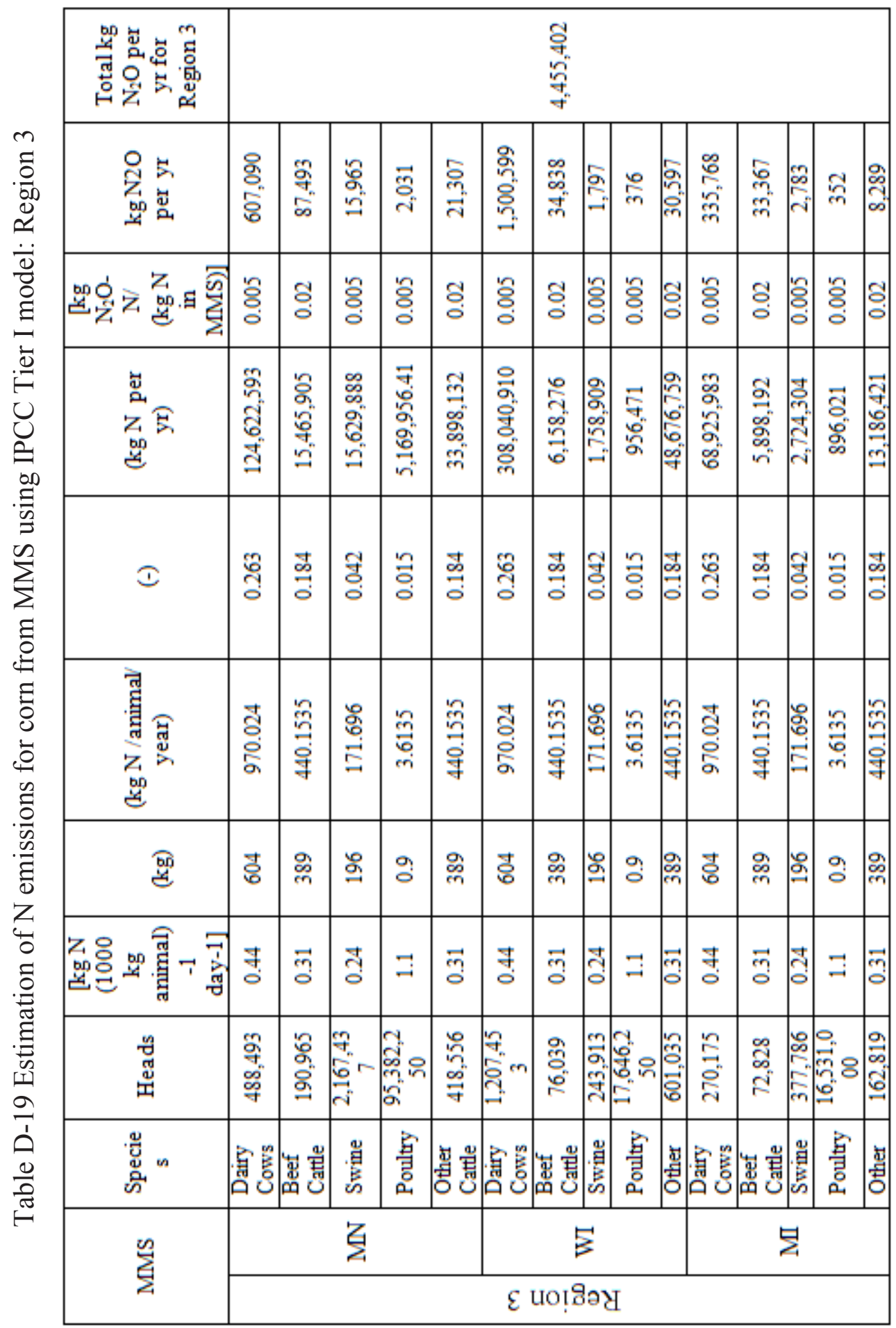




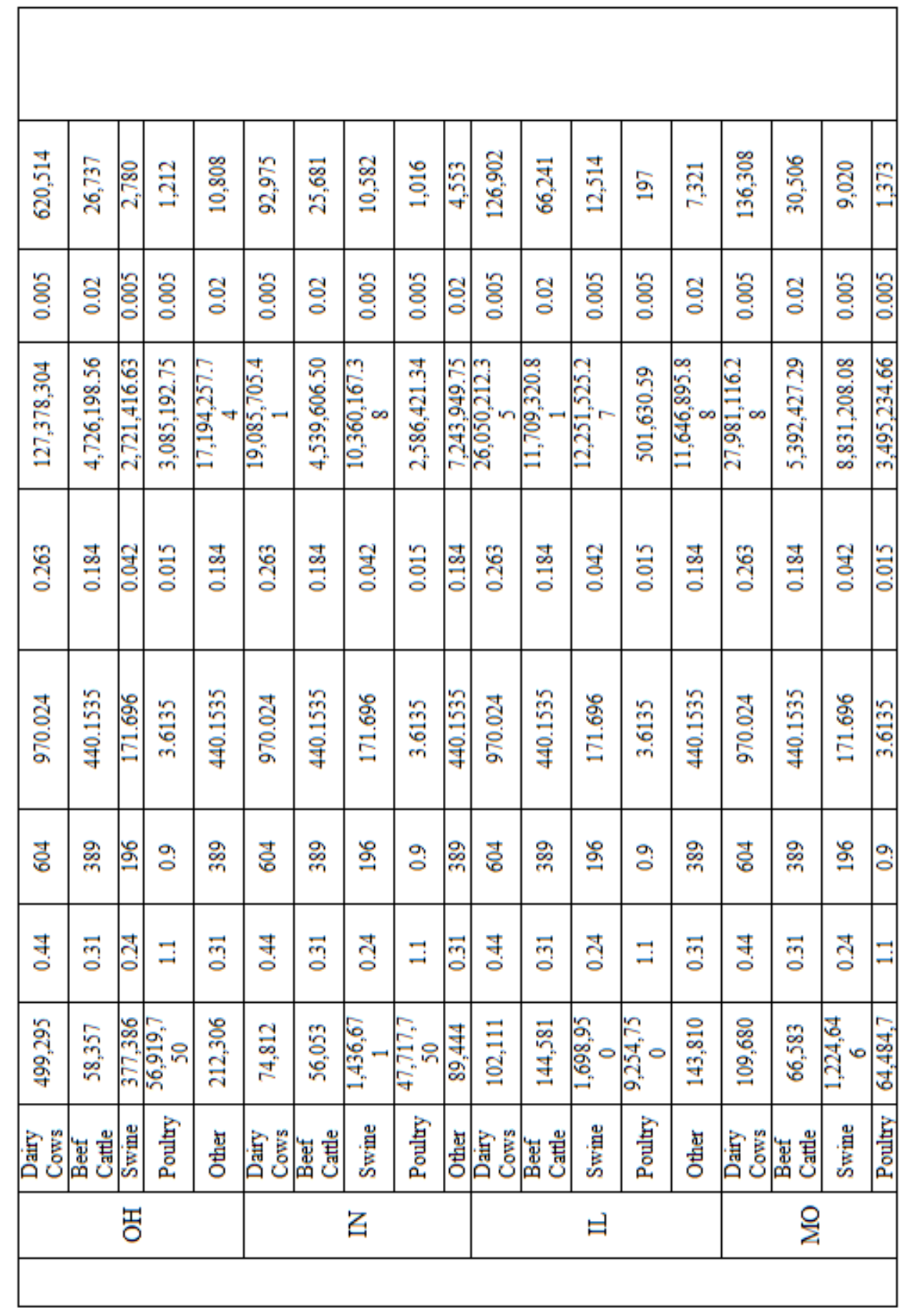




\begin{tabular}{|c|c|c|c|c|c|c|}
\hline & 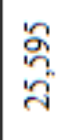 & $\begin{array}{l}\vec{y} \\
\tilde{\sigma} \\
\tilde{\sigma}\end{array}$ & $\begin{array}{l}\circ \\
2 \\
6 \\
6 \\
8\end{array}$ & 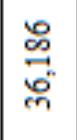 & 吕 & $\left|\begin{array}{l}\vec{y} \\
2 \\
0 \\
\hdashline\end{array}\right|$ \\
\hline & 응 & 용 & $\stackrel{8}{\circ}$ & 'ㅇㅇㅇ & 웅 & 영 \\
\hline & 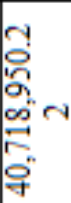 & 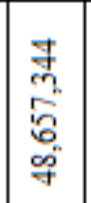 & 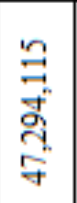 & 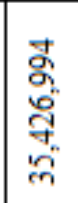 & 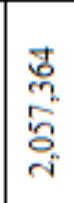 & 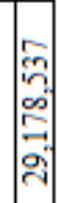 \\
\hline & $\begin{array}{l}\text { 总 } \\
\stackrel{0}{\circ}\end{array}$ & ণ্ণ & 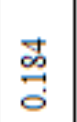 & 궁 & 응 & 志 \\
\hline & 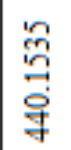 & 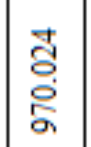 & 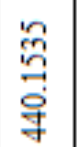 & $\begin{array}{l}\text { 吕 } \\
\stackrel{-}{\Xi} \\
\end{array}$ & 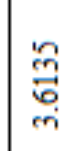 & 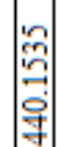 \\
\hline & 䈀 & 항 & 鼡 & 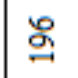 & $\stackrel{9}{\circ}$ & 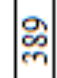 \\
\hline & $\vec{m}$ & 寻 & $\vec{m}$ & ปุํํ & $\rightrightarrows$ & $\vec{m}$ \\
\hline 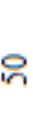 & 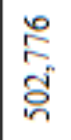 & 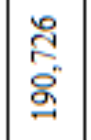 & 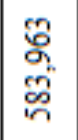 & 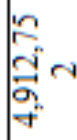 & 总。 & $\mid \begin{array}{l}\vec{\infty} \\
\text { â } \\
8 \\
\text { c }\end{array}$ \\
\hline & 营 & 舅商 & 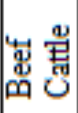 & 总 & 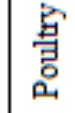 & 章 \\
\hline & & \multicolumn{5}{|c|}{ 음 } \\
\hline
\end{tabular}




\begin{tabular}{|c|c|c|c|c|c|c|c|c|c|c|c|c|c|}
\hline 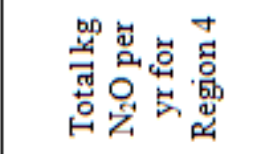 & & & & & & & $\begin{array}{l}m \\
m \\
m \\
\infty \\
\infty \\
m \\
m\end{array}$ & & & & & & \\
\hline 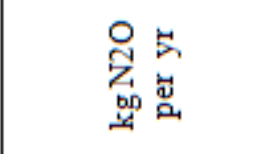 & 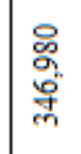 & \begin{tabular}{l}
\multirow{2}{2}{} \\
을
\end{tabular} & 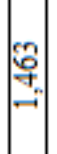 & 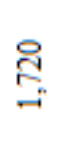 & $\begin{array}{l}\text { 'न } \\
\text { m. } \\
\text { on }\end{array}$ & \begin{tabular}{l}
$\infty$ \\
$\infty$ \\
\hdashline \\
8
\end{tabular} & 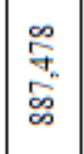 & $\overrightarrow{8}$ & 䱩 & $\underset{E}{E}$ & 管 & & ఏ్ \\
\hline 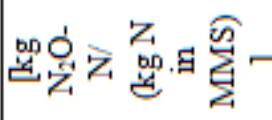 & '̊ㅇㅇㅇ & 용 & : & '용 & $\stackrel{3}{\circ}$ & '̊ㅇㅇㅇ & 웅 & 'ò & '용 & $\stackrel{8}{\circ}$ & '̊̀̊ & 영 & '0े \\
\hline 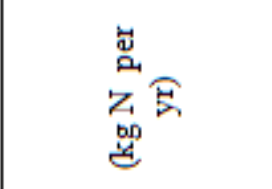 & 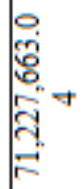 & 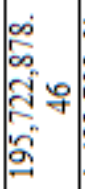 & 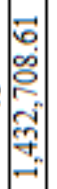 & 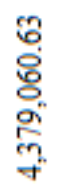 & 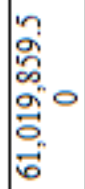 & 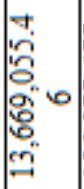 & 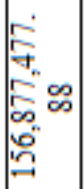 & 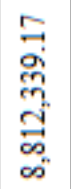 & 吕 & 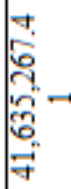 & 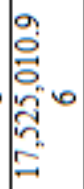 & 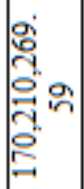 & : \\
\hline I & ֻัণิ & $\stackrel{ \pm}{\stackrel{ \pm}{二}}$ & 永 & 응 & 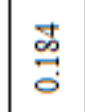 & ๙্ণ & $\stackrel{ \pm}{\stackrel{\$}{二}}$ & 궁 & 号 & $\stackrel{ \pm}{\stackrel{5}{\circ}}$ & 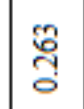 & $\stackrel{+}{\stackrel{D}{二}}$ & 楁 \\
\hline 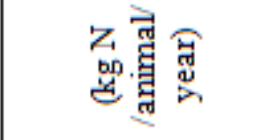 & 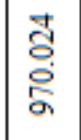 & 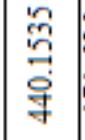 & 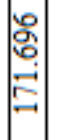 & & $\begin{array}{l}\text { '̂ } \\
\text { 官 } \\
\text { 早 }\end{array}$ & \begin{tabular}{l}
\multirow{2}{0}{} \\
$\stackrel{8}{\circ}$ \\
$\stackrel{5}{\circ}$
\end{tabular} & 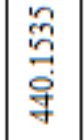 & 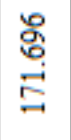 & 年 & 瓷 & 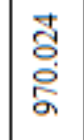 & 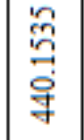 & 迢 \\
\hline बु & 范 & 鬲 & 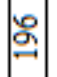 & $\stackrel{9}{\circ}$ & 鬲 & 용 & 命 & $\stackrel{2}{\stackrel{2}{2}}$ & 9 & 命 & 용 & 命 & ఏ \\
\hline 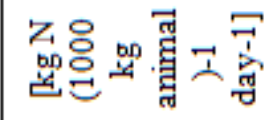 & 志 & $\vec{n}$ & 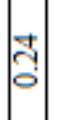 & $\exists$ & $\vec{m}$ & $\underset{0}{7}$ & $\vec{m}$ & तु & $\rightrightarrows$ & $\vec{m}$ & J & & స़े \\
\hline 总 & $\begin{array}{l}5 \\
\text { à } \\
\text { à }\end{array}$ & 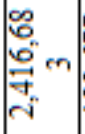 & $\mid$ & 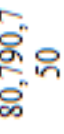 & 寻 & $\begin{array}{l}\text { } \\
\sim \\
\text { nn }\end{array}$ & \begin{tabular}{l}
0 \\
0 \\
0 \\
0 \\
2 \\
\hdashline
\end{tabular} & 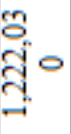 & 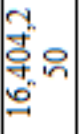 & $\begin{array}{l}8 \\
\text { 量 } \\
\text { i }\end{array}$ & $\begin{array}{l}\text { 音 } \\
\text { o. } \\
0\end{array}$ & 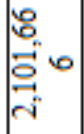 & 照 \\
\hline 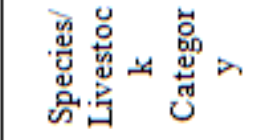 & 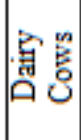 & 岁 & 竞 & 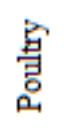 & 苛焉 & 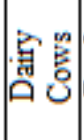 & 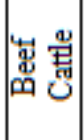 & 量 & 急 & 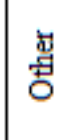 & 窞高 & 岁 密 & 总 \\
\hline \multirow{2}{*}{ 尝 } & \multicolumn{5}{|c|}{$\ddot{\Theta}$} & \multicolumn{5}{|c|}{ 㞱 } & \multicolumn{3}{|c|}{$\approx$} \\
\hline & \multicolumn{13}{|c|}{ 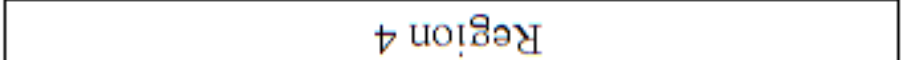 } \\
\hline
\end{tabular}




\begin{tabular}{|c|c|c|c|c|c|c|c|c|c|c|c|c|c|c|}
\hline 응 & $\begin{array}{l}\text { ga } \\
\text { c } \\
\text { g }\end{array}$ & $\begin{array}{l}\text { J } \\
\text { ल } \\
\text { से }\end{array}$ & $\begin{array}{l}\text { s. } \\
\text { 'ू̆ }\end{array}$ & $\mid$ & $\stackrel{\infty}{\infty}$ & $\begin{array}{l}\tilde{z} \\
\text { ปे }\end{array}$ & ฮ & 'g & 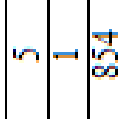 & 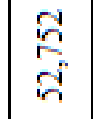 & $\begin{array}{l}\text { 总 } \\
\text { 号 }\end{array}$ & f & S & $\overrightarrow{8}$ \\
\hline '气̊̆ & 웅 & '̊ㅇㅇ & 웅 & | & '̊̀े & $\stackrel{8}{\circ}$ & '용 & $\stackrel{8}{\circ}$ & 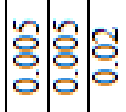 & 'ㅇํㅇ & 웅 & : & '용 & - \\
\hline 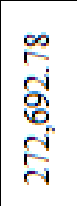 & 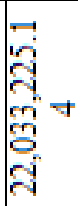 & 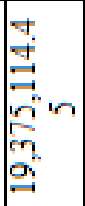 & 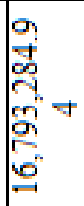 & 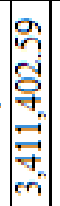 & 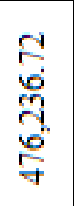 & 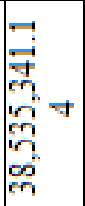 & 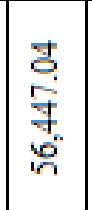 & $\begin{array}{c}\text { ñ. } \\
\text { 苛 } \\
\text { तี }\end{array}$ & 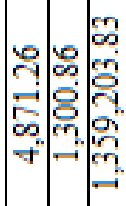 & 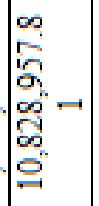 & 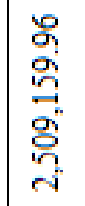 & 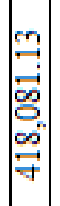 & 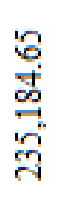 & 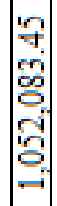 \\
\hline 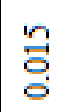 & $\begin{array}{l}\stackrel{+}{\circ} \\
\stackrel{0}{\circ}\end{array}$ & $\begin{array}{l}\text { हैं } \\
\text { तु }\end{array}$ & 䓌 & 势 & $\stackrel{2}{\circ}$ & $\stackrel{ \pm}{\stackrel{ \pm}{二}}$ & ণ্ণ & 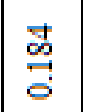 & 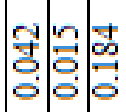 & 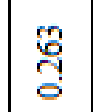 & 志 & 羿 & ?ํㅇㅇ & 竞 \\
\hline 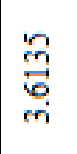 & 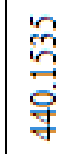 & 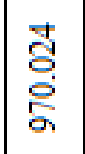 & 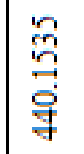 & $\mid$\begin{tabular}{l}
8 \\
8 \\
8 \\
\hdashline \\
\hdashline
\end{tabular} & 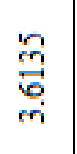 & 哭 & \begin{tabular}{l}
\multirow{2}{0}{} \\
$\stackrel{8}{\circ}$ \\
S.
\end{tabular} & $\begin{array}{l}\text { 目 } \\
\stackrel{2}{\circ} \\
\text { 导 }\end{array}$ & 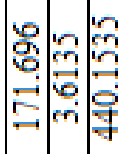 & \begin{tabular}{l}
\multirow{2}{0}{} \\
$\stackrel{8}{\circ}$ \\
S.
\end{tabular} & 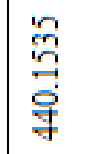 & $\mid$ & 角 & , \\
\hline 웅 & 鬲 & 훙 & 鬲 & $\stackrel{2}{\cong}$ & $\stackrel{9}{\circ}$ & 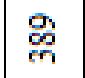 & 훙 & 蛗 & : & 훙 & 总 & 高 & 9 & 泾 \\
\hline$\rightrightarrows$ & $\stackrel{\vec{\xi}}{0}$ & 寸ै & $\vec{m}$ & ㄱ. & $\rightrightarrows$ & $\vec{n}$ & ปे & $\vec{n}$ & तु & 守 & $\vec{m}$ & $\begin{array}{l}\text { ते } \\
\text { o }\end{array}$ & $\rightrightarrows$ & $\vec{n}$ \\
\hline 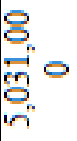 & $\begin{array}{l}\text { 㔯 } \\
\text { 究 }\end{array}$ & $\begin{array}{l}\text { 音 } \\
\text { s. } \\
2\end{array}$ & $\begin{array}{l}n \\
\text { ñ } \\
\text { ิ }\end{array}$ & $\mid$ & $\begin{array}{l}2 \\
2 \\
\infty \\
\infty \\
\infty \\
\infty \\
\infty\end{array}$ & 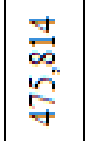 & $\overrightarrow{\mathrm{d}}$ & 曹 & 닐 & $\begin{array}{l}\text { f } \\
\text { f } \\
\text { f }\end{array}$ & 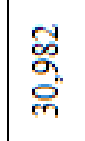 & 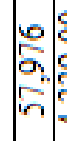 & $\begin{array}{l}8 \\
\text { gin } \\
\text { m. } \\
\text { ti }\end{array}$ & 혼 \\
\hline 葛 & 章 & 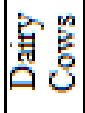 & 蓆㽦 & 罗 & 害 & 泀 & 至量 & 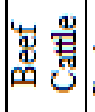 & 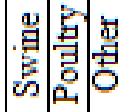 & 帘品 & 岁㽦 & 变 & 总 & 䗆 \\
\hline & & \multicolumn{5}{|c|}{ ค } & \multicolumn{3}{|c|}{ ○ } & \multicolumn{5}{|c|}{ 豆 } \\
\hline
\end{tabular}


Table D-21 U.S. annual consumption of selected nitrogen materials from 2004-2007 (short tons $\mathrm{N}$ fertilizer)

\begin{tabular}{|l|c|c|c|c|}
\cline { 2 - 5 } \multicolumn{1}{c|}{} & 2004 & 2005 & 2006 & 2007 \\
\hline Anhydrous Ammonia & $4,068,586$ & $3,857,891$ & $3,821,691$ & $4,249,988$ \\
\hline Aqua Ammonia & 521,181 & 420,879 & 397,647 & 373,817 \\
\hline Ammonium Nitrate & $1,527,964$ & $1,420,653$ & 963,710 & $1,056,148$ \\
\hline Ammonium Sulfate & $1,229,569$ & $1,181,609$ & $1,218,964$ & $1,382,310$ \\
\hline Nitrogen solutions & $11,195,765$ & $10,499,854$ & $10,104,319$ & $11,970,556$ \\
\hline Sodium Nitrate & 16,798 & 21,353 & 17,219 & 13,041 \\
\hline Urea & $5,644,619$ & $5,211,665$ & $5,369,913$ & $5,722,579$ \\
\hline Other & $2,752,062$ & $2,629,043$ & $2,839,576$ & $2,491,535$ \\
\hline
\end{tabular}

Table D-22 Fertilizer Mixtures used in this study ( $\mathrm{N}$ fertilizer). Note that the values do not add to 1.0 because ammonia is on a total compound weight basis while all others are on weight of $\mathrm{N}$ only basis

\begin{tabular}{|l|l|c|l|}
\hline \multirow{5}{*}{$\begin{array}{l}\text { US Nitrogen } \\
\text { fertilizer Mix }\end{array}$} & $\begin{array}{c}\text { kg N in N } \\
\text { fertilizer } / \mathrm{kg} \\
\mathrm{N} \text { in national } \\
\text { mix of N }\end{array}$ & EcoInvent Unit Process \\
\cline { 2 - 4 } $\begin{array}{l}\text { Fitrogen } \\
\text { Fertilizers }\end{array}$ & 0.308 & Ammonia, liquid, at region storehouse/RER U \\
\cline { 2 - 4 } & $\begin{array}{l}\text { Ammydrous } \\
\text { Aqua }\end{array}$ & 0.008 & Ammonia, liquid, at regional storehouse/RER U \\
\cline { 2 - 4 } & Ammonium nitrate & 0.038 & Ammonium nitrate, as N, at regional storehouse/RER \\
\cline { 2 - 4 } & Ammonium sulfate & 0.025 & Ammonium sulfate, as N, at regional \\
\cline { 2 - 4 } & Nitrogen Solution & 0.166 & $\begin{array}{l}\text { Urea, as N, at regional storehouse/RER U } \\
\text { Ammonium nitrate, as N, at regional storehouse/RER }\end{array}$ \\
\cline { 2 - 4 } & Sodium Nitrate & 0.132 & Potassium nitrate, as N, at regional storehouse/RER \\
\cline { 2 - 4 } & Urea & 0.0003 & Lrea, as N, at regional storehouse/RER U \\
\cline { 2 - 4 } & Other & 0.086 & Liquid ammonia, ammonium nitrate and urea \\
\hline
\end{tabular}


Table D-23 Fertilizer mixtures used in this study (P.K.S fertilizer)

\begin{tabular}{|c|c|c|}
\hline & $\begin{array}{l}\text { Amount } \\
(\mathrm{kg})\end{array}$ & EcoInvent Unit Process \\
\hline Phosphorous (P) & $\begin{array}{l}0.0104 \\
0.2767 \\
0.3741 \\
0.3178 \\
0.0210\end{array}$ & $\begin{array}{l}\text { Single superphosphate, as } \\
\mathrm{P}_{2} \mathrm{O}_{5} / \text { RER U } \\
\text { Ammonium nitrate phosphate, as } \mathrm{P}_{2} \mathrm{O}_{5} / \text { RER } \\
\mathrm{U} \\
\text { Diammonium phosphate, as } \\
\mathrm{P}_{2} \mathrm{O}_{5} / \text { RER U }\end{array}$ \\
\hline Potassium (K) & $\begin{array}{l}0.90 \\
0.05 \\
0.05\end{array}$ & $\begin{array}{l}\text { Potassium chloride, as } \\
\mathrm{K}_{2} \mathrm{O} / \mathrm{RER} \text { U Potassium } \\
\text { hydroxide / RER U }\end{array}$ \\
\hline Sulfur (S) & 1 & $\begin{array}{l}\text { Potassium sulfate, as } \mathrm{K}_{2} \mathrm{O} / \mathrm{RER} \mathrm{U} \\
\text { Sulfur is applied as } \mathrm{K}_{2} \mathrm{SO}_{4} \text {. }(32 \mathrm{~g} \mathrm{~S} \text { applied per } 110 \mathrm{~g} \mathrm{~K} 2 \mathrm{O} \text {, } \\
\left.\text { equivalent to } 174 \mathrm{~g} \mathrm{~K}_{2} \mathrm{SO}_{4} \text {. }\right)\end{array}$ \\
\hline
\end{tabular}

NB: Potassium (K) - Consumption data of potash in the US comprise of potassium chloride and other single nutrients. Personal communication with USDA indicates that single nutrients are made up of lime-potash mixture and manure salts. A 50: 50 composition was assumed between $\mathrm{KOH}$ and lime for this analysis

Table D-24 Estimation of nitrogen emission from major crop residues using IPPC Tier I model soybean (SB)

\section{IPCC Tier 1 Model Crop Residue Estimation For Soybean}

\begin{tabular}{|c|c|c|c|c|c|c|}
\hline & \multicolumn{3}{|c|}{$\begin{array}{c}\text { Nitrogen Emissions for SB } \\
\text { Residue }\end{array}$} \\
\hline & & & & Region 2 & $\begin{array}{c}\text { Region } \\
3 \\
\end{array}$ & Region 4 \\
\hline \multirow{12}{*}{\multicolumn{4}{|c|}{$\begin{array}{l}\text { Bushel of SB/acre } \\
\mathrm{kg} \mathrm{dm} \mathrm{SB} \mathrm{/} \mathrm{ha} \\
\mathrm{Mg} \mathrm{dm} \mathrm{SB} \mathrm{/} \mathrm{ha} \\
\mathrm{Mg} \mathrm{dm} \mathrm{SB} \mathrm{residue} \mathrm{/} \mathrm{ha} \\
\mathrm{Mg} \mathrm{dm} \mathrm{residue} \mathrm{/} \mathrm{Mg} \mathrm{dm} \mathrm{harvested} \mathrm{SB} \\
\mathrm{kg} \mathrm{N} \text { content / } \mathrm{kg} \mathrm{SB} \mathrm{dm} \mathrm{residue} \mathrm{above} \mathrm{ground} \\
\mathrm{kg} \mathrm{N} \text { content / } \mathrm{kg} \mathrm{SB} \mathrm{dm} \mathrm{residue} \mathrm{below} \mathrm{ground} \\
\mathrm{kg} \text { below ground dm SB residue / above ground } \\
\mathrm{dm} \text { SB residue } \\
\mathrm{kg} \mathrm{N} \text { in above and below ground dm SB residue / } \\
\mathrm{kg} \mathrm{dm} \mathrm{SB} \mathrm{harvested} \\
\mathrm{g} \mathrm{N} / \mathrm{bushel} \\
\mathrm{kg} \mathrm{N} \text { in above and below ground dm SB residue / } \\
\mathrm{kg} \mathrm{SB} \text { harvested }\end{array}$}} & 29 & 45 & 32 \\
\hline & & & & 1791 & 2757 & 1964 \\
\hline & & & & 1.791 & 2.757 & 1.964 \\
\hline & & & & 3.015 & 3.914 & 3.177 \\
\hline & & & & 1.684 & 1.420 & 1.617 \\
\hline & & & & 0.008 & 0.008 & 0.008 \\
\hline & & & & 0.008 & 0.008 & 0.008 \\
\hline & & & & 0.190 & 0.190 & 0.190 \\
\hline & & & & & 0.014 & \\
\hline & & & & $\begin{array}{l}0.010 \\
436\end{array}$ & $\begin{array}{c}0.014 \\
368\end{array}$ & $\begin{array}{l}0.015 \\
419\end{array}$ \\
\hline & & & & & & \\
\hline & & & & 0.015 & 0.012 & 0.014 \\
\hline \multicolumn{7}{|c|}{ Conversion factors } \\
\hline \multirow[b]{2}{*}{ Soybean } & slope & intercept & $\mathrm{ac} / \mathrm{ha}$ & $\mathrm{lb} / \mathrm{bu}$ & $\mathrm{lb} / \mathrm{kg}$ & $\begin{array}{c}\mathrm{kg} \mathrm{dm} / \mathrm{kg} \\
\mathrm{SB} \\
\text { harvested }\end{array}$ \\
\hline & 0.93 & 1.35 & 2.47 & 60 & 2.205 & 0.91 \\
\hline
\end{tabular}


Table D-25 Estimation of nitrogen emission from major crop residues using IPPC Tier

\section{IPCC Tier 1 Model Crop Residue Estimation For Corn Grain}

\begin{tabular}{|c|c|c|c|c|c|c|}
\hline & \multicolumn{5}{|c|}{ Nitrogen Emissions for Corn Grain Residues } \\
\hline & & $\begin{array}{c}\text { Region } \\
1\end{array}$ & $\begin{array}{l}\text { Region } \\
\quad 2\end{array}$ & $\begin{array}{l}\text { Region } \\
3\end{array}$ & $\begin{array}{c}\text { Region } \\
4\end{array}$ & Region 5 \\
\hline \multicolumn{2}{|c|}{ Bushel corn grain/ac } & 129 & 126 & 161 & 140 & 189 \\
\hline \multicolumn{2}{|c|}{$\mathrm{kg} \mathrm{dm}$ corn grain / ha } & 7115 & 6967 & 8882 & 7755 & 10427 \\
\hline \multicolumn{2}{|c|}{$\mathrm{Mg}$ dm corn grain/ ha } & 7.115 & 6.967 & 8.882 & 7.755 & 10.427 \\
\hline \multirow{2}{*}{\multicolumn{2}{|c|}{$\begin{array}{l}\mathrm{Mg} \mathrm{dm} \text { corn grain residue / ha } \\
\mathrm{Mg} \mathrm{dm} \text { residue / Mg dm harvested corn } \\
\text { grain }\end{array}$}} & 8.636 & 8.474 & 10.562 & 9.333 & 12.245 \\
\hline & & 1.214 & 1.216 & 1.189 & 1.203 & 1.174 \\
\hline \multicolumn{2}{|c|}{$\begin{array}{l}\mathrm{kg} \mathrm{N} \text { content / } \mathrm{kg} \text { corn grain } \mathrm{dm} \text { residue } \\
\text { above ground }\end{array}$} & 0.006 & 0.006 & 0.006 & 0.006 & 0.006 \\
\hline \multicolumn{2}{|c|}{$\begin{array}{l}\mathrm{kg} \mathrm{N} \text { content } / \mathrm{kg} \text { corn grain } \mathrm{dm} \text { residue } \\
\text { below ground }\end{array}$} & 0.009 & 0.009 & 0.009 & 0.009 & 0.009 \\
\hline \multirow{2}{*}{\multicolumn{2}{|c|}{$\begin{array}{l}\mathrm{kg} \text { below ground } \mathrm{dm} \text { corn grain residue / } \\
\text { above ground dm corn grain residue } \\
\mathrm{kg} \mathrm{N} \text { in above and below ground } \mathrm{dm} \text { corn } \\
\text { grain residue / } \mathrm{kg} \mathrm{dm} \text { corn grain harvested }\end{array}$}} & 0.220 & 0.220 & 0.220 & 0.220 & 0.220 \\
\hline & & 0.010 & 0.010 & 0.009 & 0.010 & 0.009 \\
\hline \multirow{2}{*}{\multicolumn{2}{|c|}{$\begin{array}{l}\mathrm{g} \mathrm{N} / \mathrm{bu} \\
\mathrm{kg} \mathrm{N} \text { in above and below ground dm corn } \\
\text { grain residue / } \mathrm{kg} \text { corn grain harvested }\end{array}$}} & 246 & 247 & 241 & 244 & 238 \\
\hline & & 0.009 & 0.009 & 0.008 & 0.008 & 0.008 \\
\hline \multicolumn{7}{|c|}{ Conversion factors } \\
\hline \multirow[t]{2}{*}{ Corn grain } & Slope & Intercept & $\mathrm{Ac} / \mathrm{Ha}$ & $\mathrm{lb} / \mathrm{Bu}$ & $\mathrm{lb} / \mathrm{kg}$ & $\begin{array}{c}\mathrm{kg} \mathrm{dm} / \mathrm{kg} \\
\text { Corn Grain } \\
\text { Harvested }\end{array}$ \\
\hline & 1.09 & 0.88 & 2.47 & 56 & 2.205 & 0.88 \\
\hline
\end{tabular}

I model corn grain 
Table D-26 Estimation of nitrogen emission from major crop residues using IPPC Tier I model corn silage

IPCC Tier 1 Model Crop Residue Estimation For Corn Silage

\begin{tabular}{|c|c|c|c|c|c|c|}
\hline & \multicolumn{5}{|c|}{ Nitrogen Emissions for Corn silage Residues } \\
\hline & & Region 1 & $\begin{array}{l}\text { Region } \\
2 \\
\end{array}$ & $\begin{array}{c}\text { Region } \\
3 \\
\end{array}$ & $\begin{array}{c}\text { Region } \\
4 \\
\end{array}$ & Region 5 \\
\hline \multirow{10}{*}{\multicolumn{2}{|c|}{$\begin{array}{l}\text { Ton corn silage/ac } \\
\mathrm{kg} \mathrm{dm} \text { corn silage / ha } \\
\mathrm{Mg} \mathrm{dm} \text { corn silage / ha } \\
\mathrm{Mg} \mathrm{dm} \text { corn silage residue / ha } \\
\mathrm{Mg} \mathrm{dm} \text { residue / Mg dm harvested corn } \\
\text { silage } \\
\mathrm{kg} \mathrm{N} \text { content / } \mathrm{kg} \text { corn grain dm residue } \\
\text { above ground } \\
\mathrm{kg} \mathrm{N} \text { content / } \mathrm{kg} \text { corn silage dm residue } \\
\text { below ground } \\
\mathrm{kg} \text { below ground dm corn grain residue / } \\
\text { above ground dm corn silage residue } \\
\mathrm{kg} \mathrm{N} \text { in above and below ground dm corn } \\
\text { grain residue / } \mathrm{kg} \text { dm corn silage harvested } \\
\mathrm{kg} \mathrm{N} \text { in above and below ground dm corn } \\
\text { grain residue / } \mathrm{kg} \text { corn silage harvested }\end{array}$}} & 18 & 16 & 17 & 17 & \\
\hline & & 13879 & 12703 & 13017 & 13095 & \\
\hline & & 13.879 & 12.703 & 13.017 & 13.095 & \\
\hline & & & 3.811 & 3.905 & 3.928 & \\
\hline & & 0.300 & 0.300 & 0.300 & 0.300 & \\
\hline & & 0.006 & 0.006 & 0.006 & 0.006 & \\
\hline & & 0.007 & 0.007 & 0.007 & 0.007 & \\
\hline & & & 0.54 & & & \\
\hline & & & & & & \\
\hline & & 0.00103 & 0.0010 & 0.0010 & 0.0010 & \\
\hline \multicolumn{7}{|c|}{ Conversion factors } \\
\hline & & & & & & \\
\hline \multirow[t]{2}{*}{ Corn silage } & Slope & Intercept & $\mathrm{Ac} / \mathrm{Ha}$ & & $\mathrm{lb} / \mathrm{kg}$ & $\begin{array}{c}\mathrm{kg} \mathrm{dm} / \mathrm{kg} \\
\text { Corn } \\
\text { Silage } \\
\text { Harvested } \\
\end{array}$ \\
\hline & 0.3 & 0 & 2.47 & & 2.205 & 0.88 \\
\hline
\end{tabular}


Table D-27 Estimation of nitrogen emission from major crop residues using IPPC Tier I model oats

\section{IPCC Tier 1 Model Crop Residue Estimation}

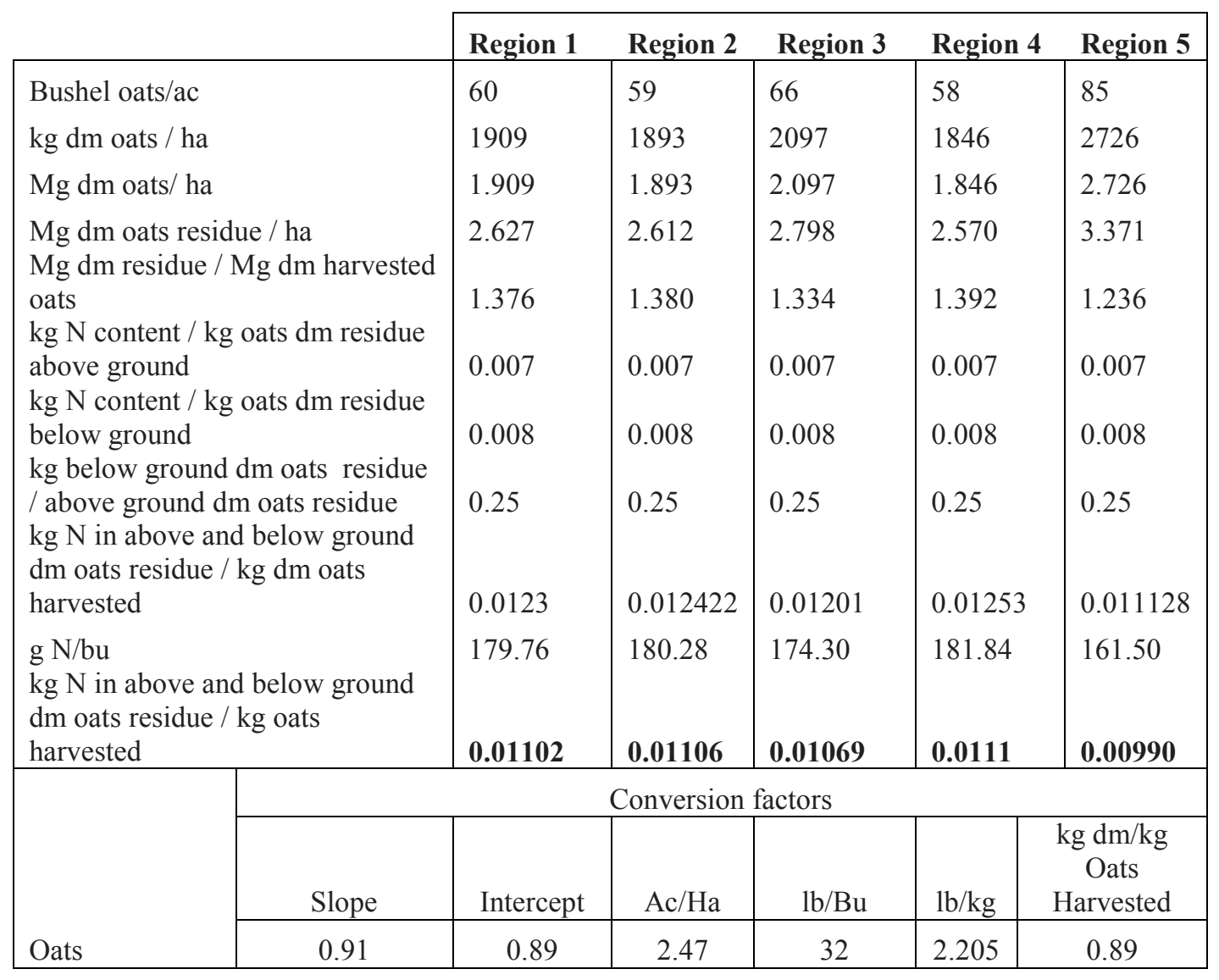


Table D-28 Estimation of nitrogen emission from major crop residues using IPPC Tier I model winter wheat

\section{IPCC Tier 1 Model Crop Residue Estimation}

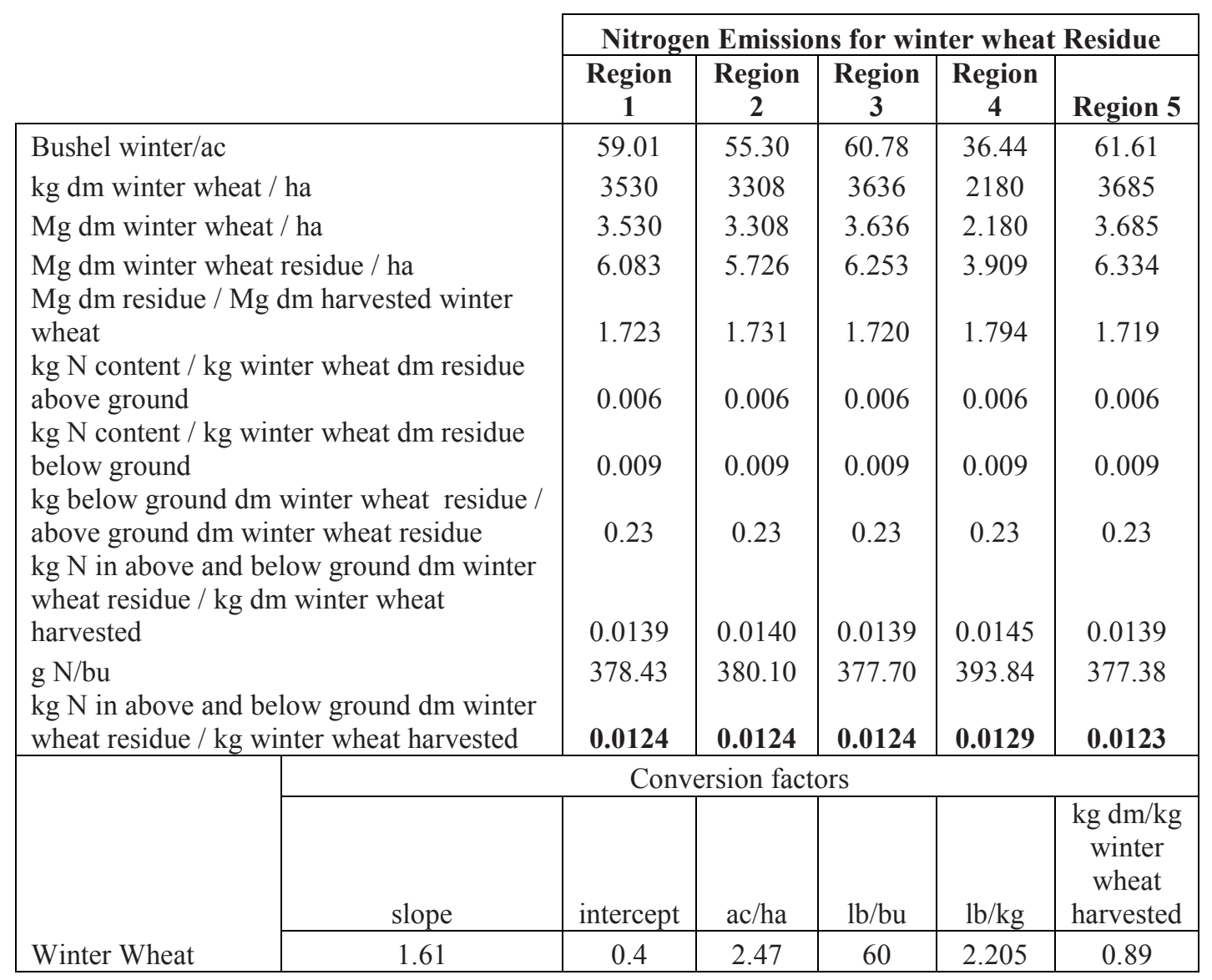


Table D-29 GHG Emission Factors of Pesticides for some major crops (Soybean)

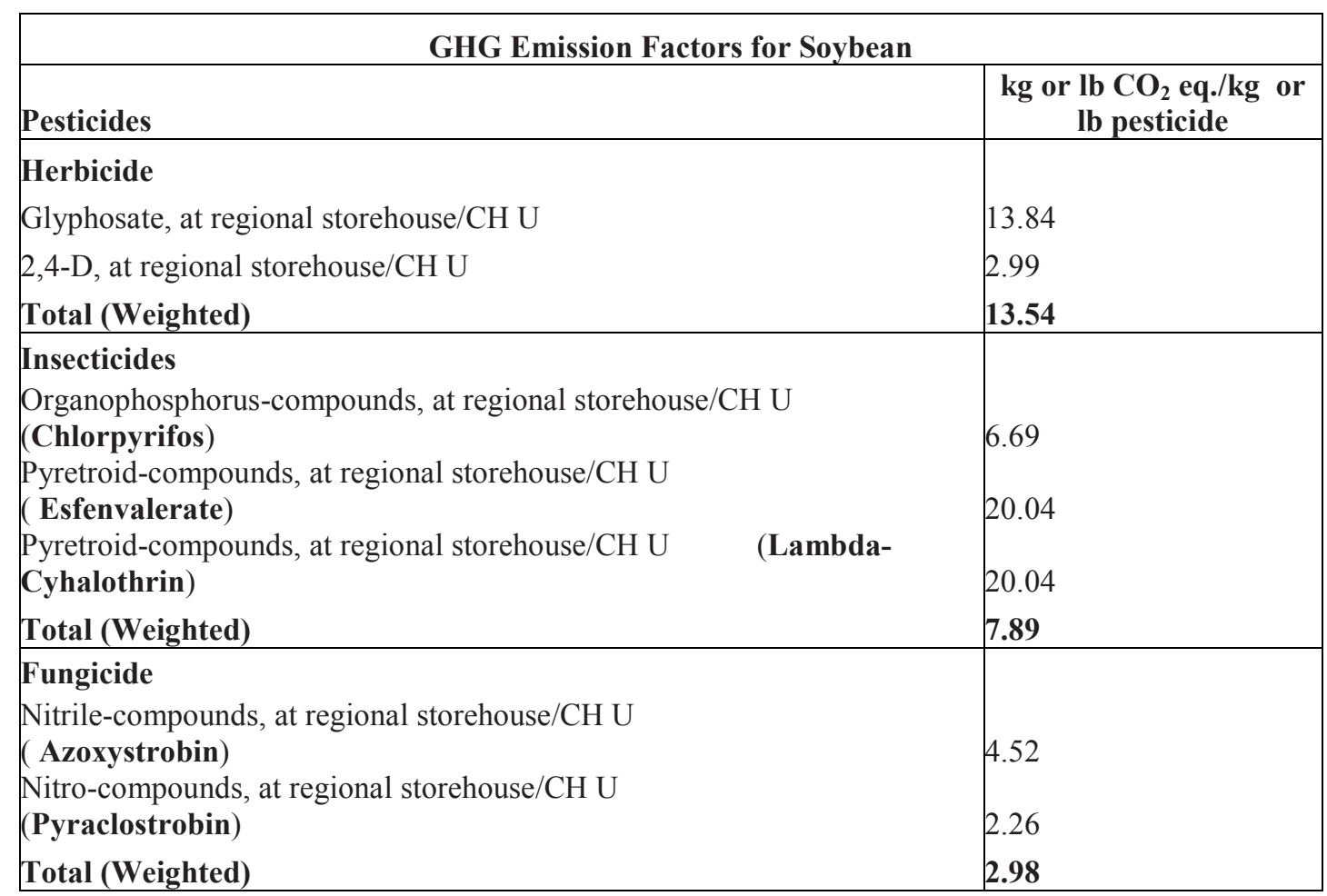

Table D-30 GHG Emission Factors of Pesticides for some major crops (corn grain/silage)

\begin{tabular}{|l|l|}
\hline \multicolumn{2}{|c|}{ GHG Emission Factors for Corn grain/silage } \\
\hline Pesticides & $\begin{array}{l}\text { kg or lb CO} \mathbf{~ e q . / k g ~ o r ~ l b ~} \\
\text { pesticide }\end{array}$ \\
\hline Herbicide & \\
Glyphosate, at regional storehouse/CH U & 13.84 \\
Atrazine, at regional storehouse/CH U & 4.88 \\
S-Metolachlor, at regional storehouse/CH U & 7.72 \\
Acetochlor, at regional storehouse/CH U & 7.72 \\
Total (Weighted) & $\mathbf{7 . 5 5}$ \\
\hline Insecticides & \\
Organophosphorus-compounds, at regional storehouse/CH U & 6.69 \\
(Tebupirimphos) & 20.04 \\
Pyretroid-compounds, at regional storehouse/CH U (Tefluthrin) & 20.04 \\
Pyretroid-compounds, at regional storehouse/CH U (Cyfluthrin) & $\mathbf{1 4 . 1 5}$ \\
Total (Weighted) & \\
\hline
\end{tabular}


Table D-31 GHG Emission Factors of Pesticides for some major crops (oats)

\begin{tabular}{|l|l|}
\hline \multicolumn{2}{|c|}{ GHG Emission Factors for Oats } \\
\hline Agrochemical & $\begin{array}{l}\text { kg or lb CO2 eq./kg or } \\
\text { lb pesticide }\end{array}$ \\
\hline Herbicide & \\
Glyphosate, at regional storehouse/CH U & 13.84 \\
2,4-D, at regional storehouse/CH U (2,4-D,2-EHE) & 2.99 \\
2,4-D, at regional storehouse/CH U (2,4-D,dimeth salt) & 2.99 \\
Total (Weighted) & $\mathbf{6 . 5 2}$ \\
\hline Insecticides & \\
Pyretroid-compounds, at regional storehouse/CH U ( Lambda- & 20.04 \\
Cyhalothrin) & $\mathbf{2 0 . 0 4}$ \\
\hline Total(Weighted) & \\
\hline
\end{tabular}

Table D-32 GHG Emission Factors of Pesticides for some major crops (winter wheat)

\begin{tabular}{|c|c|}
\hline \multicolumn{2}{|l|}{ GHG Emission Factors for winter wheat } \\
\hline Pesticides & $\begin{array}{l}\text { kg or lb CO2 eq./kg } \\
\text { or lb pesticide }\end{array}$ \\
\hline Herbicide & \\
\hline Glyphosate, at regional storehouse/CH U & 13.84 \\
\hline 2,4-D, at regional storehouse/CH U (2,4-D,2-EHE) & 2.99 \\
\hline $\begin{array}{l}\text { 2,4-D, at regional storehouse/CH U (2,4-D,dimeth salt) } \\
\text { [sulfonyl]urea-compounds, at regional storehouse/RER U } \\
\text { (Metsulfuronmethyl) }\end{array}$ & 9.23 \\
\hline Total (Weighted) & 10.594 \\
\hline $\begin{array}{l}\text { Insecticides } \\
\text { Organophosphorus-compounds, at regional storehouse/RER U } \\
\text { (Chlorpyrifos) }\end{array}$ & 6.69 \\
\hline Total & 0.0506 \\
\hline Fungicide & \\
\hline Nitro-compounds, at regional storehouse/RER U (Pyraclostrobin) & 2.26 \\
\hline $\begin{array}{l}\text { cyclic N-compounds, at regional storehouse/RER U (Propiconazole) } \\
\text { acetamide-anillide-compounds, at regional storehouse /RER U } \\
\text { (Azoxystrobin) }\end{array}$ & 4.53 \\
\hline Total (Weighted) & 5.25 \\
\hline
\end{tabular}


Table D-33 Pedigree matrix for Soybean

\begin{tabular}{|c|c|c|}
\hline \multicolumn{3}{|c|}{ Data Quality Indicator (DQI) For Inorganic Fertilizer inputs } \\
\hline Indicator & Score & Explanation \\
\hline Reliability & 2 & $\begin{array}{l}\text { The data source is official from the USDA which was obtained } \\
\text { by NASS through the annual Agricultural Resource } \\
\text { Management Survey (ARMS) }\end{array}$ \\
\hline Completeness & 2 & $\begin{array}{l}\text { Out of } 31 \text { U.S states producing Soybean, } 19 \text { of them had their } \\
\mathrm{N}, \mathrm{P}, \mathrm{K}, \mathrm{S} \text { input reported representing over } 50 \% \text { for year } \\
\text { period considered. This is adequate to cover fluctuations due to } \\
\text { different farm practices. }\end{array}$ \\
\hline $\begin{array}{l}\text { Temporal } \\
\text { Correlation }\end{array}$ & 1 & $\begin{array}{l}\text { Data covers year of study (2006). Original goal was to obtain } \\
\text { chemical/fertilizer input for the most recent year (2009), but } \\
\text { the most recent obtained was for } 2006 \text {. }\end{array}$ \\
\hline $\begin{array}{l}\text { Geographical } \\
\text { correlation }\end{array}$ & 1 & $\begin{array}{l}\text { Data was obtained from soybean producing farms in the } \\
\text { United States.(Our interest here is soybean producing farms in } \\
\text { the United States where this LCA was conducted) }\end{array}$ \\
\hline $\begin{array}{l}\text { Further } \\
\text { Technological } \\
\text { Correlation }\end{array}$ & 1 & $\begin{array}{l}\text { The data represents the estimated sum of N, P, K, S used by } \\
\text { some soybean producing states. NPKS being used in } 2006 \text { is } \\
\text { basically the same being used with regards to our reference } \\
\text { year. }\end{array}$ \\
\hline Sample size & 1 & $\begin{array}{l}\text { This survey was conducted for farms in } 31 \text { states that produces } \\
\text { soybean. }\end{array}$ \\
\hline \multicolumn{3}{|c|}{ DQI for Crop Protection Chemical Inputs } \\
\hline Reliability & 2 & $\begin{array}{l}\text { The data source is official from the USDA which was obtained } \\
\text { by NASS through the annual ARMS and Conservation Effects } \\
\text { Assessment Project (CEAP). Data for pesticides usage was } \\
\text { obtained from personal interviews with farmers. }\end{array}$ \\
\hline Completeness & 2 & $\begin{array}{l}\text { Once again, out of the } 31 \text { potentially soybean producing states, } \\
\text { data on about } 20 \text { was reported representing over } 50 \% \text {. }\end{array}$ \\
\hline $\begin{array}{l}\text { Temporal } \\
\text { Correlation }\end{array}$ & 1 & $\begin{array}{l}\text { Data covers year of study (2006). Original goal was to obtain } \\
\text { chemical/fertilizer input for the most recent year (2009), but } \\
\text { the most recent obtained was for } 2006 \text {. }\end{array}$ \\
\hline $\begin{array}{l}\text { Geographical } \\
\text { correlation }\end{array}$ & 1 & $\begin{array}{l}\text { Data was obtained from soybean producing farms in the } \\
\text { United States. }\end{array}$ \\
\hline $\begin{array}{l}\text { Further } \\
\text { Technological } \\
\text { Correlation }\end{array}$ & 1 & $\begin{array}{l}\text { The same pesticides are still on the market with no significant } \\
\text { changes.. }\end{array}$ \\
\hline Sample size & 2 & Sample size greater than ten \\
\hline \multicolumn{3}{|r|}{ DQI for Energy inputs } \\
\hline Reliability & 2 & $\begin{array}{l}\text { Data obtained from a report for DOE USA prepared by } \\
\text { Sheehan and his group. The input was originally obtained from } \\
\text { Farm Costs and Returns Survey (FCRS), FCRS was the main } \\
\text { precursor to ARMS and was conducted annually from 1985- } \\
1995\end{array}$ \\
\hline Completeness & 3 & $\begin{array}{l}14(<<50 \%) \text { Soybean producing states was considered in the } \\
\text { FCRS survey. This represents only some sites which are } \\
\text { relevant for our consideration }\end{array}$ \\
\hline $\begin{array}{l}\text { Temporal } \\
\text { Correlation }\end{array}$ & 5 & $\begin{array}{l}\text { Data from FCRS was for the year 1990, hence } 19 \text { years less } \\
\text { than the reference year (2009). }\end{array}$ \\
\hline
\end{tabular}




\begin{tabular}{|l|c|l|}
\hline $\begin{array}{l}\text { Geographical } \\
\text { correlation }\end{array}$ & 1 & $\begin{array}{l}\text { Data was obtained from 14 different soybean producing states } \\
\text { in the United States. }\end{array}$ \\
\hline $\begin{array}{l}\text { Further } \\
\text { Technological } \\
\text { Correlation }\end{array}$ & 3 & $\begin{array}{l}\text { Though data is coming from same farms, due to technological } \\
\text { advancement over the years some farming practices might } \\
\text { have changed. }\end{array}$ \\
\hline Sample size & 2 & Sample size greater than ten \\
\hline
\end{tabular}

Table D-34 Pedigree matrix for Corn grain/silage

\begin{tabular}{|c|c|c|}
\hline \multicolumn{3}{|r|}{ DQI For Inorganic Fertilizer inputs } \\
\hline Indicator & $\begin{array}{c}\text { Scor } \\
\mathrm{e}\end{array}$ & Explanation \\
\hline Reliability & 2 & $\begin{array}{l}\text { The data source is official from the USDA obtained by NASS through the } \\
\text { annual ARMS and Conservation Effects Assessment Project (CEAP). } \\
\text { Data for pesticides usage was obtained from personal interviews with } \\
\text { farmers. }\end{array}$ \\
\hline Completeness & 3 & $\begin{array}{l}\text { Out of } 41 \text { states producing corn, } 19 \text { of them had their N, P, K, S input } \\
\text { reported representing less than } 50 \% \text { for the } 2005 \text { year period. This is fairly } \\
\text { adequate to cover fluctuations due to different farm practices. }\end{array}$ \\
\hline $\begin{array}{l}\text { Temporal } \\
\text { Correlation }\end{array}$ & 2 & $\begin{array}{l}\text { Data covers year of study (2005). Original goal was to obtain } \\
\text { chemical/fertilizer input for the most recent year (2009). We are within } 6 \\
\text { years of difference to our reference year. }\end{array}$ \\
\hline $\begin{array}{l}\text { Geographical } \\
\text { correlation }\end{array}$ & 3 & $\begin{array}{l}\text { Data was obtained from corn producing farms in the United States. } \\
\text { However, some of the GHG emission factors were obtained from a similar } \\
\text { area (Europe) using values from Simapro. }\end{array}$ \\
\hline $\begin{array}{l}\text { Further } \\
\text { Technologica } \\
\text { l Correlation }\end{array}$ & 1 & $\begin{array}{l}\text { The data represents the estimated sum of N, P, K, S used by several corn } \\
\text { producing states. Life cycle of N, P, K, S in } 2005 \text { is relatively identical to } \\
\text { today's processes. }\end{array}$ \\
\hline Sample size & 1 & $\begin{array}{l}3,300 \text { reports were summarized accounting for } 93 \% \text { of the total US } \\
\text { acreage. }\end{array}$ \\
\hline \multicolumn{3}{|r|}{ DQI for Crop Protection Chemical Inputs } \\
\hline Reliability & 2 & $\begin{array}{l}\text { The data source is official from the USDA obtained by NASS through the } \\
\text { annual ARMS and Conservation Effects Assessment Project (CEAP). } \\
\text { Data for pesticides usage was obtained from personal interviews. }\end{array}$ \\
\hline Completeness & 3 & $\begin{array}{l}\text { Out of } 41 \text { states producing corn, } 19 \text { of them had their pesticide inputs } \\
\text { reported representing less than } 50 \% \text { for the } 2005 \text { year period. This is fairly } \\
\text { adequate to cover fluctuations due to different farm practices. }\end{array}$ \\
\hline $\begin{array}{l}\text { Temporal } \\
\text { Correlation }\end{array}$ & 2 & $\begin{array}{l}\text { Data covers year of study (2005). Original goal was to obtain } \\
\text { chemical/fertilizer input for the most recent year (2009). We are within } 6 \\
\text { years of difference to our reference year. }\end{array}$ \\
\hline $\begin{array}{l}\text { Geographical } \\
\text { correlation }\end{array}$ & 3 & $\begin{array}{l}\text { Data was obtained from corn producing farms in the United States. } \\
\text { However, the GHG data comes from a similar area (Europe) using values } \\
\text { from Simapro. Furthermore only the states with reported inputs are } \\
\text { averaged or summed. }\end{array}$ \\
\hline $\begin{array}{l}\text { Further } \\
\text { Technologica } \\
\text { l Correlation }\end{array}$ & 1 & $\begin{array}{l}\text { The same pesticides are still on the market. Production processes and } \\
\text { materials for these pesticides are nearly identical. }\end{array}$ \\
\hline Sample size & & $\begin{array}{l}3,300 \text { reports were summarized accounting for } 93 \% \text { of the total US } \\
\text { acreage. }\end{array}$ \\
\hline \multicolumn{3}{|r|}{ DQI for Energy inputs } \\
\hline
\end{tabular}




\begin{tabular}{|c|c|c|}
\hline Reliability & 2 & $\begin{array}{l}\text { Data was obtained from Shapouri et al } 2001 . \\
\text { This paper is based on straightforward methodology and highly regarded } \\
\text { quality data from the } 2001 \text { Agricultural Resource Management Survey } \\
\text { (ARMS), Economic Research Service, ERS/USDA, 2001 Agricultural } \\
\text { Chemical Usage, and 2001 Crop Production, National Agricultural } \\
\text { Statistics Service, NASS/USDA, and the } 2001 \text { survey of ethanol plants. }\end{array}$ \\
\hline Completeness & 3 & $\begin{array}{l}\text { Data is representative of nine major corn producing states. However, this } \\
\text { is less than } 50 \% \text { of the total market considered for dairy cattle feed. }\end{array}$ \\
\hline $\begin{array}{l}\text { Temp } \\
\text { Correl }\end{array}$ & 3 & $\begin{array}{l}\text { Data was assembled from } 2001 \text { ARMS. Therefore, we are within } 10 \text { years } \\
\text { of difference to our reference year. }\end{array}$ \\
\hline $\begin{array}{l}\text { Geographical } \\
\text { correlation }\end{array}$ & 3 & Data is from a smaller area than the total countrywide area under study. \\
\hline $\begin{array}{l}\text { Further } \\
\text { Technologica } \\
1 \text { Correlation }\end{array}$ & 3 & $\begin{array}{l}\text { Although data is coming from farms with similar farming practices, } \\
\text { technological advancement over the years may account for some change in } \\
\text { these practices. This model does not account for differences such as no- } \\
\text { till, conventional till, or other tillage practices. }\end{array}$ \\
\hline Sample size & 3 & $\begin{array}{l}\text { The figures are significantly aggregated although a portion of the sample } \\
\text { size used in these calculations stems from } 2,989 \text { reports in a } 2001 \text { NASS } \\
\text { Agricultural Chemical Usage survey accounting for } 93 \% \text { of the total US } \\
\text { acreage. }\end{array}$ \\
\hline
\end{tabular}

Table D-35 Pedigree matrix for Oats

\begin{tabular}{|c|c|c|}
\hline \multicolumn{3}{|r|}{ DQI For Inorganic Fertilizer inputs } \\
\hline Indicator & Score & Explanation \\
\hline Reliability & 2 & $\begin{array}{l}\text { The data source is official from the USDA obtained by NASS } \\
\text { through the annual ARMS and Conservation Effects Assessment } \\
\text { Project (CEAP). Data for pesticides usage was obtained from } \\
\text { personal interviews. }\end{array}$ \\
\hline Completeness & 3 & $\begin{array}{l}\text { Out of } 31 \text { states producing oats, } 15 \text { of them had their NPKS input } \\
\text { reported representing less than } 50 \% \text { for the } 2005 \text { year period. This } \\
\text { is fairly adequate to cover fluctuations due to different farm } \\
\text { practices. }\end{array}$ \\
\hline $\begin{array}{l}\text { Temporal } \\
\text { Correlation }\end{array}$ & 2 & $\begin{array}{l}\text { Data covers year of study (2005). Original goal was to obtain } \\
\text { chemical/fertilizer input for the most recent year (2009). We are } \\
\text { within } 6 \text { years of difference to our reference year. }\end{array}$ \\
\hline $\begin{array}{l}\text { Geographical } \\
\text { correlation }\end{array}$ & 3 & $\begin{array}{l}\text { Data was obtained from oat producing farms in the United States. } \\
\text { However, the GHG data comes from a similar area (Europe) using } \\
\text { values from Simapro. Furthermore only the states with reported } \\
\text { inputs are averaged or summed. }\end{array}$ \\
\hline $\begin{array}{l}\text { Further } \\
\text { Technological } \\
\text { Correlation }\end{array}$ & 1 & $\begin{array}{l}\text { The data represents the estimated sum of NPKS used by some oat } \\
\text { producing states. Life cycle of NPKS in } 2005 \text { is relatively } \\
\text { identical to today's processes. }\end{array}$ \\
\hline Sample size & 1 & 1,592 reports were summarized. \\
\hline \multicolumn{3}{|r|}{ DQI for Crop Protection Chemical Inputs } \\
\hline Reliability & 2 & $\begin{array}{l}\text { The data source is official from the USDA obtained by NASS } \\
\text { through the annual ARMS and Conservation Effects Assessment } \\
\text { Project (CEAP). Data for pesticides usage was obtained from } \\
\text { personal interviews. }\end{array}$ \\
\hline
\end{tabular}




\begin{tabular}{|c|c|c|}
\hline Completeness & 4 & $\begin{array}{l}\text { Out of } 31 \text { states producing oats, } 1 \text { of them had their pesticide } \\
\text { inputs reported representing less than } 50 \% \text { for the } 2005 \text { year } \\
\text { period. This is fairly adequate to cover fluctuations due to } \\
\text { different farm practices. }\end{array}$ \\
\hline $\begin{array}{l}\text { Temporal } \\
\text { Correlation }\end{array}$ & 2 & $\begin{array}{l}\text { Data covers year of study (2005). Original goal was to obtain } \\
\text { chemical/fertilizer input for the most recent year (2009). We are } \\
\text { within } 6 \text { years of difference to our reference year. }\end{array}$ \\
\hline $\begin{array}{l}\text { Geographical } \\
\text { correlation }\end{array}$ & 3 & $\begin{array}{l}\text { Data was obtained from oat producing farms in the United States. } \\
\text { However, the GHG data comes from a similar area (Europe) using } \\
\text { values from Simapro. Furthermore only the states with reported } \\
\text { inputs are averaged or summed. }\end{array}$ \\
\hline $\begin{array}{l}\text { Further } \\
\text { Technological } \\
\text { Correlation }\end{array}$ & 1 & $\begin{array}{l}\text { The same pesticides are still on the market. Production processes } \\
\text { and materials for these pesticides are nearly identical. }\end{array}$ \\
\hline Sample size & 1 & 1,592 reports were summarized. \\
\hline \multicolumn{3}{|r|}{ DQI for Energy inputs } \\
\hline Reliability & 3 & $\begin{array}{l}\text { Data was obtained from an extension program at Michigan State } \\
\text { University. Fuel information was obtained from Michigan State } \\
\text { University, was based on a regional study for selected farms in the } \\
\text { state of Michigan with assistance from county and regional } \\
\text { Extension staff for specialized crops. }\end{array}$ \\
\hline Completeness & 4 & $\begin{array}{l}\text { Data is representative of only the state of Michigan. This is one } \\
\text { site relevant for the market considered. }\end{array}$ \\
\hline $\begin{array}{l}\text { Temporal } \\
\text { Correlation }\end{array}$ & 3 & $\begin{array}{l}\text { Data was assembled in Winter/Spring } 2000-2001 \text { and represent an } \\
\text { estimate of } 2000-2001 \text { conditions. We are within } 10 \text { years of } \\
\text { difference to our reference year. }\end{array}$ \\
\hline $\begin{array}{l}\text { Geographical } \\
\text { correlation }\end{array}$ & 3 & Data is from a smaller area than the area under study. \\
\hline $\begin{array}{l}\text { Further } \\
\text { Technological } \\
\text { Correlation }\end{array}$ & 3 & $\begin{array}{l}\text { Although data is coming from farms with similar farming } \\
\text { practices, technological advancement over the years may account } \\
\text { for some change in these practices. }\end{array}$ \\
\hline Sample size & 5 & Unknown sample size. \\
\hline
\end{tabular}


Table D-36 Pedigree matrix for Winter wheat

\begin{tabular}{|c|c|c|}
\hline \multicolumn{3}{|r|}{ DQI For Inorganic Fertilizer inputs } \\
\hline Indicator & Score & Explanation \\
\hline Reliability & 2 & $\begin{array}{l}\text { The data source is official from the USDA obtained by NASS } \\
\text { through the annual Agricultural Resource Management Survey } \\
\text { (ARMS) and Conservation Effects Assessment Project } \\
\text { (CEAP). }\end{array}$ \\
\hline Completeness & 2 & $\begin{array}{l}\text { Data reported for all the wheat accounted well over } 50 \% \\
\text { percent of the total of the relevant sites. This is fairly } \\
\text { representative. }\end{array}$ \\
\hline $\begin{array}{l}\text { Temporal } \\
\text { Correlation }\end{array}$ & 1 & $\begin{array}{l}\text { Data covers year of study (2006). Original goal was to obtain } \\
\text { chemical/fertilizer input for the most recent year (2009), but } \\
\text { the most recent obtained was for } 2006 \text {. }\end{array}$ \\
\hline $\begin{array}{l}\text { Geographical } \\
\text { correlation }\end{array}$ & 1 & $\begin{array}{l}\text { Data was obtained from wheat producing farms in the United } \\
\text { States. }\end{array}$ \\
\hline $\begin{array}{l}\text { Further } \\
\text { Technological } \\
\text { Correlation }\end{array}$ & 1 & $\begin{array}{l}\text { The data represents the estimated sum of NPKS used by some } \\
\text { wheat producing states. NPKS being used in } 2006 \text { is basically } \\
\text { the same being used with regards to our reference year. }\end{array}$ \\
\hline Sample size & 1 & $\begin{array}{l}\text { This survey was conducted for farms in over } 20 \text { states that } \\
\text { produces wheat }\end{array}$ \\
\hline \multicolumn{3}{|c|}{ DQI for Crop Protection Chemical Inputs } \\
\hline Reliability & 2 & $\begin{array}{l}\text { The data source is official from the USDA obtained by NASS } \\
\text { through the annual ARMS and Conservation Effects } \\
\text { Assessment Project (CEAP). Data for pesticides usage was } \\
\text { obtained from personal interviews. }\end{array}$ \\
\hline Completeness & 2 & $\begin{array}{l}\text { Once again, data for all the wheat producing states, accounted } \\
\text { for over } 50 \% \text { of the relevant sites. }\end{array}$ \\
\hline $\begin{array}{l}\text { Temporal } \\
\text { Correlation }\end{array}$ & 1 & $\begin{array}{l}\text { Data covers year of study (2006). Original goal was to obtain } \\
\text { chemical/fertilizer input for the most recent year (2009), but } \\
\text { the most recent obtained was for } 2006 \text {. }\end{array}$ \\
\hline $\begin{array}{l}\text { Geographical } \\
\text { correlation }\end{array}$ & 1 & $\begin{array}{l}\text { Data was obtained from wheat producing farms in the United } \\
\text { States where we are conducting our LCA study }\end{array}$ \\
\hline $\begin{array}{l}\text { Further } \\
\text { Technological } \\
\text { Correlation }\end{array}$ & 1 & $\begin{array}{l}\text { The same pesticides are still on the market and technology } \\
\text { used in for their production has not seen any changes. }\end{array}$ \\
\hline Sample size & 1 & Sample size greater than twenty \\
\hline \multicolumn{3}{|r|}{ DQI for Energy inputs } \\
\hline Reliability & 2 & $\begin{array}{l}\text { Data obtained from a paper by researchers Piringer. G., and } \\
\text { Steinberg. L. J., (2006).The energy and fuel input were } \\
\text { originally obtained from a USDA-ERS } 2003 \text {. }\end{array}$ \\
\hline Completeness & 3 & $\begin{array}{l}\text { This paper cited the work of Briggle, in Briggle's system for } \\
\text { his energy analysis } 8 \text { wheat producing states were considered. }\end{array}$ \\
\hline $\begin{array}{l}\text { Temporal } \\
\text { Correlation }\end{array}$ & 2 & $\begin{array}{l}\text { With reference to the original energy data source from USDA- } \\
\text { ERS 2003, this was about } 6 \text { years less than our reference year. }\end{array}$ \\
\hline $\begin{array}{l}\text { Geographical } \\
\text { correlation }\end{array}$ & 2 & $\begin{array}{l}\text { Data was obtained from wheat producing farms in the United } \\
\text { States where we are conducting our LCA study }\end{array}$ \\
\hline $\begin{array}{l}\text { Further } \\
\text { Technological } \\
\text { Correlation }\end{array}$ & 3 & $\begin{array}{l}\text { Though data is coming from same farms, due to technological } \\
\text { advancement over the years some farming practices might } \\
\text { have changed. This paper cited work done as far back as } 1980 \text {. }\end{array}$ \\
\hline Sample size & 3 & Sample size greater than ten. \\
\hline
\end{tabular}


Table D-37 Pedigree matrix for DDG

\begin{tabular}{|l|c|l|}
\hline \multicolumn{3}{|c|}{ DQI For Inorganic Fertilizer inputs } \\
\hline Indicator & Score & \multicolumn{1}{c|}{ Explanation } \\
\hline Reliability & 3 & $\begin{array}{l}\text { The inventory data in the references for DDGS GHG } \\
\text { emissions are a combination of measurements and estimates } \\
\text { based on best engineering judgment. }\end{array}$ \\
\hline Completeness & 3 & $\begin{array}{l}\text { The references are unclear on this topic, so we assume a } \\
\text { middle value for completeness indicator. }\end{array}$ \\
\hline $\begin{array}{l}\text { Temporal } \\
\text { Correlation }\end{array}$ & 3 & $\begin{array}{l}\text { Data covers inputs from near the year 2000 for one reference } \\
\text { and up to 2006 for another, so we choose a middle value. }\end{array}$ \\
\hline $\begin{array}{l}\text { Geographical } \\
\text { correlation }\end{array}$ & 2 & $\begin{array}{l}\text { The inventory data in the references was national in } \\
\text { geographic extent, and therefore do not represent the } \\
\text { regional differences that are being sought in this dairy study. }\end{array}$ \\
\hline $\begin{array}{l}\text { Further } \\
\text { Technological } \\
\text { Correlation }\end{array}$ & 1 & $\begin{array}{l}\text { Inventory data from references are from processes that } \\
\text { produce ethanol from corn and DDGS, and therefore the } \\
\text { correlation is good. }\end{array}$ \\
\hline Sample size & 3 & $\begin{array}{l}\text { The references are unclear on this topic, so we assume a } \\
\text { middle value for sample size indicator. }\end{array}$ \\
\hline
\end{tabular}

Table D-38 Pedigree matrix for Alfalfa Hay and Silage

\begin{tabular}{|l|c|l|}
\hline \multicolumn{2}{|c|}{ DQI For Alfalfa Hay \& Silage inputs and yield } \\
\hline Indicator & Score & \\
\hline Reliability & 4 & $\begin{array}{l}\text { The data source is based upon production budgets from state } \\
\text { extension specialists. These budgets are based upon best or } \\
\text { expected practices, and do not represent actual data or average } \\
\text { data for a county, state or region }\end{array}$ \\
\hline Completeness & 3 & $\begin{array}{l}\text { This data represents 15 states, and although in some cases } \\
\text { multiple budgets per state }\end{array}$ \\
\hline $\begin{array}{l}\text { Temporal } \\
\text { Correlation }\end{array}$ & 1 & $\begin{array}{l}\text { Data covers primarily the year of study, but nearly all are within 3 } \\
\text { years of study }\end{array}$ \\
\hline $\begin{array}{l}\text { Geographical } \\
\text { correlation }\end{array}$ & 3 & $\begin{array}{l}\text { Data was obtained from Alfalfa producing states in the United } \\
\text { States. However, the GHG data comes from a similar area } \\
\text { (Europe) using values from Simapro. Furthermore only the states } \\
\text { with reported inputs are averaged or summed. }\end{array}$ \\
\hline $\begin{array}{l}\text { Further } \\
\text { Technological } \\
\text { Correlation }\end{array}$ & 4 & $\begin{array}{l}\text { The data represents the estimated sum of inputs from alfalfa } \\
\text { producing farms. In some cases input quantities are based upon } \\
\text { conversions from prices, and hence highly dependent upon } \\
\text { fluctuating price levels. }\end{array}$ \\
\hline Sample size & 2 & $\begin{array}{l}\text { There are 39 production budgets. While they do not represent } \\
\text { actual data, they are expected to represent approximate average } \\
\text { production methods }\end{array}$ \\
\hline
\end{tabular}


Table D-39 Pedigree matrix for Grass Hay and Silage

\begin{tabular}{|l|c|l|}
\hline \multicolumn{3}{|c|}{ DQI For Grass Hay \& Silage inputs and yield } \\
\hline Indicator & Score & Explanation \\
\hline Reliability & 4 & $\begin{array}{l}\text { The data source is based upon production budgets from state } \\
\text { extension specialists. These budgets are based upon best or } \\
\text { expected practices, and do not represent actual data or average } \\
\text { data for a county, state or region }\end{array}$ \\
\hline Completeness & 3 & $\begin{array}{l}\text { This data represents 17 states, and although in some cases } \\
\text { multiple budgets per state }\end{array}$ \\
\hline $\begin{array}{l}\text { Temporal } \\
\text { Correlation }\end{array}$ & 1 & $\begin{array}{l}\text { Data covers primarily the year of study, but nearly all are within 3 } \\
\text { years of study }\end{array}$ \\
\hline $\begin{array}{l}\text { Geographical } \\
\text { correlation }\end{array}$ & 3 & $\begin{array}{l}\text { Data was obtained from grass producing states in the United } \\
\text { States. However, the GHG data comes from a similar area } \\
\text { (Europe) using values from Simapro. Furthermore only the states } \\
\text { with reported inputs are averaged or summed. }\end{array}$ \\
\hline $\begin{array}{l}\text { Further } \\
\text { Technological } \\
\text { Correlation }\end{array}$ & 4 & $\begin{array}{l}\text { The data represents the estimated sum of inputs from grass } \\
\text { producing farms. In some cases input quantities are based upon } \\
\text { conversions from prices, and hence highly dependent upon } \\
\text { fluctuating price levels. }\end{array}$ \\
\hline Sample size & $\begin{array}{l}\text { There are 44 production budgets. While they do not represent } \\
\text { actual data, they are expected to represent approximate average } \\
\text { production methods }\end{array}$ \\
\hline
\end{tabular}

Table D-40 Pedigree matrix for Grass Pasture

\begin{tabular}{|l|c|l|l|}
\hline \multicolumn{2}{|c|}{ DQI For Grass Pasture inputs and yield } \\
\hline Indicator & Score & Explanation \\
\hline Reliability & $\mathbf{4}$ & $\begin{array}{l}\text { The data source is based upon production budgets from state } \\
\text { extension specialists. These budgets are based upon best or } \\
\text { expected practices, and do not represent actual data or average } \\
\text { data for a county, state or region }\end{array}$ \\
\hline Completeness & $\mathbf{3}$ & $\begin{array}{l}\text { This data represents 17 states, and although in some cases } \\
\text { multiple budgets per state }\end{array}$ \\
\hline Temporal Correlation & $\mathbf{1}$ & $\begin{array}{l}\text { Data covers primarily the year of study, but nearly all are within } \\
\text { 3 years of study }\end{array}$ \\
\hline Geographical correlation & $\mathbf{3}$ & $\begin{array}{l}\text { Data was obtained from grass producing states in the United } \\
\text { States. However, the GHG data comes from a similar area } \\
\text { (Europe) using values from Simapro. Furthermore only the } \\
\text { states with reported inputs are averaged or summed. }\end{array}$ \\
\hline $\begin{array}{l}\text { Further Technological } \\
\text { Correlation }\end{array}$ & $\mathbf{5}$ & $\begin{array}{l}\text { The data represents the estimated sum of inputs from grass hay } \\
\text { producing farms, but does not represent grass pasture }\end{array}$ \\
\hline Sample size & $\mathbf{2}$ & $\begin{array}{l}\text { There are 44 production budgets. While they do not represent } \\
\text { actual data, they are expected to represent approximate average } \\
\text { production methods }\end{array}$ \\
\hline
\end{tabular}


Table D-41 Pedigree matrix for Soybean Meal

\begin{tabular}{|c|c|c|}
\hline \multicolumn{3}{|r|}{ DQI For Soybean Meal inputs and yield } \\
\hline $\begin{array}{l}\text { DQI For DDGS } \\
\text { Results }\end{array}$ & Score & Explanation \\
\hline Reliability & 2 & $\begin{array}{l}\text { The inventory data in the references for SBM/O GHG emissions are a } \\
\text { combination of conversations with industry representatives and } \\
\text { modeled data. }\end{array}$ \\
\hline Completeness & 2 & $\begin{array}{l}14(>>50 \%) \text { Soybean producing states was considered in the model by } \\
\text { Sheehan et al } 1998 \text {. }\end{array}$ \\
\hline $\begin{array}{l}\text { Temporal } \\
\text { Correlation }\end{array}$ & 2 & $\begin{array}{l}\text { The crushing and extraction energy required were updated based on a } \\
\text { more recent study by Pradhan et al., (2009) }\end{array}$ \\
\hline $\begin{array}{l}\text { Geographical } \\
\text { correlation }\end{array}$ & 2 & $\begin{array}{l}\text { The inventory data in the references was national in geographic } \\
\text { extent, and therefore do not represent the regional differences that are } \\
\text { being sought in this dairy study. }\end{array}$ \\
\hline $\begin{array}{l}\text { Further } \\
\text { Technological } \\
\text { Correlation }\end{array}$ & 1 & $\begin{array}{l}\text { Inventory data from references are from processes that produce } \\
\text { soybean meal and oil from soybean, and therefore the correlation is } \\
\text { good. }\end{array}$ \\
\hline Sample size & 2 & $\begin{array}{l}\text { The sample size represents the major soybean producing states in the } \\
\text { US }\end{array}$ \\
\hline
\end{tabular}

Table D-42 Geometric standard deviation estimation (SBM: Soybean meal)

\begin{tabular}{|c|c|c|c|c|}
\hline \multicolumn{5}{|c|}{ Estimation of the square of geometric standard deviation $\left(\mathrm{SDg}_{95}\right)$} \\
\hline \multirow{4}{*}{ Corn } & Inputs & $\begin{array}{l}\text { Data Quality } \\
\text { Index } \\
\end{array}$ & Uncertainty factors $\left(\mathbf{U}_{n}\right)$ & $\mathrm{SD}_{\mathrm{g} 95}$ \\
\hline & Inorganic Fertilizer & $(2,3,2,3,1,1)$ & $(1.05,1.05,1.03,1.02,1.0,1.0,1.50)$ & 1.51 \\
\hline & $\begin{array}{l}\text { Crop Protection } \\
\text { Chemical }\end{array}$ & $(2,3,2,3,1,1)$ & $(1.05,1.05,1.03,1.02,1.0,1.0,1.2)$ & 1.22 \\
\hline & Energy & $(2,3,3,3,3,3)$ & $(1.05,1.05,1.10,1.02,1.20,1.05,1.05)$ & 1.26 \\
\hline \multirow{3}{*}{ Soybean } & Inorganic Fertilizer & $(2,2,1,1,1,1)$ & $(1.05,1.02,1.0,1.0,1.0,1.0,1.5)$ & 1.51 \\
\hline & $\begin{array}{l}\text { Crop Protection } \\
\text { Chemical }\end{array}$ & $(2,2,1,1,1,2)$ & $(1.05,1.02,1.0,1.0,1.0,1.02,1.2)$ & 1.21 \\
\hline & Energy & $(2,3,5,1,3,2)$ & $(1.05,1.02,1.0,1.0,1.0,1.02,1.05)$ & 1.57 \\
\hline SBM & For all input data & $(2,2,2,2,1,2)$ & $(1.05,1.02,1.03,1.01,1,1.02,1.05)$ & 1.08 \\
\hline \multirow{3}{*}{ Oats } & Inorganic Fertilizer & $(2,3,2,3,1,1)$ & $(1.05,1.05,1.03,1.02,1.0,1.0,1.50)$ & 1.51 \\
\hline & $\begin{array}{l}\text { Crop Protection } \\
\text { Chemical }\end{array}$ & $(2,4,2,3,1,1)$ & $(1.05,1.10,1.03,1.02,1.0,1.0,1.2)$ & 1.24 \\
\hline & Energy & $(3,4,3,3,3,5)$ & $(1.10,1.10,1.10,1.02,1.20,1.20,1.05)$ & 1.36 \\
\hline \multirow{3}{*}{ Wheat } & Inorganic Fertilizer & $(2,2,1,1,1,1)$ & $(1.05,1.02,1.0,1.0,1.0,1.0,1.5)$ & 1.51 \\
\hline & $\begin{array}{l}\text { Crop Protection } \\
\text { Chemical }\end{array}$ & $(2,2,1,1,1,2)$ & $(1.05,1.02,1.0,1.0,1.0,1.02,1.2)$ & 1.21 \\
\hline & Energy & $(2,3,2,2,3,3)$ & $(1.05,1.05,1.03,1.01,1.20,1.05,1.05)$ & 1.23 \\
\hline DDGS & For all input data & $(3,3,3,2,1,3)$ & $(1.1,1.05,1.1,1.01,1.0,1.02,1.5)$ & 1.54 \\
\hline Alfalfa & For all input data & $(4,3,1,3,1,3)$ & $(1.2,1.05,1.0,1.02,1.0,1.05,1.05)$ & 1.22 \\
\hline $\begin{array}{l}\text { Grass } \\
\text { Hay }\end{array}$ & For all input data & $(4,3,1,3,1,2)$ & $(1.2,1.05,1.0,1.02,1.0,1.02,1.05)$ & 1.22 \\
\hline \begin{tabular}{|l|} 
Grass \\
Pasture
\end{tabular} & For all input data & $(4,3,1,3,5,3)$ & $(1.2,1.05,1.0,1.02,1.0,1.05,1.05)$ & 2.06 \\
\hline
\end{tabular}


Table D-43 Estimation of upper/lower bound values of grain crops

\begin{tabular}{|c|c|c|c|c|c|}
\hline & & $\begin{array}{l}\text { Geometric } \\
\text { mean } \\
\text { equivalent } \\
\text { emission } \\
\left(\mathrm{kgCO}_{2} \mathrm{eq}\right. \\
/ \mathrm{kg} \text { feed }) \\
\end{array}$ & $\begin{array}{l}\text { Inorganic } \\
\text { fertilizers }\end{array}$ & $\begin{array}{l}\text { Crop } \\
\text { protection } \\
\text { chemicals }\end{array}$ & $\begin{array}{l}\text { Energy } \\
\text { sources }\end{array}$ \\
\hline \multirow[t]{3}{*}{ Soybean } & $\begin{array}{l}\text { Square of Geometric Standard Deviation } \\
\operatorname{GSD}^{2}\left(\sigma \mathrm{g}^{2}\right) \\
\text { minValue }(2.5 \%) \text { equivalent } \\
\text { emission }=\mu \mathrm{g} / \sigma \mathrm{g}^{2}\end{array}$ & 0.237 & $\begin{array}{l}1.510 \\
0.088\end{array}$ & $\begin{array}{l}1.210 \\
0.063\end{array}$ & $\begin{array}{l}1.570 \\
0.086\end{array}$ \\
\hline & Geometric mean $(\mu \mathrm{g})$ equivalent emission & 0.344 & 0.133 & 0.076 & 0.135 \\
\hline & $\begin{array}{l}\text { maxValue equivalent emission } \\
(97.5 \%)=\mu g^{*} \sigma g^{2}\end{array}$ & 0.505 & 0.200 & 0.092 & 0.212 \\
\hline \multirow{4}{*}{ Oats } & $\begin{array}{l}\text { Square of Geometric Standard Deviation } \\
\operatorname{GSD}^{2}\left(\sigma g^{2}\right)\end{array}$ & & 1.510 & 1.240 & 1.360 \\
\hline & minValue $(2.5 \%)^{\prime}=\mu \mathrm{g} / \sigma^{2}$ & 0.507 & 0.366 & 0.063 & 0.077 \\
\hline & Geometric mean $(\mu \mathrm{g})$ & 0.736 & 0.553 & 0.078 & 0.105 \\
\hline & $\max V$ alue $(97.5 \%)=\mu g^{*} \sigma g^{2}$ & 1.075 & 0.834 & 0.097 & 0.143 \\
\hline \multirow{4}{*}{$\begin{array}{l}\text { Corn } \\
\text { grain }\end{array}$} & $\begin{array}{l}\text { Square of Geometric Standard Deviation } \\
\operatorname{GSD}^{2}\left(\sigma \mathrm{g}^{2}\right)\end{array}$ & & 1.510 & 1.220 & 1.260 \\
\hline & minValue $(2.5 \%)^{\prime}=\mu \mathrm{g} / \sigma \mathrm{g}^{2}$ & 0.231 & 0.160 & 0.005 & 0.066 \\
\hline & Geometric mean $(\mu \mathrm{g})$ & 0.331 & 0.242 & 0.006 & 0.084 \\
\hline & $\max$ Value $(97.5 \%)=\mu g^{*} \sigma g^{2}$ & 0.478 & 0.365 & 0.007 & 0.105 \\
\hline \multirow{4}{*}{$\begin{array}{l}\text { Corn } \\
\text { silage }\end{array}$} & $\begin{array}{l}\text { Square of Geometric Standard Deviation } \\
\operatorname{GSD}^{2}\left(\sigma \mathrm{g}^{2}\right)\end{array}$ & & 1.510 & 1.220 & 1.260 \\
\hline & minValue $(2.5 \%)^{\prime}=\mu \mathrm{g} / \sigma \mathrm{g}^{2}$ & 0.049 & 0.036 & 0.003 & 0.010 \\
\hline & Geometric mean $(\mu \mathrm{g})$ & 0.071 & 0.055 & 0.004 & 0.012 \\
\hline & $\max$ Value $(97.5 \%)=\mu g^{*} \sigma g^{2}$ & 0.103 & 0.083 & 0.005 & 0.015 \\
\hline \multirow{4}{*}{$\begin{array}{l}\text { Winter } \\
\text { wheat }\end{array}$} & $\begin{array}{l}\text { Square of Geometric Standard Deviation } \\
\mathrm{GSD}^{2}\left(\sigma \mathrm{g}^{2}\right)\end{array}$ & & 1.510 & 1.210 & 1.230 \\
\hline & minValue $(2.5 \%)^{\prime}=\mu \mathrm{g} / \sigma \mathrm{g}^{2}$ & 0.270 & 0.225 & 0.001 & 0.043 \\
\hline & Geometric mean $(\mu \mathrm{g})$ & 0.395 & 0.340 & 0.001 & 0.053 \\
\hline & $\max V$ alue $(97.5 \%)=\mu g^{*} \sigma g^{2}$ & 0.581 & 0.514 & 0.001 & 0.066 \\
\hline \multirow{4}{*}{ Wet,DDG } & $\begin{array}{l}\text { Square of Geometric Standard Deviation } \\
\operatorname{GSD}^{2}\left(\sigma \mathrm{g}^{2}\right)\end{array}$ & 1.540 & & & \\
\hline & $\min V$ alue $(2.5 \%)^{\prime}=\mu \mathrm{g} / \sigma \mathrm{g}^{2}$ & 0.174 & & & \\
\hline & Geometric mean $(\mu \mathrm{g})$ & 0.268 & & & \\
\hline & $\max$ Value $(97.5 \%)=\mu \mathrm{g}^{*} \sigma \mathrm{g}^{2}$ & 0.412 & & & \\
\hline \multirow[t]{2}{*}{ Dry,DDG } & $\begin{array}{l}\text { Square of Geometric Standard Deviation } \\
\mathrm{GSD}^{2}\left(\sigma \mathrm{g}^{2}\right)\end{array}$ & 1.540 & & & \\
\hline & $\min V$ alue $(2.5 \%)^{\prime}=\mu \mathrm{g} / \sigma \mathrm{g}^{2}$ & 0.531 & & & \\
\hline
\end{tabular}




\begin{tabular}{|l|l|l|} 
& Geometric mean $(\mu \mathrm{g})$ & 0.818 \\
maxValue $(97.5 \%)=\mu \mathrm{g}^{*} \sigma \mathrm{g}^{2}$ & 1.259 \\
\hline \multirow{5}{*}{$\begin{array}{l}\text { Soybean } \\
\text { meal }\end{array}$} & $\begin{array}{l}\text { Square of Geometric Standard Deviation } \\
\mathrm{GSD}^{2}\left(\sigma \mathrm{g}^{2}\right)\end{array}$ & 1.080 \\
& minValue $(2.5 \%)^{\prime}=\mu \mathrm{g} / \sigma \mathrm{g}^{2}$ & 0.376 \\
& $\begin{array}{l}\text { Geometric mean }(\mu \mathrm{g}) \\
\text { maxValue }(97.5 \%)=\mu \mathrm{g}^{*} \sigma \mathrm{g}^{2}\end{array}$ & 0.406 \\
\hline
\end{tabular}


Table D-44 Estimation of upper/lower bound values of forage

\begin{tabular}{|c|c|c|}
\hline & & $\begin{array}{l}\text { Geometric mean } \\
\text { equivalent emission } \\
\left(\mathrm{kgCO}_{2} \mathrm{eq} / \mathrm{kg} \text { feed }\right)\end{array}$ \\
\hline Alfalfa hay & $\begin{array}{l}\text { Square of Geometric Standard Deviation } \mathrm{GSD}^{2}\left(\sigma \mathrm{g}^{2}\right) \\
\text { minValue }(2.5 \%) \text { equivalent emission }=\mu \mathrm{g} / \sigma \mathrm{g}^{2} \\
\text { Geometric mean }(\mu \mathrm{g}) \text { equivalent emission } \\
\text { maxValue equivalent emission }(97.5 \%)=\mu \mathrm{g}^{*} \sigma \mathrm{g}^{2}\end{array}$ & $\begin{array}{l}1.224 \\
0.120 \\
0.147 \\
0.180 \\
\end{array}$ \\
\hline Alfalfa silage & $\begin{array}{l}\text { Square of Geometric Standard Deviation } \mathrm{GSD}^{2}\left(\sigma \mathrm{g}^{2}\right) \\
\text { minValue }(2.5 \%)^{\prime}=\mu \mathrm{g} / \sigma \mathrm{g}^{2} \\
\text { Geometric mean }(\mu \mathrm{g}) \\
\text { maxValue }(97.5 \%)=\mu \mathrm{g}^{*} \sigma \mathrm{g}^{2}\end{array}$ & $\begin{array}{l}1.224 \\
0.127 \\
0.156 \\
0.191\end{array}$ \\
\hline Forage mix & $\begin{array}{l}\text { Square of Geometric Standard Deviation } \mathrm{GSD}^{2}\left(\sigma \mathrm{g}^{2}\right) \\
\text { minValue }(2.5 \%)^{\prime}=\mu \mathrm{g} / \sigma \mathrm{g}^{2} \\
\text { Geometric mean }(\mu \mathrm{g}) \\
\text { maxValue }(97.5 \%)=\mu \mathrm{g}^{*} \sigma \mathrm{g}^{2}\end{array}$ & $\begin{array}{l}1.224 \\
0.112 \\
0.137 \\
0.167\end{array}$ \\
\hline Grain mix & $\begin{array}{l}\text { Square of Geometric Standard Deviation } \mathrm{GSD}^{2}\left(\sigma \mathrm{g}^{2}\right) \\
\text { minValue }(2.5 \%)^{\prime}=\mu \mathrm{g} / \sigma \mathrm{g}^{2} \\
\text { Geometric mean }(\mu \mathrm{g}) \\
\text { maxValue }(97.5 \%)=\mu \mathrm{g}^{*} \sigma \mathrm{g}^{2}\end{array}$ & $\begin{array}{l}1.224 \\
0.365 \\
0.446 \\
0.546\end{array}$ \\
\hline Grass hay & $\begin{array}{l}\text { Square of Geometric Standard Deviation } \mathrm{GSD}^{2}\left(\sigma \mathrm{g}^{2}\right) \\
\text { minValue }(2.5 \%)^{\prime}=\mu \mathrm{g} / \sigma \mathrm{g}^{2} \\
\text { Geometric mean }(\mu \mathrm{g}) \\
\text { maxValue }(97.5 \%)=\mu \mathrm{g}^{*} \sigma \mathrm{g}^{2}\end{array}$ & $\begin{array}{l}1.218 \\
0.223 \\
0.272 \\
0.331\end{array}$ \\
\hline Grass pasture & $\begin{array}{l}\text { Square of Geometric Standard Deviation } \mathrm{GSD}^{2}\left(\sigma \mathrm{g}^{2}\right) \\
\text { minValue }(2.5 \%)^{\prime}=\mu \mathrm{g} / \sigma \mathrm{g}^{2} \\
\text { Geometric mean }(\mu \mathrm{g}) \\
\text { maxValue }(97.5 \%)=\mu \mathrm{g}^{*} \sigma \mathrm{g}^{2}\end{array}$ & $\begin{array}{l}2.058 \\
0.110 \\
0.226 \\
0.466\end{array}$ \\
\hline Grass silage & $\begin{array}{l}\text { Square of Geometric Standard Deviation } \mathrm{GSD}^{2}\left(\sigma \mathrm{g}^{2}\right) \\
\text { minValue }(2.5 \%)^{\prime}=\mu \mathrm{g} / \sigma \mathrm{g}^{2} \\
\text { Geometric mean }(\mu \mathrm{g}) \\
\text { maxValue }(97.5 \%)=\mu \mathrm{g}^{*} \sigma \mathrm{g}^{2}\end{array}$ & $\begin{array}{l}1.218 \\
0.230 \\
0.280 \\
0.341\end{array}$ \\
\hline
\end{tabular}




\section{Appendix E: Supplementary information for carbon footprint analysis of dairy feed from a mill in Michigan, USA}

\begin{tabular}{|c|c|c|c|}
\hline & $\begin{array}{l}\text { Preprint version (with a few } \\
\text { exceptions- see below *) }\end{array}$ & $\begin{array}{l}\text { Accepted Author } \\
\text { Manuscript }\end{array}$ & $\begin{array}{l}\text { Published } \\
\text { Journal Articles }\end{array}$ \\
\hline $\begin{array}{l}\text { Use for classroom teaching by author } \\
\text { or author's institution and presentation } \\
\text { at a meeting or conference and } \\
\text { distributing copies to attendees }\end{array}$ & Yes & Yes & Yes \\
\hline $\begin{array}{l}\text { Use for internal training by author's } \\
\text { company }\end{array}$ & Yes & Yes & Yes \\
\hline $\begin{array}{l}\text { Distribution to colleagues for their } \\
\text { research use }\end{array}$ & Yes & Yes & Yes \\
\hline $\begin{array}{l}\text { Use in a subsequent compilation of the } \\
\text { author's works }\end{array}$ & Yes & Yes & Yes \\
\hline Inclusion in a thesis or dissertation & $Y_{\text {Yes }}=-1-m$ & Yes & Yes \\
\hline $\begin{array}{l}\text { Reuse of portions or extracts from the } \\
\text { article in other works }\end{array}$ & Yes & $\begin{array}{l}\text { Yes with full } \\
\text { acknowledgement of } \\
\text { final article }\end{array}$ & $\begin{array}{l}\text { Yes with full } \\
\text { acknowledgement } \\
\text { of final article }\end{array}$ \\
\hline $\begin{array}{l}\text { Preparation of derivative works (other } \\
\text { than for commercial purposes) }\end{array}$ & Yes & $\begin{array}{l}\text { Yes with full } \\
\text { acknowledgentent of } \\
\text { final artiole }\end{array}$ & $\begin{array}{l}\text { Yes with full } \\
\text { acknowledgentent } \\
\text { of final article }\end{array}$ \\
\hline Preprint servers & Yes & $\begin{array}{l}\text { Yes with the specifio } \\
\text { written permission of } \\
\text { Elsevier }\end{array}$ & No \\
\hline $\begin{array}{l}\text { Voluntary posting on open web sites } \\
\text { operated by author or author's } \\
\text { institution for scholarly purposes }\end{array}$ & $\begin{array}{l}\text { Yes (author may later add an } \\
\text { appropriate bibliographic citation, } \\
\text { indieating subsequent publication } \\
\text { by Elsevier and journal title) }\end{array}$ & $\begin{array}{l}\text { Yes, with appropriate } \\
\text { bibliographio citation } \\
\text { and a link to the } \\
\text { article once published }\end{array}$ & $\begin{array}{l}\text { Only with the } \\
\text { specifio written } \\
\text { pernission of } \\
\text { Elsevier }\end{array}$ \\
\hline $\begin{array}{l}\text { Mandated deposit or deposit in or } \\
\text { posting to subject-oriented or } \\
\text { centralized repositories }\end{array}$ & $\begin{array}{l}\text { Yes under specific agreement } \\
\text { between Elsevier and the } \\
\text { repository }\end{array}$ & $\begin{array}{l}\text { Yes under specifio } \\
\text { agreement between } \\
\text { Elsevier and the } \\
\text { repository" }\end{array}$ & $\begin{array}{l}\text { Yes under } \\
\text { specifio } \\
\text { agreement } \\
\text { between Elsevier } \\
\text { and the } \\
\text { repository }\end{array}$ \\
\hline $\begin{array}{l}\text { Use or posting for commercial gain or } \\
\text { to substitute for services provided } \\
\text { directly by journal }\end{array}$ & $\begin{array}{l}\text { Only with the specifio written } \\
\text { permission of Elsevier }\end{array}$ & $\begin{array}{l}\text { Only with the specific } \\
\text { written permission of } \\
\text { Elsevier }\end{array}$ & $\begin{array}{l}\text { Only with the } \\
\text { specifio written } \\
\text { permission of } \\
\text { Elsevier }\end{array}$ \\
\hline
\end{tabular}

Figure E-1 Copyright clearance for Elsevier (http://www.elsevier.com/authors/authorrights-and-responsibilities)

Figure E-1 above applies to chapter 7 including all supplementary materials in Appendix-E 
Table E-1 Survey questions for milling operations

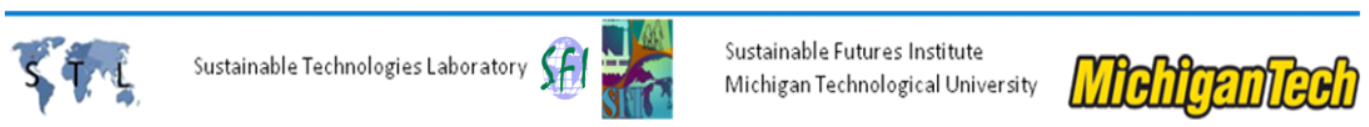

SURVEY FOR THE ANALYSIS OF FEEDMILL GREENHOUSE GAS EMISSIONS

\begin{tabular}{|l|}
\hline Company Nane: \\
\hline Date: \\
\hline Address: \\
\hline \\
\hline \\
\hline Nane of Contact Person: \\
\hline Hone: \\
\hline Engil: \\
\hline Year of data: \\
\hline
\end{tabular}

\begin{tabular}{|l|}
\hline Contact: \\
David R. Shonnard, Ph.D. \\
Robbins Professor \\
Department of Chemical Engineering \\
Sustainable Futures Institute \\
Michigan Technological Universiity \\
Houghton, MI 49931USA \\
Ph. 906-487-3468 \\
Email:drshonna@mtu.edu \\
\hline
\end{tabular}

Year of data:

\begin{tabular}{|c|c|}
\hline \multicolumn{2}{|c|}{ Totsl Annnsl Mill Energy Inpnt (1 year of nill operation) } \\
\hline Annal Fuel Inpat for Feed Mill & Quantity \\
\hline Diesel (gallons/yr) & \\
\hline Gasoline (gallons/yr) & \\
\hline Kerosene (gallons/yr) & \\
\hline Laquified Petrolemm Gas (b or volmme/yr) & \\
\hline Natural Gas/ Propane (scf or m3 or BTU/yr) & \\
\hline Fuel oil (galons / yr) & \\
\hline Coal (b/yr) & \\
\hline Electricity (kWh / yr) & \\
\hline
\end{tabular}

\begin{tabular}{|l|c|}
\hline \multicolumn{2}{|c|}{ Totsl Annul Animsl Feed Prodnction (1 year production) } \\
\hline Type of Feed & Short Tons/year \\
\hline $\begin{array}{l}\text { Dairy feed; al types } \\
\text { Other animal feed; all types }\end{array}$ & \\
\hline
\end{tabular}

\begin{tabular}{|l|l|}
\hline \multicolumn{1}{|c|}{ Dairy Feed Production (1 year prodnction) } \\
\hline \multicolumn{1}{|c|}{ Type of Feed } & \multirow{2}{|c|}{ Short Tons/year } \\
\hline Starter period & \\
\hline $\begin{array}{l}\text { Starter Feed birth } \\
\text { Open Heifer Feed } \\
\text { Bred Heifer Feed }\end{array}$ & \\
\hline Lactation period & \\
\hline High Ration & \\
Low Ration & \\
\hline Dry period & \\
\hline
\end{tabular}

Rontine Inbrication and Maintenance of Feed Mill

\begin{tabular}{|l|r|}
\hline Frequently used Lnbricant/ Flid & Anomit (Galons/year) \\
\hline $\begin{array}{l}\text { Grease } \\
\text { Others (please list) }\end{array}$ & \\
\hline
\end{tabular}


Table E-2 Survey Questions for feed ingredients inputs

Feed Type

Starter/Lactating/Dry Feed

Starter/Lactating/ Dry Feed-Based on 1 short ton production

\begin{tabular}{|c|c|c|}
\hline Kind of ingredients used in feed & $\begin{array}{c}\text { Amount } \\
\text { (Ib/ kg / Ton) }\end{array}$ & $\%$ composition \\
\hline \multicolumn{3}{|l|}{ Alfalfa Product } \\
\hline \multicolumn{3}{|l|}{ Alfalfa meal, dehydrated, $13 \%$} \\
\hline \multicolumn{3}{|l|}{ A lfalfa meal, dehydrated, $17 \%$} \\
\hline \multicolumn{3}{|l|}{ Alfalfa meal, suncured, $13 \%$} \\
\hline \multicolumn{3}{|l|}{ Others (please list) } \\
\hline \multicolumn{3}{|l|}{ Animal Products } \\
\hline \multicolumn{3}{|l|}{ Blood meal } \\
\hline \multicolumn{3}{|l|}{ Blood flour } \\
\hline \multicolumn{3}{|l|}{ Meat meal } \\
\hline \multicolumn{3}{|l|}{ Others (please list) } \\
\hline \multicolumn{3}{|l|}{ Barley Products } \\
\hline \multicolumn{3}{|l|}{ Rolled barley } \\
\hline \multicolumn{3}{|l|}{ Barley } \\
\hline \multicolumn{3}{|l|}{ Others (please list) } \\
\hline \multicolumn{3}{|l|}{ Brewers Products } \\
\hline \multicolumn{3}{|l|}{ Brewers dried grains } \\
\hline \multicolumn{3}{|l|}{ Malt sprouts } \\
\hline \multicolumn{3}{|l|}{ Others (please list) } \\
\hline \multicolumn{3}{|l|}{ Citrus Products } \\
\hline \multicolumn{3}{|l|}{ Dried citrus pulp } \\
\hline \multicolumn{3}{|l|}{ Others (please list) } \\
\hline \multicolumn{3}{|l|}{ Corn Products } \\
\hline \multicolumn{3}{|l|}{ Corn, whole shelled } \\
\hline \multicolumn{3}{|l|}{ Corn meal } \\
\hline \multicolumn{3}{|l|}{ Corn bran } \\
\hline Others (please list) & & \\
\hline
\end{tabular}


Table E-3 Survey questions for feed transportation inputs

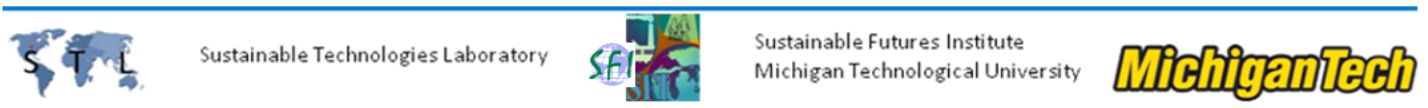

\begin{tabular}{|c|c|c|c|c|c|c|c|c|c|c|c|}
\hline \multicolumn{12}{|c|}{ Crop Input To The Mill } \\
\hline \multirow{2}{*}{$\begin{array}{ll}\text { Dich Feet } \\
\text { Crop }\end{array}$} & \multicolumn{11}{|c|}{ Mode of Transport } \\
\hline & & Velich & DC1 & Esed & & Used & DC1 & & Vetide & $\overline{\text { DC1 }}$ & Used \\
\hline & \multirow{3}{*}{ Rowed } & Latseni & & \multirow{3}{*}{$\begin{array}{l}\% \\
\% \\
\%\end{array}$} & \multirow{3}{*}{ R=il } & \multirow{3}{*}{ \% } & & \multirow{3}{*}{ water } & Ship & & \\
\hline & & \begin{tabular}{|l} 
S-il Somi \\
Futbed
\end{tabular} & & & & & & & & & \\
\hline & & Othex & & & & & & & Barge & & $*$ \\
\hline & \multirow{3}{*}{ Roned } & Lagresei & & $\%$ & \multirow{3}{*}{$\mathbf{K = 1}$} & \multirow{3}{*}{ \% } & & \multirow{3}{*}{ water } & & & $*$ \\
\hline & & S-ilsei & & $\%$ & & & & & Shp & & \\
\hline & & \begin{tabular}{|l|l|l|l|l|l} 
Fithed \\
Othe
\end{tabular} & & $\%$ & & & & & Barge & & * \\
\hline & \multirow{3}{*}{ Roed } & Lateseni & & $\%$ & \multirow{3}{*}{ Kail } & \multirow{3}{*}{$\%$} & & \multirow{3}{*}{ Wwer } & Shin & & \\
\hline & & S-vilsomi & & $\%$ & & & & & sip & & \\
\hline & & \begin{tabular}{|l|l|l|l|l} 
Fithed \\
Other
\end{tabular} & & $\%$ & & & & & Barge & & * \\
\hline
\end{tabular}

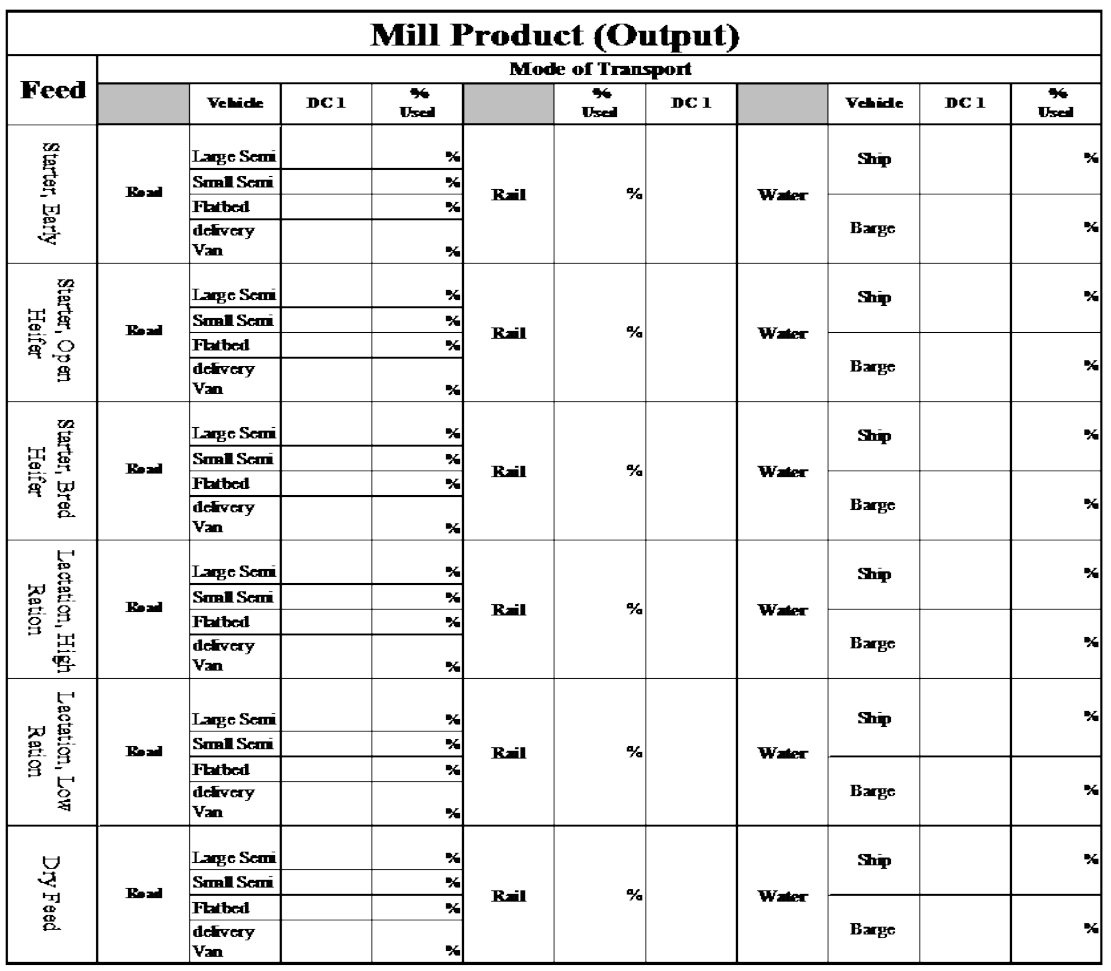

1 Please enter the following information for the Distance Code:

DC $=$ Distance Code

\begin{tabular}{|l|l|}
\hline A & $0-50$ mils \\
\hline B & $50-100$ mies \\
\hline C & $100-150$ mles \\
\hline D & $150-200$ miles \\
\hline E & Specify number of mies if greater than 200 mies \\
\hline
\end{tabular}


Table E-4 Components of Minerals Mixture (Category 2)

\begin{tabular}{|c|c|c|}
\hline \multicolumn{3}{|c|}{ Minerals Mixture } \\
\hline DESCRIPTION ( $\mathrm{T}=$ TRUCK, R = RAIL) & Kg & PERCENTAGE \\
\hline SAFEGUARD 1000 10\# (T) & 20 & $0.0002 \%$ \\
\hline IVOMEC 20\# (T) & 50 & $0.0006 \%$ \\
\hline MAXI CARE 25\# (T) & 110 & $0.0012 \%$ \\
\hline COBAN 90G 50\# (T) & 20 & $0.0002 \%$ \\
\hline SAFE-GUARD 5\% 25\# (T) & 60 & $0.0006 \%$ \\
\hline RABON BLOCK 33.3\# (T) & 420 & $0.0044 \%$ \\
\hline SUPER MICRO (T) & 110 & $0.0012 \%$ \\
\hline AVAILA-ZM 55.115\# (T) & 120 & $0.0013 \%$ \\
\hline OYSTER SHELLS 50\# (T) & 910 & $0.0094 \%$ \\
\hline CHOLINE CHLORIDE55.115\# (T) & 520 & $0.0054 \%$ \\
\hline TYLAN 10G 50\# (T) & 110 & $0.0012 \%$ \\
\hline ALTOSID TUB 225\# (T) & 410 & $0.0042 \%$ \\
\hline PURELY NAT 9T PMX 50\#(T) & 230 & $0.0023 \%$ \\
\hline BEL 90 50\# (T) & 1,810 & $0.0187 \%$ \\
\hline MGA 200 50\# BAG (T) & 20 & $0.0002 \%$ \\
\hline PEAK PLUS 37 50\# $(\mathrm{T})$ & 910 & $0.0094 \%$ \\
\hline GRIT - MEDIUM 50\# (T) & 2,720 & $0.0281 \%$ \\
\hline HY-D 55.115 \#BAG (T) & 120 & $0.0013 \%$ \\
\hline SAFE-GUARD PIG WORMER 50\# (T) & 50 & $0.0005 \%$ \\
\hline BMD $60-50 \#$ BAG $(\mathrm{T})$ & 110 & $0.0012 \%$ \\
\hline ACID-I-FRESH RUM 50\# (T) & 910 & $0.0094 \%$ \\
\hline COW'S MATCH JERSEY 50\# (T) & 450 & $0.0047 \%$ \\
\hline BOVATEC 91 50\# (T) & 70 & $0.0007 \%$ \\
\hline SEL 270 50\# (T) & 3,630 & $0.0375 \%$ \\
\hline MAXI CARE 50\# (T) & 680 & $0.0070 \%$ \\
\hline PURINA SUPP 2 20-05 50\# (T) & 1,810 & $0.0187 \%$ \\
\hline ECOCARE PAK 50\# BAG $(\mathrm{T})$ & 910 & $0.0094 \%$ \\
\hline COBAN $90(\mathrm{~T})$ & 160 & $0.0016 \%$ \\
\hline DRY COW MICRO PAK 50\# & 340 & $0.0035 \%$ \\
\hline LDH FORTIFIER 50\# $(\mathrm{T})$ & 270 & $0.0028 \%$ \\
\hline NATURA PORK SOW96 48\# (T) & 2,090 & $0.0216 \%$ \\
\hline REASHURE CHOLINE 25\# (T) & 910 & $0.0094 \%$ \\
\hline $\operatorname{AVATEC}(\mathrm{T})$ & 250 & $0.0026 \%$ \\
\hline EN140P 50\# BAG (T) & 450 & $0.0047 \%$ \\
\hline SWINE MICRO 4 50\# (T) & 910 & $0.0094 \%$ \\
\hline CROP N RICH 1000 (T) & 230 & $0.0023 \%$ \\
\hline S-700 CRUMBS 50\# (T) & 3,630 & $0.0375 \%$ \\
\hline SELENO SOURCE 2000 50\# (T) & 910 & $0.0094 \%$ \\
\hline AVAILA-4 55\# (T) & 2,000 & $0.0206 \%$ \\
\hline MEPRON 85 55\# BAG (T) & 1,000 & $0.0103 \%$ \\
\hline DAIRY FORTA PLUS -50\# (T) & 7,260 & $0.0750 \%$ \\
\hline TOTAL & 37,700 & $0.39 \%$ \\
\hline
\end{tabular}




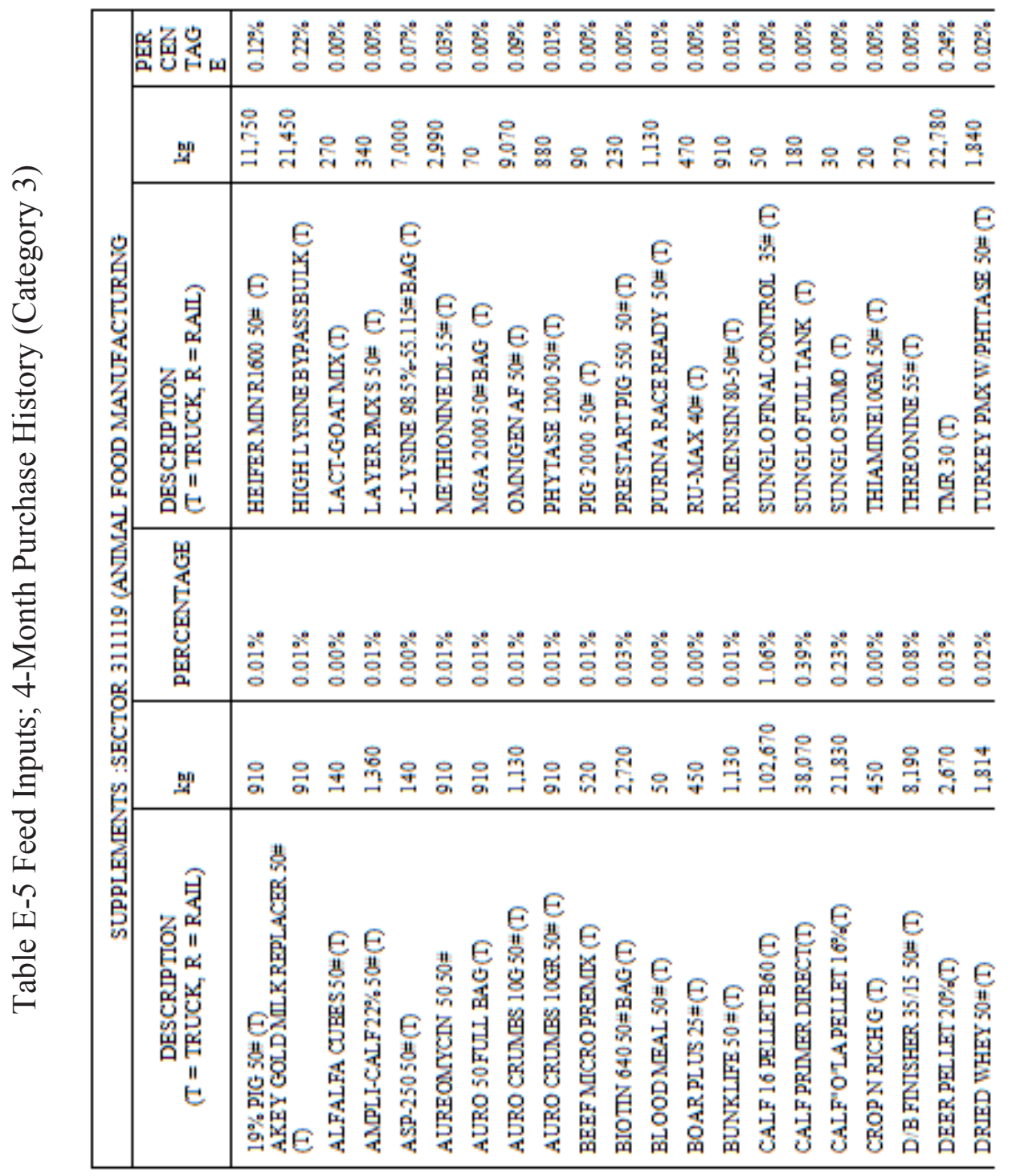




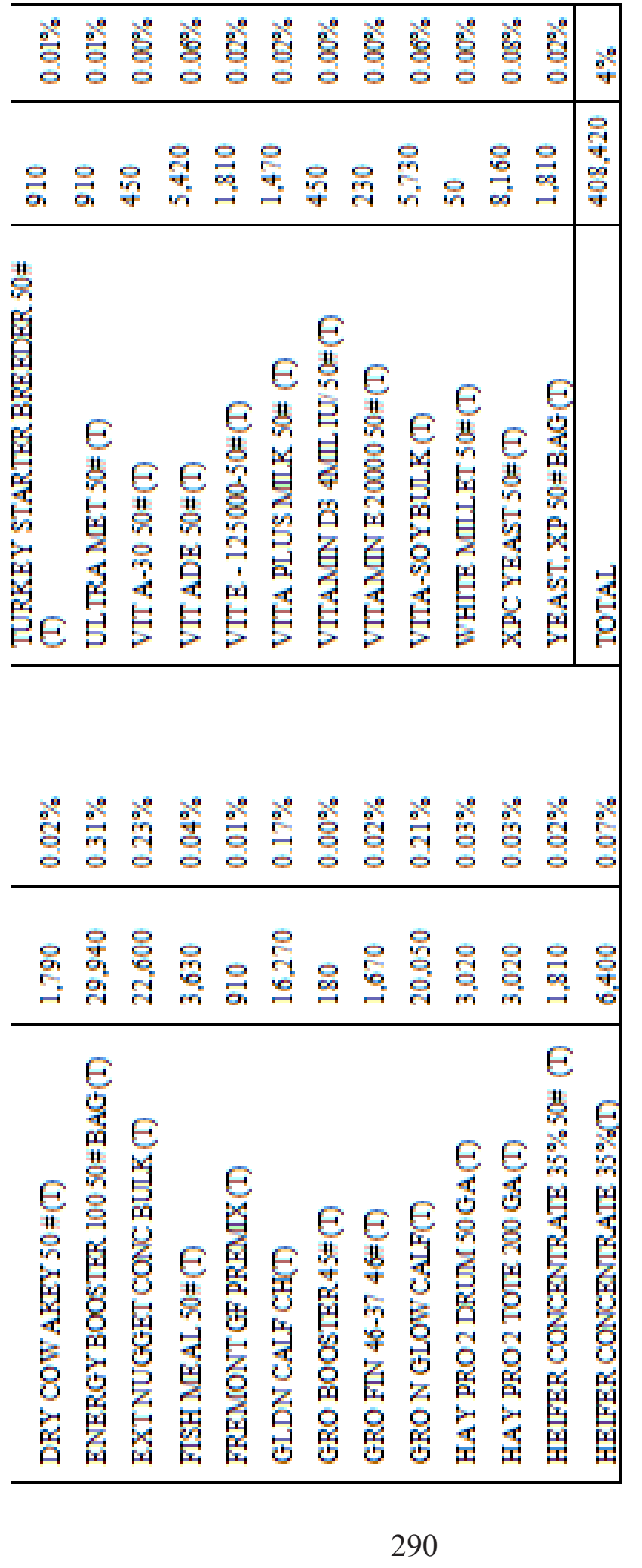




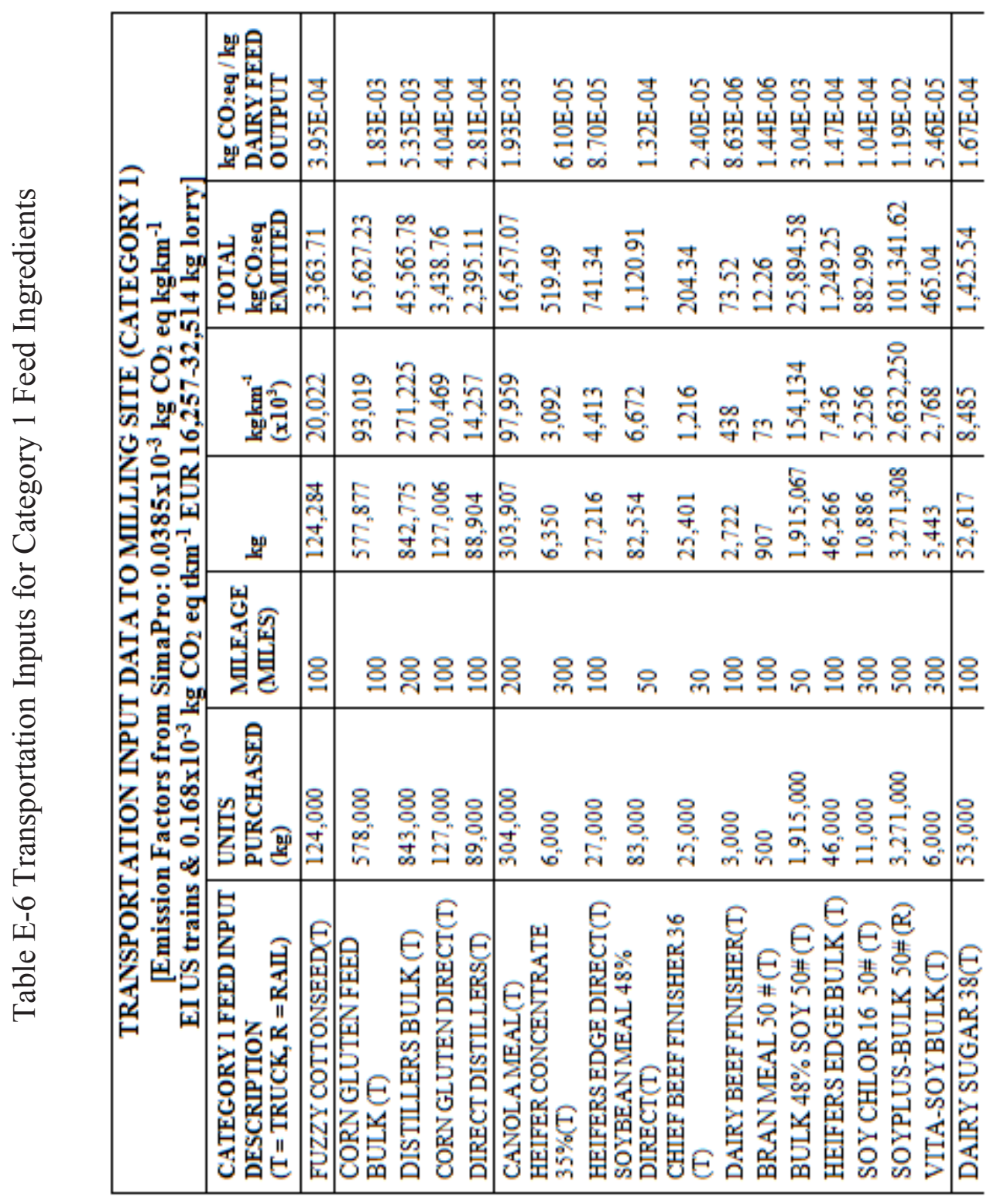




\begin{tabular}{|c|c|c|c|c|c|c|c|c|c|c|c|c|c|}
\hline 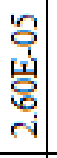 & 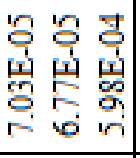 & 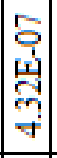 & 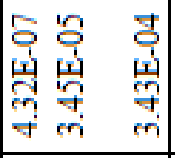 & $\begin{array}{l}\text { to } \\
\text { 岁 } \\
\text { g } \\
\text { त }\end{array}$ & $\begin{array}{l}\text { के } \\
\text { 岑 } \\
\text { तु }\end{array}$ & 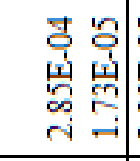 & $\begin{array}{l}\stackrel{2}{8} \\
\text { 봉 } \\
\text { लn } \\
\text { तi }\end{array}$ & & 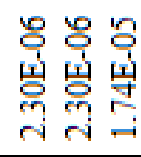 & 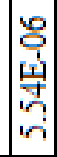 & 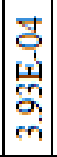 & 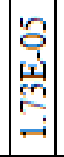 & 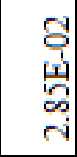 \\
\hline & 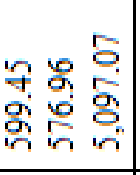 & \begin{tabular}{|l|}
$\mathscr{b}$ \\
\hdashline \\
\end{tabular} & 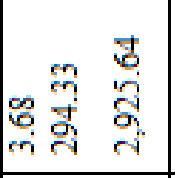 & $\begin{array}{l}\infty \\
\infty \\
0 \\
\infty \\
\text { r. } \\
\text { ri }\end{array}$ & 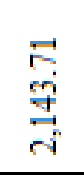 & 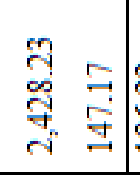 & $\begin{array}{l}\text { Â } \\
\stackrel{8}{\circ} \\
\end{array}$ & $\underset{m}{m}$ & 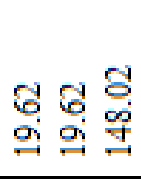 & 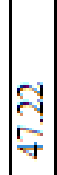 & 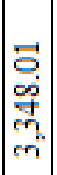 & 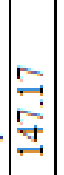 & 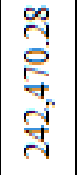 \\
\hline శ్. & 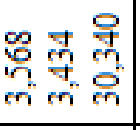 & ה & 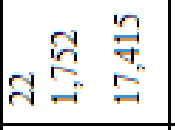 & 总 & \begin{tabular}{l}
8 \\
2 \\
\hdashline
\end{tabular} & 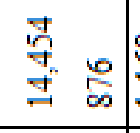 & 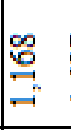 & $\begin{array}{l}5 \\
0 \\
0\end{array}$ & 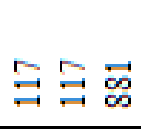 & $\overrightarrow{\text { वे }}$ & $\begin{array}{l}\text { ลे } \\
\text { g. } \\
\end{array}$ & $\begin{array}{l} \\
\infty \\
\infty \\
\end{array}$ & \\
\hline 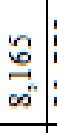 & 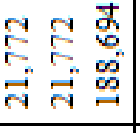 & \begin{tabular}{l}
$\infty$ \\
\hdashline \\
\hdashline
\end{tabular} & 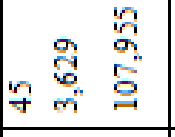 & 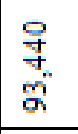 & 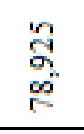 & 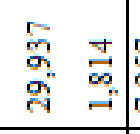 & & $\begin{array}{l}\text { 응 } \\
\text { on } \\
\text { ते }\end{array}$ & 용용 & 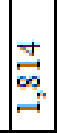 & $\begin{array}{l}0 \\
r \\
r \\
F\end{array}$ & $\begin{array}{c} \\
\dot{0} \\
- \\
- \\
\end{array}$ & \\
\hline 8 & 응 응 & 8 & 율 & 임 & 8 & ్ㅛ శ్లి| & 음 & & 8 응응 & 8 & 요 & : & \\
\hline $\begin{array}{l}8 \\
8 \\
\infty\end{array}$ & 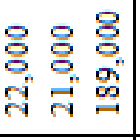 & . & 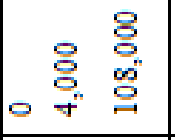 & 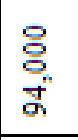 & $\begin{array}{l}8 \\
8 \\
0\end{array}$ & \begin{tabular}{cc|}
8 & 8 \\
0 & 0 \\
\hdashline & -1 \\
\end{tabular} & 8 & $\begin{array}{l}8 \\
8 \\
\text { on }\end{array}$ & $\begin{array}{l}8 \\
8\end{array}$ & $\begin{array}{l}8 \\
8 \\
-1 \\
\end{array}$ & $\begin{array}{l}8 \\
8 \\
\\
\end{array}$ & $\begin{array}{l}8 \\
0 \\
0 \\
-1\end{array}$ & \\
\hline 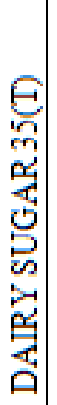 & 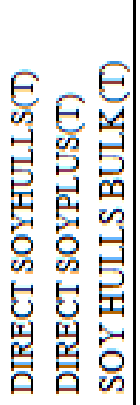 & 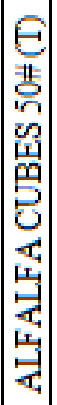 & 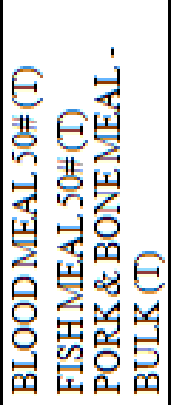 & 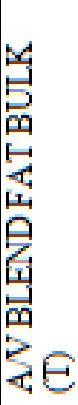 & 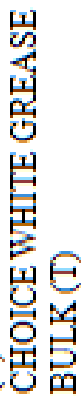 & 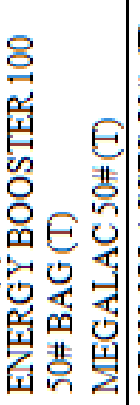 & 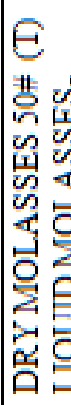 & 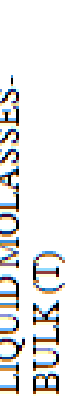 & 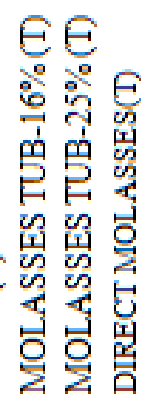 & 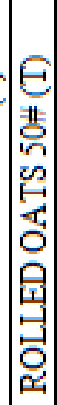 & 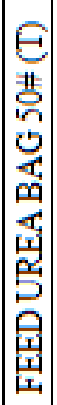 & 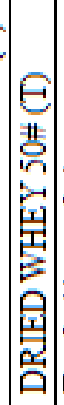 & 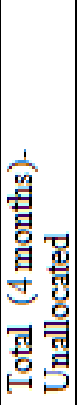 \\
\hline
\end{tabular}




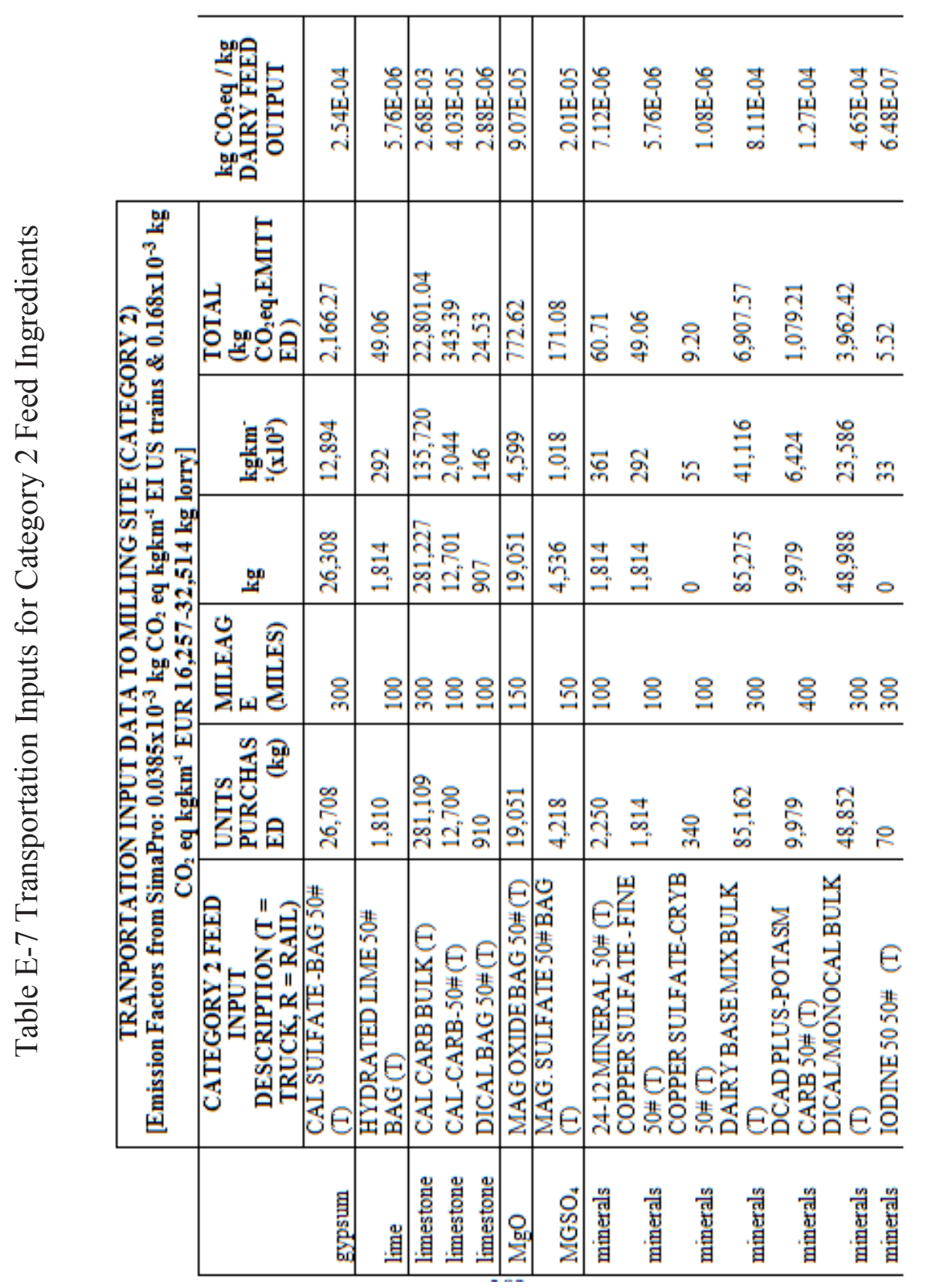




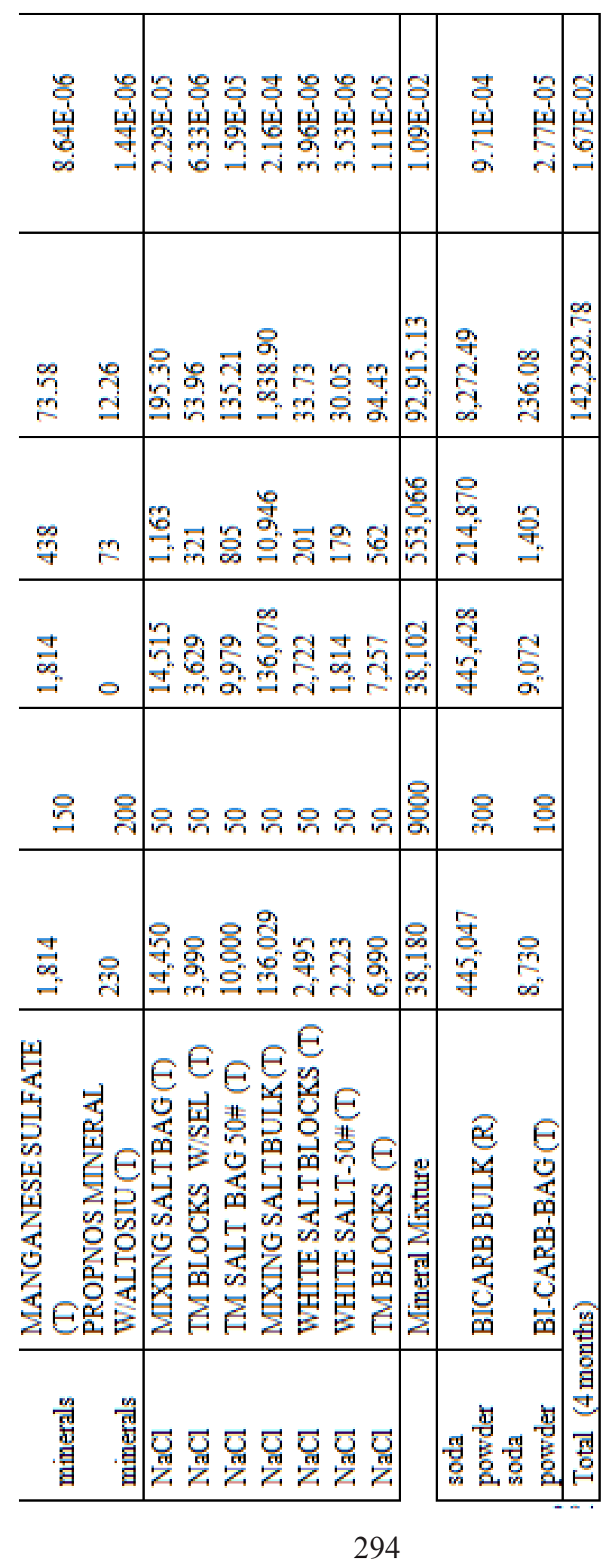




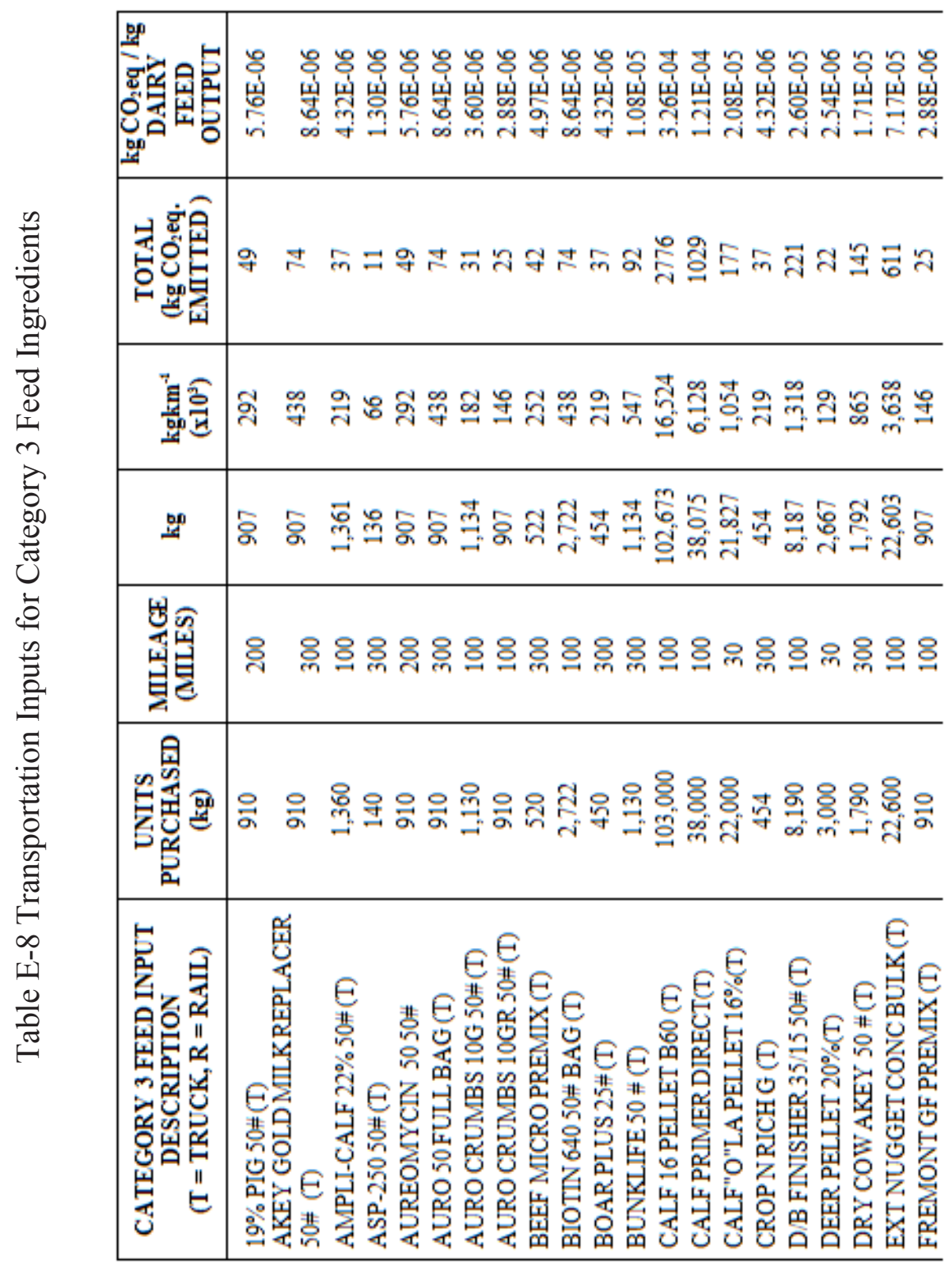




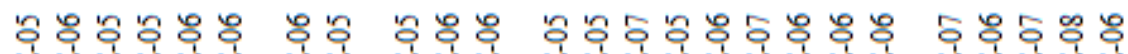

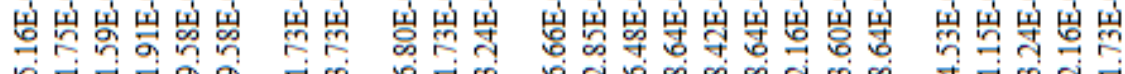

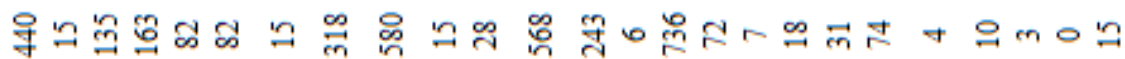

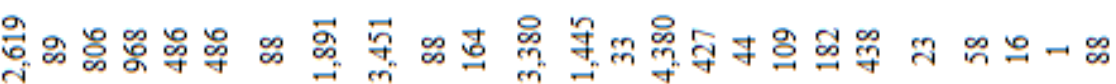

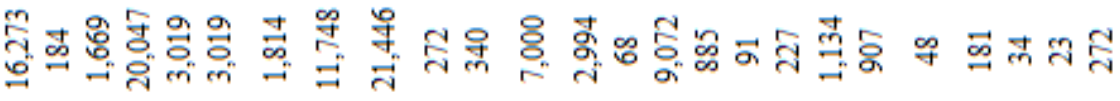

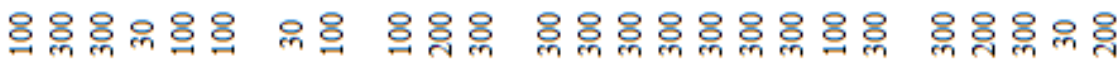

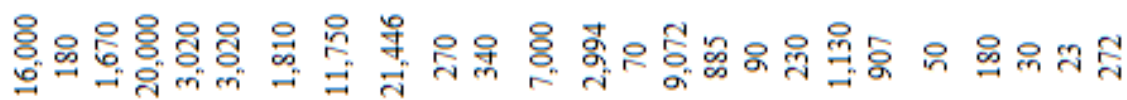

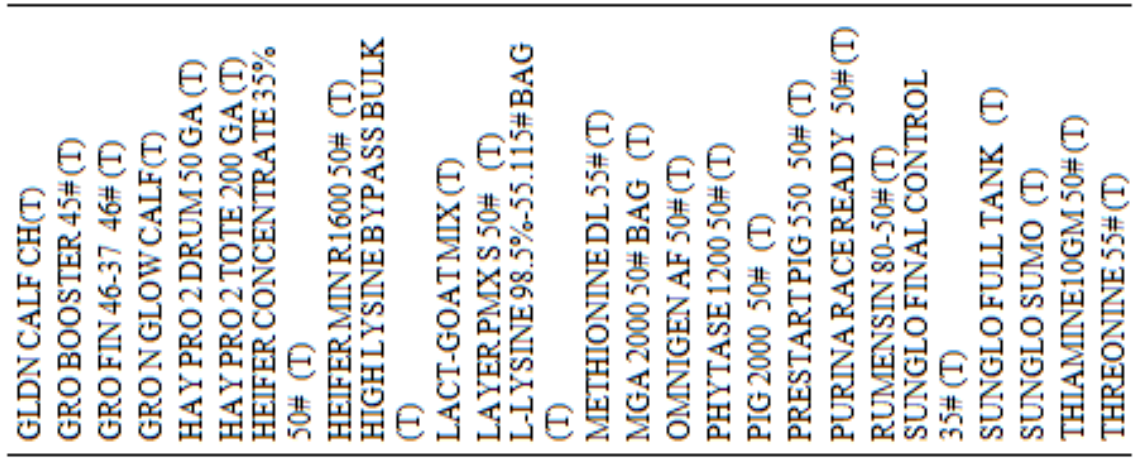




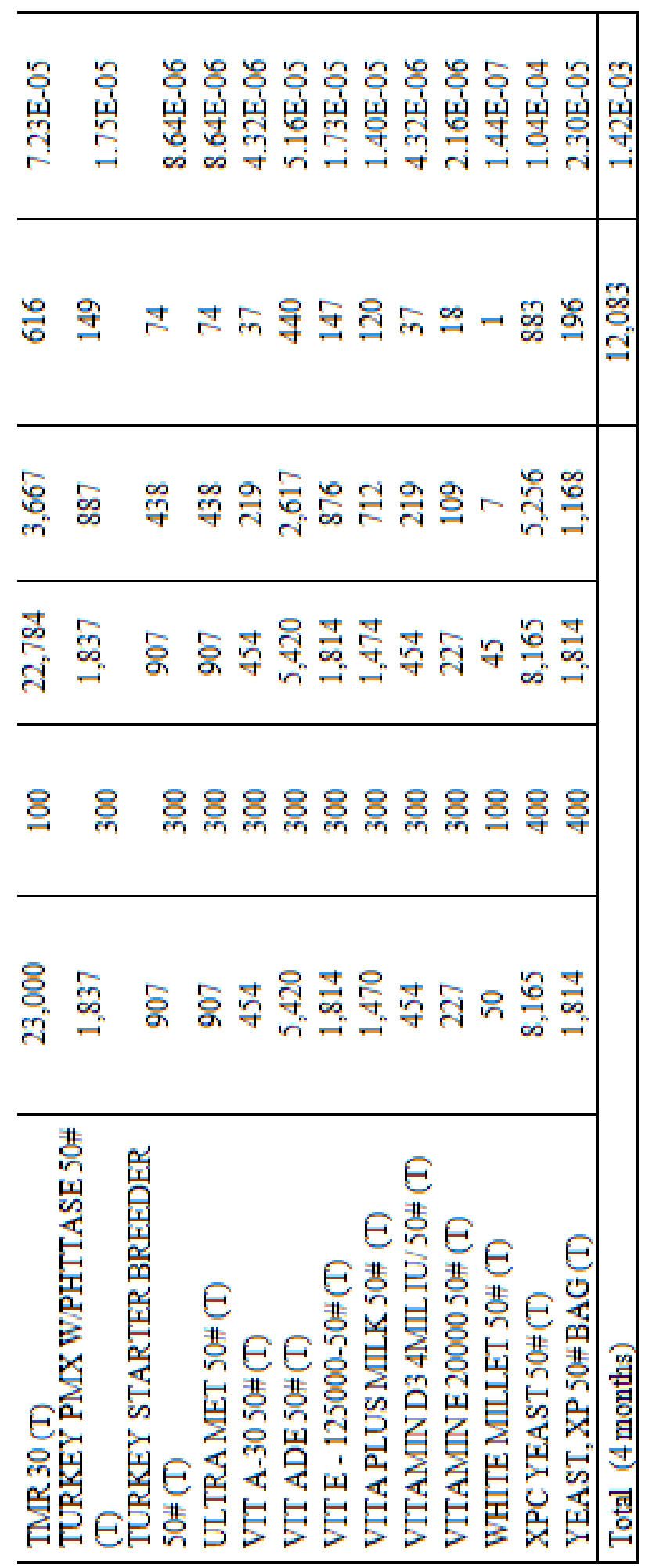


Mass Allocation (scenario 1)-DDGS, wet mill

: $0.91 \mathrm{kgCO}_{2} \mathrm{eq} \cdot \mathrm{kg}^{-1}$ dairy mill output

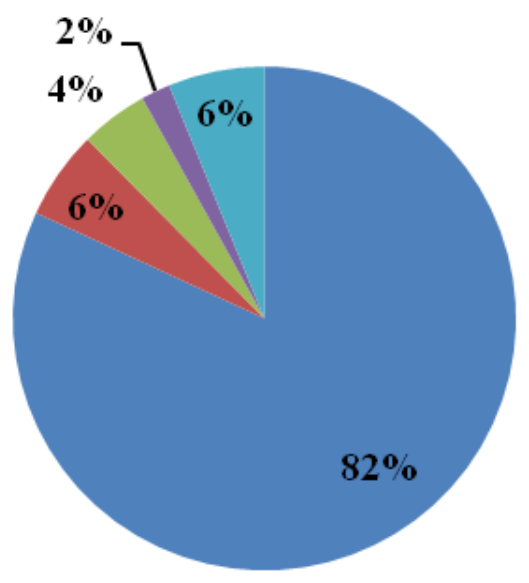

Category 1

Category 2

Category 3

Energy (Electricity \& Natural Gas)

Transp ort ( To mill \& dairy farms)

Panel A

\section{Economic Allocation (scenario 1)-DDGS, wet mill} : $0.58 \mathrm{kgCO}_{2} \mathrm{eq} \cdot \mathrm{kg}^{-1}$ dairy mill output

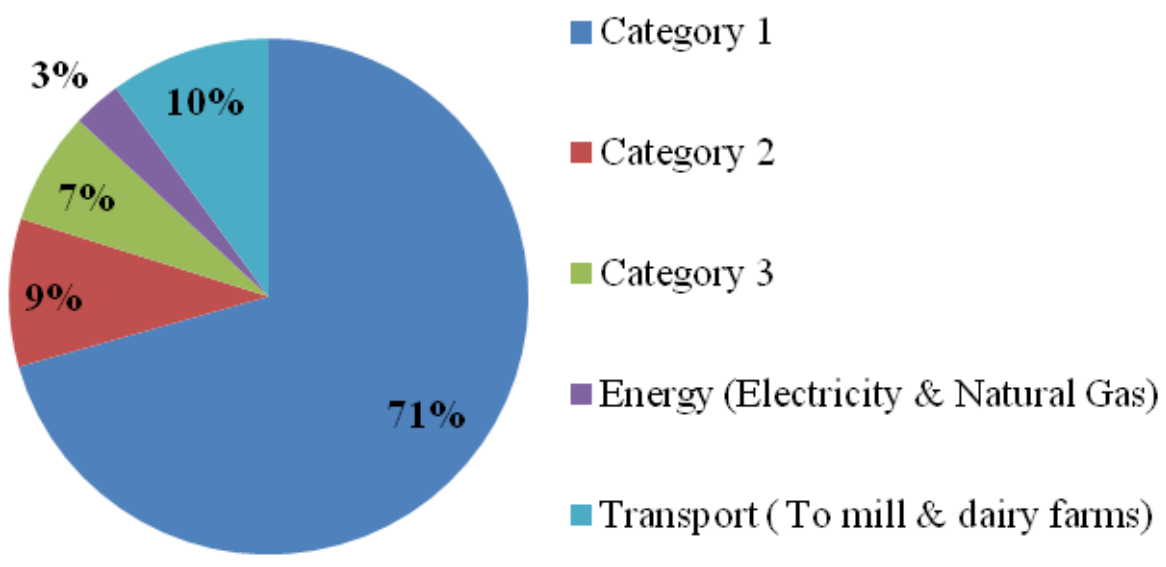

Panel B

Figure E-2 Relative Contribution to GWP of Feed Mill Dairy Feed for Scenario 1 
Mass Allocation (scenario 2)-DDGS dominant, : $1.68 \mathrm{kgCO}_{2} \mathrm{eq} \cdot \mathrm{kg}^{-1}$ dairy mill output

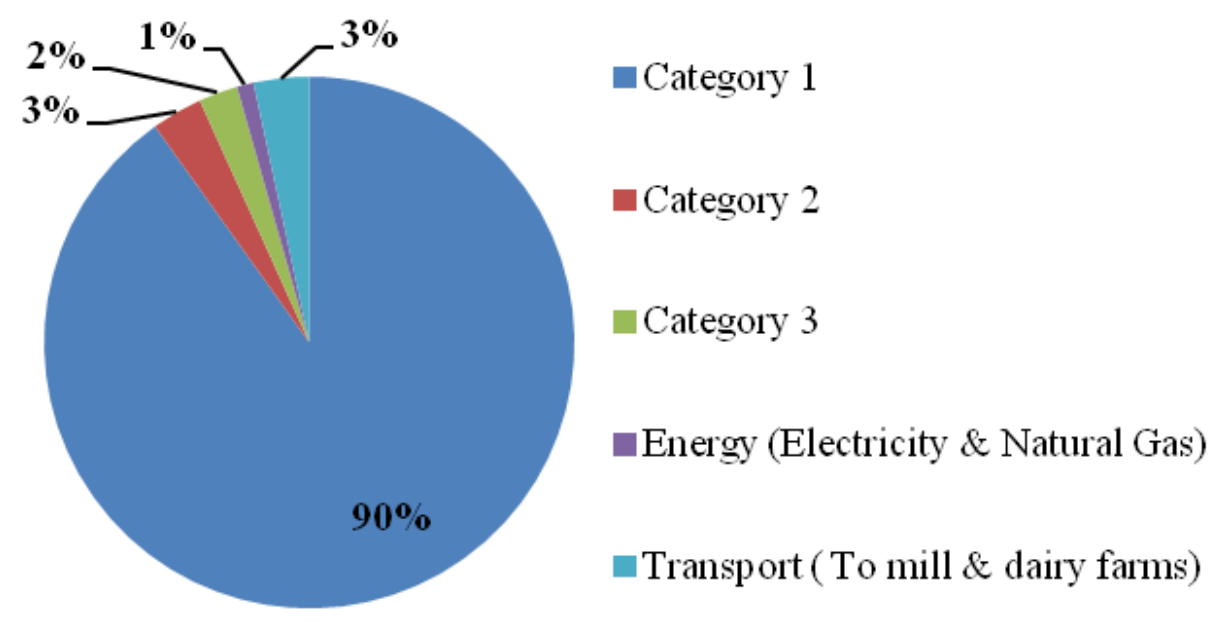

Panel A

\section{Economic Allocation (scenario 2)-DDGS} dominant,

: $0.84 \mathrm{kgCO}_{2} \mathrm{eq} \cdot \mathrm{kg}^{-1}$ dairy mill output

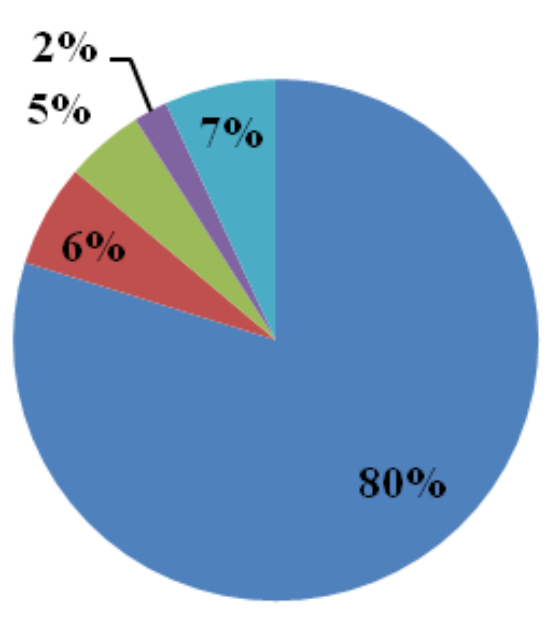

n Category 1

Category 2

Category 3

Energy (Electricity \& Natural Gas)

Transport ( To mill \& dairy farms)

Panel B

Figure E-3 Relative Contribution to GWP of Feed Mill Dairy Feed for Scenario 2 


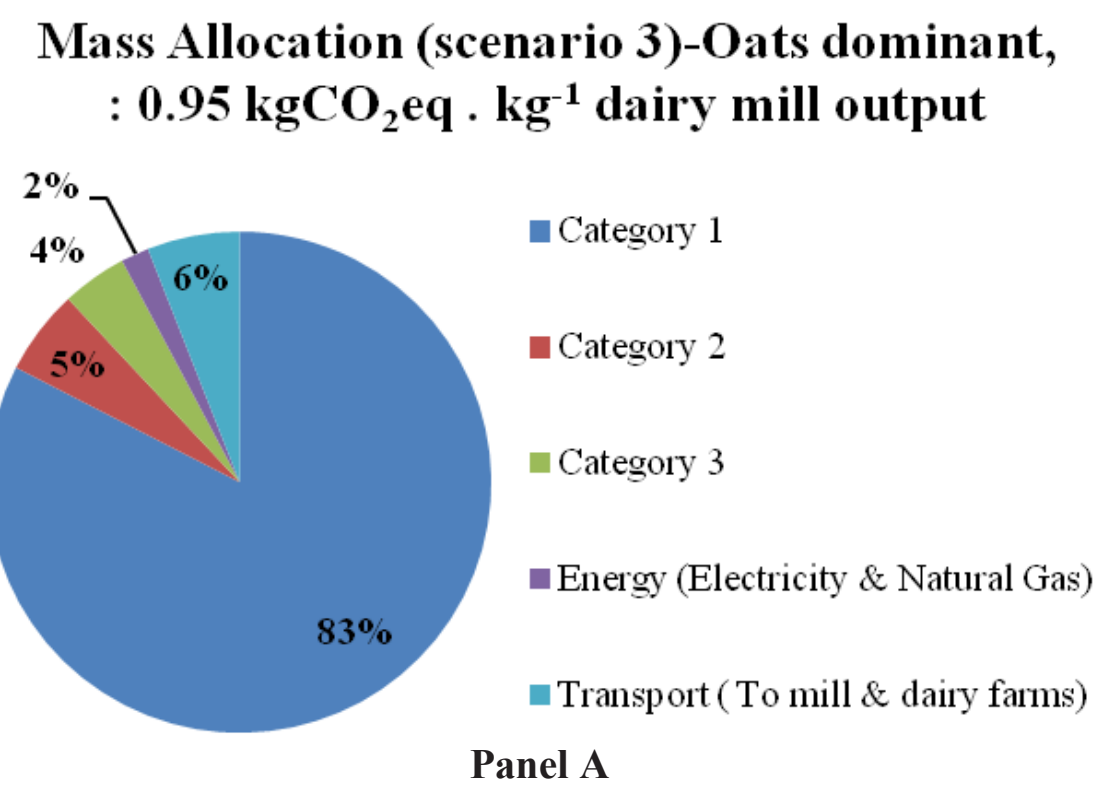

\section{Economic Allocation (scenario 3)-Oats dominant,} : $0.70 \mathrm{kgCO}_{2} \mathrm{eq} \cdot \mathrm{kg}^{-1}$ dairy mill output

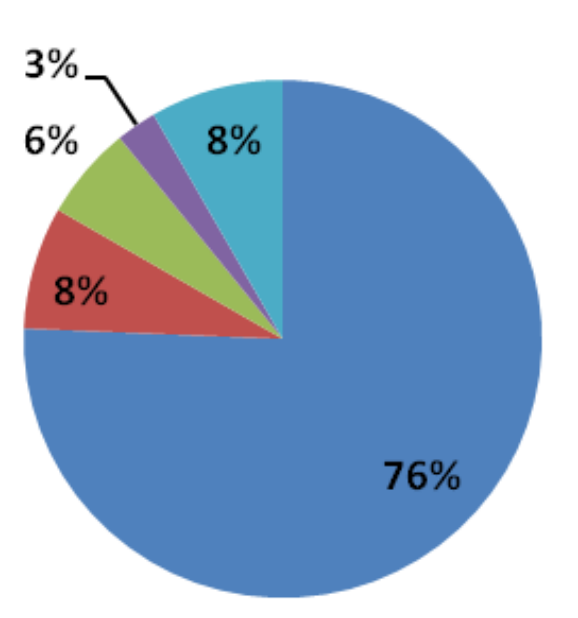

Category 1

- Category 2

Category 3

Energy (Electricity \& Natural Gas)

Transport ( To mill \& dairy farms)

Panel B

Figure E- 4 Relative Contribution to GWP of Feed Mill Dairy Feed for Scenario 3 